\title{
LA SITUACIÓN COMPETITIVA DE LA INDUSTRIA VINÍCOLA EN LA COMUNIDAD VALENCIANA. FACTORES DETERMINANTES DE LA DIFERENCIACIÓN DE PRECIOS.
}

Autor: Enrique Aroca Luján

Director de la tesis doctoral: Dr. José Miguel Ferrer Arranz

Programa de doctorado: Economía Agroalimentaria y del Medio Ambiente

Departamento de Economía y Ciencias Sociales

Escuela Técnica Superior de Ingenieros Agrónomos

Universidad Politécnica de Valencia 



\section{RESUMEN \\ (Castellano)}

El sector vitivinícola se encuentra profundamente arraigado desde antaño en la Comunidad Valenciana, y aunque su importancia económica no sea muy relevante (constituye el 5,2 \% de las ventas totales de la industria agroalimentaria regional), tiene una significativa importancia social (el cooperativismo representa cerca del $70 \%$ en los procesos iniciales de comercialización), territorial y ambiental (abarca amplias zonas desfavorecidas y de montaña con escasas alternativas en otros cultivos).

Por otro el desequilibrio entre la oferta y la demanda de vino está provocando una fuerte reducción de precios en origen que está recayendo fundamentalmente en el subsector productor de uva, el cual en muchos casos está obteniendo unos ingresos inferiores a los costes de producción.

En este contexto, los objetivos principales de la presente Tesis Doctoral son: por un lado, determinar la posición competitiva del subsector vinícola regional; por otro, determinar los factores determinantes de la calidad de los vinos, en su estrecha relación con el valor comercial y la diferenciación de los mismos, con la finalidad última de identificar aquellos aspectos que en mayor medida puedan contribuir a mejorar la competitividad del mismo, y en particular la asociada a factores de orden superior, vía precios y calidad.

La posición competitiva de la industria vinícola regional se ha resumido: a) en términos de factores endógenos y exógenos que influyen sobre ella, utilizando el conocido modelo dafo; b) según los determinantes de que consta el modelo del diamante de Porter. La intensidad o rivalidad competitiva entre la empresas que configuran el subsector ha sido definida utilizando el modelo de las cinco fuerzas de Porter.

Se concluye por ambos modelos a) y b), que la situación competitiva del subsector es débil, en el sentido de que la mayoría de las empresas son incapaces de incorporar valor añadido a sus producciones comercializadas a granel. Por otro lado, la elevada competencia observada dentro del propio sector vitivinícola debería haberse erigido en el estímulo principal para constituir una situación competitiva fuerte. La explicación por la cual no ha ocurrido así la ha aportado el modelo del diamante, ya que la contribución conjunta de las seis aristas del diamante al logro de la competitividad es baja, ninguna arista de diamante se encuentra bien desarrollada, lo que equivale a afirmar que no existe un verdadero diamante.

La identificación y cuantificación de los factores que determinan la competitividad vía diferenciación de precios se ha efectuado desde las proposiciones conceptuales de la Teoría de Recursos y Capacidades y mediante el análisis multivariante de los datos (análisis de componentes principales, análisis de regresión lineal multivariante y análisis discriminante). Como consecuencia de los trabajos anteriores se ha puesto de manifiesto que los tres factores que más contribuyen a la diferenciación de precios son por orden de importancia la variedad de la uva, el método de vinificación y esfuerzo tecnológico o inversor, que en conjunto tienen una capacidad explicativa de la variabilidad de los precios que supera el $60 \%$. 
Por último y con objeto de valorar la importancia relativa de cada una de estas dimensiones obtenidas empíricamente, se ha definido un cuestionario dirigido a los directores o responsables de la gestión de las bodegas, para comprobar el grado de desviación existente entre dichas dimensiones y la opinión subjetiva de los dirigentes. Los resultados han sido satisfactorios en el sentido de que existe un elevado grado de acuerdo entre los factores que más contribuyen así como en los que menos importancia ejercen sobre la diferenciación de precios, por lo que la sensibilización de los dirigentes de las bodegas es una dimensión clave en el proceso real de diferenciación por calidad de los vinos regionales que están llevando a cabo muchas bodegas. 


\section{SUMMARY \\ (English)}

The wine growing sector has long been deep-rooted in the Valencian Community and, even if its importance in the local economy is not so outstanding (it represents $5,2 \%$ of all sales in the food industry of the region), it shows a remarkable importance in the society (the cooperativism represents about $770 \%$ in the initial process of commercialization), as well as in the territory and the environment (it covers vast underprivileged and mountainous areas with scarce options to other crops).

However, the existing imbalance between supply and demand of wine products provokes a harsh reduction of the prices in the fields. $\mathrm{T}$ his has of course consequences for the vineyard owners, who often see that their income is lower than production costs.

Therefore, the main goals to be achieved in this thesis are: on the one hand, to determine the competitive position of the local wine growing sector; on the other hand, to determine the decisive factors for wine quality and its close relation with the commercial value and the differentiation of them, with the purpose of identifying those aspects which may mostly contribute to improve the competitivity of wine and, in particular the one related to factors of higher level, via price and quality.

The competitive position of the local wine growing industry has been summarized: a) in terms of endogenous and exogenous factors that have influence on it, using the known dafo method; b) according to the decissive factors the Porter's diamond model consists of. The competitive intensity or rivalry among the companies that form the sector has been defined using Porter's model of the five forces.

The conclusion of both a) and b) models shows that the competitive situation of the sector is weak, since most of the companies are unable to incorporate added value to their in bulk commercialized productions. On the other hand, the hard competition observed in the sector itself should have become the main stimulus to create a strong competitive edge. He explanation of why this did not happen has been illustrated by model of the diamond. The joint contribution of the six edges of the diamond to the achievement of competitivity is low. None of the edges is developed in a proper way, which means that we can affirm that a real diamond does not exist.

The identification and quantification of the factors that determine the competitivity through the differentiation of prices has been carried out from the conceptual proposals of the Theory of Resources and Abilities and from the multivariante analysis of data (analysis of main components, analysis of multivariante and linear regression, and analysis of differentiation). As a consequence of previous works, it has been revealed that the three factors that mostly contribute to the differentiation of prices are, in order of importance, the following: the variety of grapes, the method of fermentation and the technological or investment effort. These three factors together can explain the variability of prices more than $60 \%$ of the time.

Finally, whit the object of valueing the relative importance of each of dimensions empirically obtained, a questionnaire has been handed out to managers and directors of wine cellar in order to prove the level of desviation of results abovementioned and the subjective opinion of the above-mentioned managers. The results has 
been satisfactory since there is a high level of agreement on the factors that mainly contribute, as well as on those which have less importance on the differentiation of prices. This explains why the sensitizing of cellar managers is a clue dimension to the real process of differentiation of wine quality which many cellars are going through. 


\section{RESUM \\ (Valencià)}

El sector vitivinícola es troba molt arrelat des d'antany a la Comunitat Valenciana, i encara que la seua importància econòmica no siga molt rellevant (constituïx el 5,2 \% de les vendes totals de la indústria agroalimentària regional), té una significativa importància social (el cooperativisme representa entorn al $70 \%$ en els processos inicials de comercialització), territorial y ambiental (comprén àmplies zonas desfavorides i de muntanya amb escasses alternatives d'altres cultius).

Tanmateix el desequilibri entre l'oferta i la demanda de vi està provocant una forta reducció dels preus en origen, que està recaent fonamentalment en el subsector productor de raïm, el qual en molts casos està obtenint ingressos inferiors als los costos de producció.

En aquest context, els objetius principals de la present Tesi Doctoral són: d'una banda, determinar la posició competitiva del subsector vinícola regional; d'altra banda, fixar els factors determinants de la qualitat dels vins, en la seua estreta relació amb el valor comercial i la diferenciació dels mateixos, amb la finalitat última d'identificar aquells aspectes que en major mesura puguen contribuir a millorar la seua competitivitat i, particularment aquella associada amb factors d'ordre superior, via preus i qualitat.

La posició competitiva de la indústria vinícola regional ha sigut descrita: a) en términis de factors endògens i exògens que influïxen sobre la mateixa, utilitzant el conegut model dafo; b) segons els determinants del model del diamant de Porter. La intensitat o rivalitat competitiva entre les empreses que configuren el subsector ha sigut definida utilitzant el model de les cinc forces de Porter.

Es conclou per ambdós models a) i b) que la situació competitiva del subsector es feble, en el sentit que la majoria de les empreses son incapaces d'incorporar valor afegit a les seues produccions comercialitzades a l'engrós. D'altra banda, l'elevada competència observada dins del propi sector vitivinícola hauría haver-se erigit en l'estímul principal per a constituir una situació competitiva forta. L'explicació per la qual no ha ocurregut així l'ha aportada el model del diamant, perqué la contribució conjunta de les sixs arestes del diamant a la consecució de la competitivitat és baixa, cap aresta del diamant es troba ben desenvolupada, la qual cosa equival a afirmar que no existix un vertader diamant.

La identificació i quantificació dels factors que determinen la competitivitat a partir de la diferenciació de preus s'ha efectuat des de les proposicions conceptuals de la Teoria de Recursos y Capacitats, i utilitzant l'anàlisi multivariant de les dades (anàlisi de components principals, anàlisi de regressió lineal multivariant i anàlisi discriminant). A conseqüència dels treballs anteriors ha sigut posat de relleu que els tres factors, que més contribuïxen a la diferenciació de preus són per ordre d'importància la varietat del raïm, el métod de vinificació i l'esforç tecnològic o inversor, el conjunt dels quals té una capacitat explicativa de la variabilitat dels preus que supera el $60 \%$.

Per últim i per valorar la importància relativa de cadascuna d'aquestes dimensions obtingudes empíricament, s'ha definit un qüestionari dirigit als directors o responsables de la gestió dels cellers, per tal de comprovar el grau de desviació existent 
entre les dimensions dites i l'opinió subjetiva dels dirigents. Els resultats han siguts satisfactoris, en el sentit que existix un elevat grau d'acord entre els factors que més contribuïxen, així com en aquells que menys importància exercixen sobre la diferenciació dels preus, per la qual cosa, la sensibilització dels dirigents dels cellers suposa una dimensió clau en el procés reial de diferenciació per qualitat dels vins regionals que estàn portant a terme molts cellers. 
Í N D I C E 



\section{CAPÍTULO I}

INTRODUCCIÓN Y OBJETIVOS 13

1. INTRODUCCIÓN Y JUSTIFICACIÓN DE LA INVESTIGACIÓN. 15

2. OBJETIVOS DE LA INVESTIGACIÓN. 15

3. ANTECEDENTES Y SITUACIÓN ACTUAL DE LOS ESTUDIOS. APORTACIÓN DE LA INVESTIGACIÓN. 16

4. ESTRUCTURA DEL TRABAJO DE INVESTIGACIÓN. 17

\section{CAPÍTULO II}

$\begin{array}{ll}\text { METODOLOGÍA } & 21\end{array}$

1. DELIMITACIÓN DEL SECTOR. 23

2. DETERMINACIÓN DE LA POBLACIÓN. 23

3. DELIMITACIÓN DE LA MUESTRA. 24

4. FUENTES DE INFORMACIÓN. 25

5. ANÁLISIS DE LA INFORMACIÓN. 26

\section{CAPÍTULO III}

FUNDAMENTACIÓN TEÓRICA Y MODELO DE ANÁLISIS 27

1. INTRODUCCIÓN. 29

2. FACTORES MACROECONÓMICOS. 30

3. FACTORES SECTORIALES. 30

4. FACTORES EMPRESARIALES. 31

5. TEORÍA DE LOS RECURSOS Y CAPACIDADES. 35

6. MODELO DE ANÁLISIS EN FACTORES EMPRESARIALES 39

7. VARIABLES DEL MODELO EN FACTORES EMPRESARIALES 42

7.1 Identidad corporativa. 43

7.1.1 Antigüedad. 43

7.1.2 Estructura de la propiedad. $\quad 44$

$\begin{array}{lll}7.2 & \text { Recursos tangibles. } & 45\end{array}$

$\begin{array}{lll}7.3 & \text { Recursos intangibles. } & 48\end{array}$

$\begin{array}{lll}\text { 7.3.1 Recursos humanos. } & 48\end{array}$

7.3.2 Recursos tecnológicos. $\quad 50$

7.3.3 Recursos comerciales.

7.4 Comportamiento estratégico.

7.4.1 Ámbito de producto. 56

7.4.2 Estrategia de precios. 63

7.4.3 Nivel de integración vertical. 65

7.4.4 Ámbito de comercialización. 68 
7.4.5 Ámbito de mercado.

7.5 Resultados empresariales.

\section{CAPÍTULO IV}

DESCRIPCIÓN GENERAL DEL SECTOR VITIVINÍCOLA 77

1. EL VINO EN EL ENTORNO INTERNACIONAL 79

$\begin{array}{ll}1.1 & \text { La producción y el consumo mundial de vino }\end{array}$

1.2 El comercio mundial de vino 82

2. EL VINO EN LA UNIÓN EUROPEA

2.1 La producción y el consumo en la Unión Europea 85

2.2 El comercio de vino en la Unión europea $\quad 87$

3. EL VINO EN ESPAÑA 88

3.1 El balance vitivinícola $\quad 88$

3.2 Los precios del vino 91

3.3 Los mercados del vino 94

3.4 El consumo de vino 96

3.4.1 Cuantificación y evolución del consumo 96

3.4.2 Factores determinantes del consumo 98

3.5 Los canales de comercialización 103

3.5.1 Cambios en los canales de distribución 105

3.6 Las exportaciones de vino 108

3.6.1 Cuantificación y evolución de las exportaciones 108

3.6.2 Problemática de las exportaciones 111

4. EL VINO EN LA COMUNIDAD VALENCIANA 113

4.1 La producción de vino en la Comunidad Valenciana 114

4.2 El comercio de vino en la Comunidad Valenciana 117

4.3 La industria vinícola en la Comunidad Valenciana 119

5. MODELOS VITIVINÍCOLAS MUNDIALES 120

6. POLÍTICAS VITIVINÍCOLAS 127

6.1 La OCM vitivinícola en la Unión Europea 127

6.1.1 Estructura de la OCM vitivinícola 128

6.1.2 Efectos sobre el Estado Español de la OCM vitivinícola 135

6.1.3 Propuesta de reforma de la OCM vitivinícola 135

6.2 La Ley de la Viña y del Vino 137

6.3 La Ley de ordenación del sector vitivinícola en la Comunidad Valenciana

7.1 Concepto de calidad 142

7.2 Certificación de la calidad del producto 143

7.2.1 Sistemas de protección de la calidad 143

7.2.2 Agricultura Integrada y Agricultura Ecológica 149

7.3 Certificación de sistemas de calidad en las empresas 150

7.4 Sistemas de aseguramiento de higiene alimentaria 153 
8. LA REGULACIÓN INTERNACIONAL DEL MERCADO DE VINO 157

8.1 Las negociaciones comerciales multilaterales 158

8.1.1 El Acuerdo sobre Agricultura de la Ronda de Uruguay 158

8.1.2 Otros acuerdos de la Organización Mundial de Comercio 159

8.2 Las relaciones bilaterales 160

8.3 Las Organizaciones Internacionales 161

8.4 Los impactos de la ampliación al Este 162

9. OTROS ASPECTOS CON INCIDENCIA EN EL SECTOR 162

\section{CAPÍTULO V}

\section{ANÁLISIS DEL SUBSECTOR VINÍCOLA EN LA COMUNIDAD VALENCIANA 165}

1. ESTRUCTURA EMPRESARIAL DE LA INDUSTRIA VINÍCOLA 167

2. APROVISIONAMIENTO DE MATERIA PRIMA PRINCIPAL 171

2.1 Estructura varietal 171

2.2 Integración vertical hacia atrás 174

2.3 Fijación del precio de la uva 176

3. PRODUCCIÓN COMERCIALIZADA EN VOLUMEN 178

3.1 Producción comercializada total 178

3.2 Producción comercializada según la Denominación de Origen (DO) 179

3.3 Producción comercializada según el tamaño empresarial 182

3.4 Producción comercializada según la forma jurídica 185

3.5 Producción comercializada según la antigüedad de las empresas 188

3.6 Destilaciones 190

4. PRECIOS DE VENTA EN EL MERCADO. FACTURACIONES 191

5. RECURSOS HUMANOS 196

5.1 Estabilidad del empleo 196

5.2 Cualificación técnica del empleo 198

5.3 Productividad del empleo 199

6. INVERSIONES 201

6.1 Destino de las inversiones 201

6.2 Financiación de las inversiones 204

7. TECNOLOGÍA DE LAS INSTALACIONES DE ELABORACIÓN 205

7.1 Tecnología de las instalaciones de vinificación y almacenamiento 205

7.2 Tecnología de otras instalaciones de elaboración 208

7.3 Automatización. Tecnologías de la información y comunicación (TIC) 221

8. INNOVACIÓN TECNOLÓGICA 225

8.1 Causas y efectos de la innovación tecnológica 226

8.2 Indicadores de la I+D+i 226

9. CALIDAD Y SEGURIDAD ALIMENTARIA 228

9.1 Certificación de la calidad del producto 228

9.2 Certificación de la calidad de las empresas 230

9.3 El aseguramiento de la higiene alimentaria 230 
10. ESTRATEGIAS DE MARKETING 231

10.1 Estrategia de producto 232

10.1.1 Gama de productos $\quad 232$

10.1.2 Gama de marcas 233

10.1.3 Gama de presentaciones 235

10.2 Destino geográfico y ámbito de la producción comercializada 235

10.3 Canales de distribución 237

10.3.1 Agentes de distribución 238

10.3.2 Integración vertical hacia adelante $\quad 240$

10.4 Estrategias de comunicación e información 241

10.4.1 Esfuerzo comercial. Diferenciación por información al consumidor

10.5 Estrategias de precios $\quad 243$

11. RESULTADOS EMPRESARIALES 244

\section{CAPÍTULO VI}

DIAGNÓSTICO PARA LA INDUSTRIA VINÍCOLA DE LA COMUNIDAD VALENCIANA

1. SITUACIÓN COMPETITIVA DE LA INDUSTRIA VINÍCOLA SEGÚN EL MODELO DAFO.

2. ANÁLISIS ESTRUCTURAL DE LA INDUSTRIA VINÍCOLA SEGÚN PORTER.

2.1 Intensidad competitiva según el modelo de las cinco fuerzas de Porter.

2.2 Determinantes de la situación competitiva según el modelo del diamante de Porter

3. INTEGRACIÓN DEL MODELO DAFO Y MODELOS DE PORTER. 289

\section{CAPÍTULO VII}

\section{FACTORES EXPLICATIVOS DE LA COMPETITIVIDAD POR} DIFERENCIACIÓN DE PRECIOS.

1. INTRODUCCIÓN.

2. APROXIMACIÓN TEÓRICA Y ESTUDIOS EMPÍRICOS RELACIONADOS.

3. APORTACIÓN DE LA DO Y EMBOTELLADO AL PRECIO DEL VINO.

4. APORTACIÓN DE LOS FACTORES EMPRESARIALES AL PRECIO DEL VINO CON DO Y EMBOTELLADO.

4.1 Factores explicativos del precio del vino blanco joven. 302

4.2 Factores explicativos del precio del vino rosado joven. 309

4.3 Factores explicativos del precio del vino tinto joven. 317

4.4 Factores explicativos del precio del vino crianza. 325 
4.5 Factores explicativos del precio del vino reserva.

4.6 Factores explicativos del precio del vino con DO y embotellado.

5. APORTACIÓN DE LOS FACTORES EMPRESARIALES AL PRECIO DEL VINO A GRANEL.

6. APRECIACIÓN POR LOS DIRECTIVOS DE LAS BODEGAS DE LA CONTRIBUCIÓN DE LOS FACTORES EMPRESARIALES AL PRECIO DEL VINO.

\section{CAPÍTULO VIII}

CONCLUSIONES Y VALORACIÓN FINAL.

2. IMPLICACIONES PARA LA DIRECCIÓN DE LAS EMPRESAS. 356

3. LIMITACIONES DEL ESTUDIO. 358

4. FUTURAS LÍNEAS DE INVESTIGACIÓN. 360

\section{BIBLIOGRAFÍA}

\section{ANEXOS}

ANEXO I. CUESTIONARIO BODEGAS

ANEXO II. LISTADO BODEGAS ENCUESTADAS

\section{ÍNDICE DE GRÁFICOS}

Gráfico 3.1: Recursos y ventaja competitiva.

Gráfico 4.1: Evolución de la producción y consumo mundial de vino (19862002).

Gráfico 4.2: Producción mundial de vino en porcentajes por países (2002).

Gráfico 4.3: Consumo mundial de vino en porcentaje por países (2002).

Gráfico 4.4: Evolución de las importaciones y exportaciones mundiales de vino (1986-2002).

Gráfico 4.5: Exportaciones de vino (2001).

Gráfico 4.6: Importaciones de vino (2001).

Gráfico 4.7: Evolución de la producción y consumo de vino (mill hl) en la Unión Europea (1980/81-2003/04).

Gráfico 4.8: Evolución de la producción total de vino (mill hl) en los principales países de la Unión Europea.

Gráfico 4.9: Evolución de las importaciones y exportaciones de vino (mill hl) de la Unión Europea a Países Terceros (1993-2002).

Gráfico 4.10: Evolución del precio en origen del vino blanco y tinto de mesa a granel.

Gráfico 4.11: Porcentaje en volumen del consumo de vino en España, por canales y tipos de vinos (2004).

Gráfico 4.12: Evolución del consumo de vino (mill €) en los hogares (19992004).

Gráfico 4.13: Evolución de las exportaciones españolas de vino (1995-2004). 
Gráfico 4.14: Exportaciones españolas de vino en volumen (2004). 109

Gráfico 4.15: Exportaciones españolas de vino en valor (2004). 110

Gráfico 4.16: Evolución de la superficie de viña para transformación (has) en la Comunidad Valenciana (1993/1994-2002/2003).

Gráfico 4.17: Evolución de la producción de vino (hl) en la Comunidad Valenciana (1993/1994-2002/2003).

Gráfico 4.18: Evolución del rendimiento de la producción de vino (hl/ha) en la Comunidad Valenciana (1993/1994-2002/2003).

Gráfico 4.19: Evolución de producción comercializada (hl) por las DDOO según las formas de comercialización (1993/1994-2002/2003).

Gráfico 4.20: Evolución de producción comercializada (hl) por las DDOO según el destino de la comercialización (1993/1994-2002/2003).

Gráfico 4.21: Evolución de las exportaciones por grupos de países en porcentaje.

Gráfico 4.22: Pirámide de calidad en el nuevo sistema de protección de vinos 144

Gráfico 5.1: Distribución del número de empresas según la edad. 167

Gráfico 5.2: Distribución del número de empresas según la forma jurídica. 168

Gráfico 5.3: Distribución del número de empresas según el tamaño empresarial.

Gráfico 5.4: Distribución del número de empresas según la pertenencia a la Denominación de Origen (DO).

Gráfico 5.5: Distribución porcentual de la producción en (hl) por niveles de integración vertical hacia atrás.

Gráfico 5.6: Porcentaje de empresas según el tipo de control seguido para la fijación del precio de la uva.

Gráfico 5.7: Distribución porcentual de la producción comercializada en sentido amplio.

Gráfico 5.8: Distribución porcentual del personal de las empresas según la estabilidad en el empleo.

Gráfico 5.9: Distribución porcentual de la cualificación técnica del personal de las empresas.

Gráfico 5.10: Distribución porcentual de las fuentes de financiación de las inversiones realizadas por las empresas.

Gráfico 5.11: Digitalización aplicada a las diferentes áreas de la empresa.

Gráfico 5.12: Distribución porcentual de marcas propias y marcas blancas respecto del total de vino comercializado embotellado.

Gráfico 5.13: Destino de la producción comercializada en porcentaje sobre el volumen de vino en hectolitros.

Gráfico 5.14: Porcentaje de participación de los canales de distribución sobre el volumen de vino comercializado embotellado.

Gráfico 5.15: Distribución porcentual del volumen de producción de vino comercializada por niveles de integración vertical hacia adelante.

Gráfico 5.16: Distribución porcentual del gasto comercial anual medio (€).

Gráfico 5.17: Participación de los criterios de fijación de precios en porcentaje sobre el volumen de vino comercializado total. 


\section{ÍNDICE DE CUADROS}

Cuadro 2.1: Distribución de la población y la muestra por pertenencias a las distintas Denominaciones de Origen (DDOO).

Cuadro 2.2: Ficha técnica de la investigación.

Cuadro 3.1: Variables de identidad corporativa. 45

Cuadro 3.2: Variables de recursos tangibles. 46

Cuadro 3.3: Variables de recursos intangibles. $\quad 55$

Cuadro 3.4: Variables de comportamiento estratégico. 73

Cuadro 3.5: Variables de resultados.

Cuadro 4.1: Evolución de las exportaciones de vino (1981-2001) 83

Cuadro 4.2: Balance vitivinícola español (1995/1996-2003/2004) en millones de hectólitros. $\quad 89$

Cuadro 4.3: Segmentación de precios por calidades o categorías de vinos. 93

Cuadro 4.4: Problemas y acciones llevadas a cabo para superar las barreras a la exportación de productos agroalimentarios (2001).

Cuadro 4.5: Principales características de los niveles de protección de vino existentes en la Comunidad Valenciana (2002/2003)

Cuadro 4.6: Evolución del destino de la producción comercializada (hl) por las DDOO (1993/1994-2002/2003).

Cuadro 4.7: Principales indicadores de la industria alimentaria en la Comunidad Valenciana (2002).

Cuadro 4.8: Características de los dos modelos vitivinícolas predominantes en el mundo.

Cuadro 4.9: Matriz de relación entre la marca de empresa y la marca Denominación de Origen (DO).

Cuadro 5.1: Distribución porcentual de las variedades de vid según su clasificación y origen.

Cuadro 5.2: Distribución de la producción comercializada (hl) según la forma de comercialización, calificación y tipos de vino.

Cuadro 5.3: Distribución de la producción comercializada en (hl) según la forma de comercialización, calificación y tipos de vino.

Cuadro 5.4: Distribución de la producción comercializada en (hl) según las DDOO, y tipos de vino.

Cuadro 5.5: Distribución de la producción comercializada (hl) según la forma de comercialización, calificación y tamaño empresarial.

Cuadro 5.6: Distribución de la producción comercializada (hl) según el

tamaño empresarial y tipos de vino.

Cuadro 5.7: Distribución de la producción comercializada (hl) según la forma de comercialización, calificación y forma jurídica empresarial.

Cuadro 5.8: Distribución de la producción comercializada (hl) según el tamaño empresarial y tipos de vino.

Cuadro 5.9: Distribución de la producción comercializada (hl) según la forma de comercialización, calificación y antigüedad de las empresas. 
Cuadro 5.10: Distribución de la producción comercializada (hl) según la antigüedad de las empresas y tipos de vino.

Cuadro 5.11: Distribución del precio medio de venta en $(€ / l)$ de los diferentes tipos de vino según la forma de comercialización.

Cuadro 5.12: Distribución de la facturación ( $€$ ) en los diferentes tipos de vino, según la forma de comercialización.

Cuadro 5.13: Distribución de los empleos por empresa y productividad por empleado (€/empleo), según las distintas categorías de empresas.

Cuadro 5.14: Inversión media anual ( $€ /$ año) realizadas por las empresas según conceptos.

Cuadro 5.15: Porcentajes de participación en la inversión y esfuerzo inversor, según categorías de empresas.

Cuadro 5.16: Distribución de la capacidad de elaboración y almacenamiento por tipos de depósitos.

Cuadro 5.17: Distribución de la capacidad instalada (calidad y sobredimensionamiento) y producción comercializada.

Cuadro 5.18: Número de marcas y presentaciones por empresa según las categorías de empresa.

Cuadro 5.19: Destino de las exportaciones, concentración y amplitud geográfica de los mercados.

Cuadro 7.1: Orden e importancia de los factores de calidad.

Cuadro 7.2: Precios medios de los vinos (€/l) según la forma de comercialización y pertenencia a la figura de calidad.

Cuadro 7.3: Análisis factorial sobre variables de identidad corporativa en el vino blanco joven.

Cuadro 7.4: Análisis factorial sobre variables de recursos tangibles en el vino blanco joven.

Cuadro 7.5: Análisis factorial sobre variables de recursos intangibles en el vino blanco joven.

Cuadro 7.6: Análisis factorial sobre variables de comportamiento estratégico en el vino blanco joven.

Cuadro 7.7: Resumen del modelo de regresión lineal múltiple en el vino blanco joven.

Cuadro 7.8: Caracterización de los grupos de bodegas que comercializan vino blanco joven.

Cuadro 7.9: Análisis factorial sobre variables de recursos tangibles en el vino rosado joven.

Cuadro 7.10: Análisis factorial sobre variables de recursos intangibles en el vino rosado joven.

Cuadro 7.11: Análisis factorial sobre variables de comportamiento estratégico en el vino rosado joven.

Cuadro 7.12: Resultados del análisis discriminante (Prueba M. De Box) en el vino rosado joven.

Cuadro 7.13: Resultados del análisis discriminante (variables incluidas en cada paso) en el vino rosado joven. 
Cuadro 7.14: Resultados del análisis discriminante (Lambda de Wilks global) en el vino rosado joven.

Cuadro 7.15: Resultados del análisis discriminante (Coeficientes tipificados de las funciones discriminantes canónicas) en el vino rosado joven.

Cuadro 7.16: Resultados de la clasificación (matriz de confusión) en el vino rosado joven.

Cuadro 7.17: Caracterización de los grupos de bodegas que comercializan vino rosado joven.

Cuadro 7.18: Análisis factorial sobre variables de identidad corporativa en el vino tinto joven.

Cuadro 7.19: Análisis factorial sobre variables de recursos tangibles en el vino tinto joven.

Cuadro 7.20: Análisis factorial sobre variables de recursos intangibles en el vino tinto joven.

Cuadro 7.21: Análisis factorial sobre variables de comportamiento estratégico en el vino tinto joven.

Cuadro 7.22: Resumen del modelo de regresión lineal múltiple en el vino tinto joven.

Cuadro 7.23: Caracterización de los grupos de bodegas que comercializan vino tinto joven.

Cuadro 7.24: Análisis factorial sobre variables de recursos tangibles en el vino crianza.

Cuadro 7.25: Análisis factorial sobre variables de comportamiento estratégico en el vino crianza.

Cuadro 7.26: Resumen del modelo de regresión lineal múltiple en el vino crianza.

Cuadro 7.27: Características de los grupos de bodegas que comercializan vino crianza.

Cuadro 7.28: Análisis factorial sobre variables de recursos tangibles en el vino reserva.

Cuadro 7.29: Análisis factorial sobre variables de recursos intangibles en el vino reserva.

Cuadro 7.30: Análisis factorial sobre variables de comportamiento estratégico en el vino reserva.

Cuadro 7.31: Resumen del modelo de regresión lineal múltiple en el vino reserva.

Cuadro 7.32: Caracterización de los grupos de bodegas que comercializan vino reserva.

Cuadro 7.33: Caracterización de los grupos de bodegas que comercializan vino a granel.

Cuadro 7.34: Frecuencias de las valoraciones concedidas por los directivos de las bodegas. 

CAPITULO I

INTRODUCCIÓN Y OBJETIVOS 



\section{INTRODUCCIÓN Y JUSTIFICACIÓN DE LA INVESTIGACIÓN}

El sector vitivinícola de la Comunidad Valenciana se encuentra profundamente arraigado desde antaño en los hábitos alimentarios y en la cultura regional. No obstante son de destacar varios ámbitos en los que tiene reconocida presencia:

- En el económico representa el 5,2 \% de las ventas totales de la industria agroalimentaria regional.

- En el social, es de destacar la significativa presencia del cooperativismo (cerca del $70 \%$ ) en los procesos iniciales de comercialización, en lo que se refiere al acopio de uva y elaboración de vino en bodegas cooperativas; constituye la principal fuente de ingresos de aproximadamente 23.000 viticultores, y su industria emplea a más de 1.200 personas.

- Desde el punto de vista territorial y ambiental, el cultivo de la vid abarca amplias zonas del territorio calificadas como desfavorecidas y de montaña, con escasas alternativas en otros usos y cultivos, lo cual erige a dicho cultivo como la única fuente de recursos capaz de fijar la población en el medio rural despoblado.

Por otro lado el sector vitivinícola está atravesando una grave crisis que viene propiciada por el desequilibrio entre la oferta y la demanda, con producciones crecientes, una bajada constante y acelerada del consumo neto en los principales países productores y unas exportaciones estabilizadas por la pérdida de la cuota de mercado respecto los nuevos países productores.

Esta crisis está afectando principalmente al subsector vitícola o productor, vía precios percibidos en origen, que son cada vez más bajos, incluso por debajo de los costes de producción del cultivo, dificultando la posibilidad de mantener las rentas de los viticultores, lo que a su vez está poniendo en peligro la continuidad del cultivo, con las graves repercusiones económicas, sociales y medioambientales expuestas anteriormente.

\section{OBJETIVOS DE LA INVESTIGACIÓN}

Teniendo en cuenta la situación de partida expuesta anteriormente y su previsible agravamiento, el objetivo general de la investigación es de identificar aquellos aspectos relacionados con la posición competitiva del subsector elaborador de vinos o vinícola de la Comunidad Valenciana y determinar el grado de rivalidad competitiva entre sus empresas.

Los objetivos más específicos se centran: a) en la identificación y cuantificación de los factores que determinan la competitividad de las bodegas vía diferenciación de precios, o diferenciación por calidad de los vinos; b) contrastar los resultados empíricos objetivos con la apreciación subjetiva de los responsables de las bodegas, con la finalidad de poner en evidencia, si éstos están concediendo la importancia necesaria a los principales factores determinantes de la diferenciación por precios, condición 
necesaria para que tales factores sean adecuadamente gestionados por los responsables de las empresas, en la definición y ejecución de las políticas estratégicas para lograr alcanzar y mantener una posición competitiva fuerte.

\section{ANTECEDENTES Y ESTADO ACTUAL DE LOS ESTUDIOS. APORTACIÓN DE LA INVESTIGACIÓN}

Con relación al objetivo general del trabajo, que se centra en determinar las causas de la situación competitiva en sector vitivinícola regional, mencionar los siguientes trabajos:

a) Existe un claro antecedente en el trabajo elaborado por el Ministerio de Agricultura, Pesca y Alimentación en 1993, titulado "Estudio sobre la posición competitiva del sector de Alimentación y Bebidas en España", que pretendía evaluar la posición competitiva de las empresas pertenecientes al Sector de Alimentación y Bebidas en España, con el objeto de diseñar las estrategias más adecuadas en el nuevo entorno competitivo. Aunque el proyecto tiene cierto carácter sectorial, ya que se han analizado veintidós sectores agroalimentarios, desde el principio se pretendió obtener un diagnóstico global de la posición competitiva de las empresas establecidas en España, y una visión horizontal de las medidas a adoptar para mejorar la competitividad del conjunto de los sectores y subsectores analizados.

El proyecto determina la posición competitiva entre otras, del sector del vino en términos de factores internos (puntos Fuertes y Débiles) y externos (Oportunidades y Amenazas) clave de competencia, sobre la base del conocido modelo DAFO. El presente trabajo retoma ésta metodología en el sector vitivinícola, limitándola al ámbito espacial de la Comunidad Valenciana.

b) En el estudio sobre "competitividad y estrategias empresariales en el sector vínico español (J. Briz et al., 1999), describen algunos aspectos básicos sobre la posición competitiva del sector vitivinícola y diseñan posibles estrategias que la mejoren. Para ello se centran, por un lado en los factores que condicionan la competitividad según el modelo del diamante de Porter; por otro, determinan el grado de rivalidad competitiva del sector vitivinícola sobre la base del modelo de las cinco fuerzas de Porter. El presente trabajo integra los dos modelos de Porter y el modelo DAFO, con la finalidad de averiguar las causas objetivas que han conducido a una determinada posición competitiva del sector vitivinícola regional.

Con relación al objetivo específico de la presente investigación, que pretende identificar y cuantificar los factores que determinan la diferenciación por precios en el subsector vinícola de la Comunidad Valenciana, por orden cronológico se citan los siguientes trabajos relacionados de alguna manera con aquel:

a) Fregoni en 1985, establece el orden de importancia de los factores implicados en la de calidad del vino. En la viticultura tradicional europea, aparecen en primer lugar, el clima y la variedad, y en último, los gustos del consumidor. En la viticultura moderna de los países anglosajones o emergentes, la variedad es el primer factor, seguida del 
método de vinificación y los gustos del consumidor, apareciendo en los últimos puestos el clima y el terreno.

b) La Universidad de la Rioja (Sáinz, 2002), en un estudio titulado "Análisis de los factores explicativos del éxito empresarial: una aplicación al sector de denominación de origen calificada Rioja", pretende la identificación de los factores determinantes de los resultados alcanzados por las empresas adscritas a la DOC de Rioja. Esta investigación identificó y cuantificó, desde la Teoría de Recursos y Capacidades empresariales los factores implicados en los resultados empresariales. La presente investigación pretende asimismo, identificar y cuantificar desde la mencionada Teoría de Recursos y Capacidades empresariales, los factores determinantes de la diferenciación de precios en los vinos. El estudio ha retomado muchas de las variables recogidas en el trabajo de la Rioja, si bien ha ampliado tanto el grupo de variables relacionadas con los recursos tangibles (variedades de uva, método de vinificación, etc), como aquellas asociadas al comportamiento estratégico (canales comerciales, criterio de fijación de precios, etc).

c) La Universidad de la Rioja (Ruiz y al., 2004), han identificado aquellos factores que según los oferentes influyen en la determinación de los precios de los vinos. Algunos factores señalados por los agentes económicos hacen referencia a cuatro dimensiones: calidad del producto (más percibida que intrínseca); política de productomercado (marca de empresa y la marca de la Denominación de Origen “DO”); política de precios (curva de oferta y demanda) y, dimensiones relacionadas con la comunicación comercial. La presente investigación también recoge la valoración subjetiva que efectúan los oferentes (en este caso los directores o gerentes de las bodegas), sobre la influencia de diez variables en la diferenciación de los precios de los vinos.

\section{ESTRUCTURA DEL TRABAJO DE INVESTIGACIÓN}

El planteamiento del trabajo se sustenta en el análisis de un grupo de empresas pertenecientes a un mismo entorno general y específico con el objeto de poner de manifiesto los aspectos de carácter estrictamente empresarial que mejor puedan explicar la competitividad de las mismas.

El proceso de investigación empírica se ha estructurado en seis partes diferenciadas por capítulos:

\section{- Metodología}

En este capítulo se ha efectuado una delimitación del subsector vinícola, sobre el cual se ha planteado la presente investigación; posteriormente se ha determinado la población universo de las empresas pertenecientes a dicho subsector en el ámbito territorial regional, y se ha conformado la muestra con las empresas que de manera efectiva han contestado el cuestionario de la encuesta postal. Seguidamente se han descrito las principales fuentes de información utilizadas, tanto primarias (encuesta postal), como secundarias provenientes de diversos organismos e instituciones relacionadas con el sector vitivinícola. Por último, en 
el análisis de la información recogida se hace referencia a las principales técnicas de análisis utilizadas (técnicas descriptivas, univariantes, bivariantes y multivariantes, que permiten dar a conocer por categorías de empresas, los principales factores asociados a la competitividad de las mismas y, en particular a la diferenciación vía precios.

\section{- Fundamentación teórica y modelo de análisis propuesto}

En este capítulo se han desarrollado los aspectos teóricos que fundamentan la situación competitiva de las empresas y qué elementos explican las diferencias de competitividad entre las empresas, teniendo en cuenta que en la definición de está última participan muchos factores de carácter diversos, macroeconómicos, sectoriales y empresariales. Desde la teoría de los Recursos y Capacidades se considera que la empresa dispone de una serie de recursos que constituyen el fundamento sobre el que establecer una ventaja competitiva. Se concreta un modelo a contrastar, identificando los factores que son relevantes como elementos definitorios de la situación competitiva y como variables potencialmente explicativas de la diferenciación por precios.

\section{- Descripción general del sector vitivinícola}

Se han descrito un conjunto de factores o elementos externos (sociales, económicos, políticos, tecnológicos, etc.) que son relevantes, pueden ejercer influencia, y que proporcionan un marco de actuación general dentro del subsector vinícola, aunque cada empresa reciba los impactos de forma distinta en función de su realidad particular. Como entornos externos al sector se han tenido en cuenta el internacional, el europeo, el nacional y el propio regional.

\section{- Análisis del subsector vinícola en la Comunidad Valenciana}

Se han analizado un conjunto de factores o elementos internos (desde el aprovisionamiento de la materia prima, hasta la comercialización de los productos finales) que son relevantes y marcan las diferencias entre niveles de competitividad en las empresas dentro del subsector vinícola.

\section{- Diagnóstico del subsector vinícola en la Comunidad Valenciana}

En este capítulo se ha determinado respecto del subsector vinícola regional: la posición competitiva, la estructura y la dinámica estructural del mismo. La posición competitiva se ha analizado en términos de factores exógenos (Oportunidades y Amenazas) y endógenos (Fortalezas y Debilidades) según el modelo DAFO. La estructura se ha definido siguiendo el planteamiento metodológico propuesto por Porter en el modelo de las cinco fuerzas. La dinámica estructural del mismo se ha determinado a través del modelo del diamante nacional de M. Porter. Finalmente se han integrado los modelos expuestos con objeto de extraer unas conclusiones más sólidas en relación los factores relacionados con la competitividad de las empresas. 
- Factores explicativos de la competitividad por diferenciación de precios

En este capitulo se recoge en primer lugar una aproximación teórica al problema planteado en el objetivo específico de la presente investigación, describiendo sucintamente los principales estudios empíricos relacionados y las principales conclusiones que se derivan de los mismos. En segundo lugar se cuantifica la aportación de la marca colectiva y la operación de embotellado al precio del vino. En tercer lugar, y en el ámbito de los vinos con DO y embotellados se cuantifica la aportación de los factores empresariales al precio de los distintos tipos de vino (blanco, rosado, tinto, crianza, reserva y granel). Por último se cuantifica la valoración subjetiva que realizan los dirigentes de las bodegas sobre las diez posibles variables más directamente relacionadas con el precio de los vinos regionales.

\section{- Conclusiones y valoración final}

Se realiza un resumen de los principales resultados que se han derivado de la aplicación empírica, así como las principales y más relevantes implicaciones para la dirección de las empresas. También se identifican aquellas restricciones que ha afectado a su planteamiento y desarrollo, y que limitan por tanto la bondad de sus resultados y conclusiones. Por último, y teniendo en cuenta las limitaciones apuntadas, se proponen distintas líneas de trabajo, que pueden permitir progresar en el propósito de la investigación planteado, más allá de los resultados obtenidos. 

CAPÍTULO II

METODOLOGÍA 



\section{DELIMITACIÓN DEL SECTOR}

Dentro del sector vitivinícola se han establecido límites al mismo sobre las bases siguientes: el producto, el subsector y el marco geográfico del mercado.

En relación al producto, se han considerado los vinos secos (no dulces) y tranquilos (sin gas), blancos, rosados y tintos (joven, crianza y reserva), aunque muchas de las empresas acometan también la elaboración de otras bebidas o productos vitivinícolas (mostos, vinos gasificados o dulces, alcoholes, etc.).

Con referencia al subsector se considera que la cadena de valor empieza en el productor y suministradores de materias primas auxiliares, continua con el elaborador 0 industria vinícola, sigue con la comercialización o distribución, y acaba en el consumidor. En la investigación se han obviado los dos extremos de la cadena, tanto la situación de los productores como las de los consumidores, aunque lógicamente con continuas referencias a ellos, ya que la cadena es un continuo.

El subsector objeto de la investigación ha sido el elaborador de vinos o vinícola que está integrado por el conjunto de productores representativos de los procesos de elaboración, crianza, almacenamiento, embotellado, circulación y comercialización del vino, como etapas que componen la cadena de producción. No obstante dentro de este ámbito subsectorial existe una alta especialización funcional, a partir de la cual no todas las empresas inscritas participan del mismo modo en las distintas etapas que componen la cadena de producción. En este sentido, el subsector está integrado por las bodegas que al menos elaboran y/o envejecen para comercializar sus vinos, aunque existen bodegas que integran en una misma empresa todas las etapas de la cadena de valor, desde la producción hasta la comercialización de sus vinos.

En lo que se refiere al marco geográfico de actuación, el subsector vinícola está integrado por aquellas empresas cuyos establecimientos se encuentran en el territorio de la Comunidad Valenciana, aunque con referencias a escala nacional, europea y mundial.

Dentro del subsector vinícola y debido a su trascendencia económica, se han delimitado ámbitos muy concretos como las correspondientes Denominaciones de Origen (DDOO) de Alicante, Utiel-Requena y Valencia e Indicación Geográfica de la Tierra de Castellón, que reúnen a todo un conjunto de empresas que comparten de forma más restrictiva que las empresas no inscritas en tales figuras de calidad, unas condiciones de trabajo idénticas al estar sometidas a una normativa que delimita estrechamente importantes áreas de actividad productiva, tales como la política de aprovisionamiento de la materia prima principal, la definición y proceso de transformación del producto, su envasado, y finalmente su etiquetado, en el que incorporan una marca genérica común que presupone compartir una imagen colectiva en el proceso de comercialización.

\section{DETERMINACIÓN DE LA POBLACIÓN}

Si se tiene en cuenta el estudio denominado "Fichero Coordinado de Industrias Alimentarias, agrarias y forestales”, llevado a cabo por el MAPA en el año 2002, de ámbito nacional y por comunidades autónomas, el universo de las bodegas se ha 
constituido teniendo en cuenta entre otros requisitos, el de tener al menos un empleado asalariado; de este modo en la Comunidad Valenciana se cifran 130 bodegas.

Por otro lado y considerando que la población de interés está inicialmente constituida por el conjunto de bodegas pertenecientes a las figura de calidad mencionadas anteriormente, se han considerando los directorios de las empresas inscritas en los tres Consejos Reguladores de Denominaciones de Origen (Alicante, Utiel-Requena y Valencia) con 202 empresas, así como las inscritas en la Indicación Geográfica Vino de la Tierra de Castellón con 5 empresas, lo que totalizan 207 bodegas en todo el territorio regional. Esta fuente de datos por la naturaleza de tales entes se considera la más fiable y actualizada, en relación con la indicada anteriormente.

\section{DELIMITACIÓN DE LA MUESTRA}

La unidad muestral o elemento de la población del cual se obtendrán los datos son las empresas que componen el subsector vinícola anteriormente delimitado. El tamaño de la muestra en este caso coincide con el del tamaño del universo poblacional finito. Dado el reducido tamaño de la población se ha procedido a elaborar un censo en el que se recogiese la relación completa de las bodegas que lo componen. Todas ellas han conformado el grupo objetivo del trabajo de campo.

Una vez concluido éste, la muestra finalmente obtenida está constituida por 110 bodegas (todas pertenecientes a las tres DDOO), el 53 \% de la población universo que han aportado la información válida requerida a partir de la cual se ha creado la base de datos utilizada para la realización de la investigación. Este porcentaje puede considerarse alto para una encuesta postal.

El volumen total de litros de vino elaborados por estas bodegas en la campaña 2002/2003 según la información por ellas declarada ha sido de 2.119.678 hl, lo que supone entorno al 86 \% del volumen producido por la población objetivo (Cuadro 2.1).

\section{CUADRO 2.1}

DISTRIBUCIÓN DE LA POBLACIÓN Y LA MUESTRA POR PERTENENCIAS A LAS DISTINTAS DENOMINACIONES DE ORIGEN

\begin{tabular}{|l|r|r|r|r|r|r|r|r|}
\hline & \multicolumn{4}{|c|}{ POBLACIÓN } & \multicolumn{4}{|c|}{ MUESTRA } \\
\cline { 2 - 10 } & BODEGAS & \multicolumn{1}{|c|}{$\boldsymbol{\%}$} & \multicolumn{1}{c|}{ hl } & \multicolumn{1}{c|}{ \% } & BODEGAS & \% & \multicolumn{1}{c|}{ hl } & \% \\
\hline ALICANTE & 47 & 22,7 & 224.765 & 9,2 & 31 & 28,2 & 174.850 & 8,3 \\
\hline UTIEL-REQUENA & 102 & 49,3 & 1.550 .266 & 63,1 & 60 & 54,5 & 1.421 .040 & 67,0 \\
\hline VALENCIA & 53 & 25,6 & 665.174 & 27,1 & 19 & 17,3 & 523.788 & 24,7 \\
\hline CASTELLÓN & 5 & 2,4 & 16.677 & 0,6 & 0,0 & 0,0 & 0,0 & 0,0 \\
\hline TOTAL & 202 & 100,0 & 2.456 .882 & 100,0 & 110 & 100,0 & 2.119 .678 & 100,0 \\
\hline
\end{tabular}

Fuente: Elaboración propia a partir de los datos de los Consejos Reguladores.

Con relación a la Denominación de Origen (DO), la distribución de la muestra de empresas obtenida es muy similar a la de la población objetivo, con mayor presencia en las DDOO de Alicante y Utiel- Requena, en detrimento de la DO Valencia. Utilizando la prueba Chi-cuadrado se ha podido contrastar la no existencia de diferencias estadísticamente significativas entre la distribución de la población y la de la 
muestra utilizada, tanto con respecto al número de empresas, como al volumen elaborado por tipos de DDOO, por lo que se puede concluir que la muestra utilizada es representativa de la población objetivo del trabajo.

El error de muestreo máximo admisible cometido en el peor de los casos (con las hipótesis de p y q =0,5) y para un nivel de confianza del 95,5\%, considerando el tamaño de la población y el de la muestra se situaría en torno al 6,6 \%.

\section{FUENTES DE INFORMACIÓN}

Se han utilizado dos fuentes de información diferentes: una de carácter primario, la realización de una encuesta postal y otras fuentes consideradas secundarias, como son las provenientes de diversos organismos e instituciones de diferentes ámbitos territoriales y relacionados con el sector vitivinícola, tales como la Organización Internacional de la Vid y del Vino, la Unión Europea, el Ministerio de Agricultura Pesca y Alimentación, la Consellería de Agricultura, Pesca y Alimentación, etc.

En primer lugar se ha procedido a realizar una encuesta a través del envío del cuestionario por correo, que contiene las preguntas o variables de la investigación, y en el que se registran las respuestas de los encuestados. Este método de obtención de información se ha considerado el más apropiado, por un lado considerando el contenido del cuestionario, lo que ha permitido a los encuestados recabar la información que se pedía con tiempo suficiente, y por otro, el extenso ámbito geográfico de la región valenciana, ha permitido recoger la información requerida con el menor costo, en relación con otros métodos de campo.

El pre-test del cuestionario inicial se realizó en el mes de mayo de 2004, lo que obligó a realizar cambios en algunas preguntas que no se entendían bien o que no eran pertinentes.

Las cartas contenían una hoja de presentación, el cuestionario definitivo propiamente dicho, y las instrucciones para la cumplimentación del mismo, y fueron enviadas a las empresas que disponen de algún establecimiento en el ámbito de la Comunidad Valenciana por correo certificado en el mes de junio, estableciendo un plazo para la remisión del mismo, que fue el mes de julio del año 2004. Paralelamente se efectuó un seguimiento telefónico de las encuestas, con objeto de alcanzar el mayor número de respuestas posibles.

El cuestionario (ver Anexo I) se ha construido a partir de la definición de 16 preguntas con subpreguntas, cuyas respuestas permiten deducir todos los posibles factores o indicadores requeridos que se encuentran relacionados con la competitividad de las empresas. El cuestionario es de tipo estructural, con redacción sencilla, inequívoca y respuestas semicerradas y adaptadas al nivel cultural de la persona a la que va dirigido, el gerente o director comercial de la empresa. De los 207 cuestionarios enviados se ha obtenido respuesta válida de 110 bodegas, todas ellas pertenecientes a las DDOO y ninguna de las cinco pertenecientes a la Indicación Geográfica Vinos de la Tierra de Castellón. 
El Cuadro 2.2 contiene la ficha técnica que define las características de la investigación realizada.

\section{CUADRO 2.2}

\section{FICHA TÉCNICA DE LA INVESTIGACIÓN}

\begin{tabular}{|l|l|}
\hline Unidad de análisis & La empresa \\
\hline Tamaño de la población & $\begin{array}{l}\text { Las bodegas que al menos elaboran y/o envejecen para } \\
\text { comercializar vinos tranquilos. }\end{array}$ \\
\hline Ámbito geográfico & $\begin{array}{l}\text { Empresas cuyos establecimientos se encuentran en el territorio } \\
\text { de la Comunidad Valenciana. }\end{array}$ \\
\hline Tamaño de la muestra & 207 empresas \\
\hline Tasa de respuesta & $53 \%$ \\
\hline Fuentes de información & $\begin{array}{l}\text { Primaria: Encuesta postal estructurada. } \\
\text { Secundaria: Organismos e Instituciones públicas y privadas } \\
\text { relacionadas con el sector vitivinícola. }\end{array}$ \\
\hline Fecha del trabajo de campo & Mayo de 2004 a Julio de 2004. \\
\hline Ámbito temporal de la información & Campañas 2000/01 a 2002/03 \\
\hline Tratamiento de la información & Excel profesional y SPSS 11.5 \\
\hline Fuente: Elaboración propia &
\end{tabular}

\section{ANÁLISIS DE LA INFORMACIÓN}

Previamente depurada de errores, la información cuantitativa contenida en el presente cuestionario se ha analizado mediante métodos estadísticos cuantitativos, con la finalidad de su transformación en información comprensible y relevante para el establecimiento de un diagnóstico del sector y la posterior formulación de estrategias tendentes a aumentar la competitividad del mismo, en particular la basada en la diferenciación vía precios.

En la presente investigación se han utilizado las siguientes técnicas de análisis:

- Univariante. Estadísticas básicas, número de casos, suma, máximo, mínimo, media, mediana, distribución de frecuencias, tabulaciones simples.

- Bivariante. Tabulación cruzada de frecuencias y de valores para cada uno de los factores objeto de estudio.

- Multivariante. Análisis de componentes principales, análisis de regresión lineal múltiple y análisis discriminante.

En el tratamiento de la información de la encuesta han sido utilizadas las funciones de análisis de datos de la hoja de cálculo Excel Profesional y la función tablas dinámicas, que crea tablas interactivas que resume los datos para ser analizados desde diversas ópticas. También han sido empleadas diversas funciones relacionadas con el análisis multivariante de los datos que ha proporcionado el programa SPSS 11.5. 


\section{CAPÍTULO III}

FUNDAMENTACIÓN TEÓRICA Y MODELO DE ANÁLISIS 



\section{INTRODUCCIÓN}

En el presente capítulo se desarrollan los aspectos teóricos que fundamentan el propósito central de la investigación que es tratar de identificar cuales son los elementos que explican las diferencias de competitividad entre las empresas. Con relación a esta cuestión se han venido aportando explicaciones de muy diferente carácter según la perspectiva de la teoría económica o empresarial que se utilice.

La teoría neoclásica ha estado particularmente interesada por el conocimiento de los mecanismos de asignación de recursos y la racionalización del funcionamiento de los mercados en la búsqueda de soluciones estables al problema económico. Desde este punto de vista, en una situación de equilibrio a largo plazo, todas las empresas, que son consideradas como agentes económicos individuales y racionales que tienden a maximizar sus resultados a partir de una conocida e idéntica función de producción, obtendrán un beneficio extraordinario nulo.

Sin embargo, en la realidad los beneficios existen y se manifiestan en muy diferente medida entre las distintas unidades empresariales y de forma independiente de la actividad económica concreta que realicen. Los resultados obtenidos por las empresas difieren entre unas y otras, y parece existir una inercia asociada con tales diferencias (Rumelt, Schendel y Teece, 1991). En la práctica, las rigurosas condiciones impuestas por el modelo teórico de competencia perfecta no se cumplen y, a partir de aquí, surge la posibilidad de la aparición de un excedente empresarial extraordinario y sostenido en el tiempo.

No obstante, parece existir acuerdo en indicar que el problema de la competitividad de la empresa es una variable compleja en la que participan muchos factores y de carácter diverso (Cuervo1993, Fernández Rodríguez 1993, Salas 1993 y Galán y Vecino 1997), coinciden en afirmar que el conjunto de factores explicativos del éxito competitivo de la empresa se puede estructurar en tres categorías:

- Factores macroeconómicos, relacionados con el marco económico general.

- Factores sectoriales, que pueden afectar a las empresas en función de la diferente naturaleza de su actividad económica.

- Factores empresariales, que tienen que ver con las características intrínsecas de las propias empresas.

La importancia relativa que se imputa a estos diferentes factores es objeto de controversia y varía con el enfoque teórico adoptado para su discusión. A continuación, se exponen distintas consideraciones y corrientes de pensamiento que permiten desarrollar conceptualmente el significado y la capacidad de influencia que sobre los resultados de la competitividad de las empresas aportan estas variables. 


\section{FACTORES MACROECONÓMICOS.}

Desde esta perspectiva, el funcionamiento empresarial está condicionado por el entorno económico general del que participa la empresa, entorno que es común para cualquier otra unidad empresarial de su misma realidad económica y social independientemente de su cometido productivo concreto, y que queda asociado al ámbito económico de cada país. Dentro de este marco económico general existen cuatro tipos de políticas macroeconómicas que pueden ejercer una notable influencia sobre el comportamiento de la competitividad empresarial (Segura,1992): la política cambiaria que fija la paridad de la moneda y que, en consecuencia, es determinante del precio relativo de los intercambios comerciales, la política de rentas en la que se fija los niveles salariales condicionando por tanto los costes salariales, la política monetaria, la política presupuestaria y la política fiscal.

La configuración del gasto público es decisiva en la generación de un entorno favorable para la mejora de la competitividad empresarial a través de la realización de inversiones en infraestructuras, transporte, comunicaciones, y también por medio de actividades conducentes a la creación de activos intangibles tales como la formación en capital humano, a través de la política educativa, o el desarrollo tecnológico. Además de la intervención de los poderes públicos en la generación de activos de todo tipo generadores de externalidades positivas en el funcionamiento empresarial, cabe añadir la capacidad de intervención en términos del establecimiento de un marco regulador que pueda garantizar el correcto funcionamiento de los mercados corrigiendo las imperfecciones y rigideces en sus estructuras para permitir un mayor grado de eficiencia en las tareas de asignación de recursos (Viñals, 1993).

En el capítulo siguiente, dedicado a la descripción general del sector vitivinícola, se han contemplado los principales elementos relacionados con el entorno económico general en el que encuentra inmerso el sector vitivinícola en los ámbitos geográficos internacional, europeo, nacional y regional.

\section{FACTORES SECTORIALES.}

Existe otro conjunto de factores que influyen de una forma más específica en la competitividad de las empresas según cual sea el tipo de actividad que éstas desarrollen. Bajo esta orientación es el sector, entendido como "un conjunto de competidores que fabrican productos o prestan servicios y compiten directamente unos con otros" (Porter, 1991), la unidad básica de análisis para poder comprender la situación de competencia.

No todos los sectores industriales tienen las mismas características e, independientemente de sus particularidades tecnológicas, su diferente estructura y configuración organizativa ejercen una fuerte influencia sobre las empresas al determinar las reglas de juego competitivas así como sus posibilidades estratégicas (Porter, 1982). De hecho, los resultados medios de los sectores industriales son diferentes entre sí, por lo cual, las posibilidades de éxito de las empresas dependerán también del tipo de sector industrial al que pertenezcan y ello permite afirmar la existencia de factores sectoriales de competitividad (Salas, 1993). 
La Economía Industrial se distancia del análisis macroeconómico tradicional al considerar que en el funcionamiento de estos mercados se dan distintas imperfecciones y ello posibilita la aparición de grados intermedios de competencia. Su modelo teórico descansa en el análisis de las relaciones existentes entre tres conceptos básicos (Jacquemin, 1982):

- La estructura del mercado, es decir, el número de empresas que lo componen, su dimensión, el grado de diferenciación del producto, la existencia de barreras de entrada, y en general aquellos aspectos que determinan sus características más estables.

- La conducta de las empresas, manifestada a través de su estrategia competitiva y de las decisiones que adoptan en materia de productos, precios, publicidad, actividad investigadora, etc.

- Los resultados obtenidos por las empresas expresados en términos de crecimiento, beneficios, o estabilidad de los mismos.

El paradigma estructura-conducta-resultados parte del análisis de las variables estructurales que caracterizan el sector industrial, que se constituyen como elementos condicionantes del comportamiento que puede seguir la empresa que a su vez determina la rentabilidad finalmente obtenida por ésta: los resultados dependen de la conducta seguida por las empresas que a su vez está determinada por la estructura del sector industrial (Clarke, 1993).

El capítulo descriptivo del subsector vinícola de la Comunidad Valenciana, tanto en lo que respecta a los valores agregados como a los valores medios de las empresas que conforman el citado subsector, ha sido elaborado teniendo en cuenta el conjunto de factores empresariales que afectan a cada una de dichas empresas.

Igualmente el capítulo donde se describe la situación competitiva del subsector vinícola de la Comunidad Valenciana (según el modelo DAFO), se cuantifica la intensidad competitiva dentro del mismo (según el modelo de las cinco fuerzas de Porter) y, se definen los determinantes de la situación competitiva (según el modelo del diamante de Porter), tiene su base en el conjunto de los factores empresariales que se presentan en cada una de estas empresas.

\section{FACTORES EMPRESARIALES.}

En este apartado se ha tratado de efectuar una aproximación a la fundamentación teórica de los factores empresariales o más propios de cada una de las empresas del subsector vinícola, como elementos básicos, a través de los cuales se han llevado a cabo todos los análisis necesarios para la consecución de los objetivos marcados.

En los momentos actuales se viene manifestando una progresiva toma de conciencia a favor de la consideración de los factores empresariales como las variables clave de sus resultados. "La competitividad de una empresa no está determinada de forma inequívoca por las características del territorio en que actúe o de los sectores a los 
que formalmente pertenezca. La capacidad de una empresa para tener éxito en mercados cada vez más grandes, abiertos y competitivos depende sobre todo de ella misma" (Fernández Rodríguez, 1992). El éxito de la empresa debe tener un componente individual y exclusivo que se fundamenta en los conocimientos y habilidades que domina la organización entre los que se incluye su sistema de gestión. "El análisis sectorial es relevante en algunos casos, pero no determinante de los beneficios", debiéndose entender la existencia y los resultados de la empresa a partir de sus recursos y habilidades más que en las características estructurales de los sectores (Cuervo, 1993).

Por otro lado, el incumplimiento de las condiciones impuestas por un comportamiento ideal del sistema de precios que mantiene la teoría neoclásica, provoca la aparición de costes relacionados con el funcionamiento del mercado. Una importante presencia de estos costes, llamados de transacción, abre la posibilidad de utilizar otra forma de regulación de los intercambios alternativa al sistema descentralizado que suponga unos menores costes y resulte más eficiente.

La Teoría de los Costes de Transacción adopta un enfoque microanalítico para el estudio de la organización económica y sostiene que las instituciones tienen el propósito y el efecto fundamental de economizar los costes de transacción. Esta propuesta amplía por lo tanto la preocupación que la teoría tradicional manifiesta únicamente por los costes de producción, con la consideración de aquellos otros costes que se originan como consecuencia de la utilización de las distintas alternativas de organización de la economía (Williamson, 1989).

El problema de la organización de la actividad económica se establece en términos comparativos. El hecho de que las transacciones se organicen dentro de una empresa (integración vertical) o entre empresas autónomas (mercado) es una variable de decisión de tal forma que, si los costes asociados al funcionamiento del mercado son superiores a los costes asociados a la organización interna, se elegirá a la empresa como sistema de gobierno de los intercambios. Un ciclo productivo puede estructurarse de distintas formas alternativas, el criterio de decisión a adoptar es el de minimizar el coste total. Este coste se divide en dos partes: los costes de producción y los costes de transacción, que se materializan en los recursos asociados a la coordinación de los intercambios en las distintas estructuras de gobierno (Huerta, 1989).

Los costes de transacción surgen porque la organización del intercambio tiene lugar en condiciones diferentes de las exigidas por la teoría neoclásica en un correcto funcionamiento del mercado. Los costes asociados al funcionamiento del mercado son los derivados de la obtención de información, costes de negociación y los relativos al establecimiento de garantías para el cumplimiento de lo acordado.

En presencia de activos específicos o incertidumbre, estos costes aumentan y puede resultar más eficiente la internalización de las transacciones. La utilización de la fórmula empresa facilita la resolución de los problemas de negociación, la dirección tiene información que le permite limitar el comportamiento oportunista y el recurso a la autoridad es un mecanismo que permite resolver con eficacia los conflictos internos que puedan plantearse (Huerta, 1989). 
Sin embargo, la empresa también incurre en costes de funcionamiento: mantenimiento de la estructura jerárquica de gobierno, recepción y transmisión de información, y los costes de control y supervisión. Estos costes aumentan con el tamaño de las empresas limitando su crecimiento y provocando su sustitución como fórmula organizativa por el modelo de mercado.

La Teoría de los Derechos de Propiedad se encuentra relacionada con la teoría de los costes de transacción pero trata de avanzar en el conocimiento de las circunstancias que hacen que el coste de "administrar" los recursos dentro de la empresa sea bajo en relación al coste de asignar los recursos en transacciones de mercado (Alchian y Demsetz, 1972). Considera a la empresa como resultado de un conjunto de acuerdos y contratos bilaterales carentes de relaciones de autoridad, diferenciándose así de la proposición de los costes de transacción que establece dentro de la empresa el principio de la jerarquía como ordenador de los intercambios en contraposición al modelo de mercado.

La Teoría de la Agencia, trata de analizar las relaciones derivadas de un contrato por el que una o más personas (principal) encomiendan a otra persona (el agente) la realización de un servicio en su beneficio a cambio de una remuneración, relación que supone la delegación de algún grado de autoridad a ese agente (Jensen y Meckling, 1976; Salas, 1996). Desde un planteamiento más amplio (Arruñada 1990), entiende por relación de agencia "todo contrato en el que al menos una parte, el agente, se compromete a realizar algo para otra parte, el principal", no exigiéndose una delegación de capacidad decisoria por lo que esta concepción es aplicable a cualquier tipo de relación cooperativa.

El modelo de agencia supone dos condiciones (Serra, 1993): primero, la existencia de asimetría en la información disponible por las partes, dado que el principal no puede observar el esfuerzo que realiza el agente, ni tampoco lo puede identificar a posteriori, porque el resultado final depende también de otros factores que no son controlables; y, segundo, que entre ambas partes exista una divergencia de intereses, lo cual, unido a que todos los individuos participantes en la relación actúan con el objeto de maximizar su beneficio personal, origina una situación de conflicto.

Numerosos estudios empíricos indican que el efecto industria viene a explicar como máximo un $20 \%$ de la varianza de las rentabilidades de las empresas de manera que, en el mejor de los casos, queda pendiente de justificación un $80 \%$ de esa varianza. También se demuestra la existencia de una alta heterogeneidad en los resultados obtenidos por las empresas de un mismo sector, con diferencias que persisten en el tiempo superiores a las existentes entre empresas de distintos sectores (Fernández, Montes y Vázquez, 1996 y Powell, 1996). Estas consideraciones permiten colegir que los factores propiamente empresariales tienen un alto poder explicativo de los diferentes resultados alcanzados por la empresa dentro de una industria.

Durante los años ochenta, el reconocido trabajo de Michael Porter impulsa un nuevo planteamiento al tratar de vincular las condiciones estructurales con el comportamiento seguido por las empresas, relacionando de este modo la tradición del modelo estructura-conducta-resultados con una nueva actualización de la perspectiva de 
la Dirección Estratégica. El entorno de la empresa es quien establece las condiciones competitivas en las que se desenvuelve su actividad y, por lo tanto, el condicionante de sus resultados. Este medio externo es muy amplio pues incluye todo tipo de fuerzas económicas y sociales, pero la referencia clave del entorno para la empresa lo constituye el mercado en el que ésta compite.

Como indica (Porter, 1982), "la estructura de un sector industrial tiene una fuerte influencia al determinar las reglas de juego competitivas...". La intensidad de la competencia en un sector industrial no es coincidencia ni mala suerte. Más bien, la competencia en un sector industrial tiene sus raíces en su estructura económica fundamental y va más allá del comportamiento de los competidores actuales". El conocimiento de este ambiente competitivo se realiza en la fase de análisis externo del proceso estratégico. A tal fin, Porter propone su famoso modelo de las cinco fuerzas competitivas como metodología para analizar las condiciones estructurales del sector.

Ahora bien, estas variables extraempresariales establecen el marco que condiciona los resultados empresariales, pero no se constituyen como determinantes de tales resultados. Las condiciones de imperfección de los mercados suponen la condición sine qua non para la obtención de resultados extraordinarios de la empresa, pero no los garantiza. Distintas empresas de un mismo sector, compartiendo por lo tanto las mismas oportunidades y amenazas, pueden comportarse de forma diferente y obtener resultados divergentes: "dado que las fuerzas externas por lo general afectan a todas las empresas del sector industrial, la clave se encuentra en las distintas habilidades de las empresas para enfrentarse a ellas" (Porter, 1982). Las empresas actúan como agentes activos y tratan conscientemente de alterar la estructura del sector cuando adoptan decisiones que introducen un cierto grado de imperfección en su funcionamiento a partir de la cual poder obtener beneficios extraordinarios.

En consecuencia, el éxito de una empresa es función de dos aspectos: el atractivo de la industria en la que compite y su posición relativa en ese sector (Porter, 1991 y 1999). Por medio de la estrategia, la empresa fija el modo en el que ajusta su funcionamiento a través de la adopción de medidas y la incorporación de los recursos necesarios que le permitan defenderse mejor de las amenazas y peligros que se manifiesten en el entorno, y aprovechar las oportunidades que éste ofrezca. El comportamiento estratégico adoptado es por lo tanto una dimensión empresarial clave en la determinación de su rendimiento.

Por otro lado, la Teoría Ecológica sugiere que el mecanismo de ajuste al entorno que asegura el mantenimiento de una determinada especie, es el resultado de la existencia, en cada generación, de individuos de esa especie que poseen distintas características, a partir de las cuales se enfrentan a un proceso de selección natural. A través de este proceso, aquellos individuos, empresas, que no reúnen los atributos necesarios para acomodarse a las nuevas condiciones del entorno desaparecen, quedando aquellos otros que sí los tienen. Estos últimos, a su vez, transmitirán tales atributos de forma inalterada a sus generaciones posteriores.

De forma alternativa, la Teoría Evolucionista (Nelson y Winter, 1982) es compatible con la Teoría de Costes de Transacción, y considera que las organizaciones 
manifiestan un determinado comportamiento que se ha ido construyendo a lo largo del tiempo como resultado de su particular proceso de aprendizaje, a partir del cual se han venido generando determinadas rutinas y pautas de funcionamiento que la empresa utiliza para actuar. Estas rutinas establecen la idiosincrasia de la empresa, y determinan lo que la empresa es y lo que es capaz de hacer. Ahora bien, estas rutinas sí son susceptibles de modificación y, por lo tanto, es perfectamente posible considerar que las organizaciones tienen capacidad para cambiar su configuración y comportamiento, siempre que hayan sido capaces de vencer la resistencia natural al cambio que las propias rutinas imponen por su propia naturaleza.

La concepción evolucionista sobre el desarrollo de funciones y generación de rutinas, tiene una clara conexión con la generación de recursos y capacidades empresariales. La trayectoria o historia pasada seguida por las empresas es determinante de la acumulación de recursos y de la instauración de pautas de comportamiento en la utilización de esos recursos, que definen la personalidad actual de la organización y establecen sus posibilidades de actuación futura (Teece, Pisano y Shuen, 1990). Sin embargo, ante unas nuevas condiciones, el comportamiento seguido por la empresa en el pasado puede no ser garantía de supervivencia en el futuro, lo que le obliga al establecimiento de una nueva orientación estratégica.

\section{TEORÍA DE LOS RECURSOS Y CAPACIDADES}

En los últimos años de la década de los noventa, trabajos como los de Cubbin y Geroski (1987), Jacobsen (1988), Hansen y Wernerfelt (1989) o Rumelt (1991), ponen de manifiesto la existencia de resultados divergentes entre empresas pertenecientes a una misma industria y señalan la importancia que corresponde a los aspectos propiamente empresariales en la explicación de tales diferencias.

En las proposiciones de Porter (1982) la obtención del éxito estratégico es consecuencia de una restricción a la competencia en los mercados y el proceso estratégico se limita a elegir el mercado objetivo y determinar la respuesta de la empresa a la amenaza que suponen las cincos fuerzas, considerando que en todo momento la empresa podrá adquirir aquellos recursos necesarios para alcanzar sus objetivos competitivos.

La perspectiva de los recursos y capacidades considera que la clave del éxito estratégico reside en el interior de la empresa y sugiere una aproximación dinámica donde, a partir del reconocimiento de la existencia de heterogeneidad de las empresas en cuanto a su dotación de medios productivos, son determinantes los procesos de generación e incorporación de recursos distintivos sobre los cuales fundamentar su plan estratégico (Teece, Pisano y Shuen, 1990; Hunt, 1997). La clave para la consecución del éxito estratégico reside en la capacidad de la empresa para establecer una ventaja competitiva duradera. Barney (1991) dice que una empresa tiene una ventaja competitiva "cuando implementa una estrategia de creación de valor que no está siendo implementada simultáneamente por ningún otro competidor actual o potencial", y esta ventaja es sostenible "cuando estas otras empresas no pueden duplicar los beneficios de esta estrategia". Por su parte, Grant (1995) define la ventaja competitiva desde el punto de vista de su resultado cuando la empresa percibe, o potencialmente puede percibir, 
una tasa de beneficios más alta y asocia su sostenibilidad con la habilidad de los competidores para la imitación o innovación.

La Teoría de los Recursos y Capacidades parte por lo tanto de la consideración de los recursos como concepto central, constituyéndose en su elemento básico de análisis (Grant, 1991). El concepto de recurso recibe distintas expresiones y definiciones según los autores que las han formulado pero, de forma general, se puede entender como cualquier factor o elemento que utiliza la empresa para la obtención de los bienes o servicios que destina a sus clientes. Se han propuesto diferentes clasificaciones de recursos de la empresa. La más elemental y que sintetiza mejor la aportación clave de este enfoque, es la que distingue entre recursos tangibles y recursos intangibles.

Los recursos tangibles son aquellos que tienen una expresión material en forma de elementos productivos físicos o de medios financieros. Son los recursos más fácilmente identificables, apareciendo incluso en la relación de inventario del patrimonio de la empresa. Su valoración está recogida en los documentos contables por lo que, independientemente de todas las consideraciones que se deseen hacer sobre las limitaciones de la contabilidad para recoger de forma válida el valor económico de tales bienes, existen criterios comúnmente aceptados para realizar esa medición, aunque es preciso señalar que el criterio contable ignora la dimensión estratégica de tales factores, aspecto de relevancia en el presente trabajo.

Por otro lado, los recursos intangibles son aquellos factores que no tienen una manifestación material o física. Son recursos que guardan relación con el conocimiento y la información. Se refieren a factores tales como la capacidad de innovación tecnológica de la empresa, la imagen comercial de sus productos, una habilidad para abrir nuevos mercados, o el dominio de canales de distribución, etc. La identificación de tales recursos, dada su intangibilidad, es difícil y lo es aún más su valoración económica. Estos factores no aparecen recogidos en los estados financieros, si bien esta falta de reconocimiento formal no impide que cada vez exista una mayor coincidencia en considerarlos como elementos claves en el funcionamiento empresarial $\mathrm{y}$, en consecuencia, determinantes de su potencial estratégico. Dentro de la categoría de recursos intangibles se incluyen otros factores de especial importancia como son los recursos humanos. Los recursos humanos tienen evidentemente una base física, como son los individuos que forman parte de la organización, si bien su contribución a la actividad empresarial tiene un carácter intangible en términos de conocimientos, capacidad de racionalización o habilidades.

Todo el conjunto de recursos tangibles e intangibles de la empresa constituyen lo que la empresa es y son los factores de los que dispone para llevar a cabo su proyecto estratégico conducente a la construcción de una ventaja competitiva sostenible que le permita obtener un rendimiento alto y duradero.

Ahora bien, no todos los recursos son igualmente valiosos para la consecución del éxito. En la actividad de análisis estratégico, previa a la formulación del plan, se deberán identificar los puntos fuertes de la empresa, aquellos factores disponibles que domina y le pueden situar en una posición de superioridad sobre sus competidores. La 
pregunta es de qué manera se pueden distinguir estos factores, es decir, cuáles son aquellos recursos con mejor potencial de generación de rentas durante un mayor periodo de tiempo.

A partir de las aportaciones de Barney (1991), Amit y Schoemaker (1993) y Grant (1995), se pueden establecer los siguientes criterios y aspectos a considerar:

a) Una primera característica es que se trate de un recurso valioso o relevante, esto es, que aporte a la empresa la posibilidad de mejorar su desempeño al relacionarse con algún aspecto de éxito en su negocio.

b) Por otro lado debe de tratarse de un recurso escaso. Un recurso valioso pero disponible para cualquier empresa proporcionaría a todas ellas la posibilidad de obtener un aprovechamiento de igual eficacia que impediría la generación de diferencias competitivas.

c) Su durabilidad. Unos recursos son más duraderos que otros y, por lo tanto, los primeros son mejores candidatos para el sostenimiento de la ventaja generada.

d) Que sea imperfectamente sustituible, de tal manera que no existan otros recursos equivalentes en cuanto a su función estratégica que permitan generar resultados similares, manteniéndose de este modo en el tiempo el carácter de recurso escaso y único.

e) Que tengan una imperfecta movilidad, para dificultar su adquisición por parte de otras empresas. Si sus rivales competidores pueden adquirir en condiciones similares los recursos necesarios para imitar la estrategia de éxito de la empresa, su ventaja competitiva tendrá una reducida duración. Grant (1995:139) indica que las tres principales fuentes de inmovilidad son: la inmovilidad geográfica que puede implicar altos costes de recolección de los recursos, la existencia de una información imperfecta que dificulte la valoración de su capacidad productiva y el tratarse de recursos específicos de la empresa, lo cual se traduce en una pérdida de su valor cuando salen de ella.

f) Que sean imperfectamente imitables. Las dificultades que puedan existir para conseguir que el recurso sea difícilmente reproducible por otras empresas contribuyen igualmente al sostenimiento de la ventaja competitiva proporcionada.

g) Un último aspecto que es preciso tener en cuenta, es el grado de apropiabilidad que la empresa tiene sobre los resultados del recurso. En algunos casos, como sucede en general con los recursos tangibles, el derecho de propiedad está perfectamente identificado. Sin embargo, en otros supuestos de recursos intangibles, como sucede con el capital humano, la apropiación de sus rendimientos no está garantizada. Cuando existe 
ambigüedad sobre la propiedad de los recursos, la asignación de las rentas que éstos generan dependerá del poder de negociación que tengan las partes.

Ahora bien, la mera tenencia de los recursos, no garantiza por sí misma la consecución de unos buenos resultados. En palabras de Penrose (1962) "estrictamente hablando, los factores esenciales en el proceso de producción no son los recursos en sí, sino solamente los servicios que tales recursos rinden. Los servicios que rinden los recursos son una función del modo en que se emplean; el mismo recurso empleado para fines diferentes o de maneras diferentes y en combinación con tipos o cantidades diversas de otros recursos, rinde servicios también diferentes". Desde el punto de vista estratégico, lo relevante no es tanto disponer de recursos, sino conseguir su aprovechamiento eficaz en la generación de capacidades para la empresa.

De este modo, las capacidades o competencias se convierten en un elemento clave en la generación de ventajas competitivas que finalmente podrán conducir a la obtención de beneficios superiores. Al igual que en el caso de los recursos, lo relevante es llegados a este punto, proponer criterios que permitan identificar cuáles son aquellas capacidades que pueden ser fundamento para el establecimiento de una ventaja competitiva sostenible.

La Teoría de los Recursos y Capacidades ofrece un marco conceptual desde el que poder entender el origen de la ventaja competitiva y los factores que influyen en su sostenimiento. En el planteamiento y desarrollo de esta teoría se pone de manifiesto el especial protagonismo que adquieren los llamados recursos intangibles de la empresa. Esta relevancia teórica se ve reforzada por las conclusiones a las que han llegado distintos trabajos empíricos que han venido a reflejar que una característica de las organizaciones con éxito es el reconocimiento que conceden a los procesos de aprendizaje, el conocimiento tecnológico, la reputación o la lealtad del consumidor, es decir, a diversos "activos invisibles" (Itami y Roehl, 1987) que se constituyen como los factores determinantes de la ventaja competitiva de las empresas. De hecho un claro indicador de la importancia que se atribuye a los factores intangibles puede deducirse de la comparación entre el balance de situación de las empresas que cotizan en bolsa y el valor de mercado de sus acciones (Hall, 1992).

Desde el punto de vista teórico, las características propias de los recursos intangibles, hacen que estos activos tengan una especial significación en el establecimiento de una ventaja competitiva sostenible para la empresa. La valoración genérica de los activos intangibles merece las siguientes consideraciones:

a) Se trata de recursos valiosos, como lo avalan las referencias que se acaban de señalar y otros trabajos empíricos referidos más adelante.

b) La duración de los recursos intangibles puede ser en muchos casos superior ala de los recursos tangibles puesto que, así como los activos físicos se deprecian por razones de obsolescencia o por su simple uso, la utilización repetida y la experimentación de algunos recursos intangibles incrementa su nivel de dotación. Activos como la marca o la reputación, se consolidan con el tiempo. 
c) Su intangibilidad dificulta, e incluso en ocasiones impide, su adquisición en el mercado, por lo que tales recursos deben ser generados internamente por la propia empresa. Todo ello implica que se trata de recursos escasos y normalmente muy específicos de cada negocio lo que dificulta también, además de su comercialización, su sustituibilidad por otros recursos alternativos.

d) Son difícilmente transaccionables por dos motivos: primero, porque se trata de activos cuyos rendimientos se alcanzan a medio y largo plazo, por lo cual existe alta incertidumbre sobre tales resultados que dificulta la determinación de su precio en el momento de su transacción; segundo, porque su explotación se realiza por medio de su interrelación con otros recursos (Salas, 1996).

e) Esta dificultad en su movilidad propicia el sostenimiento de la ventaja competitiva generada que también queda asegurada por las dificultades de su imitación por medio de la reproducción interna. A la ambigüedad causal que se genera como consecuencia de las complejas relaciones que mantienen con otros recursos, se trata de recursos "socialmente complejos", se une la característica de manifestar deseconomías en la compresión del tiempo necesario para su acumulación (López Sintas, 1996. Los recursos intangibles exigen un largo periodo de tiempo para su acumulación, periodo que muy difícilmente puede reducirse aunque se incremente el esfuerzo en su creación.

f) La cuestión de su apropiabilidad es un aspecto que tiene en este caso un especial interés. Como indica Salas (1996) el denominador común de los recursos intangibles es que se basan en la información, lo que supone que tienen el carácter de bienes públicos. Esta condición tiene interés en tanto que su utilización puede dar origen a economías de alcance si tales recursos se aplican a usos diferentes. Algunos intangibles, como es el caso de las patentes, pueden ser objeto de protección expresa, pero en otros casos, especialmente en el supuesto del capital humano, la apropiabilidad de sus contribuciones puede ser discutida, discrepancia que afectará a la distribución de las rentas generadas por esos recursos entre la empresa que los usa y sus propietarios (Peteraf, 1993). En este último supuesto el poder negociador de la empresa aumentará en la medida en que la eficacia de ese recurso intangible no dependa de sí mismo sino de su vinculación con otros recursos diferentes.

\section{MODELO DE ANÁLISIS EN FACTORES EMPRESARIALES}

A partir de los fundamentos teóricos que han sido enunciados, en este capítulo se procede a estructurar el problema planteado en la presente investigación, identificando aquellos elementos más significativos y proponiendo el sistema de interdependencias que los relaciona. El objetivo general de este trabajo consiste en establecer la situación competitiva del subsector vinícola en la. Comunidad Valenciana. El objetivo específico 
se centra, de un lado, en intentar establecer, qué elementos y en qué grado contribuyen a la diferenciación de precios observada entre las empresas que configuran dicho subsector. Como ya ha quedado reflejado, el problema de la determinación tanto de la situación competitiva como de la competitividad por diferenciación de precios es una cuestión compleja y controvertida. En este sentido la posible resolución del mismo habrá de considerar tanto factores externos a la empresa, como también factores puramente empresariales.

Desde la Teoría de Recursos y Capacidades se considera que la empresa dispone de una serie de recursos, más amplios que los contenidos en la relación de activos que figuran en los estados contables, que constituyen el fundamento sobre el que se puede establecer su ventaja competitiva. Los recursos tangibles y de modo especial los intangibles, así como las capacidades organizativas que haya desarrollado la empresa para un mejor aprovechamiento de los mismos a través de su utilización coordinada, determinan lo que la empresa es y aquello que le permite distinguirse de los restantes competidores, estableciendo las bases para formulación e implantación de su proyecto estratégico (gráfico 3.1).

GRÁFICO 3.1

RECURSOS Y VENTAJA COMPETITIVA

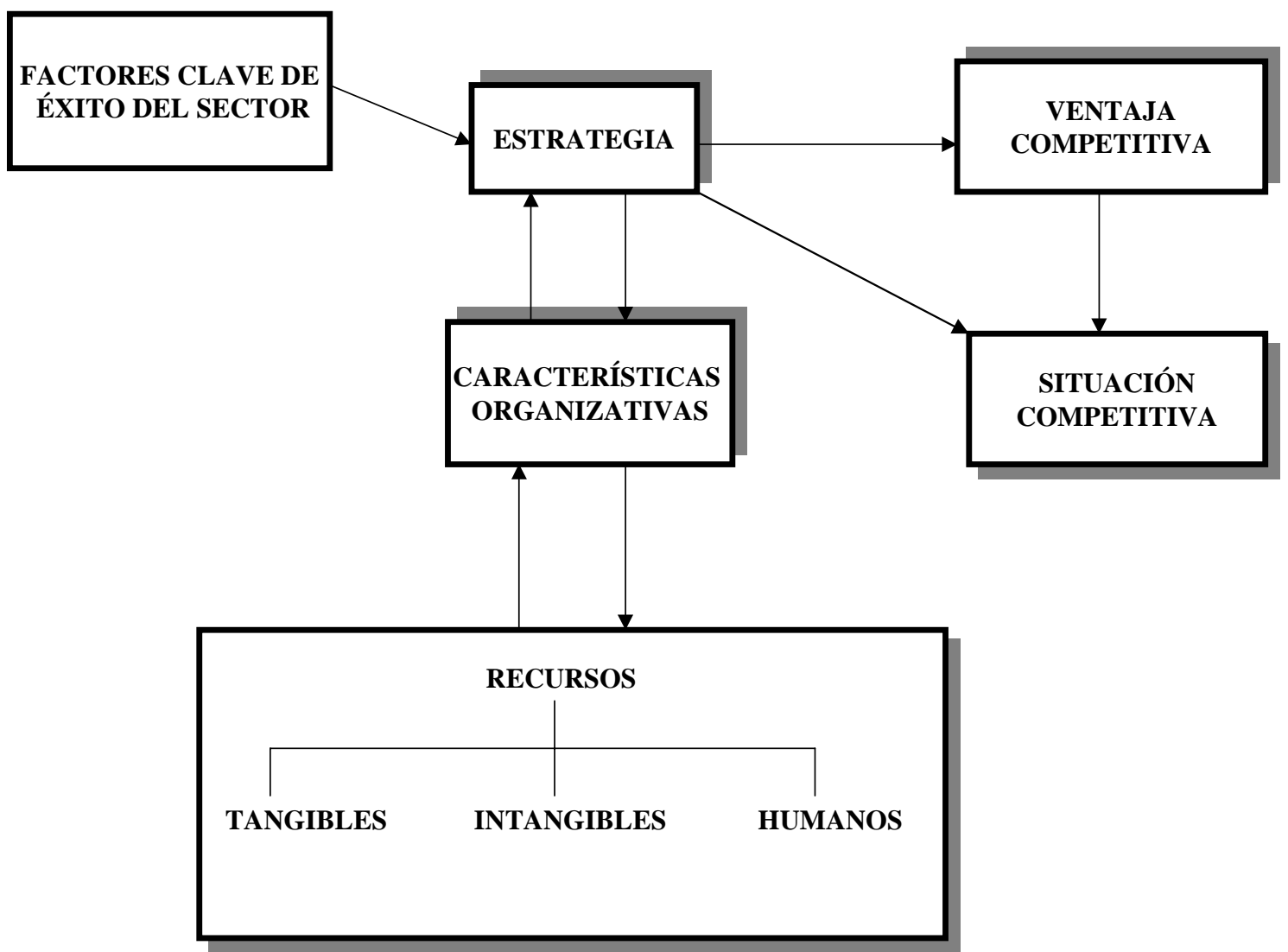

Fuente: Adaptado de Grant, 1996 
Por lo tanto, en un ánimo integrador de los planteamientos propuestos desde la Economía Industrial y la Teoría de los Recursos y Capacidades, puede considerarse que los factores que conforman el perfil específico de la empresa, junto con aquellos que configuran la estructura del sector en el que ésta opera, constituyen las referencias básicas a partir de las cuales la empresa establece su plan estratégico. El problema de la estrategia tiene que ver con el ajuste de la empresa a las oportunidades del entorno (Grant, 1996; Porter, 1982). En este mismo sentido, Henderson y Mitchell (1997) consideran que existen recíprocas relaciones entre el entorno y la empresa: ambos configuran la estrategia y el resultado y, a la vez, las interacciones entre estrategia y resultado conforman las capacidades organizativas de la empresa y su ambiente competitivo.

En el presente trabajo, la limitación del ámbito de estudio a las empresas instaladas en el mismo subsector de la industria vinícola, ha permitido ignorar los condicionantes de carácter macroeconómico y las referencias estrictamente sectoriales, para centrarse exclusivamente en aquellas variables con un contenido más empresarial. De esta manera, descontado el efecto de los factores que conforman el entorno empresarial genérico y específico, se puede identificar con mayor claridad cuál es el poder explicativo de los factores intraempresariales, intentando determinar su grado de influencia sobre la situación competitiva y, concretamente sobre la competitividad sobre la base de la diferenciación de precios obtenidos por las empresas de un mismo marco económico global y condicionadas de igual modo por su pertenencia a una misma estructura de mercado.

La investigación propuesta adopta una perspectiva transversal que incide en la búsqueda de las vinculaciones que puedan existir entre los diversos recursos disponibles por la empresa en un momento determinado en el tiempo, y que son aplicados según un proyecto estratégico en unas condiciones de entorno dadas en ese espacio temporal, con su situación competitiva y en último término con la diferenciación de precios que se están alcanzando.

La concreción del modelo a contrastar exige, en primer lugar, identificar los factores que, a la vista de fundamentos conceptuales, son relevantes como elementos definitorios de la situación competitiva, y como variables potencialmente explicativas de la diferenciación de precios $y$, en segundo lugar, establecer el significado de los términos situación competitiva y competitividad por diferenciación de precios.

Tras la revisión de algunas de las propuestas teóricas más significativas, los factores de empresa explicativos seleccionados, han sido agrupados en cuatro apartados: identidad corporativa, recursos tangibles y recursos intangibles y comportamiento estratégico. Los tres primeros tratan de recoger las variables que mejor expresan los atributos de la empresa, así como el conjunto de recursos productivos de que dispone y sobre los cuales puede fundamentar su proyecto estratégico.

Dentro del concepto de identidad corporativa se reúnen algunas variables que configuran la personalidad de la empresa y que se consideran relevantes para la comprensión de su comportamiento desde algunas perspectivas que, como la Teoría Evolucionista o la Teoría Ecológica, llaman la atención sobre la edad de la empresa 
como un aspecto que determina su capacidad de ajuste a las condiciones medioambientales y por lo tanto de éxito en su actuación; por su parte, la Teoría de los Derechos de Propiedad y la Teoría de la Agencia establecen su discusión en torno a las repercusiones que sobre la eficiencia empresarial puede tener la configuración organizativa y la asignación de las tareas de dirección, ejecución y supervisión.

La inclusión de los recursos tangibles e intangibles como factores potencialmente condicionantes del resultado empresarial, está justificada, independientemente del interés que sobre el tamaño de las empresas se ha manifestado desde la Economía Industrial, por el nuevo marco conceptual aportado por la Teoría de Recursos y Capacidades. Desde este enfoque se propone una distinción básica entre ambos tipos de recursos, separando aquellos de carácter material, como la capacidad productiva instalada, su grado de aprovechamiento, de aquellos otros de naturaleza inmaterial como es el caso del capital humano, o las habilidades tecnológicas y comerciales.

Por otro lado, la categoría de comportamiento estratégico agrupa a aquellas variables internas de la empresa que tienen un mayor carácter conductual, al sintetizar la orientación estratégica adoptada y que puede visualizarse a través de distintos aspectos que configuran la empresa y su planteamiento de negocio. El grado de integración de las actividades productivas, la amplitud y diversidad de sus mercados y productos, constituyen probablemente las dimensiones que mejor pueden caracterizar el comportamiento estratégico practicado por la empresa.

Finalmente, la valoración de la posición competitiva y de la competitividad por diferenciación de precios obtenidos por las empresas dependerá, de los criterios empleados para la medición de los mismos; cuestión igualmente controvertida sobre la que pueden formularse diferentes planteamientos.

\section{VARIABLES DEL MODELO EN FACTORES EMPRESARIALES}

Presentado el modelo general a analizar, en el presente apartado se ha desarrollado el contenido de los distintos grupos de variables inicialmente contemplados, determinando y describiendo aquellas magnitudes que se proponen como indicadores de la situación competitiva y, de los factores empresariales potencialmente explicativos de la diferenciación de precios, observada entre los productos comercializados por las mismas.

Para la mayor parte de las variables seleccionadas, se presenta una breve referencia de aquellos elementos conceptuales que permiten justificar su consideración como variable relevante en el modelo planteado y, se proponen criterios de medición específicos teniendo en cuenta, además del significado teórico de cada magnitud, su adecuación al contexto de la población objeto de este estudio.

Se ha comenzado en primer lugar por la revisión de las variables explicativas, que a su vez configuran los grandes grupos mencionados en el apartado anterior (identidad corporativa, recursos tangibles, intangibles y comportamiento estratégico), 
para acabar con las variables explicadas (situación competitiva, competitividad por diferenciación de precios).

\subsection{Identidad corporativa}

El concepto de identidad corporativa o identidad organizativa tiene que ver con aquel conjunto de variables que contribuyen a definir la personalidad de la empresa, el "estado civil" de la organización. Las dimensiones que definen la identidad corporativa de una empresa pueden tener un carácter muy diverso y vienen siendo clasificadas en dos grupos diferentes de variables (De la Fuente y otros, 1997): por un lado, están las variables llamadas demográficas, que incluyen aspectos tales como la edad de la entidad $\mathrm{y}$, por otro lado, las variables de propiedad o de dirección (Kalika, 1985) que incluyen cuestiones que tienen que ver con la forma jurídica de la empresa, la estructura de la propiedad, el carácter familiar en la gestión.

En este caso, para la caracterización de la identidad corporativa se han empleado aquellas variables más expresivas como la antigüedad de la entidad, la composición y tipología de su accionariado y la forma jurídica adoptada.

\subsubsection{Antigüedad}

La antigüedad de la entidad es una variable relevante y constituye uno de los factores de contingencia que afectan a la configuración de la estructura organizativa adoptada por una empresa (Mintzberg, 1993). En contestación a la pregunta de cuál es, si es que existe, la relación entre diseño organizativo y edad de la institución, se ha llegado a formular un modelo del "ciclo de vida organizativo" en el que se reconoce una sucesión de etapas en la vida de las organizaciones a las que están asociadas distintas estructuras organizativas caracterizadas por diferentes respuestas en términos de grado de especialización de las tareas, nivel de formalización del comportamiento, centralización-descentralización de la estructura o tipo de coordinación dominante (De la Fuente y otros, 1997). Por otro lado, la edad de la empresa está vinculada con el desarrollo de la organización, constituyendo una variable básica de referencia en los estudios interesados por la evolución y cambio organizativo, así como por el análisis de la mortandad de las organizaciones.

A partir de las consideraciones que establecen la Teoría Ecológica y la Teoría Evolucionista, la cuestión que se plantea es en qué medida la edad de la organización afecta a su propensión a la evolución y el cambio interno y si esta variable puede condicionar el éxito o fracaso de la empresa y, por lo tanto, su supervivencia o desaparición. En el presente trabajo, la edad de las empresas tiene interés en la medida en que puede poner de manifiesto la posición de ventaja de la empresa con respecto a distintas variables relevantes en la consolidación y mejora de sus resultados.

Los distintos trabajos realizados en relación con la evolución organizativa coinciden en medir la edad a través del número de años transcurridos desde la creación de la empresa (Santos, 1997; Delacroix y Swaminathan, 1991). Este ha sido el criterio utilizado en este trabajo, independientemente de los cambios que se hayan podido producir en la forma jurídica de la empresa a lo largo de su vida. 


\subsubsection{Estructura de la propiedad}

En este apartado se quiere hacer referencia al grado en el que la propiedad de la empresa es detentada por sus titulares, siendo interesante conocer no sólo cuál es su número y las participaciones que tienen, sino también su tipología.

La configuración de la propiedad de la empresa se puede expresar a través de dos aspectos clave como la distribución del capital social entre los distintos propietarios y su tipología. Estas variables pueden considerarse a su vez indicadoras de la forma en la que se manifiesta la actividad de control interno y del grado en el que éste es ejercido por la propiedad, pudiéndose caracterizar teniendo en cuenta tanto el grado de control, en términos de su intensidad, como el modo de control, dimensión que se relaciona con la personalidad del agente que lo realiza.

Para valorar el grado de control, el criterio comúnmente aceptado se basa en la estimación de la propensión al control a partir de la distribución de la propiedad, pudiéndose distinguir distintas categorías, desde aquellas que suponen un mayor poder por parte de los propietarios de la empresa, hasta el extremo contrario en el que tal poder es ejercido por sus órganos de dirección.

Con el objeto de utilizar un criterio más operativo y siguiendo el planteamiento de Galve (1992), a efectos de este trabajo se va a considerar que el grado de control existente en la empresa puede ser de dos tipos: un control efectivo, cuando el accionista o grupo afín principal detente más del $50 \%$ del capital de la sociedad y por lo tanto posee el número de votos necesario para imponer un control mayoritario sin necesidad de realizar un esfuerzo de supervisión extraordinario; o un control difuso, cuando tal accionista tenga una participación en el capital social inferior al 50\%, que impide una mayoría de voto en un único accionista obligando al establecimiento de coaliciones.

Evidentemente, este criterio, como cualquier otro que se base únicamente en la mera valoración de la participación relativa de los accionistas, puede ser insuficiente para delimitar la intensidad del control que se ejerce porque, por un lado, además de tener el poder, para que exista un control efectivo es preciso ejercerlo y, por otro lado, porque aún cuando el accionista principal tenga una participación minoritaria, su poder real puede ser diferente dependiendo del modo de asignación de la propiedad restante entre los demás accionistas y de su capacidad para establecer acuerdos que faciliten mayorías duraderas que a su vez, serán más difíciles de mantener cuanto mayor sea la fragmentación del capital.

La segunda dimensión a considerar se refiere al modo de control o forma en la que éste es llevado a cabo. Este aspecto se vincula con las características de sus titulares, pudiéndose establecer a tal fin la siguiente tipología de grupos de poder:

1. Individual o grupo accionista familiar.

2. Bancos e instituciones financieras, sociedades o grupos empresariales nacionales o extranjeros. 
Cada empresa será asignada al tipo de grupo de control que corresponda con aquella categoría a la que pertenezca su accionista principal.

Finalmente, se considerará también como posible variable explicativa de la competitividad de las empresas, otro aspecto de interés relacionado con la configuración de la propiedad de la empresa como es la forma jurídica adoptada, dadas las consecuencias que pueden derivarse de la determinación del grado de responsabilidad y de riesgo que contraen sus propietarios, así como en la adopción de la correspondiente estructura de gobierno. Dada la especial significación organizativa, económica y social de las formas societarias respecto a las que no lo son, se ha analizado esta variable en términos dicotómicos distinguiendo:

1. Bodegas cooperativas: Cooperativas agrarias de $1^{\circ}$ grado y $2^{\circ}$ grado, sociedades agrarias de transformación y cooperativas de trabajo asociado.

2. Bodegas no cooperativas: Sociedades mercantiles y personas físicas.

En el cuadro 3.1 se resumen las variables de identidad corporativa referidas anteriormente junto con su notación y medición.

\section{CUADRO 3.1}

VARIABLES DE IDENTIDAD CORPORATIVA

\begin{tabular}{|l|l|l|}
\hline VARIABLE & NOTACIÓN & MEDICIÓN \\
\hline Antigüedad & antig & $\begin{array}{l}\text { Variable ordinal: } 1=\text { joven; } 2=\text { edad media; } 3= \\
\text { antigua. }\end{array}$ \\
\hline Forma jurídica & gcontrol & $\begin{array}{l}\text { Variable dicotómica: } 1=\text { forma cooperativa; } 2= \\
\text { no cooperativa. }\end{array}$ \\
\hline Grado de control & $\begin{array}{l}\text { Variable dicotómica: } 1 \text { participación } \\
\text { accionista principal }<=50 \% ; 2=\text { participación } \\
>50 \% .\end{array}$ \\
\hline Modo de control & mcontrol & $\begin{array}{l}\text { Variable dicotómica: } 1=\text { accionista principal } \\
\text { individual } \text { o familiar; } 2=\text { institucional } 0 \\
\text { sociedad. }\end{array}$ \\
\hline
\end{tabular}

Fuente:Elaboración propia

\section{2 $\quad$ Recursos tangibles}

La empresa deberá orientar su actividad sobre la base de aquello que puede atender eficazmente a partir del conjunto de recursos que posee, e identificar aquellos recursos diferenciales a partir de los cuales se puede constituir una posición de ventaja competitiva a lo largo del tiempo.

La identificación de los recursos empresariales por lo tanto no es algo trivial. Una clasificación comúnmente aceptada es la que distingue entre recursos tangibles e intangibles. Los recursos tangibles son aquellos que tienen una manifestación material concreta y vienen a estar constituidos por el conjunto de activos de la empresa, cuya relación aparece reflejada en su inventario patrimonial. La solución que se ha adoptado 
con la finalidad de medir el potencial productivo de la empresa es utilizar diversos tipos de indicadores (cuadro 3.2).

\section{CUADRO 3.2}

\section{VARIABLES DE RECURSOS TANGIBLES}

\begin{tabular}{|c|c|c|}
\hline VARIABLE & NOTACIÓN & MEDICIÓN \\
\hline Valor de la producción media (€) & $\mathbf{v p €}$ & $\begin{array}{l}\text { valor de la producción en euros (media 2002-2003 } \\
\text { o 2003). }\end{array}$ \\
\hline Valor añadido medio (€) & vae€ & $\begin{array}{l}\text { valor añadido de la empresa en euros (media } \\
2002-2003 \text { o 2003). }\end{array}$ \\
\hline Valor del activo fijo medio ( $€$ & afijo€ & $\begin{array}{l}\text { valor del activo fijo material en euros (media } \\
2002-2003 \text { o } 2003 \text { ). }\end{array}$ \\
\hline $\begin{array}{l}\text { Empleados a tiempo completo } \\
\text { medio }\end{array}$ & etc & $\begin{array}{l}\text { equivalentes a empleados a jornada completa } \\
\text { (media 2002-2003 o 2003). }\end{array}$ \\
\hline Capacidad Instalada media (hl) & capinst & hl totales de almacenamiento en bodega. \\
\hline $\begin{array}{l}\text { Sobredimensión de la capacidad } \\
\text { instalada }(\%)\end{array}$ & sdimens & $\begin{array}{l}\text { (capacidad instalada - producción comercializada } \\
\text { o elaborada ) / capacidad instalada }\end{array}$ \\
\hline $\begin{array}{l}\begin{array}{l}\text { Permanencia } \\
\text { depósitos del } \\
\text { controlada }\end{array} \\
\end{array}$ & fermcon & $\begin{array}{l}\text { hl de fermentación controlada / hl de producción } \\
\text { elaborada. }\end{array}$ \\
\hline $\begin{array}{l}\text { Permanencia del mosto en } \\
\text { depósitos autovaciantes }\end{array}$ & autovac & Hl de autovaciantes / hl de producción elaborada. \\
\hline Incorporación de frío & frío & Frigorías por hora y hectólitro de vino elaborado. \\
\hline Incorporación de calor & calor & $\begin{array}{l}\begin{array}{l}\text { Kilocalorías por hora y hectólitro de vino } \\
\text { elaborado. }\end{array} \\
\end{array}$ \\
\hline Variedades de uva (\%) & $\begin{array}{l}\text { según } \\
\text { denominación }\end{array}$ & $\begin{array}{l}\text { hl de vino de la variedad en cuestión/ hl totales de } \\
\text { vino elaborado }\end{array}$ \\
\hline
\end{tabular}

Fuente: Elaboración propia

Respecto a la dimensión empresarial y teniendo en cuenta la Recomendación de la Comisión del 3 de abril de 1996 de la Comunidad Europea, relativa a la definición de pequeñas y medianas empresas, que establece las siguientes definiciones: gran empresa, mediana empresa, pequeña empresa y microempresa, atendiendo a una serie de criterios (volumen de negocio anual, número de empleados a tiempo completo independencia), el $84 \%$ de las bodegas quedan encuadradas en la categoría de microempresa, menos del 2 $\%$ en la de mediana empresa y ninguna en la de gran empresa.

Dado el gran inconveniente de la deficiente segmentación obtenida aplicando el criterio anterior, se ha procedido a la estratificación de las empresas, atendiendo a su capacidad total de almacenamiento o capacidad instalada en hectolitros (hl), tal y como sugiere Bernabéu et al. (2001), criterio más ajustado a la realidad de la industria vinícola en la región, el cual establece los siguientes grupos:

MUY GRANDE: igual o más de $150.000 \mathrm{hl}$

GRANDE: menos de 150.000 a $60.000 \mathrm{hl}$

MEDIANA: menos de 60.000 a $30.000 \mathrm{hl}$ 
PEQUEÑA: menos de 30.000 a $8.000 \mathrm{hl}$

MUY PEQUEÑA: menos de $8.000 \mathrm{hl}$

En este sentido, el indicador propuesto, aunque sin la segmentación establecida anteriormente ha sido comúnmente utilizado en los estudios sobre este sector (Delacroix y Swaminathan, 1991; Parker y Joo, 1998).

Por otro lado, la utilización de variables de capacidad como criterios de medición del tamaño, puede conducir a resultados divergentes de los obtenidos por los criterios de volumen de actividad, en la medida que las empresas se encuentren con un distinto grado de ocupación del potencial productivo instalado. La consecución real de las ventajas competitivas en coste esperadas de un mayor tamaño, exige un alto grado de aprovechamiento de la capacidad total instalada, que permita la absorción de los costes fijos.

Una situación de exceso de capacidad, puede anular e incluso hacer negativo, el diferencial de coste unitario asociado al tamaño de la empresa, por lo que resulta interesante arbitrar un indicador de sobredimensión de la capacidad instalada, es decir el porcentaje de las instalaciones que queda infrautilizado cada campaña por las diferencias entre la capacidad instalada y la producción comercializada o elaborada (caso de que no hayan comercializado aún),ambas medidas en hl. Esta diferencia respecto de la capacidad instalada sería el grado de sobredimensionamiento de las instalaciones.

Otros indicadores propuestos y relacionados con el tamaño han sido:

El número total de empleados como media anual de las últimas tres campañas, en equivalentes a empleados a jornada completa.

El valor de activo fijo material en euros (media 2002-2003 o 2003).

El valor de la producción en euros (media 2002-2003 o 2003).

El valor añadido de la empresa en euros (media 2002-2003 о 2003).

En cuanto a las tecnologías de elaboración de vinos, se basan de manera importante en la existencia de depósitos de elaboración (fermentación controlada y autovaciantes), almacenamiento y conservación, generalmente de acero inoxidable, provistos de instalaciones de incorporación de frío, calor y vaciado automático de los hollejos.

La elaboración de vinos de calidades organolépticas adecuadas requiere de un mínimo tiempo de permanencia de los mostos blancos, rosados o tintos en los depósitos de fermentación controlada y en los autovaciantes, así como de la incorporación del frío o calor (según el tipo de vino) al mosto en fermentación. Esta consideración se encuentra íntimamente correlacionada positivamente con la citada sobredimensión de la capacidad instalada. A este respecto se han arbitrado como indicadores: la permanencia del mosto en depósitos autovaciantes y de fermentación controlada como la relación 
entre el volumen de estos depósitos y la producción elaborada, principalmente en lo que respecta a la producción de vinos blancos, tintos y rosados; la incorporación de frío, como la relación entre Frigorías por hora y hectólitro de vino elaborado, en el caso de los rosados y blancos fundamentalmente; la incorporación de calor, como la relación entre Kilocalorías por hora y hectolitro de vino elaborado, en el caso de los tintos fundamentalmente.

Por último, las variedades de uva constituyen un recurso tangible de incuestionables importancia; en este sentido se han tenido en cuenta todas las variedades tanto blancas como tintas que participan como materia prima en la elaboración de los vinos regionales (ver cuadro 5.1 del Capítulo V). La notación que se ha dado a cada variedad se corresponde con su denominación y, la medición de cada una de ellas, se concreta como la relación entre hl de vino de la variedad en cuestión y hl totales de vino elaborado.

\section{3 $\quad$ Recursos intangibles}

Los recursos intangibles hacen referencia a aquellos de carácter inmaterial sin expresión física concreta, que se identifican genéricamente con servicios productivos proporcionados por el capital humano, tecnológico comercial, así como por el conjunto de todos ellos (Salas, 1996). A pesar de la gran importancia que tienen para 1 empresas, su intangibilidad dificulta su identificación, medición y evaluación como factores con potencial estratégico.

Los recursos intangibles pueden tener un carácter muy diverso, desde los derechos de propiedad intelectual, la reputación de la empresa, el conocimiento tecnológico de productos y de procesos o la calidad y fidelidad de los clientes, hasta cualquier otro tipo de habilidad organizativa. Grant (1996) clasifica los recursos intangibles en recursos humanos (formación, experiencia, adaptación de los empleados a la empresa), recursos tecnológicos (patentes, conocimiento y experiencia productiva, etc) y reputación de la empresa frente a sus clientes y proveedores.

El criterio adoptado en la valoración de los recursos intangibles en el contexto de las empresas en estudio, tratará de medir el esfuerzo que la empresas está realizando en el proceso de acumulación de dichos recursos, concretamente la utilización de ratios que relacionen el gasto o inversión realizado por las empresas sobre determinados recursos. Siguiendo el planteamiento sugerido por Grant, 1996 y Salas,1996, para su análisis se agruparán estos en las siguientes categorías: capital humano, recursos tecnológicos y recursos comerciales.

\subsubsection{Recursos humanos}

Los recursos humanos (Instituto Cerdá y MAPA, 2003) son valorados para el $30,4 \%$ de las pequeñas y medianas empresas (Pyme) el principal factor estratégico en el funcionamiento de las mismas. Por otra parte la totalidad de las bodegas en estudio están encuadradas dentro de la categoría de Pymes. 
Este factor incide de forma relevante sobre la estructura de costes del negocio, y plantea dos problemas para éstas empresas:

1 Por un lado el creciente aumento de la mano de obra provoca una pérdida de competitividad respecto a terceros países cuando se compite en precio.

2 Por otro lado existe dificultad creciente para contratar mano de obra en el sector, tanto especializada como no especializada, siendo necesario organizar la contratación de mano de obra extranjera.

El capital humano configura una de las variables críticas del éxito empresarial y de la competitividad de las empresas, dado que son los individuos quienes constituyen la base de toda organización y son en definitiva los protagonistas de su funcionamiento, entendiendo por capital humano "el conjunto de conocimientos, habilidades y aptitudes inherentes a los individuos que forman la organización" (Bonache, 1996). No obstante este conjunto de habilidades individuales no actúa aisladamente sino que se utiliza de forma combinada con otros recursos tangibles e intangibles, lo que permite la consecución de habilidades colectiva y la generación de ventajas competitivas.

Por otro lado las habilidades de los individuos les pertenecen a ellos y no a la empresa en la que prestan sus servicios, quien únicamente podrá beneficiarse de las mismas en la medida en la que dichos individuos sigan vinculados a la organización. En este sentido un problema adicional que se plantes es el discutible grado de propiedad que sobre este recurso puede disfrutar la empresa, lo cual limita su garantía de permanencia y debilita su capacidad como recurso válido para fundamentar sobre el una ventaja competitiva duradera.

En la estimación del potencial estratégico que posee una empresa en términos de capital humano intervienen muchos aspectos que dificultan su evaluación; aún reconociendo dichas dificultades, en el presente estudio se han considerado los siguientes estimadores del capital humano:

- El grado de estabilidad y permanencia de los empleados en la estructura de la empresa.

- La cualificación técnica.

- $\quad$ La productividad por empleado.

A través del concepto de calidad o estabilidad del empleo, se pretende considerar el grado de estabilidad y permanencia de los empleados en la estructura de la empresa, y se define como la razón entre el número de trabajadores fijos y el total de trabajadores, expresados en equivalentes en tiempo completo ( 8 horas de trabajo al día durante 240 días de trabajo efectivo al año).

Para la medición de la calidad y potencial productivo del capital humano es común la utilización de variables tales como la formación académica o experiencia profesional del personal. No obstante estas referencias, si bien pueden considerarse 
indicadores del potencial productivo del individuo, no permiten medir la aportación que éste en concreto realiza a la empresa u organización o ala capacidad de los individuos para trabajar juntos eficazmente.

Una aproximación a la calidad y potencial de los recursos humanos puede ser su nivel de formación. Así bajo la expresión de cualificación técnica del empleo se ha medido la presencia de personal con titulación superior y media con relación al total del personal empleado a tiempo completo.

Otra consideración relevante reside en que cuando estas habilidades individuales están relacionadas entre sí, y también con otros recursos de la empresa conformando habilidades organizativas complejas, las posibilidades de protección y de mantenimiento de la ventaja competitiva serán mayores debido al hecho de que, de este modo el capital humano se convierte en un activo específico de la empresa, con un alto valor intrínseco para esa organización, difícilmente exportable a otras. A la vez, y en la medida en que la competencia distintiva involucre a un amplio conjunto de elementos, no sólo disminuyen las posibilidades de transferencia a otras empresas, sino que se hace más difícil aún su reproducción e imitación por sus competidores.

Para medir la aportación que en concreto el individuo realiza a la organización, se ha tenido en cuenta la capacidad de aquellos para trabajar juntos eficazmente e integrarse en la empresa (Grant, 1996). Un medio complementario para esta estimación, es la utilización de indicadores que valoren los resultados obtenidos, de manera que no solo se compute su capacidad productiva potencial, sino su eficacia real. Se propone la utilización del concepto productividad por empleado, y se calcula dividiendo el valor añadido de la empresa por el número total de empleados en equivalentes a tiempo completo, con el objeto de corregir en alguna medida las desviaciones que pudiera originar un diferente nivel de integración en la realización de las fases de la actividad de del subsector vinícola.

\subsubsection{Recursos tecnológicos.}

Las inversiones en recursos tecnológicos en las empresas surgen como respuesta a la necesidad de adaptarse a las exigencias de la renovación tecnológica (renovación y automatización de procesos, aplicación de sistemas de calidad, reconversión de capacidades) y adaptar sus productos a las exigencias de la demanda (promoción comercial, información a los consumidores, nuevos envases, etc.), así como además de las estructuras productivas y comerciales, a las condiciones técnico sanitarias $\mathrm{y}$ ambientales exigidas por la $\mathrm{CE}$.

La dimensión tecnológica de la empresa tiene un impacto relevante sobre su capacidad competitiva, dado que constituye uno de los motores de la reducción de coste y también, sin que se trate de efectos excluyentes, es una de las fuentes más importantes en la diferenciación de las productos (Strategor, 1995). Por otro lado el sostenimiento de la empresa en el tiempo exige adaptación a los cambios ambientales a través del desarrollo de procesos de innovación que permitan la actualización de sus productos y el ajuste de su proceso productivo a las nuevas condiciones tecnológicas de cada momento (Fernández y Fernández, 1988). 
A pesar de la tipificación y estandarización exigida por los propios reglamentos reguladores a las bodegas acogidas a las diferentes DDOO, sobre los productos y procesos productivos básicos, y teniendo en cuenta la estandarización y globalización de la tecnología de la elaboración de vinos, la intervención tecnológica permite la introducción de mejoras en la calidad de los vinos, diferenciadas y ajustadas a las nuevas demandas del mercado, desde un subsector caracterizado por prácticas tradicionales de elaboración.

Dado que el subsector vinícola se trata de un colectivo con alta presencia de pequeñas empresas, con insuficientes recursos para desarrollar actividades de alta complejidad tecnológica ( $\mathrm{I}+\mathrm{D}+\mathrm{i}$, patentes, etc.), y teniendo en cuenta que cualquier nueva inversión lleva aparejada un cierto componente tecnológico se ha considerado pertinente arbitrar un indicador, que recoja los gastos de todo tipo relacionados con la adquisición de depósitos, instalaciones y maquinaria, informática, sistemas de normalización, control de calidad, etc., que se denominaría esfuerzo tecnológico $o$ esfuerzo inversor, que se define como la relación entre la cifra de inversión media anual del trienio considerado y el valor de la producción.

Por otro lado y en referencia a los recursos tecnológicos de alta complejidad, (Grant, 1996) incluye la tecnología de la propiedad (patentes, derechos de autor y secretos industriales) y la experiencia en su aplicación, así como los recursos para la innovación en términos de medios asignados a la investigación y personal científico y técnico.

La empresa puede generar recursos tecnológicos de alta complejidad, principalmente de tres formas: generándolos internamente (departamentos de $\mathrm{I}+\mathrm{D}+\mathrm{i}$ ), adquiriéndolos en el exterior por medios del régimen de intercambios del mercado, o bien a través del establecimiento de fórmulas cooperativas con otras empresa o instituciones. Estas opciones son complementarias, dada la complejidad y rapidez del cambio tecnológico, lo que permite la generación de sinergias positivas en relación con un mejor aprovechamiento de cada una de ellas.

La estimación del potencial innovador, derivado de la inversión en recursos tecnológicos de alta complejidad, que presentan las bodegas en estudio se ha efectuado mediante un indicador comúnmente utilizado y que revela la situación de la $\mathrm{I}+\mathrm{D}+\mathrm{i}$, ha sido los niveles de gasto destinados a este tipo de inversiones, los recursos humanos que se dedican a esta labor, tanto si se trata de actividades realizadas internamente en la propia empresas, como si son adquiridas en el exterior o realizadas por medio de fórmulas de cooperación. En este sentido y por considerarse suficientemente significativo se ha tomado un estimador llamado esfuerzo innovador, que ha sido definido por la relación entre la inversión anual media en el último trienio en $\mathrm{I}+\mathrm{D}+\mathrm{i}$ y el valor de la producción. 


\subsubsection{Recursos comerciales.}

La función comercial se encuentra relacionada con la reputación de la empresa entre los clientes, la estabilidad de las relaciones, la asociación entre los productos de la empresa y su calidad, fiabilidad, etc. En la elección del tipo de comunicación se deben considerar aspectos económicos y financieros, del producto a promocionar, vida del producto, mercado, consumidor al que va destinado, tipo de estrategia; todo ello con el objetivo de diferenciar los productos de una empresas de los existentes en el mercado, elevar la cuota de mercado, crear una imagen de empresa y de marca, y mejorar los resultados económicos.

Un problema que se plantea es la determinación del volumen de recursos óptimo a dedicar en la actividad de comunicación; teóricamente se debería dedicar a esta actividad un volumen económico que maximizara la diferencia entre el aumento de ingresos y los gastos. Dada la evidente dificultad de medir los efectos de cada una de las técnicas de comunicación, las empresas utilizan criterios más o menos arbitrarios (porcentaje sobre las ventas, cantidades similares a las que gastan las empresas líderes competidoras, estimaciones obtenidas a partir de la experiencia propia, de otras empresas o de la realización de la misma técnica de investigación de mercados.

La evidencia empírica muestra que no siempre el esfuerzo comunicativo se traduce en ventas, sobre todo cuando la diferenciación real del producto no la percibe el consumidor. Este caso puede producirse cuando concurren en el mercado un elevado número de marcas, junto con un excesivo número de establecimiento y de métodos comunicativos para convencer a los consumidores, debido probablemente a que se contrarrestan los esfuerzos comunicativos de las empresas.

Estudios empíricos llevados a cabo por diversos autores en relación con los efectos de la publicidad sobre el consumo, han puesto de manifiesto que la publicidad no juega un papel determinante en el proceso de elección de adquirir o no vino, por lo que sería la decisión de qué y cuanto vino adquirir la más influenciada por aquella. Resulta incierta la eficacia de las campañas genéricas de publicidad con el fin de aumentar el consumo de vino, teniendo su mayor influencia en el mantenimiento de las cuotas de mercado de determinados tipos y marcas de vinos.

Se pueden diferenciar dos tipos de publicidad: la de producto, en la cual se resaltan las características del mismo para estimular la demanda específica o selectiva de una marca, y la institucional, caso de los Consejos Reguladores de Denominaciones de Origen, en la cual la publicidad abarca a un conjunto de bodegas, con la finalidad de lograr un incremento de las ventas en todo el sector sin entablar una guerra entre las distintas bodegas.

Cuando la comunicación va dirigida al mercado internacional, debe basarse en una diferenciación del producto con relación al de los países competidores, siendo frecuente crear una contramarca a escala nacional, como es el caso de SPANIA, para los productos hortofrutícolas españoles. En el caso de actuaciones conjuntas de varios países para la publicidad y promoción de un producto es frecuente la intervención de un 
organismo internacional, en este caso la Organización Internacional de la Viña y el Vino.

El producto vino que es por naturaleza artesanal necesita cada vez más de estas estrategias, sin las cuales no se podría realizar una proyección del mismo, ya que normalmente si un producto no se conoce, no se compra por muy bueno que sea. Este aspecto se encuentra íntimamente relacionado con el de distribución, ya que de poco sirve publicitar un vino sin una adecuada red de distribución.

Considerando que el subsector vinícola presenta reducidas posibilidades para la diferenciación tecnológica de los productos, y donde la poca formación de los consumidores dificulta la utilización de criterios objetivos para la medición de su calidad tangible, otra variables más difusas, como el prestigio de la empresa y la imagen de oferta por un lado, junto con una buena red de vendedores y agentes que sean capaces de transmitir el concepto de producto, abrir nuevos mercados o seleccionar y mantener el canal de distribución, aparecen como elementos de interés en la explicación de la competitividad de las empresas.

En el presente estudio se han efectuado las divisiones del gasto comercial, que a continuación se detallan:

- La comunicación en sentido estricto (la publicidad, las promociones y las relaciones públicas) como estrategia de dar a conocer el producto el proceso y su entorno. En el sector existen acciones publicitarias tradicionales: la participación en ferias, concursos y la inclusión en la guía de vinos.

- Los gastos de personal propio en los que incurre la empresa con la finalidad de crear y desarrollar su propia red comercial (venta personal).

- La investigación comercial como instrumento de conocimiento de los mercados meta o de destino al objeto de crear productos y servicios adaptados a una demanda por naturaleza cambiante.

La finalidad de la comunicación en sentido estricto, al menos en teoría, consiste en provocar cambios cuantitativos en la demanda del producto (en el sentido de incrementarla), o bien cualitativos (ayuda a diferenciar el producto, resaltando las características objetivas del producto o de imagen del mismo).

La venta personal actúa de puente entre los consumidores finales y la empresa elaboradora, proporcionando asesoramiento al comprador y transmitiendo información desde los consumidores a la propia empresa, con lo que se configura como un instrumento importante de comunicación comercial directa que presenta una eficacia muy superior a la publicidad y otros tipos de comunicación (Olmeda, 1996).

La saturación actual de los mercados y la ineficacia de los instrumentos promocionales han propiciado que la concepción actual imperante del marketing sea la orientación al consumidor. Las empresas deben investigar el mercado para detectar las necesidades de los consumidores y orientar su oferta. Por otro lado la planificación de 
las estrategias de producto, precio, distribución y comunicación requiere contar con información (sobre los consumidores, entorno político, social, etc.), que solo pueden obtenerse a través de la investigación de mercados.

La diferenciación de la oferta no viene generada por la propiedad de los activos tangibles de la empresa, sino por razones de percepción de las diferencias reales o ficticias del producto por el consumidor, en términos de reconocimiento de marca, calidad, precio, imagen, etc., lo que puede sintetizarse en la idea de reputación de empresa, que a su vez determina la posición competitiva de la misma. La correcta valoración de la información que posee el mercado exigiría cuantificar preferencias, percepciones y grados de satisfacción, factores de difícil medición y que requerirían un trabajo específico a tal fin.

Por tal motivo los valores relativos a la reputación o imagen han sido estimados a partir del esfuerzo comercial, que ha sido medido por la relación entre el gasto comercial medio anual de los últimos tres ejercicios realizado por la empresa y el valor de la producción en euros.

La explicación del fenómeno de la diferenciación de los productos, lo constituye la información que poseen los consumidores (Porter, 1976): el consumidor recoge aquella información que tiene disponible; dado que todo proceso de búsqueda de información tiene un coste, cada consumidor buscará información hasta que el beneficio marginal de la mejor elección, se iguale al coste marginal de la información; por su parte la empresa trata de potenciar la información de su producto, interviniendo en sus atributos intrínsecos y en la información que divulga; la información de cada consumidor es incompleta y distinta de la de los otros consumidores.

No obstante para que dichas diferencias sean percibidas por los consumidores es necesario que hayan sido transmitidas a éstos por algún medio de información. El criterio de medición del grado de diferenciación eficaz de las empresas sobre la base de la dimensión informativa de sus productos, estaría relacionado con la valoración del esfuerzo que realizan las empresas con el objeto de reducir el coste de obtención de la información en el que incurre el consumidor.

A este respecto las actividades de comunicación expuestas (Jaumandreu y Mato, 1990) pueden ser medidas mediante el indicador de la diferenciación por información al consumidor, medida como el ratio del gasto medio anual durante los últimos tres ejercicios, en publicidad, promociones y relaciones públicas (comunicación en sentido estricto), en relación al valor de la producción de las empresas, y viene a sintetizar la conducta de la empresa en términos de transmisión de información, variable relevante en el sector vinícola, donde la generalidad de los consumidores carecen de la información suficiente para realizar una valoración objetiva de los atributos físicos y de la calidad de los productos.

En el cuadro 3.3 se resumen las variables relacionadas con los recursos intangibles referidas anteriormente junto con su notación y medición. 
CUADRO 3.3

VARIABLES DE RECURSOS INTANGIBLES

\begin{tabular}{|l|l|l|}
\hline VARIABLE & NOTACIÓN & MEDICIÓN \\
\hline Calidad del empleo & calemp & empleados fijos / empleados totales. \\
\hline $\begin{array}{l}\text { Cualificación técnica del } \\
\text { empleo }\end{array}$ & cualemp & $\begin{array}{l}\text { empleados con titulación superior y media / } \\
\text { empleados totales. }\end{array}$ \\
\hline $\begin{array}{l}\text { Productividad por } \\
\text { empleado. }\end{array}$ & prodemp & valor añadido de la empresa / empleados totales. \\
\hline Esfuerzo tecnológico & esftec & inversión media anual / valor de la producción. \\
\hline Esfuerzo innovador, & esfidi & $\begin{array}{l}\text { inversión anual media en I+D+i / valor de la } \\
\text { producción. }\end{array}$ \\
\hline Esfuerzo comercial & esfcom & $\begin{array}{l}\text { gasto comercial medio anual / valor de la } \\
\text { producción. }\end{array}$ \\
\hline $\begin{array}{l}\text { Diferenciación por } \\
\text { información al consumidor, }\end{array}$ & infcon & $\begin{array}{l}\text { gasto medio anual, en publicidad, promociones y } \\
\text { relaciones públicas / valor de la producción. }\end{array}$ \\
\hline
\end{tabular}

Fuente: Elaboración propia

\subsection{Comportamiento estratégico}

En realidad los mercados no manifiestan un comportamiento de competencia perfecta, esperado por la teoría económica tradicional y las empresas pueden adoptar una posición diferenciada sobre la base de sus capacidades y habilidades distintivas, que posibilite el aprovechamiento de las oportunidades que se derivan de las imperfecciones existentes en los mercados par conseguir así unos beneficios superiores que las empresas competidoras. Estas imperfecciones de mercado son condición necesaria pero no suficientes para la obtención de rendimientos empresariales extraordinarios, ya que es preciso que cada empresa defina una estrategia competitiva que para Porter, 1982, consiste en "emprender acciones ofensivas o defensivas para crear una posición defendible dentro de un sector industrial, para enfrentarse con éxito a las cinco fuerzas competitivas y obtener así un rendimiento superior sobre la inversión para la empresa".

La propuesta sugerida por Porter, además de indicar que la mejor estrategia para cada empresa es aquella proposición particular que mejor le permita ajustarse a sus condicionantes del entorno específico, establece tres tipos de estrategias genéricas, desde las cuales toda empresa puede adquirir una posición de ventaja con respecto a sus competidores y conseguir así unos resultados superiores:

- La estrategia de "liderazgo en costes", que consiste en que la empresa se dirija al mercado con un producto comparable al de sus competidores, pero obtenido a un coste total inferior.

- Estrategia de la "diferenciación", por la que la empresa es capaz de ofrecer a todo el mercado potencial, un producto percibido por el consumidor como diferente, único, por el cual éstos están dispuestos a pagar un precio superior. 
- La "segmentación de mercado", que trata de conseguir una superioridad en costes o en diferenciación, pero para una oferta dirigida a un segmento concreto del mercado, en vez de dirigirse a todo el conjunto de clientes potenciales.

A partir de este planteamiento, los criterios que se han seguido para la definición de las opciones estratégicas, han sido: el tipo de ventaja competitiva en la que se fundamentará la posición de superioridad, el ámbito de producto ofertado al mercado y el ámbito de mercado al que las empresas dirigirán su oferta. Además de estos criterios cabe añadir la decisión de la empresa sobre el número y tipo de actividades productivas que realizará internamente, frente a aquellas otras que va a adquirir a proveedores externos, es decir la determinación del grado de integración vertical adoptado por la empresa, el cual puede aportar mayores posibilidades de diferenciación por la utilización de servicios o elementos especiales resultantes de la innovación propia (Porter, 1982) y también puede ayudar a la empresa a adquirir una ventaja en costes sobre sus competidores (Miller, 1986).

\subsection{1 Ámbito de producto.}

Tradicionalmente la actividad de las bodegas ha estado orientada hacia la producción, aunque en la actualidad empieza a manifestarse una nueva actitud orientada hacia el comercio con el objeto de satisfacer las exigencias del consumo.

Dada la etapa de madurez que atraviesa la demanda de vinos, la necesidad de encontrar nuevos mercados segmentos o nichos, viene a impulsar una política de producto más abierta y diversificada.

La mayor parte de las bodegas del estudio que comercializan vino embotellado, no se limitan a ofrecer un único tipo de producto, sino que realizan una oferta más o menos amplia, justificada por el interés de la empresa en atender a los distintos segmentos de un mercado que manifiestan preferencias diferentes sobre un mismo producto básico, satisfaciendo simultáneamente los requerimientos de la distribución.

Por otro lado, la gran mayoría de las empresas comparten una misma tecnología básica impuesta de un lado, por la tecnología natural del proceso a la que se han incorporado las innovaciones resultantes de los procesos de $\mathrm{I}+\mathrm{D}$, y de otro por los requisitos establecidos en los reglamentos de las distintas DDOO. La realidad indica que es difícil establecer una "diferenciación tecnológica o por calidad intrínseca" en el sector elaborador de vinos, dado que su producción está muy estandarizada. En este sentido las bodegas se han visto afectadas por las normas comunes que regulan el etiquetado, la presentación y la publicidad de los vinos, en concreto el R (CE) 753/2002, en lo que respecta a la designación, denominación, presentación y protección de determinados productos vitivinícolas. Esta norma ha sido traspuesta a la legislación española, y tiene como finalidades: respetar los intereses legítimos de los productores, informar y proteger a los consumidores, impedir que las diferentes legislaciones nacionales entorpezcan la libre circulación de los productos vinícolas, y el fomento de los productos de calidad. 
El vino como producto presenta características o atributos propios relacionados con su calidad intrínseca, tales como la variedad, tecnología de elaboración, color, sabor, aroma, bouquet, composición, temperatura, grado de alcohol, y otros relacionados con la calidad percibida por el consumidor, como son el envase, el diseño, el embalaje, el corcho, la cánula, la etiqueta (nombre del vino y del productor, el año de producción, tiempo de envejecimiento, añada, DO, contenido, marca, procedencia, registro de la empresa productora), la contraetiqueta (características visuales, olfativas, gustativas, táctiles, etc.), los cuales están relacionados la presentación.

Del conjunto de las calidades intrínseca y percibida por el consumidor surge un intangible, la imagen del vino, la cual cobra paulatinamente más importancia relativa a medida que se van desarrollando los mercados del vino, lo que conduce a que aquella capte la mayor parte del valor total del vino. La imagen como intangible y en su relación con la calidad percibida por el consumidor es difícil de valorar por los productores y de ahí que no se le conceda la importancia que en realidad tiene. En el mundo del vino existen los líderes de opinión, los cuales ensalzan o rebajan la imagen de los vinos y marcan mucho las valoraciones que posteriormente hacen los consumidores.

En estrecha relación con la imagen se encuentran otros atributos extrínsecos al producto, como la información del proceso de producción y elaboración, el control de los procesos de trazabilidad, la garantía de inocuidad para el consumidor, el cuidado del medio ambiente, las prácticas éticas laborales y otras preocupaciones sociales.

Es probable que desde el subsector productor y elaborador se le esté concediendo excesiva importancia al producto físico (variedad, etc.) en comparación con el precio final del producto, ya que puede suponer, en muchos casos, menos del 20 $\%$ del precio de venta del vino. Pero existen otros componentes que pertenecen a los intangibles, que no son tan valorados por los productores pero a los que los consumidores prestan un enorme interés, constituyendo una fuente de valor añadido y de alta consideración en laso mercados más desarrollados. Los servicios (elementos culturales, estéticos, de relación con el medio ambiente o la seguridad alimentaria) que el consumidor valora van ligados al producto físico y la distribución es más propensa a suministrarlos, ya que se encuentran más cercanos a sus demandas (Albisu, 2003).

Las empresas tratan de diferenciar sus productos, fundamentalmente a través de dos vías: la diferenciación real, introduciendo cambios en sus atributos y la diferenciación psicológica, mediante cambios en la imagen del producto. La razón práctica de la estrategia de diferenciación de los productos es el reconocimiento de una segmentación del mercado, es decir considerar la heterogeneidad de los consumidores y su clasificación en grupos más pequeños con necesidades y deseos más homogéneos.

En principio, salvo algunas restricciones, puede pensarse en la posibilidad de combinación de los atributos físicos y los relacionados con la imagen, para concretar un tipo específico de producto, lo cual generaría una elevada multitud de opciones, cuya elección determinará el grado de amplitud de la oferta comercial de cada bodega. 
Con la intención de simplificar esta realidad tan compleja, en el estudio se han tenido en cuenta las gamas vinos, de marcas y de presentaciones que a continuación se analizan.

En cuanto a las gamas de vinos, los distintos tipos de vinos que ofertan las bodegas vienen determinados fundamentalmente por la infraestructura varietal, en el caso de los vinos blancos o tintos, y por la tecnología y extensión de proceso de elaboración, caso de los vinos rosados, de crianza y de reserva.

Una primera aproximación hacia la idea de diferenciación del producto se ha establecido atendiendo a los siguientes aspectos:

1. Estructura varietal. En los vinos varietales la variedad que da origen a la denominación del vino ha de representar como mínimo el $85 \%$. El resto de vinos que no cumplan con la citada exigencia se denominan vinos coupages. Los indicadores propuestos han sido, el número de vinos varietales y el porcentaje en volumen respecto del total embotellado.

2. Proceso productivo, de elaboración y nivel de protección de la calidad. Los vinos ecológicos y producidos mediante técnicas de agricultura integrada se refieren a los que han sido producidos y elaborados respetando la reglamentación que regulan estas figuras de calidad. Por otra parte los vinos de pago son los que ocupan el nivel más alto en la pirámide de calidad. Dado que estas figuras de calidad son testimoniales, no se ha considerado adecuada su inclusión como indicadores $\mathrm{o}$ variables de comportamiento estratégico.

En relación con la gama de marcas, posiblemente, y desde el punto de vista del consumidor el elemento más asociado a la calidad percibida sea la marca, de ahí que las bodegas traten de diferenciar sus productos mediante estrategias de marca.

La marca como signo distintivo de un vino es el nombre, término, símbolo o diseño o una combinación de los que identifican el producto (vino), el productor (bodega) o el vendedor (intermediario). La marca puede ser sinónimo de prestigio, de calidad y de garantía y tiene como objetivo prioritario mantener la mayor regularidad en la calidad de los vinos de una empresa, para lo cual ésta controla cada etapa de su elaboración, desde la vinificación, hasta el envejecimiento, embotellado y comercialización de sus vinos. La marca registrada es un término legal que protege los derechos de exclusividad en la utilización del distintivo de marca, frente a las imitaciones.

Se entiende por "valor de marca "el valor suplementario que alcanza la empresa por encima de sus activos materiales, debido a la posición que su marca ostenta en el mercado y a la posibilidad de extender la misma a otras categorías de productos y/o mercados" (Tauber, 1989).

Una de las principales actuaciones de las bodegas para obtener ventajas competitivas de diferenciación radica en construir capital comercial sobre la base del valor de la marca, que entre otros criterios puede ser medido a través del sobreprecio de 
marcas de productos comparables de otras empresas (Múgica y Yagüe, 1993). Una marca con precio alto se asocia a una percepción positiva sobre la calidad del producto, mientras que un precio bajo se relaciona con una estrategia empresarial basada en costes, que permita el sostenimiento en el tiempo de la disminución del precio.

La imagen de marca se configura en la mente del consumidor a partir de ideas, impresiones, creencias y hechos constatados que aquel percibe en relación con las aptitudes o atributos del producto para satisfacer sus necesidades. Por otro lado también interesa conocer la imagen que el consumidor tiene de otras marcas del mismo producto (posicionamiento de marcas), con la finalidad de dotar a la marca de los atributos o características más apropiadas al segmento de consumidores en que se pretende situar.

La utilización de marcas ayuda de manera decisiva a las empresas en su estrategia de diferenciación psicológica, subjetiva e intangible más que real, sin recurrir a grandes cambios en los atributos físicos, tangibles y objetivos. Las razones que justifican el empleo de una marca a pesar de su costo (estampado o marcado, protección legal, etc.) y de los riesgos que contrae caso de que el producto no proporcione la suficiente satisfacción al consumidor son:

\section{a) Para el productor}

- Facilitan las operaciones de manejo y ayudan a la agilización y abaratamiento de las tareas de distribución.

- Facilitan por un lado, la diferenciación de productos de distinta calidad y características y de otro la diferenciación en los precios.

- En caso de que las marcas gocen de prestigio y hayan creado lealtad, la empresa puede alcanzar mayor estabilidad en las ventas, y facilitar la introducción de nuevos productos de la misma empresa.

- Es una respuesta a la gran distribución y a los consumidores.

\section{b) Para el consumidor}

- Facilitan la identificación de los artículos y contribuyen a la verificación de la calidad.

- Envía señales al mercado como garantía de calidad del producto, lo que aumenta la calidad percibida del producto por el consumidor y genera lealtad hacia la misma.

- Reducción del nivel de riesgo asociado a la compra, lo que ayuda al consumidor en su decisión de compra.

- Puede facilitar al consumidor su decisión de compra de nuevos productos de la misma empresa, ya que relacionará ambos productos sintiendo una cierta garantía de calidad. 
- Es un remedio contra la inmensa variedad de vinos que confunde e incluso intimida al consumidor.

- Evita que el consumidor realice comparaciones directas a través de los precios.

También existen detractores de la marca, los cuales argumentan:

- La dificultad de mantener la marca creada en el tiempo y fidelizar los consumidores, para lo cual se necesita una calidad mantenida, el marketing y la diversificación de productos.

- Crea confusión adicional a la propia fragmentación del sector (D.O, países, variedades, etc.).

- La lealtad a la marca, no existe.

Teniendo en cuenta que las ventajas pesan más que los inconvenientes, se puede inferir la importancia de unas marcas propias fuertes y prestigiosas como instrumento de valorización del producto y en definitiva como factor de competitividad para las bodegas.

Respecto a las marcas propias y en el supuesto de que la empresa haya decidido comercializar sus productos como tales, tiene varias estrategias:

- Emplear marcas únicas, una misma marca para toda la gama de productos, lo cual permite abaratar costes aunque a costa de elevar los riesgos para toda la gama.

- Utilizar una contramarca y varias marcas como soluciones intermedias.

- La estrategia de marcas múltiples, que consiste en utilizar una marca para cada producto, debiendo es este caso de cuidar sobremanera la calidad, sobre todo en aquellos de menos categoría y precio, ya que una devaluación de la calidad puede afectar negativamente el prestigio comercial de toda la empresa. Se debe tener en cuenta que una excesiva cantidad de marcas puede difuminar la imagen de la empresa, y no se llegue a asociar la empresa con unas pocas marcas de prestigio.

- La marca propia también es demandada por la gran distribución, que ha carecido hasta hace poco de personal cualificado para vender vino.

- La mayoría de las empresas del sector no tienen masa crítica para crear una marca fuerte, ya que ello supone una inversión en publicidad muy alta, lo que solo se lo pueden permitir las grandes compañías.

En relación con las marcas blancas (de distribución o de cliente), es un proceso que se encuentra en clara expansión, sobre todo el que se refiere a la marca 
propia del distribuidor, que incluyen todos los productos vendidos bajo la marca de una empresa de distribución (principales cadenas de supermercados e hipermercados), utilizando su propio nombre o un nombre específicamente creado con esta finalidad.

Las marcas de distribuidor nacen por la necesidad del distribuidor de buscar su propia identidad y de crear una imagen propia para sus establecimientos, suponen incluso un medio de comunicación para los distribuidores. Se trata de una herramienta con una doble finalidad para el distribuidor: por un lado traslada su imagen al mercado $\mathrm{y}$, por otro, es de gran utilidad por la creación de la lealtad de la clientela hacia su propio establecimiento. Por tanto, sirven como medio de comunicación $\mathrm{y}$ de diferenciación de los detallistas.

En el ámbito de las presentaciones que pueda exhibir un producto como el vino, al objeto que pueda ser identificado, juegan un papel muy importante una serie de elementos tales como, el etiquetado, el envase y el embalaje. Precisamente porque los productos se suelen presentar en los mercados embotellados, la etiqueta como la tarjeta de presentación del vino resulta imprescindible.

Después del etiquetado el elemento que posiblemente más contribuya a definir las distintas presentaciones sea el envase, de ahí que sobre éste se haya centrado el estudio actual.

El envase de un producto alimentario, según la definición del Código Alimentario Español, es el recipiente o envoltura destinado a contener un alimento con la misión específica de protegerlo de su deterioro, contaminación o adulteración. Suele cumplir las siguientes funciones a parte de la protección y preservación:

- Contribuye a evitar el fraude.

- Aunque no modifica su naturaleza física, añade utilidades de forma, incidiendo en la imagen o calidad percibida por el consumidor.

- Mejora de la presentación del producto, siendo indispensable en la estrategia de marcas de la empresa.

- Facilita las ventas ahorrando mano de obra en el comercio tradicional.

- Ayuda a la identificación del producto, promociona las ventas y puede ser un desencadenante del impulso de compra.

Como principal inconveniente, el de su repercusión en el coste de comercialización, debido al coste de fabricación del envase y al aumento del peso del producto envasado muy relacionado este último con el coste de transporte.

Prácticamente la gran mayoría de los envase son perdidos, dado que el coste de transporte es superior al de recuperación, si se tiene en cuenta el fenómeno de la globalización, que conlleva cada vez más la distribución del producto a grandes distancias. Otro aspecto a tener en cuenta es que, cuanto más se valoricen los vinos 
menor, será la incidencia del envase sobre el valor del producto y se tenderá a la utilización del envase perdido.

Por otro lado el R (CE) 753/2002 define el embotellado como la introducción del producto con fines comerciales en envases de capacidad igual o inferior a 601 .

Teniendo en cuenta la múltiple diversidad de envases posibles existentes en el mercado, si se consideran las distintas variables que los pueden definir (material de fabricación, dimensión, forma, color, forma de grabación de caracteres, etc), y considerando a su vez que el tipo de envase predominante en el mercado para vinos con DO es la botella de vidrio de 3/4 litros, en el estudio se han tenido en cuenta sólo las variables más relacionadas con este tipo de envase:

a) Envases de vidrio con capacidades distintas $(3 / 16,3 / 8,3 / 4,1 / 2,1$, y 1,5 litros).

b) Envases de vidrio de 3/4 litros con formas distintas (bordelesa, bordelesa alta, borgoñona, rhin, california, con malla).

Se ha arbitrado el indicador número de presentaciones, atendiendo a las distintas presentaciones que pueden obtenerse por combinación de las capacidades y formas diferentes de los envases de vidrio de $3 / 4$ litros.

Estas marcas están logrando obtener un mayor nivel de participación y de fidelidad en su cesta de compra. La imagen y garantía de las grandes cadenas de distribución constituyen un aval suficiente para una mayoría de consumidores que rebajan su nivel de exigencia a cambio de descuentos en relación con otras marcas competidoras. No obstante, el factor clave en el éxito de la marca de distribuidor es el menor precio, y una calidad similar a las marcas de fabricante, lo cual viene explicado por un menor gasto en marketing y publicidad, junto a la fabricación de grandes cantidades que producen un ahorro en los costes. Otros aspectos que influyen en la elección o compra de la marca de distribuidor es la experiencia con otros productos de la misma marca y la imagen del establecimiento.

Debido a su propia esencia, la política de marcas de distribuidor sólo es posible a partir de un alto volumen de venta, ya que sólo desde esa posición es viable encargar a los fabricantes series de productos de tamaño razonable con marcas de distribuidor. Por lo tanto, el nacimiento como el desarrollo de estas marcas se encuentra directamente relacionado con la evolución en la concentración de la distribución minorista.

En el ámbito nacional las marcas de distribuidor tienen cada vez una mayor participación en el volumen comercializado y han supuesto en el año 2003, el 39\% del volumen total. La penetración de las marcas de distribuidor es mayor para el caso del vino de mesa, en el que supera el $65 \%$, mientras que para los vinos con DO está en torno al 30\%, debido a que las marcas de distribución no pueden coincidir con la enseña vinos con DO, y con grandes diferencias entre las distintas DDOO. Las marcas de distribuidor se están orientando hacia vinos de calidad económicos (entre los que se incluyen los Vinos de la Tierra) y DO poco valoradas (La Mancha, Navarra, etc.) En el 
diseño de la estrategia de marcas privadas de la distribución se recurre a marcas específicas de cada bodega, preparadas y envasadas especialmente y donde el mensaje de abanderamiento de la firma de distribución se sitúa bajo la forma "elaborado para" $o$ "seleccionado por". Otras enseñas disponen de marcas paraguas según tipos de vinos (Saborá, 2003).

Los indicadores propuestos en relación con las marcas blancas/propias han sido, el número de marcas propias/blancas por empresa y su porcentaje en volumen respecto del total embotellado.

\subsubsection{Estrategia de precios.}

El nivel de precios de un producto como el vino se encuentra muy relacionado con el valor que los consumidores perciben en él, como consecuencia de la satisfacción que les produce su consumo o su adquisición, y ésta última se produce no-solo por los atributos físicos y tangibles del producto, sino también por aspectos intangibles como la marca, la imagen e incluso por el mismo nivel de precios.

En este sentido el precio de venta del vino puede tener influencia en la percepción de los consumidores sobre la calidad o características del producto, contribuyendo a su posicionamiento en el mercado.

Desde el ámbito empresarial es aceptado que todo producto tiene un precio, aunque no todas las empresas se encuentran en las condiciones de poder fijar un precio para sus productos, ya que unas veces estará condicionada por elementos externos a la misma (circunstancias del mercado y de las empresas competidoras) y otras veces por las propias circunstancias internas (nivel de costes, márgenes, estrategias u objetivos empresariales, etc.).

Para la empresa el problema de fijación de precios es complejo, ya que de un lado, tenderá a la estrategia de maximización de beneficios, si se tiene en cuenta que el nivel de precios que fije influirá en la cuota de mercado y en la demanda, a través de la elasticidad demanda-precio.

El precio de venta de un producto debe fijarse en armonía con la estrategia global de marketing de la empresa y hacerlo compatible con las restantes variables de marketing.

En este sentido es obligado analizar la relación con la variable producto referida a su calidad intrínseca. Según la fórmula de Peter Gooden no se podría aumentar el valor de un vino elevando solamente su precio, sin elevar más que proporcionalmente la calidad en relación con el aumento de precio, ya que a largo plazo el mercado lo detectaría castigando a la empresa.

En relación con la variable distribución, el precio debe ser el adecuado, ya que para una bodega no sería posible vender al mismo precio al consumidor que a un mayorista. En cuanto a la comunicación, la bodega podrá vender a un precio elevado, si 
éste recoge el gasto en comunicación, a través del cual el consumidor informado de las buenas cualidades de su producto decide comprarlo.

Las principales estrategias de fijación de precios analizadas en las empresas del estudio han sido los basados en los elementos siguientes: en el beneficio, en los costes y el margen comercial, los que imitan a la competencia, en relación con la demanda, la estrategia de precios bajos y la de precios altos.

La fijación de precios en relación con la demanda es una estrategia en la que el precio lo establecen las condiciones de la demanda, afectando a productos poco diferenciados, como es el caso de los vinos vendidos a granel, en el que el elaborador tiene pocas posibilidades de fijar el precio del producto.

La fijación de precios a través de los márgenes es, quizás debido a su sencillez, el procedimiento más utilizado por las empresas de comercialización agraria y por los minoristas en general, los cuales añaden un margen comercial pertinente al coste de adquisición del producto al elaborador. Desde el punto de vista teórico está estrategia no conduce a una política de precios óptima, ya que no tiene en cuenta ni las condiciones de la demanda ni las de la competencia.

El criterio de fijación de precios por el beneficio, está basado en la obtención de cierta rentabilidad, y en la práctica determinan un precio suficiente que asegure un razonable rendimiento del capital invertido.

Las estrategias basadas en la competencia tratan, una vez conocida la situación y el comportamiento de las empresas competidoras, de adecuar sus precios a los predominantes en el mercado, manteniendo la estructura competitiva del mismo. Es frecuente que los precios sean establecidos por las empresas competidoras líderes, ocurriendo que las restantes empresas siguen al líder, con el fin de no incurrir en ninguna guerra de precios, fenómeno que suele darse en un sector maduro como el vino con una fuerte proliferación de marcas. La característica más distintiva es que la empresa adopta una estrategia imitativa, decidiendo situar sus precios al nivel medio o mantenerlos con ligeras diferencia al alza o a la baja, de tal manera que si los costes o la demanda se alteran, la empresa conserva el precio si la competencia no lo altera.

La estrategia de precios bajos se basa en el empleo de un precio de penetración marcado inicialmente, es decir un precio más bajo que el de las empresas competidoras, con el objetivo de alcanzar más pronto una cuota de mercado. Parece más apropiado para los productos de baja calidad, (o suele asociarse con la percepción del producto de calidad mediocre), bajos costes de producción y grandes volúmenes de producto, con la intención de que el ingreso total sea mayor que en el caso de precios más altos. Esta política es adecuada para productos de gran consumo y en mercados sensibles al precio, lo que no concuerda en general con el producto vino y su mercado.

Es de esperar que en el actual y lento cambio que se está observando en las bodegas desde los graneles hacia el embotellado, el primer paso sin experiencia empresarial en un mercado desconocido es salir con vinos de bajo precio, lo que llega a posicionar a las empresas en el segmento de precios bajos, tanto en el mercado nacional 
como en el internacional. Ocurre con frecuencia que a una empresa posicionada en segmentos de precios bajos, le resulta difícil dar saltos hacia niveles más altos. Prácticamente la única manera es sacar al mercado vinos con mejor calidad e imagen es a través de marcas distintas, lo cual conduce hacia una mayor proliferación de marcas, por lo que las empresas tienden a usar el nombre de la empresa o una marca global que configura toda la oferta de la bodega y no confunda a un consumidor ya de por sí bastante desinformado (Albisu, 2003).

La estrategia de precios altos persigue presentar una imagen de calidad del producto mediante la fijación de precios elevados, acompañados de esfuerzos publicitarios. Parece más apropiado para nuevos productos, en los que inicialmente se eleva el precio con objeto de venderlos en el segmento principal, para reducirlo posteriormente y de esta forma atraer a otros segmentos de consumidores más sensibles a los precios. Esta opción es eficaz cuando los segmentos mercados meta no son muy sensibles al precio (gamas altas de los vinos de calidad). La empresa intenta conseguir una imagen de marca o de prestigio para el producto, y la elevación del precio viene acompañada de una elevación más que proporcional de la calidad, si se pretende crear un aumento de valor sostenido del vino para el consumidor. Es posible encontrar un vino barato de excelente calidad, lo que no es aceptable es un vino caro de calidad mediocre, ya que a largo plazo el mercado lo detectará y será difícil posteriormente recuperar el reconocimiento perdido. En definitiva el mercado es el que tiene la última palabra, y si un vino se consigue vender aunque de partida parezca caro, de alguna manera el precio fijado era el correcto.

\subsubsection{Nivel de integración vertical}

La integración vertical puede entenderse como la sustitución de los intercambios contractuales o de mercado por los cambios internos dentro de los límites de la empresa, lo que en ciertas circunstancias contribuye a mejorar la eficacia competitiva y a aumentar el bienestar del consumidor. Por otro lado la integración vertical en este sector es muy importante en la obtención de productos de más calidad.

¿Por qué es interesante analizar el grado de integración vertical de las empresas y que consecuencias pueden derivarse de la existencia de diferentes grados de integración? La razón argumentada por la teoría económica es la de mejorar la eficacia como consecuencia de la existencia de interrelaciones tecnológicas entre las sucesivas etapas productivas. Para la economía de las organizaciones, la razón que promueve el desarrollo de la integración vertical es el hecho de que los mercados no sean transparentes, exista incertidumbre o diferencias de información, es decir fricciones en su funcionamiento que dificulten la utilización del sistema de precios como criterio orientador del comportamiento de los agentes. El interés por reducir los costes asociados con la realidad de las transacciones que tienen lugar en el mecanismo de mercado, puede llevar a las empresas a adoptar decisiones de integración vertical.

Desde la óptica más actual de la Teoría de Recursos y Capacidades se sugiere otro marco conceptual, en el intento de interiorizar dentro de la empresa aquellas competencias esenciales que pueden constituir fuentes reales de ventajas competitivas, 
dejando fuera de ella aquellas otras actividades que no constituyan elementos clave de éxito del negocio.

En el ámbito de la dirección estratégica se sugieren otras razones más específicas tales como: evitar efectos negativos derivados de la existencia de poder de mercado en algunas de las etapas del ciclo; asegurar la oferta y/o demanda; aportar mayores posibilidades de diferenciación por la utilización de componentes o servicios específicos resultado de una innovación propia, dando como resultados productos de más calidad; añadir un mayor grado de control sobre la oferta de la empresas; elevar las barreras de entrada a potenciales competidores o incrementar los costes de los competidores actuales; y, finalmente aumentar el resultado general de la empresa si la fase productiva en la que se centra tiene un rendimiento mayor que el coste de oportunidad del capital para la empresa.

Sin embargo y como contrapartida se pueden presentar importantes inconvenientes: la existencia de disparidad entre el volumen de productos que la empresa va a demandar o a ofrecer a la fase productiva contigua y el tamaño necesario para alcanzar una producción eficiente en esta etapa; que la integración signifique entrar en un negocio nuevo y ello exija hacer frente a barreras de ingreso que puedan existir; el aumento del riesgo comercial de la empresa; o la pérdida de flexibilidad y capacidad de ajuste a los cambios del entorno.

Como alternativa que permita lograr los beneficios de la integración vertical, pero sin incurrir en sus costos, se ha propuesto la coordinación vertical, que es una situación intermedia entre las transmisiones de libres mercado y la integración empresarial.

El grado de integración adoptado por la empresa se puede analizar desde distintas dimensiones que, haciendo una aproximación a la propuesta de Harrigan (1986), pueden expresarse atendiendo a los siguientes aspectos:

- El número de componentes que realiza la propia empresa sobre el total que conforman el producto. Una empresa estará más integrada en la medida que asuma la realización interna de un mayor número de estos componentes, algunos de los cuales serán críticos en la incorporación de valor del bien. En general no existen bodegas que realicen internamente ninguna de las actividades que proporcionan ni los equipos productivos necesarios para el proceso, ni tampoco los materiales auxiliares incorporados como productos enológicos, envases, etiquetas, tapones, etc.

- El número de etapas productivas necesarias para obtener cada elemento que es llevado a cabo por la empresa.

- El grado de autoabastecimiento entre una fase y la siguiente, en el que los inputs requeridos en una fase son ofrecidos por los outputs obtenidos por la misma empresa en la fase anterior. 
- La organización que se emplea para el desarrollo de esas actividades, es decir la realización por la propia empresa, en cooperación con otras empresas independientes y la realización por agentes independientes con los que se intercambia en términos de mercado.

Por otro lado se pueden distinguir dos direcciones distintas de integración: la integración vertical hacia atrás en relación con el grado de integración de la empresa con las etapas iniciales del ciclo productivo, y la integración vertical hacia atrás, referida al grado asunción por la empresa de las etapas finales de la actividad productiva.

De modo que la integración vertical hacia atrás puede abarcar las siguientes etapas:

- La obtención de la uva podría ser: propia, lo que significa la realización interna de una etapa anterior, consistente en el cultivo del viñedo; o ajena, adquirida a otros viticultores en el mercado.

- La transformación de la uva en vino podría ser: elaboración propia o vino adquirido a otros elaboradores.

Teniendo en cuenta lo dicho anteriormente, los distintos niveles de integración se resumen en los siguientes:

UP : Elaboración con uva propia $(\mathrm{Ci}=1)$

UA_CC: Elaboración con uva ajena con acuerdos o contratos compra $(\mathrm{Ci}=0,75)$.

UA_SC: Elaboración con uva ajena sin acuerdos o contratos compra $(\mathrm{C}=0,50)$.

VA_CC: Elaboración con vino ajeno con acuerdos o contratos compra $(\mathrm{Ci}=0,25)$.

VA_SC: Elaboración con vino ajeno sin acuerdos o contratos compra $(\mathrm{Ci}=0)$.

La integración vertical hacia atrás en cada una de las empresas, viene dada por la fórmula:

$\mathrm{IVa}=\sum_{\mathrm{i}=1}^{5} \mathrm{Ci} * \mathrm{Xi}$, donde:

IVa: Integración vertical hacia atrás.

Ci: Coeficiente de integración de la opción i.

Xi: Porcentaje sobre el volumen comercializado de la opción i.

El valor final del grado de integración hacia atrás asignado a una empresa se obtendrá por la aplicación de la expresión reseñada anteriormente, con resultados que se sitúan en una escala continua entre los valores 100 y 0 : una bodega totalmente integrada, valor 100 , será aquella cuyo $100 \%$ de la producción es obtenida partir de sus propias uvas, que lógicamente habrán sido transformadas en vino por ella misma; una bodega sin ningún grado de integración correspondería a aquella cuyo $100 \%$ de vino utilizado procede de su adquisición en el mercado a otros elaboradores. 
Para la medición del diferente grado en que la empresa asume por si misma las funciones pertenecientes a las distintas fases del proceso de distribución, una vez ya elaborado el producto, se ha arbitrado el índice de integración vertical hacia adelante, que recoge de forma sintética los factores que se han considerado determinantes de la integración: la organización que utiliza para el desarrollo e internalización por la propia bodega de las fases siguientes a la producción del vino (envasado y el grado de avance a lo largo del canal de distribución); la realización en cooperación con otras empresas independientes, y la realización con otros agentes independientes con los que se intercambia en términos de mercado (Harrigan, 1986).

De modo que la integración vertical hacia adelante puede abarcar las siguientes etapas o fases:

GRAN_MAY: La bodega vende vino a granel a mayorista $(\mathrm{Ci}=0)$.

MAY_MIN: La bodega realiza la función de mayorista vendiendo a mayoristas o minoristas $(\mathrm{Ci}=0,50)$.

MIN_CONS: La bodega realiza la función de minorista vendiendo directamente al consumidor $(\mathrm{Ci}=1)$.

La integración vertical hacia adelante en cada una de las empresas, viene dada por la fórmula:

4

$\operatorname{IVad}=\sum_{\mathrm{i}=1} \mathrm{Ci} * \mathrm{Xi}$, donde:

IVad: Integración vertical hacia adelante.

Ci: Coeficiente de integración de la opción i.

Xi: Porcentaje sobre el volumen comercializado de la opción i.

El valor final del grado de integración hacia adelante asignado a una empresa se obtendrá por la aplicación de la expresión reseñada anteriormente, obteniéndose resultados que se sitúan en una escala continua entre los valores 100 y 0 : una bodega totalmente integrada, valor 100, será aquella cuyo $100 \%$ de vino haya sido entregado directamente al consumidor final a través de una red de ventas propia; una bodega sin ningún grado de integración correspondería a aquella cuyo $100 \%$ de vino disponible es vendido a granel a otras bodegas o almacenistas mayoristas, no realizando por tanto ninguna actividad de embotellado ni de distribución posterior.

\subsection{4 Ámbito de la comercialización}

El estudio de la comercialización se ha abordado teniendo en cuenta las características que los definen, las cuales hacen referencia a:

- Los tipos de agentes que lo integran ( industrias, corredores, mayoristas, minoristas, etc.), la longitud del canal o número de agentes existentes en cada fase de la comercialización y el número y localización de los puntos de venta a los que la empresas pretende llegar (distribución intensiva, exclusiva y selectiva). 
- La organización de los agentes dentro del canal, es decir la relación entre ellos, generando los diferentes grados de integración vertical u horizontal, que será estudiado en el apartado siguiente.

La variable distribución juega un papel trascendental en cualquier estrategia comercial, y de ella depende que los productos lleguen desde la bodega hasta el consumidor final en el lugar, momento y en las condiciones óptimas para el consumo. Como variable estratégica, las decisiones que adopte la empresa tendrán consecuencias a largo plazo, repercutiendo decisivamente en el precio de venta del producto a través de la longitud de longitud del canal, así como por los márgenes comerciales a favor de los intermediarios. En este sentido también repercute en la variable comunicación, ya que en muchos casos los intermediarios son los que realizan estas actividades.

Las decisiones sobre la distribución comprenden tanto aspectos físicos (transporte y almacenamiento) como comerciales (elección de los canales, agentes participantes, formas de venta, etc.). La selección de los canales no es una tarea fácil, ya que pueden darse intereses contrapuestos entre los elaboradores y los distribuidores, y aquellos deben considerar tanto los aspectos económicos como los relativos al alcance y control del mercado.

Una bodega puede escoger distintas formas de distribución, según la gama de vinos a vender y el número de puntos de venta que pretenda alcanzar. En el caso de los vinos de gama alta, el modelo distribución escogido por las bodegas es la distribución selectiva, con un reducido número de distribuidores, que se comprometen con la bodega a realizar un volumen mínimo de ventas, aunque con la libertad de comprar y vender productos de la competencia. En el caso de los vinos de consumo frecuente y de gama baja y media, el modelo predominante es el de distribución intensiva, que utiliza canales de distribución largos, con el objeto de situar los vinos en el mayor número de puntos de venta. Los canales considerados en el estudio han sido:

- Para el vino a granel,

- $\quad$ El corredor.

- El mayorista, granelista y embotellador.

- Para el vino embotellado,

- El mayorista distribuidor.

- Los detallistas, la gran distribución, las tiendas (tradicionales, especializadas, autoservicios), canal horeca (hostelería, restauración catering), club del vino, etc.

- Venta directa al consumidor (en bodega, teléfono, Internet, fax, televisión, mensajería, correspondencia, por catálogo, etc.). 
El corredor interviene en las operaciones de venta del vino a granel desde los elaboradores a los mayoristas y normalmente percibe sobre el valor de la venta una comisión que cobra al comprador, al vendedor o a ambos. Se trata de una figura muy común en la región, ya que la mayoría de las cooperativas que no están asociadas a una cooperativa de $2^{\circ}$ grado (normalmente gestiona los graneles), y las bodegas granelistas recurren a este tipo de intermediario.

El mayorista granelista es un intermediario que normalmente compra el vino a granel, a los elaboradores añadiendo básicamente al producto un servicio de almacenamiento y transporte, y venden fundamentalmente a embotelladores. Se trata de una figura que está perdiendo relevancia.

El mayorista embotellador, que compra el vino a granel directamente a los elaboradores o a los granelistas, realiza las funciones de almacenamiento, financiación, embotellado y etiquetado para vender el producto a través de mayoristas distribuidores, aunque también puede vender el vino a granel. Suelen manejar vino como producto en exclusiva, son reducidos en número, aunque manipulan grandes cantidades y disponen de redes comerciales de ámbito nacional e internacional.

El mayorista distribuidor tiene como función principal el almacenamiento y distribución de bebidas embotelladas, muchas de ellas sustitutivas del vino (refrescos, licores, etc.), hacia los puntos de venta al consumidor.

En la gran distribución se han englobado los supermercados (incluidos los de descuento), hipermercados, grandes almacenes y centros comerciales. El fenómeno de concentración en este sector minorista está provocando entre otros efectos, la ganancia de cuota de mercado, la desaparición de intermediarios (principalmente mayoristas distribuidores), y la reducción de los márgenes comerciales (que se la traslada al elaborador en forma de disminución del precio), con el objetivo de contener los precios en el consumo.

En cuanto a las tiendas, se han agrupado los establecimientos tradicionales, autoservicios y tiendas especializadas.

Los establecimientos tradicionales que comercializan normalmente a través de mostrador, pueden ser establecimientos generalistas o bien estar especializados en una gama concreta de productos. Tienen un peso importante especialmente en áreas rurales, cuya principal ventaja radica en que los consumidores pueden encontrar todo tipo de productos, sin desplazarse hacia otras poblaciones mas alejadas. Estos establecimientos, en líneas generales han ido perdiendo importancia tanto en número como en cuota, ya que la única ventaja competitiva es la proximidad, pero que no presentan ninguna oferta de productos diferenciada.

La fórmula de autoservicio ha ido ganando cuota de mercado al tradicional por una serie de ventajas tales como, la comodidad de compra, servicio rápido, mayor libertad de elección y discreción en la elección, posibilidad de comparar precios y marcas, o precios más bajos si se trasladan a los consumidores las economías de costes 
derivadas del ahorro de mano de obra del cambio funcional entre comprador y vendedor.

Las tiendas especializadas, normalmente en régimen de autoservicio surgen por la necesidad del pequeño comerciante de aprovechar las ventajas competitivas que posee, de una parte el comercio tradicional (trato diferenciado y especializado en productos como el vino), y de otra las ventajas expuestas en el régimen de autoservicio. Así por esta vía se venden los caldos de gama más alta y para consumidores habituados a recoger información del producto antes de comprarlo. Son las que más y mejor crean opinión y probablemente el canal de comercialización de más alto nivel.

El vino por su propia naturaleza, requiere que se cuide su presentación, ya que de ella depende en buena parte el aprecio y disfrute que se haga del producto, y en definitiva la satisfacción del consumidor. Por otro lado las distintas presentaciones, formatos y contenidos, se consideran factores importantes a la hora de aprovechar las posibilidades de comercialización del canal horeca.

Los clubes de vinos nacen con el objetivo del disfrute del vino y su conocimiento boca a boca. Constituyen un canal de distribución paralelo, al hacer oferta de productos que pueden no ser canalizados por los sistemas habituales de comercialización, bien por ser vinos antiguos o cosechas pequeñas que ya no están en el mercado En estos casos se está vendiendo un estilo de hacer vino y, si la calidad intrínseca del producto resulta satisfactoria, la marca se va transmitiendo consumidor de unos a otros socios de estos clubes privados.

La venta directa como canal de distribución implica un contacto directo entre el elaborador y el comprador, ya que no existe ningún intermediario. En el caso de la venta directa en bodega es frecuente que esta disponga de una tienda en las propias dependencias de la bodega, en la que ofrecen sus productos. Como ventajas, permite a la bodega un contacto directo con sus clientes, lo que proporciona una valiosa información sobre sus gustos y necesidades, además de posibilitar a la bodega de un mayor control sobre sus productos. Este tipo de venta puede suponer un menor precio de venta para el consumidor al desaparecer los márgenes comerciales de los intermediarios. Presenta la desventaja de ser muy restringida y tiene un reducido alcance de la distribución ya que se dirige solo a los clientes que la solicitan cuando acuden al lugar de venta en la bodega, aunque permite asesorar al cliente no sólo sobre las características del vino, sino sobre el proceso de elaboración, con posibilidad de visitar las instalaciones in situ.

En cuanto a la venta por Internet, es evidente que los grandes problemas que presenta este tipo de transacciones (falta de confianza a comprar en la red al considerarse un medio inseguro, la ausencia del componente lúdico de compra, gran esfuerzo publicitario entre otras) pesan más que las grandes ventajas (amplio mercado potencial, reducidos costes, ausencia de intermediario etc.) en la decisión de compra por parte del consumidor, lo cual indica que el desarrollo de este comercio en Internet es aún demasiado novedoso. Por el momento es más bien un complemento a la distribución clásica de productos vitivinícolas con un elevado potencial de crecimiento futuro. Primero el cliente potencial conoce y se interesa por el producto en Internet, para 
posteriormente tomar la decisión final de compra y las condiciones de venta en interacción personal.

Otros canales de distribución, que estarían comprendidos dentro del marketing directo, como el teléfono, el fax, la mensajería, la correspondencia, no tienen por que ser ajenos al producto vino y deberían saber adaptarse a cualquier tipo de cliente, aunque en el caso de las bodegas en estudio nos han sido utilizados.

\subsection{5 Ámbito de mercado}

En cuanto al ámbito de mercado, se define como la distribución de las ventas en los distintos segmentos identificados con criterios geográficos, en los que la empresas tiene su presencia y dirige su oferta comercial no ocasional (Miller, 1986). Para su estimación se han utilizado dos índices: amplitud geográfica de los mercados de la empresa, alcance o grado de concentración-dispersión de los mercados de destino y, cuota de exportación. entendida ésta en sentido amplio, es decir la dirigida fuera de las fronteras de la nación española.

La amplitud geográfica de los mercados de la empresa, se ha cuantificado a partir del número medio de países en los que están presentes los productos de la empresa.

A efectos del estudio se han considerado cuatro áreas de destino de la producción comercializada, la Comunidad Valenciana, España, la Unión Europea y los Terceros Países.

El alcance o grado de dispersión de los mercados de destino, que se ha medido a través de la suma de los cuadrados de las cuotas de venta, en tanto por uno, que la empresa tiene en el mercado regional, en el nacional, en la Unión Europea y en los terceros países respecto al volumen físico total comercializado.

La expresión utilizada es $\left(1-\sum_{\mathrm{i}=1}^{4} \mathrm{Ci}^{2}\right) * 100$, donde:

$\mathrm{Ci}$ : la cuota de ventas físicas en cada una de las cuatro áreas de mercado.

El valor obtenido del índice varía entre 0 (el $100 \%$ de las ventas se realiza en un único mercado, o mínima dispersión), y 0,80 que se corresponde con la máxima dispersión.

La cuota de exportación, se ha medido a través del volumen de vino comercializado fuera de las fronteras de la nación española, en relación con el volumen total de vino comercializado.

En el cuadro 3.4 se resumen las variables relacionadas con el comportamiento estratégico referidas anteriormente junto con su notación y medición. 


\section{CUADRO 3.4}

\section{VARIABLES DE COMPORTAMIENTO ESTRATÉGICO}

\begin{tabular}{|c|c|c|}
\hline VARIABLE & NOTACIÓN & MEDICIÓN \\
\hline Número de presentaciones & npresen & $\begin{array}{l}\text { Número de presentaciones por combinación de las } \\
\text { capacidades y formas diferentes de los envases de } \\
\text { vidrio de } 3 / 4 \text { litros. }\end{array}$ \\
\hline Número de marcas propias & nmarpro & Número de marcas propias. \\
\hline Número de marcas blancas & nmarbla & Número de marcas blancas. \\
\hline Número de vinos varietales & nvivar & Número de vinos varietales. \\
\hline $\begin{array}{l}\text { Porcentaje en volumen de } \\
\text { marcas propias }(\%)\end{array}$ & \%marpro & $\begin{array}{l}\text { Volumen comercializado de vinos con marca propia } \\
\text { / volumen comercializado de embotellado. }\end{array}$ \\
\hline $\begin{array}{l}\text { Porcentaje en volumen de } \\
\text { marcas blancas }(\%)\end{array}$ & \%marbla & $\begin{array}{l}\text { Volumen comercializado de vinos con marca } \\
\text { blanca / volumen comercializado embotellado. }\end{array}$ \\
\hline $\begin{array}{l}\text { Porcentaje de vinos } \\
\text { varietales (\%) }\end{array}$ & \%vivar & $\begin{array}{l}\text { Volumen comercializado de vinos varietales / } \\
\text { volumen comercializado embotellado. }\end{array}$ \\
\hline $\begin{array}{l}\text { Precio medio de venta } \\
(€ / 3 / 41 \text { o } € / l)\end{array}$ & precio & $\begin{array}{l}\text { Precio de venta a la salida de la bodega del vino } \\
\text { embotellado }(€ / 3 / 4 \text { l) o granel }(€ / 1) \text {. }\end{array}$ \\
\hline $\begin{array}{l}\text { Criterio de fijación de } \\
\text { precios }(\%)\end{array}$ & $\begin{array}{l}\text { obeneficio } \\
\text { cmargen } \\
\text { icompetencia } \\
\text { cdemanda } \\
\text { pbajo, palto } \\
\end{array}$ & $\begin{array}{l}\text { Volumen comercializado de vino, según criterio de } \\
\text { fijación de precios / volumen comercializado } \\
\text { embotellado. }\end{array}$ \\
\hline $\begin{array}{l}\text { Integración vertical hacia } \\
\text { atrás (\%) }\end{array}$ & ivatrás & $\mathrm{IVat}=\sum_{\mathrm{i}=1}^{4} \mathrm{Ci}^{*} \mathrm{Xi}$ \\
\hline $\begin{array}{l}\text { Integración vertical hacia } \\
\text { adelante (\%) }\end{array}$ & ivadel & $\operatorname{IVad}=\sum_{\mathrm{i}=1}^{5} \mathrm{Ci}^{*} \mathrm{Xi}$ \\
\hline Canal comercial (\%) & \begin{tabular}{|l|} 
dmayorista \\
hsupermercado \\
tienda, club \\
horeca, bodega \\
internet \\
\end{tabular} & $\begin{array}{l}\text { Volumen comercializado de vino, según canal / } \\
\text { volumen total comercializado embotellado. }\end{array}$ \\
\hline $\begin{array}{l}\text { Amplitud geográfica de los } \\
\text { mercados }\end{array}$ & npaís & $\begin{array}{l}\text { Número medio de países en los que están presentes } \\
\text { los productos de la empresa. }\end{array}$ \\
\hline $\begin{array}{l}\text { Alcance o grado de } \\
\text { dispersión de los mercados } \\
\text { meta en tanto por uno. }\end{array}$ & dismer & $\begin{array}{l}\text { Suma de los cuadrados de las cuotas de venta, en } \\
\text { los mercados regional, nacional, Unión Europea y } \\
\text { Terceros Países / volumen total comercializado. }\end{array}$ \\
\hline Cuota de exportación (\%) & $\begin{array}{l}\text { cuotaexp } \\
\text { cvalencia } \\
\text { nación } \\
\text { ueuropea } \\
\text { tpaises } \\
\end{array}$ & $\begin{array}{l}\text { Volumen comercializado de vino, según mercados } \\
\text { meta / volumen total comercializado embotellado. }\end{array}$ \\
\hline
\end{tabular}

Fuente: Elaboración propia 


\section{5 $\quad \underline{\text { Resultados empresariales }}$}

La medición del rendimiento empresarial es una cuestión muy discutida, de gran interés y sobre la que pueden adoptarse diferentes planteamientos. En toso caso el resultado de las empresas se concibe como un concepto multidimensional, que exige para su estimación la utilización de múltiples indicadores (Cool y Schendel, 1987).

En una primera aproximación la calidad de los resultados obtenidos puede asociarse a la eficacia, en el sentido en que la organización alcanza los objetivos que se ha propuesto, en cuyo caso los criterios a emplear en la medición de la eficacia varían en función de los fines de la empresa y de la estrategia competitiva adoptada. La imposibilidad de aplicar el anterior planteamiento, justifica que se utilicen indicadores de carácter objetivo, que permitan medir y comparar la calidad de los resultados económicos obtenidos por las empresas analizadas.

Existe un amplio conjunto de indicadores, de entre los cuales se han seleccionado los relacionados con las medidas contables de la rentabilidad, que se construyen a partir de la documentación contable y financiera (balances y cuentas de resultados) elaborada por las empresas siguiendo los criterios legalmente establecidos para homogeneizar y hacer comparable dicha información.

Las principales ventajas de estos indicadores radican en la objetividad y accesibilidad de la información (es obligatorio su depósito en los registros oficiales, donde queda garantizada su disponibilidad pública), su facilidad de calculo y sencillez en la interpretación. También presentan desventajas, ya que a pesar de su frecuente utilización, su fundamentación en la información contable debilita la capacidad de medición de los resultados globales de la empresa (Camisón, 1999), ya que se refieren a un momento concreto en el tiempo (desplazada como mínimo un año respecto a la situación actual de la empresa), no consideran el valor del dinero en el tiempo, no incluyen información sobre el riesgo contraído por la empresa en relación con los distintos niveles de rentabilidad, y existe la posibilidad de manipulación de los datos contables.

A la vista de las consideraciones anteriores, la medición del éxito de las empresas o competitividad del sector vinícola se ha realizado a través de los indicadores más habituales y de mayor aceptación general, que sean capaces de expresar de forma objetiva los resultados globales obtenidos. Las variables fundamentales en las que se ha basado el análisis se recogen del balance y de la cuenta de resultados analítica de las empresas en el ejercicio 2003, y son las siguientes:

- Valor de la Producción (VP). Es el valor de la producción anual, con independencia de que haya sido vendida, almacenada o inmovilizada, es la variable inicial del análisis que refleja la actividad de la empresa. 
- Activo Fijo o inmovilizado (AF). Se trata de un elemento del balance y está constituido por los elementos patrimoniales cuya permanencia en la empresa es superior a un ejercicio económico, es decir aquellos elementos cuya finalidad es servir de manera duradera a la actividad de la empresa.

- Valor Añadido de la Empresa (VAE). Es la diferencia entre el valor de la producción y los consumos corrientes, recogiendo éstos últimos la diferencia entre las compras netas y los gastos externos y de explotación, aumentada o disminuida por el valor de la variación de existencia de mercaderías, materias primas y otras materias consumibles.

- Resultado de las Actividades Ordinarias (RAO). Refleja el resultado obtenido por la empresa de su actividad productiva, es decir el resultado de la actividad económica.

Los indicadores utilizados (considerando las variables anteriores), con objeto de incorporar un mayor número de referencias con las que reflejar de manera más completa el rendimiento alcanzado y también para poder conocer y analizar las diferencias que pudieran surgir entre ellos, han sido los siguientes:

- Valor Añadido de la Empresa en porcentaje (VAE \%). La relación entre el Valor Añadido de las empresas y el Valor de la Producción, indicando la capacidad de creación de valor añadido por las empresas. El índice tiene más sentido para comparar empresas del mismo sector pero aún en este caso el índice puede enmascarar el diferente grado de integración vertical (no se comparten las mismas fases productivas), los efectos de unas diferentes funciones de ingresos y costes, el diferente grado de diferenciación de los productos vendidos, un acceso favorable a la adquisición de determinados imputs o simplemente una mayor productividad interna.

- Resultado de las Actividades Ordinarias en porcentaje (RAO \%). La relación ente el beneficio antes de intereses y el valor de la producción.

En el cuadro 3.5 se resumen las variables relacionadas con los resultados empresariales referidas anteriormente junto con su notación y medición.

CUADRO 3.5

VARIABLES DE RESULTADOS

\begin{tabular}{|l|l|l|}
\hline VARIABLE & NOTACIÓN & MEDICIÓN \\
\hline $\begin{array}{l}\text { Valor Añadido de la } \\
\text { Empresa }\end{array}$ & VAE (\%) & $\begin{array}{l}\text { Valor Añadido de la Empresa / Valor de la } \\
\text { Producción. }\end{array}$ \\
\hline $\begin{array}{l}\text { Resultado de las } \\
\text { Actividades Ordinarias }\end{array}$ & RAO (\%) & $\begin{array}{l}\text { Resultado de las Actividades Ordinarias / Valor de } \\
\text { la Producción. }\end{array}$ \\
\hline
\end{tabular}

Fuente: Elaboración propia 

CAPITULO IV

DESCRIPCIÓN GENERAL DEL SECTOR VITIVINÍCOLA 



\section{EL VINO EN EL ENTORNO INTERNACIONAL}

Se ha analizado brevemente el comportamiento de este sector en el contexto internacional y nacional. El conocimiento de las tendencias globales de la actividad vitivinícola permitirá contextualizar y valorar de un modo más ajustado la realidad de ésta en la Comunidad valenciana.

\subsection{La producción y el consumo mundial de vino}

La vid es un cultivo que se realiza, en mayor o menor medida y con realidades muy diferentes de un país a otro; según fuentes de la Organización Internacional de la Viña y del Vino (OIV), la extensión total en 2002 ascendía 7.879.000 has, superficie que permanece con fluctuaciones interanuales a inferiores al $2 \%$ desde 1996. Esta superficie es casi un $20 \%$ inferior a la existente en el quinquenio 1981-85, momento a partir del cual ha venido disminuyendo la superficie de plantación y de forma especial los grandes productores tradicionales como Francia, Italia, España y Portugal junto con Argentina, en contraposición con los nuevos países productores, Australia, Chile, USA y Sudamérica que han visto aumentada su superficie desde el quinquenio referenciado.

\section{GRAFICO 4.1}

\section{EVOLUCIÓN DE LA PRODUCCIÓN Y CONSUMO MUNDIAL DE VINO (1986-2002)}

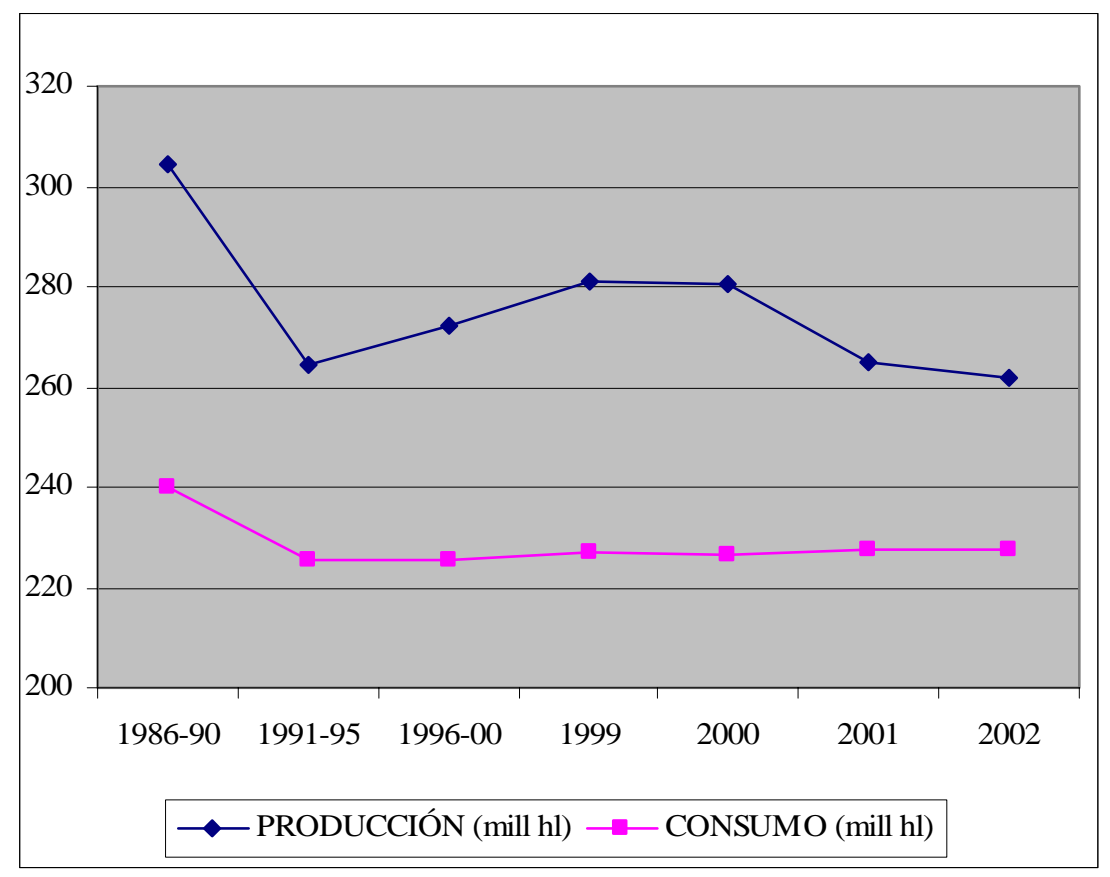

Fuente :OIV

A nivel mundial, la producción de vino viene a situarse a lo largo de los últimos años en torno a los 261,60 millones de hectolitros, si bien con fluctuaciones relevantes que no impiden observar una tendencia de disminución (gráfico 4.1). Algo similar ha ocurrido con las producciones de vino en los dos grupos de países, lo que queda reflejado en el gráfico 4.2. La evolución de la producción de vino es resultado de las 
variaciones en la superficie de plantación, de la influencia del efecto climático y de las modificaciones en las técnicas de cultivo y prácticas enológicas.

\section{GRAFICO 4.2}

PRODUCCIÓN MUNDIAL DE VINO EN PORCENTAJE POR PAISES (2002)

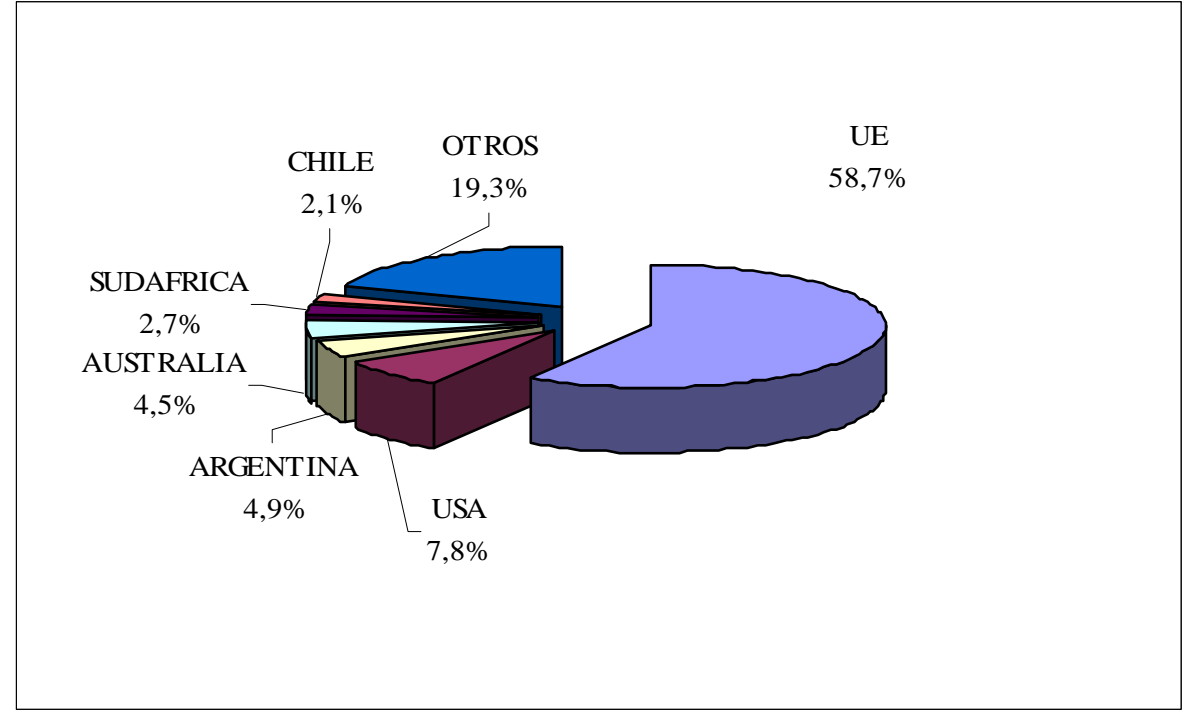

Fuente :OIV

La distribución de esta producción por países manifiesta una alta concentración, ya que la Unión Europea aporta el 58,7 de la producción total y los seis primeros países productores concentran más del 71 \% de la producción total mundial.

Esta distribución de la producción de vino por países no coincide con la que corresponde según la superficie de plantación debido a la existencia de importantes diferencias en los rendimientos del cultivo. La evolución de la media de producción de uva por superficie de plantación viene mejorando en todos los países, pero de forma muy desigual, acentuándose las diferencias existentes inicialmente. España, junto con Portugal, Rumania y algunos países de la ex Unión Soviética, obtiene uno de los peores rendimientos de los países productores, que se sitúa en torno al $40 \%$ del rendimiento medio de la Unión Europea, hecho que afecta negativamente a la rentabilidad económica del cultivo.

El consumo mundial de vino se estima por la OIV en unos 227,5 millones de hectolitros referidos al año 2002. En cuanto a la evolución el consumo, Los seis países consumidores más importantes coinciden con los seis mayores productores y demandan cerca del 60\% del total mundial (gráfico 4.3). 


\section{GRÁFICO 4.3}

CONSUMO MUNDIAL DE VINO EN PORCENTAJE POR PAISES (2002)

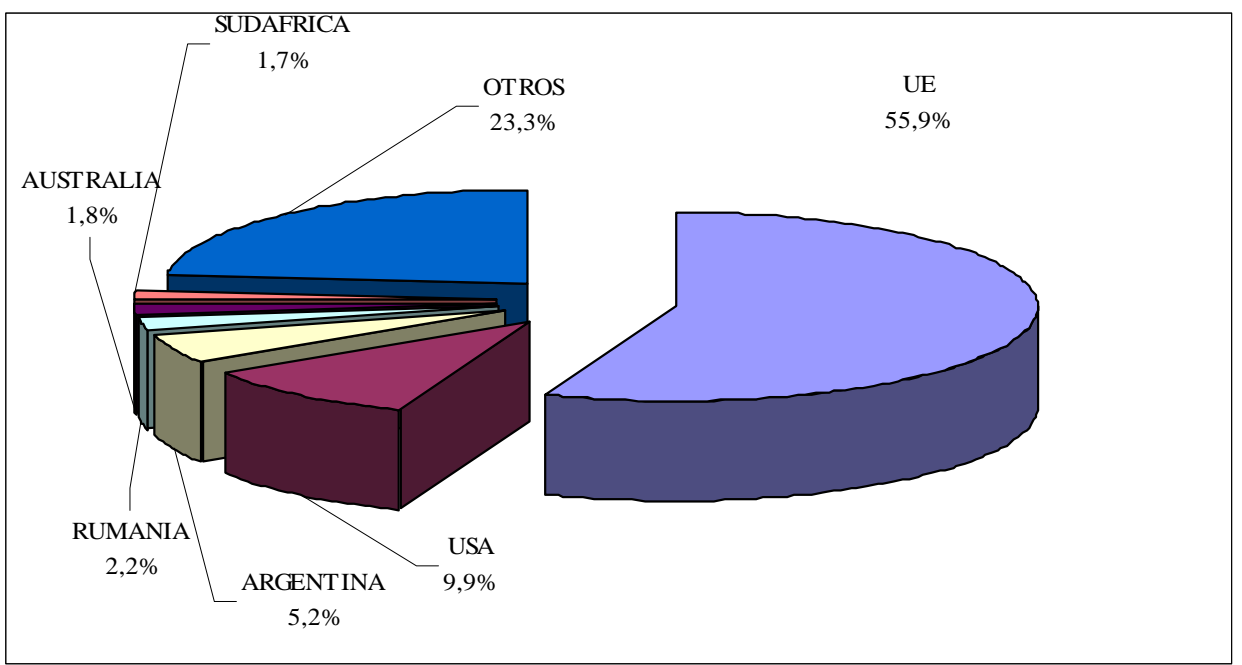

Fuente :OIV

En términos generales se manifiesta un sostenimiento en el consumo de vino entorno a una media en los últimos seis años de 226 millones de hl, en dicho periodo las variaciones interanuales en el consumo no han alcanzado ni el $1 \%$. Es notable la disminución producida en los grandes países productores como Francia, Italia, España y Portugal, dentro de la Unión Europea, o Argentina. Por el contrario, se aprecia un fuerte incremento en países europeos no productores como Reino Unido, Dinamarca, Bélgica y Países Bajos, y también en otros países como Japón, Australia, Canadá o África del Sur, si bien, debido a sus bajos niveles de consumo, tales aumentos no permiten compensar la importante reducción de los países más consumidores.

Relacionando las cifras de consumo de vino con las de su producción, se puede constatar una tradicional generación de excedentes a nivel mundial, que son destinados fundamentalmente a la producción de alcohol alimentario, y que las medidas restrictivas propuestas por los países productores miembros de la Unión Europea han conseguido resolver en parte. En el mercado internacional del vino existe una situación de desequilibrio a la que, en los últimos años, se ha sumado la oferta de nuevos países productores, como Estados Unidos, Chile, Australia o África del Sur, que, si bien con una todavía pequeña capacidad exportadora, han demostrado una capacidad comercial creciente.

A pesar de que los países de la Unión Europea siguen dominando el mercado mundial del vino, su participación en el mismo está disminuyendo y son estos nuevos países vinícolas quienes están desarrollando desde mediados de los años ochenta un comportamiento más dinámico. Este comportamiento se ve impulsado por la ausencia de las políticas de intervención (que se han autoimpuesto los países tradicionales), la existencia de altos niveles de rendimiento en los cultivos y una diferente estructura productiva y empresarial que ha incorporado una nueva estrategia de comercialización orientada hacia los segmentos de vinos de calidad con precio reducido, que facilita la 
acomodación de la producción a las características de la demanda en los mercados que muestran un consumo creciente como el Reino Unido, Japón y Holanda entre otros (Bardají, 1993; Roca, 1997).

Las hipótesis con las que trabaja la Organización Internacional del Vino en el horizonte del año 2010 sitúan la superficie mundial de viñedo en 7,12 millones de hectáreas, con una producción de vino de 267 millones de hectolitros, un consumo de 207 y un comercio mundial de unos 90. El estudio realizado por la consultora británica IWSR/GDR para Vinexpo prevé un aumento de la producción mundial de vino del 6,4\% entre los años 2004 y 2008, un aumento del valor de los intercambios de vino del 14,7\% y cambios importantes en el consumo, con aumento en EEUU (de 18,1 millones de hectolitros en 1999 a 27,6 millones de hectolitros en 2008), Alemania (de 19,6 a 23,6) y Reino Unido (de 8,7 a 12,3) y descenso significativo en Francia y España.

\subsection{El comercio mundial de vino}

Respecto al comercio mundial de vinos, el crecimiento proporcionalmente mayor del consumo en países no productores frente al descenso en los productores tradicionales, junto a la necesidad de la exportación como mercado con más posibilidad para crecer, tienen como efecto la creciente importancia del comercio mundial de vinos tanto exportaciones como importaciones, como se refleja en el gráfico 4.4.

\section{GRAFICO 4.4}

\section{EVOLUCIÓN DE LAS IMPORTACIONES Y EXPORTACIONES MUNDIALES DE VINO} (1986-2002)

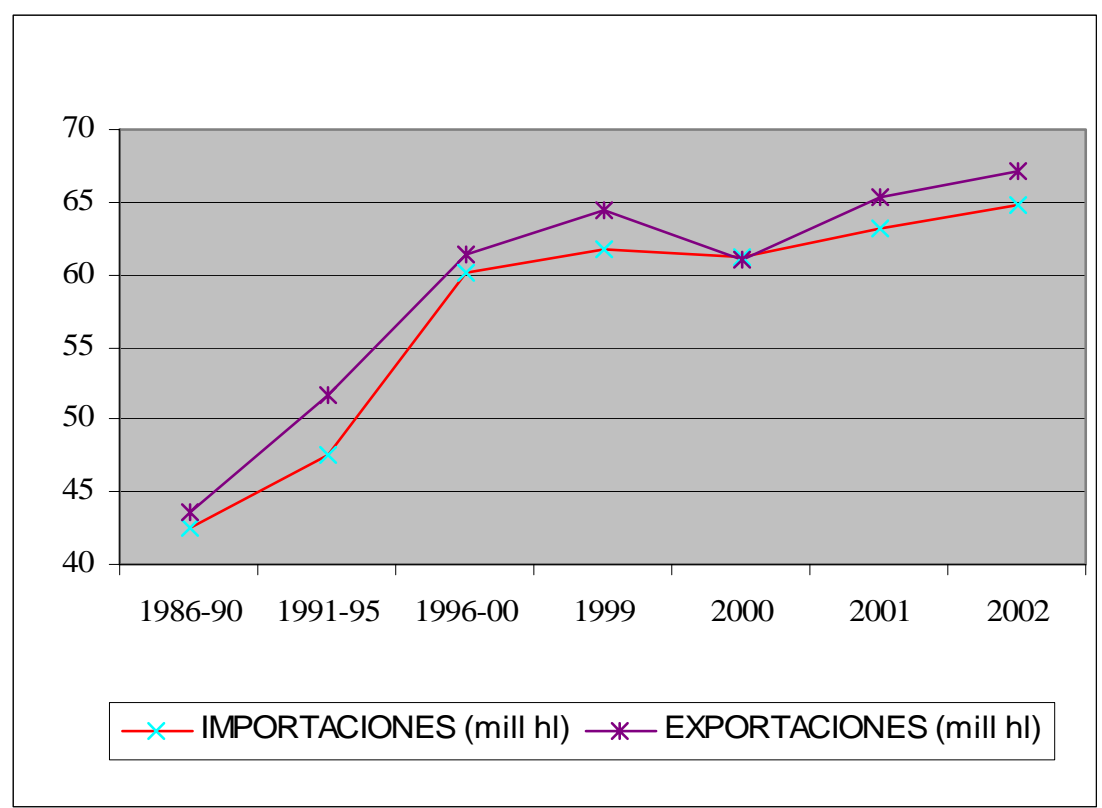

Fuente :OIV 
En la década de los noventa se ha producido un cambio importante en la dinámica comercial de la Unión Europea y su posición competitiva en el mercado mundial, ya que los países denominados emergentes, que han experimentado, en los años finales de los 90, crecimientos exponenciales en sus exportaciones, fundamentalmente derivado de la etapa de precios excesivamente altos en la Unión Europea, que ha propiciado la entrada competitiva vía precios de estos países, por lo cual la UE ha abandonado los segmentos de precios más bajos (Cuadro 4.1).

\section{CUADRO 4.1}

EVOLUCÓN DE LAS EXPORTACIONES DE VINO (1981-2001).

\begin{tabular}{|c|c|c|c|c|}
\hline & 81-85 & $86-90$ & 91-95 & 96-01 \\
\hline Alemania & $2.604(5)$ & 2.756 & 2.715 & 2.337 (6) \\
\hline España & $5.901(3)$ & 4.645 & 7.353 & 8.472 (3) \\
\hline Francia & $10.164(2)$ & 12.776 & 11.478 & 15.098 (1) \\
\hline Italia & 17.319 (1) & 12.551 & 15.069 & $14.920(2)$ \\
\hline Portugal & $1.399(8)$ & 1.554 & 1.948 & 2.004 (8) \\
\hline Chile & 131 (20) & 183 & 868 & 3.525 (4) \\
\hline Australia & $84(24)$ & 249 & 1.002 & $2.298(7)$ \\
\hline Estados Unidos & 301 (17) & 623 & 1335 & 2.402 (5) \\
\hline Bulgaria & $2.428(6)$ & 1.804 & 1.162 & 1.024 (11) \\
\hline Argentina & 182 (19) & 221 & 591 & $1.103(\mathbf{1 0})$ \\
\hline Sudáfrica & $68(25)$ & 46 & 371 & 1.244 (9) \\
\hline
\end{tabular}

Fuente :OIV

La posición de los tres principales productores mundiales, Italia, Francia y España sigue siendo una posición de privilegio en el comercio mundial ya que estos tres países representan más del $64 \%$ de las exportaciones en el ámbito mundial. (Gráfico 4.5). Por su parte, los tres países emergentes más exportadores, Australia, Chile y USA representan en conjunto apenas el 15\% de la cuota exportadora mundial, aunque con una dinámica muy expansiva, de ahí el apelativo de emergentes, que se les ha asignado en el contexto vinícola. 


\section{GRÁFICO 4.5}

EXPORTACIONES DE VINO (2001)

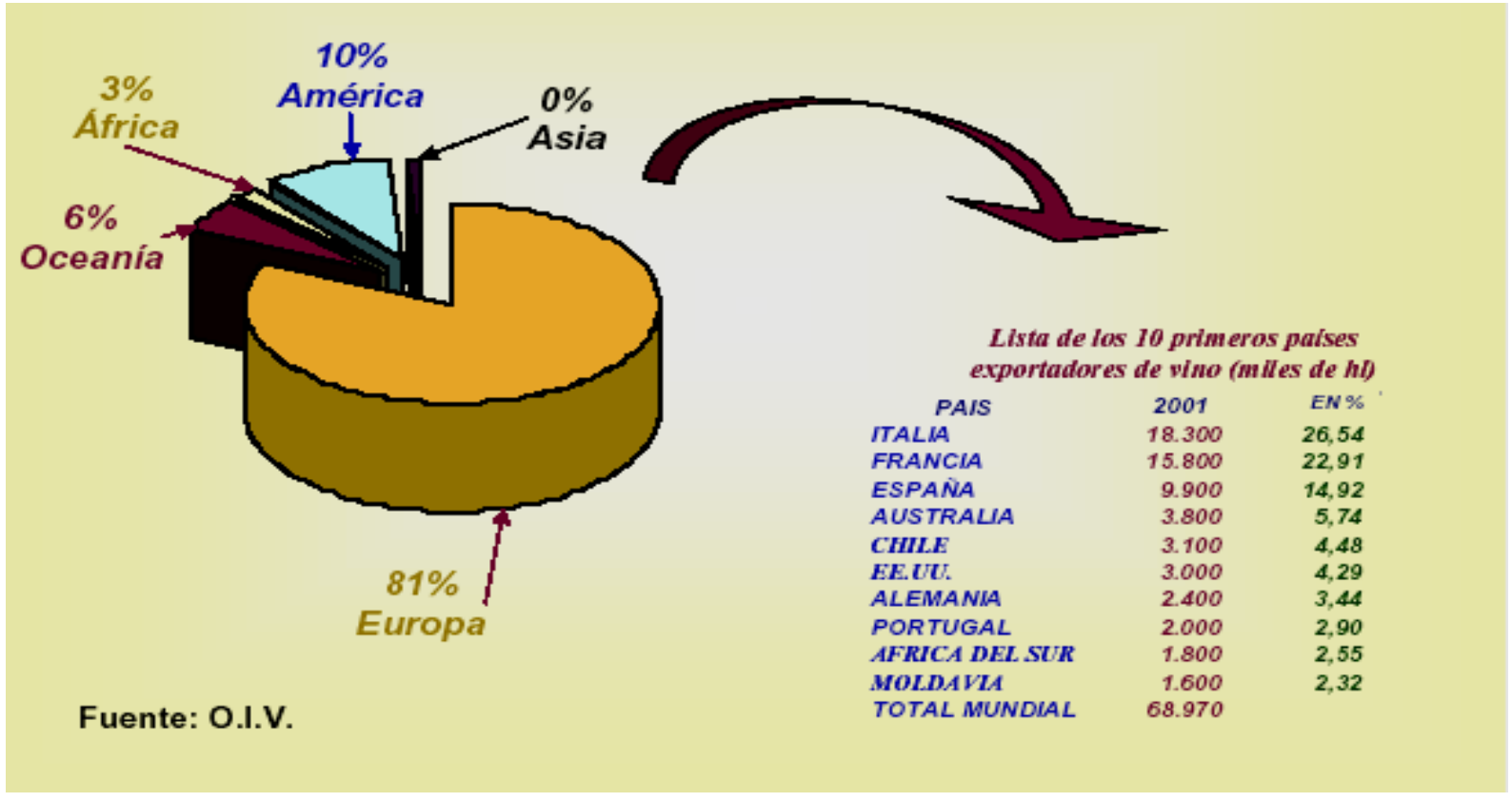

Respecto de las importaciones (Gráfico 4.6), Alemania, Reino Unido y Francia concentran más del $44 \%$ de las importaciones mundiales de vino.

\section{GRAFICO 4.6}

\section{IMPORTACIONES DE VINO (2001)}

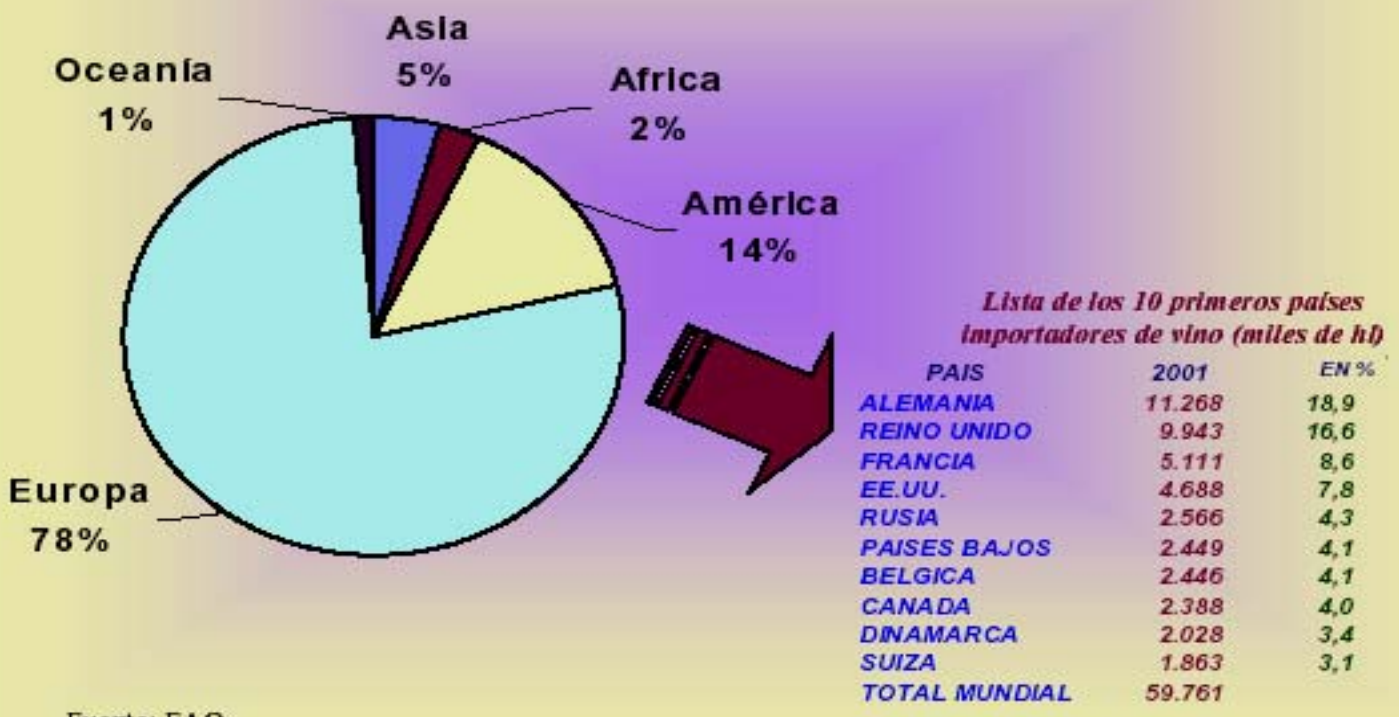

Fuente: FAO 


\section{EL VINO EN LA UNIÓN EUROPEA}

Se han analizado los datos del sector vitivinícola en la UE-15, utilizando como fuente los datos todavía provisionales del Comité de Gestión de Vinos de la Dirección General de Agricultura de la Comisión Europea de la producción de vino en la UE para la campaña 2003-2004 y, los relativos al comercio en el citado ámbito territorial.

\subsection{La producción y el consumo en la Unión Europea de vino}

La producción vinificada en la campaña 2003-2004 ha representado 152,4 mill de hl, y es por tercer año consecutivo una cosecha bastante reducida, se tienen en cuenta los 176,5 mill de hl de la campaña 1999-2000 (gráfico 4.7).

\section{GRAFICO 4.7}

EVOLUCIÓN DE LA PRODUCCIÓN Y CONSUMO DE VINO (mill. hl) EN LA UNIÓN EUROPEA (1980/81-2003/04)

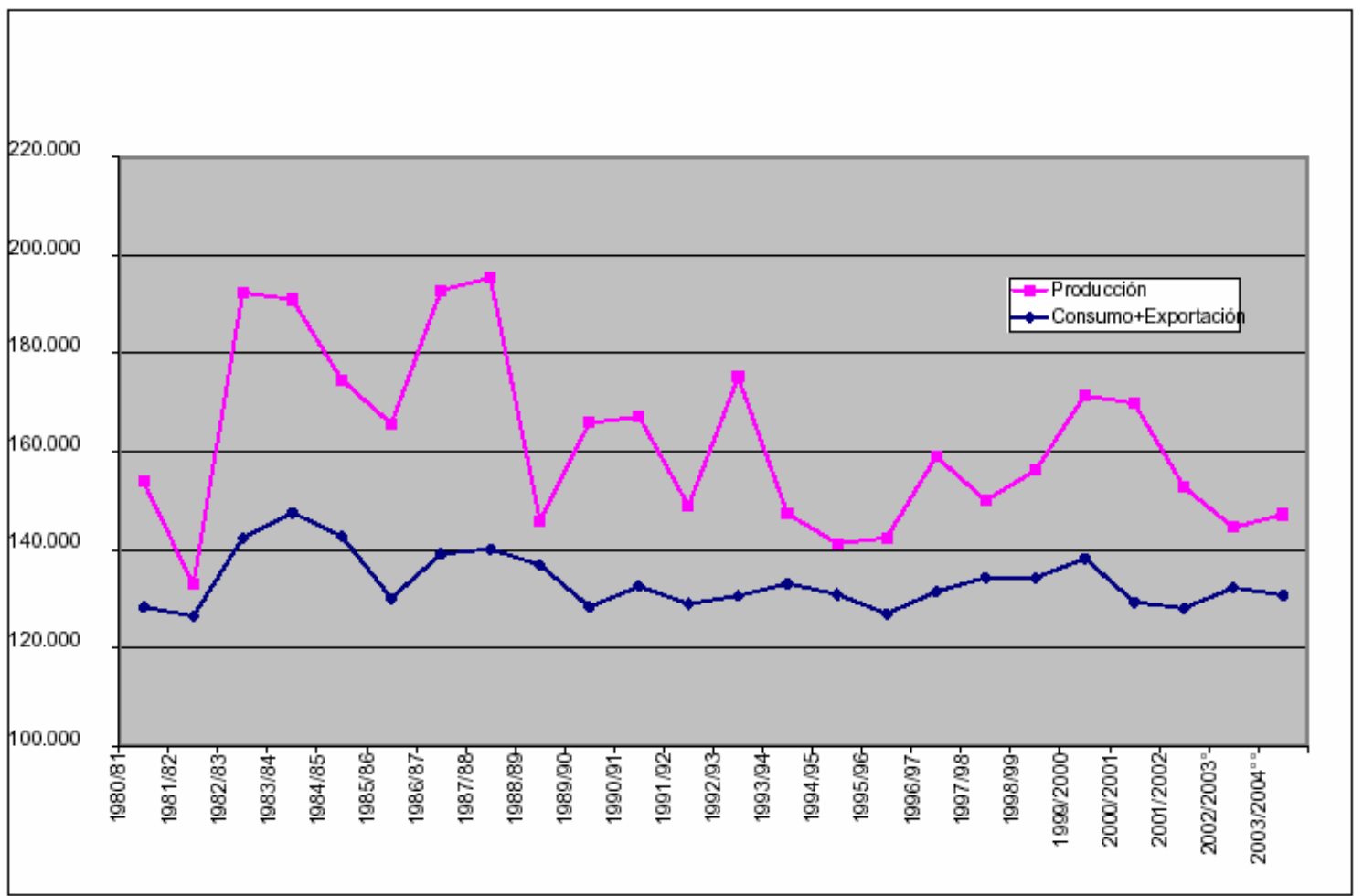

Fuente: La Comisión Europea

Los principales países productores, Francia, Italia y España concentran cerca del 86 \% de la producción vinificada total de la UE (gráfico 4.8), destacando lo siguiente:

- Francia es la primera nación productora de la UE, con una cuota de participación del $30 \%$ de su producción vinificada total, aunque desde la campaña 2000-2001 su producción ha ido en descenso constante. El rendimiento medio de las campañas 1998/99-2001/02 ha sido de 65,4 hl/ha. También cuenta con la mayor cuota de producción de vino de calidad 
producido en regiones determinadas (vcprd), respecto de su producción nacional (56,6 \%).

- Italia es la segunda nación productora de la UE, con una cuota de participación del 29 \% de su producción vinificada total, si bien desde la campaña 2000-2001 su producción ha ido igualmente que Francia en descenso constante. El rendimiento medio de las campañas 1998/99-2001/02 ha sido de 66,8 hl/ha Cuenta con la menor cuota de producción de vcprd, respecto de su producción nacional (29,7 \%).

- España es la tercera nación productora de la UE, con una cuota de participación del 26,6 \% de su producción vinificada total. El rendimiento medio de las campañas 1998/99-2001/02 ha sido de 30,7 hl/ha, cifra inferior al $50 \%$ de las registradas tanto en Francia como en Italia. Su cuota de producción de vcprd, respecto de su producción nacional es del 31,5 \%.

\section{GRAFICO 4.8}

\section{EVOLUCIÓN DE LA PRODUCCIÓN TOTAL DE VINO (mill. hl) EN LOS PRINCIPALES PAÍSES DE LA UNIÓN EUROPEA}

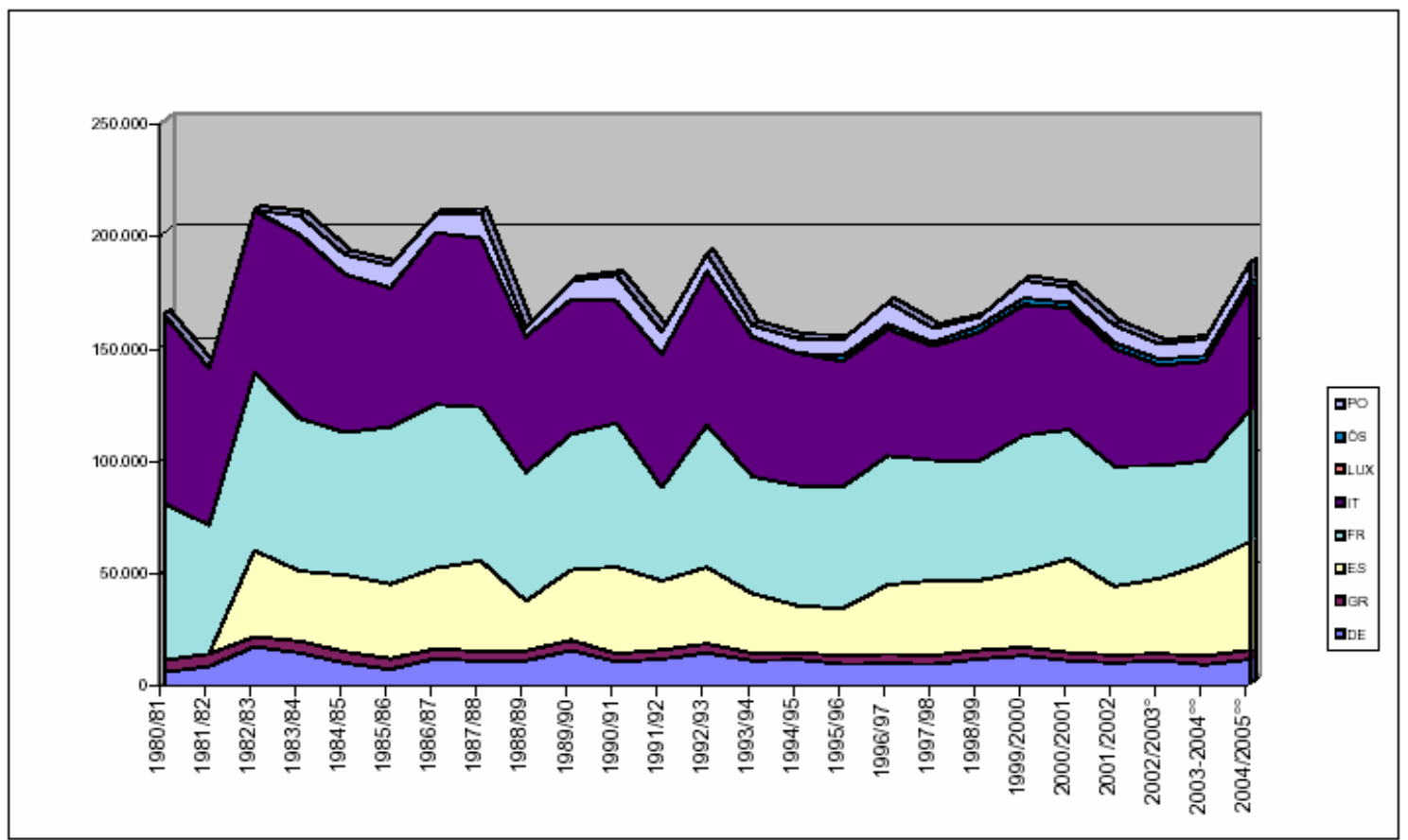

Fuente: La Comisión Europea

El consumo de vino en la UE en la campaña 2003/2004 ha ascendido a 129,4 mill de hl (supone el 85 \% de la producción en esa campaña). Los principales consumidores por orden de importancia son Francia, Italia, Alemania e Inglaterra, que concentran cerca del $84 \%$ en volumen de dicho consumo. 


\section{$2.2 \quad$ El comercio del vino en la Unión Europea}

Las exportaciones desde la UE durante el 2003 a países terceros ascienden a un total de 12,82 mill de hl, observándose en el gráfico 4.9 que se han mantenido muy estables en volumen de vino desde el año 2002, por fuertes aumentos de precio del vino en la UE, junto con la estrategia de los países emergentes de menor precio, lo cual ha generado el estancamiento de la exportación en volumen. Los principales países terceros, destino de las exportaciones han sido, por orden de importancia USA, Suiza, Canadá, Japón y Rusia.

Las exportaciones totales UE incluidas las intracomunitarias durante el año 2003 ascienden a un total de 47,53 mill de hl, de lo cual se desprende que solamente las exportaciones intracomunitarias suponen unas 2,7 veces de las registradas con terceros países. Los principales países implicados por orden de importancia en estas exportaciones totales son, Francia Italia, España, Portugal y Alemania, que concentran cerca del $95 \%$ del total de dichas exportaciones.

\section{GRAFICO 4.9}

\section{EVOLUCIÓN DE LAS IMPORTACIONES Y EXPORTACIONES DE VINO (mill. hl) DE LA UNIÓN EUROPEA A PAISES TERCEROS (1993-2002)}

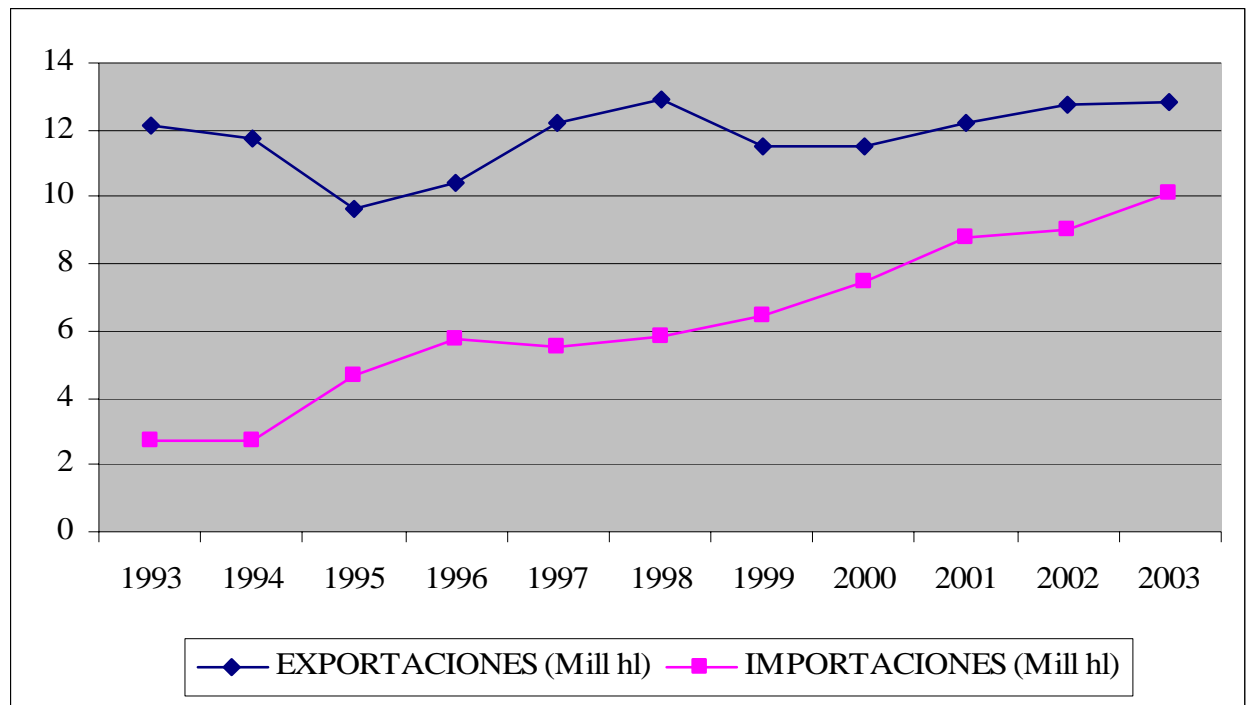

Fuente: La Comisión Europea

Las importaciones en la UE durante el 2003 de países terceros ascienden a un total de 10,12 mill de hl, observándose en el gráfico 3.9 el fuerte crecimiento en volumen de vino desde el año 1998 por fuertes aumentos de precio del vino en la UE, junto con la estrategia de los países emergentes de menor precio, lo cual ha generado el estancamiento de la exportación en volumen produciendo fuerte reducción del saldo comercial en volumen, con ligero crecimiento del mismo en valor, aunque el saldo exterior vitivinícola es favorable a la UE, con 2,69 mill de hl. 
Australia se erige como el principal suministrador de la UE, tanto en volumen como en valor, reflejando un espectacular crecimiento desde el año 1994. Le siguen a cierta distancia en volumen Sudáfrica, Estados Unidos, Chile y Nueva Zelanda.

\section{EL VINO EN ESPAÑA}

España es el primer país en el mundo en superficie de viñedo, con 1.166.347 has en el año 2003, la cual es el resultado de la reducción habida desde el año 1980 de un 30 \%, principalmente debido a los planes de arranque, reestructuración y reconversión, impulsados por la política comunitaria de la Unión Europea.

La producción de vino en la campaña 2003/04 ascendió a 47,30 Mill de hl, que coincide con los valores máximos del último decenio, el cual presenta unos valores medios de 34,93 Mill de hl y mínimos de 22,38 Mill de hl en la campaña 1995/96.

Por Comunidades Autónomas, Castilla-La Mancha participa en más del 51 \% en el volumen de producción nacional, seguida de Cataluña (7,8 \%), Comunidad Valenciana (6,9 \%), Extremadura (6,6 \%), La Rioja (5,4 \%) y Andalucía (4,8 \%). El conjunto de estas seis regiones representan prácticamente el $83 \%$ de la producción nacional.

\subsection{Balance vitivinícola}

El balance vitivinícola (cuadro 4.2) permite observar para cada campaña el total de vino disponible u oferta, constituido por el stock al inicio de la campaña, la producción de vino nuevo y las importaciones; del lado de la demanda, viene conformada por el consumo de zumo y mosto, el consumo nacional de vino, las exportaciones, la destilación y el stock final.

La producción anual, a pesar de estar muy intervenida (prohibición europea de nuevas plantaciones y control de rendimientos en vinos de calidad) es muy variable (entre los 21 y los 47 mill de hl en los últimos diez años), debido fundamentalmente a la variable climatológica en situaciones de secano.

El factor más importante de los últimos años es no sólo el fuerte crecimiento que se produce en España, sino su coincidencia en 2004 con la recuperación de la producción en nuestros países competidores, Francia e Italia tras años de producción en descenso. Esta generalización de elevadas producciones supone un crecimiento de la competencia mundial y hace más difícil la salida de volúmenes españoles en la medida en que lo han hecho en los dos últimos años, coincidentes con producciones reducidas de los dos citados países vecinos.

Se mantiene, sin embargo, el crecimiento en las cifras de elaboración de mosto que, de cifras cercanas a los 1,5 mill de hl a mediados de los años noventa, subió a los 4 mill de hl a finales de la década y lleva tres años consecutivos superando una media de 6 mill de hl. De nuevo, lo que muchas veces se ha considerado como un mero regulador de la oferta de vino se está convirtiendo en España en un posible mercado comercialmente interesante. 
De forma similar y pasando a la demanda del vino español, la destilación para uso de boca se mantiene en unos niveles elevados de 10,4 mill de hl en la campaña 2000-2001, 7,8 millones en las dos siguientes y de 9 mill de hl en la campaña 20032004, propiciados por menores producciones en otros países europeos y, por tanto, su menor demanda de destilación subvencionada. La media de participación en la producción total nacional del último decenio es del $21 \%$, que representa casi las tres cuartas partes del total comunitario realizado con ayudas.

\section{CUADRO 4.2}

\section{BALANCE VITIVINÍCOLA ESPAÑOL (1995/1996-2003/2004)EN MILLONES DE HECTÓLITROS}

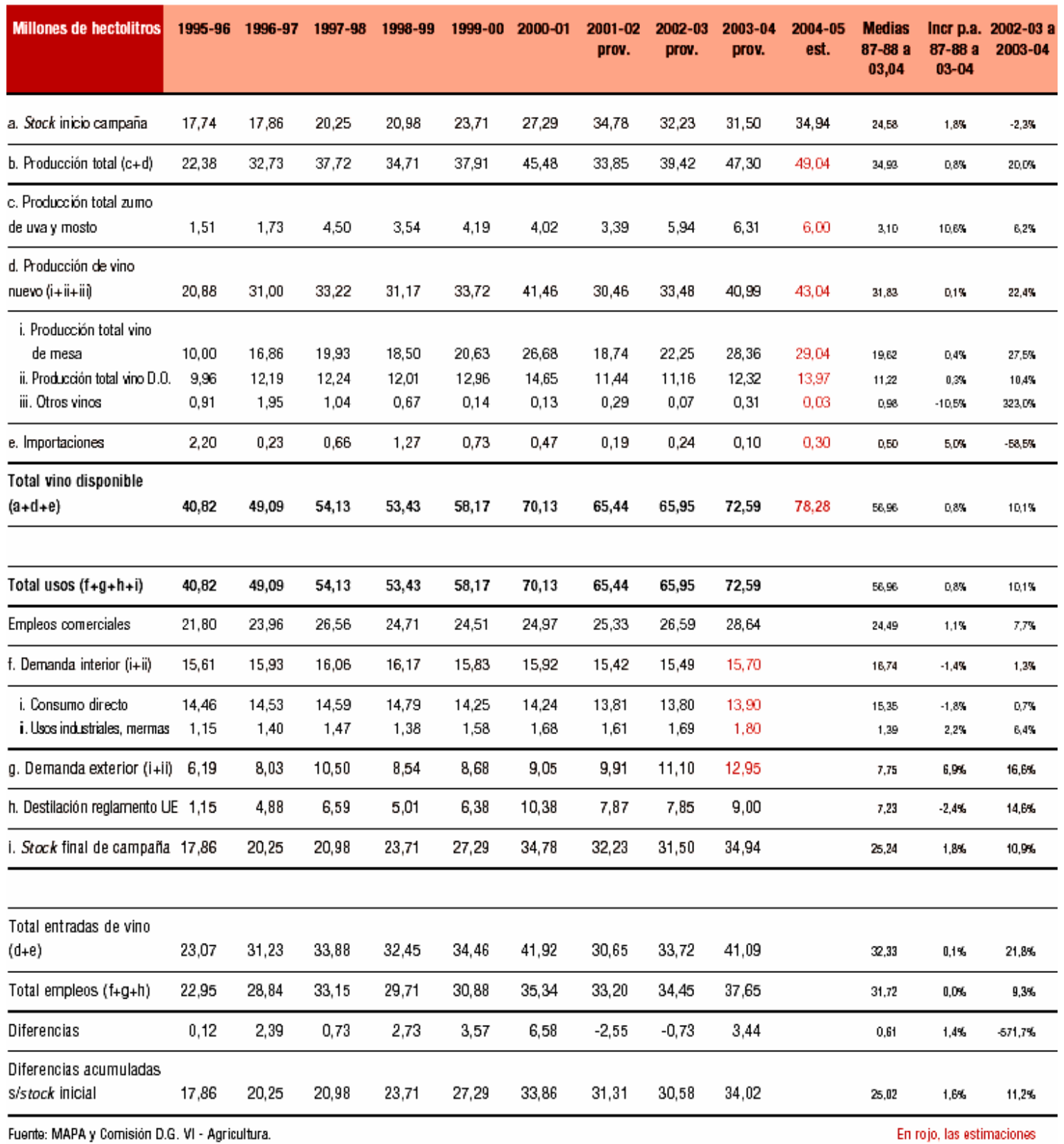


En definitiva, la destilación de productos vínicos se mantiene en niveles elevados en España, ya que gozan de una importante subvención europea, captada por una potente industria alcoholera capaz de suministrar las necesidades del brandy español y exportar alcohol en cantidades importantes. El aspecto negativo es la excesiva dependencia de las ayudas comunitarias, que se han convertido en una de las salidas más importantes de la producción española, lo que no deja de ser preocupante, si se observa como se han mantenido volúmenes elevados en la destilación, aún con reducidas producciones, lo que refleja la reducción de su papel tradicional como regulador de la oferta en situaciones de crisis.

La ayuda de la destilación en alcohol de uso de boca es un tema particularmente controvertido, puesto de manifiesto por la Comisión en el "Informe Innova” de evaluación ex post de la OCM del Vino, ya que subvenciona parte de mercado de alcohol de la UE mediante el aprovisionamiento de materias primas baratas, sobre la base de que constituye una salida tradicional para el vino de la UE. No parece haber una buena razón para impedir el establecimiento de un sistema de aprovisionamiento para la industria de espirituosas más orientado al mercado.

En cuanto a la destilación de crisis es un método efectivo, pero caro a la hora de tratar con excedentes coyunturales, puesto que implica el almacenamiento y la eliminación del alcohol resultante. La destilación no es un método rentable a la hora de tratar con excedentes estructurales continuados. Las evidencias muestran que la nueva destilación de crisis es más cara que la anterior destilación obligatoria, a pesar de que en algunos casos (Ej. Francia), esto no es efectivo si no se obtiene una ayuda nacional adicional.

Más difíciles son las estimaciones del pasado año para los principales componentes de demanda nacional, el consumo interior y las exportaciones, por las diferencias que se encuentran entre las distintas fuentes de datos disponibles.

En el mercado interior, donde la tendencia viene siendo desde hace años la caída constante del consumo y donde el año 2003 se registró un descenso importante en el consumo de vinos de calidad en hostelería. Con un volumen global que supera los 15 millones de hl, la demanda interior ha absorbido como media de los últimos 16 años, aproximadamente el 48 \%de la producción total de vino, cifra muy inferior a la que presentan otros países como Francia e Italia, donde se consume internamente alrededor del 60 \% de la producción.

Las exportaciones configuran el factor más dinámico del balance vitivinícola pasando de 6,9 a 12,95 mill de hl entre1995/96-2003/2004, con unas cifras medias de 8 mill de hl en el periodo 1987/88-2003/04, que representan alrededor del $23 \%$ de la producción nacional.

La distinta evolución de oferta y demanda de vino modifica el factor más influyente sobre los precios, el stock de vino almacenado en las bodegas, que ha sido elevado en las cuatro últimas campañas y ha reducido la necesidad de nuevas compras. Todo ello tiene su reflejo en el precio percibido por los agricultores que en las tres ultimas campañas se encuentra muy estabilizados a la baja y con clara referencia al 
precio del vino destilado (sobre todo en los vinos blancos) de 2,40 €/hectogrado que actúa como limite inferior para el resto de los vinos.

En cuanto a las restituciones a la exportación, más del 68 \% del total de subvenciones comunitarias a la exportación son utilizadas en España. Los acuerdos alcanzados en el seno de la Organización Mundial de Comercio incluyen substanciales reducciones de las ayudas, lo que afectará a las exportaciones de vinos de mesa.

Referente a las importaciones de vino, son marginales, con cifras medias de 0,50 mill de hl en el periodo 1987/88-2003/04.

Como resumen de lo expuesto, las variables de la ecuación de oferta y demanda de vino en España han evolucionado desde una situación de relativa escasez (déficit en 1,43 mill de hl), en la primera mitad de los años 90, hacia una relativa abundancia (superávit 2,2 mill de hl) en los últimos 8 años, con el efecto previsible en los precios: fuerte subida en la primera mitad de los años 90 y disminución cada vez más acusada en los últimos 8 años.

De entre los tres principales productores de vino comunitarios, España es el país con las menores proporciones de consumo directo y de exportaciones respecto de sus producciones medias y por consiguiente el país que presenta las mayores diferencias relativas o excedentes entre lo que produce y lo que utiliza en el mercado interior y en la exportación, lo cual genera una mayor necesidad de incrementar las salidas de la producción nacional, es decir exportar más, para asumir mayores producciones.

Las grandes cifras del sector que se desprenden del balance vitivinícola español apuntan para los próximos años las siguientes hipótesis: aumento de la producción, descenso de la demanda interna y menor volumen de vino destilado. En estas hipótesis la única vía que queda es la exportación (FEV, 2004).

\subsection{Los precios del vino}

En relación con los precios del vino, hay que hacer una clara diferenciación entre los precios de los vinos de calidad y los de mesa.

Por otro lado, los precios de los vinos de mesa están muy influenciados por la variabilidad entre cosechas. En este sentido, la elevada producción de la campaña 2000/01 ha llevado a situar a niveles muy bajos los precios del vino, después de haber conocido subidas importantes en los años anteriores. Así, el vino de mesa blanco se situó en 1,8 €/hectogrado y los vinos tintos en 2,3 €/hectogrado. Las elevadas producciones de vino tienen un efecto negativo en la recuperación de los precios, aún cuando las cosechas posteriores se sitúen a niveles que se consideran como normales (gráfico 4.10).

Es importante señalar que la mayor caída de precios que ha tenido lugar en los últimos años se ha dado en los vinos tintos de mesa. Ello se debe básicamente a dos hechos: en primer lugar, a la red de seguridad que suponen las medidas de regulación del mercado para los vinos blancos, al ser sus precios inferiores al de los tintos; y, en 
segundo lugar, a la autorización de las mezclas de los vinos blancos y tintos que conllevan a una aproximación de precios entre ambos.

Otro hecho relevante en relación con las cotizaciones que alcanzan los productos del sector vitivinícola, es el diferencial de precios existente entre nuestras producciones y la de los países de nuestro entorno. En este sentido, hay que señalar que las cotizaciones del vino de mesa blanco en Francia se sitúan en 3,4 €/hectogrado, precio muy superior a la cotización que alcanza este vino en España, diferencia de precios difícil de entender en un mercado único. Este hecho nos muestra uno de los grandes problemas del sector vitivinícola español, que no es otro que la deficiente comercialización de nuestras producciones (Libro Blanco, 2003).

En el gráfico 4.10 se puede apreciar que persiste la grave crisis de precios que el sector está padeciendo desde la campaña 1999/00, sin que se vislumbre ningún síntoma de recuperación. Los vinos más afectados por esta crisis están siendo los que se comercializan a granel, cuya oferta está creciendo a un ritmo muy superior al de su demanda. A lo largo del último año, los precios del vino de mesa se han mantenido muy estables, en torno a 2,2 €/hectogrado en los vinos blancos y 2,8 €/hectogrado en los tintos.

Es destacable que el diferencial en el precio de los vinos de mesa blancos y tintos es bastante menor que en el año 1999. Esta evolución puede deberse a que en la reestructuración la mayoría de viñas arrancadas eran de variedades blancas, por lo que la oferta de vinos blancos es más escasa en comparación con su demanda que la de vinos tintos.

Respecto a los precios de la uva, la situación se puede catalogar como catastrófica en muchas regiones españolas. Por ejemplo, en Castilla la Mancha y Valencia las uvas blancas se han llegado a pagar por debajo de $0,15 € / \mathrm{kg}$ y las tintas a $0,2 € / \mathrm{kg}$, lo que supone a los viticultores la venta de sus producciones por debajo del umbral de rentabilidad.

Los precios de los vinos de calidad son superiores a los vinos de mesa, encontrándose sometidos a fluctuaciones en sus cotizaciones, aunque no tan amplias como en los vinos de mesa. Estas fluctuaciones se dan pese a ser unos vinos con una mayor estabilidad en su demanda, que exista una limitación de las producciones por hectárea fijadas en sus reglamentos, y de que los costes financieros que conlleva la elaboración de vinos de crianza o reserva intervienen de forma casi constante en la formación del precio. Esta situación es más acusada en aquellas denominaciones de origen con menor implantación local o nacional. 


\section{GRAFICO 4.10}

\section{EVOLUCIÓN DEL PRECIO EN ORIGEN DE VINO BLANCO Y TINTO DE MESA A GRANEL}
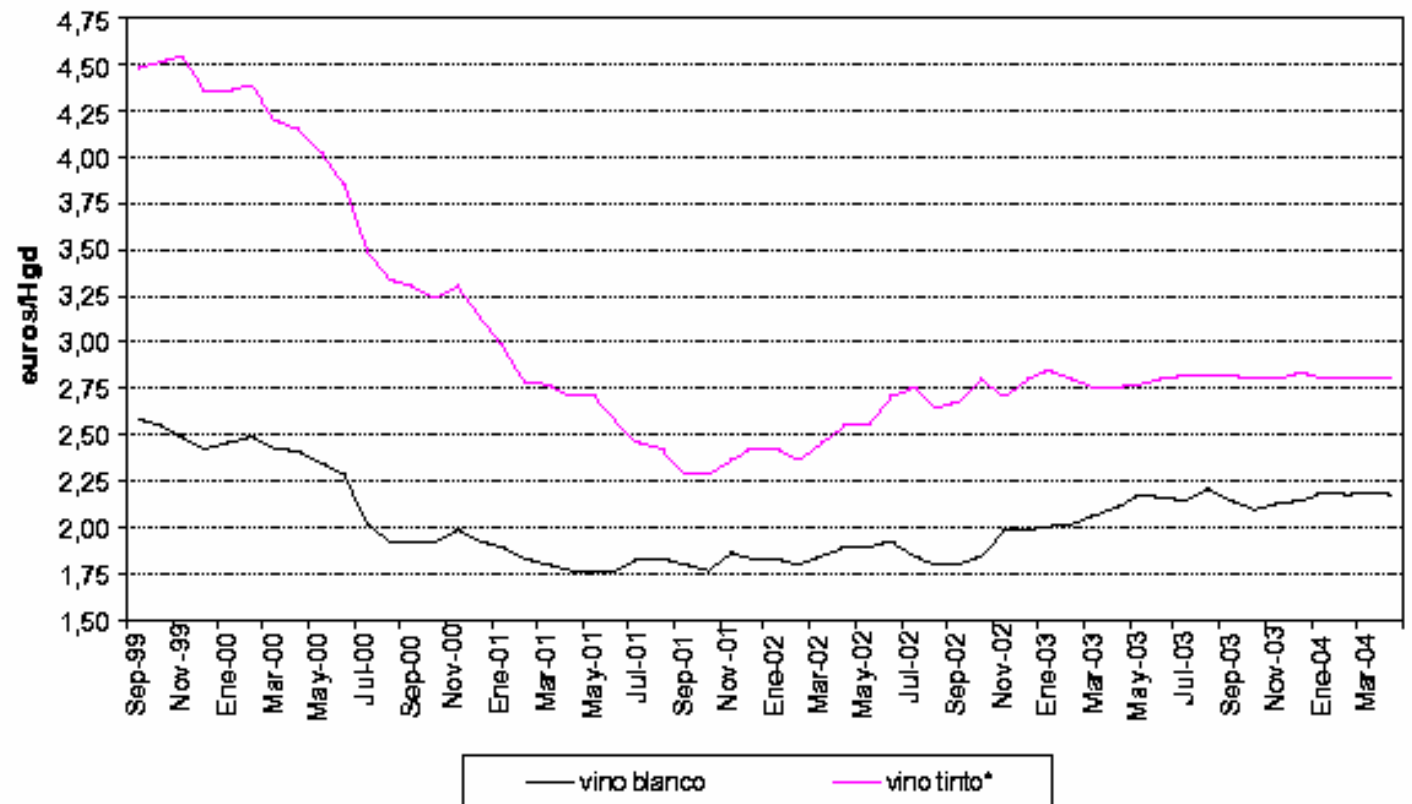

Fuente: La Semana Vitivinícola

El gran rango de precios que existe en los mercados internacionales del vino conlleva la existencia de multitud de segmentos de mercados. Las pequeñas y medianas bodegas que constituyen la parte mayoritaria en cuanto el número de empresas, concurren en segmentos de mercados muy parecidos (Basic y Popular Premium) en todo el mundo. En estos segmentos de precios el conocimiento de las marcas es mínimo, por lo que las empresas han de apoyarse en marcas paraguas, DDOO, etc. o simplemente en la mención del país de origen (Albisu, 2004).

\section{CUADRO 4.3}

\section{SEGMENTACIÓN DE PRECIOS POR CALIDADES O CATEGORÍAS DE VINOS}

\begin{tabular}{|c|c|c|c|}
\hline Categoria & $\begin{array}{l}\text { Europa } \\
\text { ExBodega } \\
\text { EUR/Bofella }\end{array}$ & $\begin{array}{l}\text { Europa } \\
\text { Consumo } \\
\text { EUR/Botella }\end{array}$ & Requisitos \\
\hline tcon & $>30$ & $>150$ & $\begin{array}{l}\text { Gran Marca e imagen (esto Neva mucho tiempol) complejidad, altas notas por los criticos. } \\
\text { Muy diffcil astablecer ef precio }\end{array}$ \\
\hline Uitra Premium & $3.35-30$ & $14-150$ & Marca de calidad, onigen. imagen, varietal o una buena mezcla, más complejictad. \\
\hline Super Premium & $2,25-3.35$ & $7.5-14$ & Imagen, potencial para bodega, complejidad, bien recibjo por los criticos. \\
\hline Premium & $1,65-2,25$ & $5.5-7$ & Reconocimiento de marcs, origen, tipico para mono o muli varietal, más carácter, full body. \\
\hline Popular Premium & $1,10-1,65$ & $3.5-7$ & $\begin{array}{l}\text { Combinación de carácter y accessibilidad, caracier reconocido de variedades, onigen y } \\
\text { mezcla. Veria según paises : Espaffe y Francia } 1,5 E \text { botella y USA }>3 E\end{array}$ \\
\hline Basic & $<1,10$ & $<3$ & Varietal, ainutado, accesible, marca. \\
\hline
\end{tabular}

Fuente: Rabobank Internacional 2004 
Si se analiza el consumo de vinos en el mercado europeo por segmentos de categorías o calidades de vinos (Rabobank Internacional, 2004), la demanda europea de vino "Basic" (menos de $3 €$ botella de $3 / 4$ al consumo) continúa bajando en casi todos los países, y la demanda de vino "Premium”(5-10 €) está compensando esta caída. El segmento "Basic" y "Popular Premium" representa el 70 \% del volumen consumido en Europa, y supone el $45 \%$ del valor total del mercado (cuadro 4.3).

Uno de los factores decisivos y determinantes de la gran variabilidad de precios, es lógicamente el coste de producción de la uva, sobre todo para aquellos vinos de precios más bajos, en los que el porcentaje del precio de la uva es significativo respecto del precio final del vino. En umbrales más elevados de precios, el porcentaje que el coste de producción de la uva tiene sobre el precio final del vino es pequeño, por lo que las diferencias en el coste de producción no tienen un gran efecto en el precio final.

\subsection{Los mercados del vino}

Referente al mercado de la uva, para el conjunto de España apenas existen mercados de uva debido a que la mayor parte de la vinificación se encuentra en las cooperativas. Existe una parte creciente aunque pequeña de la producción de vinos con DO en manos de las bodegas elaboradoras. Queda un mercado de uva residual que supone entre el $20 \%$ y $25 \%$ de la producción total de uva, una parte del cual se realiza bajo acuerdos de producción, a veces con especificaciones de prácticas vitícolas. Su precio se fija por referencia al precio del vino. Cabe destacar que este mercado de uva, aunque no tenga mucho peso en el conjunto de España, es muy alto en algunas zonas (Saborá, 2003).

En relación con el mercado de graneles existe un importante mercado de vino debido a la falta de integración vertical para una gran parte de la producción entre la elaboración del vino de una parte y el envejecimiento y/o embotellado por otra. La dimensión de este mercado de graneles de vino supone en torno al $70 \%$ del vino elaborado. Esta cifra es mayor en los vinos destinados a vinos de mesa que en los vinos de calidad. Los mercados de graneles de vino se ven afectados por la estacionalidad de la producción frente a su consumo a lo largo del año. Esta dicotomía es la causa del valor estratégico de la capacidad de almacenamiento. Se estima que hay en España una capacidad de almacenamiento en el entorno de 50-55 millones de hectolitros, la mayor parte de la cual está en manos de bodegas cooperativas de 1 y $2^{\circ}$ grado (Saborá, 2003).

Los graneles de vino suponen para muchas bodegas la solución económica en la actualidad, siendo el precio el factor más importante para competir, resultando que en el bajo precio que alcanzan en el mercado, el precio de la uva supone una parte muy significativa de mismo. Aparte del precio, la calidad y las características del mismo también influyen en la diferenciación de estos mercados, apreciándose una cierta tendencia hacia la cualificación del mercado de graneles, fruto de las mejoras en las condiciones de transformación de las bodegas.

Un elemento que condiciona los mercados de vinos es el envejecimiento de una parte de la producción para elaborar crianzas y reservas. Esto supone que se retrae del mercado un volumen, que crece a la vez que el volumen de vino de crianza en el 
mercado, con un periodo de maduración mucho más largo. No existen cifras exactas ni oficiales sobre la capacidad de envejecimiento disponible en España, pero, aunque no se utilice toda, se estima que está en torno a 4 millones de hectolitros. La mayor parte del envejecimiento se concentra en la Denominación de Origen Calificada Rioja, donde se envejece en torno al 50\% de la producción (aunque varía según los años) y en la DOP (Denominación de Origen Protegida) Jerez. A mucha distancia está Ribera del Duero, con un $20 \%$ aproximadamente. En las restantes DOP, el volumen envejecido es muy inferior, aunque está subiendo. La inmensa mayoría del vino español se vende como vino joven, lo que explica que el ratio entre existencias y ventas anuales sea inferior a 1 , en contraste con lo que ocurre en Rioja, donde este ratio es superior a 3. Los mercados de graneles de vino presentan una segmentación múltiple que se refleja mal en las fuentes estadísticas. Esta segmentación responde principalmente a los siguientes criterios, entre otros (Saborá, 2003):

- Categoría según sean vinos de mesa, vinos con DO, Vinos de la Tierra o Vinos de Pago.

- Cada una de las Denominaciones de Origen (DDOO), que conforman mercados distintos.

- Color (Blancos / tintos).

- Variedad de la uva.

Estos criterios, algunos de ellos muy rígidos debido a la normativa vigente, dan lugar a la existencia de segmentos de mercado impenetrables para otros vinos. Eso explica la existencia de grandes diferencias en los precios de la uva y de los graneles de vino. El mercado de los graneles de vino está condicionado por el precio fijado para la destilación por la Comisión, que en la práctica establece un suelo a los precios.

Los mercados de consumo de los vinos embotellados están muy fragmentados calidad, tipo de vino, calidad diferencial, etc. La primera gran división la constituyen los vinos de mesa y los vinos de calidad. Dentro de los primeros, los vinos de la tierra tienden a configurar un segmento específico. Los mercados finales de los vinos de calidad se fragmentan en todas denominaciones existentes, pero además dentro de ellas conforman mercados distintos, los crianzas, reservas y vinos jóvenes y tienen un peso relevante las marcas. Por su parte, los análisis realizados desde las organizaciones industriales introducen criterios del nivel de precios en los mercados al consumo y establecen un estrato "vinos económicos de calidad" tranquilos, al que conceden un gran valor estratégico, entendiendo que es en este segmento donde se localiza la competencia entre los europeos y los de los países emergentes. En esta categoría se encuentran vinos de calidad, vinos de mesa y vinos de la tierra, así como vinos jóvenes y crianzas. La característica común es una buena relación calidad precio dentro de un precio que no exceda los 3-4 euros al consumo por botella de tres cuartos.

Cabe reseñar la gran influencia que el comportamiento de los precios de los vinos Rioja tienen en el conjunto de los vinos de calidad españoles. Esto se debe a que 
esta Denominación de Origen se constituye como la referencia para vinos tranquilos de calidad y posiciona en el mercado la mayor parte de los envejecidos españoles.

\subsection{El consumo de vino}

\subsubsection{Cuantificación y evolución del consumo}

Según los datos del "panel de consumo" (gráfico 4.11) que mensualmente publica el Ministerio de Agricultura, Pesca y Alimentación (MAPA), se comprueba que el consumo de vino en España vuelve a descender por quinto año consecutivo.

Este panel daba una cifra global de consumo en España de 11,57 mill de hl en el año 2003. Si se consideran los datos disponibles del panel, que se remontan al año 1987, se aprecia una pérdida acumulada de 6,57 mill de hl, lo que equivale al 36,21 \% del consumo de vino en España en el citado periodo de 17 años.

Por canales de distribución, el 43,5\% ha sido consumido en alimentación (5,03 mill hl) y el 56,5 \% en hostelería e instituciones (6,54 mill hl).

Por canales de distribución y tipos de vino, en lo que se denomina "mapa del consumo", se detecta un predominio considerable de los vinos de mesa (66,6 \% del total, divididos casi a partes iguales entre alimentación, 31,9 \%, y Horeca, 34,8 \%). Desde el año 1987 al 2003 se han perdido 6,44 mill de hl (45,5 \%) de vino de mesa, evolucionando de 14,14 mill de hl consumidos en el 1987 a los 7,70 mill de hl del 2003, pérdida importante no compensada con la ganancia en el caso de los vinos con DO.

En el caso de los vinos con DO predomina el canal Horeca con el $19 \%$ del consumo total, frente al 8 \% consumido en el hogar o alimentación; una composición habitual en el consumo interno de vino, que contrasta con los hábitos de consumo en otros países (principalmente los anglosajones), donde la mayor parte del vino se consume en los hogares. Desde el año 1987 al 2003 se ha producido una ganancia 0,60 mill de hl (24,5 \%) de vino con DO, evolucionando de 2,45 millones de hl consumidos en el 1987 a los 3,05 mill de hl del 2003. 


\section{GRÁFICO 4.11}

PORCENTAJE EN VOLUMEN DEL CONSUMO DE VINO EN ESPAÑA, POR CANALES Y TIPOS DE VINO (2004)

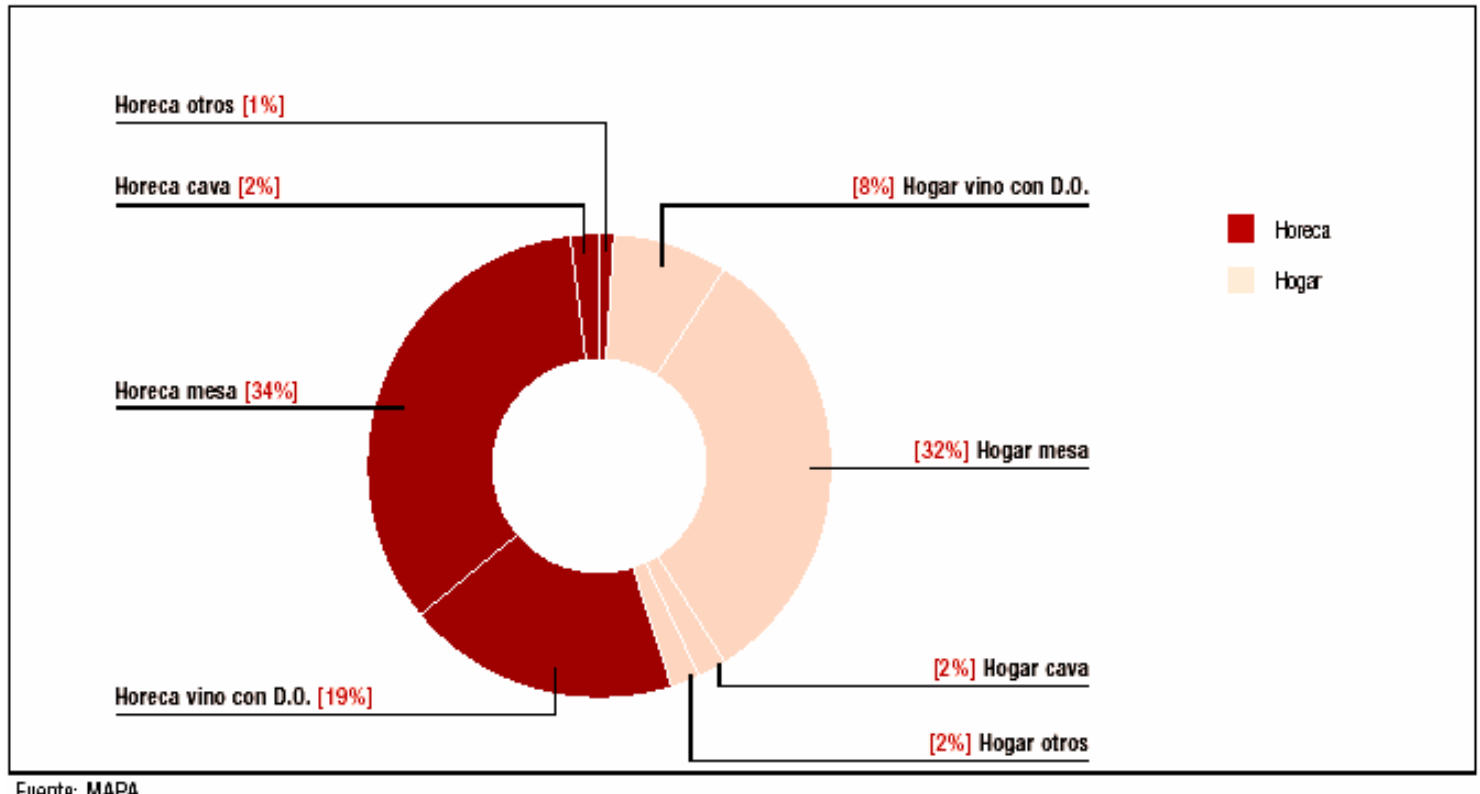

\section{GRÁFICO 4.12}

EVOLUCIÓN DEL CONSUMO DE VINO (mill. hl) EN LOS HOGARES (1999-2004)

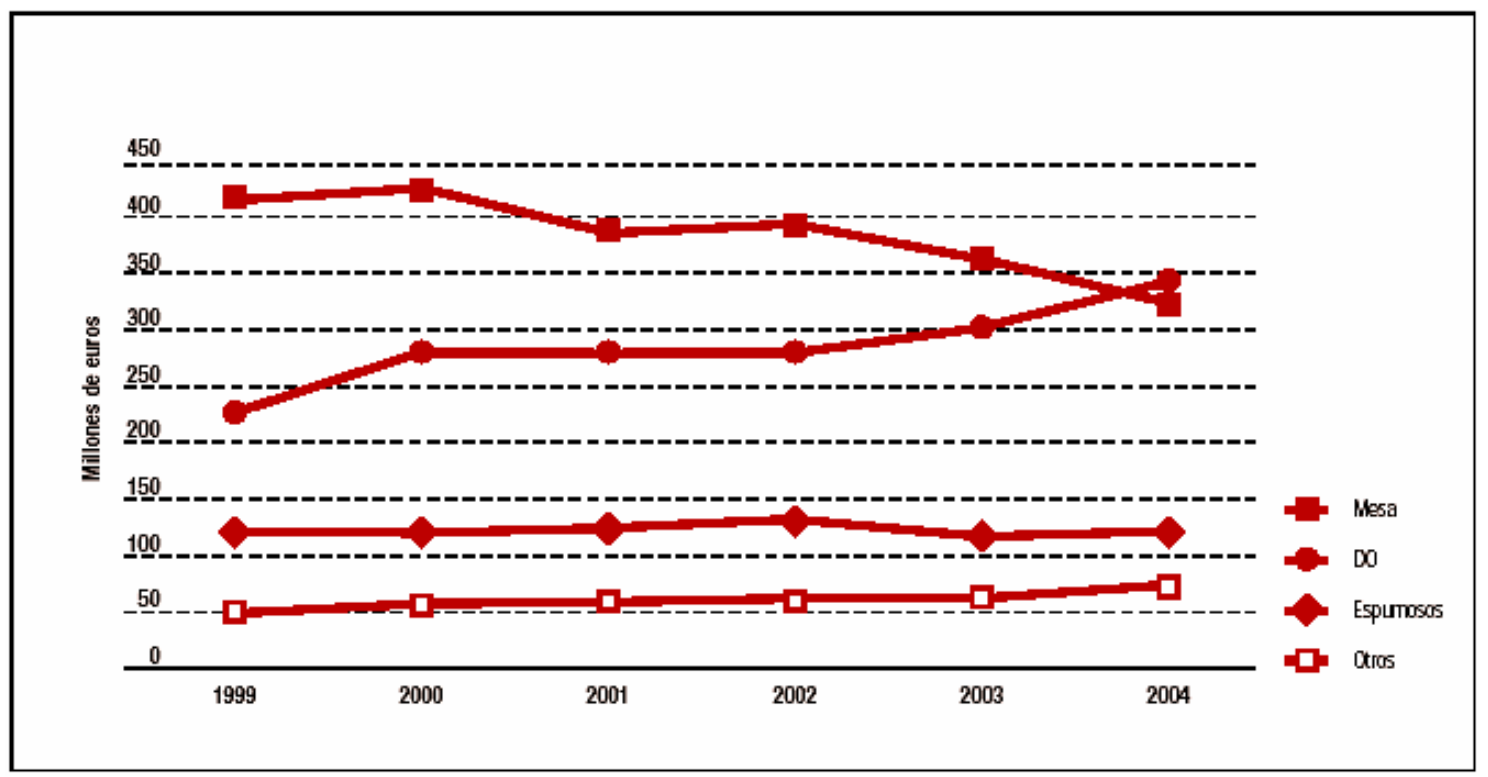

Fuente: MAPYA

En términos de valor (gráfico 4.12) y teniendo en cuenta que solo se encuentran disponibles datos mensuales en valor para el canal de alimentación, se observa una pérdida del vino de mesa y ganancia del vino con DO con lo que, según estos datos, la 
cifra de negocios del vino con DO supera por primera vez la del vino de mesa que sin embargo en volumen es mucho mayor.

En cuanto al consumo per capita, la evolución es similar a la comentada en el caso del volumen en hl, ya que de los 18,37 litros por habitante y año que se han perdido de consumo de vino entre 1987 y 2003, 17,6 litros por habitante y año se han dejado de consumir en vinos de mesa, 1,92 litros por habitante y año bajan otros vinos, mientras sube el consumo de vino con DO 1,15 litros por habitante y año. En el año 2003 el consumo per capita del vino de mesa y con DO ha sido de 18,8 y 7,5 litros por habitante y año respectivamente.

En cuanto a los productos sustitutivos del vino, lo que más consumen los españoles per cápita en el año 2003 son, gaseosas y refrescos, agua mineral y cervezas con cifras de 66,4, 66,1 y 57,5 litros por habitante y año respectivamente (MAPA, 2004).

En definitiva, el consumo de vino en España mejora en el año 2004 respecto de la tendencia que viene marcándose en los últimos 17 años: caída progresiva (algo atenuada este ultimo año), liderada por la pérdida de consumo del vino de mesa en el canal de alimentación y no compensada por el crecimiento del consumo de vinos en hostelería y restauración, ni por el mayor consumo de vinos con denominación de origen en el propio canal de alimentación.

Esta evolución del "mapa del consumo" hacen prever disminuciones en el consumo de vino de mesa en los hogares, acompañadas de aumentos del consumo de vino de calidad en el canal horeca, siempre que se practique una contención de precios en este canal, donde los precios pueden llegar a superar el $300 \%$ del coste en bodega (Alimarket, 2004), ya que la evolución de los precios de venta está afectando negativamente el consumo interior, frenando la tendencia alcista de la demanda de vinos con DO, especialmente en el segmentos de precios medios.

\subsubsection{Factores determinantes del consumo}

De los citados datos es posible deducir que la fuerte caída del vino de mesa en el hogar, es debido a varios factores: al cambio de los hábitos de consumo entre los españoles, que disminuyen su consumo como acompañamiento habitual de las comidas, al aumento de renta de los consumidores que desplaza la demanda hacia vinos de calidad más caros, y, por último al espectacular aumento que han experimentado en el citado periodo otros productos sustitutivos, que por orden de importancia son, el agua mineral, zumos de frutas y gaseosas y refrescos.

De ahí, que se manifieste un interés creciente en el análisis de los factores que influyen en el consumo de vino, ya que su conocimiento permitiría establecer las tendencias globales del consumo y los segmentos de mercado con un potencial de crecimiento mayor, con la finalidad de penetrar y mantenerse en los distintos mercados meta. A través de una revisión de los estudios que en los últimos años se han ocupado de esta materia, se van a poner en evidencia los factores más importantes. 
- Una mayor renta provoca mayores consumos de vino de calidad y de una demanda diferenciada, y menores de vino de mesa, fenómeno observado tanto en los países grandes productores tradicionales como en los pequeños consumidores y no productores, donde se considera un producto casi de lujo.

- Las variaciones en el precio del propio vino producen variaciones en el consumo global menos que proporcionales. Una vez tomada la decisión discreta de comprar o no comprar vino, el precio tiene influencia en la decisión continua de qué y cuanto vino comprar, lo cual se revela fundamental para una vez determinados los segmentos de mercado con mayor interés hacia la compra de vino, fijar el precio con el fin de inducir al consumidor a adquirir una mayor o menor cantidad de un determinado tipo y marca de vino. La diferenciación exigida por el consumidor, exige no solo estar disponible permanentemente, sino también ser accesible económicamente.

- El efecto del precio de la cerveza o el de otras bebidas parecen contradictorios, en función de su comportamiento con respecto al vino de bebida sustitutiva (fuera de las comidas) o complementaria (en las comidas). En España, con la costumbre del chateo, la cerveza de menor graduación alcohólica ha venido a sustituir al vino.

- No existe ninguna bebida sustitutiva del vino de consumo diario, por lo que la disminución del consumo de vino diario se debería a los cambios hacia formas de vida donde el vino como bebida de graduación alcohólica no tiene cabida en la dieta diaria (Pyörälä, 1990).

- Con la creciente preocupación por la salud y la imagen el consumo de vino queda relegado a ocasiones especiales, no entrando en la dieta cotidiana.

- Otra variables sociales y demográficas como la edad, nivel de estudios, y dimensión de la población en general ejercen una influencia directa y positiva sobre el consumo de vino.

Un estudio llevado a cabo en la Universidad de Castilla- La Mancha al respecto (Bernabeu, 2001), permite extraer las siguientes conclusiones muy relacionadas con las comentadas anteriormente:

- La frecuencia de compra de vino está estrechamente relacionada con la frecuencia de consumo y a su vez ésta parece estar relacionada con la actitud del consumidor en el momento de la compra (actitud de compra), su actitud personal y los factores demográficos en los que se desenvuelve de tal manera que, mientras la actitud de compra influye de una forma positiva y directa sobre la frecuencia de consumo de vino, la actitud personal y los factores demográficos la condicionan de una forma negativa e inversa.

- Los factores que determinan la actitud de compra, son: la zona de origen, la variedad de uva, si es o no de denominación de origen (ya que la asocian a un 
vino de calidad), la marca (asociada a una imagen de prestigio) y el precio. Todos positivos excepto el precio, como cabría esperar, ya que precios altos disminuyen la frecuencia de consumo de vino.

- Los factores que determinan la actitud personal del consumidor de vino son: su preocupación por la salud y la alimentación sana, la práctica de ejercicio físico, disfrutar de la buena mesa, leer la prensa diariamente y considerar el vino como objeto de regalo y un acto social, de tal manera que, cuanto más se preocupa por los factores anteriores menor es la frecuencia de consumo de vino.

- Los factores demográficos que le influyen, son: los ingresos familiares mensuales (renta), estudios y la edad. Así, cuanto más renta y estudios, menor es la frecuencia de consumo, probablemente debido a que estos consumidores consumen vinos de calidad más caros, en los establecimientos hosteleros, durante los fines de semana. Por el contrario, cuanto mayor es la edad del consumidor mayor es la frecuencia de consumo, generalmente basada en el vino de mesa en el hogar.

Por otro lado El Instituto de Investigaciones de Mercado y Marketing estratégico IKERFEL, S.A, a petición del Ministerio de Agricultura, Pesca y alimentación, en el año 2000 han llevado a cabo un estudio que consistía en analizar y estudiar las variables relacionadas con el consumo de vino, recogiendo el sentir del mercado, lo que suponía partir en todo momento de la percepción del conocimiento del consumidor y no de la realidad objetiva del mercado, siendo que los resultados responden siempre a una realidad percibida.

El estudio comprende cuatro áreas:

- Conocimiento y categorización del vino.

- Hábitos de compra y consumo.

- Actitudes ante el vino.

- Nuevos canales de venta.

Los principales resultados para cada área son los siguientes:

\section{a) Conocimiento y categorización del vino.}

- Las principales características de un vino de calidad son por orden de importancia en \% de la muestra: el sabor, el aroma y bouquet, la DO, y por último el color.

- Los criterios que externamente definen un buen vino son por orden de importancia en \% de la muestra:

1. La DO.

2. La añada, aunque sin un conocimiento específico, se conoce su importancia genérica. 
3. La zona de origen, muy relacionada con la DO Rioja y otras tradicionales.

4. La marca.

5. El precio a partir de $3,6 €$ es garantía de buen vino, y el precio psicológico a partir de $6 €$ certifica la calidad.

6. Color oscuro es sinónimo de vino de calidad.

7. La variedad de la uva, el etiquetado y la graduación, por debajo del $10 \%$ de la muestra.

- Se tiene un conocimiento general por orden de importancia de los vinos siguientes: tinto, blanco, clarete-rosado, dulce, espumosos, reserva, gran reserva, DO, crianza, y el resto por debajo del $10 \%$ de muestra.

- Los vinos de la DO Rioja son conocidos por el $94 \%$ de la muestra, los de Utiel-Requena por el $9 \%$, los de Valencia por el $8 \%$ y los de Alicante por el $6 \%$ de la muestra.

- Las variedades de uva más conocidas son por orden de importancia en porcentaje de la muestra: moscatel, albariño, tempranillo, garnacha, cabernetsauvignon, cariñena y por debajo del $10 \%$ de la muestra las restantes.

- Las DO más compradas en el área Este, son por orden de importancia: Rioja (58 \%), Utiel-Requena (28 \%), Ribera del Duero (26\%), La Mancha (23\%) y Valdepeñas (12 \%).

- El 37 \% de la muestra estaría bastante o muy abierto a consumir vinos de otras DDOO, que evidencia la baja predisposición a probar vinos de una DO que no se haya consumido, siendo una buena prueba de la alta tasa de fidelización ante los consumidores que han alcanzando las DDOO más prestigiosas.

- El recuerdo de las marcas está muy diversificado, ya que tan solo 6 marcas de Rioja y Ribera del Duero (Marqués de Cáceres, Vega Sicilia, Faustino, Paternina y Marqués de Riscal), superan el $10 \%$ de las menciones espontáneas.

- Existe un importante vacío del conocimiento tanto de la existencia como de las funciones de los Consejos Reguladores de las DOOO (CRDO).

- Entre la minoría más conocedora de los CRDO, realizan una valoración positiva el $64 \%$ de la muestra y confirman que garantizan la calidad el $71 \%$ de la muestra.

- Mas del 60 \% de la muestra considera al vino español bastante o mucho mejor que el del resto de los países, y tan solo el $4 \%$ considera que es peor que el de otros países. Este hecho podría explicarse a la memoria gustativa de los consumidores, que supone que el consumidor español habituado a un tipo 
de vino le resulta difícil aceptar otro, siendo que esta barrera no tiene que ver con el precio ni otros condicionantes que afectan a la venta.

\section{b) Hábitos de compra y de consumo}

- La compra del vino de calidad se realiza:

1. En el súper/hipermercado en el 78 \% de la muestra, debido: al buen precio, a la gama de variedades ofertadas, y por ser práctico y cómodo.

2. En la bodegas en el $29 \%$ de la muestra, debido: a la buena conservación, a la mejor garantía, al asesoramiento.

3. En las tiendas especializadas, debido: al asesoramiento y a la existencia de vinos especiales.

- En la iniciación al consumo:

1. El $71 \%$ de la muestra adquiere los hábitos de consumo con 25 años o menos.

2. Es fundamental la disposición de un determinado nivel adquisitivo, un entorno social y cultural propicio (tradición en el consumo, fórmula de relación social) y la figura de algún prescriptor ya sea familiar o no.

3. Momentos y vinculaciones del vino de calidad.

4. El vino tiende a consumirse en mayor medida en situaciones especiales de celebración o fiesta o negocios, relacionado con la comida y el placer de comer.

5. El vino de calidad constituye un símbolo de aprecio social a través del regalo, principalmente en el segmento de más edad.

6. Pierde peso en la cotidianeidad tanto de comidas en el hogar, como se consumo en hostelería (tapeo en la barra), donde compite con otras bebidas en precio y facilidad de consumo (agua, cerveza, refrescos).

7. Presenta un claro componente de estacionalidad.

8. Los consumidores habituales en hostelería lo son también en el hogar y no a la viceversa, probablemente debido a que el precio puede ser la causa de la diferencia.

\section{c) Actitudes ante el vino}

- Las actitudes positivas ante el vino se encuentran relacionadas con:

1. Un público más informado y exigente.

2. Una cierta moda del conocimiento y consumo de vinos de calidad.

3. La percepción de que un consumo moderado resulta saludable.

4. La componente social y de prestigio.

5. Existencia de un maridaje vino-gastronomía.

6. Aspectos positivos para la salud: facilita la digestión, reduce el colesterol, bueno para el corazón y la circulación, es antiestrés. 
- Las actitudes negativas ante el vino se encuentran relacionadas con:

1. La interiorización de un consumo moderado.

2. El riesgo para la salud de un consumo mayor al moderado.

3. Precio en el vino de calidad como limitador del consumo.

4. La competencia de bebidas alternativas muy apoyadas publicitaria y comercialmente.

5. Aspectos negativos para la salud: perjudica al hígado, puede degenerar en alcoholismo, el alcohol engorda, es incompatible con algunos tratamientos médicos.

- Globalmente la opinión predominante señala una percepción del producto beneficioso si se consume moderadamente.

- En el interés por el mundo del vino el 49 \% de la muestra toma algún tipo de iniciativa procedente de información general, y tan solo el $6 \%$ de la muestra compra publicaciones especializadas. Entre quienes muestran menor interés destacan los segmentos más jóvenes y las mujeres.

\section{d) Nuevos canales de venta}

- Aparece una contraposición conceptual entre el vino (relacionado con lo tradicional, lo cuidado, lo natural, lo que requiere tiempo, lo selecto, etc.) frente a los nuevos canales (relacionados con lo moderno, lo masivo, lo artificial, lo inmediato, lo rápido, lo impersonal, lo tecnificado, etc.), lo que genera cierta resistencia al uso de nuevos canales de distribución.

Por ultimo, las empresas de sector han de ser conscientes de la existencia de dos grupos diferentes de consumidores, la elite o prescriptores, constituida por una minoría de personas expertas e informadas del vino como producto y su entorno, capaces de detectar sutiles diferencias organolépticas, y el consumidor medio que en el mejor de los casos solo es capaz de conocer el vino de una manera muy limitada.

Conviene matizar la afirmación anterior diciendo que el precio psicológico de garantía de la calidad de $6 €$ se da en ciertos segmentos de mercado con ciertas peculiaridades (mínimo nivel adquisitivo, situaciones excepcionales, y sobretodo cuando el vino no se ha probado). En los restantes segmentos de mercado, que por otra partes son mayoritarios, la elasticidad demanda precio es negativa y subiendo el precio de todos los vinos a ese umbral mínimo no conseguiríamos aumentar la demanda de vino, sino lo contrario.

\subsection{Los canales de comercialización}

Según se ha visto en el apartado dedicado al consumo referidos al año 2003, el 43,5\% del vino total ha sido consumido en alimentación (hogar) y el 56,5 \% en hostelería restaurantes, catering e instituciones (horeca). Estos canales cuentas con vías de distribución específicas, siendo que la información disponible sobre los canales comerciales dirigidos a horeca es escasa. 
a) En el caso de los hogares

El análisis de los lugares de compra en el año 2003 en el caso de hogares, muestra un dominio de la gran distribución (casi 74\%) con una participación de supermercados e hipermercados del $50 \%$ y $24 \%$ respectivamente, con decidida tendencia a aumentar la cuota.

Las características principales de la gran distribución son:

- El éxito se basa en el gran volumen de ventas, márgenes de explotación pequeños, gran rotación de productos y control de costes.

- Sus armas de defensa se sustentan: en la demora del pago a los proveedores, en la concentración y consolidación nacional e internacional y en la marca blanca.

- En Europa las TOP 5 del sector tiene una cuota del 70 \%.

- Alto poder de negociación (en volúmenes, variedades y condiciones de compra) por su elevada concentración, frente a una oferta atomizada de proveedores de vino. Este poder ejerce una gran presión sobre las bodegas.

- Solo se ofrecen determinados vinos de gamas bajas y medias.

- Contacto diario con el consumidor, al que intentan atraer mediante las promociones y las bajos precios, por lo que condicionan las compras de los primeros.

- Grandes tiendas con presencia internacional, lo cual puede facilitar la entrada de vinos en determinados mercados.

La tienda tradicional supone un 12 \% de las compras, con caída de la participación. En este sector se mantiene un tipo de tienda especializada en vinos que se encuentra en auge y juega un papel importante en la cualificación del consumo de vinos. Su importancia en el consumo de vinos elaborados por bodegas de tamaño más reducido en los segmentos de precios superiores es significativa. Su papel en relación con el consumo es relevante: asesoran a sus clientes, elaboran la carta de vinos de los restaurantes, buscan vinos distintos y se configuran como una vía para dar a conocer bodegas principalmente pequeñas desconocidas.

Se mantiene una participación relativamente alta (más del $13 \%$ ) del canal “otros”, que incluye clubes de consumidores de vinos, asociaciones de amigos del vino, Internet, venta por catálogo, teléfono, fax, correo, mensajería con tendencia aunque leve también al alza.

La utilización de Internet en la comercialización, contribuiría a la creación de una imagen de la empresa, y a bajar los costes de transacción. Actualmente las compras realizadas son pocas debido a problemas logísticos y de confianza. Para la mayoría de 
las empresas con página Web, ésta es una vía de comunicación y sólo un 20-25 \% tiene tienda virtual.

\section{b) Canal Horeca}

Si bien la información disponible sobre los canales comerciales dirigidos a horeca es escasa, la mayoría de las compras de vino en este canal en el año 2003 se han realizado a distribuidores (84 \%) y mayoristas (9\%), frente al cash and carry que alcanza solo un $2 \%$ de las compras. Los distribuidores de vinos están muy fragmentados. Únicamente las grandes bodegas cuentan con red propia en sus principales destinos. Los distribuidores suelen trabajar a comisión, disponen de almacenes propios y cumplen una función logística fundamental (Saborá, 2003).

\subsubsection{Cambios en los canales de distribución}

La gran distribución es fundamental en la comercialización de los vinos españoles, aunque también constituye una buena entrada para los vinos europeos y, especialmente, los de los países emergentes.

La gran distribución ha cambiado en los últimos años su estrategia en cuanto a los vinos (anteriormente basada en los precios) de forma que en la actualidad la sección de vinos se ha convertido en uno de los referentes para las enseñas que han optado por situarse en la gama alta de calidad. En concreto los hipermercados se orientan hacia los vinos de más calidad, con un mayor espacio dedicado a los vinos, su mejor localización, el cuidado en la presentación, y el gran número de referencias. La oferta de vinos de la gran distribución incluye vinos de distintas DDOO españolas, marcas bien posicionadas, vinos de importación y vinos con marca de distribución, incluyendo entre estos los vcprd.

En esta línea destaca la preocupación por la mejora de la calidad, lo que ha conducido a revisar los criterios sobre selección de su oferta. Ahora las empresas cuentan con enólogos para la selección de sus vinos, organizan catas y concursos en colaboración con los diferentes Consejos Reguladores de la región en que se encuentran ubicados sus establecimientos y los gobiernos autonómicos.

Los cambios en el consumo y la nueva estrategia de la distribución, se encuentran estrechamente vinculadas, lo que junto a la mejora en la producción de grandes zonas, han abierto la posibilidad de poner en el mercado de vinos de buena calidad provenientes de distintas zonas y variedades, que en general se mueven en estratos de precios muy ajustados, generando un nicho de mercado propio en contraste con los mercados tradicionales de los vinos de las DDOO más cualificadas y prestigiosas (Rioja, Ribera del Duero) por un lado, y los vinos de mesa por otro. Estos hechos han redundado en mejoras significativas de la calidad en todas sus fases, en una cualificación de los mercados de graneles y un incremento del embotellado.

En esta línea, se encuentran los "vinos de calidad económicos" (entre 1,2 y 3 euros). Ese conjunto de vinos responde muy bien a la nueva demanda de vinos de calidad asequibles (frente a la escalada de precios del Rioja, etc.), en los que se mueven 
mayoritariamente los vinos de los países emergentes y en los que las grandes zonas productoras españolas son muy competitivas, bien a través de vinos con DO (La Mancha, Valdepeñas, Cariñena, etc.), y a los Vinos de la Tierra. Aproximadamente el $50 \%$ de los vinos vendidos a los hogares embotellados pertenece a este estrato de precios. Las etiquetas de estos vinos suelen informar de la variedad e incluso el tipo de elaboración, lo que raramente suele reflejarse en los vinos más caros (Saborá, 2003).

Esta concentración del comercio de vino en el mercado interior pone de manifiesto la importancia que la gran distribución tiene para el relanzamiento del consumo de vino, especialmente en los segmentos de precio medio, ya que la gama de vinos resulta complementaria de otras bebidas al ser productos que tienen una logística y canales de distribución similares.

Por otro lado es necesario un sector elaborador y abastecedor fuerte y concentrado, capaz de ofrecer vinos en cantidad y homogeneidad dentro de una oferta diversificada con objeto de abastecer estos canales progresivamente concentrados que demandan vinos diversificados para satisfacer los distintos segmentos de demanda de un producto extremadamente diferenciado y a unos precios adecuados.

\section{Las tendencias actuales del sector son:}

- Incremento de la superficie en los puntos de venta y disminución progresiva de éstos.

- Aumento del tamaño de las cadenas de distribución, principalmente por unión, absorción y fusión entre ellas.

- Fomento Marcas Blancas.

- Mayor venta de productos y mejor presentación.

- Presencia y consolidación internacional de la distribución (internacionalización y globalización).

Las consecuencias de la evolución de la distribución:

- La competencia entre las empresas de distribución casi perfecta pasa hacia la competencia oligopolística, donde las acciones individuales tienen un efecto considerable sobre el conjunto. Ello implicará la lucha entre proveedores atomizados, y pérdida del poder negociador de éstos últimos para seguir abasteciendo a aquella.

- Aprovechamiento de las economías de costes (escala, experiencia, alcance) con mayores márgenes de beneficios, presionando para obtener precios más bajos de los fabricantes, que luego se trasladarán en parte a los consumidores o serán empleados en mayores servicios a estos. 
- La integración de las funciones mayoristas en las empresas minoristas, con la consiguiente desaparición de los tradicionales mayoristas.

- Presión de los precios a la baja para los proveedores, mayores aplazamientos de los pagos, mayores exigencias en las condiciones de entrega.

- Reducción de los márgenes comerciales, y todo lo que baje de precio, la distribución se lo pasará al productor o elaborador.

- Excesiva dependencia de la oferta ante las decisiones de la distribución.

- Aumento del riesgo en servicios añadidos además del propio de proveedor por parte de la oferta.

- La calidad ha dejado de ser un mero factor de competitividad, para convertirse en un factor indispensable para estar en el mercado a través de la distribución.

Los comercios especializados han aumentado en los últimos años vinculados al consumo de vinos de gama alta.. Muchos establecimientos tradicionales poseen personas cualificadas al frente, que dieron el salto de la venta de graneles a los cuidados establecimientos actuales; otros son de creación reciente, regentados con frecuencia por grandes aficionados que han logrado una alta cualificación. Cada vez más se nota su presencia en las publicaciones sobre vinos, en concursos, catas, ferias, etc.

En cuanto al canal horeca, los bares, tabernas, restaurantes y las empresas de catering han decidido cada vez en mayor medida cuidan su carta de vinos en los más prestigiosos se encuentra la figura del somelier. Estas empresas se abastecen progresivamente más de las tiendas especializadas (para vinos cualificados), aunque con más frecuencia, recurren a distribuidores independientes y representantes propios de las firmas del sector que tienen una cierta entidad, que están incrementando los vinos de calidad en el canal horeca, aspecto muy vinculado a la mejora de la producción en muchas regiones y al desarrollo del embotellado en numerosas bodegas cooperativas.

En el pasado las bodegas y, en general, las grandes firmas de vinos se han mantenido al margen de las restantes empresas de bebidas. Actualmente la concentración se esta produciendo en el sector viene a través de:

- La ampliación directa de las instalaciones de grandes empresas nacionales o multinacionales líderes en el sector del vino, que ha dado origen a las grandes "wineries", centradas en pocas marcas.

- La compra de nuevas bodegas nacionales especializadas en vino, ligadas al territorio generando firmas con presencia en varias denominaciones de origen y dispuestas a valorizarlas.

- La entrada de las grandes firmas mundiales (multinacionales) de bebidas alcohólicas y analcohólicas (multisector) en el sector vínico, con acciones de 
reestructuración tendentes a la ampliación de gama, al establecimiento de marcas líderes y a la búsqueda de sinergias con sus circuitos comerciales internacionales ya preexistentes, que incluyen redes de distribución propias muy potentes. Esta opción plantearía un cambio fundamental, ya que de un lado su capacidad económica y negociadora es muy superior a los líderes mundiales del sector, y de otro, desplazarían a los actuales distribuidores independientes en la función principal de proveer al canal horeca.

\subsection{Las exportaciones de vino}

\subsubsection{Cuantificación y evolución de las exportaciones}

Con cifras de la Dirección General de Aduanas relativas al año 2004 se comprueba que se ha producido un aumento importante en volumen hasta los 14,5 mill de $\mathrm{hl}$, y menor en valor (1.546 mill de euros) con un nuevo descenso en los precios medios, derivado más del cambio de la oferta vitivinícola hacia productos de menor valor añadido que por disminución del precio de cada una de las categorías de vinos exportados (gráfico 4.13).

\section{GRÁFICO 4.13}

EVOLUCIÓN DE LAS EXPORTACIONES ESPAÑOLAS DE VINO (1995-2004)

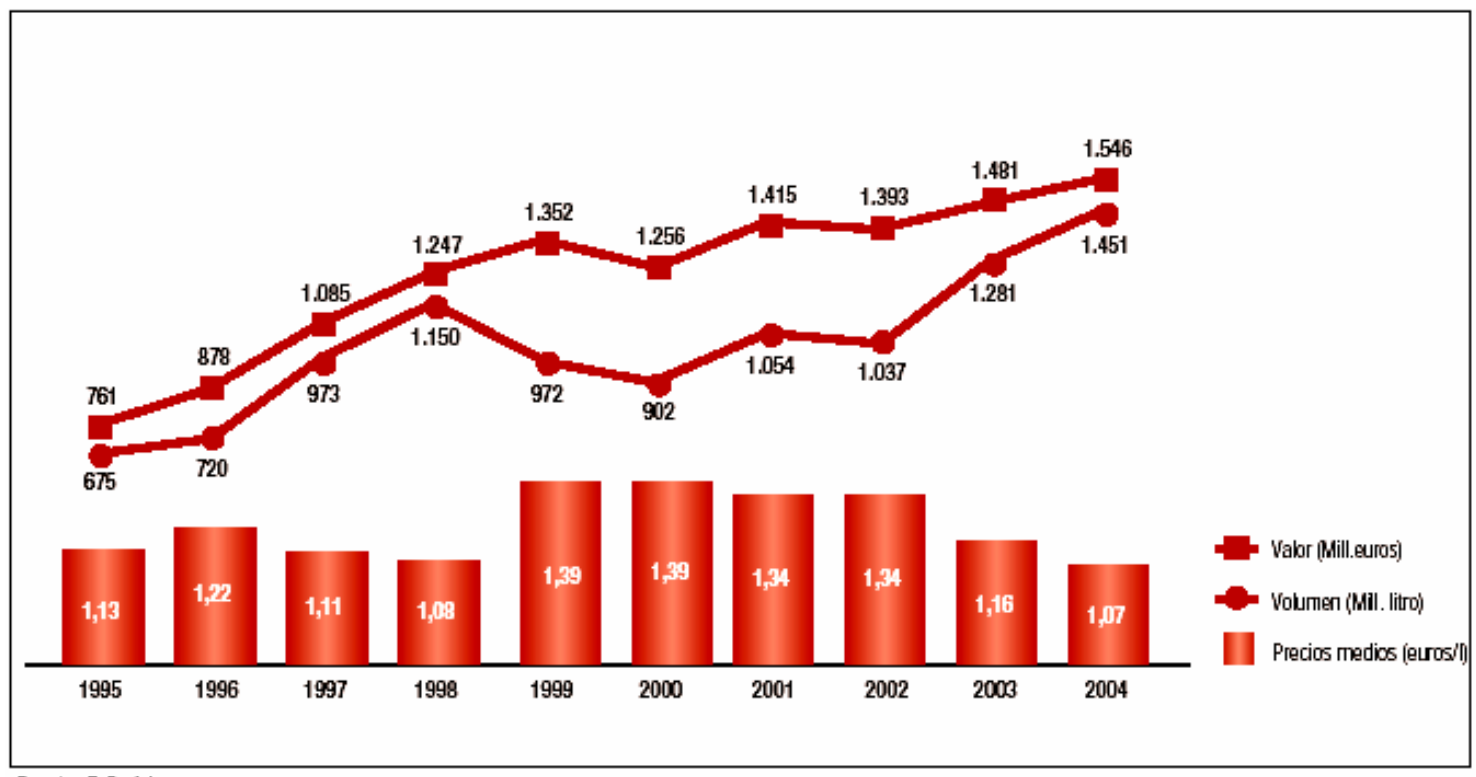

Fuente: D.G. Aduanas.

En el gráfico 4.13 se observa para los últimos dos años, el elevado crecimiento de las exportaciones en volumen, junto al moderado incremento en valor, situándose en el año 2004 en 1.546 mill de $€$ y 1.451 mill de litros. Esto nos muestra que la exportación es la única solución para que mayores producciones no se transformen en excedentes para España.

En el gráfico se comprueba que la mayor parte del crecimiento, tanto en volumen como también en valor, se genera gracias a la categoría de vinos de mesa a 
granel. En definitiva, tanto en valor como en volumen, el crecimiento de nuestras exportaciones en el año 2004 se ha debido básicamente a la mejor venta exterior de los vinos de mesa a granel y a cierto retroceso de las de vinos con denominación de origen.

La composición de las exportaciones en el año 2004 (gráficos 4.13, 4.14 y 4.15) queda dominada por las ventas de vinos de mesa a granel en términos de volumen y las de vinos con denominación de origen en valor.

En términos de volumen, el $51 \%$ del vino español, exportado en dicho año es vino de mesa a granel, frente a un $17 \%$ de DO envasado, un 5\% de DO. a granel, y un $14 \%$ de vino de mesa envasado (donde pueden incluirse los vinos de la tierra). Por el contrario, en términos de valor el vino de mesa a granel sólo representa un $16 \%$ del total de la facturación exterior, mientras que el DO envasado supone el 45 \% del valor.

\section{GRÁFICO 4.14}

\section{EXPORTACIONES ESPAÑOLAS DE VINO EN VOLUMEN (2004)}

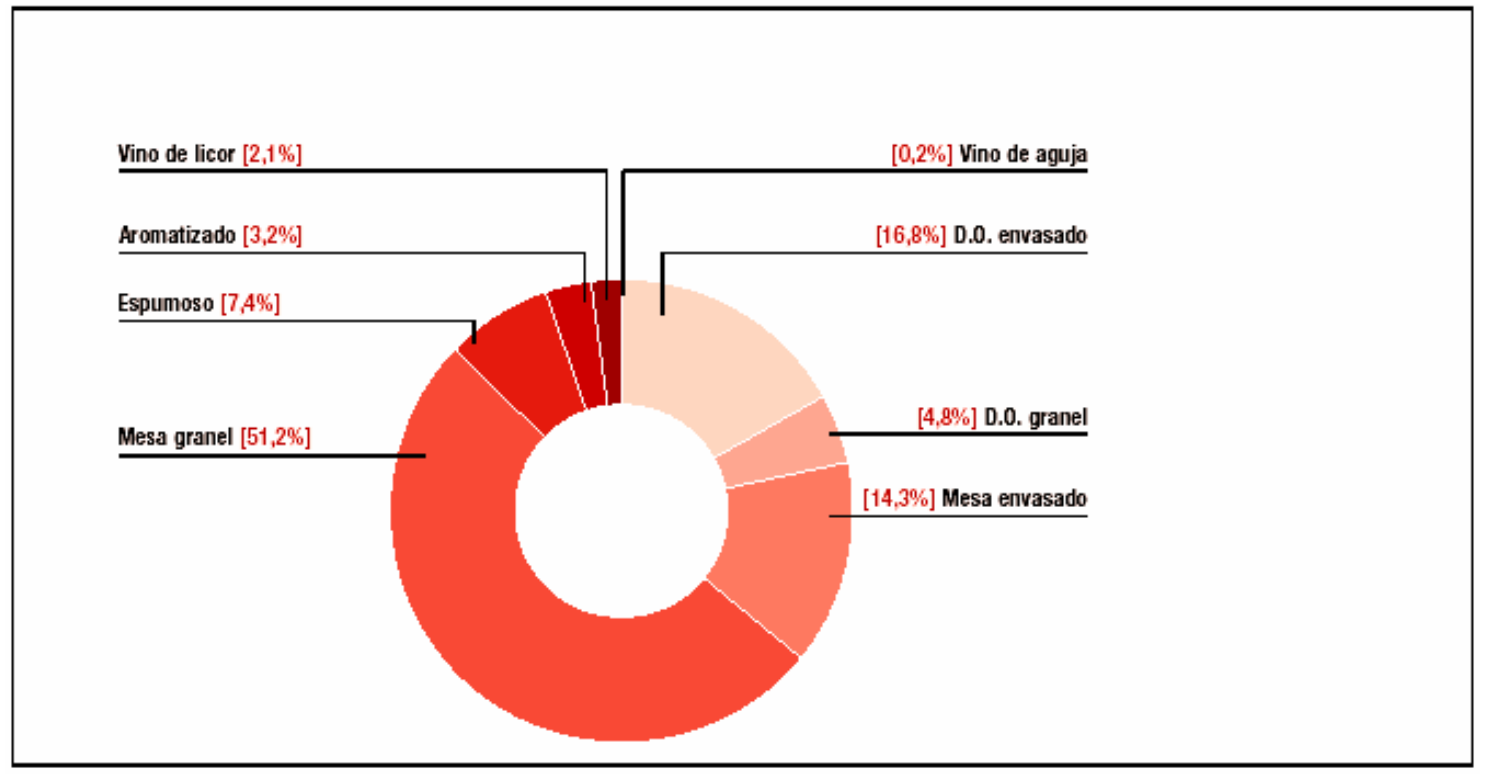

Fuente: Dirección General de Aduanas

La mayor parte del volumen que se exporta se hace a un precio medio bajo, mientras que se exporta relativamente poco volumen de los vinos de mayor valor medio.

Añadir, que las exportaciones mayoritarias de vinos de bajo valor se hacen en condiciones de difícil estabilidad por las siguientes razones:

- Muy dependientes del precio y, por tanto, del comprador que ofrezca un precio más elevado en cada momento.

- Por depender de unos pocos compradores que coinciden que son productores de vino y principales competidores, lo cual las hace vulnerables y dependientes de la evolución coyuntural de sus cosechas anuales. 
- Se trata de una estrategia coyuntural, exenta de competitividad y consolidación de los vinos españoles en mercados internacionales, ya que la mayoría de las exportaciones son vinos de mesa a granel de bajo valor añadido, lo cual hace problemático su mantenimiento en el tiempo, particularmente en años de buenas cosechas en el resto de laso países comunitarios.

\section{GRÁFICO 4.15}

EXPORTACIONES ESPAÑOLAS DE VINO EN VALOR (2004)

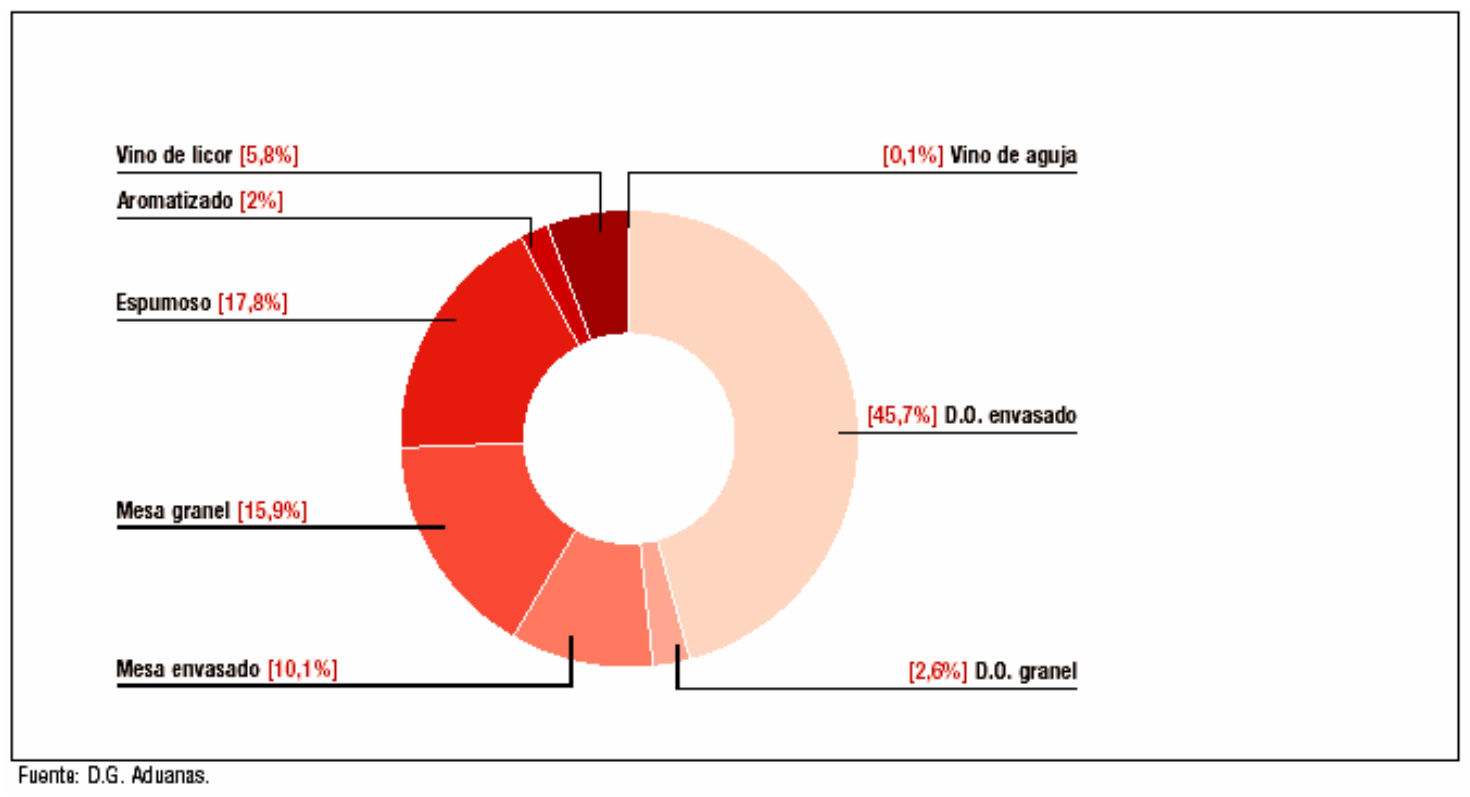

En cuanto al destino de las exportaciones españolas de vino, es posible diferenciar dos grupos de países:

- Los destinos más coyunturales, que actúan como reguladores de la oferta, y que en gran parte van a cubrir los déficits de los países comunitarios, entre los que se encuentran por orden de importancia en volumen, Francia, Alemania, Italia y Portugal, que concentran más del $75 \%$ del total de volumen exportado, tratándose de un mercado muy concentrado, donde un número reducido de países realizan la mayor parte de los intercambios. Fuera de Europa destacan las exportaciones realizadas a países del centro y Este de Europa, de África o de Asia.

- En cuanto a los mercados más atractivos por su demanda creciente de vinos de calidad y por tanto más competitivas, se encuentran el Reino Unido, USA, y algunos países del norte de Europa o del Sureste Asiático, en los que las exportaciones españolas han mostrado una tendencia al aumento, aunque muy inferiores a las protagonizadas por los países del nuevo mundo. 
La caída en precios observada desde el año 2002 hasta 1,07 €/l en el año 2004 viene explicada por el aumento de la exportación de productos de menor valor añadido dentro del total (vinos de mesa a granel). Este precio medio esconde diferencias notorias en el precio de las distintas categorías de vino, desde $0,34 € / l$ en vinos de mesa a granel, pasando por los $0,77 € / l$ para los vinos de mesa envasados, hasta 2,29 €/l en el caso de los vinos con DO.

Este valor medio de los vinos con DO exportados, son inferiores a las exportaciones de vinos de calidad franceses o italianos, con valores de 6,44 /l y 3,14 €/l, respectivamente. Es decir los vinos españoles se sitúan en segmentos de precios más reducidos, que son los que mayor potencial de aumento mantienen, lo cual constituye una ventaja competitiva frente a los principales competidores en mercados exteriores (Langreo, 2002).

\subsubsection{Problemática de las exportaciones}

Según se puede desprender del análisis anterior, existe margen para la exportación, con lo cual y partiendo de dicha premisa se exponen algunos aspectos clave para llevarla a cabo (FEV, 2004):

- La toma de conciencia de la necesidad de exportar establemente.

- Una nueva mentalidad dirigida a nuevos consumidores ("puede no valer lo que hemos hecho siempre”).

- La decisión de destinar nuevos y mayores recursos a la exportación principalmente enfocados a la investigación de mercados, distribución y promoción.

- La voluntad de concentrar esfuerzos en los mercados de mayor potencial de crecimiento.

- La decisión de establecerse en los países objetivo para conocer bien el mercado, sus características y las necesidades de sus consumidores.

- Cierto tamaño de empresa para poder dedicarse establemente a la exportación

- Apoyo específico a la internacionalización.

- Un producto estable en su calidad, disponibilidad y precio, para lo que se requiere un marco legal donde poder combinar indicaciones de calidad y distintos tipos de vino para una cartera atractiva adaptada a los distintos segmentos de consumidores objetivo.

- Imagen donde prime la sencillez y la identificación de las marcas.

- Un marco global de mejora de la imagen de España como proveedor de vinos de calidad (ICEX, MAPA, sector). 
En definitiva, un marco legal de vinos de mesa, vinos de la tierra, denominaciones de origen, vinos de pagos que los operadores (bodegas y productores) puedan utilizar para, vender más y mejor el vino español de forma estable en todos los mercados. En este marco se encuadra la propuesta de una gran zona de vinos españoles que puedan etiquetarse con garantías de éxito comercial, siempre que demuestren fehacientemente la realidad de las menciones. Sólo con medidas que favorezcan mayores exportaciones estables (cuotas de mercado con valor añadido) será posible mantener la producción de vinos en España.

Por otra parte el Ministerio de Agricultura, Pesca y Alimentación en el año 2001 ha llevado a cabo un estudio sobre el comportamiento y problemática de la exportación a terceros países, sobre una muestra de 1000 empresas agroalimentarias de diferentes sectores.

Las estrategias comerciales que se han revelado más eficaces, tanto para iniciar como mantener la exportación, por orden de importancia han sido:

- Las ferias comerciales en el $33 \%$ de la muestra.

- Los viajes comerciales privados, en el $26 \%$ de la muestra.

- La intermediación comercial de distribuidores en terceros países, en el 13 \% de la muestra.

- Las promociones directas de a la empresa, en el $9 \%$ de la muestra.

- La iniciativa de los clientes en el país de destino, en el $6 \%$ de la muestra.

- Los viajes comerciales con apoyo institucional tanto a nivel nacional como regional, en el $6 \%$ de la muestra.

Otras acciones consideradas eficaces y no desarrolladas por algunas empresas, han sido:

- La promoción en revistas especializadas.

- Los estudios de mercado en terceros países.

- Las acciones comerciales en Internet.

Los principales problemas o barreras con que se han encontrado para exportar, y las acciones llevadas a cabo para superarlos se resumen en el cuadro 4.4.

Los principales problemas o barreras que han provocado la renuncia a comercializar ciertos productos han sido por orden de importancia: sanitarios, arancelarios, burocráticos, culturales, falta de información y el transporte y la logística. 


\section{CUADRO 4.4}

PROBLEMAS Y ACCIONES LLEVADAS A CABO PARA SUPERAR LAS BARRERAS A LA EXPORTACIÓN DE PRODUCTOS AGROALIMENTARIOS (2001)

\begin{tabular}{|l|r|r|r|l|}
\hline \multirow{2}{*}{ PROBLEMAS } & \multicolumn{3}{|c|}{ \% DE MUESTR } & \multirow{2}{*}{ ACCIONES ACOMETIDAS } \\
\cline { 2 - 5 } & TOTAL & $\begin{array}{l}\text { PROBLEMAS } \\
\text { SUPERADOS }\end{array}$ & $\begin{array}{l}\text { PROBLEMAS } \\
\text { SIN SUPERAR }\end{array}$ & \multicolumn{1}{|c|}{$\begin{array}{l}\text { Búsqueda de expertos } \\
\text { Solicitud de ayudas }\end{array}$} \\
\hline Burocráticos & 27 & 13 & 7 & Acuerdos internacionales \\
\hline Arancelarios/contingente & 22 & 5 & 4 & $\begin{array}{l}\text { Solicitud de ayudas } \\
\text { Sustitución de ingredientes }\end{array}$ \\
\hline Sanitarios & 18 & 8 & 3 & $\begin{array}{l}\text { Promoción del producto } \\
\text { Análisis de gustos nacionales }\end{array}$ \\
\hline Culturales & 13 & 3 & 1 & $\begin{array}{l}\text { Información de requisitos } \\
\text { Análisis de gustos nacionales }\end{array}$ \\
\hline Etiquetado/información & 8 & 5 & &
\end{tabular}

Fuente: Elaboración propia en base al estudio del MAPA

Las claves del éxito, por orden de importancia en porcentaje de la muestra han sido:

- Calidad del producto (89 \%).

- Red de distribución (80 \%).

- Precio del producto (77\%).

- Red de transporte (61\%).

- Apoyo institucional (54\%).

- Promoción mediante ferias (41\%).

- Otras promociones (41\%).

- Política de promoción del producto a nivel institucional (38 \%).

En definitiva, el comercio internacional precisa estar con unos productos de calidad adecuada y regular en los mercados meta pertinentes con regularidad, por lo que fallos en algunas las variables del marketing (producto, precio, distribución y promoción) pueden provocar la perdida de la batalla de la competitividad internacional.

\section{EL VINO EN LA COMUNIDAD VALENCIANA}

En este apartado se tratará los siguientes aspectos relacionados con el sector del vino en la región:

- La producción de vino en el ámbito regional, su evolución y los aspectos ligados a la misma, tales como las superficies y rendimientos.

- El comercio de vino en la región y su evolución, diferenciando por mercados de destino (mercado interior y exterior o exportación) y por formas de comercialización (embotellado y granel).

- La industria vinícola en la Comunidad Valenciana, evolución e importancia actual dentro de la industria agroalimentaria regional. 


\subsection{La producción de vino en la Comunidad Valenciana}

La superficie ocupada por el viñedo con destino a las transformación en la campaña 2002/2003 es de 74.471 has, y se encuentra estabilizada entorno a las 75.000 has en las tres últimas campañas. La superficie ha experimentado una reducción cercana al $16 \%$ en los últimos 10 años, debida principalmente a la implementación en la región de las medidas de arranque emanadas de la anterior política vitivinícola (gráfico 4.16).

Respecto a la dimensión de las explotaciones dedicadas al cultivo del viñedo en la región, según el Censo Agrario de 1999 toma un valor de 8,2 has de superficie agraria útil (SAU) por explotación, valor que supera ligeramente la media nacional (7,8 has por explotación), pero inferior a la media comunitaria.

\section{GRÁFICO 4.16}

\section{EVOLUCIÓN DE LA SUPERFICIE DE VIÑA PARA TRANSFORMACIÓN (has) EN LA COMUNIDAD VALENCIANA (1993/1994-2002/2003).}

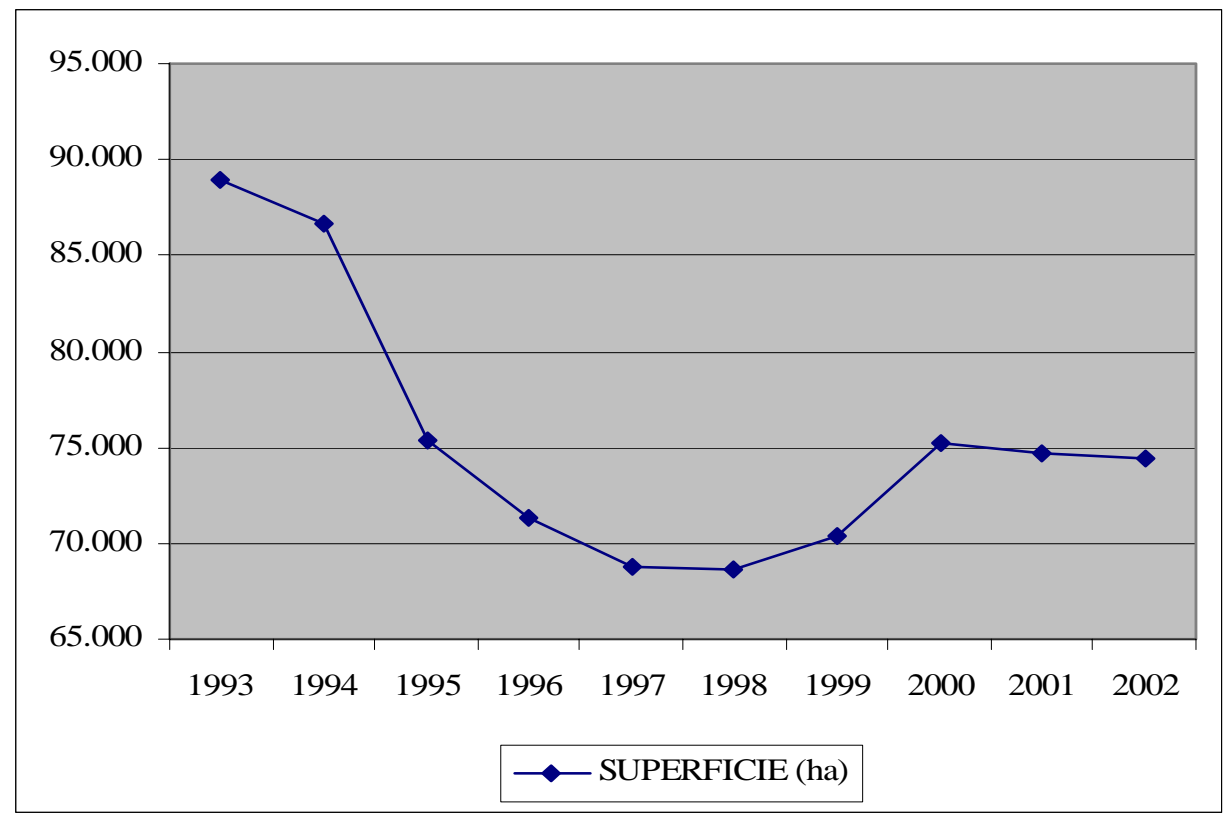

Fuente: Elaboración propia en base a los datos del Informe del sector agrario en la Comunidad Valenciana

La producción en la campaña 2002/2003 ha sido de 2.452 .882 hl, cifra que supone una ruptura al alza de la media observada en los últimos 6 años (gráfico 4.17), que toma un valor cercano a 2.120.000 hl. Ocupa el tercer puesto en volumen de producción de entre las regiones del Estado Español.

El rendimiento medio anual de los últimos siete años rebasa los $32 \mathrm{hl} / \mathrm{ha}$. (gráfico 4.17), habiendo experimentado un crecimiento respecto de periodos anteriores debido principalmente a varias causas : el incremento de la superficie puesta en regadío (la campaña 2002/2003 supuso el 7 \% de la superficie total dedicada a viñedo de transformación), mejora de las técnicas de cultivo (espaldera, etc.) y a la entrada en 
producción de plantaciones reconvertidas varietalmente. El rendimiento regional en el periodo considerado ha sido inferior aproximadamente en $1 \mathrm{hl} / \mathrm{ha}, 3 \mathrm{hl} / \mathrm{ha}$ y $20 \mathrm{hl} / \mathrm{ha}$ a los registrados a nivel nacional y mundial y Unión Europea respectivamente.

\section{GRÁFICO 4.17}

EVOLUCIÓN DE LA PRODUCCIÓN DE VINO (hl) EN LA COMUNIDAD VALENCIANA $(1993 / 1994-2002 / 2003)$.

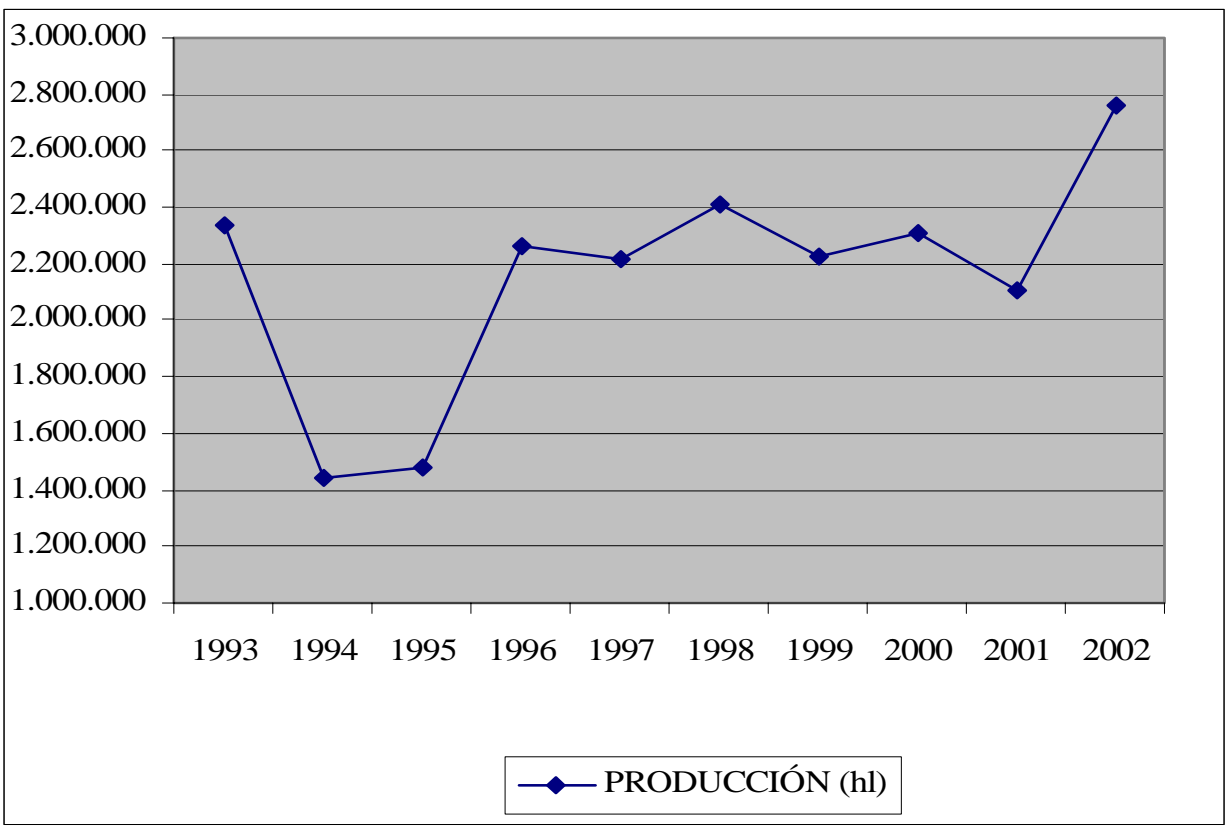

Fuente: Elaboración propia en base a los datos del Informe del sector agrario en la Comunidad Valenciana

Dado el gran calado que tienen las figuras de calidad de los vinos en el territorio de la Comunidad Valenciana, es decir las Denominaciones de Origen (DDOO) en los casos de Alicante, Utiel-Requena y Valencia y los Vinos de Calidad con Indicación Geográfica en el caso de Castellón, se ha confeccionado el cuadro 4.5, con los datos facilitados casi exclusivamente por los Consejos Reguladores de las citadas DDOO, ya que prácticamente no existen datos de la reciente figura de Vinos de Calidad con Indicación Geográfica. 


\section{GRÁFICO 4.18}

EVOLUCIÓN DEL RENDIMIENTO DE LA PRODUCIÓN DE VINO (hl/ha) EN LA COMUNIDAD VALENCIANA (1993/1994-2002/2003).

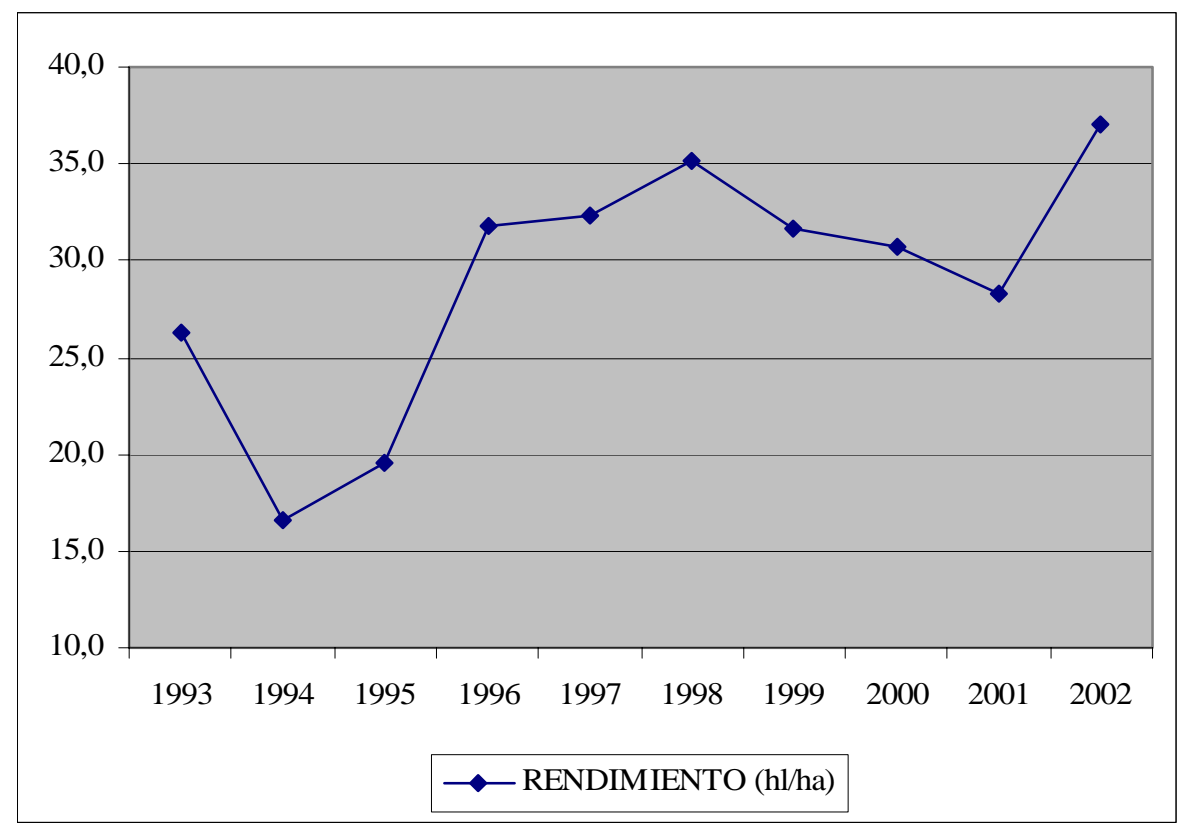

Fuente: Elaboración propia en base a los datos del Informe del sector agrario en la Comunidad Valenciana

Destacar que la producción regional declarada con DO supone algo más del 50\% de la producción total regional, ostentando la DO de Valencia el mayor porcentaje (87\%), seguidos de Alicante (41 \%) y Utiel-Requena (37\%). Por otro lado, la producción total comercializada con DO supone tan solo el $36 \%$ de la producción comercializada total regional.

\section{CUADRO 4.5}

PRINCIPALES CARACTERÍSTICAS DE LOS NIVELES DE PROTECCIÓN DE VINO EXISTENTES EN LA COMUNIDAD VALENCIANA (2002/2003)

\begin{tabular}{|l|r|r|r|r|r|}
\hline & ALICANTE & \multicolumn{1}{|c|}{$\begin{array}{c}\text { UTIEL- } \\
\text { REQUENA }\end{array}$} & \multicolumn{1}{|c|}{ VALENCIA } & CASTELLON & $\begin{array}{c}\text { COMUNIDAD } \\
\text { VALENCIANA }\end{array}$ \\
\hline $\mathbf{N}^{\mathbf{0}}$ VITICULTORES & 2.900 & 7.089 & 12.411 & 300 & 22.700 \\
\hline $\begin{array}{l}\mathbf{N}^{\mathbf{0}} \text { BODEGAS } \\
\text { INSCRITAS }\end{array}$ & 47 & 102 & 53 & 5 & 207 \\
\hline $\begin{array}{l}\text { SUPERFICIE } \\
\text { INSCRITA (ha) }\end{array}$ & 13.393 & 39.988 & 19.940 & 1.150 & 74.471 \\
\hline $\begin{array}{l}\text { PRODUCCIÓN } \\
\text { DECLARADA DO } \\
\text { (hl) }\end{array}$ & 92.617 & 572.411 & 577.168 & & 1.242 .196 \\
\hline $\begin{array}{l}\text { PRODUCCIÓN } \\
\text { TOTAL (hl) }\end{array}$ & 224.765 & 1.550 .266 & 665.174 & & 2.452 .882 \\
\hline
\end{tabular}

Fuente: Elaboración propia en base a los datos del Informe del sector agrario en la Comunidad Valenciana 


\subsection{El comercio de vino en la Comunidad Valenciana}

En el cuadro 4.6 se puede apreciar la evolución en las campañas 1993/1994 y 2002/2003 de los volúmenes comercializados por las tres DDOO existentes en la región, con destino al mercado interior y exportación (entendida a cualquier país fuera de las fronteras nacionales), según la forma de comercialización (granel o embotellado).

\section{CUADRO 4.6}

EVOLUCIÓN DEL DESTINO DE LA PRODUCIÓN COMERCIALIZADA (hl) POR LAS DDOO (1993/1994-2002/2003)

\begin{tabular}{|l|r|r|r|r|r|r|}
\hline & \multicolumn{2}{|c|}{$\mathbf{1 9 9 3 / 1 9 9 4}$ INTERIOR } & \multicolumn{3}{|c|}{$\mathbf{2 0 0 2 / 2 0 0 3}$ INTERIOR } \\
\hline & GRANEL & \multicolumn{1}{|c|}{ EMB } & \multicolumn{1}{|c|}{ TOTAL } & GRANEL & EMB & \multicolumn{1}{c|}{ TOTAL } \\
\hline ALICANTE & 29.607 & 34.089 & 63.696 & 37.425 & 32.279 & 69.704 \\
\hline U-REQUENA & 75.003 & 31.365 & 106.368 & 14.302 & 64.688 & 78.990 \\
\hline VALENCIA & 141.003 & 45.866 & 186.869 & 15.178 & 76.263 & 91.441 \\
\hline C-VALENCIANA & 245.613 & 111.320 & 356.933 & 66.905 & 173.230 & 240.135 \\
\hline & $\mathbf{1 9 9 3 / 1 9 9 4}$ & EXPORTACION & $\mathbf{2 0 0 2 / 2 0 0 3 ~ E X P O R T A C I O ́ N ~}$ \\
\hline & GRANEL & \multicolumn{1}{|c|}{ EMB } & TOTAL & GRANEL & EMB & TOTAL \\
\hline ALICANTE & 19.418 & 6.471 & 25.889 & 20.119 & 19.994 & 40.193 \\
\hline U-REQUENA & 73.392 & 15.418 & 88.810 & 115.616 & 112.277 & 227.893 \\
\hline VALENCIA & 188.916 & 93.866 & 282.782 & 182.262 & 203.260 & 385.522 \\
\hline C-VALENCIANA & 281.726 & 115.755 & 397.481 & 317.997 & 335.531 & 653.608 \\
\hline TOTAL C-VALENCIANA & $\mathbf{5 2 7 . 3 3 9}$ & $\mathbf{2 2 7 . 0 7 5}$ & $\mathbf{7 5 4 . 4 1 4}$ & $\mathbf{3 8 4 . 9 0 2}$ & $\mathbf{5 0 8 . 7 6 1}$ & $\mathbf{8 9 3 . 7 4 3}$ \\
\hline
\end{tabular}

Fuente: Elaboración propia en base a los datos del Informe del sector agrario en la Comunidad Valenciana

La campaña 1993/1994 presentó las siguientes cifras:

- Del total de vino producido el 38 \% se comercializó con DO (754.414 hl).

- Del total de vino comercializado con DO, el $30 \%$ se embotelló, y éste fue destinado casi a partes iguales entre el mercado interior y exportación.

- Del total de vino comercializado con DO, el 53 \% fue exportado (de manera mayoritaria a granel, $71 \%$ ).

La campaña 2002/2003 ha presentado las siguientes cifras:

- $\quad$ Del total de vino producido el 36 \% se ha comercializado con DO (893.743 hl).

- Del total de vino comercializado con DO, el $57 \%$ se ha embotellado, con destino casi a partes iguales entre el mercado interior y exportación.

- Del total de vino comercializado con DO, el $73 \%$ fue exportado (mayoritariamente a granel con el $49 \%$ ). 
Una mejor evolución de estas cifras puede observarse en los gráficos 4.19 y 4.20, de los que puede extraerse el buen ritmo de crecimiento de los vinos embotellados y con destino a la exportación en el segmento de vinos con DO.

\section{GRÁFICO 4.19}

\section{EVOLUCIÓN DE LA PRODUCIÓN COMERCIALIZADA (hl) POR LAS DDOO SEGÚN LAS FORMAS DE COMERCIALIZACIÓN (1993/1994-2002/2003)}

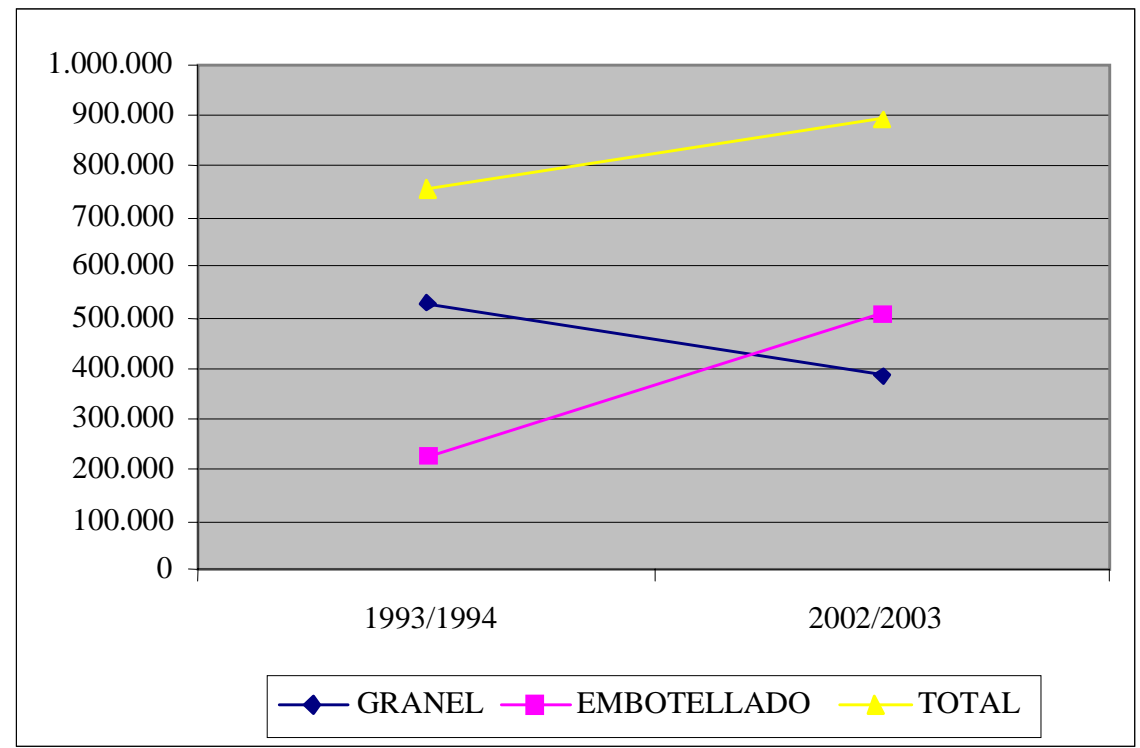

Fuente: Elaboración propia en base a los datos del Informe del sector agrario en la Comunidad Valenciana

Resaltar el estancamiento a la baja que presenta en la última década el vino comercializado con DO, respecto de la producción total regional (36 \% en la campaña 2002/2003), valor que oculta diferencias importantes entre las distintas DO (72 \% en la DO Valencia, 49 \% en la DO Alicante y 20 \% en la DO Utiel-Requena para la misma campaña).

En cuanto al destino de las exportaciones más del 80 \% se dirigen hacia la UE15, destacando como principales clientes por orden de importancia en volumen físico, Alemania, Reino Unido, Dinamarca, Francia, Finlandia y Holanda. 


\section{GRÁFICO 4.20}

EVOLUCIÓN DE LA PRODUCCIÓN COMERCIALIZADA (hl) POR LAS DDOO, SEGÚN EL DESTINO DE LA COMERCIALIZACIÓN (1993/1994-2002/2003)

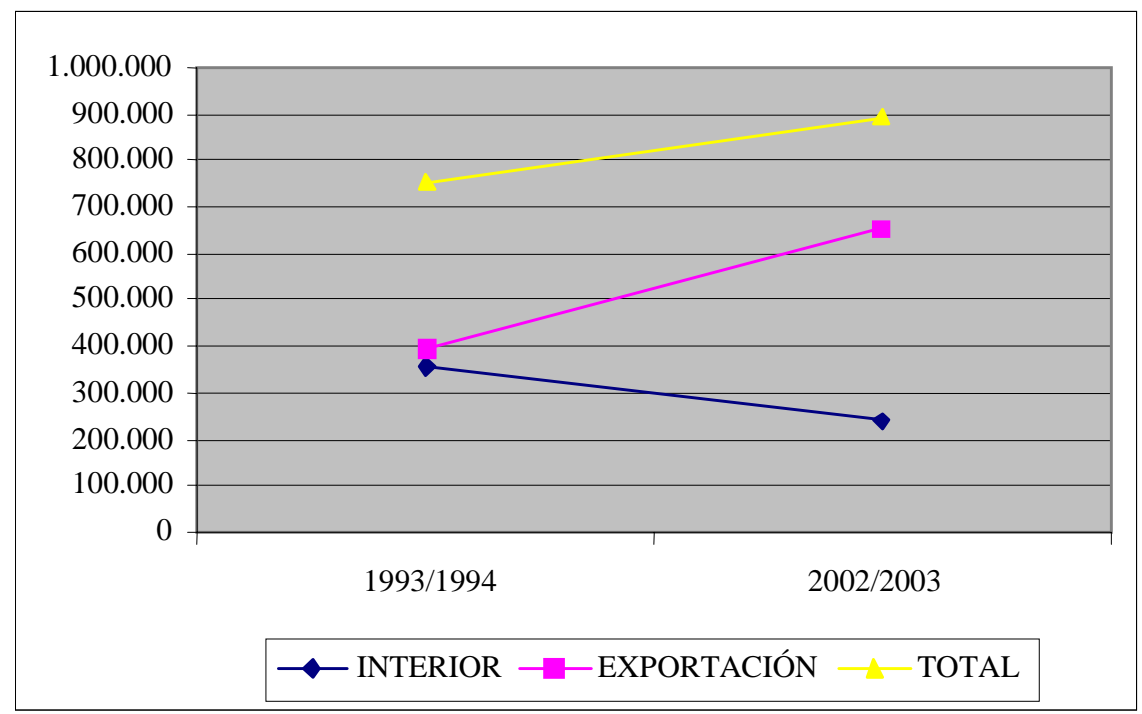

Fuente: Elaboración propia en base a los datos del Informe del sector agrario en la Comunidad Valenciana

\subsection{La industria vinícola en la Comunidad Valenciana}

La industria vinícola en la Comunidad Valenciana (cuadro 4.7) en el año 2002 ocupaba a 1.251 personas, cifra que supone un porcentaje cercano al $4 \%$ del total de empleados en la industria agroalimentaria de la región.

\section{CUADRO 4.7}

\section{PRINCIPALES INDICADORES DE LA INDUSTRIA ALIMENTARIA EN LA COMUNIDAD VALENCIANA (2002)}

\begin{tabular}{|c|c|c|c|c|c|c|c|c|}
\hline \multirow[b]{2}{*}{ SUBSECTORES } & \multicolumn{2}{|c|}{ PERSONAS OCUPADAS } & \multicolumn{2}{|c|}{ VENTAS PRODUCTO } & \multicolumn{2}{|c|}{ CONSUMO M. PRIMAS } & \multicolumn{2}{|c|}{ INVERS.ACTIVOS MAT. } \\
\hline & Núm. & $\begin{array}{c}\% / \text { Total } \\
\text { s/l.Aliment. }\end{array}$ & $\begin{array}{l}\text { Miles de } \\
\text { Euros }\end{array}$ & $\begin{array}{c}\% / \text { Total } \\
\text { s/l.Aliment. }\end{array}$ & $\begin{array}{l}\text { Miles de } \\
\text { Euros }\end{array}$ & $\begin{array}{c}\% / \text { Total } \\
\text { s/l.Aliment. }\end{array}$ & $\begin{array}{l}\text { Miles de } \\
\text { Euros }\end{array}$ & $\begin{array}{c}\% / \text { Total } \\
\text { s/l.Aliment. }\end{array}$ \\
\hline IND. CARNICA & 4.925 & 15,49 & 954.132 & 18,83 & 657.805 & 22,93 & 27.074 & 9,79 \\
\hline IND. PESCADO. & 1.482 & 4,66 & 258.335 & 5,10 & 195.610 & 6,82 & 8.706 & 3,15 \\
\hline CONSERVAS VEGETALES. & 3.681 & 11,58 & 621.855 & 12,27 & 399.638 & 13,93 & 30.843 & 11,16 \\
\hline ACEITES-GRASAS. & 405 & 1,27 & 179.427 & 3,54 & 154.569 & 5,39 & 3.952 & 1,43 \\
\hline IND LACTEAS. & 2.841 & 8,93 & 485.432 & 9,58 & 171.930 & 5,99 & 21.802 & 7,89 \\
\hline MOLINERIA. & 1.096 & 3,45 & 368.661 & 7,28 & 251.801 & 8,78 & 25.662 & 9,28 \\
\hline ALIMENTACIÓN ANIMAL. & 529 & 1,66 & 299.562 & 5,91 & 239.672 & 8,35 & 9.778 & 3,54 \\
\hline PAN-GALLETAS. & 8.954 & 28,16 & 488.030 & 9,63 & 178.319 & 6,22 & 37.710 & 13,64 \\
\hline AZUCAR. & & & & * & & * & * & \\
\hline CACAO-CHOCOLATE. & 1.980 & 6,23 & 286.357 & 5,65 & 159.676 & 5,57 & 17.971 & 6,50 \\
\hline OTROS PRODUCTOS. & 2.316 & 7,28 & 222.841 & 4,40 & 95.538 & 3,33 & 8.447 & 3,06 \\
\hline OTRAS BEB ALCOHÓLICAS. & 244 & 0,77 & 39.565 & 0,78 & 34.103 & 1,19 & 195 & 0,07 \\
\hline VINOS. & 1.251 & 3,93 & 263.376 & 5,20 & 154.029 & 5,37 & 26.660 & 9,64 \\
\hline CERVEZA. & & & * & * & * & & & * \\
\hline AGUA Y BEB ANALCOH. & 1.313 & 4,13 & 399.861 & 7,89 & 149.164 & 5,20 & 36.741 & 13,29 \\
\hline $\begin{array}{l}\text { TOTAL IND. ALIMENTARIA } \\
\text { TOTAL IND. CA. VALENCIANA }\end{array}$ & $\begin{array}{r}31.798 \\
356.555\end{array}$ & 100,00 & $\begin{array}{r}5.066 .923 \\
40.976 .541\end{array}$ & 100,00 & $\begin{array}{r}2.868 .707 \\
17.996 .071\end{array}$ & 100,00 & $\begin{array}{r}276.488 \\
2.443 .920\end{array}$ & 100,00 \\
\hline
\end{tabular}

Fuente: Cuadernos de la Industria Agroalimentaria 
En cuanto a las ventas de producto alcanzan el valor de $263.376 .000 €$ que representa el 5,2 \% del total de la industria agroalimentaria regional y la novena posición en el conjunto estatal. Este reducido índice de especialización de la industria vinícola regional contrasta con los elevados valores que alcanzan los ratios de consumo de materias primas por ventas de producto (58,5 \%) e inversiones en activos materiales por ventas de producto (10,1\%), respecto de los valores alcanzados a nivel nacional (50\% y 8,7\% respectivamente).

La productividad por empleado, medida como la relación entre las ventas de producto y el número de empleados en el mismo año ha sido de $210.523 €$ inferior en un $10 \%$ a la observada en el conjunto nacional. En los últimos años la evolución del ratio ha sido a la baja, propiciada por la reducción de los precios en origen del vino.

\section{MODELOS VITIVINÍCOLAS ACTUALES}

El futuro del sector vitivinícola, desde hace tiempo que pasa más por la exportación que por la destilación, como se ha comentado en apartados anteriores.

Desde hace algunos años están concurriendo en el comercio mundial de vinos, dos grupos de países: el denominado de los Países Productores Tradicionales (PPT) Francia, Italia, España, etc. de la vieja Europa, y el de los Nuevos Países Productores (NPP o del Nuevo Mundo o emergentes), Australia, Estados Unidos, Argentina, Chile, Sudáfrica, Nueva Zelanda, etc.

En un mercado mundial, y por mucha capacidad que se quiera reconocer en la calidad vinculada al origen para crear mercados aislados, no tiene ningún sentido pensar que los vinos protegidos por alguna DO están al margen del comportamiento general del sector, porque el agente económico principal, el consumidor, forma parte del citado escenario como último eslabón de la cadena integrada en ese mercado globalizado. Con las hipótesis realizadas por la OIV, y expuesta en el apartado 1.1 de este capítulo, la posición de cada país en el comercio mundial de vino es un factor clave en cualquier estrategia de futuro.

Nueve países (Alemania, Reino Unido, Francia, Estados Unidos, Holanda, Japón, Suiza, Dinamarca y Suecia) representan las dos terceras partes de las importaciones mundiales de vino y delimitan, por este orden, escenarios de dura competencia para los principales productores y exportadores (Italia, Francia, España, Alemania y Portugal), que el año 2000 generaron el 69\% de las exportaciones, en tanto que el grupo de NPP realizaron el 17\% de los intercambios mundiales.

Este reparto del comercio mundial de vino está cambiando muy rápidamente en los últimos años, con el avance de los NPP, que están consiguiendo una gran penetración en los principales mercados del mundo, al mismo tiempo que consolidan sus mercados interiores. La evolución de las exportaciones por países muestra cómo, en las dos últimas décadas, los cinco primeros exportadores (pertenecientes al grupo PTP) han pasado de representar el 76\% del comercio mundial al 69\% y los nuevos países exportadores han pasado del 2 al 17\%, con un crecimiento más fuerte en los últimos 
cinco años (Gráfico 4.21). Según sus previsiones, y por ahora se están cumpliendo esperaban alcanzar el $25 \%$ en el horizonte 2005.

Alemania, Reino Unido y Estados Unidos son las principales zonas importadoras de vino (representan el 40\% del total) y constituyen, junto a los países emergentes en consumo de vino (China, Rusia y Japón principalmente), el objetivo fundamental para productores/exportadores de cara a mantener o aumentar su cuota de mercado.

\section{GRÁFICO 4.21}

\section{EVOLUCIÓN DE LAS EXPORTACIONES POR GRUPOS DE PAÍSES EN PORCENTAJE}

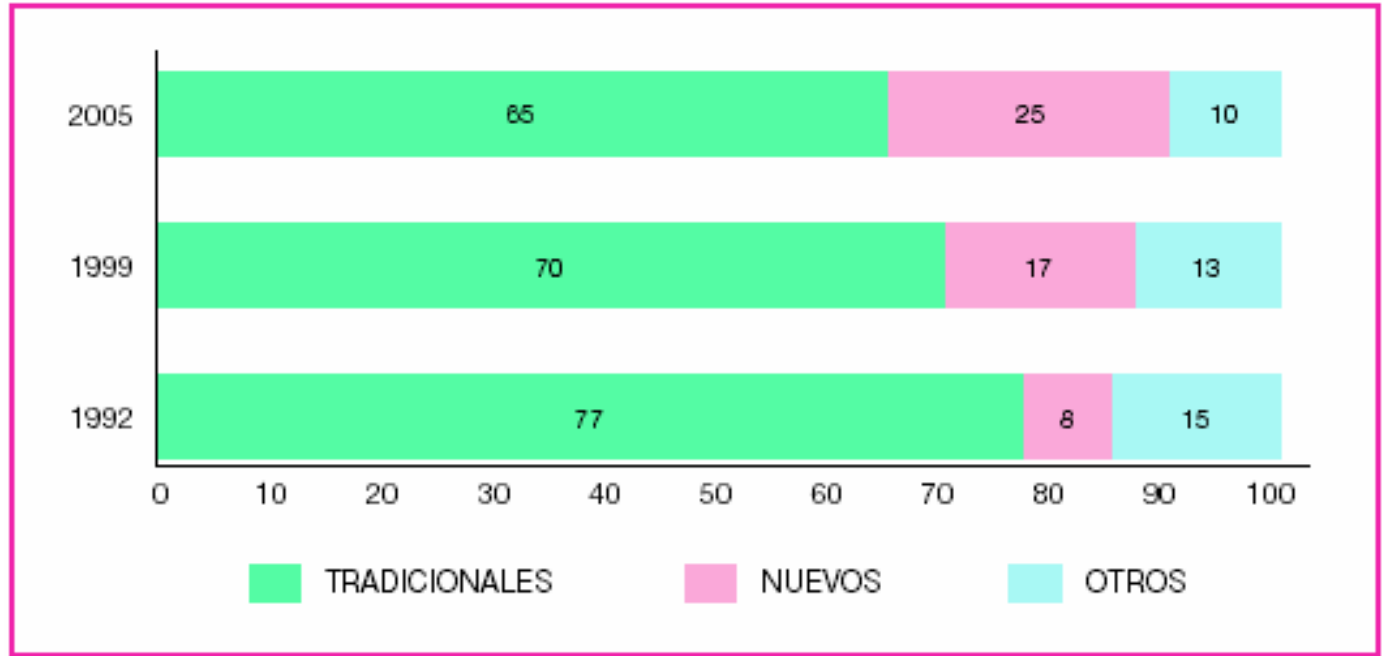

Fuente: Distribución y Consumo

El avance registrado, puede de crear serios problemas a los países tradicionalmente exportadores (especialmente a Francia), además de contribuir al debate sobre los modelos de producción/comercialización existentes en ambos grupos de países, fijando su atención en la regulación del modelo europeo de DO frente al modelo australiano no regulado.

La planificación estratégica con la finalidad de aumentar la cuota de participación de las empresas de los países NPP en el mercado mundial del vino conlleva algunos costes para los mismos: las inversiones en marketing y promoción (que suponen entre el 7 y el 16\% de las ventas dependiendo del tamaño de las empresas, y la reducción de los beneficios para las empresas del sector como consecuencia inmediata de fijar precios bajos (en algunos casos por debajo del coste de producción), con objeto de aumentar las ventas en volumen.

Se perfilan así dos modelos del sector esquematizados en el cuadro 4.6, que resume los cambios cualitativos que subyacen a los notorios cambios cuantitativos que se han observado referentes a las elevadas tasas crecimiento de los países NPP en el comercio internacional. 


\section{CUADRO 4.8}

\section{CARACTERÍSTICAS DE LOS DOS MODELOS VITIVINÍCOLAS PREDOMINANTES EN EL MUNDO}

\begin{tabular}{|lll}
\hline & \multicolumn{1}{c}{$\begin{array}{c}\text { DENOMINACIÓN DE ORIGEN } \\
\text { (PRODUCTORES TRADICIONALES) }\end{array}$} & \multicolumn{1}{c}{$\begin{array}{c}\text { MEJORA DE LA COMPETITIVIDAD } \\
\text { (NUEVOS PRODUCTORES) }\end{array}$} \\
\hline LOCALIZACIÓN & EURCPA & AMÉRICA, AUSTRALIA Y ÁRICA DEL SUR \\
\hline ACTIVIDAD & TRADICIONAL AGROINDUSTRIAL & INDUSTRIAL COMERCIAL \\
\hline DIFERENCIACIÓN & POREL ORIGEN & POR LA MARCA Y POR LA VARIEDAD \\
\hline MODERNIZACIÓN & POR MEJORADE LA CALIDAD & REDUCCION DE COSTES \\
\hline ESTRATEGIA & IMAGEN DE CALIDAD REFORZADA CON: & AUMENTO DE LA OFERTA Y ANIMACIÓN DE LA DEMANDA \\
\hline GARANTIA & HISTORIA, CULTURA, TRADICIÓN, TERRITORIO... & CON HERRAMIENTAS DE MERCADO \\
\hline
\end{tabular}

Fuente: Distribución y consumo

Ambos grupos tratan de diseñar las reglas de juego en el mercado mundial de vinos de acuerdo a sus preferencias Así por ejemplo, política vitivinícola internacional de la UE se ha visto cuestionada con el Acuerdo de Mutuo Reconocimiento de Prácticas Enológicas, firmado inicialmente por EE UU, Canadá, Australia y Nueva Zelanda, y al que se van adhiriendo nuevos países, que armoniza las diferentes normas enológicas de los países firmantes, de forma que si un vino es apto para ser comercializado y consumido en el país productor, automáticamente lo es en los países que han firmado el acuerdo, sin ningún tipo de certificación requerida por el país de destino. Los países europeos se oponen, EE UU abandona la OIV y trata de crear una nueva organización integrada básicamente por los nuevos países productores/ exportadores.

Las principales características del modelo europeo (Barco, 2003) son:

- Existe una mayor orientación a la producción que hacia la comercialización.

- Centrados en elaboración de vinos coupages procedentes de múltiples variedades autóctonas regionales, que al ser poco conocidas cuesta más introducirlas en los mercados internacionales.

- La actividad es agroindustrial, caracterizada por sus vinculaciones territoriales, culturales, históricas, etc.

- La coexistencia de dos tipos de vinos, uno común de mesa, y otro con la garantía de calidad se encuentra apoyada por el origen y la marca colectiva (DO, etc.).

- Posicionado en todos los segmentos de mercado y fundamentalmente en los de precios más elevados. 
- Proceso de producción, elaboración y comercialización muy condicionados por marcos normativos y reglamentarios, que vienen a constituir la base de la garantía de calidad del producto.

- Escasa homogeneidad, no solo entre países, sino entre regiones de un mismo país, lo que genera fuertes discrepancias entre los organismos e instituciones involucradas y los agentes económicos que operan en el sector.

- No siempre existe coherencia o equilibrio entre precio/calidad.

- En general se realiza poco inversión en promoción e información al consumidor.

- El modelo de competitividad está basado en la diferenciación geográfica del producto (con control de calidad) vía prestigio.

- Concepto de calidad basado en los derechos de propiedad.

El modelo de los países NPP sustenta el acelerado desarrollo de las exportaciones de los países del nuevo mundo o emergentes, y ha logrado una imagen favorable entre los consumidores en países sin tradición de producción (Reino Unido, EEUU, etc.), en detrimento de los vinos de mesa de Italia y Francia, que eran los que tenían mayor presencia en los mercados mundiales. Este modelo se basa en una serie de aspectos básicos (Barco, 2003):

- La producción se encuentra orientada al mercado, con la utilización de variedades internacionalmente reconocidas.

- Los marcos reglamentarios de producción elaboración y comercialización son más laxos que en el modelo europeo y se corresponden casi exclusivamente a criterios mercantiles, establecidos mayoritariamente por las unidades de producción (wineries).

- Apoyado en la biología de la planta limita la materia prima a un número limitado de variedades concretas, aunque cultivadas en distintas regiones geográficas, lo que proporciona únicamente homogeneidad varietal.

- Consiste en una actividad industrial comercial más que agroindustrial, que elabora los vinos mediante sistemas de producción a escala industrial en unidades wineries (con un elevado nivel en tecnología enológica), lo que permite la producción de grandes cantidades de vino, con las consiguientes economías de escala y con características varietales similares.

- La garantía de calidad está sustentada en la variedad y en la marca, garantizando un alto grado de homogeneidad en el nivel de calidad del vino a pesar del distinto origen geográfico de la uva. 
- Comercialización del vino con ayuda de un importante esfuerzo en publicidad promoción de las marcas, y demás instrumentos de marketing.

- Los precios de los vinos se corresponden con la calidad que presentan, por lo que son una compra segura para los consumidores.

- Modelo de competitividad basado en los costes de producción.

El caso australiano resulta paradigmático. A principio de los años ochenta el sector vitivinícola atravesaba una profunda crisis, con un consumo estabilizado y déficit en la balanza comercial vitivinícola, lo que indujo en 1996 al gobierno de Australia junto con los principales agentes del sector a proponer la Estrategia 2025, un plan estratégico con el objetivo de impulsar la industria vitivinícola, estableciéndose como meta final convertir a Australia en uno de los productores lideres a nivel y cuya aplicación ha permitido la reconversión y expansión del sector, tal y como se ha reflejado anteriormente. El plan se estructuró en tres etapas claramente definidas:

- Etapa de crecimiento en volumen (1996-2002): Durante este periodo se planeo un rápido crecimiento de la presencia de los vinos Australianos en los principales mercados mundiales. Objetivo aumento de puntos de venta en los mercados existentes y penetración en nuevos mercados.

- Etapa de crecimiento en valor (2002-2015): Durante este periodo se plantea una estrategia de construcción de marca "vino de Australia" aumentando los márgenes a través de economías de escala en los mercados seleccionados.

- Etapa de consolidación (2015-2025): En este periodo Australia ya se habría posicionado en los mercados estratégicos como un referente estableciendo y fortaleciendo el liderazgo de marca.

Las principales oportunidades que ha aprovechado el modelo NPP (MarcoGardoqui, 2004)

- Crecimiento de la población en Asia-Pacífico y sus mercados emergentes, unido al crecimiento de los mercados de exportación de Reino Unido, EEUU, Alemania y Japón.

- Crecimiento de la población por segmentos de edad y estilos de vida, consumidores de vino.

- Cambio en la tendencia del consumo, desde los vinos del Viejo Mundo a los vinos del Nuevo Mundo.

- Economía global sin barreras al comercio y colaboración internacional.

- Preocupación de la población por el Medio Ambiente, la salud y la responsabilidad corporativa. 
- Creciente importancia de la calidad y personalización del producto, haciendo a los consumidores más receptivos al marketing.

Los principales puntos fuertes del modelo son:

- Aprovechamiento de las ventajas competitivas naturales, como las menores restricciones climáticas y gran disponibilidad de recursos naturales.

- Un sector productivo compuesto por grandes compañías corporaciones multinacionales (las 10 primeras bodegas concentran el $85 \%$ de la producción total de vino).

- Empresas de tamaño suficiente para desarrollar distribuidores propios (distribución directa) en los mercados tanto nacionales como internacionales. Elevado poder de negociación con la gran distribución.

Los principales factores clave del éxito del modelo son (Marco-Gardoqui, 2004):

- Selección de proveedores mediante parámetros objetivos (eficiencia en costes, especificaciones de calidad, sostenibilidad medioambiental e identificación de las características regionales), que permitan disminuir los costes de aprovisionamiento de la uva.

- Reducción de costes mediante la innovación aplicada, economías de escala e introducción de nuevas tecnologías.

- Selección de inversiones orientadas al eficiencia en costes, especificaciones de calidad y localizaciones idóneas.

- Formación y profesionalización de los empleados en el sector.

- Relación proactiva con el mercado y con sus canales.

- Desarrollo de estrategias de posicionamiento, investigación de mercados, distribución, promoción y marcas regionales.

- Adaptación de la oferta a la identidad regional y subregional.

- Inversiones agresivas en marketing con la creación de fuertes imágenes de marcas globales (el $6 \%$ de la marcas aglutinan el $75 \%$ de la ventas) en los principales mercados y con innovación constante (envases, etiquetas, sabores).

- Diferenciación por información al consumidor acerca de la naturaleza del producto (principalmente de su variedad y marca).

- Fuerte internacionalización en todos los segmentos productivos en mercados afines culturalmente y en mercados geográficos “próximos”. 
- Gran compromiso con redes de distribución muy potentes facilitadas por el tamaño de las empresas.

- Alianzas y joint-ventures con socios locales y colaboración con operadores turísticos y autoridades del turismo.

- Fuerte a puesta por la venta directa (bodega, correo).

- Fuerte control de las operaciones a través de sistemas de información mediante el conocimiento: de los márgenes y rentabilidades por dimensiones, de los mercados y de los clientes.

- Colaboración público-privada (I+D, ámbito impositivo y gravámenes en el mercado nacional, acuerdos multilaterales de comercio, revisión de la valoración global de existencias).

- Comercialización de los segmentos de vinos de calidad a un precio económico.

- Posicionarse al principio en las gamas bajas de precios, Basic, Popular premium y Premium, para después aumentar su presencia en las gamas de precios más altas (donde se encuentran posicionados los productores europeos). Es decir cuanto mayor es la calidad y el precio del vino, menor es la incidencia de este tipo de producción.

Cuando Australia lanzó la "Strategy 2025" nadie le siguió en este empeño, pero a la vista de los resultados obtenidos en los diferentes objetivos previos planteados, existen los siguientes planes, visiones y estrategias en pensamiento o en ejecución:

\section{Planes}

- Francia, "Informe Berthomeaau".

- Argentina, "Plan Regúnaga".

- Chile, "Chilevinos".

- España, "Plan estratégico".

- La Rioja, "Acuerdo interprofesional".

\section{Visiones}

- África del Sur, "Vision 2020".

- Estados Unidos, "Wine Vision StrategicPlanning 2020".

\section{Estrategias}

- Australia, "Strategy 2025".

- Canadá, "Stratégie 2020". 
Estos dos modelos vitivinícolas mundiales y las estrategias que los soportan, conllevan una deslocalización de la producción hacia zonas de bajo coste y tienden a equiparar a la baja los precios en origen de la uva en todo el mundo, lo cual es preocupante para los productores europeos con alto coste. Los países tradicionalmente productores y las denominaciones como instrumento del mismo, se encuentran en la tesitura de ser totalmente fieles a sus tradiciones o adaptarse de manera rápida a las prácticas y conceptos que se manejan en los países emergentes.

Es posible que una solución intermedia sea lo más recomendable, de manera que la referencia la territorio se mantenga, ya que tiene la ventaja de integrarse con el concepto de la trazabilidad del producto (son procesos más controlados desde la materia prima a los productos finales) pero se vayan incorporando variedades, prácticas en el viñedo y procesos de elaboración y flexibilización en la aplicación de las normas. Los vinos de la tierra o vinos de calidad a precios económicos compaginan las componentes más atractivas de ambos modelos, la alusión al territorio y la variedad; otros ingredientes necesario para el funcionamiento de este tercer modelo habría que buscarlos en las condiciones de producción más laxas, la innovación enológica y sobre todo el marketing con la finalidad de colocar el vino con una relación calidad precio regular y adecuada, en el lugar y momento pertinentes (Barco, 2002).

\section{POLÍTICAS VITIVINÍCOLAS}

\subsection{La OCM vitivinícola de la Unión Europea}

Desde que se creó la Organización Común de Mercado vitivinícola (OCM), el mercado del vino ha evolucionado considerablemente:

- Comenzó siendo liberal, sin limitaciones de plantación y con pocos instrumentos de regularización del mercado, prácticamente los destinados a hacer frente a las fuertes variaciones anuales de la producción.

- Posteriormente combinó la libertad de plantación, con una quasigarantía de venta, lo que generó excedentes estructurales importantes.

- A partir de 1978 pasó a ser dirigista, al limitar los derechos de replantación, aplicar un régimen de precios y de intervención a los vinos de mesa, excluyendo los "vinos de calidad producidos en regiones determinadas" (vcprd), en base a la destilación, lo que suponía la retirada a un precio mínimo garantizado de los excedentes de producción, para su posterior transformación en alcohol de beber o en combustible.

- A finales de la década de los ochenta, se concedieron primas por arranque de viñas, lo que permitió aproximarse al equilibrio, aunque sin alcanzarlo totalmente.

- Posteriormente, en vista de que los acuerdos del GATT habían eliminado la protección exterior, y de que la demanda en claro descenso neto se orientaba hacia un nivel cualitativo que el viñedo existente no era capaz de ofrecer, 
surgió la reforma en el contexto de la Agenda 2000 y de la reforma general de la PAC.

La OCM está pensada y estructurada para la etapa expansiva en precios y producciones en la que se generó y ofrece un enfoque novedoso, puesto que fomenta la reestructuración del viñedo en lugar del arranque, aunque mantiene la idea de limitar el potencial productivo para evitar la acumulación de excedentes (Castillo, 2003).

Los objetivos de esta nueva OCM (Reglamento CE 1493/1999) se centran en mejorar y simplificar la anterior y adaptar cualitativa y cuantitativamente la producción a la demanda del mercado, mejorando la calidad y la competitividad de los vinos. Al final del proceso de reestructuración del viñedo se pretende la desaparición de la intervención como salida artificial a la producción excedentaria.

\subsubsection{Estructura de la OCM vitivinícola}

La Organización Común del Mercado vitivinícola adoptada en marzo de 1999, dentro del paquete de modificaciones de la PAC conocido como "Agenda 2000", ha introducido dos medidas de apoyo con las que no contaba la anterior regulación. Por una parte, el apoyo a la reestructuración del viñedo, con objeto de adaptarlo a las exigencias del mercado, y por otra, se arbitra la destilación de usos de boca con el fin de garantizar el suministro de alcohol vínico a los utilizadores de este tipo de alcohol.

Para ello, incluye reglas relativas a los siguientes aspectos a lo largo de todos sus títulos y anexos:

- Planes de reestructuración y reconversión del viñedo.

- Mecanismos de regulación de mercado.

- Potencial de la producción de vino.

- Agrupaciones de productores.

- Prácticas y tratamientos enológicos y las especificaciones de los productos.

- Descripción, denominación, presentación y protección de determinados productos.

- Vinos de calidad producidos en regiones determinadas (vcprd).

- Régimen de intercambios comerciales con terceros países.

Todas estas medidas de apoyo al sector contempladas en la OCM se engloban dentro de dos grandes grupos. Por un lado, se encuentran las destinadas a adaptar la oferta a la demanda mediante las ayudas a la reestructuración y reconversión del viñedo. Por otro, las tendentes a regular la oferta de vinos, entre las que se encuentran las destilaciones, ayudas al almacenamiento de vinos y mostos, así como las destinadas a otras utilizaciones del mosto y las restituciones a la exportación.

\section{Planes de reestructuración y reconversión de viñedo}

La ayuda a la reestructuración y reconversión de viñedo es una nueva medida que se ha introducido en la OCM vitivinícola para adecuar las producciones al mercado. La ayuda está constituida por una prima por hectárea en función del coste de las 
acciones que se lleven a cabo para la reestructuración o reconversión del viñedo, y que pueden ir desde la sustitución de una plantación hasta el reinjertado de un viñedo existente, o bien la modificación del sistema de conducción. Estas actuaciones se encaminan principalmente al cambio varietal para la producción de vinos de mayor calidad. Se sustituyen variedades blancas por tintas, que en la actualidad son las más demandadas por los consumidores, aunque son variedades menos productivas. Estas acciones de reestructuración y reconversión buscan la obtención de vinos de mayor calidad y la mejora de las estructuras productivas, y no aumentar el potencial productivo.

Como aspectos positivos habría que resaltar la ausencia de la promoción del arranque del viñedo de modo imperativo, la apuesta por la calidad, y la regulación potencial y control de derechos más transparentes (Castillo, 2003).

Las citadas medidas están mejorando la calidad de las áreas de viñedo de Europa, lo cual debería conducir a aumentar la producción de vino de calidad en todos los Estados Miembros (incluidos Alemania, Austria y Luxemburgo, a pesar de que tengan normativas diferentes). El total de producción de vino podría crecer en los próximos años debido a los nuevos rendimientos, pero existen serias dudas en relación a la capacidad del mercado de absorber la futura producción de vino tinto. Los efectos de reestructuración y conversión tienen un impacto a largo plazo, pero es probable que estas medidas de la OCM tendrán finalmente un efecto importante sobre las rentas en tanto que aumentará los ingresos para los productores de vino de calidad (Informe Innova de evaluación ex post de la OCM del Vino, 2004).

El aspecto negativo principal es la auto limitación del potencial vitícola, lo que afecta a su competitividad, cuando en el resto del mundo no se acomete la misma actuación, es más se está aumentando el potencial productivo en los nuevos países productores, los cuales están continuamente aumentando su cuota de mercado mundial entrando en los segmentos de gama baja vía precios. En un mercado abierto, todo lo que la UE deje de producir, lo producirá otro país, que venderá más, adquirirá mayor cuota de mercado y forzará a la UE a seguir bajando producciones en busca del equilibrio. Por lo tanto, reducir la oferta para lograr un equilibrio que sustente las rentas de los productores no es una solución de futuro, más bien de pasado.

Dado el continuado cambio en la demanda de los consumidores, que está desplazándose de los vinos de mesa de baja calidad hacia los vinos de calidad, las medidas relacionadas con los derechos de plantación introdujeron un elemento de rigidez en el mercado en tanto que dificulta la rápida adaptación del sector del vino europeo e indirectamente contribuyen a mantener el excedente de la UE. La reforma para liberalizar el comercio de la Agenda 2000, y el aumento de presión por parte de países terceros implica que aquellos productores de la UE que podrían aumentar su producción de vinos de calidad para acoplarse a la demanda de los consumidores, no deberían ser entorpecidos por nuevas restricciones de plantación. Tampoco el mercado debería ser perturbado con la presencia continua de excedentes de vino de mesa de baja calidad que reduce el nivel general de rentas de los productores. Debería fomentarse la transferencia de derechos de producción, y asegurarse un control eficiente del potencial 
de producción a través de la obtención de datos fiables de áreas de viñedos de la UE (Informe Innova de evaluación ex post de la OCM del Vino, 2004).

Las reconversiones masivas, principalmente dirigidas hacia la implantación de variedades tintas, han desembocado en muchas regiones en las que las salida principales de vino son graneles con poco valor añadido, en una etapa depresiva de precios del vino tinto más que del blanco (Castillo, 2003).

\section{Medidas tendentes a actuar sobre la oferta}

\subsection{Destilación de subproductos}

El objeto de esta destilación y a la vez su aspecto positivo es aumentar la calidad de las producciones evitando el sobre-prensado de los subproductos. Para ello se obliga a todos los productores a entregar todos los subproductos y, como mínimo, al menos un 10\% de la graduación alcohólica de la producción.

\subsection{Destilación de crisis}

Como se ha comentado anteriormente, en aquellos casos excepcionales de alteración de las condiciones normales de mercado, se prevé la posibilidad de proceder a una destilación de crisis en una región o país, y que puede afectar tanto a los vinos de mesa como a los de calidad. Esta medida solo se aplica en situaciones de precios bajos, como consecuencia del exceso de oferta y las bodegas de forma voluntaria pueden destilar parte de su producción de vino a un precio reducido.

El aspecto negativo se deriva del análisis de su funcionamiento, el cual revela que es un sistema poco eficaz y que supone un gasto importante con escasa repercusión en la renta de los viticultores. Sólo el $60 \%$ del gasto se emplea en la compra de vino para destilar, el resto son gastos de almacenamiento, destilación y pérdidas al vender el alcohol para biocarburantes a un precio inferior al de la compra del vino. Por otro lado esta ayuda es recibida por el destilador y en muchos casos no garantiza la renta de los productores, principal objetivo de cualquier OCM.

Asimismo, el sistema de destilaciones condiciona el mercado de alcoholes y ha convertido a las alcoholeras en empresas dependientes de la actividad de los organismos de intervención de forma directa.

\subsection{Destilación de uso de boca}

Esta destilación tiene como finalidad, satisfacer las necesidades de alcohol vínico de los utilizadores, principalmente elaboradores de brandy y vinos de licor, a un precio competitivo frente al procedente de otros productos agrícolas. Este destino de la producción conduce a una disminución de la oferta en el mercado, con su consiguiente efecto dinamizador.

Como aspecto positivo resaltar que el precio de 2,48 €/hectogramo resulta atractivo para determinados vinos y regiones. 
Como aspectos negativos, resaltar que esta destilación tiene distinta aceptación en los países vitícolas de la UE, debido a la diferencia de precios existentes en sus mercados. El hecho de que algunos estados complementen los precios de las destilaciones con fondos nacionales supone una renacionalización de las ayudas y la aparición de agravios comparativos con los viticultores de los estados que no aportan fondos. Éste es el caso de España, cuyos viticultores tienen que competir en un mercado único en condiciones de desventaja.

Por otro lado no es un método rentable a la hora de tratar con excedentes estructurales continuados. La ayuda de la destilación en alcohol de uso de boca es un tema particularmente controvertido puesto que subvenciona parte de mercado de alcohol de la UE mediante el aprovisionamiento de materias primas baratas, sobre la base de que constituye una salida tradicional para el vino de la UE. No parece haber una buena razón para impedir el establecimiento de un sistema de aprovisionamiento para la industria de espirituosos más orientado al mercado.

En el mercado europeo hay un excedente de vino que se traspasa a la destilación. Es difícil darle salida a este excedente, y aumentar la demanda de espirituosos entraría en conflicto con la creciente preocupación sobre el riesgo de la salud. Por otro lado, se podría producir bioetanol para uso industrial a menor coste usando otras plantaciones agrícolas.

Esta medida ha provocado que muchas bodegas destinen una parte importante de su producción a la elaboración de alcohol y no dispongan de estrategias ni de estructuras comerciales adecuadas para la venta de sus vinos, con lo que el mantenimiento de su actividad se encuentra ligado a la subvención.

Las medidas de destilación de la UE son medios efectivos de influir en el volumen de vino que se pone en el mercado; actúa como una demanda adicional (artificial) y por tanto las importaciones no se ven dañadas, sino indirectamente apoyadas. El impacto que sobre los precios tiene la medida de destilación de la OCM puede observarse principalmente entre los productos dentro del rango de precios más bajos, particularmente en España, Francia e Italia. En el segmento bajo del mercado, los ingresos de la destilación generan unas rentas significativas para algunos productores. Este efecto estabilizador de los ingresos satisface los objetivos de la política agrícola de la UE, pero al mismo tiempo da pie a la perpetuación de excedentes estructurales. Es decir, hay un aparente conflicto entre los objetivos de ingresos y desarrollo regional, y de orientación de la producción al mercado. El uso regular continuado que se viene dando en la destilación desde 1999/2000 de uvas de doble uso podría ser un indicador de la rigidez estructural, ya que sugiere que los productores no están respondiendo a las demandas de los consumidores.(Informe Innova de evaluación ex post de la OCM del Vino, 2004). 


\subsection{Ayudas al almacenamiento privado de vino y mostos.}

La OCM vitivinícola incluye una ayuda al almacenamiento privado de vino de mesa y mosto, con el objetivo de regular la oferta de vino en el mercado en aquellas campañas con elevados volúmenes de producción, permitiendo una salida escalonada del vino en el mercado.

Esta medida ha incidido en su aspecto positivo, en el mejora de la gestión comercial, y en su aspecto negativo, en el aumento de la capacidad instalada de almacenamiento en las bodegas.

\subsection{Ayudas a favor de usos alternativos de la producción de mostos}

La OCM vitivinícola contempla ayudas para fomentar del uso alternativo a la vinificación de los mostos de uva, como pueden ser para el aumento del grado alcohólico de los vinos, la elaboración de zumo de uva, obtención de productos comestibles a partir de zumo de uva, etc.

Como aspecto positivo la medida está generando una diversificación creciente de la producción en algunas bodegas del sector, que destinan parte de la producción de uva a la fabricación de mostos, dando lugar a un nuevo segmento empresarial. Por otro lado se trata de evitar el recurso fácil de las bodegas a la destilación.

\subsection{Restituciones a la exportación y restricciones a la importación.}

Con el fin de mejorar la competitividad de los vinos de mesa europeos en el mercado mundial, caracterizado por unos precios más bajos que los comunitarios, se han venido concediendo restituciones a la exportación. Sin embargo, estos últimos años se ha visto disminuido el volumen y los presupuestos destinados a tal fin, como consecuencia de los Acuerdos de la Ronda Uruguay del GATT y de la liberalización progresiva de los mercados agroalimentarios mundiales.

Las importaciones están gravadas con el arancel aduanero común, excepto los contingentes arancelarios resultado de los acuerdos comerciales de la UE con terceros países. Con el fin de desincentivar las importaciones existen una serie de restricciones técnicas al empleo de estos productos, como la prohibición de vinificación de mostos de terceros países, y la mezcla de vinos comunitarios con vinos importados.

El modelo de distribución de restituciones entre los Estados Miembros, que puede simplemente ser el resultado de diferentes estrategias de exportación, resulta netamente positivo, aunque dentro de este marco existente, se han detectado algunos aspectos negativos, como la ineficiente distribución de los recursos destinados a las restituciones a la exportación entre los diferentes países, lo cual genera discriminaciones entre los operadores afectados. Por otra parte, desde los acuerdos agrícolas de la Ronda de Uruguay, nunca se han aplicado las medidas disponibles para proteger el mercado de la UE ante serios problemas (arancel adicional, prohibición del uso de acuerdos internos, cláusulas de salvaguarda). 
Considerando que la competencia en el mercado del vino mundial está aumentando, que los principales competidores mundiales están sufriendo problemas de exceso de producción, y que el riesgo de graves desequilibrios en el mercado está muy presente, se recomienda un análisis riguroso de la efectividad de los procedimientos llevados a cabo para una rápida aplicación de las medidas (Informe Innova de evaluación ex post de la OCM del Vino, 2004).

\subsection{Prácticas enológicas}

En la OCM se definen las prácticas y tratamientos enológicos autorizados en la elaboración, conservación y crianza del vino. Se prohibe la comercialización de cualquier vino de origen comunitario que haya sido sometido a una operación no autorizada. Estas normas se aplicarán igualmente a los vinos importados, excepto en el caso de que haya un reconocimiento de prácticas enológicas del país productor por parte de la UE.

Como aspectos negativos destacar que la práctica de la chaptalización crea tensiones en el mercado, desvirtúa el concepto de calidad y hace inoperantes las medidas adoptadas para reducir el volumen de producción total y sus excedentes. En este sentido esta medida no es bien recibida por el sector español, ya que la permisividad de prácticas como la chaptalización y otras más, no llevan implícita la necesidad de anunciarlo al consumidor en las etiquetas, lo que conlleva de un lado, una desconsideración hacia el consumidor y de otro, la generación de agravios comparativos entre los mismos países de la UE.

Por otro lado la mayor restricción de prácticas enológicas resta competitividad al modelo de producción europeo, respecto a los vinos del exterior, que concurren en un mismo mercado en definitiva, pero con reglamentaciones más laxas.

\subsection{Designación, denominación, presentación y protección de determinados productos}

El Reglamento establece normas de designación, denominación y presentación de los productos regulados por la OCM, así como normas de protección de indicaciones geográficas y menciones tradicionales, con los fines siguientes:

- Informar y proteger los intereses de productores y consumidores.

- Preservar el buen funcionamiento del mercado interior e impedir que las legislaciones nacionales entorpezcan la libre circulación de los vinos.

- Fomentar los productos de calidad.

Respecto a las indicaciones geográficas, con carácter general, para que un vino pueda ser comercializado con una designación relacionada con un lugar geográfico, debe ser un vino de calidad y haber sido producido íntegramente en dicho lugar geográfico. 
Sabor, envase, imagen, estilo, son los factores más importantes que han permitido a los importadores de Chile y Australia conseguir cuota de mercado en la UE. Por esta razón debería realizarse un mayor esfuerzo inversor sobre el marketing mix del vino: revitalización de productos (desarrollo de marcas, etiquetado, percepción de calidad), control de los circuitos de distribución y comunicación, con la finalidad de aumentar la competitividad de la producción de vino en la UE.

\subsection{Vinos de calidad producidos en regiones determinadas}

En la OCM se incluyen las normas específicas que deben cumplir los vcprd: delimitación de las zonas de producción y transformación; variedades de vid, métodos de producción de uva y vinificación, y características del producto.

El productor puede descalificar aquellos vinos vcprd que no cumplan las exigencias requeridas y comercializarlos como vinos de mesa. El organismo competente designa-do por el Estado Miembro también podrá descalificar un vino vcprd tanto en fase de producción como de comercialización.

El régimen de producción de los vinos de calidad en Europa parece ser muy restrictivo. Se producen grandes volúmenes de vinos de mesa a pesar de que podrían considerarse vinos de calidad, porque cuentan con menos restricciones que los vinos de calidad para obtener su calificación. Cuando el consumidor valora la calidad, toma no sólo en cuenta la diferenciación por calidad (vinos de mesa, vinos de calidad), sino también otros factores que influyen en su percepción del ratio "calidad-precio", por ejemplo, envase, origen y precio.

Las marcas registradas están obteniendo mucho éxito en el mercado de la UE, y se usan no sólo por los países de la UE, sino también por los países del "nuevo mundo". Los elaboradores australianos han demostrado que un nivel más alto de restricciones para los vinos de mesa (vinos de la tierra o vinos de calidad a precios económicos) previstos en principio para facilitar la producción de vinos de calidad baratos para el consumo diario, es hoy en día un factor importante para proveer un marco propicio para desarrollos innovadores en el sector del vino. La competencia en precios no es la única explicación para el rápido crecimiento en la importación de vinos de mesa extranjeros. La liberalización del mercado de la UE ha permitido la importación de vinos de mesa (en particular) y de espumosos procedentes de terceros países, que eran competitivos. En conclusión, los métodos de producción de vino utilizados en terceros países deberían ser autorizados en la UE, siempre y cuando sean tanto seguros como aceptados por los consumidores. Por ello, una nueva tarea para la OCM sería mejorar la competitividad del sector del vino de la UE. Son necesarias inversiones en marketing, información fiable del mercado, y desarrollo del producto, para permitir a los productores encontrar destino para sus vinos, y con ello evitar futuros excedentes estructurales.

\subsection{Agrupaciones de productores}

La OCM establece la posibilidad de reconocer a Agrupaciones de Productores encaminadas a adaptar la oferta a la demanda y promover la concentración de la oferta y métodos de cultivo respetuosos con el medio ambiente. Por otro lado, las 
Organizaciones Interprofesionales del sector vitivinícola constituidas en cada EM podrán establecer normas para la comercialización de vcprd o vinos de mesa con indicación geográfica, con el fin de mejorar las operaciones de estos mercados.

\subsubsection{Efectos sobre el estado español de la OCM vitivinícola}

La OCM vitivinícola entró que en vigor en la campaña 2000/2001, por lo que no permite hacer una valoración en profundidad de las ventajas que ha podido aportar al sector español, debido al reducido número de campañas en las que se ha aplicado. Sin embargo, se puede apreciar que es beneficiosa para España. Por un lado, su aplicación ha permitido hacer frente a los desequilibrios de mercado, impidiendo una bajada de los precios. Por otro, las medidas de reestructuración y reconversión del viñedo hacen prever un cambio importante en las estructuras productivas del sector que a su vez facilitarán una mejora en las condiciones de comercialización de los vinos.

En el conjunto del presupuesto de la OCM vitivinícola, España está captando más del la tercera parte del los fondos comunitarios, seguida por Italia y Francia. En cifras, la puesta en marcha de la actual OCM ha propiciado que nuestro país haya destilado en los últimos años más del 55\% del total de la destilación de usos de boca, haya captado cerca del $50 \%$ de los fondos de reestructuración y reconversión de viñedo, cerca del 60\% de las restituciones a la exportación y alrededor del $20 \%$ del conjunto de la destilación de crisis. Estas cifras reflejan claramente la excesiva dependencia actual del sector español del vino de los presupuestos comunitarios, y el incierto futuro para el sector en el caso de restricciones importantes de las ayudas, propiciadas de un lado, por adhesión de los Países de Europa Central y del Este (PECOS), y de otro por las consecuencias que se deriven de la nueva ronda de negociaciones de la Organización Mundial de Comercio (OMC).

\subsubsection{Propuesta de reforma de la OCM vitivinícola.}

La Comunicación de la Comisión Europea al Consejo y al Parlamento Europeo, del 22 de junio de 2006, titulada "Hacia un sector vitivinícola europeo sostenible", para subsanar las deficiencias de la OCM vitivinícola actual, ha establecido cuatro opciones con sus consiguientes estudios de impacto publicados por la Comisión en apoyo de sus propuestas.

Opción 1: Statu quo con ajustes limitados, que resulta totalmente inadecuada, ya que no permite eliminar los excedentes y restaurar la competitividad.

Opción 2: Reforma en profundidad de la OCM vitivinícola. Parece la más apropiada.

Opción 3: Integración de la OCM vitivinícola en el modelo de PAC reformada, que presenta en principal inconveniente que habida cuenta del presupuesto disponible, el nivel de ayudas disociadas pagadas a los explotadores sería insuficiente en la mayoría de los casos. 
Opción 4: Desregulación total del mercado vitivinícola, que tendría efectos devastadores para el sector, con la desaparición masiva de la producción en regiones con una situación competitiva débil, en que la producción vitícola es la única capaz de garantizar el empleo rural y la conservación del espacio rural.

La opción 2 presenta las siguientes variantes: la variante A que propugna la supresión rápida de los derechos de plantación y el programa de arranque; la opción $\mathrm{B}$, propone en primer lugar un programa voluntarista de arranque, seguido de una restauración de la competitividad. El programa de arranque pretende incitar a los productores menos eficaces a abandonar la actividad (400.000 has en cinco años), y acogerse posteriormente al régimen de pago único. Las disposiciones comunes a ambas variantes se resumen en:

- Conservar y profundizar en las medidas que han resultado eficaces (reestructuración y reconversión del viñedo).

- Eliminar las limitaciones a la producción que no existen en nuestros competidores (régimen de los derechos de plantación y prohibición de nuevas plantaciones).

- Suprimir los programas de destilación y otras ayudas ligadas a la producción de excedentes que no hayan resultado eficaces (destilaciones, ayudas al almacenamiento y chaptalización) y, limitar las ayudas a la utilización de mosto concentrado).

- Fomentar la utilización de medidas de desarrollo rural (cese anticipado de la actividad agraria, instalación de jóvenes, medidas agroambientales, ayudas a la transformación y comercialización del vino), que permita el ajuste estructural indispensable en el sector.

- Normas de calidad, etiquetado y prácticas enológicas más sencillas y en consecuencia más eficaces, que permitan mejorar la competitividad en relación con los denominados "vinos del Nuevo Mundo".

Por otro lado y teniendo en cuenta el diagnóstico que se ha efectuado en el apartado anterior, la variante B de la Opción 2, es la que mejor reforzaría los aspectos positivos o fortalezas y, mitigaría el efecto de los aspectos negativos o debilidades. Desde el punto de vista del autor, se apoya esta propuesta, con las siguientes matizaciones:

- Respecto de la reestructuración y reconversión, debe orientarse hacia actuaciones en un nivel micro y olvidarse del concepto de reconversión masiva que ha desembocado en una etapa depresiva de precios y generación de excedentes de vino procedentes de las reconversiones varietales.

- La implantación de una diferenciación medioambiental y territorial y en definitiva el carácter multifuncional del cultivo del viñedo, de acuerdo con las limitaciones territoriales: cultivo del paisaje, acción antierosiva, 
mantenimiento de una cultura rural ancestral, el ecoturismo, etc., deberían imbricar el sector con el desarrollo rural, con la finalidad de hacerlo viable, sin menoscabo de la dimensión liberalizadora mundial.

- El establecimiento de una política de demanda, y no sólo de oferta, que perfile el sentido comercial de ayudas públicas a comercialización, marketing e I+D, diferenciación del producto e identificación de los gustos del consumidor.

- Para llevar a cabo una política de intervención con éxito es necesaria una información más fiable sobre oferta y demanda de vinos. Una nueva tarea para la OCM debería consistir en ayudar al sector vitivinícola, cofinanciando la obtención y distribución de información de la evolución de la demanda como de la oferta. Muchos de los operadores del sector reconocen la necesidad de adoptar un enfoque de la producción y del marketing más orientado al consumidor, pero para poder adaptarse a los mercados en evolución es necesario disponer de información más fiable y puntual. Esto crearía una mayor transparencia tanto para grandes como para pequeños productores y sus clientes. Por lo tanto, sería necesario:1. Asegurar un nivel apropiado de inversión en infraestructura básica de control. Para la recopilación de datos a nivel nacional, será necesario un mayor nivel de inversión, un control de la evo-lución del mercado y una mayor capacidad de procesamiento de datos. 2. Establecer mecanismos para la provisión de la información pertinente para la OCM por parte de Estados Miembros. 3. Seguimiento de la evolución en tiempo real de los mercados de vino con objeto de propiciar la regulación de la oferta y su adaptación a la demanda tanto interior como exterior.

- La creación de un grupo de expertos para ayudar al proceso de cambio, explorando mejoras posibles en la producción y marketing de vinos de la UE para asegurarse un mejor equilibrio de mercado a largo plazo (Informe Innova de evaluación ex post de la OCM del Vino, 2004).

- Establecimiento de mecanismos que repercutan un mayor porcentaje del presupuesto sobre la renta del viticultor, ya que aproximadamente sólo la tercera parte del presupuesto se transfiere directamente a los productores, vía reestructuración.

\subsection{La ley de la viña y del vino}

La Ley 24/2003, de 10 de julio, de la Viña y del Vino, se presenta como una ley básica, de aplicación en todo el territorio español y enmarcada dentro de una política nacional de liberalización de las actividades económicas. Transita por un estrecho margen, limitado por la normativa comunitaria y por las competencias de las comunidades autónomas, tratando de establecer unas reglas de juego que sirvan de referencia para las leyes específicas autonómicas o sea aplicada por aquellas comunidades que no cuentan con este tipo de norma. La Ley nace con la voluntad de 
garantizar la leal competencia entres empresas, respetando el ámbito competencial de las comunidades autónomas.

La importancia de la Ley estatal deriva de tres aspectos principales:

- Por derogar la muy obsoleta Ley de 1970.

- Por haber suscitado años de intensos debates sobre aspectos fundamentales para el desarrollo de nuestro sector como el uso de marcas, las indicaciones geográficas (su número y posibilidades de utilización) y la gestión y control de estas indicaciones geográficas; es decir, la reforma de los consejos reguladores.

- Por incitar a muchas comunidades autónomas a regular su sector vitivinícola, algunas con carácter previo a la aprobación de la Ley (Cataluña, La Rioja y Castilla-La Mancha), otras tras su entrada en vigor (Comunidad Valenciana).

La Ley puede dividirse en cuatro grandes apartados:

- Definiciones y viticultura.

- Indicaciones de calidad.

- Gestión y control de los vcprd.

- Régimen sancionador y otros.

\section{a) Definiciones y viticultura}

Quizás lo más relevante sea la definición del vino, por primera vez en un texto legal, como "alimento natural” y la específica autorización a la Administración General del Estado para que pueda "financiar campañas de información, difusión y promoción del viñedo, del vino y de los mostos de uva...", con directrices específicas que se refieren al fomento de su consumo moderado, sus beneficios como alimento dentro de la dieta mediterránea, o sus aspectos tradicionales y culturales. En la lucha por una consideración específica del vino como bebida y alimento con sus propias características, estos dos preceptos resultan esenciales. El apoyo público en campañas de promoción es importante, en un momento especialmente delicado en el consumo interno.

Destacar el mantenimiento de un estricto régimen de autorizaciones para las transferencias de derechos de plantación, una redacción relativamente suave pero aun exigente de que se autorice expresamente el riego en los vcprd (su forma y condiciones siempre que esté justificado), la inclusión de la prohibición de mezclas de vinos ( la norma europea ya establecía para España a partir de 2005 y que la Ley adelanta al 1 de agosto de 2003), y la prohibición de adición de sacarosa y otros azúcares no procedentes de la uva de vinificación para aumentar la graduación alcohólica de los vinos.

Asimismo destacar que la escasa alusión a las prácticas enológicas permitidas o prohibidas puede deberse a las siguientes razones: a la complejidad de tales prácticas, 
debido a que están muy condicionadas por el derecho comunitario y que se encuentran sujetas a frecuentes modificaciones.

\section{b) Indicaciones de calidad}

El Título sobre indicaciones geográficas, intenta, por una lado, poner orden en las indicaciones que puedan existir para vinos en España, indicando su nombre y características principales; Así, dentro del esquema marcado por la Unión Europea, la nueva Ley establece seis "niveles de calidad" o tipo de indicación geográfica (pirámide de calidad.) No obstante este aspecto que ha atendido las demandas de modernización de los grandes operadores puede incrementar la confusión de unos consumidores ya desinformados a priori.

Destacar el segundo nivel empezando por la base de la pirámide, referente a los vinos de mesa con indicación geográfica (vinos de la tierra), que en realidad son vinos de calidad a precios económicos o de precio bajo y en la práctica superan en calidad a los vinos de calidad mediocre o mala vendidos con al marchamo de DO (como es sabido la DO no garantiza una calidad superior). Este segmento de vinos de la tierra, por su buena relación calidad-precio, son los que mayor potencial de competir presentan con respecto a los vinos de los nuevos países productores o del nuevo mundo en los mercados nacionales e internacionales.

Por otro lado, regula la forma en que los operadores puedan trabajar en tales indicaciones. Así una misma viña podrá proporcionar uvas para la elaboración de vinos con destino a un único o a diferentes niveles de protección, lo que ya existe hoy en el caso de indicaciones superpuestas, sobre la base de la voluntariedad de la calificación de uvas y vinos. Este aspecto contribuirá a flexibilizar las posibilidades de comercialización de los operadores.

Más novedoso aún es el nuevo régimen de protección de las indicaciones geográficas que, declarándose bienes de dominio público, obtienen la protección habitual para sus nombres, respecto del posible fraude por uso en vinos no acogidos, pero no llegan a prohibir el uso de marcas privadas en vinos de distintos niveles de protección. La ausencia de prohibición de uso simultáneo de marcas en vinos de distintos niveles o procedencias o la ausencia de un régimen marcario especial frente a la regulación general contenida en la Ley de Marcas es una de las más importantes novedades de esta Ley respecto del sistema establecido en su antecedente de Estatuto de 1970, y hace que nada pueda restringir ya este libre uso de marcas. Este aspecto resulta básico para la consolidación de empresas y marcas fuertes, clave para el éxito, principalmente en los mercados exteriores.

En definitiva, la posibilidad de utilización sin restricciones de una marca por su bodega titular, para la comercialización de cualquier producto en cualquier indicación geográfica, está permitida por el hecho de que la Ley del Vino no introduce ningún régimen marcario especial, frente a la regulación general, contenida en la Ley 17/2001, de Marcas. Dado que según la Constitución, las competencias legislativas en materia de propiedad industrial residen en el Estado, ninguna comunidad autónoma tiene 
competencias para legislar en materia de uso de marcas y menos para parcelar el derecho exclusivo que en el tráfico jurídico tiene el titular sobre su marca.

\section{c) Gestión y control de los vcprd.}

Se plantea la reforma de los actuales consejos reguladores. De entrada, la Ley habla de dos tipos de órganos (gestión y control), lo que da una primera idea de la voluntad de separar ambos conceptos.

Cambian, además, las funciones que se encomiendan al órgano de gestión respecto de las actuales de los consejos reguladores (más amplias en algunos aspectos pero menos referidas al control de los productos). El sistema de control en todo caso estará separado de la gestión del mismo. No obstante está separación es más teórica que real, ya que los agentes controladores que son teóricamente independientes de los consejos reguladores son nombrados a propuesta o iniciativa de éstos últimos.

Establecido este principio de separación teórica de funciones, la Ley da múltiples posibilidades para que, en cada zona, se organicen los sectores y las indicaciones de calidad como mejor prefieran: el órgano de gestión podrá ser público o privado o una organización interprofesional que se constituya con el mismo ámbito de actuación que el vcprd, y el órgano de control podrá ser un órgano público, una entidad privada de certificación o una entidad privada de inspección que remita sus resultados a un órgano distinto de certificación o un órgano de control. En definitiva, dos posibilidades de órgano de gestión y cuatro de control que podrán combinarse entre sí para que cada vcprd desarrolle el modelo más acorde con sus intereses, desde lo más parecido al actual sistema hasta distintas posibilidades de innovación.

Estas opciones contribuirán a garantizar la calidad de los vinos en su categoría correspondiente con rigor e independencia.

\section{d) Régimen sancionador y otros}

Recoge el régimen aplicable a las infracciones administrativas en materia de vitivinicultura, que necesariamente debe establecerse en una norma de rango de ley, en cumplimiento del principio de legalidad recogido en la Constitución.

Por último, la Ley regula el Consejo Español de Vitivinicultura, como órgano solicitado por el sector para la colaboración entre la Administración central, las comunidades autónomas y representantes del propio sector, tanto en la obtención de datos del sector como en el establecimiento de sus grandes líneas estratégicas, actuando como órgano de carácter consultivo del Ministerio de Agricultura, Pesca y Alimentación como observatorio sectorial y con capacidad de proponer futuras reformas del sector. 


\subsection{La Ley de ordenación del sector vitivinícola en la Comunidad Valenciana}

La Ley 2/2005, de ordenación del sector vitivinícola de la Comunidad Valenciana, tiene como principal objeto como su propio título indica, la ordenación del sector vitivinícola en el ámbito territorial regional, de conformidad con la normativa estatal y comunitaria. Además tiene como finalidad establecer las reglas que deben de regir para todos los sectores implicados que operen en el marco de la leal competencia, así como la protección del consumidor en todo el proceso.

La Ley se encuentra estructurada en los siguientes Títulos:

El Título Preliminar establece el objeto y ámbito de aplicación, las competencias, los principios de actuación pública en la ordenación vitivinícola, y las definiciones.

El Título I regula la viticultura, trata de los derechos para plantar viñedo, de la autorización para la plantación, la regularización de superficies de viñedo, la reestructuración y reconversión del viñedo, las variedades y cultivo de la vid, la declaración de cosecha y los registros.

El Título II regula la vinicultura. Se establecen las normas relativas a las prácticas y tratamientos enológicos autorizados (en relación con el aseguramiento de la calidad del producto) en la elaboración y almacenamiento, las declaraciones de producción y de existencias, los libros-registro, la designación denominación y presentación y la publicidad de los productos (para garantizar la seguridad del consumidor).

El Título III establece el sistema de protección del origen, promoción y fomento de los vinos de calidad, definiendo los niveles del sistema de protección, y determinando los órganos de gestión u consejos reguladores.

El Título IV regula el régimen sancionador, tratando la competencia y facultades de la administración, la inspección y las infracciones y sanciones.

A continuación se comentarán los aspectos positivos y negativos de la presente Ley, respecto del la Ley de la Viña y del Vino, de la que directamente emana.

Entre los aspectos positivos habría que destacar:

- Se busca una regulación extensa del sector, incluyendo el concepto de trazabilidad.

- Regula los derechos de tanteo y retracto para derechos de plantación que se transfieran fuera de Valencia, que es una versión ampliada y mejorada de la regulación de tales derechos en la Ley del Vino de Castilla-La Mancha.

- Liberalización del uso de marcas, aunque con cierta confusión. 
Entre los aspectos negativos destacar:

- La escasa regulación del sistema de control.

\section{CALIDAD Y SEGURIDAD ALIMENTARIA}

\subsection{Concepto de calidad}

El término calidad, aplicado al sector agroalimentario, es un concepto complejo que puede definirse en base a la satisfacción de las preferencias del consumidor final, que puede incluir conceptos diferentes en relación con la seguridad alimentaria: la sostenibilidad, el medio ambiente, el bienestar animal, los valores nutricionales, y los atributos de valor, entre otros (Niño de Zepeda y Echevarri, 2001).

La Organización Internacional de Normalización (ISO) define calidad como la "capacidad de un producto o servicio de satisfacer las necesidades declaradas o implícitas del consumidor a través de sus propiedades o características”. Mediante la gestión de la calidad, las organizaciones (empresas, instituciones, explotaciones agrarias, etc.) tratan de mejorar en la satisfacción del cliente.

Desde este punto de vista, el concepto de calidad es una noción subjetiva (ligada al sujeto, al consumidor), la cual además está sometida a los cambios y modas que se suceden en la sociedad con el tiempo. Es modificable por la promoción y la publicidad y puede ser manipulada por los presciptores o líderes de opinión. La calidad de un vino tampoco es universal, variando con cada zona vitivinícola e incluso dentro de una misma zona.

En los último años se encuentran de moda los “vinos de “alta expresión”, en el sentido que manifiesten al máximo las características de las uvas y de las zonas; los vinos de "garaje o de autor", con mensajes llenos de simpatía y artesanía en donde se informa sobre las circunstancias concretas de su origen y elaboración, relacionadas con micro producciones procedentes de parcelas muy seleccionadas, vinificadas, criadas y conservadas con el máximo grado de detalle en pequeñas bodegas, capaz de alcanzar los más altos precios del mercado.

La mejora de la calidad ha de ser una constante en todas las etapas de la cadena de producción, y sobre todo en lo que respecta a la materia prima y al proceso de vinificación. Las líneas de actuación futuras deberían estar orientadas hacia los siguientes aspectos:

- Estudio y mejora de la materia prima, con el aumento del conocimiento y revalorización de las variedades autóctonas.

- Mezcla adecuada de variedades.

- Selección clonal.

- Técnicas de cultivo encaminadas a la calidad y estudios de maduración.

- Valoración y selección de la uva a la entrada de la bodega.

- Mejora de los procesos extractivos ante, durante y después de la fermentación. 
- Mejora de los enzimas exógenos y potenciación de los naturales.

- Perfeccionamiento de los productos enológicos que ayuden a la mejor conservación de los vinos.

- Mejora de los procesos de crianza, con el concepto de adaptarla al tipo de vino.

- Estudio y potenciación de las sustancias que existen en el vino y que pueden ser beneficiosas para la salud.

\subsection{Certificación de la calidad del producto}

Pese a este carácter subjetivo del concepto de calidad, cada día parece más importante disponer de mecanismos que aseguren la posesión de ciertos atributos subjetivos de calidad o el cumplimiento de requisitos en los procesos productivos relacionados con ésta. Es aquí donde las certificaciones de calidad tienen su razón de ser.

Actualmente es posible certificar la calidad de productos, servicios, personas e incluso de sistemas de producción. En el sector agroalimentario, los sistemas de aseguramiento de calidad se orientan más hacia la certificación de productos, aunque cada vez más se incluyen en estos esquemas aspectos más relacionados con los sistemas y procesos productivos.

Una de las dimensiones del concepto de calidad referidas anteriormente ha sido calidad definida por los atributos de valor. Estos atributos están más allá de la calidad básica nutricional o de inocuidad de un alimento, y diferencian los productos de acuerdo con:

- Sus características organolépticas (color, olor o sabor de los alimentos) y a la satisfacción del acto de alimentarse ligada a factores socioculturales, medio ambientales, éticos, tradicionales (caso de los vinos con denominación de origen y de los vinos de calidad con indicación geográfica).

- El respeto al medio ambiente a lo largo de la cadena productiva (caso de los productos ecológicos y los producidos mediante técnicas de producción y elaboración integradas).

- El respeto a los trabajadores encargados de la producción y elaboración (ej.: comercio justo).

\subsubsection{Sistemas de protección de la calidad}

El nuevo escenario normativo del sector vitivinícola, establecido en la Ley 24/2003 de la Viña y del Vino, define un sistema de protección de los vinos (gráfico 4.22). 


\section{GRÁFICO 4.22}

\section{PIRÁMIDE DE CALIDAD EN EL NUEVO SISTEMA DE PROTECCIÓN DE VINOS}

\section{NUEVO SISTEMA DE PROTECCIÓN DE VINOS}

\section{Vinos \\ de pago}

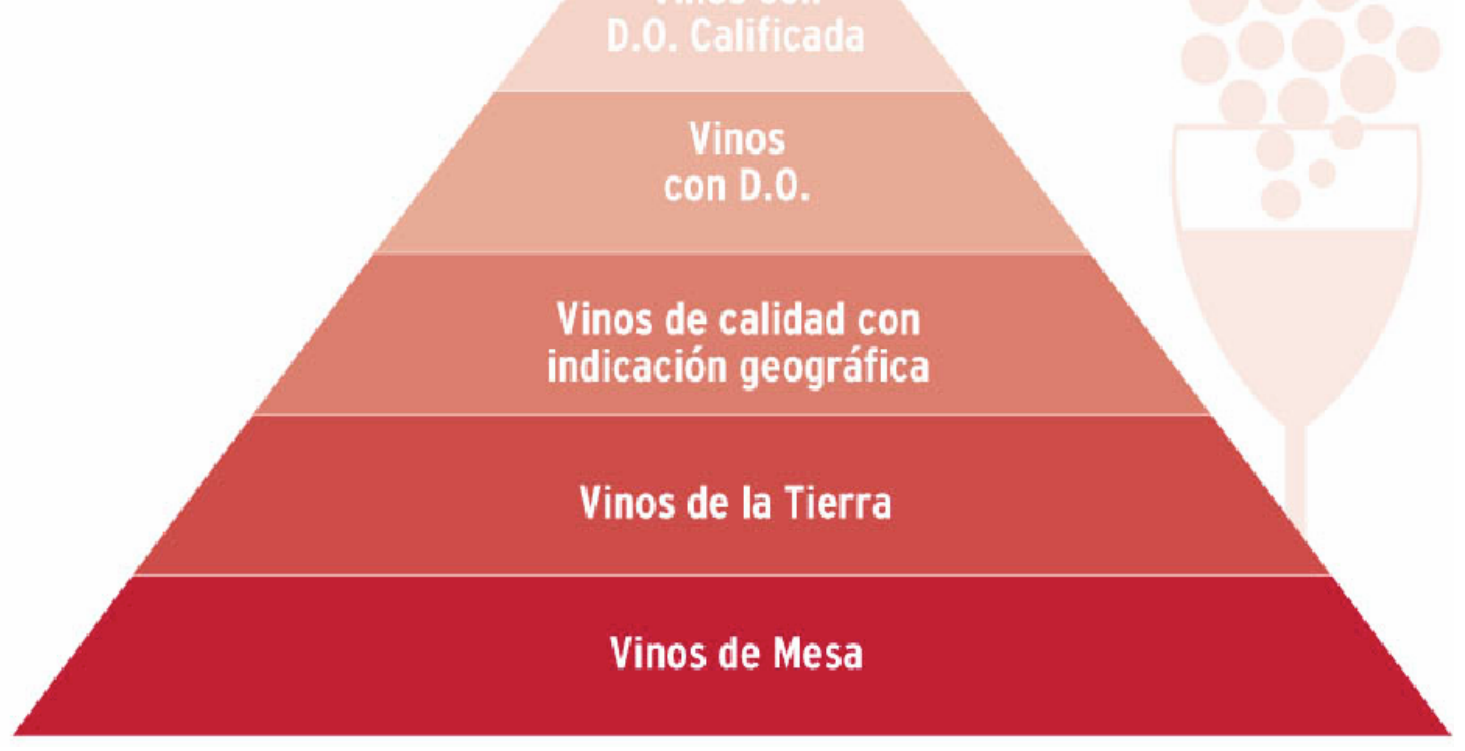

Fuente: Federación Española del Vino

De dichas figuras, la más notoria y mejor valorada por los consumidores es la Denominación de Origen (DO), que por otra parte es la marca colectiva generalizada en las bodegas del estudio. Se entiende por DO, el nombre de una región, comarca, localidad o lugar determinado, que sirva para designar un producto del mismo que haya sido elaborado en dichas localizaciones por uvas procedentes de las mismas, que disfruten de un elevado prestigio, y cuya calidad y características se debe fundamental o exclusivamente al medio geográfico, comprendidos los factores naturales y los factores humanos. El Reglamento (CE) n ${ }^{\circ}$ 1493/1999 del Consejo regula los Vinos de Calidad Producidos en Regiones Determinadas (VCPRD), estableciendo un conjunto de reglas comunes a la producción de estos vinos. Se puede compatibilizar la calificación Denominación de Origen de la normativa estatal con la denominación comunitaria VCPRD.

Por tanto los tres presupuesto básicos sobre los que se sustenta la DO son:

- La defensa de la calidad, en forma de segmentación y diferenciación del producto.

- La protección de las características diferenciales de los productos, con el fin de que no generen fraudes o utilizaciones espurias de la denominación protegida. 
- La autogestión por los productores de la DO, mediante la creación de un Consejo Regulador, encargado de gestionar y controlar la calidad.

El contenido económico de las DDOO radica:

- La DO precisa de la delimitación de un espacio de producción lo que implica la exclusión de los demás y con ello la fragmentación de la oferta.

- La DO conlleva la definición de unas prácticas culturales que, generalmente, implican un aumento de los costes de producción.

- El criterio de calidad mínima definido en las DDOO aparece, en muchos casos, vinculado a la cantidad de producción. Cantidad y calidad se compatibilizan al establecer rendimientos máximos, y se impide la reducción de coste por la vía del aumento del rendimiento.

- Cada DO dispone de un órgano de gestión y de un órgano de control que hay que financiar.

En el mercado de productos vinícolas, existen dos modelos diferentes para explicar la relación que se establece entre la calidad y el precio:

- Modelo europeo de DDOO o de los productores tradicionales, en el que el valor del producto (desde la perspectiva del consumidor) puede expresarse como una función de dos variables: calidad intrínseca y origen, siendo además la calidad una variable dependiente del origen.

DO = Información sobre el Origen (calidad percibida por el consumidor) + Calidad intrínseca u organoléptica, por lo que las estrategias de las denominaciones de origen deben tener en cuenta estos dos sumandos con objeto de valorizar al máximo el producto.

- Modelo anglosajón o de los nuevos productores, en el que el valor del producto se expresa como una función de tres variables: calidad intrínseca, imagen y precio, Peter Godden utiliza la siguiente fórmula: el valor de un producto es igual a su calidad intrínseca multiplicada por su imagen y dividida por su precio. De esta manera si se quiere elevar el valor de un vino habrá que actuar no solo elevando su precio sino también su calidad e imagen.

Un producto amparado por una DO tendrá un precio mayor que un producto genérico si y solo si la DO dispone de los instrumentos necesarios para controlar y garantizar la calidad ofrecida al consumidor (calidad intrínseca) y si le ha aportado la información necesaria sobre el origen del producto que le facilita su identificación y la apreciación de la calidad que se le oferta (calidad percibida). Sería el caso de una DO consolidada y eficiente.

Con respecto a los vinos de calidad con indicación geográfica, legalmente se refiere el producido y elaborado en una región, comarca, localidad, o lugar determinado, 
con uvas de los mismos, cuya calidad, reputación o características se deban al medio geográfico, al factor humano o a ambos, en lo que se refiere a la producción de la uva, a la elaboración del vino o a su envejecimiento.

Las DDOO como marcas colectivas se encuentran vinculadas a un ámbito geográfico específico, a un mayor prestigio de calidad y a una mayor diferenciación. Han surgido a consecuencia de un aumento del nivel de competencia entre las marcas de empresa, en un escenario en que elevada proliferación de éstas por parte de las pequeñas y medianas bodegas han originado una levada confusión y mínimo conocimiento de las marcas por parte de los consumidores.

En toda DO se superponen dos tipos de marca: la genérica o colectiva con el nombre de la DO y las marcas privadas o de empresa de los agentes económicos que participan en ella. Tal duplicidad ofrece para los consumidores la ventaja de la doble garantía (pública y privada) y, al mismo tiempo, plantea problemas de convivencia y de conjugación de intereses, a veces, no coincidentes (Barco, 2004).

La estrategia DO permite dar a los consumidores referencias (Origen) para diferenciar y elegir en la oferta tan heterogénea, tratando de alcanzar tres objetivos aparentemente contradictorios:

- Aumentar la diferenciación con otros productos competidores pertenecientes a otras marcas colectivas, al tiempo que reduce el coste de diferenciación para las empresas, mediante la marca colectiva.

- Mantener una gama diversa en la oferta (en oposición a la estandarización), a través de las marcas privadas.

- Disminuye las diferencias entre productores dentro de una misma DO, al garantizar una calidad tipo mínima para el conjunto de la DO.

- Reducir el coste de elección para el consumidor.

El interrogante que surge a partir de ahí es doble:

- El primero tiene que ver con el número óptimo de DDOO (evitando una proliferación excesiva que confunda al consumidor, y manteniendo un número suficientemente alto como para que se garantice la diversidad).

- El segundo con las diferencias dentro de la propia DO.

La relación entre la marca DO y cada marca privada de las bodegas no siempre genera sinergias positivas e incluso pueden producirse situaciones conflictivas. En sus decisiones de compra, el consumidor se enfrenta a un número considerable de DO que amparan a un número aún mayor de bodegas y éstas, a su vez, a un gran número de marcas. Este hecho puede plasmarse en distintas situaciones detectadas y reflejadas en la matriz de relación entre la marca de empresa (en ordenadas) y la DO (en abscisas) del cuadro 4.9). 


\section{CUADRO 4.9}

\section{MATRIZ DE RELACIÓN ENTRE LA MARCA DE EMPRESA Y LA MARCA DENOMINACIÓN DE ORIGEN}

\begin{tabular}{|l|c|c|c|}
\hline \multicolumn{2}{|c|}{} & \multicolumn{2}{|c|}{ NOTORIEDAD DE LA IMAGEN DE LA DENOMINACIÓN DE ORIGEN } \\
\cline { 2 - 4 } \multicolumn{2}{|c|}{} & ALTA & BAJA \\
\hline & SITUACIÓN IDEAL & $\begin{array}{c}\text { CONTRIBUCIÓN DE LA MARCA A LA IMAGEN DE LA } \\
\text { DENOMINACIÓN DE ORIGEN (2) }\end{array}$ \\
\hline
\end{tabular}

Se evidencia que en las DDOO más notorias existen marcas más fuertes que la propia DO, donde la DO no es más que otro argumento de venta. Estas marcas han servido para crear y hacer funcionar las DDOO existiendo una complementariedad después (cuadrante 1). Por tanto, entre la marca y la DO debe existir una relación de colaboración. Sin embargo, en otras situaciones una marca que se lanza al mercado se apoya en el valor de la DO pudiendo amparar la DO vinos de menor calidad (cuadrante 3). No obstante, cuando los vinos tienen una cierta posición en el mercado se prefiere que se valore el producto específico, es decir, la marca, no la contraetiqueta que comparte con otros vinos (cuadrante 2). Finalmente cabe destacar la situación de incertidumbre creada cuando las DDOO contribuyen de forma negativa a la valoración de los productos o juegan un papel neutro porque son DDOO impersonales y, a su vez, las marcas de los vinos no tienen notoriedad (cuadrante 4). Este hecho plantea problemas de gestión como el decidir qué debe ir primero, la marca de empresa o la DO.

Existe unanimidad por parte de los agentes económicos en dar más importancia a crear marcas prestigiosas con reconocimiento propio que a crear una marca genérica como es la DO. Las bodegas no amparadas a las DDOO argumentan que en la decisión de compra influye más el asesoramiento del distribuidor que la DO del vino. Pese a todo se ha detectado el elevado valor simbólico de la marca DO.

Un estudio realizado por la Universidad de la Rioja en 2002 detecta que las aportaciones de la DO al vino desde el punto de vista de la oferta son:

- La definición de estilos de vino por zona geográfica, zonas climáticas, tipos de suelos o variedades de uvas.

- Un concepto nuevo en el ámbito legislativo avalado por una tradición o herencia histórica asociada a la zona de procedencia de un producto.

- Un origen o procedencia del producto. Una garantía y una seguridad para el consumidor al aplicar unas técnicas y control (función técnica). 
- La aportación de información sobre el producto al consumidor, reduciendo tanto el riesgo en la fase de elección como el esfuerzo de compra por parte de éste (función comercial).

- Aumentan el valor añadido del producto.

Con referencia a las críticas manifestadas por los agentes económicos entrevistados son las siguientes:

- La procedencia como un atributo del que se apropia exclusivamente las DDOO, de tal forma que una bodega que abandone la DO no podrá especificaren su vino ni la variedad, ni otra información relevante para el consumidor, identificándolo como vino de mesa.

- El tamaño de determinadas DDOO que intentan homogeneizar el vino en zonas demasiado amplias con tipos de suelo y climas diferentes.

- El excesivo número de DDOO que, en opinión de algunos oferentes, está generando confusión al consumidor y, por tanto, banalizando la propia marca DO.

- Puede resultar una señal engañosa, en el sentido de que el valor de la DO se asocia a cada marca de empresa, lo cual pudiera no ser cierto.

- La regulación de las DDOO por ser excesiva y rígida predominando la tradición sobre la innovación, por no ser garante de calidad, no estar actualizada para introducir nuevas variedades o formas de etiquetado perjudicando la competencia a nivel internacional.

- Favorecer intereses de ciertos sectores como el comercial en detrimento del productivo.

- La gestión de los consejos Reguladores en cuanto al control de calidad o a la falta de control de algunos aspectos como el precio de venta del producto.

- La actuación del consejo regulador hasta ahora como "juez y parte” en las relaciones de mercado que no supone una garantía para el mercado, criticándose su actuación con fines lucrativos.

- La escasa profesionalización del productor.

Los consejos reguladores han priorizado en el pasado los aspectos técnicos relacionados con la calidad intrínseca del vino; en el futuro las DDOO también deben reforzar la calidad percibida por el consumidor, mediante la potenciación de la marca colectiva, la cual requeriría mayores presupuestos comerciales existiendo la posibilidad de realizar no sólo acciones individuales, sino también acciones colectivas con el fin de aumentar la demanda global de vino de calidad. 
Por último resaltar la importancia que tiene la influencia del país de origen para la venta de los vinos y que ha sido utilizada por los países no productores tradicionales, en especial el paradigma de Australia. España de replantea actualmente su estrategia de promoción de sus vinos en el extranjero, sintiendo la necesidad de crear una imagen global del país, al que sean receptivos los mercados internacionales. Por tanto en orcen descendente actuarían la imagen del país, de la región o denominación y de la bodega o empresa (Albisu, 2004).

\subsubsection{Agricultura integrada y agricultura ecológica}

Uno de los objetivos de la reforma de la Política Agraria Comunitaria (PAC) de 2003 es fomentar la producción dirigida a la obtención de productos de calidad respetuosos con el medio ambiente. En este sentido aplica medidas agroambientales, en apoyo de prácticas agroalimentarias, que trascienden el nivel básico de las "buenas práctica agrarias”, y que contribuyen fundamentalmente a proteger el medio ambiente. Entre las citadas medidas se encuentran la gestión agraria integrada y la agricultura ecológica.

La preocupación por conseguir productos de calidad que aporten garantías al consumidor sobre su seguridad y que se obtengan con procesos respetuosos con el medio ambiente, será la componente clave de la demanda en el futuros. En este sentido, la producción integrada se ha ido desarrollando inicialmente a partir de las normativas autonómicas y más recientemente a nivel estatal, en concreto a través del R.D.1201/2002, por el que se regula la producción integrada de productos agrícolas. En relación con el sector vitivinícola la Comunidad Valenciana tiene publicadas la normas de producción de uva para vinificación.

La agricultura ecológica, es un sistema productivo que básicamente se caracteriza por la no-utilización de los productos químicos de síntesis. Como consecuencia de lo anterior se logra conservarla fertilidad de la tierra, respetar el medio ambiente, y obtener alimentos de la máxima calidad.

Ha sido regulada a nivel europeo a través del R (CEE) 2092/1991, sobre la producción agrícola ecológica y su indicación en los productos alimenticios. En el ámbito regional, la defensa de la producción obtenida de acuerdo con el anterior reglamento, su aplicación y la vigilancia de su cumplimiento, así como el fomento y control de la calidad de los productos amparados (en las fases de producción, elaboración, envasado y comercialización) quedan encomendados al Comité de Agricultura Ecológica de la Comunidad Valenciana, a la Consellería de Agricultura, Pesca y Alimentación y al Ministerio de Agricultura, Pesca y Alimentación, en el ámbito de sus respectivas competencias. 


\subsection{Certificación de sistemas de calidad en las empresas}

Uno de los grandes propósitos de la gestión de calidad consiste en mejorar los sistemas y procesos de manera que puedan conseguirse mejoras continuas en la calidad.

En este caso el objeto de la certificación y portador final del distintivo de calidad es el sistema organizativo y funcional capaz de producir el producto, que en este caso es el la misma empresa, a través de una serie de procesos que son a su vez objeto de certificación.

La familia de estándares ISO 9000 fue creada en 1987 por la Organización Internacional de Normalización (International Organization for Standardization-ISO). ISO es una asociación de organismos nacionales de normalización que ha desarrollado un conjunto de normas sobre normalización de cumplimiento voluntario para el establecimiento de sistemas de gestión de calidad en diversos sectores económicos. La familia de normas ISO 9000 es utilizada en todos los países miembros de este sistema; primero se aprueba como norma internacional y después se desarrolla en cada país miembros.

Las normas ISO 9000 no son una exigencia administrativa sino del mercado, lo cual quiere decir que a pesar de su carácter voluntario, las grandes empresas alimentarias se dirigen sólo a proveedores que cumplen estos requisitos, por lo cual en la práctica se convierten en normas necesarias para poder acceder al mercado en buenas condiciones de aceptación.

Entre las ventajas que ofrece la titularidad de una certificación ISO se encuentran las siguientes:

- Una ampliación de la credibilidad de los clientes o de mercados extranjeros que ven en la certificación un modo de homologación plausible y ello redunda en una ampliación de las oportunidades de negocio.

- Elemento de diferenciación que les puede ayudar a afianzar su posición en el mercado. En un gran número de ocasiones, la obtención de la certificación se constituye en un requisito de los propios clientes.

- La adaptación que exige el sistema ISO puede suponer una disminución de costes en función de la clase de materiales empleados y del ajuste de procedimientos de fabricación.

- Ofrece una mayor posibilidad de control de riesgos de producción.

Actualmente el único estándar de certificación por el que es posible certificarse es el ISO 9001:2000, que viene a englobar los estándares ISO 9001, 9002 y 9003 creados en 1994.

El sistema de gestión de la calidad abarca aspectos más allá de la producción, elaboración y distribución del producto, tales como la política de calidad, el 
compromiso de la dirección o el enfoque al cliente, y además se adapta de forma más conveniente a las necesidades de las empresas, ofreciendo las siguientes ventajas:

- Más fácil de implantar (menor necesidad de documentación y procedimientos).

- Fácil integración con otros sistemas de gestión (ISO 14000, etc.).

- Adaptable a cualquier tipo de actividad y tamaño de empresa.

- Incluye la consideración de la mejora continua.

- La implicación de la gerencia y su compromiso con la calidad.

La nueva norma ISO 9000:2000 pretende integrar en un solo sistema la gestión de la calidad, los riesgos laborales y el medioambiental. Esta nueva estructura introduce un mayor grado de simplificación y, por lo tanto, de reducción de costes del sistema, lo que puede suscitar un mayor interés por parte de las empresas en cuanto a su implantación.

La norma internacional ISO 22000:2005 ha sido publicada recientemente en inglés y francés, estando previsto que a finales del año 2005 sea publicada en castellano. Las principales novedades que introduce radican, en que ofrece una herramienta para la implantación del APPCC a lo largo de todos los eslabones de la cadena alimentaria y asegura que la organización tenga establecida una política de seguridad alimentaria.

Respecto al entorno ambiental de las empresas, cualquier actividad (agrícola, industrial o de servicios) genera una serie de impactos sobre el territorio (emisiones, residuos, aguas residuales, contaminación de suelos, etc.), que pueden repercutir negativamente en su futuro desarrollo así como en el de la propia empresa. Ante este escenario, se ha ido creando un marco legislativo con el objetivo de proteger y conservar el medio ambiente. A nivel estatal, la aparición de la ley 16/2002, de Prevención y Control Integrados de la Contaminación (IPPC), crea en la necesidad de disponer de autorización ambiental que integra todos los condicionantes ambientales asociados a la actividad legalizada.

En el marco del sector vinícola agroalimentario, la ley define, como actividades sujetas a esta autorización el tratamiento y transformación destinados a la fabricación de productos alimenticios a partir de materia prima vegetal de una capacidad de producción de productos acabados superior a 300 toneladas/día (valor medio trimestral).

La aplicación de esta ley, que exige disponer de la autorización ambiental integrada para las actividades ya existentes da como plazo límite para la adaptación del sector, el 30 de octubre de 2007. Por tanto, todas aquellas actividades agroalimentarias que estén incluidas en el ámbito de aplicación de esta ley tendrán que adaptarse a la misma. 
En la actualidad existen dos sistemas de gestión medioambiental regulados por normas o reglamentos comunitarios que potencian la integración de los aspectos ambientales en la gestión estratégica y organizativa de las empresas.

- El Sistema Comunitario de Gestión y Auditoria Medioambiental (EMAS), que permite la participación voluntaria de las empresas en la evaluación y mejora de los resultados de sus actividades en relación con el medio ambiente, sin perjuicio del cumplimiento de las disposiciones legales y reglamentarias.

- La Norma ISO 14001, que especifica los procedimientos para que las empresas formulen una política y unos objetivos medioambientales y sólo exige un compromiso de cumplimiento de la normativa medioambiental que les afecten.

Los sistemas de gestión ambiental promueven la mejora continua del comportamiento ambiental de las organizaciones mediante:

- La implantación de un sistema integral.

- La evaluación sistemática, periódica y objetiva de este sistema.

- La información al público y a las partes interesadas.

- La formación e implicación activa de los trabajadores.

Por tanto, los sistemas de gestión ambiental son una herramienta que ha de servirá las empresas para:

- El cumplimiento de la legislación y la mejora de las relaciones con la Administración.

- La mejora de la imagen.

- El aumento de la motivación y la sensibilización de los trabajadores.

- El ahorro de costes a medio/largo plazo.

En cuanto a los recursos para la adaptación de las empresas al entorno ambiental, de acuerdo al marco legal vigente, estas se encontrarán cada vez más con un entorno ambiental exigente y complejo. La gestión ambiental ya no se reduce a la gestión de los residuos o de las aguas residuales de manera individualizada, sino que cada vez más integra todos los vectores ambientales.

No obstante, en este entorno tan complejo, existe el peligro que las exigencias ambientales puedan ser un escollo para las empresas que deseen concentrar sus esfuerzos internos sólo en producir y distribuir mejor sus productos. En este contexto, tiene delante de sí la alternativa de buscar un gestor ambiental integrado que aporte solución a las exigencias del entorno ambiental, sin que la empresa se desvíe de su propio fin: introducir un producto de valor añadido y diferenciado en el mercado.

En términos generales podemos dibujar un futuro halagüeño para los sistemas de certificación de la calidad, aunque son también patentes las amenazas que hay que vencer. Uno de los ejes vertebradores sobre el que discurrirá su desarrollo futuro es la seguridad alimentaria. Dentro del contexto europeo, y en parte debido a la aparición de crisis alimentarias, el consumidor se preocupa paulatinamente más porque los alimentos 
se encuentren libres de contaminaciones que supongan una amenaza para la salud .Y a pesar de que la Unión Europea respalda una de las Reglamentaciones Técnico Sanitarias (RTS) más exigentes del mundo, existe una creciente demanda en estándares alimentarios más estrictos que los legalmente exigibles.

\subsection{Sistemas de aseguramiento de higiene alimentaria}

La importancia de la alimentación en la salud de los ciudadanos y la creciente preocupación de éstos por la calidad y sanidad de los alimentos, unidas a las crisis alimentarias recientes, han hecho de la seguridad alimentaria un objetivo horizontal de la Unión Europea que, como tal, está integrado en todas las políticas comunitarias.

Por este motivo, la reforma de la PAC, realizada en el marco de la Agenda 2000, incorporó la seguridad e higiene de los alimentos a los objetivos de la PAC y, posteriormente, lo reforzó en la revisión intermedia de 2003. La nueva política europea de seguridad alimentaria se basa en la aplicación de un enfoque integrado "de la granja a la mesa" que cubre todas las fases de la cadena alimentaria, incluida la producción de piensos, la producción primaria, la transformación de alimentos, el almacenamiento, el transporte y la venta al por menor y que supone un cambio en las obligaciones de las explotaciones agrarias, que hasta ahora habían quedado al margen de algunas obligaciones como la aplicación de las normas relativas al Sistema de Análisis de Peligros y Puntos de Control Críticos (APPCC).

La aplicación de las nuevas normas está restringida al territorio de la Unión Europea. En los productos importados, la trazabilidad empieza en el importador, sin que la UE pueda legislar sobre lo que hagan los agentes de los países suministradores; eso significa que, en caso de alarma alimentaria, el importador será el responsable y deberá asumir todos los riesgos y las actuaciones podrán alcanzar a grandes volúmenes de producto.

El nuevo enfoque introducido en la política de seguridad alimentaria de la UE, tras la aprobación en 2000 del Libro Blanco sobre la seguridad alimentaria, ha implicado la reforma de gran parte de las disposiciones legislativas comunitarias sobre la materia. En los últimos años, la UE ha adoptado un considerable número de normas, tanto de carácter horizontal como vertical, sobre seguridad e higiene alimentaria, entre las que destacan:

- El R(CE) 178/2002, por el que se establecen los principios y los requisitos generales de la legislación alimentaria, se crea la Autoridad Europea de Seguridad Alimentaria y se fijan procedimientos relativos a la seguridad alimentaria. Es una norma marco de carácter horizontal que afecta a todas las etapas de la producción, transformación y comercialización de los alimentos y los piensos. Uno de los principios generales de seguridad alimentaria que establece este reglamento es la obligación de asegurar la trazabilidad de los alimentos en todas las etapas de la producción, la transformación y la distribución de los mismos. 
- El R(CE) 852/2004, relativo a la higiene de los productos alimenticios, que deroga la Directiva 93/43/CEE, relativa a la higiene de los productos alimenticios tiene por objeto garantizar la de los productos alimenticios en todas las etapas del proceso de producción, desde la producción primaria hasta la venta al consumidor final. Establece que los operadores agroalimentarios, desde la producción primaria hasta el consumidor final, garantizarán que en el proceso de producción se aplican los requisitos de higiene contemplados en este reglamento.

El R (CE) 178/2002 es una norma de aplicación directa y obligatoria en todo el territorio de la Unión Europea a partir del 1 de enero de 2005. Esta norma define la trazabilidad como: "La posibilidad de encontrar y seguir el rastro, a través de todas las etapas de producción, transformación y distribución, de un alimento, un pienso, un animal destinado a la producción de alimentos o una sustancia destinados a ser incorporados en alimentos o piensos o con probabilidad de serlo.

Para facilitar su aplicación, la Agencia Española de Seguridad Alimentaria (AESA) ha elaborado la "Guía para la aplicación del sistema de trazabilidad en la empresa agroalimentaria, que no tiene carácter vinculante y, por tanto, su aplicación es voluntaria.

Consecuentemente el Plan de Seguridad Alimentaria de la Comunidad Valenciana, establece que la eficacia del mismo exige un sistema de rastreabilidad de los alimentos y de sus ingredientes, que permita, ante la pérdida de seguridad de un producto, evitar el riesgo a los consumidores mediante la aplicación de los procedimientos adecuados para sus retirada del mercado sólo de los lotes o partidas afectadas, evitando perjuicios innecesarios a las empresas.

Todos los agentes que operan en alguna de las fases del proceso de producción y comercialización de un alimento tienen la obligación de aplicar mecanismos que faciliten la trazabilidad del producto.

No hay que olvidar que el objetivo básico de la trazabilidad es la capacidad para localizar y retirar en un tiempo muy breve un lote completo de productos en los que se hayan detectado cualquier problema. En ese contexto, el hecho de disponer de mayor información se transforma, de un lado en una protección para el empresario que así puede evitar o acotar el alcance de cualquier incidencia, y de otro en una mayor transparencia en las condiciones de producción y comercialización.

Según la Asociación Española de Codificación Comercial (AECOC), la seguridad del consumidor se ha convertido en una de las prioridades de la cadena alimentaria y la trazabilidad nace como un sistema de control total sobre los productos que ayuda a garantizar la seguridad alimentaria y a disminuir el riesgo. Por otra parte, los consumidores finales perciben las ventajas de sistemas que les permitan conocer quién, cómo, dónde y cuándo se ha producido el alimento que van a consumir, lo cual les genera confianza y seguridad en los alimentos. 
El desarrollo de este tipo de proyectos presenta una serie de ventajas:

- Fomentar la seguridad del producto describiendo la correcta actuación de los agentes que aportan valor a la cadena alimentaria.

- Supone una respuesta a la exigencias del mercado, tanto desde la óptica del consumidor como desde el punto de vista higiénico-sanitario.

- Potencia el concepto de calidad del producto, así como la imagen de marca.

- Garantiza el origen del mismo; especialmente beneficioso en los productos con denominación de origen.

- Supone una excelente motivación para la mejora continua e integral de los procesos de la empresa y se constituye como una herramienta básica de la certificación de sistemas.

- Es una excelente estrategia de diferenciación comercial.

- Fomenta y favorece el cumplimiento del marco regulatorio establecido.

- Permite ocupar un lugar en el mercado agroalimentario acorde con la creciente concienciación social en materia de salud y bienestar.

- Puede y debe ser gestionada a través de las adecuadas herramientas informáticas; además de acercar al sector primario a las nuevas tecnologías y fomentar la utilización como manifestación de progreso del sector.

- Implica poner en marcha procesos colaborativos entre proveedores, productores y clientes, basados en el intercambio de información entre los distintos eslabones de la cadena de suministro. Procesos de colaboración que resultarán inmanejables sin el uso del conocimiento y de la tecnología.

- Mejora la utilización de los recursos técnicos y económicos de la empresa.

Los principales inconvenientes pueden resumirse:

- La trazabilidad sea un aspecto difícil de determinar y no es fácil la implantación de un sistema de rastreabilidad inequívoca de los alimentos, así como de sus ingredientes.

- Existen muchos condicionantes, económicos (costes adicionales, disminución del margen a corto plazo), socioculturales (compromiso de todo el personal de la empresa, enfoque multidisciplinario) y tecnológicos (informatización, automatización de procesos), que impiden su desarrollo. 
- Se ha detectado cierta confusión sobre el concepto, confundiendo la simple disponibilidad de sistemas de lectura de códigos de barras con la gestión integral de la información que permita asegurar la trazabilidad.

El sistema APPCC es un sistema para asegurar la inocuidad de los alimentos que tiene base científica y enfoque preventivo y es utilizado para la identificación, evaluación y control de los peligros encontrados durante las fases de producción, procesado, manufacturas, almacén y uso de alimentos, que permite anticiparse a los riesgos propios de los procesos de producción, dando normas concretas y sencillas que deben seguir los trabajadores que intervienen en dichas para evitar peligros, con la finalidad de asegurar un nivel adecuado de higiene alimentaria.

Supone una evolución de los sistemas reactivos clásicos de control, basados exclusivamente en la inspección de las instalaciones y análisis de los productos finales a los sistemas de prevención.

En el plano internacional las principales normas que deben tenerse en cuenta en el ámbito de la calidad alimentaria son el Codex Alimentarius y los convenios multilaterales en materia alimentaria. El primero es el resultado efectivo de la comisión del Codex Alimentarius (compilación de normas alimentarias de carácter voluntario, códigos de buenas prácticas y directrices) creada en el seno de la Organización de Naciones Unidas para la Agricultura y la Alimentación (FAO) y la Organización Mundial de la Salud (OMS).

La Comisión del Codex elaboró el Código General de prácticas y principios de higiene de los alimentos o Código de Buenas Prácticas de Manufactura (BPM), donde se recomienda la aplicación del sistema de análisis de riesgos y control de puntos críticos (APPCC) con el propósito de elevar el nivel de inocuidad alimentaria.

En este sentido el RD 2207/95, por el que se establecen las normas de higiene de los productos alimenticios (consecuencia de la incorporación de la Directiva 93/43 CEE al ordenamiento jurídico español), establece que las empresas del sector agroalimentario deberán realizar actividades de autocontrol basadas en los principios APPCC.

El cumplimiento de los sistemas APPCC es apoyado por guías de buenas prácticas de higiene y fabricación (BPF), que constituyen un requisito previo a la aplicación del sistema. El sistema de APPCC es un mecanismo que complementa los sistemas de calidad implantados a través de las normas ISO 9000:2000, si bien la norma no es susceptible de ser certificada.

Respecto a la situación actual, son cada vez más las empresas que han implantado o están en fase de implantación del sistema Sin embargo, en las implantaciones actuales las empresas se encuentran con algunas dificultades:

- Implantación por normativa legal. La visión del APPCC como un sistema que nos viene dictado por ley implica en ocasiones la necesidad de implantarlo más por cumplir con la norma que por las bondades que proporciona. 
- El elevado componente técnico implica que la responsabilidad de la implantación recaiga en el departamento de calidad de las empresas, lo cual puede conllevar que la implantación sea observada por el resto de la empresa como algo lejano al proceso natural de venta, fracasando porque muchos eslabones importantes de la cadena no le encuentran sentido, no entienden este sistema o lo ven muy complejo.

- Mentalización de las bondades del sistema. En muchas ocasiones se genera la sensación de que el sistema es redundante, dado que afirma algo que ya se cumple.

- Revisión continuada del sistema. Se trata de un sistema vivo que cambia con las novedades que se producen en las empresas y/o en las tiendas. No hay que olvidarse que es un proceso de mejora continua que se retroalimenta y que puede tardar años en funcionar de manera óptima.

- Coste. Es una de las principales dificultades. Implantar un APPCC tiene un coste que se origina a través de la contratación de asesores externos, formación del personal, desarrollo del plan y posterior implantación, designación de personal que tenga una implicación directa en la vigilancia del sistema, auditorías, actualizaciones, etc. Y eso en el marco de un sector con márgenes ajustados y con una fuerte presión en la variable precio crea cierto temor a los empresarios en incurrir en nuevos gastos frente a la obtención de resultados. Sin embargo uno de los retos más importantes en el sector distribución en relación al APPCC pasa por establecer una estrategia que genere un retorno de la inversión (nótese que habla de inversión y no de coste) que supone la implantación.

Desde el punto de vista estratégico y de valor al cliente, el APPCC debe ser considerado un aspecto básico, de apoyo o diferenciador. Es importante conseguir que se perciba que la empresa se preocupa por la protección de la salud de los consumidores estableciendo como prioridad lograr la máxima calidad en los distintos procesos de producción, elaboración, distribución y venta.

Si se pretende explotar el APPCC será necesario que el cliente sepa qué es, para qué sirve, cómo se realiza, con qué medios se cuenta. Por ello el aspecto técnico imprescindible en el desarrollo de la implantación debe ser complementado con la inclusión en el plan de marketing de la empresa.

\section{LA REGULACIÓN INTERNACIONAL DEL MERCADO DE VINO}

El mercado vitivinícola en la actualidad se caracteriza por presentar escasas restricciones arancelarias y no arancelarias, estando su comercio sometido a políticas internacionales que afectan las condiciones de competencia entre los distintos países. Se trata de uno de los sectores agrícolas más expuesto a la competencia internacional, por lo que la globalización no es una novedad para este sector. La inestabilidad del marco político del comercio internacional (por ejemplo, represalias a las exportaciones europeas hacia EEUU) es esencial para el futuro del sector vitivinícola. 
El proceso de globalización junto con su presión liberalizadora ha expuesto al sector vitivinícola europeo a una mayor competencia de los nuevos países productores, debido a varios factores: mayor dimensionamiento de las explotaciones, menores costes laborales, clima menos errático con rendimientos superiores y más estables.

\subsection{Las negociaciones comerciales multilaterales}

La PAC, desde la entrada en vigor de los acuerdos de la Ronda de Uruguay del GATT, se encuentra sometida a los normas del sistema multilateral de comercio. Antes de la creación de la Organización Mundial de Comercio (OMC) las restricciones internacionales al comercio eran débiles, pero actualmente condicionan las políticas de apoyo y protección de la agricultura, prácticamente de los gobiernos de todos los países.

\subsubsection{El acuerdo sobre agricultura de la Ronda de Uruguay}

Desde los primeros Acuerdos de la OMC en relación con la agricultura (Acuerdo sobre agricultura de la Ronda de Uruguay), hasta los actuales (Acuerdo sobre agricultura de la Declaración de Doha), los gobiernos de los países miembros de la OMC, se han comprometido a celebrar negociaciones con el objetivo fundamental de establecer un sistema de comercio equitativo y orientado al mercado, que prevenga las restricciones y distorsiones en los mercados agropecuarios mundiales, mediante reformas en materia de ayuda y protección oficiales a la agricultura.

Su finalidad es contribuir a aumentar la liberalización del comercio agropecuario, lo que beneficiará los países que pueden competir basándose en la calidad y precio y no en el volumen de sus subvenciones. Este es especialmente el caso de los países en desarrollo, cuyas economías dependen cada vez más de productos agropecuarios primarios y elaborados, exportados a cada vez más mercados, fundamentalmente a otros países en desarrollo.

Los principales pilares de la reforma son:

- Mejora del acceso a los mercados (aranceles, contingentes arancelarios, salvaguardias especiales, empresas comerciases del Estado importadoras y otras cuestiones) a través de la eliminación de precios de referencia y reducción de los derechos de aduana o arancelarios, por su elevado nivel principalmente fuera de los contingentes arancelarios.

- Reducciones de todas las formas de apoyo a la exportación (subvenciones, créditos garantías y seguros, ayuda alimentaria, empresas comerciales del Estado exportadoras, y restricciones e impuestos a la exportación).

- Reducción de la ayuda interna en relación con las medidas de ayuda interna que se consideran distorsionadoras de la producción y del comercio (medidas de control y mantenimiento de la oferta, destilaciones, arranque $y$ reconversión de viña, almacenamiento privado, etc.). 
La UE es el primer actor comercial mundial en el sector del vino (primer importador y exportador), por lo que todas las actuaciones en pro de la liberalización del comercio internacional, tendrán un elevado impacto en los flujos internacionales en los que participan los países miembros de la UE, y entre ellos España.

Teniendo en cuenta de la buena adaptación de la actual OCM al sector vitivinícola español y como consecuencia su elevada dependencia de los presupuestos de la OCM, cabe plantearse los efectos que sobre la misma tendrán los futuros compromisos que la UE pueda adquirir en las negociaciones de la OMC, en el sentido de que cualquier modificación futura podría significar una limitación del acceso del sector productor español a las diferentes medidas, lo que conduce a que el sector sea más frágil que el de otros países.

Las perspectivas que se derivan de la nueva ronda de negociaciones de la OMC permiten prever una profundización en la liberación de los mercados, lo que puede suponer una reducción importante de las restituciones a la exportación del vino de mesa, así como un recorte de los volúmenes de alcohol destinado a carburantes que son exportados a terceros países. La reducción de las ayudas internas, llevará a una reducción del nivel de apoyo a las destilaciones, lo que podría significar la ruptura del frágil equilibrio de mercado, ya que supondría un aumento de la oferta de vino y, por consiguiente, una caída de las cotizaciones y una pérdida de renta de los productores (Libro Blanco de la Agricultura y Desarrollo Rural, 2003).

\subsubsection{Otros acuerdos de la Organización Mundial de Comercio}

Del resto de los acuerdos aprobados en la Ronda de Uruguay, probablemente el más importante para la UE en el sector del vino es el de los Aspectos de los Derechos de Propiedad Intelectual relacionados con el Comercio (ADPIC). Los objetivos de la UE son modificar el citado acuerdo en el sentido de aumentar la protección de las Indicaciones Geográficas (IG), que están consideradas como propiedad intelectual y por tanto protegidas por el Acuerdo ADPIC.

La regulación de las IG requiere a los miembros para que proporcionen medios legales que protejan, de un lado a los consumidores asegurándoles una información fiable y precisa relativa a la autenticidad del producto que goza de una IG; de otro a los productores contra la competencia desleal de las usurpaciones y de las imitaciones de las IG. Por otro lado, las indicaciones geográficas son una parte importantísima para la diferenciación de los productos del sector.

En el marco del acuerdo actual, todos los países miembros de la OMC están obligados a otorgar una protección mínima a las IG en sus legislaciones. El Acuerdo sobre los ADPIC establece un nivel más elevado de protección para las indicaciones geográficas de vinos y bebidas espirituosas que para otros productos, lo cual significa que los primeros deben ser protegidos incluso si no hay riesgo de que se engañe a los consumidores o de que se instaure una competencia desleal.

El problema para la UE es que ese nivel mínimo para las IG de los vinos es demasiado bajo y existe un disparidad de mecanismos de protección, lo que implica 
riesgo de nuevas usurpaciones de IG. La UE propone elaborar una lista de las denominaciones que, actualmente utilizada por otros productores de forma engañosas y desleal, deben quedar reservadas a sus legítimos titulares de los países de origen. Las IG están al alcance de cualquier productor de la localidad o región de que se trate, lo cual constituye un factor de competitividad para los territorios y productores de la UE y un instrumento estratégico para el desarrollo de la agricultura europea, y no solo para ésta agricultura sino para los productores de todo el mundo; ahora bien será preciso proteger estos productos contra las usurpaciones si se pretende garantizar condiciones justas a los productores y consumidores.

Por el contrario los países productores del nuevo mundo están a favor de una base de datos normativa y sin valor jurídico, mientras que la UE busca una solución jurídicamente más restrictiva que especifique lo que un país debería hacer en caso de conflicto.

El fracaso en el año 2003 de las negociaciones multilaterales de comercio en Cancún, en las que se impulsaba un acuerdo para un registro multilateral de indicaciones geográficas, obligan a una revisión parcial de la defensa internacional del sector, que deberá acomodar sus estructuras económicas para un mayor protagonismo de las marcas, sin dejar de lado los tradicionales elementos de diferenciación de las producciones europeas de vinos.

\subsection{Las relaciones bilaterales}

La UE, como la mayor potencia comercial en el sector del vino, ha asumido el compromiso de promover el justo y libre comercio con todos los socios comerciales, cooperando intensamente con éstos. En el marco de los tratados bilaterales en el sector vitivinícola son de destacar los tratados vigentes en la actualidad con Sudáfrica y Chile y los futuros con Mercosur, Canadá, EEUU y Australia.

El Acuerdo con Sudáfrica presenta dos ejes fundamentales: los métodos productivos y las protección a las denominaciones e indicaciones geográficas. Respecto a la producción de vino el protocolo especifica las prácticas y tratamientos enológicos autorizados para cada una de las partes. En lo referente a la designación y presentación, se protegen las denominaciones e IG referidas a ambas partes, mediante una lista que recoge las indicaciones protegidas para cada estado miembro y Sudáfrica.

El Acuerdo con Chile presenta las características de un acuerdo norte-sur, en el que se potencia el intercambio de bienes de acuerdo con las ventajas competitivas de cada parte: bienes agrícolas en el sur e industriales en el norte, por lo que acentuará las presiones competitivas sobre el vino, teniendo en cuenta el elevado ritmo de participación de este país en el mercado internacional del vino. Como aspecto positivo resaltar las concesiones obtenidas por la UE en cuanto a protección de las IG, así como a la eliminación de las usurpaciones genéricas y de marcas, lo cual es importante ya que Chile pertenece al Grupo Cairns, al que pertenecen los principales países nuevos productores o emergentes, Argentina, Australia y Nueva Zelanda. En este sentido la diferenciación cualitativa por el territorio constituye la mejor protección frente a la competencia internacional. 
El acuerdo incluye temas referentes al comercio de vinos, a la protección de indicaciones geográficas de las denominaciones del vino, las prácticas y tratamientos enológicas, así como los requisitos de los productos. Gracias a esta negociación Chile protegerá las indicaciones tradicionales de la UE a cambio del derecho a utilizar en el mercado europeo menciones especiales de calidad que destaquen las ventajas naturales del vino chileno, sobre la base de unas listas negociadas, de manera que cada parte evitará que una designación protegida en una parte sea utilizada en vinos de la otra parte si no figuran en las listas pactadas por ambas partes.

El Acuerdo con Mercosur persigue un escenario de cooperación entre las dos partes, así como una compatibilidad de estándares, incluyendo las medidas sanitarias y fitosanitarias. En relación con EEUU, este mercado sigue siendo la primera salida exportadora de los vinos de la UE, y de ahí el interés europeo de regular cuestiones relacionadas con las prácticas enológicas y con los semigenéricos, proporcionando las normas a seguir en el reconocimiento mutuo de prácticas enológicas y en la protección de las IG. El "Wine Accord "con EEUU es cada día más necesario para evitar una escalada de iniciativas legislativas estadounidenses contra la entrada de vinos comunitarios en sus fronteras.

Así, desde el 1 de enero de 2005, tras la entrada en vigor de la ley denominada "Miscellaneous Trade and Technical Corrections Act”, se exigirá el certificado de elaboración para la importación de vino en Estados Unidos, que garantice que el vino ha sido elaborado mediante prácticas aceptadas en el país. Este certificado no debe ser considerado como una nueva barrera técnica al comercio con Estados Unidos, dado que no es sino una medida de justa reciprocidad a la certificación que la Unión Europea exige a los vinos norteamericanos que se importan en territorio comunitario.

\subsection{Las organizaciones internacionales}

Históricamente el vino cuenta con la Organización Internacional de la Viña y del Vino (OIV) que trabaja como organismo internacional relacionado con los aspectos científicos y técnicos, con un lógico protagonismo de los países europeos donde se localiza la mayor producción. La OIV efectúa recomendaciones en materias relacionadas con las condiciones de producción, las práctica enológicas, la definición o descripción de los productos y sus métodos de análisis y valoración, siendo que un gran numero de normas de la OIV han sido transformadas en reglamentación por la UE. El grado de reconocimiento que la OIV obtenga de otros organismos internacionales, como la FAO, la OMS y la OMC es importante ya que de ello dependerá que las recomendaciones emanadas de la OIV se conviertan en prácticas internacionalmente aceptadas.

Para contrarrestar la actividad de a OIV y de la UE en la creación de normas internacionales, los países del Nuevo Mundo se reúnen en el seno de la Organización de Productores de Vino del Nuevo Mundo( (NWWPO), de la cual se están derivando acuerdos sobre prácticas enológicas, con el objetivo oficial de evitar que éstas sean utilizadas como obstáculo al comercio por razones ajenas a la información a los consumidores sobre seguridad de los alimentos, lo que representa un paso importante hacia la constitución de una alianza estratégica frente a la UE. 


\subsection{Los impactos de la ampliación al Este}

En lo que respecta a la viticultura tanto de los países recientemente incorporados como de los candidatos futuros, no todos ellos son productores de vino. Según las estadísticas de FAOSTAT referidas al periodo 1999-2002, la media del conjunto de todos ellos concentra una producción de vino que no alcanza el $10 \%$ de la producción de la UE-15. Por otro lado las producciones de estos países se encuentran muy concentradas en tres de ellos: Rumania, Hungría y Bulgaria, que participan con más del 80 \% de la producción del conjunto de los países del Este. Los países del Este no presentan en la actualidad un potencial productivo capaz de amenazar a corto plazo el sector en la UE-15, aunque el impacto de la ampliación no resulta fácil de predecir.

Como amenazas para la viticultura española se podrían mencionar: la mayor presión sobre las ayudas estructurales y de desarrollo rural; el acceso a un mercado y entorno económico más estable impulsará los rendimientos; la disminución de la protección en frontera.

Las oportunidades para el sector pueden citarse: la ampliación del mercado para el vino de los países de la UE-15, si se tiene en cuenta el potencial de crecimiento económico de los países del Este; el sometimiento de éstos países a las reglas del juego en el sector vitivinícola de la UE-15.

En resumen la incorporación de los PECOS supone mayor potencialidad que amenaza, puesto que la ampliación del mercado es muy superior al aumento de la oferta derivada de su integración.

\section{OTROS ASPECTOS CON INCIDENCIA EN EL SECTOR}

\section{Presentación, designación y publicidad}

La propuesta de Reglamento del Parlamento Europeo y del Consejo, promovida por la DG de Sanidad y Protección de los consumidores, establece la prohibición de alegaciones nutricionales y de salud en el etiquetado, la presentación y la publicidad de las bebidas con una graduación superior al 1,2\% en volumen de alcohol. De prosperar en su enfoque inicial, la iniciativa de la Comisión tendría consecuencias negativas para el sector en el ámbito de la publicidad y las promociones. La prohibición de la propuesta de reglamento no afectaría en cuanto al etiquetado, en el que nuestra legislación específica limita las indicaciones permitidas a las referidas a la naturaleza, calidad y origen de los vinos, no teniendo cabida las que puedan entenderse como de "propiedades" nutricionales o "virtudes" saludables de los mismos; pero no es aceptable porque se ha demostrado en los últimos años, según estudios científicos rigurosos, la relación directa entre el consumo moderado de vino y la mejora y/o prevención de ciertas patologías. El sector tiene derecho a informar de ello a los profesionales concernidos y al consumidor en general, y a rechazar toda limitación de este derecho. No es aceptable, por tanto, una iniciativa de la Comisión que acabaría de pleno con toda línea de comunicación (en campañas colectivas o de marca) en favor del consumo moderado de vino en el marco de la dieta mediterránea, como un alimento saludable, 
menos aún en un momento en el que el mercado interno del vino está en regresión (FEV, 2004).

Otro aspecto relacionado con la publicidad, es que las bebidas con una graduación superior al 1,2\% en volumen de alcohol quedarían excluidas del campo de aplicación de un reglamento del Parlamento europeo y del Consejo sobre promoción de ventas en el mercado interior, el cual modificaría la Directiva 98/27/CE del Parlamento y del Consejo sobre protección del consumidor. A tenor de la última redacción propuesta por Bruselas, el reglamento no cubriría, las promociones de ventas de bebidas alcohólicas, lo cual sería muy negativo para el sector.

\section{Tratamiento fiscal del vino}

Las empresas vitivinícolas debido a las características de su proceso de crianza, mantienen unos enormes stocks de vino en bodega. Estas existencias reducen su competitividad frente a los nuevos países productores, que tienen mayor integración vertical de una parte y sus vinos no están tan diferenciados por un proceso de envejecimiento característico de muchas denominaciones de origen españolas. Una bonificación fiscal contribuirá a mejorar los resultados de las empresas e invertir en la mejora de sus acciones en comercialización con un claro resultado en las exportaciones de vinos españolas. En este sentido se ha modificado la Ley 43/95 de Impuesto de Sociedades, con la siguiente redacción: “Las empresas del sector vitivinícola podrán practicar una deducción del 1\% de las existencias de vino al cierre del ejercicio sobre la cuota íntegra”.

\section{Ley de Bioterrorismo}

Nuevas Secciones de la Ley de Bioterrorismo (y por tanto nuevas obligaciones) entrarán progresivamente en vigor, en concreto sobre detención administrativa y sobre mantenimiento de registros para permitir obtener la trazabilidad de un producto. Precisamente el espíritu con el que se ha redactado la citada Ley fue el de permitir una trazabilidad perfecta del producto, con el objetivo de determinar responsabilidades en la cadena de producción cuando surge un problema.

Sin embargo, esa trazabilidad ya era factible de lograr con las iniciativas como las de Alerta Rápida y no era necesario poner en marcha todo un dispositivo que se va a traducir en mayor carga administrativa, y que creará serias barreras al comercio, por la necesidad de disponer de un agente, de conexión a Internet, etc.(FEV, 2004).

\section{Ley sobre prevención del consumo indebido de bebidas alcohólicas}

El Ministerio de Agricultura consiguió un importante compromiso con el Ministerio del Interior, mediante la introducción en el texto del anteproyecto de Ley de una disposición adicional, por la que se exime al vino de una gran parte del contenido de la Ley, sobretodo y lo que es más importante, de los objetivos de la Ley. También se le exime al vino de las restricciones de la publicidad contenidas en el articulado. El vino solo quedaba afectado en lo referente al acceso: horarios y normativa para menores de edad. 
Por tanto ése fue un reconocimiento expreso a la realidad específica del consumo del vino, y se entendió desde el primer momento que esta cuestión era un primer fruto, muy inmediato, de la Ley de la Viña y el Vino y el reconocimiento del vino como un alimento, con derecho a campañas de promoción incluso con fondos públicos.

\section{Vertebración del sector}

Tres organizaciones agrarias, ASAJA, UPA y COAG, aunque con sus diferencias regionales, representan al sector productor nacional junto con la Confederación de Cooperativas Agrarias (CCAE).

Las bodegas embotelladoras y comercializadores se encuentran mayoritariamente en la Federación Española del Vino (FEV).

Las bodegas y comerciantes de vinos de mesa o de la tierra, se agrupan la Federación del Comercio Interior de Vinos.

La Confederación Española del Vino, juega un papel importante como lazo de unión entre comercializadores-cooperativas y comercializadores-bodegas.

Los productores, las cooperativas y las bodegas independientes de vino de mesa o vinos de la tierra están representados por la Organización Interprofesional Agroalimentaria del Vino de Mesa y Vino de la Tierra.

En el camino de la necesaria integración de intereses, aún respetando escrupulosamente la independencia, planteamientos y actividad de cada cual, dos inconvenientes siguen frenando una mayor unión: a) las diferencias regionales que, de tanto en tanto, afloran entre zonas vitivinícolas de España por creerse todas muy diferentes unas de otras, cuando la diferencia realmente es cada vez menor; b) las rivalidades locales entre entidades y personas.

Ambos riesgos adolecen de un mismo error: un exceso de visión local y a corto plazo, frente a la necesaria visión más amplia y hacia adelante. Lo mismo ocurre a veces en las relaciones entre producción y comercialización, donde parece suponerse que debe existir un cierto enfrentamiento, aunque la realidad y un poco de análisis nos muestren que son más los intereses comunes por el bien del conjunto del sector, los que deben de ganar las batalla a los intereses personalistas, locales, regionales o subsectoriales.

Finalmente, la fragmentación y atomización del sector está compensada muy escasamente aún con intentos de vertebración a los que les queda un largo camino por recorrer. Existen multitud de organizaciones nuevas, entrecruzadas y superpuestas, muchas veces con fuertes protagonismos personales, pendientes de derivar hacia organizaciones sólidas con voz potente en defensa del sector. Se torna absolutamente necesario el desarrollo de programas ligados al fomento de la interprofesión con la participación de los productores, sus organizaciones, la economía social y los consejos reguladores como agentes vertebradotes del sector (FEV, 2004). 


\section{CAPÍTULO V}

ANÁLISIS DEL SUBSECTOR VINÍCOLA EN LA COMUNIDAD VALENCIANA 



\section{ESTRUCTURA EMPRESARIAL DE LA INDUSTRIA VINÍCOLA}

La caracterización estructural de la industria vinícola en la comunidad Valenciana se ha realizado mediante variables más expresivas como la antigüedad, la forma jurídica adoptada, la estructura de la propiedad de las empresas (tipo y modo de control del capital social), la dimensión y tamaño empresarial, y la distribución territorial de las empresas.

La antigüedad se ha medido a través del número de años transcurridos desde la creación de la empresa, habiéndose adoptado la siguiente segmentación por edades:

- JOVEN: Hasta15 años.

- EDAD MEDIA: Entre 16 y 29 años.

- $\quad$ ANTIGUA: Más de 30 años.

\section{GRAFICO 5.1}

DISTRIBUCIÓN DEL NUMERO DE EMPRESAS SEGÚN LA EDAD

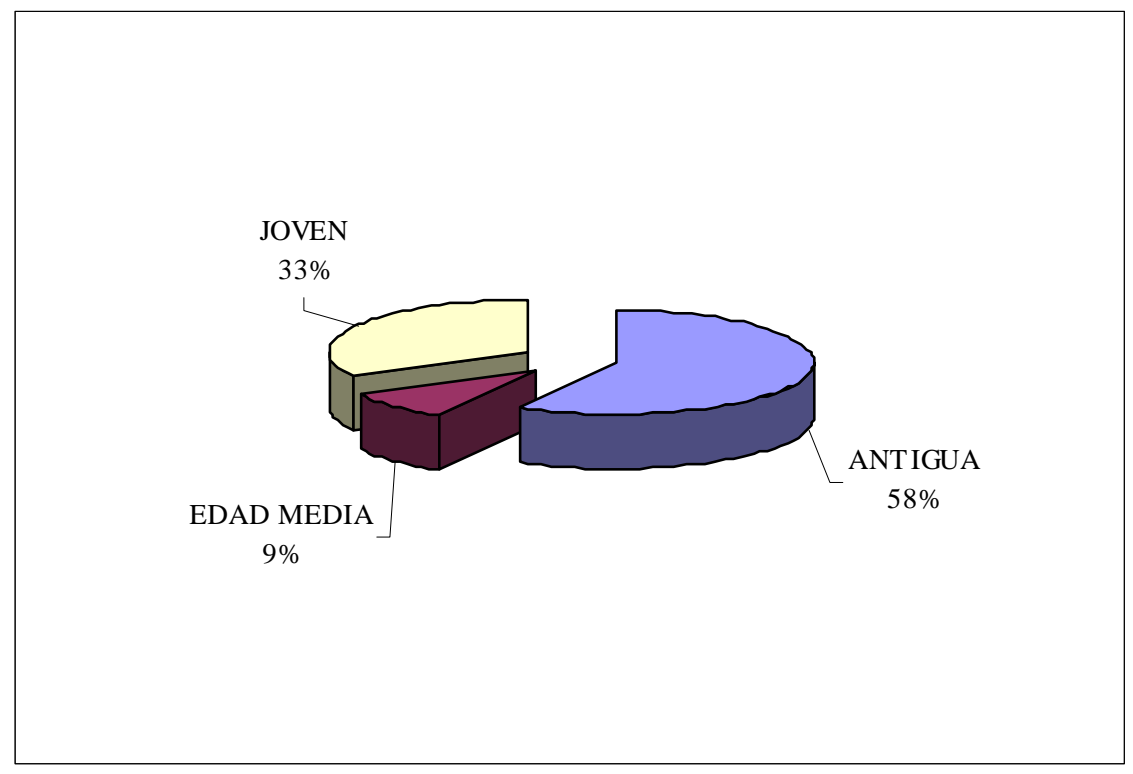

Fuente: Elaboración propia 
En el Gráfico 5.1 se puede observar la distribución por edades de las 110 empresas encuestadas, estando catalogadas el $58 \%$ como antiguas, cerca de la tercera parte de edad media y el resto jóvenes.

La personalidad jurídica es otra variable relacionada con la configuración de la propiedad. La segmentación adoptada en el capítulo y con la finalidad de no perder información ha sido la siguiente:

- S_MERCANTIL: Sociedad mercantil, que engloba a las sociedades anónimas y limitadas.

- SAT: Sociedad agraria de transformación.

- S_COOP: Sociedad cooperativa agrarias de $1^{\circ}$ grado y de trabajo asociado.

- S_COOP2: Sociedad cooperativa de $2^{\circ}$ grado.

- S_COOPS2: Sociedad cooperativa agraria de $1^{\circ}$ grado, asociada a la de $2^{\circ}$ grado.

- P_FÍSICA: Persona física, que engloba a las unipersonales y comunidades de bienes.

Del gráfico 5.2 se desprende que la mayor parte (más del 50 \%) de las bodegas pueden considerarse entidades de economía social, seguidas de las sociedades mercantiles (39\%) y personas físicas (8 \%). En el mismo gráfico es posible observar, frente al gran arraigo que presentan las cooperativas de $1^{\circ}$ grado, considerar la escasa incidencia de las de $2^{\circ}$ grado (solo 3 cooperativas en la región), como posible vía de concentración, homogeinización, embotellado y comercialización de los productos.

\section{GRÁFICO 5.2}

\section{DISTRIBUCIÓN DEL NÚMERO DE EMPRESAS SEGÚN LA FORMA JURÍDICA}

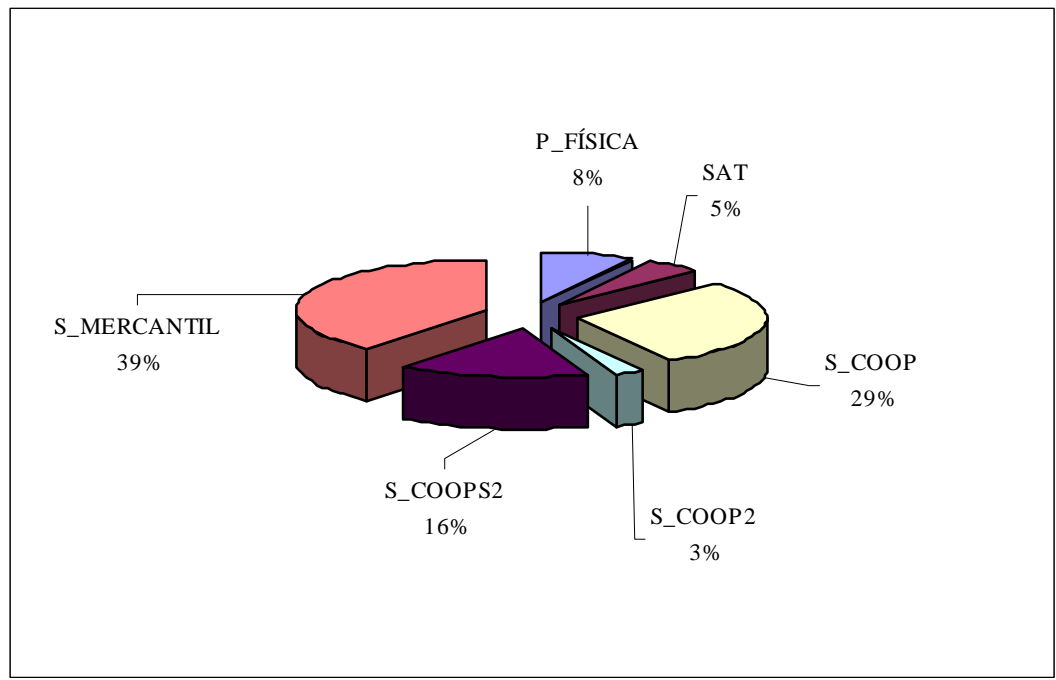

Fuente: Elaboración propia 
La configuración de la propiedad de la empresa se ha expresado a través de dos aspectos clave:

Referente al grado de control existentes en la empresa, en el ámbito de la Comunidad Valenciana, el 83 \% de las empresas presentan un control difuso (el accionista principal posee menos del 50 \% del capital social), obligando a la formación de coaliciones con otros accionistas tendentes al establecimiento de mayorías suficientes, que serán más inestables cuanto mayor sea el número de propietarios.

Con relación al modo de control, en el ámbito regional, en el $62 \%$ de las empresas los accionistas son personas individuales; en el $29 \%$ de las bodegas los accionistas principales son personas físicas unidas por lazos familiares (matrimonios, hijos, primos); 6 empresas están participadas por accionistas societarios nacionales: 2 empresas están participadas por sociedades extranjeras y otras 2 por multinacionales. Con ésta distribución del modo de control queda mermada la posibilidad de que empresas adscritas a un grupo económico más amplio, adquieran un mayor potencial estratégico a partir de recursos financieros, productivos, comerciales y organizativos superiores a los que les correspondería según su propia dimensión, con la consiguiente generación de economías de escala y de alcance superiores. El control difuso es menos frecuente con la disminución del tamaño empresarial, lo que equivale a afirmar que el control se encuentra más asociado a tamaños pequeños de las empresas.

Respecto a la dimensión empresarial, en el gráfico 5.3 se observa que el 37 \% de las empresas corresponde a la categoría de muy pequeñas, seguidas de las pequeñas (25\%). El conjunto de las muy grandes y grandes supone el $27 \%$, y sólo un porcentaje cercano al 4 \% (4 empresas), corresponden a la categoría de muy grandes empresas.

\section{GRÁFICO 5.3}

\section{DISTRIBUCIÓN DEL NÚMERO DE EMPRESAS SEGÚN EL TAMAÑO EMPRESARIAL}

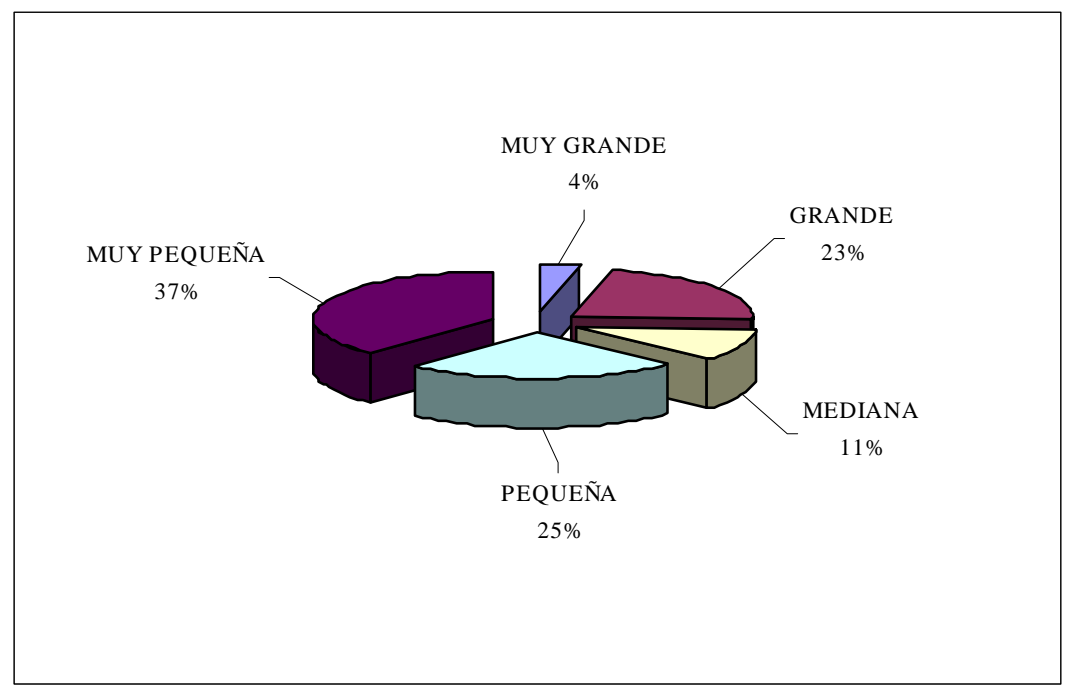

Fuente: Elaboración propia 
En la distribución territorial de las empresas, con el objetivo de configurar grupos homogéneos bodegas, y dada la circunstancia de que todas la bodegas están inscritas en al menos una Denominación de Origen (DO), se ha adoptado el criterio de clasificarlas de acuerdo con la pertenencia a las tres Denominaciones de Origen existentes en el ámbito regional:

- ALICANTE

- UTIEL-REQUENA

- VALENCIA

Según el Gráfico 5.4, más del 50 \% de las empresas pertenecen a la DO UtielRequena, seguidas de las de Valencia y Alicante, ésta última con una representación del $17 \%$.

\section{GRÁFICO 5.4}

DISTRIBUCIÓN DEL NÚMERO DE EMPRESAS SEGÚN LA PERTENENCIA A LA DENOMINACIÓN DE ORIGEN

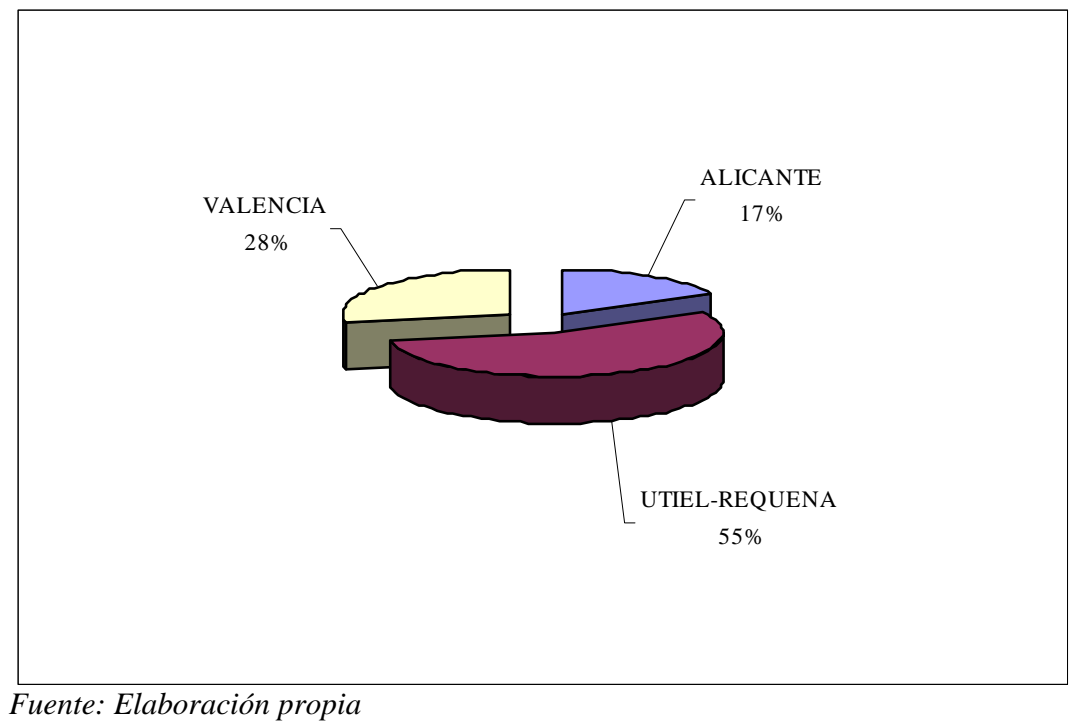

Cruzando entre sí las variables consideradas, es importante destacar los siguientes aspectos.

En el caso de las sociedades mercantiles, el 60 \% son jóvenes con una edad media de 33 años; en las sociedades cooperativas de $\mathbf{1}^{\circ}$ grado, el $91 \%$ son antiguas con 48 años de edad; la totalidad de las sociedades cooperativas de $\mathbf{1}^{\circ}$ grado socios de cooperativas de $2^{\mathbf{0}}$, son antiguas con 57 años y llevan prácticamente la mitad de su vida constituidas como socias de las cooperativas de $2^{\circ}$ grado. Una posible interpretación a este comportamiento habría que buscarla en el periodo mínimo de maduración que necesitan éstas cooperativas base para tomar la decisión de constituirse en cooperativas de $2^{\circ}$ grado.

Son antiguas empresas, la totalidad de las muy grandes empresas, el $84 \%$ tanto de las grandes como de las medianas, el $60 \%$ de las pequeñas empresas, más de la 
mitad de las bodegas pertenecientes a la DO de Alicante y Utiel-Requena, y más de las dos terceras partes de la DO Valencia. Cerca del 70 \% de las jóvenes empresas son muy pequeñas empresas.

Son muy pequeñas empresas, cerca del $90 \%$ de las personas físicas, alrededor del $60 \%$ tanto de las sociedades agrarias de transformación como de las sociedades mercantiles, y casi el $60 \%$ de las bodegas pertenecientes a la DO Alicante. Son medianas empresas más del $50 \%$ sociedades cooperativas de $1^{\circ}$ grado socios de cooperativas de $2^{\circ}$ grado.

Se encuentran dentro de la DO Utiel-Requena, la totalidad de las sociedades agrarias de transformación y más de la mitad de: las sociedades cooperativas de $1^{\text {o }}$ grado, de las sociedades cooperativas de $1^{\circ}$ grado socios de cooperativas de 2 , y de las sociedades mercantiles.

Existe una sociedad cooperativa de $\mathbf{2}^{\mathbf{0}}$ grado en cada una de las tres denominaciones de origen mencionadas, aunque solo en la de Valencia el tamaño es grande, ya que elabora conjuntamente el vino de las sociedades cooperativas de $1^{\circ}$ grado asociadas. En el resto de las denominaciones de origen las sociedades cooperativas de $2^{\circ}$ grado presentan un tamaño medio y pequeño, ya que solo se dedican a concentrar homogeneizar, embotellar y comercializar una parte relativamente pequeña de las producciones de sus asociados.

\section{APROVISIONAMIENTO DE MATERIA PRIMA PRINCIPAL}

En este apartado se tratan aspectos relacionados con al estructura varietal de la uva como materia prima principal en la elaboración del vino, el grado de integración vertical hacia atrás que presentan las bodegas, y el método de fijación de l precio para las uvas.

\subsection{Estructura varietal}

Los factores naturales determinantes de la producción vitícola son clima, suelo y material vegetal. El genotipo empleado adquiere un papel estratégico si se considera que puede ser escogido libremente por el viticultor, a diferencia de los otros dos factores ambientales que están prácticamente definidos y son poco modificables por el hombre. Cada variedad posee unas características específicas cuya expresión puede ser modulada por los otros elementos naturales (clima y suelo), por técnicas de cultivo (densidad, poda, conducción, riego, protección contra plagas y enfermedades, elección de la fecha de vendimia, etc.) y técnicas enológicas, de manera que una misma variedad podrá dar productos diferentes, según la combinación de los factores de producción vitícola y enológica elegidos.

La disponibilidad de un amplio y diversificado patrimonio genético original utilizable por los viticultores, constituye por tanto, una importante riqueza explotable para la obtención de vinos de calidad cada vez más típicos y diferenciados. El reto tradicional de la viticultura de calidad ha sido el de la producción de uva de la más alta calidad. La evolución de la vitivinicultura mundial en los últimos años ha producido, 
por un lado, una mejora generalizada de los vinos y, por otro una pérdida de la originalidad que los liga a la zona de producción.

Esta tendencia general conduce, con la excepción de algunos grandes vinos, hacia productos indudablemente buenos, pero de gusto estandarizado, en abierta concurrencia entre ellos y donde el único elemento de diferenciación es el precio. La única forma de salir de esta espiral es la de producir vinos con perfiles de calidad peculiares ligados ala territorio y diferenciando más los productos.

En los últimos años están adquiriendo notoriedad los denominados vinos de "alta expresión”, que manifiesten hasta su máximo concepto las características de la variedad y de la zona o "terroir”. El carácter de una variedad ayuda a definir el perfil de un vino y determina su personalidad, en función de la adaptación al hábitat de la zona (clima y suelo.) Por tanto el reto actual de la viticultura no es sólo producir uva de la más alta calidad sino que, además ha de conseguir mayores cotas de diversidad, diferenciación y tipicidad.

La competitividad del sector a escala regional debe fundamentarse en las posibilidades de diferenciación que aporta la variedad de vid, y en el aprovechamiento de las variedades minoritarias y/o autóctonas, que pese a que están despreciadas o desvalorizadas en la viticultura actual, pueden aportar a los vinos las suficientes características diferenciales como para hacerlos singulares e irrepetibles; en definitiva, extraer el máximo potencial de la uva para conseguir la máxima expresión de calidad en el vino. Por otro lado, desde el punto de vista de la estrategia de marketing, el producto (del cual la variedad es un elemento emblemático) tiene una importancia fundamental, ya que en la producción de un buen vino es elemento necesario aunque no suficiente el disponer de una buena materia prima.

El colectivo vitícola de la región lo configuran gran número de variedades, todas pertenecientes al género Vitis y a la especie vinífera (L.) Según datos de la Organización Internacional de la Viña y del Vino, en el mundo se encuentran catalogadas 136 variedades.

El Reglamento (CE) 1493/1999, por el que se establece la organización común del mercado vitivinícola, dispone, que los estados miembros clasificarán las variedades de vid destinadas a la producción de vino. El Real Decreto1472/2000, por el que se regula el potencial de producción vitícola, establece las definiciones y categorías de clasificación relativas a las variedades de vid. En lo que se refiere a variedades de vinificación, destinadas a a la elaboración de vino para el consumo humano directo, establece dos categorías de variedades:

- Variedades recomendadas. Las que produzcan normalmente vinos cuya buena calidad esté reconocida.

- Variedades autorizadas. Las que produzcan un vino cabal y comercial cuya calidad no alcance a la del vino elaborado con las variedades recomendadas.

La Comunidad Autónoma Valenciana, en virtud de sus competencias ha efectuado la clasificación de las variedades de vid en el ámbito de su territorio, de 
acuerdo con las necesidades de su viticultura, y en base a ello autorizan a las Denominaciones de Origen que les son de su competencia, a elaborar las listas de variedades a partir de las cuales deben elaborarse los vinos por ellas amparados.

Otra característica interesante de analizar, es el origen de las variedades, para lo cual se han establecido dos categorías de variedades:

- Variedades autóctonas. Las originarias de la Comunidad Valenciana, ancestralmente adaptadas a su complejo edafo-climático.

- Variedades adaptadas. Aquellas adaptadas y cultivadas en la región con mayor o menor grado de adaptabilidad y antigüedad. Normalmente se trata de variedades de éxito ya contrastado en el exterior y utilizadas en la región como variedades mejorantes, bien como varietales o en coupage con las variedades autóctonas.

En el cuadro 5.1 puede observarse una estructura varietal muy concentrada en unas pocas variedades, ya que la participación en tonelaje total $(282.624 \mathrm{tm})$ de las cuatro variedades principales (bobal, tempranillo, monastrell, y tintorera) supera el 80\%, correspondiendo a la primera el $49 \%$; por otro lado, el $57 \%$ de las variedades minoritarias supone solamente el $3 \%$ de la producción. Respecto al número de variedades presentes, la cifra de 24 podría calificarse como medianamente diversificada.

La DO Utiel Requena concentra cerca del $97 \%$ y $71 \%$ de las variedades bobal y tintorera respectivamente; la de Alicante cerca del $68 \%$ del total de monastrell, y la de Valencia el $46 \%$ del tempranillo.

Referente a la clasificación de variedades, el 71 \% en número y 96,8 \% en producción son recomendadas, lo cual resulta muy positivo desde el punto de vista de la calidad final de los productos.

El origen de las variedades es mayoritariamente autóctono, el $71 \%$ en número y 86,5 \% en tonelaje, aspecto también interesante desde el punto de vista de las ventajas que se derivan de la elevada adaptabilidad (rendimiento elevados, mayor control enológico, etc.) cuando se combina con una introducción de variedades mejorantes (más adaptadas a los gustos del consumidor).

En las jóvenes empresas las variedades adaptadas representan un $28 \%$ de su producción, seguidas de las de edad media y las antiguas, debido probablemente a que aquellas nacen con una mayor orientación al mercado. También se ha constatado que estas variedades elevan considerablemente su representación respecto a la media del conjunto (13,5 \% en tonelaje de variedades alóctonas) en la Denominación de Origen Valencia y en las muy pequeñas empresas.

Resaltar que, de las ocho variedades adaptadas, seis son recomendadas suponiendo menos del 0,5 \% del total de producción de aquellas. 
CUADRO 5.1

\section{DISTRIBUCIÓN PORCENTUAL DE LAS VARIEDADES DE VID SEGÚN SU CLASIFICACIÓN Y ORIGEN}

\begin{tabular}{|l|r|r|l|l|}
\hline \multicolumn{1}{|c|}{ VARIEDAD } & tm & \% DEL TOTAL & CLASIFICACIÓN & ORIGEN \\
\hline BOBAL & 138.045 & 48,844 & Recomendada & Autóctona \\
\hline TEMPRANILLO & 35.099 & 12,419 & Recomendada & Adaptada \\
\hline MONASTRELL & 28.542 & 10,099 & Recomendada & Autóctona \\
\hline TINTORERA & 26.431 & 9,352 & Recomendada & Autóctona \\
\hline MACABEO & 12.496 & 4,421 & Recomendada & Autóctona \\
\hline MOSCATEL & 8.389 & 2,968 & Recomendada & Autóctona \\
\hline MERSEGUERA & 7.602 & 2,690 & Recomendada & Autóctona \\
\hline PLANTA NOVA & 6.259 & 2,215 & Autorizada & Autóctona \\
\hline GARNACHA & 5.040 & 1,783 & Recomendada & Autóctona \\
\hline MALVASIA & 4.892 & 1,731 & Recomendada & Autóctona \\
\hline ROYAL & 1.937 & 0,685 & & Autóctona \\
\hline MERLOT & 1.883 & 0,666 & Recomendada & Adaptada \\
\hline FORCALLAT & 1.820 & 0,644 & & Autóctona \\
\hline AIREN & 1.438 & 0,509 & Autorizada & Autóctona \\
\hline TORTOSÍ & 1.188 & 0,420 & Autorizada & Autóctona \\
\hline C.SAUVIGNON & 934 & 0,330 & Recomendada & Adaptada \\
\hline P. XIMENEZ & 323 & 0,114 & Recomendada & Autóctona \\
\hline SYRAH & 126 & 0,044 & Autorizada & Adaptada \\
\hline CHARDONAY & 78 & 0,028 & Recomendada & Adaptada \\
\hline PINOT NOIR & 30 & 0,011 & Recomendada & Adaptada \\
\hline VERDIL & 22 & 0,008 & Autorizada & Autóctona \\
\hline BONICAIRE & 19 & 0,007 & Autorizada & Autóctona \\
\hline PARELLADA & 15 & 0,005 & & Autóctona \\
\hline SAUVIGNON BLANC & 15 & 0,005 & Autorizada & Adaptada \\
\hline TOTAL & $\mathbf{1 0 0 , 0 0 0}$ & & \\
\hline FO2.624 & & & \\
\hline & & & \\
\hline
\end{tabular}

Fuente: Elaboración propia

\section{$2.2 \quad$ Integración vertical hacia atrás}

Los distintos niveles de integración considerados han sido los siguientes:

UP : Elaboración con uva propia.

UA_CC: Elaboración con uva ajena con acuerdos o contratos compra.

UA_SC: Elaboración con uva ajena sin acuerdos o contratos compra.

VA_CC: Elaboración con vino ajeno con acuerdos o contratos compra.

VA_SC: Elaboración con vino ajeno sin acuerdos o contratos compra .

En el gráfico 5.5 aparece la distribución porcentual del volumen comercializado en hl, en función de los cinco niveles de integración definidos, constatándose que más de las dos terceras partes de dicho volumen procede de uvas propias con un grado de integración máximo, seguida de la opción vino adquirido sin contratos, que supone la mitad del tercio restante. 


\section{GRAFICO 5.5}

\section{DISTRIBUCIÓN PORCENTUAL DE LA PRODUCCIÓN (hl) POR NIVELES DE INTEGRACIÓN VERTICAL HACIA ATRÁS}

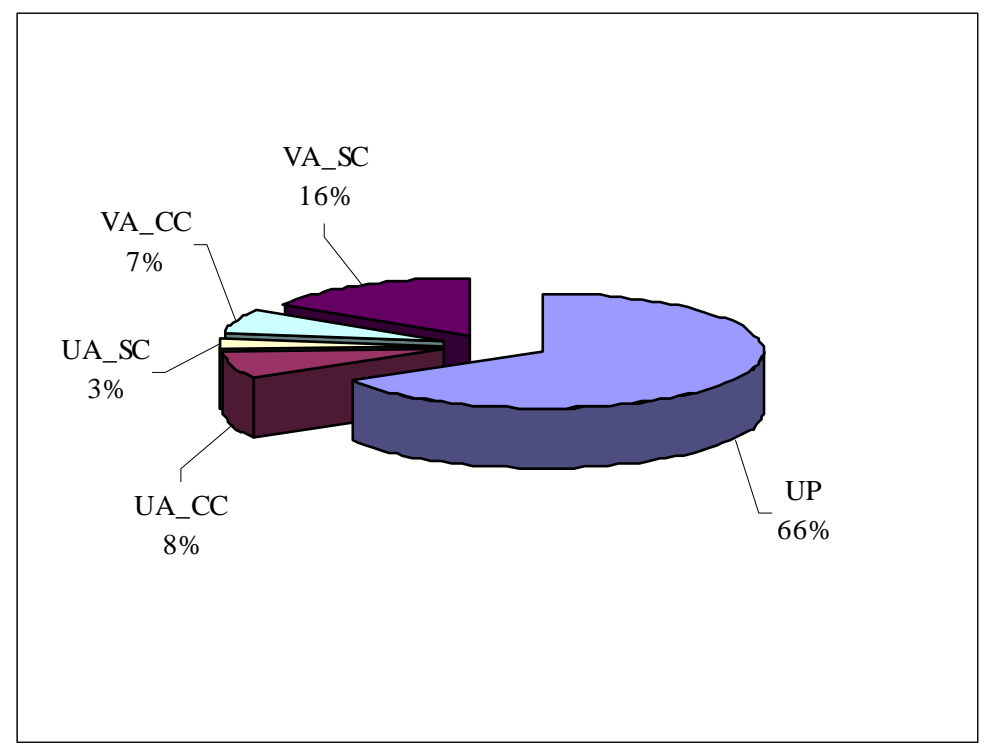

Fuente: Elaboración propia

Aplicando la fórmula a las empresas encuestadas, se obtiene un grado de integración medio del 76, el cual puede calificarse de notable, lo que es muy positivo si se tienen en cuenta todas las ventajas comentadas anteriormente.

Las empresas antiguas presentan el mayor grado de integración vertical hacia atrás (77), seguidas a cierta distancia de las jóvenes (68) y medianas (63).

Las empresas de la DO Alicante presentan el mayor grado de integración (77), seguidas muy de cerca por las de Utiel-Requena (76) y Valencia (7).

Las sociedades cooperativas de $1^{\circ}$ grado asociadas a las de $2^{\circ}$ grado exhiben lógicamente el mayor grado de integración (cerca del 99), seguidas muy de cerca por las de $1^{\circ}$ grado (98), contrastando con el menor valor observado en las mercantiles (33). Entre los socios y la cooperativa se establecen flujos de mercancías, financieros, de información y decisión que circulan en ambas direcciones, por lo que las estructuras empresariales cooperativas, facilitan la superación de algunos problemas derivados d la fragmentación en las primeras fases de la cadena de producción.

Respecto al tamaño empresarial, las de mayor integración son medianas (93) y grandes (88), y las de menor grado las muy grandes (50).

Estos resultados son coherentes con la realidad observada dentro de la fase elaboradora de vinos, en el sentido de que las muy grandes empresas con forma jurídica de sociedad mercantil compran vino a granel para embotellarlo, previo tratamiento, mezcla y tipificación; por otro lado, las empresas muy pequeñas mayoritariamente 
jóvenes con forma jurídica sociedad mercantil generalmente compran el vino a granel para embotellarlo, previo envejecimiento.

\subsection{Fijación del precio de la uva}

Hasta los años 1980 la forma de fijación del precio para las uvas ha sido de manera generalizada, el contenido en azúcares que está directamente relacionado con el contenido de alcohol en el vino. En la comercialización de vinos a granel el hectógrado (hectólitro grado) es el elemento actualmente utilizado para fijar el valor de las producciones. Este criterio ha propiciado que históricamente los viticultores se decantasen hacia variedades altamente productivas y hacia vendimias con cierta sobremaduración, no orientadas al concepto actual de calidad.

En la década de los 80 se generaliza el uso del refractómetro para la determinación de la densidad y grado de alcohol probable, y se introducen penalizaciones y mejoras para tratar de mejorar la estimación de dicha calidad. En la década de los 90 se comienza a hacer distinciones en función de las variedades y del estado sanitario y se empieza a manejar el concepto de "maduración fenólica".

En los años 2000 y teniendo en cuenta la relevancia de los polifenoles y resto de sustancias aromáticas en las características organolépticas de los vinos (principalmente color, olor y sabor) y en definitiva en la calidad intrínseca de los mismos, se ha observado una apuesta decidida por su determinación, aunque todavía disponible se encuentra en las primeras fases de desarrollo a escala práctica. Se está conforme con el criterio de fijación del precio para las uvas más ajustado al concepto de calidad intrínseca, pero aún no se cuenta con sistemas suficientemente rápidos y precisos en bodega para poder determinar los polifenoles, no solamente desde el punto de vista cuantitativo, sino de su capacidad ulterior de polimerización. En este sentido se observa la introducción de potentes analizadores en las bodegas con el objetivo de mejorar la estimación rápida de la calidad de la uva en fase de recepción.

Por otro lado se observa una preocupación creciente por la selección de uvas de calidad tintas, que son las que presentan el mayor potencial de demanda, por lo que las características de calidad de uva y vino más interesantes son el color y el aroma cuyos compuestos responsables principales son también los polifenoles. En este sentido es posible evaluar el potencial de las uvas para producir vinos de calidad midiendo el color que éstas pueden proporcionar al vino, lo que se denomina "color probable"; no obstante se necesitan métodos analíticos fiables, capaz de establecer una correlación entre el color de la uva y del vino resultante, lo cual hoy por hoy se encuentra en estado de experimentación.

Existe un consenso generalizado dentro del sector vinícola sobre el interés de los polifenoles como factor determinante de la calidad de la uva, aunque sin dejar de lado la importancia de la maduración en cuanto a la riqueza en azúcares naturales, acidez (fija y total), $\mathrm{pH}$, estado sanitario y calidad varietal del racimo.

De acuerdo con la información que proporcionen estos métodos, podría ser pagada la uva al viticultor según la calidad y no sólo en función de los grados de azúcar. 
Para ello se podría añadir al precio tradicional por grados de azúcar o Baumé, un plus de calidad según el color o aroma probable que tendrá el vino, lo que induciría al agricultor a producir uvas de calidad, en detrimento de la cantidad, ya que éstos dos parámetros son opuestos.

Teniendo en cuenta las consideraciones expuestas, los controles considerados en la encuesta como criterios de fijación del precio de la uva han sido:

- AZÚCAR: Control del grado de azúcares.

- VARIETAL: Control varietal.

- SANITARIO: Control sanitario.

- FENÓLICO: Control fenólico.

En el gráfico 5.6 se refleja que casi las tres cuartas partes de las empresas utilizan el control de azúcares como forma de fijación del precio para las uvas, lo cual prima al agricultor que usa técnicas de cultivo que favorecen el rendimiento (riego y fertilizantes principalmente), en detrimento de aquellos que aportan mejores calidades varietales, que normalmente dan menores rendimientos pero con mejores índices de polifenoles, principales responsables de la calidad organoléptica.

\section{GRÁFICO 5.6}

\section{PORCENTAJE DE EMPRESAS SEGÚN EL TIPO DE CONTROL SEGUIDO PARA LA FIJACIÓN DEL PRECIO DE LA UVA}

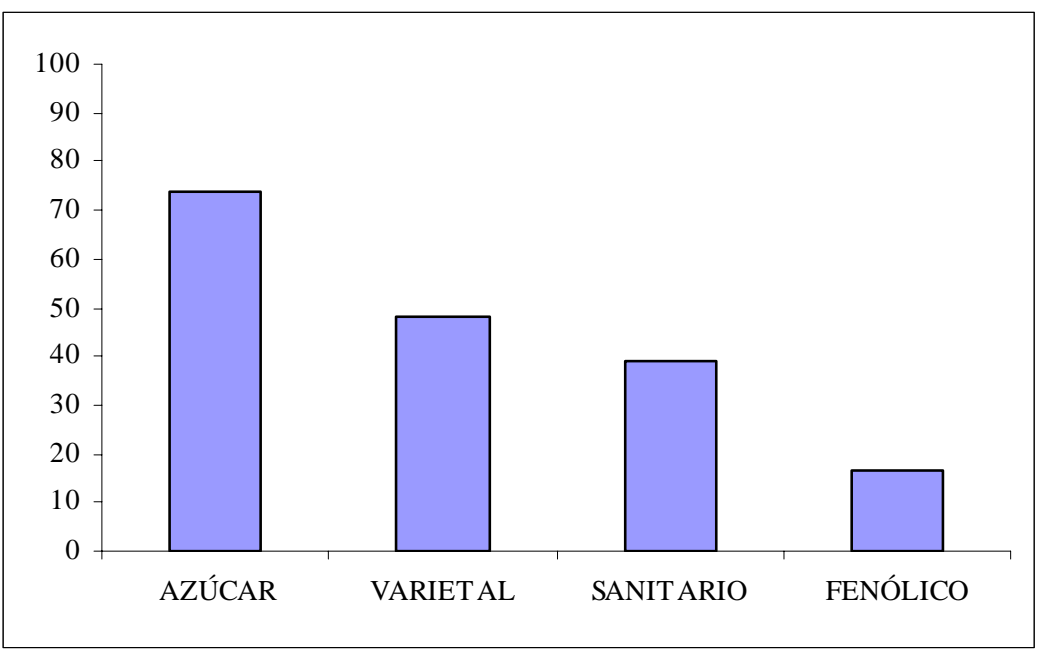

Fuente: Elaboración propia

El control por grado de azúcar predomina, con valores por encima de la media apuntada, en las empresas antiguas, en sociedades cooperativas, en las grandes y medianas empresas y, en la DO Valencia. También se ha observado que este tipo de control es menos frecuente a medida a que disminuye la edad de las empresas.

Los controles varietal y sanitario, los realizan el 48 \% y 39 \% respectivamente, de las empresas y predominan en las bodegas con la forma jurídica de personas físicas, en las muy grandes y en las pertenecientes a la DO Valencia. 
El control fenólico tiene una baja representación en las bodegas, ya que sólo el $16 \%$ de éstas llevan a cabo algún análisis en mayor o menos relación con los polifenoles. Resaltar que, el control es más frecuente conforme disminuye la edad de las empresas, en las mercantiles y en las muy grandes empresas.

\section{PRODUCCIÓN COMERCIALIZADA EN VOLUMEN}

En este apartado se ha analizado la producción comercializada de vino en volumen, dentro del ámbito de todas las empresas encuestadas de la Comunidad Valenciana. Antes de realizar el análisis de la producción comercializada por las bodegas es necesario señalar que éstas presentan peculiaridades, en el sentido de que se trata de empresas que a pesar de estar inscritas la totalidad de ellas en alguna Denominación de Origen (DO), comercializan vino con DO y de mesa, así como embotellado y a granel; dichas posibilidades se han recogido en el presente estudio.

En relación al producto comercializado, como ya se ha dicho anteriormente, se han considerado de toda la gama de productos vinícolas, los vinos secos (no dulces) y tranquilos (sin gas). Respecto al tipo de vino, el estudio recoge los siguientes tipos: blanco, rosado, tinto, crianza y reserva.

Referente a la forma de comercialización del producto se ha tenido en cuenta la presentación en granel o embotellado y, en cuanto al nivel de protección del producto se ha efectuado distinción entre, si el vino comercializado se encuentra amparado por alguna DO o simplemente se trata de vino de mesa. En este sentido las distintas segmentaciones o posibilidades distintas de comercialización, a que dan lugar estos considerandos son las siguientes:

- Vino comercializado con DO embotellado.

- Vino comercializado con DO a granel.

- Vino comercializado de mesa embotellado.

- Vino comercializado de mesa a granel.

De aquí en adelante cuando se hable de producción, se entenderá siempre referida a la producción comercializada.

\subsection{Producción comercializada total}

Respecto del número total de empresas que han comercializado vino, que ascienden a 104 (6 empresas de reciente creación todavía no han comercializado su producción), destacar:

- $\quad$ El $84 \%$ han comercializado vino a granel.

- El $51 \%$ han comercializado vino embotellado.

- El 63 \% han comercializado vino de mesa.

- El $85 \%$ han comercializado vino con DO.

- El 59 \% han comercializado vino de mesa a granel.

- El 64 \% han comercializado vino con DO a granel. 
- $\quad$ El $14 \%$ han comercializado vino de mesa embotellado.

- El 48 \% han comercializado vino con DO embotellado.

La producción media comercializada por empresa es próxima a $27.220 \mathrm{hl}$, correspondiendo en el caso de la comercialización de mesa a granel (22.767 hl), la cual se reduce aproximadamente a la mitad en cada una de las tres posibilidades de comercialización mencionadas restantes.

La producción comercializada total (cuadro 5.2) asciende a $2.830840 \mathrm{hl}$, de la cual casi el $50 \%$ es vino de mesa a granel, seguido del $25 \%$ con DO a granel, lo que supone que casi un $75 \%$ de vino sea comercializado a granel. El vino con DO embotellado asciende aproximadamente al $19 \%$, y el restante $5 \%$ se comercializa como vino de mesa embotellado.

Por tipos de vino, más de las dos terceras partes se trata de vino tinto, secundados por el blanco y rosado crianza y reserva, con un $16 \%$, $13 \%$, 3 \% y $1 \%$ del total de producción respectivamente.

Tanto en rosado y tinto, el vino de mesa a granel supera el $50 \%$ seguidos del DO a granel con más del $20 \%$ en ambos tipos de vino. En vinos blancos el de DO aumenta hasta el $61 \%$, en detrimento del vino de mesa a granel, que disminuye hasta el $35 \%$.

CUADRO 5.2

DISTRIBUCIÓN DE LA PRODUCCIÓN COMERCIALIZADA (hl) SEGÚN LA FORMA DE COMERCIALIZACIÓN, CALIFICACIÓN Y TIPOS DE VINO

\begin{tabular}{|c|c|c|c|c|c|c|}
\hline FORMA DE & \multicolumn{5}{|c|}{ TIPO DE VINO } & \\
\hline COMERCIALIZAR & BLANCO & ROSADO & TINTO & CRIANZA & RESERVA & TOTAL \\
\hline DO EN BOTELLA & 128.180 & 56.720 & 267.817 & 77.973 & 31.723 & 562.413 \\
\hline DO A GRANEL & 148.692 & 80.718 & 481.045 & 0 & 0 & 710.455 \\
\hline MESA EN BOTELLA & 16.605 & 8.292 & 144.292 & 0 & 0 & 169.189 \\
\hline MESA A GRANEL & 159.153 & 214.879 & 1.014 .751 & 0 & 0 & 1.388 .783 \\
\hline TOTAL & 452.630 & 360.609 & 1.907 .905 & 77.973 & 31.723 & 2.830 .840 \\
\hline
\end{tabular}

\subsection{Producción comercializada según la Denominación de Origen}

En este apartado se efectuará un análisis de la producción comercializada (cuadros 5.3 y 5.4), según la forma de comercialización del vino (granel o embotellado), la calificación del vino (mesa o DO), el tipo de vino (blanco, rosado, tinto, crianza y reserva) y DDOO existentes (Alicante, Utiel-Requena y Valencia). 5.3):

La DO Utiel-Requena presenta las características básicas siguientes (cuadro

- El $67 \%$ de las empresas venden vino de mesa a granel, seguido del DO a granel (58 \%), DO embotellado (47 \%) y mesa embotellado (4 \%). 
- La producción media por empresa es de 34.317 hl con máximos en el caso del vino de mesa embotellado (cerca de 50.000 hl) y, mínimos en el caso de vinos con DO (entorno a 11.000 hl.).

- Concentra una producción anual de 1.887.411 hl, lo que supone más de las dos terceras partes de la producción total regional. Participa con un $51 \%$ tanto en el vino embotellado como en el vino con DO total regional.

- Por tipos de vinos, agrupa respecto del total regional, el $34 \%$ del vino blanco, el $81 \%$ del vino rosado, el $71 \%$ del vino tinto, el 86\% de crianza, y el $54 \%$ del reserva.

- El $60 \%$ de la producción es vino de mesa a granel, seguido del DO a granel (20\%), DO embotellado (15\%) y mesa embotellado (5 \%). El $72 \%$ de la producción es vino tinto (cuadro 5.4), secundados por el rosado, blanco, crianza y reserva.

- Más de la tercera parte de las bodegas envejecen vinos de crianza, con una producción del 86 \% del total regional; la cuarta parte de las bodegas producen reserva, lo que representa en producción, más del $50 \%$ del total regional.

\section{CUADRO 5.3}

DISTRIBUCIÓN DE LA PRODUCCIÓN (hl) SEGÚN LA FORMA DE COMERCIALIZACIÓN, CALIFICACIÓN Y DENOMINACIONES DE ORIGEN

\begin{tabular}{|l|r|r|r|r|}
\hline \multirow{2}{*}{$\begin{array}{c}\text { FORMA DE } \\
\text { COMERCIALIZAR }\end{array}$} & \multicolumn{2}{|c|}{ DENOMINACIÓN DE ORIGEN } & \multirow{2}{*}{ TOTAL } \\
\cline { 2 - 4 } & ALICANTE & UTIEL-REQ & VALENCIA & \\
\hline DO EN BOTELLA & 48.938 & 274.729 & 238.746 & 562.413 \\
\hline DO A GRANEL & 112.239 & 378.692 & 219.524 & 710.455 \\
\hline MESA EN BOTELLA & 6.823 & 99.876 & 62.490 & 169.189 \\
\hline MESA A GRANEL & 67.669 & 1.134 .114 & 187.000 & 1.388 .783 \\
\hline TOTAL & 235.669 & 1.887 .411 & 707.760 & 2.830 .840 \\
\hline Fuente: Elaboración propia.
\end{tabular}

La DO Valencia presenta las características básicas siguientes (cuadro 5.3):

- El $71 \%$ de las empresas venden vino con DO a granel, seguido del DO embotellado (54 \%), mesa a granel (52\%) y mesa embotellado (36 \%).

- La producción media por empresa es de 22.831 hl con máximos en el caso del vino con DO embotellado (14.044 hl) y, mínimos en el caso de vinos de mesa embotellados (5.681 hl).

- Concentra una producción anual de 707.760 hl, lo que supone una cuarta parte de la producción total regional. Participa con el $42 \%$ del vino embotellado total, así como en el 36 \% del vino comercializado con DO total regional. 
- Por tipos de vino agrupa respecto del total regional el $62 \%$ del vino y el $36 \%$ del vino reserva.

- El 65 \% de la producción es vino con DO, distribuido casi a partes iguales entre la forma embotellado y granel, seguidos del mesa a granel (26 \%) y del mesa embotellado (9\%).

- Algo más del 50 \% de la producción es vino tinto (cuadro 4.4), secundados por el blanco (40\%), rosado, reserva y crianza.

- Cerca del 40 \% de las bodegas envejecen vinos de crianza, con una producción del $8 \%$ del total regional; casi la cuarta parte de las bodegas producen reserva, lo que representa en producción, más de la tercera parte del total regional.

\section{CUADRO 5.4}

DISTRIBUCIÓN DE LA PRODUCCIÓN (hl) SEGÚN LAS DENOMINACIONES DE ORIGEN Y TIPOS DE VINO

\begin{tabular}{|c|c|c|c|c|c|c|}
\hline \multirow{2}{*}{$\begin{array}{c}\text { DENOMINACIÓN } \\
\text { DE ORIGEN }\end{array}$} & \multicolumn{5}{|c|}{ TIPO DE VINO } & \\
\hline & BLANCO & ROSADO & TINTO & CRIANZA & RESERVA & TOTAL \\
\hline ALICANTE & 19.818 & 19.919 & 187.884 & 4.985 & 3.063 & 235.669 \\
\hline UTIEL-REQUENA & 152.213 & 291.946 & 1.359 .064 & 67.044 & 17.144 & 1.887 .411 \\
\hline VALENCIA & 280.599 & 48.744 & 360.957 & 5.944 & 11.516 & 707.760 \\
\hline TOTAL & 452.630 & 360.609 & 1.907 .905 & 77.973 & 31.723 & 2.830 .840 \\
\hline
\end{tabular}

Fuente: Elaboración propia.

En la DO Alicante las características básicas de esta figura de calidad son las siguientes (Cuadro 5.4):

- El $67 \%$ de las empresas venden vino con DO a granel, el $44 \%$ de mesa a granel, el 39 \% con DO embotellado, y el 6 \% como mesa embotellado.

- La producción media por empresa supera los $13.000 \mathrm{hl}$ con máximos en el caso del vino con DO a granel (más de $9.000 \mathrm{hl}$ ), y mínimos en el caso de vinos de mesa embotellados (por debajo de $7.000 \mathrm{hl}$ ).

- Concentra una producción anual de 235.669 hl, lo que supone algo más del 8 \% de la producción total regional. Participa con el 7 \% del vino embotellado total, así como en el $13 \%$ del vino comercializado con DO total regional.

- Cerca del 69\% de la producción es vino con DO (48 \% a granel y $21 \%$ embotellado), seguidos del mesa a granel (29\%) y de mesa embotellado (cerca del $3 \%$ ).

- Casi el 80 \% de la producción es vino tinto (cuadro 5.4), secundados por el rosado y blanco (algo más del 8 \% cada uno), reserva y crianza. 
- Más del 30 \% de las bodegas envejecen vinos de crianza, y el 16 \% elaboran vinos de reserva, con una producción del $6 \%$ del total regional en el primer caso y próxima al $10 \%$ en éste último.

\subsection{Producción comercializada según el tamaño empresarial}

Si se mide la concentración de la producción comercializada por el índice CR4, es decir la cuota de mercado de las cuatro primeras bodegas respecto al total de producción, se obtiene un valor por debajo del $30 \%$, lo cual indica que se trata de un sector poco concentrado.

Es notorio que el $44 \%$ de las empresas no concentren ni el $4 \%$ de la producción o que casi las tres cuartas partes de las empresas acaparen poco más de la cuarta parte de la producción comercializada, circunstancia que refleja el elevado grado de atomización de la industria vinícola, con las graves desventajas que este hecho lleva aparejadas, en relación con la competitividad de las empresas.

Si se efectúa un análisis de la producción comercializada, considerando la forma de comercialización del vino (granel o embotellado), la calificación del vino (mesa o DO), el tipo de vino (blanco, rosado, tinto, crianza y reserva) y el tamaño de las empresas (muy grande, grande, mediana, pequeña y muy pequeña), según se refleja en los cuadros 5.5 y 5.6, los principales aspectos a destacar se comentan a continuación.

\section{CUADRO 5.5}

DISTRIBUCIÓN DE LA PRODUCCIÓN COMERCIALIZADA(hl) SEGÚN LA FORMA DE COMERCIALIZACIÓN, CALIFICACIÓN Y TAMAÑO EMPRESARIAL

\begin{tabular}{|l|r|r|r|r|r|r|}
\hline \multirow{2}{*}{$\begin{array}{c}\text { FORMA DE } \\
\text { COMERCIALIZAR }\end{array}$} & \multicolumn{5}{|c|}{ TAMAÑO DE LA EMPRESA } & \multirow{2}{*}{ TOTAL } \\
\cline { 2 - 6 } & M GRANDE & GRANDE & MEDIANA & PEQUEÑA & M PEQUEÑA & \\
\hline DO EN BOTELLA & 200.936 & 238.182 & 26.881 & 86.760 & 9.654 & 562.413 \\
\hline DO A GRANEL & 156.831 & 293.027 & 112.407 & 109.713 & 38.477 & 710.455 \\
\hline MESA EN BOTELLA & 95.601 & 46.250 & 0 & 22.060 & 5.278 & 169.189 \\
\hline MESA A GRANEL & 305.264 & 749.513 & 141.319 & 167.859 & 24.828 & 1.388 .783 \\
\hline TOTAL & 758.632 & 1.326 .972 & 280.607 & 386.392 & 78.237 & 2.830 .840 \\
\hline
\end{tabular}

Fuente: Elaboración propia.

\section{Empresas muy grandes}

- La totalidad de estas empresas (cuatro de la muestra) venden vino con DO, ya sea embotellado o a granel.

- La producción media por empresa es de 189.658 hl con máximos en el caso del vino de mesa a granel (más de 100.000 hl) y, mínimos en el caso de vinos con DO a granel (menos de $40.000 \mathrm{hl}$ ).

- Concentran una producción de 758.632 hl, (casi una cuarta parte de la producción regional), encontrándose aproximadamente repartida entre vino 
con DO al $47 \%$ y vino de mesa en un porcentaje del $53 \%$. Participan con el $28 \%$ del vino embotellado total, así como en el $40 \%$ del vino comercializado con DO total regional.

- Por tipos de vino, respecto del total regional agrupan el $71 \%$ del vino de crianza. Las cuatro empresas envejecen vinos, tanto de crianza, como de reserva, reuniendo más del $70 \%$ del vino de crianza regional y tan solo el $8 \%$ del vino de reserva regional.

\section{CUADRO 5.6}

DISTRIBUCIÓN DE LA PRODUCCIÓN COMERCIALIZADA (hl) SEGÚN EL TAMAÑO EMPRESARIAL Y TIPOS DE VINO

\begin{tabular}{|c|c|c|c|c|c|c|}
\hline \multirow{2}{*}{$\begin{array}{c}\text { TAMAÑO } \\
\text { EMPRESARIAL }\end{array}$} & \multicolumn{5}{|c|}{ TIPO DE VINO } & \multirow[t]{2}{*}{ TOTAL } \\
\hline & BLANCO & ROSADO & TINTO & CRIANZA & RESERVA & \\
\hline MUY GRANDE & 91.036 & 84.408 & 525.235 & 55.418 & 2.535 & 758.632 \\
\hline GRANDE & 240.120 & 221.647 & 847.018 & 6.360 & 11.827 & 1.326 .972 \\
\hline MEDIANA & 38.653 & 31.209 & 194.498 & 6.903 & 9344 & 280.607 \\
\hline PEQUEÑA & 68.959 & 17.483 & 286.368 & 6.759 & 6823 & 386.392 \\
\hline MUY PEQUEÑA & 13.862 & 5.862 & 54.786 & 2.533 & 1.194 & 78.237 \\
\hline TOTAL & 452.630 & 360.609 & 1.907 .905 & 77.973 & 31.723 & 2.830 .840 \\
\hline
\end{tabular}

\section{Empresas grandes}

- El 96 \% de las bodegas grandes comercializan vino de mesa a granel.

- La producción media por empresa es de 53.079 hl con máximos en el vino de mesa a granel (más de $31.000 \mathrm{hl}$ ) y, mínimos en el caso de vinos de mesa embotellados (menos de $12.000 \mathrm{hl}$ ).

- Estas bodegas concentran una producción de 1.326.972 hl, (casi la mitad de la producción regional), correspondiendo al vino de mesa a granel más del 56\%. Participan con el $42 \%$ del vino embotellado total, así como en el $39 \%$ del vino comercializado con DO total regional.

- Aglutinan respecto de la producción regional, el 62 \% del vino rosado, el 53\% del blanco, el $44 \%$ del tinto y el $37 \%$ del reserva (cuadro 5.6).

- Alrededor de la tercera parte de las empresas envejecen vinos, reuniendo el $37 \%$ de la producción de crianza regional.

\section{Empresas medianas}

- Un 82 \% de las bodegas medianas comercializan vino a granel, el 54 \% vino de mesa a granel y, ninguna vino de mesa embotellado. 
- La producción media por empresa es de 25.510 hl con máximos en el vino de mesa a granel (más de $20.000 \mathrm{hl}$ ) y, mínimos en el caso de vinos con DO embotellados (menos de $9.000 \mathrm{hl}$ ).

- Estas bodegas concentran una producción de 280.607 hl, (inferior al $10 \%$ de la producción regional), de la cual el 50 \% es vino de mesa a granel y, el 40\% es DO a granel. Participan con el $11 \%$ del vino embotellado total, así como en el $4 \%$ del vino comercializado con DO total regional.

- Solamente una bodega envejece vino de reserva y cuanta con una producción del 30 \% respecto a la producción de crianza regional.

\section{Empresas pequeñas}

- Un 73 \% de las bodegas pequeñas comercializan vino con DO a granel y, la mitad tanto vino de mesa a granel como vino de mesa embotellado.

- La producción media por empresa es de 14.861 hl, con máximos en el vino de mesa a granel (cerca de $13.000 \mathrm{hl}$ ) y, mínimos en el caso de vinos de mesa embotellados (menos de $6.000 \mathrm{hl}$ ).

- Estas bodegas concentran una producción de 386392 hl, (equivalente al 14 \% de la producción regional), de la cual el $44 \%$ es vino de mesa a granel y, el $29 \%$ es vino con DO a granel. Participan con el $15 \%$ tanto del vino embotellado total, como del vino comercializado con DO total regional.

- Cerca del $30 \%$ de la pequeñas empresas envejecen crianza y menos de la mitad elaboran reserva, si bien la producción en ambos tipos de vino no alcanza el 10 \% respecto a la producción tanto de crianza como de reserva regional.

\section{Empresas muy pequeñas}

- Un 55 \% de las bodegas muy pequeñas comercializan vino con DO embotellado. La producción media por empresa es de 2.059 hl, con máximos en el vino con DO a granel (más de $2.000 \mathrm{hl}$ ) y, mínimos en el caso de vinos con DO embotellados (menos de $1.000 \mathrm{hl}$ ).

- Estas bodegas concentran una producción de $78.237 \mathrm{hl}$ (equivalente a menos del $3 \%$ de la producción regional), de la cual el $49 \%$ es vino con DO a granel $\mathrm{y}$, menos de la tercera parte se trata de vino de mesa a granel. Participan con el $4 \%$ del vino embotellado total, así como en el $2 \%$ del vino comercializado con DO total regional.

- Más del 40 \% de las pequeñas empresas envejecen crianza y el 23 \% elaboran reserva, si bien la producción en ambos tipos de vino no alcanza el $16 \%$ y $4 \%$ respecto a la producción tanto de crianza como de reserva regional. 


\subsection{Producción comercializada según la forma jurídica}

Si se efectúa un análisis de la producción comercializada, considerando la forma de comercialización del vino (granel o embotellado), la calificación del vino (mesa o DO), el tipo de vino (blanco, rosado, tinto, crianza y reserva) y la forma jurídica de las empresas (persona física, sociedad agraria de transformación, sociedad cooperativa de $1^{\circ}$ grado, sociedad cooperativa de $2^{\circ}$ grado, sociedad cooperativa de $1^{\circ}$ grado socia de la de $2^{\circ}$ grado y sociedad mercantil), según se refleja en los cuadros 5.7 y 5.8 los principales aspectos a destacar se comentan a continuación.

\section{CUADRO 5.7}

DISTRIBUCIÓN DE LA PRODUCCIÓN COMERCIALIZADA(hl) SEGÚN LA FORMA DE COMERCIALIZACIÓN, CALIFICACIÓN Y FORMA JURÍDICA EMPRESARIAL

\begin{tabular}{|c|c|c|c|c|c|c|c|}
\hline \multirow{2}{*}{$\begin{array}{c}\text { FORMA DE } \\
\text { COMERCIALIZAR }\end{array}$} & \multicolumn{6}{|c|}{ FORMA JURÍDICA } & \multirow[t]{2}{*}{ TOTAL } \\
\hline & P FISICA & SAT & S COOP & S COOP2 & S COOPS2 & S MERC & \\
\hline DO EN BOTELLA & 2.071 & 464 & 43.403 & 44.670 & 104.690 & 367.115 & 562.413 \\
\hline DO A GRANEL & 10.552 & 9.753 & 225.902 & 29.756 & 312.145 & 122.347 & 710.455 \\
\hline MESA EN BOTELLA & 0 & 0 & 31.203 & 0 & 11.825 & 126.161 & 169.189 \\
\hline MESA A GRANEL & 9.950 & 35.968 & 624.924 & 52.969 & 392.854 & 272.118 & 1.388 .783 \\
\hline TOTAL & 22.573 & 46.185 & 925.432 & 127.395 & 821.514 & 887.741 & 2.830 .840 \\
\hline
\end{tabular}

Fuente: Elaboración propia

\section{Personas físicas}

- El 56 \% de las estas empresas comercializan, tanto vino de mesa a granel, como vino con DO a granel.

- La producción media por empresa es de 2.508 hl, la menor de todas las formas jurídicas.

- Estas bodegas concentran una producción de 22.573 hl (sin alcanzar el $1 \%$ de la producción regional), distribuyéndose casi a partes iguales entre vino blanco y tinto y también equitativamente entre las dos formas de comercialización a granel, lo que supone más del 90 \% de la producción de esta personalidad jurídica.

- El 22 \% de las bodegas personas físicas envasan solo crianza, aunque la participación en la producción comercializada respecto del crianza regional solo supone el 0,22\%.

\section{Sociedades agrarias de transformación (SAT)}

- Un 75 \% de las bodegas comercializan vino con DO a granel. 
- La producción media por empresa es de 11.546 hl con máximos que triplican dicha cifra en el vino de mesa a granel y, mínimos de 232 hl en el caso de vinos con DO embotellados.

- Estas bodegas concentran una producción de 46.185 hl, (inferior al 2 \% de la producción regional), de la cual más del $90 \%$ se vino tinto.

- El 40 \% de las SAT envejecen solo crianza, aunque la participación en la producción comercializada respecto del crianza regional solo supone el $0,12 \%$.

\section{CUADRO 5.8}

DISTRIBUCIÓN DE LA PRODUCCIÓN COMERCIALIZADA (hl) SEGÚN EL TAMAÑO EMPRESARIAL Y TIPOS DE VINO

\begin{tabular}{|l|r|r|r|r|r|r|}
\hline \multirow{2}{*}{$\begin{array}{c}\text { FORMA } \\
\text { JURÍDICA }\end{array}$} & \multicolumn{5}{|c|}{ TIPO DE VINO } & \multirow{2}{*}{ TOTAL } \\
\cline { 2 - 6 } & \multicolumn{1}{|c|}{ BLANCO } & \multicolumn{1}{c|}{ ROSADO } & \multicolumn{1}{c|}{ TINTO } & CRIANZA & RESERVA & \\
\hline P_FISICA & 10.713 & 700 & 10.989 & 171 & 0 & 22.573 \\
\hline SAT & 86 & 3.280 & 42.724 & 95 & 0 & 46.185 \\
\hline S_COOP & 113.667 & 106.386 & 698.465 & 1.827 & 5.087 & 925.432 \\
\hline S_COOP2 & 32.667 & 30.280 & 47.021 & 8.051 & 9.376 & 127.395 \\
\hline S_COOPS2 & 108.963 & 105.938 & 597.338 & 2.515 & 6.760 & 821.514 \\
\hline S_MERCANTIL & 186.534 & 114.025 & 511.368 & 65.314 & 10.500 & 887.741 \\
\hline TOTAL & 452.630 & 360.609 & 1.907 .905 & 77.973 & 31.723 & 2.830 .840 \\
\hline
\end{tabular}

\section{Sociedades cooperativas de $1^{\circ}$ grado (S COOP)}

- Más del 70 \% de las éstas cooperativas comercializan, tanto vino con DO a granel como vino de mesa a granel.

- La producción media por empresa es de 29.853 hl, con valores máximos que rebasan los $27.000 \mathrm{hl}$ en el vino de mesa a granel, y mínimos de menos de $6.000 \mathrm{hl}$ en el caso de vino con DO embotellado.

- Estas bodegas concentran una producción de 925.432 hl, (equivalente a la tercera parte de la producción regional), de la cual más de las tres cuartas partes corresponde a tinto y más del $90 \%$ a granel (68 \% vino de mesa a granel). Participan con el $10 \%$ del vino embotellado total, así como en el $21 \%$ del vino comercializado con DO total regional.

- Solo el $16 \%$ de estas empresas envejecen, tanto crianza como reserva, si bien la producción en ambos tipos de vino no alcanza el 1 \% de la producción de éstas cooperativas. 


\section{Sociedades cooperativas de $2^{\circ}$ grado (S COOP2)}

- Las tres cooperativas de $2^{\circ}$ grado comercializan en todas las posibles formas, excepto en el caso del vino de mesa embotellado.

- La producción media por empresa es de 42.465 hl, con máximos en el vino de mesa a granel (excede de $17.000 \mathrm{hl}$ ) y, mínimos en el caso de vinos con DO a granel (menos de $10.000 \mathrm{hl}$ ).

- Estas bodegas concentran una producción de 127.395 hl (menos del 5 \% de la producción regional), de la cual más del 50 \% se comercializa con DO. Participan con el $6 \%$ tanto del vino embotellado total, como del vino comercializado con DO total regional.

- Las tres cooperativas envejecen vino y participan con el $30 \%$ y $10 \%$ de la producción de reserva y crianza regional respectivamente.

\section{Sociedades cooperativas de $1^{\circ}$ grado asociadas a las de $1^{\circ}$ grado(S COOPS2)}

- Cerca del 90 \% de las éstas cooperativas comercializan, vino con DO a granel $\mathrm{y}$, aproximadamente el 80 \% lo hacen como vino de mesa a granel.

- La producción media por empresa es de 45.640 hl, con máximos en el vino de mesa a granel (más de $28.000 \mathrm{hl}$ ) y, mínimos en el caso de vino de mesa embotellado (menos de 6.000hl).

- Estas bodegas concentran una producción de 821.514 hl, (equivalente aproximadamente al $30 \%$ de la producción regional), de la cual más del $70 \%$ corresponde a tinto y casi el $50 \%$ es vino de mesa granel. Participan con el $16 \%$ del vino embotellado total, así como en el 33 \% del vino comercializado con DO total regional.

- Solo el $14 \%$ de estas empresas envejecen, tanto crianza como reserva, si bien la producción en ambos tipos de vino apenas sobrepasa el $1 \%$ de la producción de éstas cooperativas.

\section{Sociedades mercantiles}

- El 70,7\% de las éstas cooperativas comercializan, vino con DO embotellado, porcentaje que se reduce significativamente en el caso de las restantes formas de comercialización.

- La producción media por empresa es de 22.763 hl, con máximos en el vino de mesa a granel (más de 19.000 hl) y, mínimos en el caso de vinos con DO a granel (menos de $8.000 \mathrm{hl}$ ).

- Estas bodegas concentran una producción de 887.741 hl (más del 30 \% de la producción regional), de la cual más del $40 \%$ se comercializa con DO 
embotellado y, el $58 \%$ es tinto. Participan con el $67 \%$ del vino embotellado total, así como en el 38 \% del vino comercializado con DO total regional.

- Una media cercana al 50 \% de las bodegas envejecen y participan con el 84\% y el $33 \%$ en la producción comercializada de reserva y crianza regional respectivamente.

\subsection{Producción comercializada según la antigüedad de las empresas}

Si se efectúa un análisis de la producción comercializada, considerando la forma de comercialización del vino (granel o embotellado), la calificación del vino (mesa o DO), el tipo de vino (blanco, rosado, tinto, crianza y reserva) y la antigüedad de las empresas (antigua, media edad, joven), según se refleja en los cuadros 5.9 y 5.10, los principales aspectos a destacar se comentan a continuación.

\section{CUADRO 5.9}

DISTRIBUCIÓN DE LA PRODUCCIÓN COMERCIALIZADA (hl) SEGÚN LA FORMA DE COMERCIALIZACIÓN, CALIFICACIÓN Y ANTIGÜEDAD DE LAS EMPRESAS

\begin{tabular}{|l|r|r|r|r|}
\hline \multirow{2}{*}{$\begin{array}{c}\text { FORMA DE } \\
\text { COMERCIALIZAR }\end{array}$} & \multicolumn{2}{|c|}{ ANTIGÜEDAD DE LA EMPRESA } & \multirow{2}{*}{ TOTAL } \\
\cline { 2 - 4 } & ANTIGUA & EDAD MEDIA & \multicolumn{1}{c|}{ JOVEN } & \\
\hline DO EN BOTELLA & 451.201 & 21.011 & 90.201 & 562.413 \\
\hline DO A GRANEL & 651.753 & 13.280 & 45.422 & 710.455 \\
\hline MESA EN BOTELLA & 159.749 & 0 & 9.440 & 169.189 \\
\hline MESA A GRANEL & 1.199 .093 & 86.970 & 102.720 & 1.388 .783 \\
\hline TOTAL & 2.461 .796 & 121.261 & 247.783 & 2.830 .840 \\
\hline Fuente: Elaboración propia &
\end{tabular}

\section{Empresas Antiguas}

- Cerca del 80 \% de las bodegas antiguas comercializan vino con DO a granel $\mathrm{y}$, entorno al $70 \%$ lo hacen como vino de mesa a granel.

- La producción media por empresa es de, en este segmento de edad es el mayor de los tres (38.466 hl), habiéndose observado una relación directa entre tamaño y antigüedad. Los valores máximos (más de $27.000 \mathrm{hl}$ ) se registran en el caso de vinos de mesa a granel, y los mínimos (alrededor de $13.000 \mathrm{hl}$ ) en el caso de vinos con DO a granel.

- Estas bodegas concentran una producción de 2.461.796 hl (equivalente al $87 \%$ de la producción regional), de la cual cerca del 70 \% corresponde a tinto y casi el 50 \% es vino de mesa granel. Participan con el $83 \%$ del vino embotellado total, así como en el 86 \% del vino comercializado con DO total regional. 
- Una media del 9 \% de las bodegas antiguas envejecen crianza, y la mitad elaboran reserva, si bien la cuota de participación en el crianza y reserva regional es de $90 \%$ y $80 \%$ respectivamente.

\section{CUADRO 5.10}

DISTRIBUCIÓN DE LA PRODUCCIÓN COMERCIALIZADA (hl) SEGÚN LA ANTIGÜEDAD DE LAS EMPRESAS Y TIPOS DE VINO

\begin{tabular}{|l|r|r|r|r|r|r|}
\hline \multirow{2}{*}{$\begin{array}{c}\text { ANTIGÜEDAD } \\
\text { EMPRESA }\end{array}$} & \multicolumn{5}{|c|}{ TIPO DE VINO } & \multicolumn{1}{c|}{ TOTAL } \\
\cline { 2 - 6 } & \multicolumn{1}{|c|}{ BLANCO } & \multicolumn{1}{|c|}{ ROSADO } & \multicolumn{1}{c|}{ TINTO } & CRIANZA & RESERVA & \\
\hline ANTIGUA & 372.997 & 306.886 & 1.686 .470 & 70.371 & 25.072 & 2.461 .796 \\
\hline EDAD MEDIA & 42.504 & 5.224 & 70.204 & 2.585 & 744 & 121.261 \\
\hline JOVEN & 37.129 & 48.499 & 151.231 & 5.017 & 5.907 & 247.783 \\
\hline TOTAL & 452.630 & 360.609 & 1.907 .905 & 77.973 & 31.723 & 2.830 .840 \\
\hline
\end{tabular}

Fuente: Elaboración propia

\section{Empresas de edad media}

- Las dos terceras partes de estas empresas comercializan, vino de mesa a granel y, más del $40 \%$ tanto vino con DO embotellado como con DO a granel, sin que existan empresas que comercialicen vino de mesa embotellado.

- La producción media por empresa es de 13.473 hl, menos de la mitad de la producción media regional.

- Estas bodegas concentran una producción de 126.261 hl (equivalente aproximadamente al $4 \%$ de la producción regional), de la cual cerca del $60 \%$ corresponde a tinto y más del $70 \%$ se comercializa como vino de mesa a granel. Participan con el 3 \% tanto del vino embotellado total, como del vino comercializado con DO total regional.

- El $40 \%$ de estas empresas envejecen crianza y, el $10 \%$ elaboran reserva, con producciones en ambos tipos de vino inferiores al $4 \%$ de la producción de la producción de crianza y reserva regional.

\section{Empresas jóvenes}

- Más de las dos terceras partes de estas empresas comercializan, vino con DO embotellado, prácticamente el doble que el conjunto muestral.

- La producción media por empresa no alcanza los 7.993 hl, con máximos en el vino de mesa a granel (más de $9.000 \mathrm{hl}$ ) y, mínimos en el caso de vino de mesa embotellado (menos de $2.000 \mathrm{hl}$ ).

- Estas bodegas concentran una producción de $247.783 \mathrm{hl}$, (equivalente a menos del $9 \%$ de la producción regional). Participan con el $14 \%$ del vino 
embotellado total, así como en el 11 \% del vino comercializado con DO total regional.

- Más del 50 \% de estas empresas envejecen crianza y menos del $30 \%$ reserva, si bien participan con el 7 \% y el 19 \% en la producción de crianza y reserva respectivamente.

\subsection{Destilaciones}

Un instrumento muy importante de intervención lo constituye la destilación. El objetivo que persigue es la retirada del mercado de los excedentes de producción a un precio mínimo garantizado.

Uno de los destinos de la producción de vino es la destilación de uso de boca, que tiene por finalidad la obtención de alcoholes para su utilización en la elaboración de vinos de licor y de brandy. Los vinos utilizados para esta destilación son casi en su totalidad blancos de mesa. Los reglamentos reguladores establecen el límite de las destilaciones voluntarias en el 40 \% de la producción más elevada de vino de mesa que haya declarado una bodega en las tres últimas campañas.

Otra modalidad de destilación a la que puede acogerse el sector con carácter excepcional, cuando las condiciones del mercado así lo aconsejan, es la destilación de crisis, cuya finalidad es retirar del mercado importantes volúmenes de vino que impiden que los precios de los vinos se sitúen en niveles rentables para el viticultor. El alcohol obtenido tanto en la destilación de crisis como en la destilación de subproductos debe ser destinado a fines distintos de los contemplados en la destilación de uso de boca, con objeto de que los alcoholes obtenidos en las diferentes destilaciones no interfieran en el mercado de estos últimos.

En el presente estudio y por razones contables de las empresas que han aportado los datos, la producción comercializada por el total de las empresas y vista en apartados anteriores $(2.830 .840 \mathrm{hl})$ puede considerarse en sentido amplio, ya que recoge la producción comercializada en sentido estricto $(2.665 .767$ hl) y la producción enviada a destilación (165.073 hl).

En el gráfico 5.7 puede comprobarse que el vino destinado a destilación supone menos del 6 \% de la producción comercializada total, correspondiendo a la destilación para uso de boca el $95 \%$ del total destilado.

Este porcentaje se encuentra muy por debajo del límite del 40 \% establecido en los reglamentos reguladores, por lo que se puede concluir que es una producción orientada al mercado y que apenas participa de los mecanismos de regulación de mercado previsto en la OCM del vino.

Las empresas pertenecientes a la D.O. Utiel, las antiguas empresas, las grandes y medianas, así como las bodegas sociedades cooperativas participan con unos porcentajes cercanos al 70 \% en cuanto al número de empresas que destilan y próximos al $80 \%$ respecto al volumen total destilado. 


\section{GRÁFICO 5.7}

\section{DISTRIBUCIÓN PORCENTUAL DE LA PRODUCCIÓN COMERCIALIZADA EN SENTIDO AMPLIO}

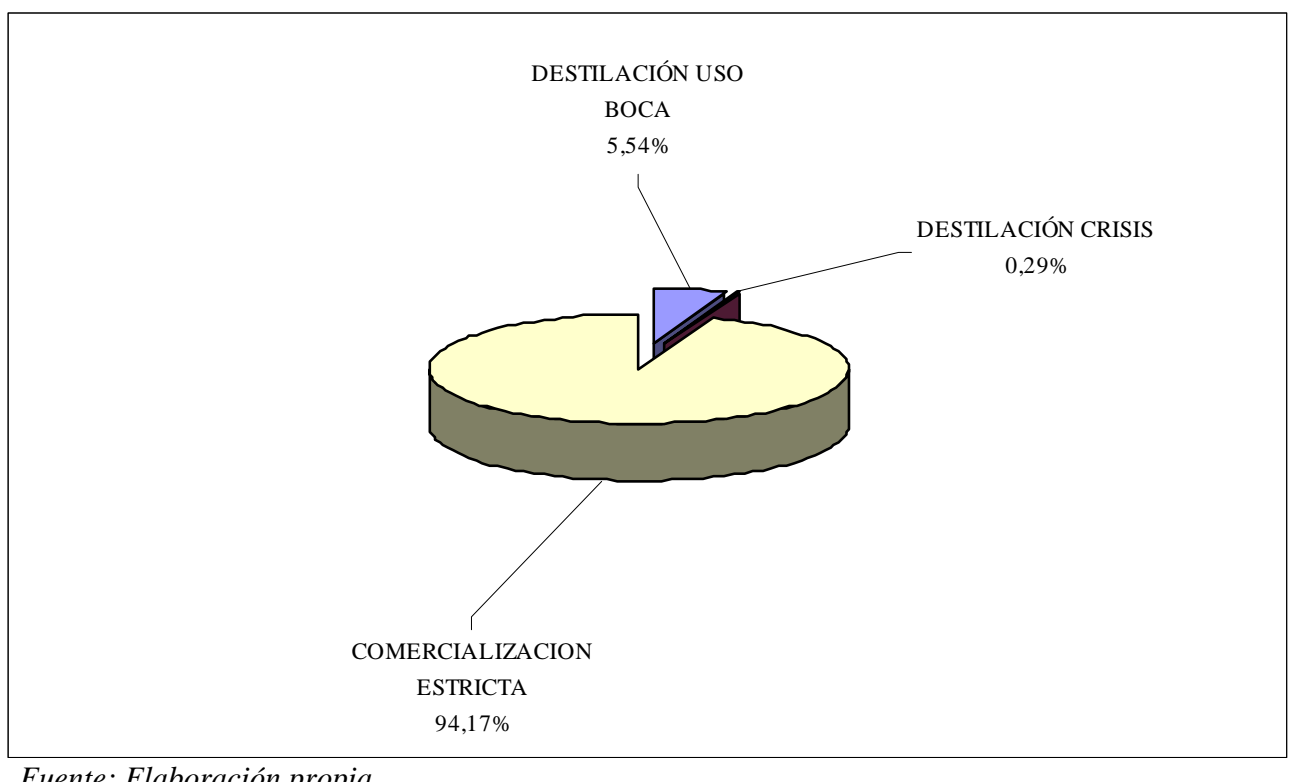

\section{PRECIOS DE VENTA EN EL MERCADO. FACTURACIONES}

En este apartado se analizarán los precios percibidos por las bodegas, que solo coincidirán con los precios pagados por los clientes finales o consumidores, en los casos en que las empresas vendan el vino directamente al consumidor, como en el caso de la venta en bodega, Internet, etc. No obstante la mayoría de las ventas de vino realizadas por las bodegas se producen a través de intermediarios, como los mayoristas, distribuidores, hipermercados, supermercados, hostelería, y otros canales de comercialización.

Debido a la dificultad que existe en las empresas de aportar datos sobre precios de venta en los diferentes canales de distribución que utiliza, el precio medio de venta para cada tipo de vino (blanco, rosado, tinto, crianza y reserva) en las diferentes formas de comercialización (DO embotellado, DO a granel, mesa embotellado y mesa granel), se ha obtenido dividiendo la cifra de ingresos por venta de vino o facturación en euros por el volumen vendido en litros (cuadro 5.11). 


\section{CUADRO 5.11}

DISTRIBUCIÓN DEL PRECIO MEDIO DE VENTA (€/l) DE LOS DIFERENTES TIPOS DE VINO SEGÚN LA FORMA DE COMERCIALIZACIÓN

\begin{tabular}{|l|r|r|r|r|r|}
\hline \multirow{2}{*}{$\begin{array}{c}\text { FORMA DE } \\
\text { COMERCIALIZAR }\end{array}$} & \multicolumn{6}{c|}{ TIPOS DE VINO } & \multicolumn{1}{c|}{ BLANCO } & ROSADO & \multicolumn{1}{c|}{ TINTO } & CRIANZA & RESERVA \\
\hline DO EN BOTELLA & 1,21 & 1,26 & 1,26 & 2,17 & 2,69 \\
\hline DO A GRANEL & 0,33 & 0,39 & 0,37 & & \\
\hline MESA EN BOTELLA & 0,93 & 1,17 & 0,95 & & \\
\hline MESA A GRANEL & 0,36 & 0,34 & 0,34 & & \\
\hline Fuente: Elaboración propia & \multicolumn{7}{|l}{}
\end{tabular}

Se ha aplicando el test de significación estadística, denominado análisis de la varianza (ANOVA), con el objeto de comparar varios grupos en una variable cuantitativa ( los precios medios de venta). Este análisis ha sido efectuado en los siguientes sentidos:

1. Definiendo los grupos a comparar de acuerdo con las cuatro distintas formas de comercialización, se destaca que:

1a) En el caso de los vinos blancos rosados y tintos:

- Para el conjunto de dichos tipos de vino, el precio medio de los comercializados con DO a granel $(0,37 € / 1)$ no difiere significativamente del que alcanzan los de mesa a granel $(0,34 € / l)$.

- El precio medio de los vinos comercializados con DO embotellados $(1,24 € / 1)$ difiere significativamente (cerca de 3,65 veces más) del que alcanzan los comercializados de mesa a granel $(0,34 € / l)$.

- El precio medio de los vinos comercializados de mesa embotellados (0,96 €/l) difiere significativamente (2,82 veces más) del que alcanzan los comercializados de mesa a granel $(0,34 € / l)$.

- El precio medio de los vinos comercializados con DO embotellados $(1,24 € / 1)$ difiere significativamente (cerca de 1,29 veces más) del que alcanzan los de mesa embotellados $(0,96 € / l)$.

- El precio medio de los vinos comercializados con DO embotellados $(1,24 € / 1)$ difiere significativamente (cerca de 3,35 veces más) del que alcanzan los comercializados de mesa a granel $(0,37 € / l)$.

1b) En cuanto a los vinos de crianza y reserva:

- Los precios medios de estos vinos comercializados exclusivamente con DO embotellados (2,17 $€ / l$ en el crianza y 2,69 $€ / 1$ en reserva) difieren significativamente entre las restantes formas de comercialización de cada uno 
de los restantes tipos de vino, tratándose de vinos encuadrados en un segmento de precios superior.

2. Definiendo los grupos a comparar de acuerdo con los cinco distintos tipos de vino, es de destacar:

2a) En el caso de los vinos blancos rosados y tintos:

- Para cada una de las cuatro formas de comercialización, no existen diferencias significativas en el precio medio entre cada uno de dichos vinos.

Por otro lado, presentan los precios de venta más elevados las siguientes categorías de empresas:

- Las bodegas de edad media en todos los tipos de vinos comercializados con DO embotellados.

- Las sociedades mercantiles en todos los tipos de vinos y formas de comercialización, seguidas de las cooperativas de $2^{\circ}$ grado.

- Las empresas muy grandes en todos los tipos de vino comercializados a granel y las pequeñas y muy pequeñas empresas en todos los tipos de vinos con DO embotellados.

- Las pertenecientes a la DO Alicante, en todos los tipos de vinos con DO embotellados.

Por otra parte, presentan los precios de venta más bajos las siguientes categorías de empresas:

- Las bodegas antiguas, prácticamente en todos los tipos de vinos comercializados con DO embotellados.

- Las cooperativas de $1^{0}$ grado en todos los tipos de vinos comercializados con DO embotellados y las personas físicas prácticamente en todos los tipos de vinos.

- Las empresas muy grandes y grandes en el caso de los vinos blancos, rosados y tintos, para todas las formas de comercialización.

- Las pertenecientes a la DO Valencia en los vinos blancos, rosados y tintos, en todas las formas de comercialización y también en el caso del reserva.

Referente a las categorías de precios en las que se hallan encuadrados los citados precios, destacar: 
- Los niveles de precios medios en bodega de los vinos blancos, rosados y tintos comercializados con DO y embotellados pertenecen a la categoría “Basic”, con 0,93 € por botella de 3/4.

- Los niveles de precios medios en bodega para los vinos crianza con 1,62 € por botella de 3/4 y reserva con 2,01 $€$ por botella de 3/4 se encuadran en la categoría "Popular premium" y Premium", respectivamente.

No obstante estos niveles de precios medios esconden diferencias por categorías de vinos y por categorías de empresas que seguidamente se comentan:

\section{En los vinos jóvenes blancos, rosados o tintos}

- Una media del $85 \%$ en volumen del vino comercializado embotellado, corresponde al segmento "Basic", seguido del "Popular premium" y “Premium”con el 10 \% y 5 \% respectivamente.

- El segmento de gama más baja "Basic” predomina por encima de la anterior media en las antiguas empresas, las cooperativas de $1^{\circ}$ grado en su conjunto, en las empresas muy grandes, grandes y medianas, y en las pertenecientes a la DO Valencia.

- Los segmentos "Popular premium” y “Premium” predominan por encima de la media anterior en las empresas de edad media, las jóvenes, las cooperativas de $2^{\circ}$ grado, las pequeñas y muy pequeñas empresas y las pertenecientes a la DO Alicante.

\section{En los vinos de crianza y reserva}

- Una media del $78 \%$ en volumen del vino comercializado embotellado, corresponde al segmento "Popular premium", seguido del "Ultrapremium" con el $10 \%$.

- El segmento "Popular premium" destaca por encima de la media anterior, en las empresas antiguas, en las cooperativas de $2^{\circ}$ grado y sus asociadas en las mercantiles y las pertenecientes a las DDOO Utiel-Requena y Valencia.

- Los segmentos de gama más alta "Superpremium” y "Ultrapremium" predominan por encima de de la media en empresas de edad media, las jóvenes, las mercantiles, las pequeñas y muy pequeñas empresas y las pertenecientes a la DO Alicante.

Respecto a la facturación en euros (cuadro 5.12) como función del precio medio de venta (en euros el litro) por el volumen en litros, resaltar que tanto las distintas formas de comercialización como los diferentes tipos de vinos con mayores precios de venta, tenderán a elevar su participación en la facturación total en comparación con la su cuota en la producción total o regional. 
CUADRO 5.12

\section{DISTRIBUCIÓN DE LA FACTURACIÓN (€) EN LOS DIFERENTES TIPOS DE VINO SEGÚN LA FORMA DE COMERCIALIZACIÓN}

\begin{tabular}{|l|r|r|r|r|r|r|}
\hline \multirow{2}{*}{$\begin{array}{c}\text { FORMA DE } \\
\text { COMERCIALIZAR }\end{array}$} & \multicolumn{1}{c|}{ TIPO DE VINO } & \multirow{2}{*}{ TOTAL } \\
\cline { 2 - 6 } & \multicolumn{1}{c|}{ BLANCO } & \multicolumn{1}{c|}{ ROSADO } & \multicolumn{1}{c|}{ TINTO } & \multicolumn{1}{c|}{ CRIANZA } & \multicolumn{1}{c|}{ RESERVA } & \\
\hline DO EN BOTELLA & 15.454 .983 & 7.027 .064 & 33.634 .926 & 16.943 .430 & 8.520 .365 & 81.580 .768 \\
\hline DO A GRANEL & 4.888 .361 & 3.126 .621 & 17.937 .368 & & & 25.952 .350 \\
\hline MESA EN BOTELLA & 1.546 .512 & 969.385 & 13.648 .383 & & & 16.164 .280 \\
\hline MESA A GRANEL & 5.660 .879 & 7.373 .785 & 34.005 .830 & & & 47.040 .494 \\
\hline TOTAL & 27.550 .735 & 18.496 .855 & 99.226 .507 & 16.943 .430 & 8.520 .365 & 170.737 .892 \\
\hline
\end{tabular}

Fuente: Elaboración propia

De la facturación total que asciende a $170.737 .892 €$ el vino comercializado con DO embotellado, con una cuota del $48 \%$ en aquella, ha más que duplicado la que tenia en producción. Al igual que ha ocurrido con la forma de venta de mesa embotellado, que con una cuota del $9 \%$ en la facturación, ha multiplicado por 1,5 veces la que tenia en producción.

En el lado opuesto las cuotas de participación en las facturaciones del vino de mesa a granel (28 \% de la total) y del vino con DO a granel (15\%) han visto reducidas sus cuotas en más de 1,5 veces respecto de la misma en las producciones.

Por tipos de vino, el vino blanco sigue manteniendo la misma participación en la facturación que en la producción (16\%); el tinto y rosado con el $58 \%$ y el $11 \%$ de la facturación respectivamente la ven reducida respecto de su cuota en la producción y, el crianza ( $9 \%$ de la facturación) y reserva (5\% de la facturación) aumentan su participación de la producción en cifras que multiplican ésta por tres y por cinco respectivamente.

Por categorías de empresas, en las antiguas la participación del granel en la facturación total es del $46 \%$, cifras que disminuyen con la juventud de las empresas hasta acercarse a la mitad en las empresas jóvenes. De igual manera en las antiguas el vino con DO posee una contribución del 60 \% de su facturación, cifras que se elevan hasta el $78 \%$ en las jóvenes.

Tanto en las cooperativas de $2^{\circ}$ grado como las mercantiles se presentan las menores cuotas de participación del granel en la facturación (23 \% en ambos casos), y las mayores cuotas del vino comercializado con DO (87\% en las cooperativas de $2^{\circ}$ grado y 69 \% en las mercantiles).

En las empresas pequeñas y muy pequeñas, las cuotas del vino con DO son las más elevadas (superan en ambos casos el $70 \%$ ). En el medianas y grandes empresas las participaciones en la facturación del vino vendido a granel son las más elevadas (63 \% y $46 \%$ de las facturaciones, respectivamente). 
En DO de Utiel-Requena el vino a granel presenta la mayor participación en su facturación (cerca del $50 \%$ ), que contrasta con la menor cuota registrada en la DO de Valencia (30 \%). En la DO de Alicante se encuentra la mayor participación del vino comercializado con DO (83 \% de la facturación), y en la DO Utiel-Requena la menor (53\% de su facturación).

En cuanto a la participación en el valor de la producción total comercializada por las distintas categorías de empresas, destacar:

- La facturación del conjunto de las cooperativas de $1^{\circ}$ grado asciende sólo al $40 \%$ de la facturación total de la región, cuando aglutinan el 63 \% de la producción en volumen, lo que viene a demostrar que el valor añadido se genera en las etapas finales de la cadena de producción (comercialización y distribución), y éstas cooperativas, salvo excepciones, como tendencia media participan en niveles bajos en éstas últimas etapas.

- Las mercantiles y las cooperativas de $2^{\circ}$ grado conjuntamente participan con el 59 \% de la producción comercializada en valor, frente a una participación en volumen del $35 \%$.

- Las empresas muy grandes y las pequeñas y muy pequeñas concentran el $41 \%$ de la producción comercializada en volumen y el $71 \%$ en valor.

\section{RECURSOS HUMANOS}

\subsection{Estabilidad del empleo}

En referencia a la eventualidad, y dado el carácter estacional de la industria vinícola en lo que respecta a la fase de elaboración del vino, los datos que se recogen tanto en lo que respecta a los trabajadores fijos como eventuales se refieren siempre a equivalentes a tiempo completo (8 horas de trabajo al día, durante 240 días de trabajo efectivos al año), por lo que en lo sucesivo las referencias al empleo se entenderán como equivalentes a tiempo completo.

En el gráfico 5.8 se refleja que, de los cerca de 800 trabajadores, el $86 \%$ corresponde a personal fijo continuo. El elevado valor de éste ratio, puede considerarse como indicador de un mayor nivel de integración del personal con la organización, una mayor ausencia de conflictos relevantes y un mayor avance en el proceso de aprendizaje conjunto, adquiriendo así un mayor valor para las empresas. Este tipo de personal suele corresponderse con la ocupación de puestos de trabajo de mayor responsabilidad en las empresas, como gerentes, directores, técnicos, enólogos, administrativos, contables y comerciales fundamentalmente. Se caracterizan porque llevan inherentes cierta permanencia en la empresa, aspecto necesario para la continuidad de las mismas. 


\section{GRAFICO 5.8}

\section{DISTRIBUCIÓN PORCENTUAL DEL PERSONAL DE LAS EMPRESAS SEGÚN LA ESTABILIDAD EN EL EMPLEO}

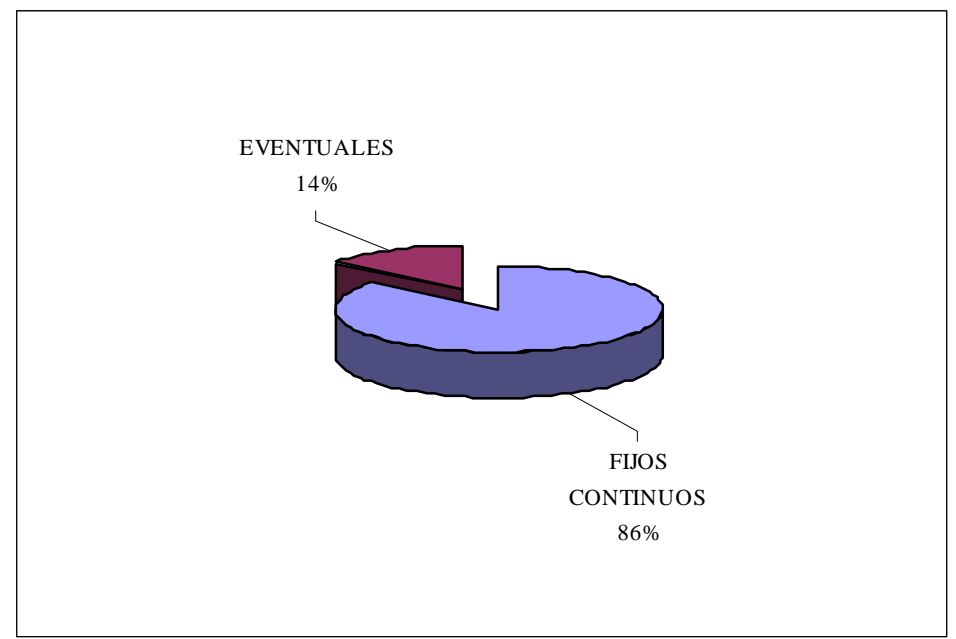

Fuente: Elaboración propia

En referencia a los empleos eventuales, el $14 \%$ se corresponden con 113 trabajadores empleados a tiempo completo y aproximadamente con el mismo número que en el caso de los fijos continuos si se considera el trabajo a tiempo parcial. Este aspecto viene explicado por el hecho de que una parte mayoritaria de los empleos eventuales suele corresponderse con los trabajadores que son contratados en la campaña de vendimia, la cual puede considerarse de una duración media de dos meses, contando las limpiezas anteriores y posteriores de bodega. Este tipo de trabajos generalmente son poco especializados, aunque en numerosas bodegas también se relacionan con contrataciones de enólogos por campaña y personal contable que está contratado fijo pero a tiempo parcial.

Destacar que el $44 \%$ del empleo eventual regional se concentra en las cooperativas de $1^{\circ}$ grado no asociadas a las de $2^{\circ}$ grado. Dentro de este empleo precario se encuentra una figura trascendental en el proceso de vinificación, el enólogo, el cual es contratado por estas empresas en el mejor de os casos por campaña, siendo bastante frecuente el cambio de enólogo de una campaña a otra, lo que impide la vinculación de estos profesionales con las organizaciones o empresas.

Los aspectos más relevantes según los diferentes grupos de empresas, son los siguientes:

- Las bodegas de media edad y antiguas presentan los grados de estabilidad más elevados (87\%), y las jóvenes los menores (82 \%), si bien las diferencias no son significativas.

- Las sociedades cooperativas de $2^{\circ}$ grado y las mercantiles, presentan lo mayores valores de estabilidad con el $96 \%$ y $94 \%$ respectivamente. Las 
sociedades agrarias de transformación y las personas físicas los menores con cifras del 48 \% y $57 \%$ de estabilidad respectivamente.

- En las empresas muy grandes más del 99 \% del personal es fijo y en las pequeñas el $90 \%$. Los valores más reducidos de estabilidad se dan en las medianas empresas (76 \%).

- La DO Alicante presenta el 88 \% de estabilidad, seguidas muy de cerca por la DO de Valencia y Utiel con valores cercanos a la media del $86 \%$.

\subsection{Cualificación técnica del empleo}

Partiendo de cuatro niveles de formación: titulación superior, titulación media, formación profesional y sin titulación, la cualificación técnica (número de personas con titulación superior y media con relación al total del personal a tiempo completo), asciende a un valor del $24,08 \%$, que se distribuye casi de forma equitativa entre titulación superior y media. En el gráfico 5.9 puede comprobarse que conforme disminuye el grado de titulación del personal aumenta el porcentaje de personas que lo poseen; en este sentido el $55 \%$ del personal no tiene ninguna titulación.

\section{GRÁFICO 5.9}

\section{DISTRIBUCIÓN PORCENTAL DE LA CUALIFICACIÓN TÉCNICA DEL PERSONAL DE LAS EMPRESAS}

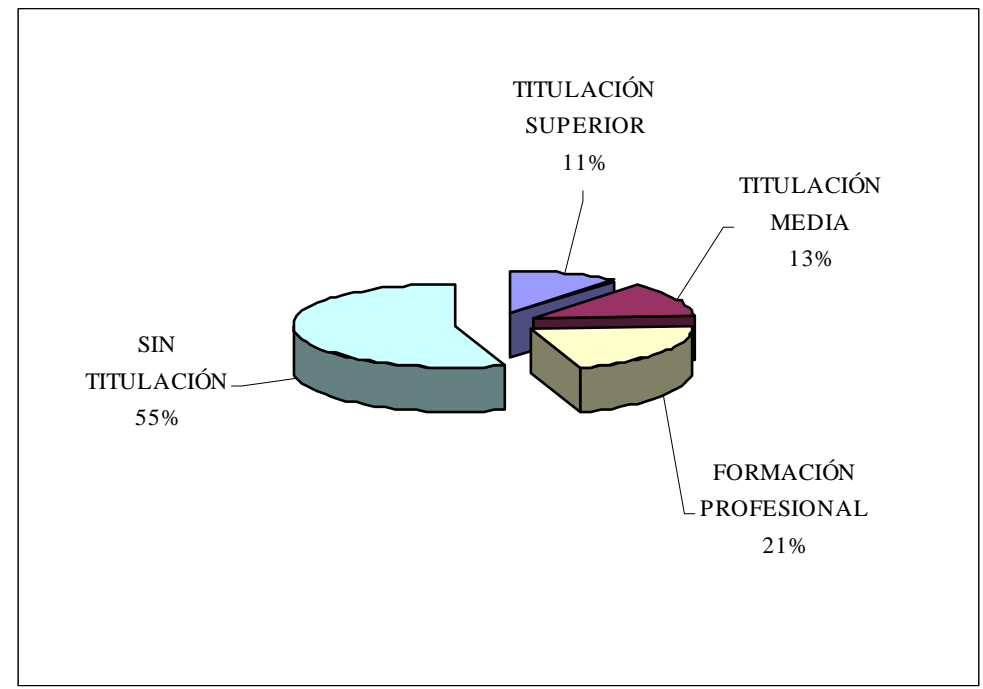

Fuente: Elaboración propia

Los aspectos más relevantes según los diferentes grupos de empresas, son los siguientes:

- Las bodegas antiguas concentran casi las tres cuartas partes del empleo (87 \% de la producción), aunque es el único estrato con la cualificación técnica por debajo de la media. 
- Cerca del 20 \% del empleo corresponde a las jóvenes, con las cualificaciones más altas (próximas al $30 \%$ ), habiéndose observado que la cualificación aumenta con la juventud de las empresas.

- Las sociedades mercantiles concentran más de la mitad del empleo (menos de la tercera parte de la producción), aunque con una cualificación por debajo de la media.

- Las cooperativas en su conjunto muestran una cuota del 45 \% del empleo, destacándose por cualificación las cooperativas de $2^{\circ}$ grado y las asociadas de estas (entorno al $27 \%$ en ambos casos). En cambio la menor cualificación se da en las cooperativas de $1^{\circ}$ grado (cerca del $20 \%$ ).

- Las personas físicas presentan la mayor cualificación (cerca del 33 \%), secundadas por las sociedades agrarias de transformación, con valores que superan la media regional.

- La grandes y muy grandes bodegas concentran el $55 \%$ del empleo (cerca del 75 \% en producción), con niveles de cualificación cercanos a la media. Las empresas muy pequeñas agrupan el $14 \%$ del empleo (menos del $3 \%$ de la producción) y presentan las cifras más altas de cualificación (cerca del 33 \%).

- La DO Utiel-Requena agrupa más del 50 \% del empleo (67 \% de la producción), con la cifra de cualificación más baja de todas (23 \%). La DO Alicante concentra sólo el $13 \%$ del empleo, el cual presenta el nivel de cualificación más alto (28 \%).

Respecto a la formación continua y capacitación del personal de las bodegas, la actitud de las Pymes ante la formación ha sido tradicionalmente de tipo reactivo, es decir, la formación no se planifica sino que se contempla cuando existe cierta obligatoriedad (normativa) o cuando son temas claves para la propia supervivencia y funcionamiento de las empresas. Por ello la formación en las empresas es más bien contemplada como un gasto y no como una inversión. En general las bodegas no disponen de un departamento de formación del personal y normalmente la figura del responsable de formación es poco relevante, siendo las necesidades de formación en muchos casos detectadas por el propio empleado.

\subsection{Productividad del empleo}

Antes de entrar a analizar la productividad del empleo y en estrecha relación con ésta, se encuentra en número de empleos medios por empresa, que presenta las siguientes particularidades según las diferentes categorías de empresas definidas en las segmentaciones realizadas (cuadro 5.13).

- En general el número de empleos por empresa crece con la antigüedad y con el tamaño de las empresas. Puntualmente presentan los mayores valores las bodegas antiguas ( 9 empleos por empresa), las cooperativas de $2^{\circ}$ grado (23 empleos por empresa), las muy grandes empresas (43 empleos por empresa) y 
las DO de Valencia (9 empleos por empresa), frente a un valor medio muestral de 7 empleos por empresa.

- Muestran los menores valores las bodegas jóvenes (4 empleos por empresa), las personas físicas (1 empleos por empresa), las muy pequeñas empresas (3 empleos por empresa) y las DO de Alicante (5 empleos por empresa).

\section{CUADRO 5.13}

DISTRIBUCIÓN DE LOS EMPLEOS POR EMPRESA Y PRODUCTIVIDAD POR EMPLEADO (€/EMPLEO) SEGÚN LAS DISTINTAS CATEGORIAS DE EMPRESAS

\begin{tabular}{|c|c|c|c|}
\hline $\begin{array}{c}\text { SEGMENTACIÓN DE LAS } \\
\text { EMPRESAS }\end{array}$ & CATEGORIA & $\begin{array}{c}\text { EMPLEOS } \\
\text { POR EMPRESA }\end{array}$ & $\begin{array}{l}\text { PRODUCTIVIDAD } \\
\text { (€/EMPLEO) }\end{array}$ \\
\hline \multirow{3}{*}{ ANTIGÜEDAD } & ANTIGUA & 9 & 48.401 \\
\hline & MEDIA EDAD & 5 & 48.458 \\
\hline & JOVEN & 4 & 31.131 \\
\hline \multirow{6}{*}{ FORMA JURÍDICA } & P FISICA & 1 & -858 \\
\hline & SAT & 5 & 20.298 \\
\hline & S COOP & 5 & 41.910 \\
\hline & S COOP2 & 23 & 40.888 \\
\hline & S COOPS2 & 7 & 41.288 \\
\hline & S MERCANTIL & 9 & 50.619 \\
\hline \multirow{5}{*}{$\begin{array}{l}\text { TAMAÑO DE LAS } \\
\text { INSTALACIONES }\end{array}$} & MUY GRANDE & $\overline{56}$ & 77.548 \\
\hline & GRANDE & 10 & 42.790 \\
\hline & MEDIANA & 7 & 31.332 \\
\hline & PEQUEÑA & 6 & 40.247 \\
\hline & MUY PEQUEÑA & 3 & 15.671 \\
\hline \multirow{3}{*}{$\begin{array}{l}\text { DENOMINACIÓN DE } \\
\text { ORIGEN }\end{array}$} & ALICANTE & 5 & 36.960 \\
\hline & UTIEL-REQUENA & 7 & 54.683 \\
\hline & VALENCIA & 9 & 33.135 \\
\hline MEDIA & & 7 & 44.964 \\
\hline
\end{tabular}

Fuente: Elaboración propia

En cuanto a la productividad por empleado (relación entre el valor añadido de la empresa y el número total de empleados a tiempo completo), los aspectos más relevantes a destacar según la categoría de las empresas son:

- Las empresas de edad media y antiguas muestran los mayores valores (entorno a 48.000 €/empleo), seguidas por las jóvenes (algo más de 31.000 $€ /$ empleo), frente al valor medio de $44.964 €$ €/empleo, lo que parece indicar que una mayor tradición en el negocio puede conducir a un mejor desenvolvimiento de las habilidades individuales y capacidades colectivas relacionadas con la organización interna de los recursos humanos (economías de experiencia).

- Las sociedades mercantiles muestran el valor más elevado (cerca de 51.000 $€ /$ empleo), seguidas de las cooperativas en su conjunto (valores próximos a $41.000 € /$ empleo), sociedades agrarias de transformación (20.000 €/empleo). 
- Las empresas muy grandes muestran lo mayores valores (cerca de 78.000 $€ /$ empleo) y las muy pequeñas los menores (no alcanza los $16.000 € /$ empleo) habiéndose detectado en líneas generales una relación directa entre tamaño empresarial y productividad del empleo. Este fenómeno observado de reducción de coste total unitario de los recursos humanos o aumento de su productividad al aumentar la capacidad o tamaño de las empresas puede ser explicado por lo que se denomina economías de escala.

- La mayor productividad por empleo (más de 54.000 €/empleo) se ha registrado en la DO Utiel-Requena (a pesar de que cerca de la mitad de la facturación sea vendida a granel), ya que en su territorio se encuentran más de la mitad de las bodegas antiguas, casi las dos terceras partes de las muy grandes y grandes empresas, y más del $50 \%$ de las mercantiles. La menor cifra (cerca de 33.000 €/empleo) la muestra la DO Valencia.

\section{INVERSIONES}

En este apartado se analiza, por un lado el destino de las inversiones medias anuales que han llevado a cabo las bodegas en el último trienio (2000/2001-2002/2003), según los diferentes conceptos o capítulos objeto de la inversión. Por otro lado también se ha estudiado el esfuerzo inversor y la procedencia o fuente de los recursos a través de las cuales se han financiado dichas inversiones.

\subsection{Destino de las inversiones}

Una parte muy significativa de las inversiones, como se verá en el siguiente apartado, han sido financiadas mediante el Fondo Europeo de Orientación y Garantía Agrícola (FEOGA), el cual establece como condición para financiar a las empresas, que las inversiones acometidas por éstas alcancen alguno de los objetivos siguientes:

- Orientación de la producción de acuerdo con las tendencias del mercado.

- Mejora o racionalización de los canales de comercialización o los procedimientos de transformación.

- Mejora del acondicionamiento y presentación de los productos.

- Aplicación de nuevas tecnologías.

- Fomento de las inversiones innovadoras.

- Mejora y control de calidad.

- Mejora y control de las condiciones sanitarias.

- Protección del medio ambiente.

La inversión anual media total (€/año) registrada en el último trienio asciende a 26.233.911 € (cuadro 5.14). Los destinos principales de las inversiones en las bodegas por orden de importancia son:

- Depósitos de elaboración (autovaciantes y fermentación controlada fundamentalmente) con una participación del $27 \%$.

- Terrenos y construcciones con el $27 \%$.

- Depósitos de almacenamiento (acero inoxidable) con el $20 \%$. 
- Líneas de embotellado con una participación del 10 \%.

- Instalaciones y maquinaria con menos del $9 \%$.

Estos destinos principales se repiten prácticamente aunque con algún cambio de orden, en todas las categorías de empresas.

\section{CUADRO 5.14}

\section{INVERSIÓN ANUAL MEDIA (€/AÑO) REALIZADAS POR LAS EMPRESAS SEGÚN CONCEPTOS}

\begin{tabular}{|l|r|r|}
\hline \multicolumn{1}{|c|}{ CONCEPTO } & INVERSIÓN (€/AÑO) & \% DEL TOTAL \\
\hline DEPÓSITOS DE ELABORACIÓN & 7.113 .422 & 27,12 \\
\hline TERRENOS Y CONSTRUCCIONES & 7.089 .019 & 27,02 \\
\hline DEPÓSITOS DE ALMACENAMIENTO & 5.302 .125 & 20,21 \\
\hline LINEA DE EMBOTELLADO & 2.626 .404 & 10,01 \\
\hline INSTALACIONES Y MAQUINARIA & 2.219 .177 & 8,46 \\
\hline INFORMÁTICA & 553.199 & 2,11 \\
\hline INVESTIGACIÓN Y DESARROLLO & 461.695 & 1,76 \\
\hline CONTROL DE CALIDAD & 380.374 & 1,45 \\
\hline MEDIO AMBIENTE & 300.916 & 1,15 \\
\hline DEPÓSITOS DE ENVEJECIMIENTO & 147.309 & 0,56 \\
\hline TRANSPORTE EXTERNO Y OTRAS & 40.270 & 0,15 \\
\hline TOTAL & $\mathbf{2 6 . 2 3 3 . 9 1 1}$ & $\mathbf{1 0 0 , 0 0}$ \\
\hline
\end{tabular}

Fuente: Elaboración propia

En cuanto al número de empresas, considerando el conjunto de las inversiones, más del 80 \% de las empresas han invertido en algún concepto de los señalados, si bien al desagregar por destinos, es de destacar que entorno al $50 \%$ de las empresas han efectuado inversiones en depósitos de elaboración, almacenamiento, terrenos y construcciones, informática, y tan solo el $8 \%$ de las bodegas han realizado alguna inversión en depósitos de envejecimiento e investigación, desarrollo e innovación.

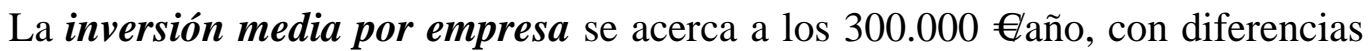
apreciables que multiplican dicho valor por dos en el caso de las cooperativas de $2^{\circ}$ grado, y por más de cuatro de las bodegas muy grandes. Respecto a la participación en la inversión total por categorías de empresas, es necesario puntualizar que las mayores cuotas de inversión corresponden a las siguientes categorías de empresas (cuadro 5.15):

- Las antiguas empresas, con una participación del 57 \%, seguidas de las jóvenes, con cuotas que rondan la tercera parte.

- Las sociedades mercantiles, con cuotas del $41 \%$, seguidas de las cooperativas de $1^{\circ}$ grado con cifras que se reducen a la mitad.

- Las grandes empresas (superan el $31 \%$ ), seguidas de las muy pequeñas (entorno al $27 \%$ ) y las muy grandes (cerca del $20 \%$ ).

- Las empresas pertenecientes a la DO Utiel-Requena (56 \%), seguidas de las instaladas en la DO Valencia (32 \%). 
CUADRO 5.15

PORCENTAJES DE PARTICIPACIÓN EN LA INVERSIÓN Y ESFUERZO INVERSOR SEGÚN CATEGORÍAS DE EMPRESAS

\begin{tabular}{|l|l|r|r|}
\hline $\begin{array}{c}\text { SEGMENTACIÓN DE } \\
\text { EMPRESAS }\end{array}$ & CATEGORIA & $\begin{array}{c}\text { PARTICIPACIÓN EN LA } \\
\text { INVERSIÓN (\% DEL TOTAL) }\end{array}$ & $\begin{array}{c}\text { ESFUERZO } \\
\text { INVERSOR (\%) }\end{array}$ \\
\hline \multirow{4}{*}{ ANTIGÜEDAD } & ANTIGUA & 57,34 & 8,89 \\
\cline { 2 - 5 } & MEDIA EDAD & 10,42 & 8,15 \\
\cline { 2 - 5 } & JOVEN & 32,24 & 23,86 \\
\hline \multirow{5}{*}{ FORMA JURÍDICA } & P FISICA & 0,74 & 39,76 \\
\cline { 2 - 5 } & SAT & 8,8 & 60,95 \\
\cline { 2 - 5 } & S COOP & 15,5 & 9,31 \\
\cline { 2 - 5 } & S COOP2 & 8,75 & 15,18 \\
\cline { 2 - 5 } & S COOPS2 & 21,11 & 11,83 \\
\cline { 2 - 5 } & S MERCANTIL & 41,1 & 9,15 \\
\hline \multirow{3}{*}{ INSTALACIONES DE LAS } & MUY GRANDE & 19,34 & 8,12 \\
\cline { 2 - 5 } & GRANDE & 31,41 & 9,57 \\
\cline { 2 - 5 } & MEDIANA & 10,62 & 12,01 \\
\cline { 2 - 5 } & PEQUEÑA & 12,11 & 8,62 \\
\cline { 2 - 5 } & MUY PEQUENA & 26,52 & 59,23 \\
\hline \multirow{2}{*}{$\begin{array}{l}\text { DENOMINACIÓN DE } \\
\text { ORIGEN }\end{array}$} & ALICANTE & 12,57 & 13,02 \\
\cline { 2 - 5 } & UTIEL-REQUENA & 56,05 & 8,88 \\
\cline { 2 - 5 } & VALENCIA & 31,38 & 13,90 \\
\hline MEDIA & & $\mathbf{1 0 , 7 3}$ \\
\hline TOTAL(\%) & & $\mathbf{1 0 0}$ & \\
\hline TOTAL (€) & & $\mathbf{2 6 . 2 3 3 . 9 1 1}$ & \\
\hline
\end{tabular}

Fuente: Elaboración propia

Referente al esfuerzo tecnológico (relación entre la cifra de inversión media anual del trienio considerado y el valor de la producción), según se aprecia en el cuadro 5.15, muestra un valor medio para el conjunto de las bodegas en estudio, próximo a $11 \%$, cifra que puede calificarse como aceptable, si se tiene en cuenta el valor a nivel nacional para el sector del vino (8,7 \%), así como el valor para el conjunto de la industria agroalimentaria en la Comunidad Valenciana (5,5 \%).

Los valores anormalmente elevados que presentan las empresas jóvenes, las SAT, las personas físicas y las empresas muy pequeñas conviene tomarlos con mucha cautela, debido a las siguientes razones:

- En más del 40 \% de las empresas jóvenes las cifras de inversión no pueden ser consideradas como mejora de las condiciones de transformación y comercialización, ya que en realidad se trata de inversiones de nueva instalación, que lógicamente son mayores que aquellas.

- $\quad$ El 60 \% de las SAT, el 59 \% de la empresas muy pequeñas, y el $33 \%$ de las personas físicas son jóvenes por lo que no hay más que aplicar el razonamiento del párrafo anterior. 
Efectuadas estas salvedades, presentan valores del esfuerzo inversor por encima de la media, las siguientes categorías de empresas: las cooperativas de $2^{\circ}$ grado y sus asociadas, las medianas empresas y las pertenecientes a las DO Valencia y Alicante.

\subsection{Financiación de las inversiones}

De las diferentes fuentes de financiación de las inversiones, en el estudio se han considerado los fondos propios, los préstamos y las subvenciones (gráfico 5.10).

En el ámbito regional, los recursos que han generado más inversión han sido los fondos propios con el $43 \%$, seguidos de los préstamos con el 38 \% y las subvenciones, que aportan una contribución del 50 \% respecto a los préstamos.

\section{GRAFICO 5.10}

\section{DISTRIBUCIÓN PORCENTUAL DE LAS FUENTES DE FINANCIACIÓN DE LAS INVERSIONES REALIZADAS POR LAS EMPRESAS}

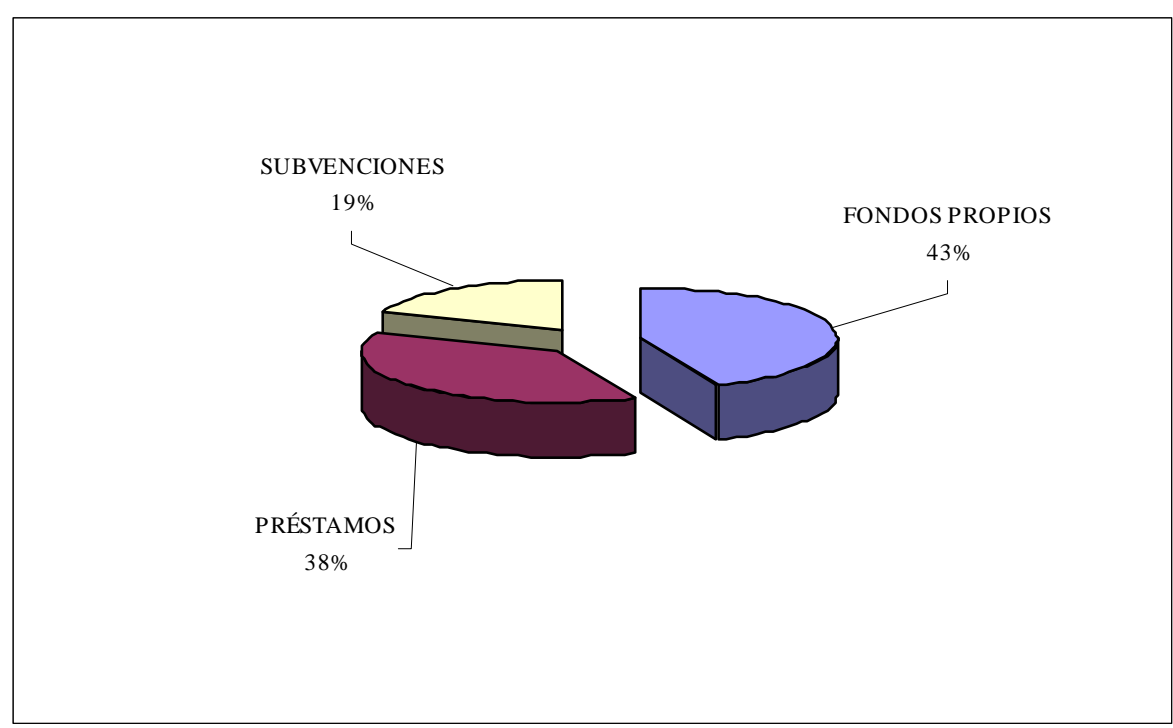

Fuente: Elaboración propia

Se ha detectado una cierta especialización en la captación de fuentes de financiación por categorías de empresa que merece ser destacada:

- Se ha observado una participación en los fondos propios más elevada en: las bodegas de media edad, las mercantiles, las empresas muy grandes, así como las pertenecientes a la DO Utiel-Requena.

- Respecto de los préstamos, se presenta la mayor cuota de participación en: las empresas jóvenes, las sociedades cooperativas en conjunto, las medianas empresas, y las incluidas en la DO Valencia. Dado el elevado esfuerzo inversor que esta realizando el sector en su conjunto, resulta preocupante el elevado grado de endeudamiento que éstas categorías de empresas están resgistrando. 
- En cuanto a las subvenciones, la mayor cuota de participación se ha observado en: las antiguas empresas, las cooperativas en general, las bodegas muy grandes y las pertenecientes a la DO Alicante.

El hecho de que las sociedades cooperativas concentren más del $65 \%$ del total de las subvenciones otorgadas en la región, puede explicarse por una serie de motivos: la mayor avidez de éstas empresas en la captación de los recursos público; el mayor porcentaje de subvención a fondo perdido que en muchas líneas de ayuda se les concede a las formas asociativas, y porque ciertas líneas se diseñan teniendo en cuenta de modo preferente las sociedades de economía social.

Respecto a la canalización de los fondos públicos, las subvenciones a fondo perdido se han canalizado por orden de importancia a través de las siguientes líneas de apoyo al sector:

- Las ayudas a las inversiones en mejora de las condiciones de transformación y comercialización de los productos agrícolas, silvícolas, pesqueros y de la alimentación (Orden del 12 de marzo de 2001 de la CAPA).

- Los Programas operativos, regulados por el R(CE) 2200/96, a los que pueden acogerse las Organizaciones de productores de frutas y hortalizas (prioritariamente sociedades cooperativas y SAT), aunque también tienen acceso las sociedades mercantiles.

- El Programa Regional de Iniciativa Comunitaria Leader Plus (Orden del 2 de noviembre de 2001 de la CAPA).

- El Programa Operativo Integrado de Fondos Estructurales de la Comunidad Valenciana 2000-2006 o PRODER-2 (Orden del 28 de noviembre de 2001 de la CAPA).

- Incentivos Regionales (Ley 50/1985, de 27 de octubre).

\section{TECNOLOGÍA DE LAS INSTALACIONES DE ELABORACIÓN}

Se ha analizado la capacidad y grado tecnológico de las instalaciones de vinificación, en cuanto a los aspectos más determinantes de la calidad intrínseca del producto final, así como el nivel de automatización e información de procesos en estrecha relación con las tecnologías de la información y la comunicación (TIC).

\subsection{Tecnología de las instalaciones de vinificación y almacenamiento}

En esta apartado se ha explorado la capacidad de transformación de la uva en vino, (considerando que coincide con la capacidad de los depósitos de elaboración y almacenamiento), nivel tecnológico de dicho volumen, así como el grado de sobredimensionamiento. 
La capacidad total de depósitos (cuadro 5.16) asciende a $4.191 .076 \mathrm{hl}$, de la cual cerca del $50 \%$ corresponde a depósitos de acero inoxidable, que se dividen en tres grupos:

- Depósitos de fermentación controlada (12 \% de la capacidad), que son cilíndricos normalmente de base plana, con sistemas de refrigeración y calentamiento y se utilizan fundamentalmente para la vinificación los vinos blancos y rosados.

- Autovaciantes (concentran el 13 \% del volumen), depósitos cilíndricos de base cónica o plana, con camisas de refrigeración y calentamiento y sistemas de vaciado automáticos, utilizados para macerar (en caliente o no ) y fermentar, que son empleados para la elaboración de vinos blancos, rosados y tintos.

- Depósitos de almacenamiento (23 \% de la capacidad), exentos de sistemas de refrigeración y/o calentamiento que se utilizan con fines de almacenamiento en sentido estricto en el ámbito de las nuevas tecnologías de elaboración, aunque puedan ser empleados para la vinificación tradicional, es decir, sin control auxiliar de la temperatura en la fermentación y sistemas de maceración del hollejo manuales.

\section{CUADRO 5.16}

DISTRIBUCIÓN DE LA CAPACIDAD DE ELABORACIÓN Y ALMACENAMIENTO POR TIPOS DE DEPÓSITOS

\begin{tabular}{|l|r|r|}
\hline \multicolumn{1}{|c|}{ TIPO DE DEPÓSITOS } & $\begin{array}{c}\text { CAPACIDAD } \\
\text { INSTALADA } \\
\text { TOTAL (hl) }\end{array}$ & $\begin{array}{c}\text { CAPACIDAD INSTALADA } \\
\text { MEDIA POR } \\
\text { EMPRESA (hl) }\end{array}$ \\
\hline FERMENTACIÓN CONTOLADA & 520.056 & 7.028 \\
\hline AUTOVACIANTES & 541.767 & 7.852 \\
\hline ACERO NEGRO & 338.040 & 24.146 \\
\hline ACERO INOXIDABLE & 967.164 & 13.070 \\
\hline HORMIGÓN ARMADO & 1.497 .031 & 21.386 \\
\hline POLIÉSTER-FIBRA DE VIDRIO & 200.166 & 3.849 \\
\hline BARRICAS Y CONOS DE MADERA & 125.852 & 1.824 \\
\hline TOTAL & $\mathbf{4 . 1 9 0 . 0 7 6}$ & $\mathbf{3 8 . 0 9 2}$ \\
\hline
\end{tabular}

Fuente: Elaboración propia

La calidad tecnológica de la capacidad instalada (razón existente entre la suma de los depósitos autovaciantes y de fermentación controlada y la capacidad total instalada en la bodega) ha quedado reflejada en el cuadro 4.17, y presenta una media del $25 \%$, presentando los mayores valores por encima de la citada media, las empresas jóvenes lógicamente, las cooperativas de $1^{0}$ grado, las empresas muy pequeñas y pequeñas, y las correspondientes a la DO Valencia. Los valores más reducidos y por debajo de la media, aparecen relacionados con las empresas antiguas, las cooperativas de $2^{\circ}$ grado, las mercantiles, las personas físicas, y las empresas muy grandes. Se ha 
detectado una relación negativa entre calidad de la capacidad tanto con la antigüedad como con el tamaño de las empresas.

Los depósitos de hormigón armado y de acero negro, que representan el 36 \% y $8 \%$ del volumen total de la capacidad, respectivamente, están siendo paulatinamente sustituidos en las antiguas y medianas empresas principalmente, por los de acero inoxidable, ya sean de elaboración o almacenamiento estricto; en este sentido, tal y como ha sido puesto de manifiesto en el apartado referente al destino de las inversiones, el $48 \%$ de éstas últimas han estado dirigidas a la compra de este tipo de depósitos. Aunque el cemento revestido de resinas epoxídicas parece un material interesante, especialmente debido a su inercia térmica, la generalización del acero inoxidable se debe a varios motivos:

- Adaptación a las condiciones de higiene deseadas por su facilidad de limpieza.

- Ofrece la posibilidad de conferir a los depósitos formas apropiadas para los distintos métodos de elaboración de los vinos elegidos.

En cuanto a los depósitos de policloruro de vinilo (PVC) reforzado con fibra de vidrio son poco empleados (menos del $5 \%$ de la capacidad) a pesar de que dispongan de buena flexibilidad y bajo costo.

Las barricas y conos de madera están destinados principalmente al envejecimiento de los vinos de crianza y reserva y muy raramente a la fermentación de los mostos, y participan como media tan solo en un $3 \%$ de la capacidad total instalada, que supone menos de la mitad de la existente a nivel nacional (Saborá 2003). Muestran las cifras más elevadas y por encima de la media, las empresas jóvenes, las cooperativas de $2^{\circ}$ grado, las mercantiles, las empresas muy pequeñas y pequeñas y las pertenecientes a la DO Valencia.

La capacidad instalada media por empresa supera los $38.000 \mathrm{hl}$, aumentando con la antigüedad de las bodegas (más de $55.000 \mathrm{hl}$ en las antiguas y aproximadamente la quinta parte en las jóvenes) y el tamaño de las empresas( las muy grandes multiplican por seis la media y las muy pequeñas la dividen por doce). Las cooperativas aparecen con los mayores valores, que en algunos casos duplican la media anterior; las correspondientes a la DO Utiel-Requena, con cerca de $45.000 \mathrm{hl}$ doblan los valores de dicha media con respecto a las de la DO Alicante.

La sobredimensión de la capacidad instalada puede apreciarse en el cuadro 5.17, del que se desprende, que por término medio solo se utiliza el $68 \%$ de la capacidad de las instalaciones (32 \% de sobredimensión), aunque se aprecian grandes diferencias por categorías de empresas, siendo que las bodegas que hacen un bajo aprovechamiento de su capacidad o que presentan un elevado grado de sobredimensión se corresponden con las empresas de edad media, las personas físicas, las sociedades cooperativas de $1^{\circ}$ grado, las medianas empresas, y las pertenecientes a la DO Alicante. Por otro lado la sobredimensión de las bodegas podría justificarse de una parte por las fuertes oscilaciones de la producción, muy condicionadas por las características 
climáticas en un cultivo fundamentalmente de secano, como es el caso que nos ocupa; de otra a las propias condiciones del mercado que obligan a dejar grandes volúmenes sin vender de una campaña para otra.

\section{CUADRO 5.17}

DISTRIBUCIÓN DE LA CAPACIDAD INSTALADA (CALIDAD Y SOBREDIMENSIONAMIENTO) Y PRODUCCIÓN COMERCIALIZADA

\begin{tabular}{|c|c|c|c|c|}
\hline $\begin{array}{l}\text { CATEGORIA } \\
\text { EMPRESA }\end{array}$ & $\begin{array}{c}\text { CAPACIDAD } \\
\text { ALMACEN (hl) }\end{array}$ & $\begin{array}{c}\text { CAPACIDAD } \\
\text { COMERCIALIZ. (hl) }\end{array}$ & $\begin{array}{c}\text { SOBRE } \\
\text { DIMENSIÓN (\%) }\end{array}$ & $\begin{array}{c}\text { CALIDAD } \\
\text { CAPACIDAD (\%) }\end{array}$ \\
\hline ANTIGUA & 3.569 .572 & 2.461 .796 & 31 & 25 \\
\hline MEDIA EDAD & 227.053 & 121.261 & 47 & 31 \\
\hline JOVEN & 393.451 & 247.783 & 37 & 35 \\
\hline P FISICA & 66.510 & 22.573 & 66 & 19 \\
\hline SAT & 65.448 & 46.185 & 29 & 62 \\
\hline S COOP & 1.646 .018 & 925.432 & 44 & 29 \\
\hline S COOP2 & 156.386 & 127.395 & 19 & 15 \\
\hline S COOPS2 & 1.335 .687 & 821.514 & 38 & 26 \\
\hline S MERCANTIL & 920.027 & 887.741 & 4 & 18 \\
\hline MUY GRANDE & 884780 & 685.529 & 23 & 17 \\
\hline GRANDE & 2171421 & 1.400 .075 & 36 & 25 \\
\hline MEDIANA & 538.787 & 280.607 & 48 & 30 \\
\hline PEQUEÑA & 459.926 & 363.730 & 21 & 34 \\
\hline MUY PEQUEÑA & 135.162 & 100.899 & 25 & 39 \\
\hline ALICANTE & 403.422 & 235.669 & 42 & 25 \\
\hline UTIEL-REQUENA & 2.691 .241 & 1.887 .411 & 30 & 24 \\
\hline VALENCIA & 1.095 .413 & 707.760 & 35 & 29 \\
\hline TOTAL (hl) & 4.190 .076 & 2.830 .840 & & \\
\hline MEDIA & 38.092 & 25.735 & 32 & 25 \\
\hline
\end{tabular}

Fuente: Elaboración propia

El mejor grado de aprovechamiento de la capacidad de las instalaciones se registra en aquellas empresas cuya producción comercializada supera ampliamente a la elaborada en las propias empresas y cuya actividad principal consiste en comprar vino a granel, tipificarlo y embotellarlo en sus propias instalaciones. Estas bodegas compran el vino según necesidades a las bodegas que elaboran fundamentalmente y por ello no tienen que sufrir el fenómeno de las estacionalidad y vecería de las producciones.

\subsection{Tecnología de otras instalaciones de elaboración}

Este apartado trata de aproximarse hacia el nivel tecnológico existente en las bodegas, en relación con las operaciones más comunes de las diferentes vinificaciones: toma de muestras, análisis de las muestras, recepción de la uva, la separación del raspón, el estrujado, el prensado, el desfangado, sistemas de control de la fermentación, la adición de levaduras, la clarificación, la filtración, la estabilización, el envejecimiento, y el embotellado. 
De cada una de las operaciones mencionadas en el párrafo anterior se han expuesto, en la manera de lo posible los fines, los riesgos asociados desde el punto de vista de la calidad intrínseca de los productos finales, los riesgos económicos que puede implicar la ruptura de un solo eslabón de la cadena de operaciones, en unos equipos que funcionan de manera muy intensa, a veces mas de 20 horas al día en un periodo de tiempo muy corto, y por último la situación en el mundo de la tecnología de los equipos asociados a estas operaciones.

La toma de muestras para su posterior análisis se realiza en el $68 \%$ de las bodegas por procedimientos manuales, el pincho, seguido del sistema de brazo articulado, que supone un nivel mayor de automatización del muestreo, y se encuentra instalado en $16 \%$ de las empresas.

El análisis de las muestras, tiene como fin, determinar los parámetros a través de los cuales se pondrá precio a la uva. Tradicionalmente el parámetro más utilizado ha sido el grado de azúcares, aunque en la actualidad se están incorporando otros indicadores como la acidez fija y total, el pH, tasa de lacasa de Botrytis cinerea, polifenoles, etc., si bien como ya ha sido puesto de manifiesto en el apartado de sistemas de fijación del precio para la uva, la introducción de éstos últimos parámetros está escasamente generalizada, debido sobretodo a dificultades en la puesta en práctica de métodos eficaces y rápidos capaces de determinar compuestos muy complejos.

En las dos terceras partes de las bodegas se utiliza el refractómetro, seguido del densímetro, que lo emplean la cuarta parte, y el analizador de infrarrojos que supone poco más del $6 \%$.

La recepción de la uva en la bodega se realiza en la totalidad de las bodegas mediante tolvas de varias toneladas de capacidad, equipadas de sistemas de pesada con una precisión de $1 \mathrm{~kg}$, para evitar los riesgos de litigios comerciales, aunque los principales riesgos asociados se encuentran en lo que respecta a la calidad del producto final:

- Los materiales de contacto, antiguamente de hormigón y ladrillos de cerámica, están siendo sustituidos por el acero inoxidable a un ritmo imparable.

- El tiempo de permanencia en la tolva que si es excesivo implica oxidaciones, y el aplastamiento excesivo de la uva que causará fermentaciones anticipadas e incontroladas lo que implicará el deterioro de la calidad del vino.

El despalillado tiene como función principal separar las bayas del raspón e incluso de todas las partículas vegetales presentes, respetando la integridad de las bayas y en particular las pepitas o semillas. En la vinificación en blanco los raspones comunican un sabor herbáceo al vino, siendo los impactos sobre el perfil gustativo del vino negativos, por lo que se prefiere que estos sean eliminados; en el caso de los tintos los raspones comunican al vino mayor volumen en boca e intensidad tánica, astringencia y sequedad. Por otro lado la ausencia de raspones incide en un peor drenaje de los orujos y en una mayor productividad en el llenado de los depósitos o prensas, ya 
que el volumen ocupado por una vendimia despalillada es claramente inferior al de una vendimia únicamente estrujada o entera.

Las despalilladoras más antiguas son centrífugas, diseñados en su mayor parte sobre todo por objetivos de productividad de las grandes bodegas, con el consiguiente riesgo de trituración. Hoy en día la gran mayoría de las despalilladoras son de eje horizontal y rejilla rotativa que respetan la integridad de la baya.

El estrujado tiene como objetivo provocar el reventamiento de las bayas, y así liberar zumo de las células de la pulpa, sin romper, dañar o aplastar las pepitas o semillas ni los raspones cuando aun están presentes.

Las estrujadoras más corrientes consisten en dos rodillos de superficie de metal o caucho que giran en sentido contrario con un espacio de separación regulable para adoptar el estrujado a la dimensión de la baya. En la mayoría de los casos de manera justificada el estrujado se sitúa tras la despalilladora en la línea de elaboración, ya que el estrujado de bayas enteras que caen por gravedad de una despalilladora no provoca trituración complementaria. Muy a menudo las operaciones se realizan en una sola máquina.

El estrujado no tiene, injustificadamente una imagen muy positiva entre ciertos vinificadores, debido a la utilización que han hecho líneas muy productivistas de elaboración de los años sesenta, asociados a sistemas centrífugos que provocaban trituraciones muy fuertes que implican efectos negativos (degradación de los aromas, aumento de las tasas de fangos, etc.). La operación de estrujado, cuando se maneja bien, y se respeta la uva proporciona numerosas ventajas, siendo que su colocación se convierte en imprescindible.

El $70 \%$ de las bodegas encuestadas cuenta con máquinas integrales de despalillado y estrujado de eje horizontal y rejilla rotativa, y el $36 \%$ disponen de estrujadora de rodillos, por lo que tan solo el $6 \%$ de las bodegas tienen sistemas centrífugos de eje horizontal o vertical que traten agresivamente y de manera poco recomendable el raspón y la bayas conjuntamente.

El prensado presenta como principal función la de extraer el mosto contenido en la vendimia estrujada y escurrida o el vino de los orujos de uva fermentada en el caso de la elaboración con la técnica de la maceración carbónica. El escurrido suele considerarse como un prensado, estribando la diferencia en el nivel de presión aplicado sobre la baya. Otras funciones del prensado son: limitar la producción de fangos la rotura de las pepitas y los daños a los raspones en el caso de las vendimias no despalilladas.

El prensado tiene un impacto muy fuerte sobre el tipo de vino, siendo la operación que permite alcanzar más completamente las diferentes partes de la baya, por lo que se convierte en una operación que debe ser concebida y manejada con mucha inteligencia. 
La separación de las fracciones de prensado es una acción esencial de vinificación en blanco y en tinto. El impacto del prensado sobre la productividad global de líneas de elaboración de vino es muy importante, siendo en muchos casos el principal cuello de botella. Los compromisos entre la productividad y la gestión de los riesgos cualitativos son muy difíciles, dado que en esta etapa la productividad necesita desplazamientos rápidos de la uva y presiones elevadas, que son factores que presentan altos riesgos de trituraciones.

Tradicionalmente se utilizaban las prensas de un solo plato vertical accionadas a mano y después mediante un gato hidráulico, que han sido desplazadas (aunque permanecen en algunas bodegas o regiones como referencia cualitativa) por cuestiones de productividad por las horizontales discontinuas de platos ( 1 o 2) de cajas cilíndricas caladas, que prensan la uva aplicando una presión según el eje del cilindro.

Las prensas continuas de caja horizontal cilíndrica prensan la uva por medio del movimiento de un tornillo sinfín que comprime la uva sobre una compuerta de salida parcialmente abierta. La uva es sistemáticamente desplazada varios metros con frotamientos importantes sobre la caja y los efectos secundarios (tasa de fangos, dificultades de clarificación del mosto y de los vinos, concentraciones en compuestos fenólicos etc.) pueden entrañar costes de tratamientos suplementarios que minimizan sus ventajas simples de productividad.

Se ha extendido el uso de prensas de membrana, que están desplazando progresivamente las prensas anteriormente citadas continuas de tornillo o de impulsión, las horizontales de platos o las prensas verticales Las prensas neumáticas discontinuas de membrana de cajas cilíndricas caladas o cerradas prensan la uva por presión radial ejercida por una membrana inflada con aire comprimido o con agua, dándose que el espesor de las uvas es débil, no sobrepasando en cualquier caso el diámetro de la caja, con las consiguientes ventajas cualitativas que este factor conlleva (extracción de mostos de calidad). Las condiciones de utilización (llenado, programación de los ciclos) tienen una incidencia determinante sobre el rendimiento de estos equipos.

Entre los sistemas menos extendidos se puede citar la prensa de bandas transportadoras, que prensan la uva sin frotamiento por medio de una disminución progresiva del espacio entre las dos bandas, combinando, al menos a escala teórica las ventajas cualitativas de las prensas discontinuas neumáticas y el funcionamiento continuo.

Por ultimo, en el ámbito de la investigación y desarrollo los esfuerzos se dirigen hacia la puesta a punto de prensas con un funcionamiento continuo o secuencial de calidad, que puedan obtener grandes caudales.

En el ámbito del estudio, el $63 \%$ de las empresas utilizan las prensas continuas horizontales de tornillo sinfín, un $23 \%$ han instalado prensas neumáticas, otro $6 \%$ disponen de prensas discontinuas de platos y menos de un $1 \%$ lo hacen con prensas de bandas. 
La función del transporte de la vendimia entera o estrujada es desplazar ésta de una operación unitaria a otra, si bien se debe utilizar desde el punto de vista cualitativo el efecto de la gravedad siempre que sea posible, limitando el número de trasiegos como tales. Los sistemas de transporte con cinta están desplazando progresivamente los de tornillo sinfín, ya que las bandas transportadoras de caucho o poliéster limitan el desgranado de las bayas y el aplastamiento de la vendimia.

El transporte de la más estrujada se realiza de manera generalizada en todas las bodegas en estudio con bombas de vendimia, las cuales han sufrido numerosos cambios en los últimos veinte años. El uso del acero inoxidable se ha generalizado, desplazando al acero normal o al bronce. Existen muchos tipos: bombas de engranajes, de pistón y de claveta rotativa, de rotor elíptico, o helicoidal, o de paletas, cuyos rendimientos dependen estrechamente de las velocidades de rotación y de las cilindradas.

Respecto a la operación del transporte de mostos y vinos, las principales misiones son la continuidad del funcionamiento de la línea de elaboración de vino, y el respeto de los mostos y los vinos a la salida de la operación unitaria precedente. Los riesgos principales son los frotamientos y las alteraciones del estado coloidal o de las partículas en suspensión y las oxidaciones por entradas no controladas de aire.

Los transportes de vinos y mostos son muy variables de una bodega a otra, pudiéndose citar medios tan variados como los que utilizan la simple gravedad, las tuberías, las bombas de pistón, las bombas de rotor helicoidal, los canales de obra, los planos inclinados etc.

El desfangado consiste en la clarificación del mosto por eliminación más o menos importantes de las materias sólidas, los fangos (esencialmente restos vegetales en suspensión), traduciéndose su influencia normalmente en la mejora de la calidad organoléptica a través de la modificación del aroma fermentativo o secundario, sobre todo en vinos blancos de "tipo tecnológico", que cuidan la calidad del aroma secundario procedente de la fermentación alcohólica.

La técnica de desfangado más simple, consiste en la sedimentación o decantación estática de las partículas, que sigue siendo el método más extendido de clarificación de mostos antes de la fermentación, pero con la desventaja de inmovilizar un volumen importante de depósitos. Más del 88 \% de las bodegas cuentan con sistemas de sedimentación.

Se pueden utilizar igualmente medios mecánicos, como las técnicas que hacen uso de la centrifugación o la filtración, que permiten trabajar en continuo. En este último caso la filtración con filtro rotativo a vacío permite la clarificación más avanzada, aunque algunos autores indican que la realiza en exceso. Esta técnica no se aplica a la clarificación del vino, ya que provoca una eliminación importante de gas y de aromas, debido a la aspiración por vacío. Su principal aplicación son productos muy cargados como los fangos y las lías cuando su valor cualitativo y económico puede ser interesante. Los filtros prensa permiten recuperar fangos en las condiciones anteriormente expuestas. En ambos casos, el nivel de implantación en las bodegas no alcanza el $5 \%$ de las mismas. 
La práctica de adición de enzimas (pectinasas) se ha convertido en algo corriente, siendo un medio eficaz para conseguir mostos bien clarificados, aunque en la realidad menos del 3 \% de las bodegas efectúan esta práctica.

Por último y a pesar de que ninguna de las bodegas la tenga implantada, una técnica de desarrollo reciente, la flotación que asegura la eliminación de los fangos hacia la parte superior de la cuba a clarificar gracias a un flujo ascendente de finas burbujas de aires o de nitrógeno, permitiendo un desfangado eficaz y en continuo.

Respecto al control de la fermentación, la introducción de las instalaciones frigoríficas en las bodegas ha supuesto una auténtica revolución, permitiendo el indispensable control de la temperatura. Siempre que el objetivo sea optimizar la calidad del aroma, es necesario manejar la fermentación a una temperatura baja (entre $15-20^{\circ} \mathrm{C}$ ) y constante sobre todo deseable en vinificación en blanco y rosado.

Antes de la fermentación los tratamientos frigoríficos con ayuda de intercambiadores de calor ya sean multitubulares (mostos sin desfangar) o de placas (para mostos desfangados e incluso filtrados), proporcionan a la masa de mosto una reducción importante de la temperatura (de $28{ }^{\circ} \mathrm{C}$ a $15{ }^{\circ} \mathrm{C}$ aproximadamente) con la finalidad de favorecer la decantación de mostos y ralentizan los arranques de la fermentación.

Una vez enfriado el mosto mediante el salto térmico anterior, es necesario mantener constante esa temperatura de fermentación, donde el agua fría es bombeada hasta un intercambiador. Gracias al desarrollo generalizado de los intercambiadores de calor instalados en cada cuba en forma de camisas perimetrales de enfriamiento, es posible una intervención en cualquier momento sobre el desarrollo de las fermentaciones, con un mejor control y un menor gasto energético. La seguridad (higiene sin riesgo de fuga) y el confort (sin necesidad de manejo manual) que aportan las camisas de enfriamiento, o dobles paredes, las convierten en la mejor solución para los depósitos de acero inoxidable.

Para los depósitos fabricados en poliéster o en hormigón no existe otra solución que la inmersión en el interior de las cubas de intercambiadores adecuados, en relación con la forma (placas, radiadores, etc.) y en cuanto al material de construcción (inox, polietileno reticulado, etc.).

El $88 \%$ de las empresas poseen algún sistema de refrigeración de los referidos, totalizando una cifra a asciende a 19.871.060 Frigorías/hora, con un valor medio por empresa de 225.808 Frigorías/hora.

En cuanto la incorporación de frío por volumen comercializado, la cifra media se acerca a 8 Frigorías/hectólitro y hora, cantidad que varía de manera importante atendiendo a los siguientes aspectos:

- Que la empresa elabore todo el vino que comercializa, en cuyo caso la tasa anterior será superior, respecto de las que comercializan un volumen significativamente mayor en relación con el elaborado, ya que en éste caso el 
frío será destinado preferentemente a las operaciones de filtración y estabilización de los vinos.

- La relación de vinos blancos y rosados elaborados respecto de los tintos, ya que en los primeros casos, el frío necesario por unidad de volumen elaborada normalmente triplica el valor que se precisa en el caso de los tintos.

EI 60 \% de las empresas encuestadas disponen de camisas perimetrales, cerca de la tercera parte, tanto de placas inmersas como de intercambiadores tubulares o de placas, y solo el 5 \% dispone de sistema de ducha de agua en los depósitos. Estos últimos sistemas conllevan una serie de desventajas frente a los mencionados anteriormente, ya que necesitan una vigilancia higiénica especial y no permiten mantener la temperatura del mosto en un valor predeterminado.

Por el contrario, los comienzos de la fermentación pueden acelerarse gracias a los calentamientos del mosto (intercambiadores de calor multitubulares con agua caliente, tuberías de calentamiento, circulación del mosto a través de calentadores eléctricos o a gas, etc. ). Por otra parte en la vinificación en tinto la maceración en caliente favorece la extracción de los taninos y el color.

El 34 \% de las empresas poseen algún sistema de calentamiento, totalizando una cifra a asciende a 11.955.900 Kcalorías/hora, con un valor medio por empresa de 323.132 Kcalorías/hora. Es evidente que la mayor parte de las empresas no disponen de sistemas de calentamiento, y utilizan el calor propio de la fermentación para la maceración de los hollejos en la elaboración del vino tinto.

Respecto a la adición de levaduras, la función principal es la de controlar las fermentaciones en los que se refiere al ritmo y acabado, aportando los perfiles aromáticos y gustativos a los vinos, dependiendo de las potencialidades de la uva.

En el mundo los dos casos más frecuentes son: la no aplicación de levaduras (utilización de la microflora indígena o autóctona) y la aplicación directa de levaduras seleccionadas en forma liofilizada, es decir las levaduras secas activas (LSA).

En cuanto a las levaduras seleccionadas, la mayor variabilidad proviene de la levadura utilizada, ya que en el mercado se tienen disponibles actualmente más de cien cepas diferentes presentadas como LSA, aunque todas no tienen la misma frecuencia de utilización, ya que las diez cepas más utilizadas representan más del $50 \%$ del total de las toneladas producidas y vendidas. En las bodegas de gran volumen se asiste a un reagrupamiento de las utilizaciones alrededor de 405 cepas, para los vinos de gama baja y media. Por el contrario y para los vinos producidos en condiciones específicas y personalizadas, se constata el mantenimiento de un número importante de cepas diferentes. resumirse:

Las ventajas que ofrece la utilización de levaduras seleccionadas podrían

- Una mayor rapidez en el desarrollo del proceso fermentativo. 
- Un incremento en la relación entre el alcohol desarrollado y el azúcar consumido.

- Una menor formación de ácidos volátiles, una más rápida clarificación y una mayor conservabilidad del vino.

- Una mayor expresión aromática y gustativa en el vino de las características varietales, y ausencia de alteraciones de la calidad organoléptica del vino, lo que se traduce un una mayor calidad intrínseca del mismo.

Los principales inconvenientes:

- Complicada manipulación del inóculo y pérdida de viabilidad de las células.

- La difícil selección de las cepas para que proporcionen las características organolépticas buscadas.

- Riesgo de contaminaciones de las levaduras seleccionadas al combinarse con las autóctonas.

Más del 70 \% de las bodegas de la región emplean levaduras seleccionadas y tan solo la tercera parte utiliza levaduras autóctonas.

En la operación de trasiego, una vez finalizada la fermentación alcohólica, el vino se separa de las lías, que son materias sólidas en suspensión restos vegetales (fracciones de raspón, piel, pulpa, pepitas), levaduras y otros microorganismos muertos susceptible de desarrollarse, que constituyen fuentes de alteraciones potenciales.

Esta separación, que puede ser natural mediante el fenómeno de la sedimentación la realizan el 80 \% de las empresas.

Cuando estas operaciones deben ser realizadas en continuo, en espacios de tiempo reducidos o con recursos en manos de obra limitados, existe la posibilidad de la centrifugación, que permite separar las partículas sólidas dispersas en el vino y eliminar en una etapa, sin consumo de coadjuvantes las partículas responsables del turbio. Los índices de clarificación son inferiores a los obtenidos por filtración por aluvionado y no son suficientes para el embotellado del vino. Por su polivalencia la separación centrífuga constituye una tecnología de futuro en asociación con las técnicas de membrana. En el caso de las bodegas estudiadas sólo se utiliza en el $5 \%$ de las mismas.

En referencia a la clarificación, a excepción de casos raros que se corresponden con vinos de prestigio de una cosecha relativamente antigua, o de la nueva tendencia a tolerar leves depósitos como garantía de la máxima integridad del producto, en general el mercado no acepta la presencia de depósitos de cristales y/o materia colorante. 
Normalmente el consumidor exige una buena limpidez, sea cual sea la edad del producto degustado; por otra parte las normas de intercambios comerciales son cada vez más severas en cuanto al número de gérmenes residuales microbianos.

Para responder a esta demanda el vinificador debe clarificar y después estabilizar el vino con respecto a los defectos de limpidez o desequilibrios fisicoquímicos o microbiológicos, ya que las especificaciones a cumplir por los productores son cada vez más severas, y tiende hacia la ausencia de defectos.

En el ámbito de las bodegas en estudio, generalmente tanto la clarificación como la estabilización sólo la llevan a cabo aquellos establecimientos que realizan directamente la operación de embotellado.

Actualmente, las principales técnicas de filtración disponibles son :

a) La filtración por aluvionado o kielserguhr

Es una filtración sobre tamiz que utiliza un coadyuvante (tierra de diatomeas, perlitas) puesto en suspensión en el medio a filtrar, que empobrece el vino de levaduras y bacterias susceptibles de desarrollarse y de alterar gravemente el vino. Esta filtración es delicada de manejar, aunque está muy extendida en las bodegas y es en general un tratamiento satisfactorio. Retiene partículas hasta de $10.10^{-6} \mathrm{~m}$, por los que a menudo es considerada como de desbaste.

Es utilizada por el $70 \%$ de las bodegas embotelladoras.

b) Filtración sobre placas y cartuchos

Son filtros de profundidad y actúan mediante retención mecánica en sentido amplio y electrostática (fija por adsorción los elementos cargados negativamente como microorganismos y coloides). Las placas son generalmente realizadas a partir de celulosa y pueden comunicar al vino un ligero gusto a papel. Los umbrales de retención están comprendidos entre 0,1 y $10.10^{-6} \mathrm{~m}$. embotellan.

Esta técnica es utilizada aproximadamente por el $60 \%$ de las empresas que

\section{c) Filtración sobre membranas}

Son filtros de superficie de espesor limitado, denominados también membranas filtrantes (policarbonato y polímeros porosos a partir de celulosa) que trabajan por tamizado superficial, con umbral de utilización en enología de $0,5.10^{-6} \mathrm{~m}$.

Esta filtración es una práctica habitual y universalmente adoptada en enología, que suele coincidir con la última etapa de clarificación de los vinos, realizándose antes del embotellado después de una filtración sobre placas o cartuchos.

Disponen de esta filtración el 37 \% de las bodegas que embotellan. 
Cada una de estas técnicas aplicadas a la filtración de los vinos independientemente una de otra, se revelarían insuficientes, no obstante asociadas entre si, constituyen una herramienta de clarificación muy interesante, bien adaptada al caso complejo del vino. Por esta razón se ha desarrollado mucho su utilización por embotelladores y productores dando lugar a resultados técnicos satisfactorios, ya que en la mayoría de los casos los vinos no ofrecen dificultades de filtración que sean infranqueables.

Los principales inconvenientes son los siguientes: utilización de fungibles con costes de compra no despreciables, a los que hay que añadir el coste de eliminación, ligado al vertido de una elevada carga contaminante; automatización difícil de éstas técnicas, y por último, los riesgos de parada por colmatado de los filtros.

\section{d) Microfiltración tangencial}

Cuando los problemas de filtración se hacen demasiado cotidianos (renovación frecuente de pasteles de filtración, de placas o de cartuchos de membranas), la microfiltración tangencial aparece como una tecnología alternativa mejor adaptada para el tratamiento de vinos difíciles de clarificar. El diámetro medio de los poros es del orden de 0,05 a $1.10^{-6} \mathrm{~m}$.

La Organización Internacional de la Viña y del Vino (OIV) recomienda la utilización de membranas de microfiltración, a condición de que los materiales de las membranas en contacto con el vino sean conformes a la reglamentación, excluyendo la utilización de ultrafiltración (con diámetros de retención hasta $0,001.10^{-6} \mathrm{~m}$.), que provoca retenciones demasiado fuertes de los constituyentes de los vinos, con incidencias negativas sobre las cualidades organolépticas de los vinos.

Actualmente existe una falta de competitividad económica, resultante de las pequeñas densidades de flujo de esta técnica en comparación con las descritas anteriormente. No obstante existen ventajas comparativas relacionadas con la reducción sustancial de los fungibles, funcionamiento continuo y automático, que genera ganancias de productividad, vertidos contaminantes despreciables y reducidas pérdidas de vino que son interesantes en vinos de gran valor añadido.

Esta técnica está apoyada en constantes trabajos de investigación, ya que posee bastantes posibilidades de implantarse progresivamente según el ritmo de diseño de las nuevas cadenas de tratamiento de vino y de renovación de los equipos de filtración que necesariamente se ha de realizar al final de la explotación de la instalación correspondiente. Su desarrollo puede depender también de los condicionantes reglamentarios ligados a los vertidos, $\mathrm{y}$ a la disponibilidad de coadyuvantes de filtración regenerables.

\section{Por último, y como era de suponer, ninguna de las bodegas en estudio tienen instalada esta técnica.}

Con referencia a la estabilización, tiene por objeto conservar la limpidez y evitar las desviaciones o los accidentes durante la conservación, aunque sin bloquear la 
evolución normal y armoniosa del vino, su maduración. Es una operación complementaria y no sustituyente a la de clarificación.

Asegurar una perfecta estabilidad físico química de los vinos se ha convertido para el embotellador en una regla de comercialización y en un imperativo de aseguramiento de la calidad exigido por los clientes, en el contexto de una comercialización mundial.

Existen en la actualidad dos vías de estabilización con sus correspondientes técnicas:

- Vía física, que son en general métodos de eliminación. Son más numerosas y sobre todo las únicas autorizadas actualmente, aunque solo se estudian la técnica del frío artificial y la electrodiálisis.

- Vía química, que utiliza esencialmente aditivos de tipo coloides protectores, cuyo principio es inhibir la cristalización de un medio en estado de saturación. La utilización de coadyuvantes se tendría más bien que evitar, de un lado, por el respeto cualitativo de los vinos, y de otro por la eficacia difícilmente controlable en el tiempo. De las muchas técnicas disponibles, el estudio se ha centrado en el encolado e intercambio iónico.

\section{a) Tratamiento por frío artificial}

El denominador común de todas las técnicas de estabilización por frío es provocar de forma repentina una cristalización con objeto de eliminar los elementos de sobresaturación que son inestables a corto plazo en las condiciones normales de uso. Es la técnica más tradicional y por lo general, un intercambiador de calor permite llevar el vino hasta una temperatura de $-4{ }^{\circ} \mathrm{C}$, que se mantiene durante una semana en el caso de los vinos blancos o varias en el caso de los tintos.

\section{Esta técnica es utilizada en el 87 \% de las bodegas que embotellan}

\section{b) Tratamiento por electrodiálisis}

El desarrollo de esta técnica de inscribe en un planteamiento que privilegia los medios de eliminación físicos en detrimento de la utilización de aditivos químicos.

Un campo eléctrico continuo aplicado entre dos electrodos permite la extracción en forma iónica del potasio, calcio y tartrato principalmente. Es igualmente un procedimiento tecnológico continuo que se integra muy bien en la línea de elaboración justo antes del embotellado, y regulable, adaptándose la tasa de tratamiento al mínimo impuesto por el grado de inestabilidad propia del vino a tratar.

Esta técnica garantiza el acabado, es complementaria al frío, aunque en numerosas ocasiones puede presentarse como alternativa. El procedimiento es nuevo en enología (de hecho, ninguna de las bodegas lo posee), si bien es ya ampliamente utilizada en el sector agroalimentario y en farmacia, donde presenta ya ciertas garantías 
en estos ámbitos de fuertes condicionantes cualitativos. El proceso que actualmente se encuentra en estado de experimentación industrial se orienta hacia el riesgo cero y el aseguramiento de la calidad.

Proporciona además, gracias a la trazabilidad dada por el automatismo, la integración en un sistema de certificación de las empresas vinícolas. Su desarrollo industrial es perfectamente probable, después de las recomendaciones favorables de la OIV y actualmente es una técnica autorizada en el registro de práctica enológicas, reguladas por el Reglamento (CE) 1622/2000, que introduce un código comunitario de prácticas y tratamientos enológicos.

\section{c) Encolado}

El encolado consiste en incorporar al vino mas o menos turbio e inestable unas sustancias capaces de flocular y de sedimentar, arrastrando las partículas en suspensión o en estado coloidal (macromoléculas de tamaño variable ente 3.000 y $300.00010^{-6} \mathrm{~m}$ ), que se corresponden con las proteínas, los poliósidos, los polifenoles, y los compuestos férreos o cúpricos.

Existen dos grandes grupos de colas: las orgánicas (gelatinas, cola de pescado, albúmina, caseinas, etc.) y las inorgánicas (bentonitas y ferrocianuro de potasio principalmente). En la práctica es recomendable evitar todo exceso en las dosis de cola, ya que enflaquecen el vino y suprimen muchos aromas. tratamiento.

Solamente el $17 \%$ de las empresas que embotellan utilizan este tipo de

\section{d) Intercambio iónico}

Consiste en una técnica sustitutiva que trata de reemplazar preventivamente los compuestos del ácido tartárico inestables por compuestos más estables. Se halla extendida fuera de los países de la Unión Europea (donde esta práctica no está autorizada), y en consecuencia se ha constatado que ninguna de las bodegas en estudio utiliza este procedimiento.

Las resinas intercambiadoras de cationes aseguran el reemplazo de los cationes potasio y calcio por cationes sodio y magnesio, que dan lugar con el ácido tartárico a sales mucho más solubles, y por tanto menos precipitables, lo que conduce a una garantía real de estabilidad frente al frío, pero también a una intensa evolución de las características organolépticas del vino, causadas por esta profunda modificación salina.

Lo seductor de esta proceso, por su carácter económico del coste del tratamiento, no debe prevalecer sobre su efecto desnaturalizante. La técnica es difícilmente modulable y adaptable a las características particulares de los vinos a tratar, con el estado actual de la tecnología y su conocimiento.

En lo que respecta al control de las condiciones de conservación de los vinos, cada vez se considera más importante. En efecto, las temperaturas elevadas de 
almacenamiento aceleran los fenómenos de oxidación y alteran la calidad aromática de los vinos. Una primera posibilidad consiste en asegurar una ventilación natural o mecánica de las bodegas, realizando preferentemente la aireación de noche, durante el verán, y por el día durante el invierno. Sin embargo solo el aislamiento y la climatización de la bodega permiten un verdadero control de la temperatura.

En el ámbito del estudio las condiciones de conservación se cuidan especialmente en los vinos que son destinados a envejecerse en madera de roble, bien sean crianzas o reservas. En este sentido, de las bodegas que envejecen, aproximadamente la mitad lo hacen en cavas subterráneas y, la otra mitad emplea sistemas de climatización artificiales, consistentes en naves debidamente aisladas y con sistemas de refrigeración que controlan la temperatura en el interior de éstas.

Por último y en lo que respecta al embotellado, preparar un vino para esta operación, es hacer que reúna las condiciones necesarias para poner en valor su aspecto visual, y asegurar su estabilidad microbiológica y fisicoquímica, sin alterar sus cualidades organolépticas presentes y futuras. Las operaciones a realizar para alcanzar este objetivo dependerán, por una parte, del conocimiento del estado del vino en el momento de esta preparación para el embotellado (su historia), y por otra parte, del futuro que le espera, en cuanto al tiempo de conservación posterior, y en cuanto a las condiciones de transporte y de crianza antes del consumo.

El embotellado es la operación más próxima a la comercialización y sufre de lleno las exigencias de los clientes, siendo la razón por la que a menudo se considera como la primera zona de producción para poner en marcha un aseguramiento de la calidad.

De la muestra en estudio, el $48 \%$ de las bodegas embotellan, lo que supone en volumen el $26 \%$ de la producción comercializada, correspondiendo los valores por encima de la media a las empresas jóvenes, a las pertenecientes a la DO Valencia, las sociedades cooperativas de $2^{\circ}$ grado, las sociedades mercantiles, las empresas muy grandes, las pequeñas y muy pequeñas empresas.

Se consideran tres tipos de técnica de embotellado, que normalmente son las más utilizadas en el sector: la termolización o embotellado en caliente, la pasteurización, y la filtración estéril.

\section{a) La termolización o embotellado en caliente}

El tratamiento térmico de los vinos, que busca sobre todo la eliminación de los microorganismos presentes (levaduras y bacterias), constituye una tecnología relativamente poco extendida hoy en día, debido a los inconvenientes reales relacionados con las modificaciones de la calidad organoléptica de los vinos. Este procedimiento que ha sido ampliamente practicado para el acondicionamiento de los vinos de calidad corriente, sólo se utiliza en el ámbito del estudio en el 13 \% de las bodegas embotelladoras. 


\section{b) La pasteurización}

Consiste en llevar el vino a la temperatura de pasteurización lo más rápidamente posible y mantenerlo durante un tiempo dado a esta temperatura, antes de volverlos a llevar a la temperatura ambiente. En la práctica los tiempos de mantenimiento utilizados más frecuentemente para vinos con una carga microbiana normal, son 20 segundos y con una temperatura de $72{ }^{\circ} \mathrm{C}$. Se ha demostrado que la inocuidad del tratamiento es total sobre las cualidades organolépticas de los vinos presentes y futuros.

Además de la eliminación del riesgo microbiológico, limita la precipitación tartárica. A pesar de las citadas ventajas sólo es utilizado en el 13 \% de las bodegas embotelladoras.

\section{c) Filtro estéril}

Hace referencia a la filtración sobre membranas y tiene por objeto retener los microorganismos presentes en el vino. Generalmente esta filtración se realiza antes del embotellado, después de una filtración sobre placas o cartuchos. Para vinos de calidad o cuando el tipo de vino lo exija, la filtración final sobre placas y membranas esterilizantes permite obtener una esterilidad correcta sin tratamiento térmico y con una reducción de las dosis de anhídrido sulfuroso. Así los han entendido las bodegas del estudio, en las que está implantadas esta técnica en más del 90 \% de las mismas.

Como conclusión resaltar el aceptable nivel en general registrado, en la tecnología de las instalaciones que intervienen en todo el proceso de elaboración, resultado del importante esfuerzo inversor que se ha producido en el subsector en los últimos años.

\subsection{Automatización. Tecnologías de la información y la comunicación (TIC)}

Las nuevas tecnologías y en concreto la informatización de las empresas contribuyen a aumentar la eficacia y productividad de los procesos productivos y de la comercialización, convirtiendo a la tecnología en un factor de competitividad. El desarrollo del software es absolutamente necesario para la implantación de sistemas automatizados de trazabilidad, controles de la calidad, gestión de stocks, seguimiento de las distintas operaciones, garantía del control productivo, constituyendo una aportación fundamental al concepto de calidad total.

La informática que en principio ayudaba principalmente a la gestión contable y comercial, se generaliza y hoy en día se aplica a las tecnologías de vinificación. Un ejemplo es el control de las fermentaciones con sistemas expertos. El $80 \%$ de las empresas disponen de software para la gestión contable, y aproximadamente la mitad de ésta cifra cuentan con software con finalidades comerciales. Destacar que sólo en el 15 $\%$ de las bodegas disponen de software de apoyo a las operaciones de elaboración, envejecimiento y envasado. 
En el marco de aseguramiento de la calidad están apareciendo sistemas de información y de ayuda a la decisión para registrar los datos técnicos, simular los procesos y emitir diagnósticos.

Los automatismos se desarrollaron en primer lugar, en las instalaciones de recepción de las grandes unidades de producción, con el fin de aumentar la productividad y la seguridad de las operaciones de transporte. El principal inconveniente es la difícil amortización de las inversiones correspondientes, que no se utilizan más de dos meses al año. No obstante los automatismos se están desarrollando en la gestión de los procesos unitarios y los equipos. El objetivo buscado es el control en tiempo real de los procesos complejos tales como el prensado, la fermentación o la estabilización por frío, y el aumento de la fiabilidad de equipos tales como los de embotellado y manutención.

La automatización de los procesos implica disponer de sistemas u otras herramientas que permitan capturar la información recogida por sensores, autómatas u otros elementos incorporados a la maquinaria y equipos de cada operación o proceso unitario, para su posterior envío a las unidades de tratamiento y gestión de la información mediante elementos informáticos (hardware y software), con el objetivo de regular y controlar de manera automática todo el proceso de elaboración desde la recepción de la materia prima hasta la comercialización del vino.

En este último sentido, la operación más asistida por este tipo de sensores es la fermentación (la más compleja del proceso de vinificación), presente en el $30 \%$ de las bodegas, seguidas en importancia por las operaciones de recepción de la uva, prensado, estabilización, embotellado, envejecimiento y estrujado, siendo que en esta última operación, los sensores están presentes en el 10 \% de las bodegas.

La incorporación de las Tecnologías de la Información y las Comunicaciones (TIC) en las empresas está suponiendo que la información se pueda procesar y transferir a otros lugares (o empresas) mediante las redes de comunicación. La gestión adecuada de la información pasa a ser un elemento clave para la competitividad de las empresas. La digitalización implica no solamente un cambio en las organizaciones y procesos para un mismo tipo de producto, sino un cambio en la propia concepción y definición de los tipos de negocio y de los nichos de mercado donde poder competir.

La digitalización de procesos abarca tanto los internos de una empresa producción, recursos humanos, etc.) como los externos (básicamente, relación con clientes y gestión de compras) y supone:

- Disponer de procesos de producción más flexibles.

- Coordinar los diferentes ámbitos de actuación de las empresas.

- Disponer más fácilmente de la información que es relevante para su negocio, así como el acceso a nuevos conocimientos económicos y tecnológicos. 
En la digitalización en la Pyme agroalimentaria como puede observarse en el gráfico 5.11, las TIC pueden ser aplicables, con mayor o menor facilidad, a todo el conjunto de procesos de una empresa, obteniendo en cada caso un determinado grado de mejora en la ejecución de los procesos empresariales. Además, permite disponer a su vez de información digitalizada referente a los procesos de la empresa lo que facilita la gestión documental y de la información referente al negocio, que constituye la base del Sistema de Gestión del Conocimiento.

\section{GRAFICO 5.11}

\section{DIGITALIZACIÓN APLICADA A LAS DIFERENTES ÁREAS DE LA EMPRESA}

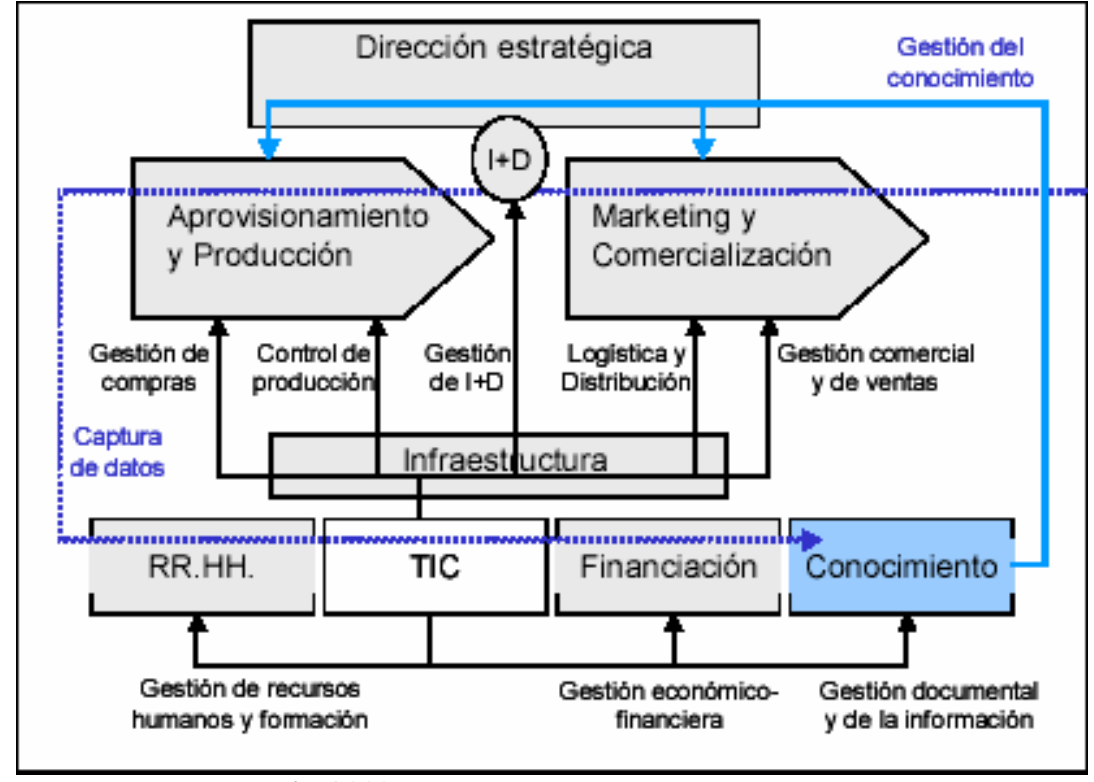

Fuente: Instituto Cerdá, 2003

Sin embargo (encuesta PYMES 2003, Instituto Cerdá) la percepción extraída de dicho estudio es que la Pyme agroalimentaria está interesada en adoptar las TIC en las diferentes áreas funcionales de su empresa, con la contabilidad por delante de los clientes, en general, y específicamente con unos mayores intereses en el área de elaboración (este último aspecto no ha sido confirmado con los resultados obtenidos de la encuesta).

Finalmente, el proceso de digitalización se completa con el aprovechamiento de la posibilidad de intercambiar información por medios digitales para establecer relaciones de colaboración por medios electrónicos. Estas relaciones de colaboración con diferentes agentes, y de diferente tipo, se definen como:

- Intranet, herramienta interna de la empresa, donde la colaboración va enfocada a los empleados.

- Extranet, incluye la colaboración de agentes externos, como proveedores o clientes. 
- ERP, permite automatizar e integrar la mayor parte de los procesos de un negocio, compartir datos, producir y acceder a información en tiempo real entre las diversas áreas de la empresa (compras, ventas, producción, finanzas, recursos humanos etc.

- CRM, herramienta de colaboración diseñada para conocer en mayor detalle las necesidades y hábitos de compra de los clientes.

- SCM, herramienta de colaboración a lo largo de toda la cadena logística de entrada, y permite optimizar su gestión en los campos de compras, planificación, aprovisionamiento, producción, almacenaje y transporte.

- Banca electrónica, que permite trasladar la operativa con la banca a medios electrónicos.

En lo relativo a los paquetes de gestión integrada (ERP, CRM, SCM),en general, este tipo de herramientas todavía están en fase de introducción en las empresas del ámbito del estudio ya que la gran mayoría de las bodegas que disponen de paquetes de software, éstos son independientes entre las áreas críticas de la empresa (elaboración, comercial, logística, contabilidad, etc.), aunque esta fórmula será sustituida progresivamente por los sistemas de gestión integrados (ERP), cuya implantación es más difícil y costosa.

En lo que respecta a la introducción de Internet, como vehículo de comunicación entre la empresa y su entorno exterior (clientes, proveedores, administración etc.), se destacan las principales funciones que realiza en el ámbito de las bodegas:

- Publicidad. Las páginas web de las empresas vitivinícolas que se anuncian a través de Internet, muestran por lo general una gran información al consumidor acerca de la propia empresa, del emplazamiento de la bodega y de los viñedos en su caso, del proceso enológico, de la viticultura y fundamentalmente de los productos que elaboran (publicidad informativa), junto a otra información complementaria. Existen además de las páginas web de las bodegas, denominaciones de origen, vinotecas, foros de debate, servidores de noticias y grupos de discusión, donde se "reúnen" personas movidas por las mismas inquietudes y apasionadas por el mundo del vino.

- La publicidad no pagada. Es otra herramienta de comunicación con el objeto de dar a conocer sus productos, marcas, bodegas, etc., pero con la particularidad de que dicha información nos es ofrecida por la propia empresa, sino por terceros (organismos oficiales, instituciones públicas, aficionados al vino, sociedades de sumillieres etc.), que actúan como páginas anfitrionas sin coste alguno para las bodegas.

- El patrocinio. En ocasiones la bodega actúa de patrocinadora de una página web que normalmente tiene relación con el sector del vino. Se puede citar el caso de tiendas de vinos virtuales en la que se anuncian varias bodegas, que se pueden visitar con un simple linkaje. 
- Las relaciones públicas. Con el correo electrónico (e-mail)se permite una estrecha comunicación entre la empresa y el visitante (cliente potencial o real), a la vez que se mejora la comunicación, con lo que se favorece un servicio más rápido al cliente.

- La venta electrónica. La empresa vitivinícola además de informar realiza la venta des sus productos, estableciéndose mercados con escala en el ámbito mundial y más, teniendo en cuenta que por lo general los usuarios de Internet disponen de un cierto poder adquisitivo.

La relación efectividad-coste de este conjunto de técnicas comerciales hacen de Internet una herramienta especialmente adecuada para las Pymes, entre las que se encuentran las práctica totalidad de las empresas bodegueras.

En el caso de las bodegas en estudio, la totalidad de las empresas poseen correo electrónico, por lo que al menos potencialmente las empresas pueden aprovechar la agilidad y economía que esta red proporciona en el intercambio de información con todos los agentes con los que se relaciona, tato internos (Intranet), como externos (proveedores, clientes, etc.) de la Extranet.

Con respecto a la página web, sólo alrededor de la tercera parte de las bodegas dispone de este medio, habiéndose detectado que esta frecuencia crece con la juventud de las empresas (42 \% de las jóvenes, frente al $27 \%$ de las antiguas). En las sociedades mercantiles la presencia de página web supera el $50 \%$, frente a las cooperativas de primer grado que en ningún caso superan el $28 \%$. Esta frecuencia también es mayor en las empresas muy grandes seguidas de las pequeñas y muy pequeñas. Por último la DO Alicante con el $42 \%$ de sus empresas con página web, casi duplica en frecuencia observada en la DO Valencia.

Como conclusión, en la actualidad las bodegas no aprovechan suficientemente las posibilidades tecnológicas de la información y las comunicaciones, presentando un grado de adopción que no se corresponde ni con su peso en la economía de la región, ni con su capacidad competitiva en relación con el resto de países productores de vino de la Unión Europea.

\section{INNOVACIÓN TECNOLÓGICA}

En el escenario actual, las empresas se encuentran con el reto de la internacionalización de mercados, la globalización de la economía y la necesidad de aumentar su competitividad, con el objetivo de mantenerse en un mercado cambiante, caracterizado por una oferta de nuevos productos mayor que la capacidad de demanda, nuevos mercados emergentes, etc. Con estos condicionantes, la supervivencia de las empresas pasa por su capacidad de innovación, tanto en la generación de nuevos conceptos, como de nuevos productos o nuevos procesos. 


\subsection{Causas y efectos de la innovación tecnológica}

Durante los últimos años el sector agroalimentario ha dado un gran salto cualitativo gracias a la incorporación de la investigación, desarrollo e innovación $(\mathrm{I}+\mathrm{D}+\mathrm{i})$ en la cultura empresarial. Esta incorporación ha venido promovida por factores como (Institut Cerdá, 2003):

- Nuevas demandas del consumidor (especialmente en materia de calidad y seguridad).

- Entorno competitivo que fuerza a las empresas a innovar en sus procesos productivos (nuevas tecnologías de envasado, maduración y fermentación, automatización de procesos, etc.) y, por otro lado, promueve la innovación en productos (nuevos alimentos funcionales, nuevos productos alimentarios intermedios de base tecnológica que dan lugar a un mayor valor añadido, etc.).

- Entorno normativo para el aseguramiento de la trazabilidad y la sostenibilidad a lo largo del ciclo de vida de los productos agroalimentarios.

La inversión en innovación se encuentra bastante repartida entre:

- Nuevos procesos productivos, donde se encuentran las tecnologías de producción y automatización (por ejemplo, tecnologías enzimáticas, tecnologías de maduración y fermentación mediante el desarrollo de cepas de microorganismos).

- Nuevos productos. La industria agroalimentaria tiene necesidad de encontrar nuevas materias primas y desarrollar nuevos productos intermedios que mejoren las condiciones de la cadena de producción, especialmente aquellos productos nutricionales y funcionales con características activas de cara al consumidor.

- Nuevas formas organizativas. La incorporación de las TIC a las empresas, muchas veces impulsada desde proveedores o clientes (por ejemplo, implantación de sistemas de transmisión electrónica de datos y sistemas de gestión en tiempo real de la cadena de aprovisionamiento), ha modificado considerablemente las formas de organización de las empresas.

Respecto a los beneficios aportados por la innovación se pueden mencionar, la mejora de producto, reducción de costes y la mejora de procesos. Es decir la innovación supone una fuente de competitividad que permite a las empresas afianzar su posición en el mercado.

\subsection{Indicadores de la $\mathbf{I}+\mathrm{D}+\mathbf{i}$.}

En lo que respecta al esfuerzo innovador (relación entre la inversión anual media en el último trienio en $\mathrm{I}+\mathrm{D}+\mathrm{i}$ y el valor de la producción), los resultados 
obtenidos en las bodegas del estudio muestran que sólo el $8 \%$ de las empresas han realizado han efectuado inversiones por este concepto, que ascienden a $461.695 €$ lo cual supone un esfuerzo inversor del 0,22 \%, cifra claramente insuficiente, si se tiene en cuenta que el objetivo fijado por la Unión Europea en la Cumbre de Lisboa se sitúa en el $3 \%$ de gastos sobre ventas.

Las causas de los bajos ratios de inversión en $\mathrm{I}+\mathrm{D}+\mathrm{i}$ que se observan hay que buscarlas en aspectos intrínsecos de las empresas pero también en factores del entorno. A continuación se describen los factores identificados como posibles determinantes de estos resultados(Institut Cerdá, 2003):

- El marco fiscal existente en España no favorece especialmente a las empresas para aumentar el esfuerzo innovador de aquellas empresas que se encuentran con dificultades para financiar estas actividades con recursos propios. Recientemente, con la creación de la Agencia de Acreditación en Investigación, Desarrollo e Innovación Tecnológica (AIDIT), dependiente del Ministerio de Ciencia y Tecnología (MCYT), se ha puesto fin a la inseguridad de las empresas en el momento de diferenciar de manera objetiva $\mathrm{y}$ cualificada los contenidos de $\mathrm{I}+\mathrm{D}+\mathrm{i}$ de un proyecto y en la conceptualización de estos contenidos. Esta inseguridad implicaba riesgos empresariales y también fiscales muy importantes que actuaban como freno para el uso de este instrumento.

- Capacidad de financiación. Es preciso crear los instrumentos financieros necesarios para asegurar la financiación de iniciativas de I+D+i. En general, los instrumentos que cubren el riesgo del proyecto no están suficientemente al alcance de la Pyme. Basta comentar la cantidad de empresas que se ven obligadas a renunciar a Anticipos Reembolsables del Programa PROFIT ya que no pueden avalarlos. Esta deficiencia se ve resuelta en parte con la prometedora creación de las Sociedades de Garantía Recíproca (SGR) y la lenta expansión de las compañías de capital riesgo, si bien en este último caso los capitales mínimos de entrada son tan elevados que dejan fuera a multitud de empresas con interesantes proyectos de $\mathrm{I}+\mathrm{D}+\mathrm{i}$.

- Promoción de la competencia. Un marco competitivo donde la I+D sea una fuente de diferenciación es siempre una fuente de ventajas competitivas fruto de las propias sinergias de mercado. En el caso español, caracterizado por un altísimo porcentaje de Pymes, a menudo ha primado la capacidad de adaptación de la empresa a su entorno, más que una estrategia ideada para convertirse en pioneros de sus respectivos sectores. Esto ha configurado, por un lado, un perfil de empresa muy flexible, pero poco dada a estrategias decididas en favor de la $\mathrm{I}+\mathrm{D}$.

No obstante esta flexibilidad se convierte en un valor añadido para la Pyme, teniendo en cuenta las nuevas tendencias en $\mathrm{I}+\mathrm{D}$, descritas por Chesbrough, según las cuales, hoy las ventajas competitivas a menudo vienen, por la incorporación y adaptación a la empresa de descubrimientos externos. Este nuevo modelo requiere de una nueva forma de organizar la gestión de la 
innovación, más allá de las ideas internas, y también del apoyo de estructuras tales como Observatorios tecnológicos, adaptados a las nuevas necesidades.

- Mejora del capital humano. Se ha detectado una elevada carencia tanto en personal como en formación específica para la innovación dentro de la propia empresa. Todos los proyectos de investigación emprendidos por las bodegas han tenido apoyo externo de centros de investigación sectoriales, universidades, etc.

- Defensa de la propiedad intelectual. La protección de resultados de actividades de $\mathrm{I}+\mathrm{D}+\mathrm{i}$ es uno de los factores que generan mayor desconcierto e inseguridad en los procesos de $\mathrm{I}+\mathrm{D}$. A menudo, las empresas se encuentran indefensas ante violaciones de sus patentes. Una queja generalizada en el sector es la indefensión existente desde que se solicita la patente hasta que se la concede a todos los efectos. Este lapso de tiempo, considerado a todas luces excesivo, es aprovechado frecuentemente por la competencia para copiar los nuevos desarrollos con total impunidad.

- Cultura empresarial. La Pyme debe interiorizar la necesidad de innovar, ya que arrastra un déficit histórico de cultura empresarial para la innovación, visualizando los beneficios derivados de ésta y, de que en definitiva la competitividad y supervivencia en el mercado, está directamente relacionada con la inversión en $\mathrm{I}+\mathrm{D}+\mathrm{i}$.

Como conclusión, destacar que la innovación no ha logrado extenderse y generalizarse a lo largo de todo el sector vinícola, y como consecuencia está utilizando en un bajo grado la inversión en I+D+i como estrategia de competitividad.

\section{CALIDAD Y SEGURIDAD ALIMENTARIA}

\subsection{Certificación de la calidad del producto.}

En el ámbito de la Comunidad Valenciana, las figuras de calidad predominantes son los vinos con Denominación de Origen (DO), caso de las de Alicante UtielRequena y Valencia, y los vinos de calidad con indicación geográfica, caso de la Indicación Geográfica Vino de la Tierra de Castellón (de la cual ninguna bodega ha contestado el cuestionario).

A pesar de que la totalidad de las bodegas de la muestra se encuentran inscritas en alguna DO, el $85 \%$ de las empresas han comercializado vinos con DO, lo cual supone solamente el 45 \% de la producción comercializada total efectuada por las bodegas de la muestra, habiendo registrado los mayores porcentajes las empresas pertenecientes a las DO Alicante y Valencia, las cooperativas de $2^{\circ}$ grado y las mercantiles, las empresas jóvenes y las muy pequeñas y pequeñas empresas.

En relación con la Producción Integrada la Consellería de Agricultura, Pesca y Alimentación autoriza la utilización del logotipo o marca especial de "Producción integrada” a los productores, elaboradores y envasadores que cumplan las condiciones y 
asuman los compromisos en el Decreto 121/1995, sobre valorización de productos agrarios obtenidos por técnicas de agricultura integrada.

En cuanto al nivel de implantación, sólo el 16 \% se encuentran inscritas, a pesar de los estímulos y ayudas técnicas y económicas reguladas en las diferentes normativas de ámbito europeo, estatal y autonómico y de la existencia del logotipo que valoriza este tipo de producción.

Respecto a la Agricultura Ecológica, a escala regional en el año 2003 existían 1.849 has de viña para vinificación (lo que supone sólo el 2,3 \% de la superficie regional de este cultivo) y 24 elaboradores inscritos en agricultura ecológica. En el ámbito de la muestra el $9 \%$ de las bodegas se encuentran inscritas en esta figura de calidad.

Desde el punto de vista empresarial, la producción ecológica constituye una importante alternativa para diferenciar comercialmente un producto ecológico del resto de los productos convencionales.

Aunque se constata una gran preocupación social por disponer de procesos productivos respetuosos con el medio ambiente, la producción ecológica no ha logrado en la actualidad el suficiente nivel de desarrollo que haga sus productos fáciles de adquirir por el consumidor, tanto por su presencia continua en los habituales puntos de venta de productos alimentarios, como por su adecuación comercial a las exigencias del consumidor en cuanto a homogeneidad, precio y aspecto visual (Rivera, 2003).

Las causas del bajo nivel de desarrollo de los vinos ecológicos podrían estar relacionadas con los siguientes aspectos:

- El precio del producto ecológico (hasta un 50 \% más elevado que un producto convencional), si bien resulta ser un estímulo para el productor, constituye un freno para el consumo de cualquier producto alimentario, con graves consecuencias comerciales, dada la gran cantidad de productos sustitutivos existentes. En relación con la gran distribución, el precio elevado es incompatible con la filosofía de esta, donde se encuentra asentada la idea de que el precio es la única variable relevante de un alimento.

- La actual proliferación de etiquetas está propiciando la confusión de un producto de agricultura ecológica con uno artesano, regional, de la tierra, etc.

- El consumidor no encuentra diferencias en sabor con respecto al convencional contribuyen a la reducida demanda en este tipo de productos.

Por otro lado, dado que en la actualidad, el principal destino de los productos ecológicos nacionales es el mercado exterior, (no exento de dificultades comerciales, debido a la preferencia de estos mercados hacia los productos de origen local), sería pertinente la difusión de estos productos en el mercado nacional (con un gran potencial de mercado). 
Como consecuencia del reducido nivel de implantación de la agricultura ecológica, la Comisión ha elaborado el "Plan de acción europeo para los alimentos ecológicos y la agricultura ecológica”, que contiene nuevas iniciativas dirigidas a fomentar el mercado de los alimentos ecológicos, y a mejorar las normas de calidad, mediante un aumento de la eficacia de éstas, de la transparencia y de la confianza de los consumidores.

Por otra parte el Ministerio de Agricultura, Pesca y Alimentación ha redactado para el periodo 2004-2006 el "Plan Estratégico para la Agricultura Ecológica”, que consta de múltiples acciones dentro los siguientes objetivos:

- Fomento y desarrollo de las producciones agrícola y ganadera ecológicas.

- Fomento de la transformación y elaboración de productos.

- Mejora de las condiciones de comercialización y venta.

- Mejora del nivel de confianza de los consumidores.

- Incremento del nivel de formación del sector.

- Armonización y potenciación de los mecanismos de control.

- Fomento de líneas de investigación y desarrollo en materia de producción ecológica.

- Impulso para la vertebración del sector.

\subsection{Certificación de la calidad de las empresas}

En relación con la Prevención y Control Integrados de la Contaminación (IPPC), en el ámbito de la muestra, ninguna bodega en estudio supera la capacidad de producción de productos acabados de 300 toneladas/día (valor medio trimestral), y como consecuencia ninguna bodega se encuentra sujeta a la autorización ambiental integrada, por lo que seguirán rigiéndose por el Reglamento de actividades molestas, insalubres, nocivas y peligrosas o, en su defecto, por la normativa autonómica que derogue el anterior.

Respecto a las Normas ISO 9000:2000, en el ámbito del sector vinícola regional, en el año 2003 existían 6 establecimientos certificados (5 en la muestra en estudio), que representan menos del $5 \%$ de las bodegas en estudio.

En el ámbito del sector vinícola regional, en el año 2003 existía 1 establecimiento certificado (ninguno en la muestra en estudio) según la normas ISO 14001. Es evidente que las innumerables ventajas a largo plazo que implica la instauración de un sistema de gestión medioambiental (eliminación de multas y sanciones, reducción de primas de seguros de responsabilidad civil, reducción del consumo de recursos naturales, diferenciación de producto, etc.) tienen un menor peso específico que los costes de implantación en que a muy corto plazo habría que incurrir por dicha implantación.

\subsection{El aseguramiento de la higiene alimentaria}

No obstante y a pesar de la obligatoriedad para las empresas del sector vitivinícola de disponer de los sistemas de Análisis de Peligros y Puntos de Control 
Críticos (APPCC) y de Trazabilidad, parece ser que los inconvenientes y dificultades señaladas Capítulo III, pesan más que las ventajas y beneficios para las empresas, ya que en al ámbito de la muestra, solo tienen implantado el sistema de trazabilidad el 15\% de las empresas y en el caso del sistema APPCC el $22 \%$ de las mismas.

En general, la adopción de este tipo de sistemas en el futuro va a depender en gran medida, de las condiciones impuestas por la gran distribución, de las exigencias necesarias para la exportación y para el cumplimiento de la legislación vigente.

\section{ESTRATEGIAS DE MARKETING}

Superada la orientación a la producción, cuando la demanda era superior a la oferta y la única preocupación era producir más para vender más, se ha pasado a una orientación al producto.

La orientación al producto se produce cuando aumenta la competencia y ello le permite al consumidor elegir, lo cual implica mejorar el producto, con la finalidad de hacerlo más competitivo. La competencia tiende a reducir los costes de producción hasta equipararse en casi todas las empresas lo cual reduce el margen de maniobra vía precios y tiende a igualarlos. Por otro lado la misma competencia tiende a mejorar los procesos de elaboración, y dado que los bodegueros utilizan tecnología semejante, el resultado no puede ser otro que generar productos muy parecidos.

Como consecuencia surge en las empresas el fenómeno de la orientación hacia las ventas, con la finalidad de persuadir a los consumidores para que compren sus productos, aunque esta etapa también presenta límites, ya que la ampliación de los departamentos de venta y el aumento de presupuestos en publicidad no garanticen que el producto se venda más de manera sostenida.

Por último la orientación al marketing sitúa la actuación de las empresas en su relación comercial con el consumidor. Partiendo de las necesidades y deseos del consumidor, tiene como fin su satisfacción del modo más beneficioso, tanto para el consumidor como para la entidad, (Santesmases, 1993), lo cual significa que se debe analizar la demanda de manera continuada e ininterrumpida, para poder satisfacer sus necesidades.

Aunque sin existir un departamento específico de marketing, prácticamente en todas las empresas por pequeñas que sean se lleva a cabo, aunque de manera inconsciente, decisiones sobre el producto (producir vino joven o crianzas, embotellar o venderlo a granel), sobre el precio (plazos de pago, promociones, etc.), sobre los canales (distribuidor venta directa, etc.), y sobre la comunicación (publicidad, impacto de las campañas, etc.).

En la actualidad no se discute la importancia del departamento de marketing en las empresas, no porque esté por encima de las restantes áreas de la empresa, sino por ser el puente entre la empresa y el cliente/consumidor. Esta misión permite al resto de los departamentos el correcto desarrollo de sus respectivas funciones, con el objetivo 
último de ofrecer al cliente el producto deseado, a un precio adecuado, en un lugar y momento determinado.

Las variables sobre las que se asienta el marketing o la estrategia comercial son: el producto, el precio, la distribución y la comunicación en sus diversas formas. Dichas variables serán estudiadas en los apartados siguientes.

\subsection{Estrategia de producto}

La estrategia de producto se ha analizado desde tres ámbitos: la gama de productos, gama de marcas y gama de presentaciones. Dichas estrategias se analizan a continuación.

\subsubsection{Gama de productos}

En relación con la diferenciación del producto o tecnológica (relación entre el volumen de ventas de vinos crianzas y reservas, sobre el volumen de las ventas de embotellado de la bodega), los mayores índices de diferenciación los ostentan las empresas de media edad, las cooperativas de $2^{\circ}$ grado, las medianas, las muy pequeñas empresas y las pertenecientes a la DO Utiel-Requena.

\section{CUADRO 5.18}

NUMERO DE MARCAS YPRESENTACIONES POR EMPRESA SEGÚN LAS CATEGORIAS DE EMPRESA

\begin{tabular}{|c|c|c|c|}
\hline $\begin{array}{l}\text { CATEGORIA } \\
\text { EMPRESA }\end{array}$ & $\begin{array}{c}\text { No }^{\circ} \text { MARCAS } \\
\text { PROPIAS } \\
\text { POR EMPRESA } \\
\end{array}$ & $\begin{array}{c}\mathrm{N}^{\circ} \text { MARCAS } \\
\text { BLANCAS } \\
\text { POR EMPRESA } \\
\end{array}$ & $\begin{array}{c}\mathrm{N}^{\circ} \mathrm{DE} \\
\text { PRESENTACIONES } \\
\text { POR EMPRESA } \\
\end{array}$ \\
\hline ANTIGUA & 3,94 & 12,03 & 2,59 \\
\hline MEDIA EDAD & 1,40 & 0,00 & 1,80 \\
\hline JOVEN & 1,04 & 2,73 & 0,99 \\
\hline P FISICA & 0,50 & 0,00 & 0,50 \\
\hline SAT & 0,70 & 0,60 & 0,80 \\
\hline S COOP & 1,67 & 6,00 & 2,16 \\
\hline S COOP2 & 3,87 & 0,00 & 2,00 \\
\hline S COOPS2 & 7,96 & 13,33 & 3,92 \\
\hline S MERCANTIL & 1,89 & 9,16 & 1,51 \\
\hline MUY GRANDE & 5,80 & 21,67 & $\overline{5,55}$ \\
\hline GRANDE & 6,22 & 6,20 & 3,40 \\
\hline MEDIANA & 2,80 & 0,00 & 0,67 \\
\hline PEQUEÑA & 1,94 & 3,10 & 1,58 \\
\hline MUY PEQUEÑA & 0,68 & 1,30 & 0,85 \\
\hline ALICANTE & 1,51 & 0,00 & 1,91 \\
\hline UTIEL-REQUENA & 1,98 & 9,04 & 1,38 \\
\hline VALENCIA & 3,35 & 9,44 & 2,32 \\
\hline MEDIA & 2,44 & 9,24 & 1,81 \\
\hline
\end{tabular}

Fuente: Elaboración propia 
En cuanto a los vinos varietales, la media muestral de vinos varietales por empresa es de 5,22, habiéndose observado que:

- Esta cifra disminuye con la menor edad de las empresas (5,8 en las antiguas y 3,6 en las jóvenes), y con la menor dimensión (12,3 en las muy grandes y 2,8 en las muy pequeñas).

- La DO Alicante presenta el valor más alto $(6,0)$ frente al más bajo de la DO Utiel-Requena $(5,0)$.

- Las mercantiles muestran la cifra más alta $(6,2)$, seguidas de las cooperativas, con 4,6.

Referente a la participación de los vinos varietales en el volumen embotellado precisar que:

- El porcentaje medio del conjunto muestral asciende al $38 \%$.

- Esta cifra aumenta con la menor edad de las empresas (28 \% en las antiguas y $88 \%$ en las jóvenes), y con la menor dimensión (35 \% en el conjunto de las grandes y muy grandes y $50 \%$ en el grupo de las pequeñas y muy pequeñas).

- La DO Alicante presenta el valor más alto (41 \%).

El grupo de las personas físicas presenta la cifra más alta (100 \%) seguidas de las cooperativas (54\%), y las mercantiles con el $30 \%$.

En lo que respecta a los vinos de pagos, la producción es meramente testimonial, ya que sólo una empresa elabora esta gama de vinos, representando el 0,3\% del total embotellado de las bodegas en estudio. De manera similar los vinos ecológicos están representados de manera minoritaria por dos bodegas que comercializan el 0,4 \% del total comercializado embotellado de la muestra.

\subsubsection{Gama de marcas}

Respecto a la política de marcas se ha detectado una estrategia enfocada hacia las marcas propias, ya que de las bodegas en estudio, todas las que embotellan utilizan marcas propias, las cuales suponen en volumen $79 \%$ del total embotellado (gráfico 5.12). Por tipos de empresas, las mayores cuotas de participación (el $100 \%$ del volumen embotellado) se corresponden con las empresas de edad media, las pertenecientes a Alicante, las sociedades cooperativas de $2^{\circ}$ grado, las personas físicas, y las medianas y pequeñas empresas.

En cuanto al número de marcas propias por empresa la media muestral es de 2,4 con las siguientes observaciones: 
- Esta cifra disminuye con la menor edad de las empresas (3,9 en las antiguas y 1,0 en las jóvenes), y con la menor dimensión (6,0 en la muy grandes y 0,68 en las muy pequeñas.

- La DO Valencia presenta el valor más alto $(3,35)$ frente al más bajo de la DO Alicante $(1,5)$.

- Las cooperativas muestran la cifra más alta $(3,9)$, frente a las mercantiles, que con 1,9 exhiben el valor más bajo.

\section{GRÁFICO 5.12}

\section{DISTRIBUCÍÓN PORCENTUAL DE MARCAS PROPIAS Y MARCAS BLANCAS RESPECTO DEL TOTAL DE VINO COMERCIALIZADO EMBOTELLADO}

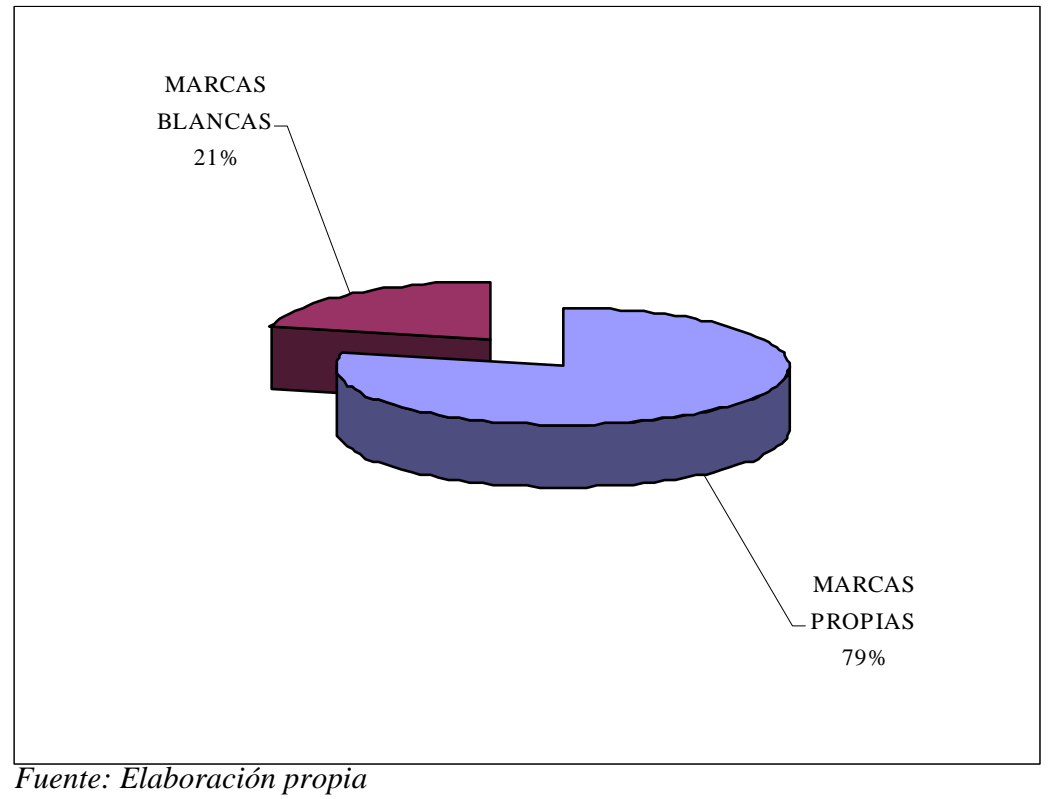

De las bodegas en estudio, sólo el $19 \%$ de las que embotellan utilizan marcas blancas, lo que supone el $21 \%$ del total embotellado en volumen. Por tipos de empresas, las mayores cuotas de participación en volumen las ostentan, las antiguas empresas (94\%), las pertenecientes a la DO Valencia (81 \%), las sociedades mercantiles (68 \%) y las empresas grandes y muy grandes (97\% en conjunto).

El incremento en el número de marcas surge como consecuencia de las buenas perspectivas del mercado para el consumo de los vinos de calidad. La inacertada política comercial de la gran mayoría de las empresas conduce a una gran proliferación de marcas que tienen el efecto de confundir al consumidor y propician que estos recurran a determinadas marcas colectivas reconocidas (caso de Rioja o Ribera del Duero.) Es necesario que las bodegas cuiden los diferentes aspectos que configuran una adecuada política marquista, con el fin de consolidar una buena imagen de marca del vino y que éstas sean fácilmente identificables por el consumidor (Barco, 1995). 
En este sentido los países emergentes o del nuevo mundo han enfocado su política comercial en relación con las marcas, hacia el uso sobre todo de los nombres de las bodegas y de las variedades de sus vinos; en este último caso también existen inconvenientes, como el de usar finalmente marcas genéricas (debido al número limitado de variedades), que no les diferencia de la competencia.

De los resultados del estudio se desprende que el valor medio del número de marcas propias por empresa $(2,4)$ es una cifra adecuada, en el sentido de que no es excesiva y por tanto no tiende a propiciar la confusión de los consumidores.

En cuanto al número de marcas blancas por empresa la media muestral es de 9,2 habiéndose observado que:

- Esta cifra disminuye con la menor edad de las empresas (12,0 en las antiguas y 2,7 en las jóvenes), y con la menor dimensión (21,7 en las muy grandes y 1,3 en las muy pequeñas.

- La DO Valencia presenta el valor más alto (9,4 frente al valor nulo de la DO Alicante.

- Las cooperativas muestran la cifra más alta $(11,5)$, frente a las mercantiles, que con 9,2 exhiben el valor más bajo.

\subsubsection{Gama de presentaciones}

Los resultados del estudio en cuanto al número de presentaciones por empresa y por tipo de vino presentan una media de 1,8, habiéndose observado que (cuadro 4.18):

- Esta cifra disminuye con la menor edad de las empresas (2,6 en las antiguas y 1,0 en las jóvenes), y con la menor dimensión (5,6 en las muy grandes y 0,9 en las muy pequeñas).

- La DO Valencia presenta el valor más alto $(2,3)$, junto a las cooperativas $(2,6)$, que son seguidas por las mercantiles $(1,5)$.

\subsection{Destino geográfico y ámbito de la producción comercializada}

Las ventas de vino se encuentran muy polarizadas hacia la Comunidad Valenciana, que concentra el $46 \%$ de las mismas en volumen, siguiendo en importancia el resto del mercado nacional (27 \%), las expediciones a la Unión Europea (23\%) y las exportaciones a Terceros Países, que sólo suponen el 4 \% en volumen de la producción comercializada (gráfico 5.13).

Considerando las exportaciones en sentido amplio, como los intercambios comerciales fuera de la frontera nacional, únicamente se exporta el $27 \%$ de la producción total de las bodegas de la muestra, valor que resulta claramente insuficiente. Superan esta cifra media de exportación (cuadro 5.19 ) las bodegas jóvenes (34 \%), las pertenecientes a las DO de Utiel-Requena y Valencia (cerca del 29 \%), las mercantiles 
(63 \%) y las empresas muy grandes (49 \%), detectándose en general una relación positiva entre el tamaño de las instalaciones de la bodega y el volumen de exportaciones.

Poseen una mayor especialización en el mercado regional y por tanto por encima de la media reflejada en el gráfico, las empresas de edad media (54\%), las incluidas en la DO Alicante $(85 \%)$, las cooperativas de $1^{\circ}$ grado no socias de cooperativas de $2^{\circ}$ grado (68\%), y la medianas (76\%).

\section{GRAFICO 5.13}

\section{DESTINO DE LA PRODUCCIÓN COMERCIALIZADA EN PORCENTAJE SOBRE EL VOLUMEN DE VINO}

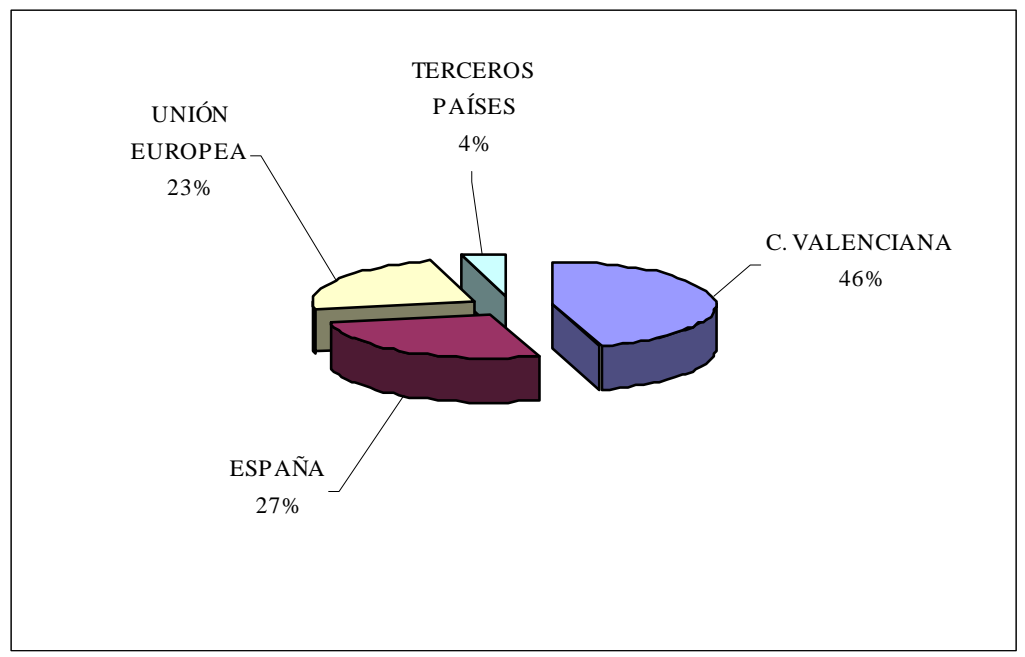

Fuente: Elaboración propia

El valor medio del alcance o grado de dispersión (suma de los cuadrados de las cuotas de venta, en tanto por uno, que la empresa tiene en el mercado regional, en el nacional, en la Unión Europea y en los terceros países respecto al volumen físico total comercializado) ha sido 0,67, valor que se considera adecuado, ya que una buena dispersión diversifica los riesgos inherentes para la propia empresa que pudiera suponer una situación de saturación coyuntural de alguno de los mercados meta. Se ha observado una mayor dispersión de los mercados (Cuadro 5.19) en las empresas jóvenes, cooperativas de $2^{\circ}$ grado, mercantiles, muy grandes empresas y las incluidas en las DO de Utiel-Requena y Valencia, en contraste en este último caso con la elevada concentración que presentan las bodegas pertenecientes a la DO de Alicante $(0,27)$. 
CUADRO 5.19

DESTINO DE LAS EXPORTACIONES, CONCENTRACIÓN Y AMPLITUD GEOGRÁFICA DE LOS MERCADOS

\begin{tabular}{|l|r|r|r|}
\hline $\begin{array}{c}\text { CATEGORIA } \\
\text { EMPRESA }\end{array}$ & $\begin{array}{c}\text { EXPORTACIÓN } \\
\mathbf{( \% )}\end{array}$ & $\begin{array}{c}\text { DISPERSIÓN } \\
\text { MERCADOS }\end{array}$ & \multicolumn{2}{c|}{$\begin{array}{c}\text { No PAÍSES POR } \\
\text { EMPREA }\end{array}$} \\
\hline ANTIGUA & 27,8 & 0,66 & 3,7 \\
\hline MEDIA EDAD & 11,3 & 0,58 & 5,9 \\
\hline JOVEN & 33,6 & 0,68 & 3,4 \\
\hline P FISICA & 8,8 & 0,56 & 1,1 \\
\hline SAT & 1,1 & 0,51 & 1,6 \\
\hline S COOP & 3,5 & 0,46 & 1,3 \\
\hline S COOP2 & 23,2 & 0,66 & 18,3 \\
\hline S COOPS2 & 18,5 & 0,63 & 4,8 \\
\hline S MERCANTIL & 63,2 & 0,66 & 5,1 \\
\hline MUY GRANDE & 49,0 & 0,71 & 15,5 \\
\hline GRANDE & 22,0 & 0,65 & 4,2 \\
\hline MEDIANA & 12,5 & 0,40 & 2,8 \\
\hline PEQUEÑA & 18,3 & 0,61 & 4,9 \\
\hline MUY PEQUEÑA & 11,7 & 0,62 & 2,1 \\
\hline ALICANTE & 9,2 & 0,27 & 3,5 \\
\hline UTIEL-REQUENA & 29,3 & 0,68 & 3,5 \\
\hline VALENCIA & 28,9 & 0,68 & 4,7 \\
\hline MEDIA & $\mathbf{2 7 , 0}$ & $\mathbf{0 , 6 7}$ & $\mathbf{3 , 8}$ \\
\hline Fuente: Elaboración propia & & & \\
\hline
\end{tabular}

En relación con la amplitud geográfica de los mercados de la empresa (número medio de países en los que están presentes los productos de la empresa), la media muestral toma el valor de 3,8, y por categorías de empresa, los valores más elevados corresponden a las empresas de mediana edad $(5,9)$, las pertenecientes a la DO Valencia $(4,7)$, las cooperativas de $2^{\circ}$ grado $(18,3)$ y las empresas muy grandes $(15,5)$, detectándose en general una relación positiva entre el tamaño de las instalaciones de la bodega y el número de países en que están presentes los productos de la empresa.

En términos generales ha sido observada una relación positiva en la mayor parte de las categorías de empresas, entre la dispersión de los mercados, la amplitud y la cuota de volumen comercializado en exportación.

\subsection{Canales de distribución}

EI vino comercializado a granel supone el $73 \%$ del total comercializado por las bodegas del estudio, a través de las figuras de corredores y mayoristas (granelistas o embotelladores), en cisternas y cerca del $1 \%$ es vendido también a granel al detall en las propias bodegas de elaboración en forma de venta directa.

EI vino comercializado embotellado supone tan solo el $27 \%$ del total. Del gráfico 4.14 se desprende que cerca del $88 \%$ del vino embotellado se distribuye casi a partes iguales entre los mayoristas distribuidores y la gran distribución (hipermercados 
y supermercados), seguidos de la distribución en el canal horeca (hostelería, restauración y catering), tiendas, venta directa en bodega, club de vino e Internet.

\subsubsection{Agentes de distribución}

Los agentes de distribución que se han considerado han sido: el distribuidor mayorista, la gran distribución y, los canales alternativos: tiendas, club, horeca, bodega e internet (gráfico 5.14).

\section{GRAFICO 5.14}

\section{PORCENTAJE DE PARTICIPACIÓN DE LOS CANALES DE DISTIBUCIÓN SOBRE EL} VOLUMEN DE VINO COMERCIALIZADO EMBOTELLADO

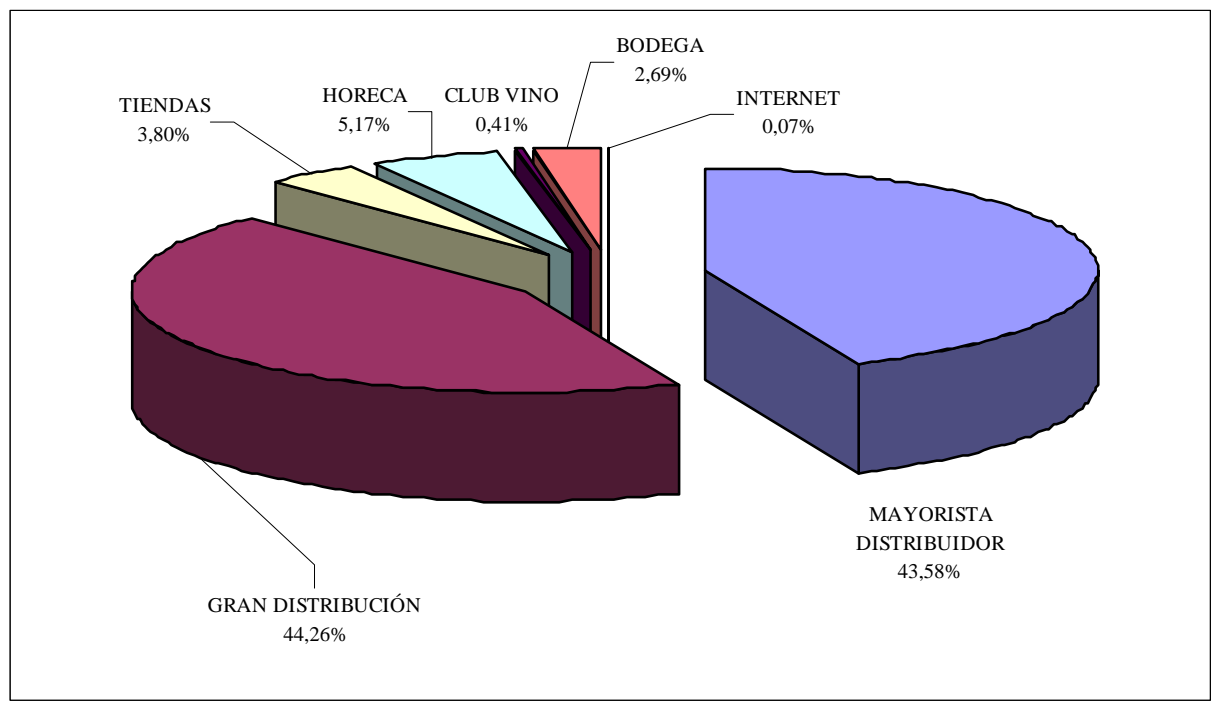

Fuente: Elaboración propia

La participación media del mayorista distribuidor en el total de vino embotellado en volumen físico es una cifra cercana al 44 \%. Por categorías de empresa:

- La mayor participación se presenta en las de mediana edad (73 \%), seguidas de las antiguas y jóvenes, que muestran una cifra cercana a la media.

- En las pertenecientes a la DO Alicante se observan las mayores cuotas (73\%), seguidas de las DO Valencia (69 \%) y Utiel-Requena (19\%).

- En las SAT se constata una especialización muy elevada en este canal, ya que éste representa el 99,69 \% del vino total comercializado, seguidas por las personas físicas (90\%). La menor cuota en cambio, se registra en las cooperativas de $1^{\circ}$ grado no asociadas a las de $2^{\circ}$ grado (33\%).

- La participación aumenta con el menor tamaño de las empresas, desde el 21\% en las muy grandes, hasta el $71 \%$ en las muy pequeñas empresas. 
La participación de la gran distribución en el total de vino embotellado en volumen físico es del $44 \%$. Por categorías de empresa, resaltar:

- La participación aumenta con edad de las empresas, desde el $7 \%$ en las jóvenes hasta el $51 \%$ en las antiguas.

- En las pertenecientes a la DO Utiel-Requena se observan las mayores cuotas (63\%), seguidas de las DO Valencia y Alicante (11\%).

- En las cooperativa de $1^{\circ}$ grado no asociadas a las de $2^{\circ}$ grado, aparecen las cuotas mayores (56\%), seguidas de las mercantiles (46\%). Las personas físicas y las SAT no comercializan por este canal.

- La participación aumenta con el tamaño de las empresas, desde el 4 \% en las muy pequeñas hasta el $74 \%$ en las muy grandes empresas, al contrario de lo registrado en el canal anterior. El aumento de la concentración y del poder de negociación de la gran distribución implica la transacción comercial con empresas capaces de ofertarles mayores cantidades de producto en unas condiciones acordadas.

La participación media de conjunto de las tiendas en el total de vino embotellado en volumen físico es una cifra cercana al 4 \%. Por categorías de empresa:

- La participación aumenta con el menor tamaño de las empresas, desde el 1\% en las antiguas hasta el 18 \% en las jóvenes.

- En las pertenecientes a la DO Utiel-Requena se exhiben las mayores cuotas (7\%), seguidas de las DO Alicante y Valencia (menos del $1 \%$.)

- En las mercantiles aparecen las cuotas mayores (5\%), seguidas de las cooperativas de $2^{\circ}$ grado (menos del $2 \%$ ).

- En las grandes empresas se dan las mayores cuotas de participación de este canal con el $6 \%$.

El canal horeca (hoteles, restaurantes, catering e instituciones) en el ámbito del estudio participa con el $5 \%$ en el volumen total comercializado. Por categorías de empresa las mayores cuotas de participación se han observado en las empresas jóvenes (26\%), las pertenecientes a la DO Alicante (9\%), las personas físicas (10\%) y las pequeñas y muy pequeñas empresas, en las cuales con el 12 \% y $10 \%$ respectivamente.

Los clubes de vinos en la actualidad no aparecen como un canal alternativo, ya que sólo el $0,41 \%$ de la producción comercializada emplea esta canal, aunque si poseen un cierto potencial de crecimiento.

La participación de la venta en bodega en el total de vino embotellado en volumen físico es cercana al 3 \%. Por categorías de empresa resaltar: 
- La participación aumenta con la menor edad de las empresas, desde el 2 \% en las antiguas hasta el $7 \%$ en las jóvenes.

- Aparecen con las cuotas mayores, las personas físicas (10 \%) y las cooperativa de $1^{\circ}$ grado no asociadas a las de $2^{\circ}$ grado $(6 \%)$.

- La participación aumenta en general con el menor tamaño de las empresas, desde el $1 \%$ en las muy grandes hasta el $10 \%$ en las muy pequeñas empresas.

Los inconvenientes de la venta directa se palian en parte al considerar otras alternativas de venta directa, como el marketing directo, el cual supone emplear medios de comunicación directa para hacer proposiciones de venta dirigidas a segmentos de mercado específicos.

En lo que respecta a Internet, la cuota de participación del comercio electrónico en el vino comercializado embotellado en las bodegas del estudio es del 0,07 \%, con solo dos empresas que realicen este tipo de transacciones.

Como conclusión resaltar, de un lado el reducido porcentaje sobre la producción comercializada total, del vino comercializado embotellado (26\%), de otro la excesiva concentración de las ventas de vino embotellado (más del 88 \%), repartido casi a partes iguales entre la gran distribución y los distribuidores mayoristas.

\subsubsection{Integración vertical hacia adelante}

En la integración vertical hacia adelante han sido consideradas las siguientes etapas o fases:

GRAN_MAY:La bodega vende vino a granel a mayorista.

EMB_MAY:La bodega vende vino embotellado a mayorista.

MAY_MIN: La bodega realiza la función de mayorista vendiendo a minoristas.

MIN_CONS:La bodega realiza la función de minorista vendiendo directamente al consumidor.

En el gráfico 5.15 aparece la distribución porcentual del volumen comercializado en hl, en función de los cuatro niveles de integración definidos, constatándose que casi las tres cuartas partes de dicho volumen se comercializa a granel por medio de mayoristas almacenistas

Aplicando la fórmula a las empresas encuestadas, se obtiene un grado de integración medio del 13, el cual puede calificarse de muy bajo. Los mayores grados de integración se han registrado en las empresas jóvenes (22), las mercantiles (30), las muy grandes (23) y las pertenecientes a la DO Valencia (18). Los menores índices de integración vertical hacia delante por el contrario, se presentan en las empresas de edad media (7), las SAT (menos de 1), las medianas empresas (4) y las pertenecientes a la DO Alicante (10). 


\section{GRAFICO 5.15}

DISTRIBUCIÓN PORCENTUAL DEL VOLUMEN DE PRODUCCIÓN DE VINO COMERCIALIZADA POR NIVELES DE INTEGRACIÓN VERTICAL HACIA ADELANTE

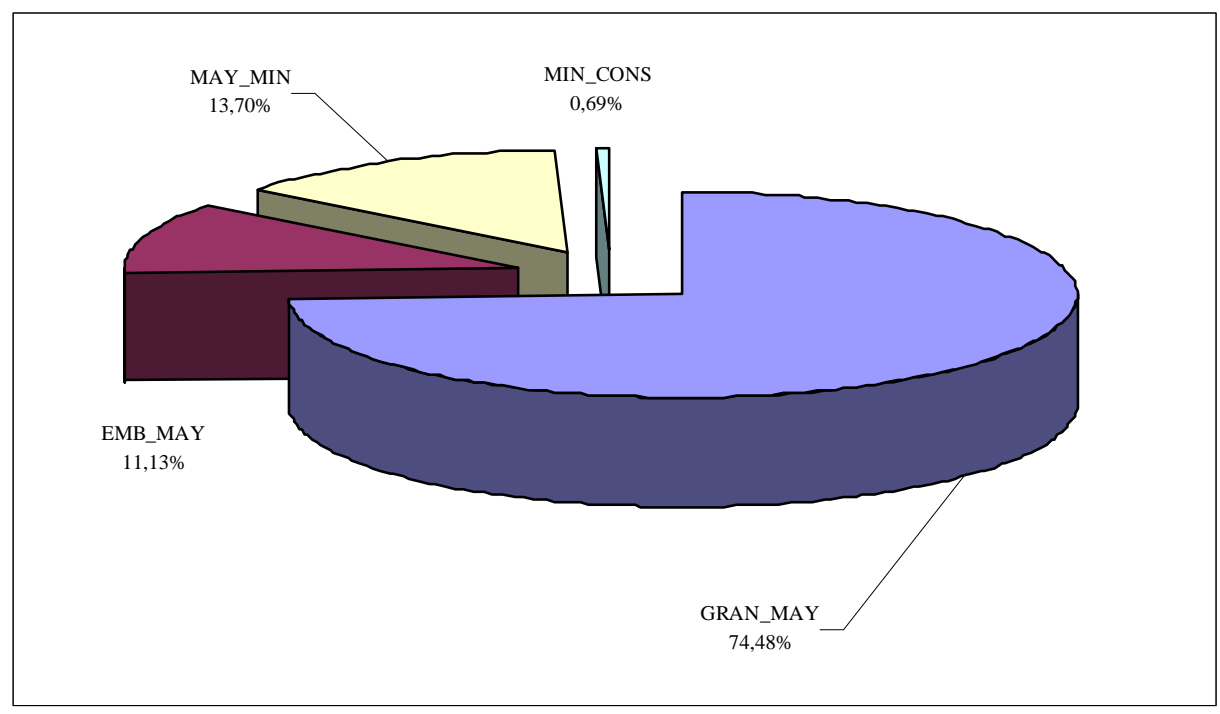

Fuente: elaboración propia

\subsection{Estrategias de comunicación e información}

En el presente estudio se han efectuado las divisiones del gasto comercial, que a continuación se detallan (gráfico 5.16).

\section{GRAFICO 5.16}

DISTRIBUCIÓN PORCENTUAL DEL GASTO COMERCIAL ANUAL MEDIO (€)

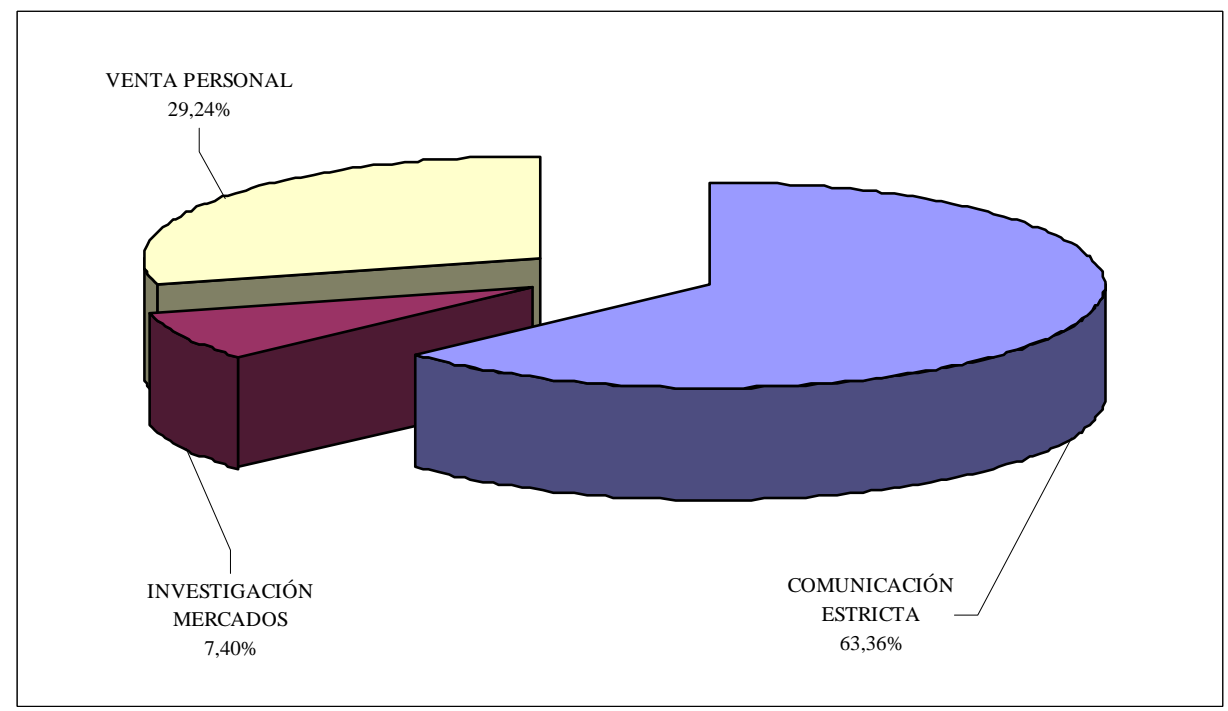

Fuente: Elaboración propia 
- La comunicación en sentido estricto (la publicidad, las promociones y las relaciones públicas), que representa el $63 \%$ del gasto comercial total.

- Los gastos de personal propio (venta personal), que representa el $29 \%$ del gasto comercial total.

- La investigación comercial, que supone el 8 \% del gasto comercial total.

En el presente estudio los gastos en comunicación en sentido estricto representan un porcentaje cercano a las dos terceras partes del gasto total comercial del total de la muestra. Por categorías de empresas, las mayores participaciones en estos gastos se presentan en las empresas de mediana edad y en las antiguas, en las pertenecientes a la DO Valencia, en las cooperativas de $2^{\circ}$ grado y sus asociadas en las muy grandes empresas, habiéndose observado el crecimiento de los gastos de comunicación con la antigüedad y el tamaño de las empresas.

En el ámbito del estudio, los gastos relacionados con el personal comercial suponen una cifra cercana al $30 \%$ del gasto comercial total, presentándose las mayores cuotas de participación en las empresas jóvenes (en detrimento de los gastos destinados a publicidad), en las pertenecientes a la DO Alicante, en las mercantiles, y en las pequeñas y muy pequeñas empresas, habiéndose observado en general, el crecimiento de los gastos de personal comercial con la menor edad y el menor tamaño de las empresas, contrariamente a lo detectado en el caso de la publicidad.

Resaltar el reducido número de empresas que realizan algún tipo de investigación de mercados (aproximadamente el $30 \%$ de las empresas que han incurrido en algún tipo de gasto comercial), lo cual no deja de sorprender si se tiene en cuenta que esta última actividad es necesaria para llevar a cabo el diseño, planificación y control de toda acción comercial efectiva.

El gasto de comunicación total de la muestra asciende a 6.984.866 € que supone tan solo el 3,42 \% del valor de la producción. Este valor puede calificarse de claramente insuficiente, si se tiene en cuenta que los nuevos países productores presentan ratios comprendidos entre el $7 \%$ y el $16 \%$, dependiendo del tamaño de las empresas.

\subsubsection{Esfuerzo comercial. Diferenciación por información al consumidor}

El esfuerzo comercial (relación entre el gasto comercial medio anual de los últimos tres ejercicios realizado por la empresa y el valor de la producción en euros) presenta un valor medio muestral de 3,42 \%, cifra calificada de muy baja.

La diferenciación por información al consumidor (ratio del gasto medio anual durante los últimos tres ejercicios, en publicidad, promociones y relaciones públicas con relación al valor de la producción de las empresas), presenta un valor medio muestral de $2 \%$.

Por la propia definición, estos dos indicadores, se encuentran relacionados positivamente, dándose los mayores valores en ambos indicadores, en las bodegas de 
edad media, las jóvenes, en las pertenecientes a la DO Alicante, en las cooperativas, de $2^{\circ}$ grado, en las mercantiles, y en las muy grandes y pequeñas empresas.

\subsection{Estrategias de precios}

La participación de los criterios de fijación de precios en porcentaje sobre el volumen de vino comercializado por las empresas del estudio aparece reflejada en el gráfico 5.17. A continuación se tratan por separado cada uno de estos criterios por orden de importancia en el citado porcentaje.

\section{GRAFICO 5.17}

\section{PARTICIPACIÓN DE LOS CRITERIOS DE FIJACIÓN DE PRECIOS EN PORCENTAJE SOBRE EL VOLUMEN COMERCIALIZADO TOTAL}

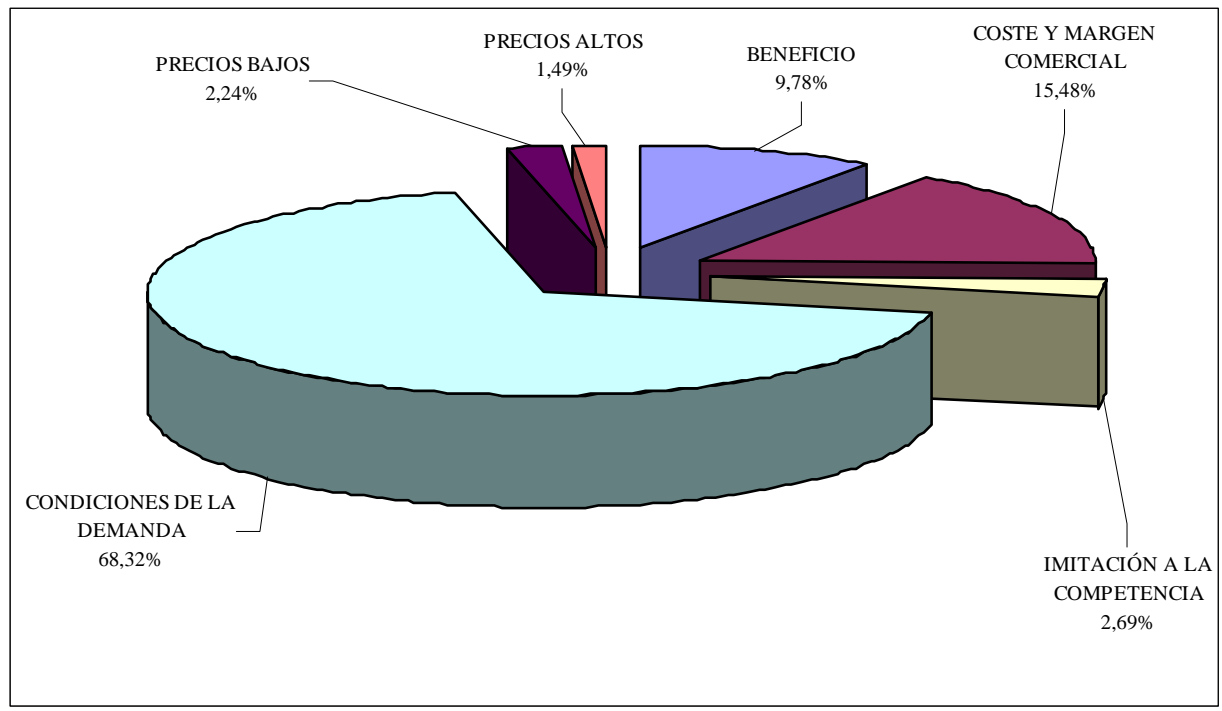

Fuente: Elaboración propia

La fijación de precios en relación con la demanda es una estrategia que representa más de las dos terceras partes de la producción comercializada en volumen. Por categorías de empresas esta política presenta las mayores participaciones en las empresas antiguas, las pertenecientes a la DO Utiel-Requena, las cooperativas de $1^{\circ}$ grado en su conjunto, y las mediana y grandes empresas, categorías de empresas en las cuales el peso específico de los graneles es elevado. Solamente ha sido detectada una relación positiva entre la antigüedad de las empresas y la adopción de esta estrategia de precios.

La fijación de precios a través de los márgenes es la segunda estrategia más utilizada para la comercialización de los vinos, ya que participa entorno al $16 \%$ de media en el volumen comercializado por aquellas. Por categorías de empresas, se dan las mayores participaciones en las jóvenes (42\%), las pertenecientes a la DO Valencia (25\%), las cooperativas de $2^{\circ}$ grado (54\%), y las empresas muy pequeñas (40 \%) y pequeñas (27\%). 
El criterio de fijación de precios por el beneficio, en la práctica y dentro del ámbito del estudio, el $10 \%$ del vino es comercializado mediante esta opción, la cual predomina en las empresas jóvenes, en las perteneciente a la DO Utiel-Requena, en las mercantiles y en las empresas muy grandes.

Las estrategia basada en la competencia es seguida en mercados de productos homogéneos, entre los cuales no se puede calificar el vino, por la diversidad de factores que intervienen en su elaboración. En este sentido una cifra que no alcanza el 3 \% de la producción en volumen es comercializada mediante dicha estrategia.

La estrategia de precios bajos ha sido la opción empleada en solo el 2 \% del volumen total comercializado por las bodegas de la muestra, predominando en las empresas jóvenes, y en las mercantiles. En referencia a los graneles de vino, dada su importancia cuantitativa en la comercialización del vino, en la venta de éstos, el precio es el factor más limitante para poder competir, ya que se trata de productos poco diferenciados, comercializados a bajo precio, donde el coste de la materia prima es elevado en relación con el precio final del producto.

La estrategia de precios altos ha sido la menos empleada (menos del $2 \%$ del volumen total comercializado por las bodegas de la muestra), lo que no sorprende, ya que el precio medio del conjunto de los vinos mayoritarios en volumen, blanco, tinto y rosado se encuadra dentro de los de gama baja "Basic”. Esta estrategia predomina en las bodegas pertenecientes a la DO Alicante y en las cooperativas de $2^{\circ}$ grado.

Las estrategias expuestas no son utilizadas de manera exclusiva por las bodegas, más bien todo lo contrario, estas tienden a utilizar una combinación de las mismas dependiendo entre otros factores del producto a ofrecer en un momento dado, así como de las condiciones de la demanda y de la competencia.

Como conclusión de las estrategias de marketing en el sector vinícola de la Comunidad Valenciana y considerando un escenario con un mercado nacional saturado en el consumo de vino y un mercado exterior con un elevado nivel de competencia entre los operadores, parece que la única estrategia comercial posible para superar la fuerte competencia en el mercado pasa por adaptarse a las exigencias del mismo y la satisfacción de sus consumidores. En la mejora de los procesos de comercialización y de marketing no basta con el diseño de una estrategia de mercado y de imagen, se precisa también una estrategia de productos de calidad y marcas a precios competitivos y que estén presentes en los mercados meta en tiempo y lugar a través de unos adecuados canales comerciales. Las bodegas regionales sólo podrán afrontar el gran reto de la globalización y la competencia internacional en el mercado del vino, actuando de manera inteligente sobre las variables de marketing.

\section{RESULTADOS EMPRESARIALES}

Los valores medios observados de los ratios VAE (valor añadido / valor de la producción), y RAO (beneficio antes de impuestos / valor de la producción) han sido respectivamente 17,58 \% y 4,19 \%, habiéndose observado en general una relación 
positiva y directa entre esos indicadores. Por categoría de empresas, presentan los mayores valores:

Las bodegas jóvenes, con valores de VAE (19,26 \%) y RAO (8,21 \%). Se podría pensar que una mayor antigüedad, pudiera conducir a un mejor desenvolvimiento de habilidades individuales y capacidades colectivas relacionadas con la organización interna de las empresas, los procesos de elaboración de los vinos, dado el carácter acumulativo del proceso de aprendizaje tecnológico, así como también puede contribuir activamente a la consolidación e la imagen de la empresa y de sus productos. Del mismo modo, el hecho de entrar primero en el sector puede proporcionar, por ejemplo, ventajas derivadas de un acceso favorable para la captación de recursos productivos, por medio de la adquisición de viñedo, formalización de contratos de suministro, o para el establecimiento de relaciones con los canales de distribución. La evidencia empírica apoya la perspectiva "evolucionista lamarkista" sobre la cual una joven bodega puede configurarse sobre la base de nuevos recursos que le proporcionen mayores posibilidades de ajuste a las actuales condiciones de los mercados.

Las bodegas incluidas en la DO Utiel-Requena, con valores de VAE (18,32 \%), y RAO (5,61 \%). Se podría pensar que una mayor especialización productiva de esta comarca pudiera conducir a estos mejores resultados.

Las sociedades mercantiles con valores de VAE (21,50 \%) y RAO (7,74 \%), seguidas por las cooperativas de $2^{\circ}$ grado refuerzan la evidencia empírica (puesta de manifiesto por Galve y Salas, 1993) de que la propiedad y el control de la empresa influyen en su eficiencia y rentabilidad. En concreto, el mantenimiento de "un control mayoritario en el grupo familiar o un control difuso con bajo número de accionistas tiene una consecuencia positiva en términos de mayor eficiencia frente a una situación donde el control se difumina trasladándose a los numerosos socios en el caso de las sociedades cooperativas, lo que dificulta la agilidad en la toma de decisiones estratégicas.

Las empresas muy pequeñas exhiben los mayores valores de VAE (26,10 \%), y RAO (8,27 \%), seguidas de las empresas muy grandes. Aunque ha sido ampliamente reconocido (desde una perspectivas estructuralista y de gestión), que las empresas de mayor tamaño poseen un potencial de generación de beneficios superior (a través de efecto de economías de escala, mayor poder de negociación y de mercado), en ocasiones las empresas de menor tamaño alcanzan mayores rendimientos, debido a otro tipo de ventajas (acceso favorable a recursos, diferenciación, etc.), o también que coexistan diferentes funciones de coste derivadas de una distinta configuración de la oferta, o simplemente la presencia de un distinto nivel tecnológico. 



\section{CAPÍTULO VI}

\section{DIAGNÓSTICO DEL SUBSECTOR VINÍCOLA EN LA COMUNIDAD VALENCIANA}





\section{SITUACIÓN COMPETITIVA DE LA INDUSTRIA VINÍCOLA SEGÚN EL MODELO DAFO.}

En este apartado se ha tratado de resumir la posición competitiva de la industria vinícola regional en términos de factores endógenos y exógenos que influyen sobre ella.

La determinación de los puntos fuertes (F) y débiles (D) se ha obtenido identificando la posición competitiva del conjunto de las empresas que integran la industria vinícola con respecto a los factores internos a ésta, de manera que los puntos fuertes son aquellos factores donde el sector tiene una posición competitiva favorable. Por el contrario los puntos débiles son aquellos factores internos en los que el sector presenta una posición competitiva desfavorable.

La determinación de las oportunidades (O) y amenazas (A) se ha obtenido identificando la posición competitiva de las empresas que integran la industria vinícola con respecto a los factores externos a ésta, de manera que las oportunidades son aquellos factores que ejercen una influencia positiva en la posición competitiva de la industria vinícola. Por el contrario las amenazas son aquellos factores que ejercen una influencia negativa en la posición competitiva de la industria vinícola.

El análisis DAFO es una técnica utilizada preferentemente para estudios de las estrategias de las empresas. Dada la gran fragmentación empresarial del subsector vinícola en estudio, existen empresas que presentan fortalezas y debilidades diferentes y que están situados de forma distinta ante las oportunidades y amenazas, por lo que se tendrían que realizar tantos análisis como empresas existen, lo que impediría hacerse una idea sintética del conjunto del sector, apartándonos en principio del objetivo del estudio.

Teniendo en cuenta las dificultades apuntadas se ha optado por realizar un análisis DAFO para la media del sector, resaltando las categorías de empresas que despuntan por arriba o por debajo de la citada media, respecto a cada uno de los factores que inciden interna o externamente en el sector.

A continuación, para cada uno de los factores considerados relevantes en relación con el sector en estudio, se han identificado y analizado los puntos fuertes y débiles, las oportunidades y amenazas.

\section{Factor: Cultivo de la viña}

\section{Puntos fuertes}

- El incremento del rendimiento medio en los últimos siete años debido fundamentalmente al aumento de la superficie de regadío, mejora de las técnicas de cultivo y a la entrada en producción de plantaciones reconvertidas varietalmente. 
- Adecuada diversificación de la estructura varietal en cuanto al número de variedades, con la existencia de 24 variedades, en las que debe basarse fundamentalmente las posibilidades de diferenciación del producto.

- Cerca del 97 \% de la producción está conformada por variedades recomendadas y el 87 \% de la misma por variedades autóctonas.

- $\quad$ El 75 \% de las variedades adaptadas son recomendadas.

- La reconversión varietal está favoreciendo la introducción fundamentalmente de variedades recomendadas con una calidad reconocida internacionalmente. Por otro lado la reestructuración del viñedo en relación con la introducción de formas de cultivo que se adapten a la recolección mecanizada, conducirá a una disminución de los costes de esta operación de cultivo, que por otra parte supone un elevado porcentaje del total de costes de cultivo.

\section{Factor: Coste de los imputs}

\section{Amenazas}

- La evolución creciente del coste que supone la adquisición de activo inmovilizado y los factores de producción fungibles, en relación as desarrollo a la baja de los precios percibidos por los viticultores/elaboradores están conduciendo a una situación de crisis, en la que los costes de producción superan los ingresos percibidos, con el consiguiente riesgo de abandono de la actividad.

\section{Puntos débiles}

- La superficie de cultivo con más del 90 \% en secano conlleva unos bajos rendimientos (algo más del $60 \%$ de la media en la UE) y una enorme variabilidad de las cosechas.

- La excesiva parcelación de las explotaciones y la escasa mecanización del cultivo propician unos elevados costes de producción en relación con el precio final del vino, lo que resta competitividad vía costes respecto a las empresas radicadas en los países emergentes.

- Elevada concentración de la producción (el 80 \% de la misma) en las cuatro variedades principales (bobal, tempranillo, monastrell y tintorera), con predominio de la variedad bobal, que participa en un porcentaje cercano al 50 $\%$ de la producción total. Como consecuencia queda reducida la diversidad de la producción elaborada.

- La sustitución de variedades blancas por tintas resultado de la reconversión varietal, se ha traducido en la realidad, y en el caso de la comercialización de los vinos a granel en un mayor deterioro proporcional de los precios de los vinos 
tintos en origen (por crecimiento de su oferta) que en el caso de los vinos blancos.

\section{Oportunidades}

- Condiciones edafoclimáticas susceptibles de aportar elevado grado de azúcar natural a los vinos.

- Posibilidad de externalizar las labores de cultivo, mediante la creación de secciones de cultivo, desarrollo de servicios profesionales y cultivo en común que compensen la excesiva parcelación, y en su caso, falta de profesionalización de los agricultores.

\section{Amenazas}

- Severas restricciones climáticas por efecto de las heladas, las sequías y la escasez de recursos hídricos que impiden unas producciones regulares tanto en volumen como en calidad entre campañas.

\section{Factor: Antigüedad de las empresas}

\section{Puntos fuertes}

- Predominio de las bodegas antiguas, o de más de 30 años de antigüedad, tanto en el número de empresas (58\%), como en producción comercializada en volumen (87 \%) y facturación (83 \%), con posibilidad de acceso a economías de experiencia.

\section{Puntos débiles}

- Mayor inercia y menor capacidad de adaptación a las cambiantes condiciones de los mercados vitivinícolas.

\section{Factor: Tamaño empresarial}

\section{Puntos fuertes}

- Buena capacidad de adaptación a las crecientes variaciones de las condiciones de los mercados vinícolas.

\section{Puntos débiles}

- Índice CR4 o cuota de mercado en producción comercializada en volumen de las cuatro primeras bodegas inferior al $30 \%$, por lo que puede calificarse de bajo índice de concentración o alta atomización o dispersión.

- Baja instauración de empresas muy grandes (4 empresas), que concentran una producción comercializada del $27 \%$ en volumen, equivalente al $35 \%$ del 
valor de la facturación total, lo que conlleva el desaprovechamiento de economías de escala y de alcance.

- Predominio de las muy pequeñas y pequeñas empresas, que suponen el $40 \%$ y $23 \%$ de las bodegas respectivamente, y concentran conjuntamente tan solo el $16 \%$ de la producción comercializada en volumen o el $20 \%$ de la misma en valor de la facturación. Estos tamaños son insuficientes para poder desarrollar distribuidores propios (con objeto de acortar canales de comercialización y acaparar el valor añadido de las últimas fases de la cadena de valor), para negociar en condiciones de igualdad con el poder que supone la gran concentración en la distribución y para tener un acceso favorable a las fuentes de financiación de las inversiones.

- El reducido tamaño empresarial impide o limita fuertemente: realizar actividades de investigación y desarrollo, mantener una continua modernización de procesos productivos, crear marcas fuertes, ya que sus inversiones en publicidad y marketing no alcanzan un umbral mínimo de impacto, e incorporar herramientas de gestión total, sistemas de aseguramiento de la calidad y aseguramiento de la higiene alimentaria (trazabilidad, APPCC, normas ISO, etc.).

\section{Factor : Asociacionismo agrario}

\section{Puntos fuertes}

- Adecuado asociacionismo agrario de $1^{0}$ grado, el $45 \%$ de las empresas presentan la fórmula jurídica de cooperativas, las cuales agrupan el 62 \% de la producción comercializada en volumen o el 40 \% de la misma en valor de la producción.

\section{Puntos débiles}

- Muy bajo asociacionismo agrario de $2^{\circ}$ grado, tanto en número de empresas (3 bodegas concentran el $16 \%$ de las bodegas cooperativas de $1^{\circ}$ grado), como en producción comercializada en volumen (15,5\%), como en valor de la misma (la tercera parte del valor del conjunto de la producción comercializada por las bodegas asociadas).

\section{Factor: Modo de control del capital social entre los propietarios}

\section{Puntos fuertes}

- Agilidad en las empresas jóvenes, muy pequeñas y mercantiles con modos de control mayoritarios individual o familiar y bajo número de accionistas para la toma de decisiones estratégicas. 


\section{Puntos débiles}

- El modo de control (tipología de los accionistas o grupos de poder) mayoritario es el individual, con el 62 \% de las bodegas, seguido del familiar, con el $29 \%$. Solamente seis empresas están participadas por accionistas societarios y otras cuatro se encuentran participadas por sociedades extranjeras o por multinacionales; como consecuencia queda mermada la posibilidad de que empresas adscritas a un grupo económico más amplio adquieran un mayor potencial estratégico por la generación de economías de escala y alcance superiores a las que les correspondería según su propia dimensión.

\section{Factor: Grado de control del capital social entre los propietarios}

\section{Puntos débiles}

- El 83 \% de las empresas presentan un control difuso (ningún accionista detenta más del $50 \%$ del capital de la sociedad) sobre el capital social, lo que obliga al establecimiento de coaliciones tendentes al establecimiento de mayorías suficientes, lo que dificulta la aprobación y puesta en funcionamiento de cualquier decisión estratégica que adopte en un determinado momento la gerencia o dirección, máxime cuando la base societaria esta muy fragmentada y poco profesionalizada.

\section{Factor: Integración vertical hacia atrás}

\section{Puntos fuertes}

- Muy alto grado medio de integración vertical hacia atrás (76 \% en la escala de 0 a 100), lo que conlleva para las empresas un mayor grado de control sobre la materia prima principal, la seguridad del abastecimiento, la elevación de las barreras de entrada de nuevos competidores, etc. Este factor se ha mostrado especialmente elevado en las empresas antiguas, en cooperativas de $1^{\circ}$ grado, grandes y medianas empresas, y las pertenecientes a la DO Alicante.

\section{Factor: Método de fijación del precio para la uva}

\section{Puntos débiles}

- Bajo porcentaje de empresas que utilizan el control varietal (48 \% del total) y sanitario (39 \% del total) y muy bajo porcentaje de bodegas que recurren al control fenólico (16 \% del total) como criterio para la fijación del precio para la uva, lo que propicia que el agricultor ponga énfasis en técnica de cultivo que propician la cantidad antes y en detrimento de la calidad. 


\section{Factor: Estabilidad del empleo}

\section{Puntos fuertes}

- Muy alto grado medio de estabilidad del empleo, ya que el $86 \%$ del total corresponde a personal fijo continuo, especialmente en las bodegas de edad media, las cooperativas de $2^{\circ}$ grado, las mercantiles y las empresas muy grandes.

\section{Puntos débiles}

- Inestabilidad laboral de los enólogos, figura de trascendental importancia en etapas del proceso de producción como la elaboración, el envejecimiento y la conservación y el embotellado de los vinos; principalmente en las bodegas cooperativas de $1^{\circ}$ grado no asociadas a las de $2^{\circ}$ grado, lo que dificulta la vinculación e integración de estos profesionales con las organizaciones.

\section{Factor: Cualificación del empleo}

\section{Puntos fuertes}

- Adecuada cualificación media del empleo, ya que el 45 \% de los empleados poseen algún tipo de titulación superior, media o formación profesional, especialmente en las bodegas de edad media, las jóvenes, las mercantiles, las cooperativas de $2^{\circ}$ grado y las muy pequeñas.

\section{Amenazas}

- Baja disponibilidad de mano de obra no cualificada principalmente en la operación de vendimia, dada la estacionalidad, duración y cantidad de mano de obra requerida, lo que propicia la conflictividad laboral y elevación del coste de la misma.

\section{Factor: Formación continua}

\section{Puntos débiles}

- La formación no se planifica, sino que se aborda cuando existe cierta obligatoriedad impuesta por normativa o por temas esenciales para la supervivencia y funcionamiento de las empresas. En general las bodegas no disponen de departamento de formación de personal, siendo la figura del responsable de formación poco o nada relevante. 


\section{Factor: Productividad por empleado}

\section{Puntos fuertes}

- Adecuadas productividades en las empresas muy grandes (explicadas por el fenómeno de economías de escala), las mercantiles y las empresas de edad media y antiguas (economías de experiencia).

\section{Puntos débiles}

- Baja productividad media por empleo (medida como la razón entre el valor añadido de la empresa y el número de empleos a tiempo competo), correspondiente a una actividad en general poco intensiva en mano de obra, pues el $75 \%$ del volumen comercializado se vende a granel, no realizando las bodegas las etapas posteriores a la estricta elaboración del vino, es decir, el envejecimiento, la conservación, el embotellado y su posterior comercialización.

\section{Factor: Producción con destino a la destilación}

\section{Puntos fuertes}

- Escaso recurso a la destilación en general como mecanismo de regulación de mercado previsto en la OCM vitivinícola, con menos del $6 \%$ como media de la producción comercializada en volumen, lo cual viene a significar que la producción se encuentra orientada hacia el mercado.

\section{Factor: Producción comercializada con DO}

\section{Puntos débiles}

- Bajo porcentaje medio de vino comercializado con DO, el cual supone el 36 $\%$ del total producido, especialmente reducido en las cooperativas de $1^{\circ}$ grado, las de edad media, en las muy grandes y grandes empresas y en las perteneciente a la DO Utiel-Requena.

- Estancamiento a la baja en la última década del vino comercializado con DO.

\section{Factor: Producción comercializada embotellada}

\section{Puntos fuertes}

- Evolución muy positiva del vino con DO comercializado embotellado respecto del total con DO, que en el último decenio prácticamente ha duplicado su participación y pasa a suponer en la campaña 2002/03 el 57 \%. 


\section{Puntos débiles}

- Bajo porcentaje medio del número de empresas que embotellan (el 48 \% del total).

- Muy bajo porcentaje medio del volumen comercializado embotellado (26 \% respecto del total), predominantemente bajo en las cooperativas de $1^{\circ}$ grado, las de edad media, las antiguas, las medianas y grandes empresas así como las pertenecientes a las DDOO Utiel-Requena y Alicante.

- Muy baja capacidad de envejecimiento de las producciones con el $3 \%$ de la capacidad instalada, que supone menos de la mitad de la existente a nivel nacional.

\section{Factor: Precios a la salida de bodega}

\section{Puntos fuertes}

- Buena relación calidad-precio de los vinos regionales que se comercializan embotellados, lo que está impidiendo la entrada y posicionamiento en los mercados regionales y nacionales de los vinos procedentes de los países emergentes.

\section{Puntos débiles}

- En más de las dos terceras partes de la producción comercializada en volumen, el precio viene fijado por las condiciones de la demanda, en las cuales las empresas tienen pocas posibilidades de negociar. Este hecho es una consecuencia del gran volumen de vinos comercializados a granel (casi las tres cuartas partes de la producción comercializada total) con escasa diferenciación del producto, donde el precio es el factor más limitante para poder competir.

- Como consecuencia de la estrategia de precios a la baja que marca la demanda en los graneles, y que el coste de la materia prima es elevado en relación con el precio final de los productos, los precios a la baja del vino se transfieren casi íntegramente a la uva como materia prima principal y en definitiva a los precios percibidos por viticultores que en muchos casos obtienen unos precios inferiores al coste de producción.

- El principal motivo de compra de los graneles radica en su precio bajo, por lo que no se recupera en la venta el valor añadido que proporciona al vino el aceptable grado de tecnología de las instalaciones de elaboración. Estos graneles no son competitivos en precio (ya que los costes de producción y elaboración son elevados en relación con el precio final del producto), por lo que no pueden competir en condiciones ventajosas en el segmento de productos no diferenciados. 
- Descalificación de las producciones de vino con DO con objeto de comercializarlos fuera de las fronteras regionales como vinos de mesa a granel. Esta actuación viene explicada porque en los casos de los vinos blancos, rosados y tintos, el precio medio a la salida de bodega de los vinos comercializados con DO a granel alcanzan unos precios de $0,37 € /$ litro, cifra que no difiere significativamente del precio alcanzado por los vinos de mesa comercializados a granel $(0,34 €$ /litro), por lo que el valor añadido que supone la DO no se incorpora al vino cuando este es comercializado a granel.

- Respecto las bodegas embotelladoras, menos del $2 \%$ del volumen total comercializado embotellado emplea la estrategia de precios altos, la cual persigue presentar una imagen de calidad del producto, acompañada de esfuerzos publicitarios en gamas de vinos altas. En el caso de los vinos jóvenes el $85 \%$ de las ventas en volumen se encuentran situadas en la gama más baja de precios, el "Basic". En relación con los vinos envejecidos sólo el $10 \%$ de las ventas están posicionadas en los segmentos más altos "Superpremium” y "Ultrapremium”.

- La percepción por un segmento importante de consumidores de vino de calidad de que un menor precio está asociado a la baja calidad, incrementa el nivel psicológico del precio del vino asociado a la certificación de la calidad del mismo, muy por encima de los precios que fluctúan dentro de la gama baja, en la cual se mueve la parte mayoritaria de los vinos embotellados por las bodegas de la región.

\section{Factor: Capacidad instalada en las bodegas}

\section{Puntos fuertes}

- Aceptable grado medio introducción de depósitos de acero inoxidable tanto para elaboración como para almacenamiento (cerca del 50 \% de la capacidad instalada total), particularmente en las empresas jóvenes, las cooperativas de $2^{\circ}$ grado, las empresas muy pequeñas y las pertenecientes a la DO Valencia.

- Aceptable calidad media de la capacidad instalada (capacidad total de autovaciantes y depósitos de fermentación controlada respecto de la capacidad instalada total), que alcanza la cifra del $25 \%$, y muy concretamente en las empresas jóvenes, las cooperativas de $1^{\circ}$ grado en su conjunto, y las empresas muy pequeñas.

\section{Puntos débiles}

- Alto grado de sobredimensionamiento medio de la capacidad instalada (diferencia entre la capacidad instalada y la producción comercializada respecto de la capacidad instalada), que alcanza el $32 \%$, particularmente elevado en el caso de las empresas de edad media, las cooperativas de $1^{\circ}$ grado no asociadas a las de $2^{\circ}$ grado, las medianas empresas y las pertenecientes a Alicante. 
El bajo grado de aprovechamiento medio de la capacidad eleva los costes fijos para las empresas. No obstante esta sobredimensionamiento podría justificarse: por la saturación de los mercados y aparición de excedentes que han de almacenarse en esta sobrecapacidad; por la ayuda al almacenamiento privado que permita una salida escalonada de la producción; y por la irregularidad de las producciones entre campañas.

\section{Factor: Tecnología de otras instalaciones de elaboración}

\section{Puntos fuertes}

- Aceptable nivel medio en la tecnología de las instalaciones que intervienen en todo el proceso de elaboración: toma y análisis de muestras, recepción de la uva, separación del raspón, prensado, desfangado, controles de fermentación, clarificación, filtración, estabilización, envejecimiento y embotellado. Dicha tecnología favorece los procesos que inciden sobre la calidad organoléptica del producto (aroma, color, polifenoles, etc.).

\section{Factor: Informatización en las empresas}

\section{Puntos fuertes}

- Muy alto nivel medio de informatización de la gestión contable, ya que el 80 $\%$ de las bodegas disponen tanto de de equipos como de programas informáticos.

\section{Puntos débiles}

- Muy bajo grado medio de informatización (el 15 \% de las bodegas disponen de sistemas de informatización) para apoyo a las operaciones de elaboración, conservación, envejecimiento, y embotellado. Este factor se considera absolutamente necesario para la implantación de sistemas automatizados de trazabilidad, controles de la calidad, gestión de stocks, seguimiento de las distintas operaciones, garantía del control productivo, constituyendo una aportación fundamental al concepto de calidad total.

\section{Factor: Automatización de procesos}

\section{Puntos débiles}

- En general muy bajo nivel medio de automatización de procesos, ya que sólo el $30 \%$ de las empresas disponen de sensores para asistir a la operación de fermentación y tan solo el $10 \%$ de aquellas disponen de sensores de apoyo en las operaciones de elaboración conservación, envejecimiento y embotellado. 


\section{Factor: Tecnologías de la información y comunicaciones (TIC)}

\section{Puntos fuertes}

- La totalidad de las empresas disponen de Internet, lo cual hace posible el intercambio de información por medios digitales para el establecimiento de relaciones de coordinación, cooperación o colaboración dentro de la empresa (Intranet) o con los agentes externos, proveedores, clientes, Administración (Extranet).

\section{Puntos débiles}

- En general las empresas no poseen paquetes de gestión integrada en relación con los procesos internos del negocio (ERP), ni en relación con los clientes (CRM), ni con los proveedores (SCM).

- Bajo nivel medio de instauración de página Web (el 33 \% de las empresas disponen de ella), de manera especial en las empresas antiguas, las cooperativa de $1^{\circ}$ grado y medianas y grandes empresas.

- En general las bodegas no aprovechan suficientemente las posibilidades tecnológicas de las TIC, presentando un grado de adopción bajo, el cual les resta competitividad en un entorno cada vez más globalizado en el cual estas últimas tecnologías tienen un papel preponderante.

\section{Factor: Esfuerzo innovador}

\section{Puntos débiles}

- Muy bajo esfuerzo innovador medio en el subsector, ya que la inversión en $\mathrm{I}+\mathrm{D}+\mathrm{i}$ respecto a la cifra del valor de la producción representa un $0,22 \%$. En número de empresas solo el $8 \%$ de las mismas han llevado a cabo alguna inversión en este sentido.

El marco fiscal existente, la escasa capacidad de financiación, la actitud reactiva de la adaptación de la empresa a su entorno, la carencia de personal con formación específica, y la dudosa defensa de la propiedad intelectual entre otros, son las principales razones que frenan este esfuerzo.

\section{Factor: Diferenciación por certificación de la calidad del producto}

\section{Puntos débiles}

- Muy bajo nivel de implantación medio entre las bodegas de vinos elaborados ecológicamente (el $9 \%$ de las bodegas), debido entre otras, a las siguientes causas: el sobreprecio del producto ecológico, que freno el consumo y es incompatible con la filosofía de la gran distribución; su contribución a la confusión del consumidor con otros menciones como artesano, regional, de la 
tierra, etc.; diferencias en sabor no detectadas por el consumidor respecto al convencional.

- Muy bajo nivel de introducción medio entre las bodegas de vinos elaborados mediante técnicas de producción integrada (el 16 \% de las bodegas), debido fundamentalmente a la inexistencia en el mercado actual de los vinos de un diferencial de precios con respecto al vino elaborado convencionalmente, que sea un estímulo para la implantación de este tipo de técnica.

- Producción estrictamente testimonial acogida a la figura situada en el vértice de la pirámide de calidad, en referencia a los vinos de pago, ya que solo una empresa en el ámbito regional realiza producciones bajo esta figura de calidad.

\section{Factor: Diferenciación de la calidad de las empresas}

\section{Puntos débiles}

- Muy bajo nivel de implantación medio entre las bodegas de sistemas de aseguramiento integral de la calidad, normas ISO 9000:2000, e ISO14001, con el $5 \%$ y $0 \%$ respectivamente en cuanto al número de bodegas encuestadas.

- En relación con el aseguramiento de la higiene alimentaria, existe un muy bajo nivel de implantación medio entre las bodegas de los sistemas de Análisis de Peligros y Puntos de Control Críticos (APPCC) y de Trazabilidad, con el $15 \%$ y el $22 \%$ del número de empresas encuestadas respectivamente a pesar de la existencia de una obligatoriedad legal para las empresas.

En general, la adopción de este tipo de sistemas en el futuro va a estar muy relacionadas con las condiciones impuestas por la gran distribución, con las exigencias necesarias para la exportación y con el cumplimiento de la legislación vigente.

\section{Factor: Diferenciación del producto}

\section{Puntos fuertes}

- En los vinos comercializados embotellados es aceptable la producción de vinos varietales (variedad que da origen a la denominación del vino representa como mínimo el $85 \%$ ), con un porcentaje medio en volumen respecto al total embotellado del $38 \%$.

\section{Puntos débiles}

- Muy baja diferenciación del producto en los vinos comercializados a granel, a pesar de que la calidad intrínseca sea aceptable. 
- Muy baja diferenciación media del producto en los vinos embotellados (relación entre el volumen de ventas de crianzas y reservas y el volumen de embotellado), con el $15 \%$, que indica un bajo interés por la adopción de estrategias de diferenciación a través del perfeccionamiento de los productos de las empresas.

- Insuficiente notoriedad de la marca, medida como el precio medio a la salida de la bodega del vino de crianza en el mercado nacional (1,62 €/botella de 3/4). lo cual significa que los vinos de gama elevada, como las de crianza y reserva se encuentran situados por término medio en el segmento más bajo de consumo en Europa, es decir el segmento "Basic".

- Excesiva valoración de los aspectos físicos ligados al vino por los productores y elaboradores y descuido de los intangibles ligados el vino y enormemente valorados por los consumidores, tales como los servicios, información de los productos y su entorno, estética, medio ambiente y seguridad alimentaria entre otros. La valoración de estos intangibles no resulta fácil, lo que ha propiciado que el productor-elaborador haya descuidado estos aspectos, que constituyen una continua creación de valor añadido y alta consideración en los mercados más desarrollados.

- Escasas posibilidades de diferenciación tecnológica del producto, la cual confiere la calidad intrínseca u organoléptica del mismo, debido tanto a la estandarización de la tecnología de elaboración, conservación y envejecimiento, como a la limitación de las prácticas que impone la propia reglamentación de las distintas DDOO.

\section{Factor: Política de marcas}

\section{Puntos fuertes}

- En los vinos embotellados, la estrategia se encuentra enfocada a marcas propias, puesto que casi el $80 \%$ del total de volumen embotellado se comercializa con marcas propias. En el caso de las bodegas de edad media, las cooperativas de $2^{\circ}$ grado, las medianas y pequeñas empresas y las pertenecientes a la DO Alicante la totalidad del vino embotellado se comercializa con marcas de las empresas o propias.

\section{Puntos débiles}

- Aunque el número medio de marcas por empresa y tipo de vino, alcanza un valor de 2,4, que no puede considerarse elevado, la excesiva dispersión del subsector conlleva a un elevado número de marcas, que posiblemente tienda a crear confusión adicional en el consumidor, y se sume a la ya creada por la propia fragmentación del subsector (DDOO, variedades, categorías de vinos, etc.). 
- Esta gran profusión de marcas dificulta la penetración en las cadenas de distribución.

\section{Factor: Destino geográfico de la producción comercializada}

\section{Puntos fuertes}

- Evolución muy positiva del vino comercializado con DO exportado, que ha visto aumentar su participación respecto del total comercializado con DO en el último decenio del $53 \%$ al 73 \% (campaña 2002/03).

- Adecuado grado medio de dispersión de los mercados (0,67 en la escala de 0 a 0,8), ya que una buena dispersión diversifica los riesgos inherentes para la propia empresa que pudiera suponer una situación de saturación coyuntural de alguno de los mercados meta.

- Suficiente amplitud geográfica media de los mercados, ya que el número medio de países por empresa en los que se comercializa el vino alcanza la cifra de 4, y adecuada cuota de exportación media con el $27 \%$ de la producción comercializada total en volumen. Presentan valores por encima de la media, en ambos indicadores, las mercantiles, las cooperativas de $2^{\circ}$ grado y las empresas muy grandes.

\section{Puntos débiles}

- Elevada especialización en el mercado regional (relación entre el volumen comercializado en el mercado regional y el volumen total comercializado) en el caso de las bodegas pertenecientes a la DO Alicante (85 \%) medianas empresas (76 \%), y las cooperativa de $1^{\circ}$ grado no asociadas a las de $2^{\circ}$ grado (68\%), con el consiguiente riesgo en caso de saturación de estos mercados.

- Exportaciones muy concentradas en la UE-15, que concentra el $80 \%$ de las mismas, y muy localizadas en los siguientes países por orden de importancia: Alemania, Reino Unido, Dinamarca, Francia, Finlandia y Holanda.

\section{Factor: Canales de comercialización en vinos embotellados}

\section{Puntos débiles}

- Excesiva concentración media de las ventas de vino embotellado en los distribuidores mayoristas, que concentran el $44 \%$ de aquellas. Especialmente concentradas con un porcentaje que ronda en $70 \%$ en las empresas de edad media, las cooperativas de $2^{\circ}$ grado, empresas muy pequeñas y pequeñas y las pertenecientes a la DO Alicante.

- Excesiva concentración media de las ventas de vino embotellado en la gran distribución, que igualmente concentran el 44 \% de aquellas. Especialmente 
concentradas en las empresas muy grandes (74\%) y las pertenecientes a la DO Utiel-Requena.

- Escasa participación media en la comercialización de vino embotellado de los canales alternativos: horeca con el 5,2 \%, tiendas especializadas con el $4 \%$, venta directa en bodega con menos del $3 \%$, club del vino e Internet con menos el $1 \%$ en cada uno de éstos últimos canales. Esta escasez de redes comerciales propias de las bodegas en su conjunto dificultan las oportunidades de acceso de los vinos valencianos con DO a los mercados de destino, ya que deben competir en su acceso hacia estos mercados con otros vinos de otras DDOO e incluso de otras naciones, ganándose los favores tanto de los distribuidores no propios como de la gran distribución.

\section{Oportunidades}

- La calidad ha dejado de ser un mero factor de competitividad, para convertirse en un factor indispensable para estar en el mercado a través de la gran distribución.

- Aparición de nuevas alternativas de distribución que aumenten las posibilidades de acceso directo al consumidor y equilibre el creciente poder de la gran distribución.

- El elevado precio que están alcanzando las DDOO de mayor notoriedad puede abrir mercados a las DDOO en estudio, menos conocidas con niveles aceptables de calidad y precios inferiores, que en caso de conseguir un lugar en la distribución podrían llegar a posicionarse favorablemente.

- La gran distribución es fundamental para la comercialización de los vinos regionales y a que se está observando un incipiente cambio de aquella en la estrategia de distribución, destacando el mayor espacio dedicado a los vinos, el cuidado en la presentación y el gran número de referencias provenientes de distintas zonas y variedades y DDOO, que en general se mueven es estratos de precios muy ajustados, donde encajan la mayoría de los vinos regionales.

- Se precisa un sector elaborador y abastecedor fuerte y concentrado capaz de ofrecer vinos en cantidad y homogeneidad dentro de una oferta diversificada con objeto de dar respuesta en igualdad de condiciones a la demanda de la gran distribución.

\section{Amenazas}

- Enorme poder de negociación de la gran distribución supermercados, hipermercados y centrales de compra), propiciado por la actual e imparable concentración, lo que da lugar a una situación débil (cada vez más) en la negociación de las condiciones de venta, principalmente presionando los precios ofrecidos a los elaboradores a la baja y mayores aplazamientos en los pagos. 
- La gran distribución, al menos hasta ahora, frente a otras alternativas no prescribe, no informa y no siempre cuidan lo suficiente el vino como producto.

- En el canal horeca (hostelería, restauración y catering), el sobreprecio en ocasiones abusivo supone un freno al incremento del consumo, sobretodo en el segmento juvenil.

- Las nuevas tendencias de colaboración y gestión por categorías, sólo serían posibles con acuerdos amplios entre los productores de vinos de calidad.

- Todavía persiste el mensaje residual de otros tiempos, de que lo que no está incluido en las grandes DDOO, es peor y no responde a los niveles de calidad que pueden ofrecer éstas.

\section{Factor: Integración vertical hacia adelante}

\section{Puntos fuertes}

- Adecuado grado de integración hacia adelante en un segmento de bodegas con escaso peso en el conjunto de la producción, que comparten algunas características: suelen ser jóvenes y con la forma jurídica de mercantiles, cuentan con marcas de prestigio y se encuentran notablemente e incluso totalmente verticalizadas, en el sentido en que integran o asumen en la misma empresa las etapas de cultivo, elaboración envejecimiento y embotellado del vino.

\section{Puntos débiles}

- Muy bajo grado medio de integración vertical hacia adelante (13 en la escala de 0 a 100), lo que indica que las bodegas están muy poco integradas con las últimas etapas de la cadena de producción posteriores a la elaboración, lo que impide ganar agilidad en la adaptación de la oferta a la demanda El índice es especialmente bajo en las empresas de edad media, en las cooperativas de $1^{\circ}$ grado y en las medianas empresas.

La consecuencia más inmediata es la existencia de una importante masa empresarial de bodegas elaboradoras orientadas al mercado de graneles de vino muy poco estructurado, y de unas relaciones entre éstas bodegas y empresas de envejecimiento o embotelladoras escasamente verticalizadas (sin la existencia en este caso ni siquiera de acuerdos o contratos), en las que la mayor parte de los intercambios tienen forma de operaciones de compraventa en el mercado abierto, en el mejor de los casos con indicación varietal.

- Los viticultores limitan su participación al suministro de materia prima (uva o vino) y no participan en el comercio, quedando al margen de las señales del mercado, y aíslan la producción de las tendencias del mercado. 
- Escasa colaboración entre los diferentes operadores pertenecientes a los distintos subsectores.

\section{Factor: Esfuerzo comercial}

\section{Puntos débiles}

- Muy bajo valor medio del esfuerzo comercial medido como la relación entre el gasto comercial y el valor de la producción con el 3,42 \%, especialmente en las bodegas antiguas, las cooperativas de $1^{\circ}$ grado y las empresas grandes, por lo cual queda muy mermada la posibilidad de una diferenciación por información al consumidor.

- Muy baja inversión media en investigación de mercados, con el 0,25 \% del valor de la producción, con lo cual, la orientación actual imperante del marketing, en lo referente a la orientación de los productos a las necesidades del consumidor no es abordada por el sector con los recursos imprescindibles capaz de proporcionar algún resultado en esta dirección.

\section{Factor: Generación de valor añadido}

\section{Puntos fuertes}

- La gran dispersión empresarial y el reducido tamaño no ha impedido que un cierto número de empresas sean competitivas en base a la diferenciación del producto en el segmento de empresas que embotellan.

\section{Factor: Políticas vitivinícolas, alimentarias, monetarias y fiscales}

\section{Oportunidades}

- Planes de reestructuración y reconversión para adecuar las producciones al mercado. Ausencia de la promoción del arranque de modo imperativo.

- Inexistencia de una política de precios, lo cual permite el libre posicionamiento en los mercados internacionales.

- Desarrollo de una política de calidad.

- Contempla la formación de las agrupaciones de productores y organizaciones sectoriales para contribuir a la realización de los objetivos de la OCM vitivinícola.

- Definición del vino en la Ley de la Viña y del Vino como “alimento natural”, lo que autoriza el apoyo público a través de la Administración Estatal en campañas de información, difusión y promoción del vino en un momento de disminución acelerada del consumo interno. 
- La Ley sobre prevención de consumo indebido de bebidas alcohólicas, exime al vino de las restricciones de la publicidad contenidas en su articulado.

- Los tipos de interés a la baja, mantenidos durante la última década han reactivado y fomentado las inversiones en las bodegas, si se tiene en cuenta que el 38 \% de las mismas por término medio han sido financiadas con préstamos.

\section{Amenazas}

- Auto limitación del potencial vitícola, lo que afecta a su competitividad, cuando en el resto del mundo no se acomete la misma actuación. En un mercado abierto, todo lo que deje de producir la UE, lo producirá otro conjunto de países, que sucesivamente forzará a la UE a seguir bajando producciones en busca del equilibrio.

- Reglamentación homogénea de un producto extremadamente heterogéneo como el vino, lo que propicia la intensa proliferación de reglamentaciones nacionales y regionales contradictorias.

- Ausencia de una diferenciación medioambiental y territorial y en definitiva multifuncional del cultivo que lo haga viable en zonas como la Comunidad Valenciana con fuertes restricciones medioambientales.

- Inexistencia de una política de demanda que oriente las ayudas públicas hacia la comercialización, el marketing, la $\mathrm{I}+\mathrm{D}+\mathrm{i}$, diferenciación del producto e identificación de los gustos del consumidor.

- Los mecanismos de destilación a medio y largo plazo retrasan la necesaria apuesta de las bodegas por las estrategias de comercialización de su producción en el mercado y propician que la situación de excedentes coyunturales se conviertan en estructurales. Además estos mecanismos generan una salida artificial de las producciones que indirectamente producen el efecto del aumento de las importaciones.

- La legislación española es más restrictiva que la comunitaria, respecto a determinadas práctica de cultivo y elaboración (regadío del viñedo y enriquecimiento con sacarosa o mosto concentrado rectificado.

- La práctica de la chaptalización desvirtúa en concepto de calidad, convierte en inoperantes las medidas para reducir el volumen de producción total, y perjudica principalmente a regiones como la Comunidad Valenciana, que elabora vino de un modo "natural", restando competitividad al modelo de producción europeo respecto a los vinos del exterior, dado que el fenómeno de la globalización tiende a converger en los mismos mercados meta los dos tipos de producciones. 
- Inexistencia de una información fiable sobre la oferta y demanda de vinos, ya que a pesar de existir muchos datos debido a la intervención pública en el propio sector, procedente de información exigida a los operadores, no existen suficientes recopilaciones, tratamiento y análisis de la información disponible.

- No se ha desarrollado y consecuentemente tampoco se ha dotado económicamente el Título IV del R (CE) 1493/1999, relativo a Agrupaciones de Productores y Organizaciones Sectoriales.

- La propuesta de la DG de Sanidad y protección de los consumidores, sobre la prohibición de alegaciones nutricionales y de salud en el etiquetado, la presentación y la publicidad de las bebidas con una graduación superior a 1,2 $\%$ de alcohol, junto con la propuesta sobre la exclusión de la promoción de ventas de bebidas alcohólicas (más de 1,2 \% de graduación alcohólica), de prosperar, serían muy negativas para el sector, anulando el posible apoyo público procedente d la Administración Estatal.

- La tasa de cambio del euro respecto al dólar está ralentizando un mayor crecimiento de las exportaciones fuera de las fronteras de la UE, que representan aproximadamente el $25 \%$ del total del volumen exportado.

- El proceso de envejecimiento de los vinos requiere mantener grandes stocks en bodega, que reducen los resultados de las empresas. Las reducidas bonificaciones fiscales no contribuyen a mejorar la rentabilidad de las empresas.

\section{Factor: Comercio mundial del vino}

\section{Oportunidades}

- La competencia de las empresas de los países emergentes debe servir como revulsivo para adecuar estructuras de producción, elaboración y comercialización y reposicionar al alza los vinos regionales en los mercados.

- La incorporación de los PECOS supone mayor potencialidad que amenaza, puesto que la ampliación del mercado es muy superior al aumento de la oferta derivada de su integración, ya que los únicos países que incorporan un cierto nivel de producción son Hungría, Bulgaria y Rumania.

\section{Amenazas}

- Acelerada tasa de crecimiento de las exportaciones de los países no productores principales o emergentes en detrimento de la perdida de cuota de los países productores tradicionales, debido principalmente a la existencia de un modelo de producción mas liberalizado, basado en los menores costes de producción, con equilibrio entre el precio y la calidad, y orientado a la comercialización, respecto al caso del modelo europeo. 
- El proceso de globalización junto con su presión liberalizadora ha expuesto al sector vitivinícola europeo a una mayor competencia entre las producciones de diferentes orígenes, especialmente de los nuevos países productores, debido a varios factores: mayor dimensionamiento de las explotaciones, menores costes laborales, clima menos errático con rendimientos superiores y más estables, etc. La internacionalización propiciará mayores problemas en la exportación al incrementarse la competitividad a nivel internacional.

- Las Indicaciones Geográficas (IG), están consideradas como propiedad intelectual y por tanto protegidas por el Acuerdo ADPIC. El problema para la UE es que ese nivel mínimo para las IG de los vinos es demasiado bajo y existe una disparidad de mecanismos de protección, lo que implica riesgo de nuevas usurpaciones de IG.

- La globalización supone estar en muchos mercados algunos distantes de la zona de procedencia, por lo que esta estrategia se puede llevar en producciones de cierto valor añadido y margen unitario por botella, ya que la situación de pequeños volúmenes en muchos mercados conlleva mayores costes logísticos. Los graneles que constituyen una parte mayoritaria de las producciones regionales y los vinos embotellados de gama baja y con poco margen unitario por botella no encajan bien en el marco que impone la internacionalización de los mercados, por lo que en la actualidad la oportunidad de apertura de nuevos mercados que supone la globalización constituye una amenaza neta para la mayor parte de las producciones regionales.

\section{Factor: Características del mercado de la demanda}

\section{Oportunidades}

- Leve tasa de aumento del consumo nacional per cápita de vinos de calidad, situándose en el año 2003 en 7,5 litros por habitante y año. Esta tasa se encuentra lejos de compensar el fuerte detrimento que se está observando en los vinos de mesa.

- Interés creciente y proactividad (búsqueda activa de información) con relación al mundo y cultura del vino.

- Afianzamiento de la relación de los conceptos vino y salud, siempre ligada a un consumo moderado y con el beneficio de verse incluido en la "dieta mediterránea”.

- Reafirmación del papel social del consumo de vino de calidad.

- El consumidor español considera el vino español como mejor o mucho mejor que el de otros países, lo que protege a los vinos nacionales de la competencia de otros vinos foráneos. 
- Valoración positiva entre los consumidores de las figuras de los Consejos Reguladores de las distintas DDOO en general, y en particular supone una garantía de calidad cuando el vino no se ha probado.

\section{Amenazas}

- Apreciable disminución desde el 1992 de la cerveza y otras bebidas alcohólicas, con reorientación del consumidor hacia bebidas sin alcohol, por el aumento del consumo de agua mineral, zumos de frutas y gaseosas y refrescos, bebidas que por otra parte son más sencillas de elegir por un consumidor poco instruido, pero además porque la estructura empresarial de las empresas relacionadas con estas bebidas alcohólicas y analcohólicas esta mucho más concentrada y les permite decidir más fácilmente acciones de promoción y publicidad.

- Muy elevada tasa de disminución del consumo nacional per cápita en vinos de mesa, hasta situarse en el año 2003 en 18,8 litros por habitante y año.

- Muy baja predisposición a la prueba de vinos de DDOO diversas, distintas y con precios más bajos a las más conocidas y consumidas (Rioja, Ribera del Duero, etc.), lo que constituye una buena prueba de la alta tasa de fidelidad que han alcanzado algunas DDOO.

Es necesario un determinado poder adquisitivo par el acceso de los jóvenes principalmente, a un consumo habitual de los vinos de calidad.

- Dura competencia del vino de calidad, sobretodo en comunicación y en precios con otras bebidas sustitutivas.

- La opinión médica no consigue dar un mensaje unánime en relación al consumo de vino para la salud, o sobre el concepto de consumo moderado. Este elemento de contradicción conlleva que entre algunos segmentos de la población subyaga la idea de que cualquier bebida alcohólica y en cualquier cantidad es perjudicial siempre para la salud.

- El elevado precio psicológico que se atribuye a un vino con garantía de calidad (6 $€$ por botella de $3 / 4$ ), constituye el elemento clave en la diferenciación de un vino de calidad frente al que no lo es. Este aspecto perjudica a los vinos de calidad económicos o vinos de la tierra, que presentan una buena relación precio-calidad y que sin embargo están posicionados en unos niveles de precios inferiores y que según la afirmación anterior su calidad debería ser mala o a lo sumo mediocre.

- Baja predisposición a probar vinos de una DO que no se haya consumido anteriormente, siendo una buena prueba de la alta tasa de fidelización ante los consumidores que han alcanzando las DDOO más prestigiosas. 
- Falta de estructuración y coherencia en la comunicación del vino de calidad, con falta de definición clara de los componentes de la calidad que sea accesible a la mayoría de los consumidores.

- Consecuencia de la deficiente comunicación del vino de calidad es la muy baja cualificación de los consumidores en general, poco entendidos y exigentes, lo cual impide la diferenciación de los productos.

Teniendo en cuenta el "Estudio sobre la posición competitiva del sector de alimentación y bebidas en España (MAPA, 1993)“, y considerando los factores internos clave de competitividad propuestos por orden de importancia para el vino (gestión de la calidad, imagen de marca, gestión comercial y de marketing, grado de innovación y estructura financiera adecuada), así como los factores externos clave por orden de importancia (política agraria comunitaria, tasa de crecimiento de la demanda, evolución de los costes de mano de obra del personal, disponibilidad de capital riesgo, y disponibilidad de mano de obra cualificada), se podría calificar situación competitiva media del subsector vinícola como baja, en el sentido de que la mayoría de las empresas son incapaces de incorporar valora añadido a sus producciones comercializadas a granel.

\section{ANÁLISIS ESTRUCTURAL DE LA INDUSTRIA VINÍCOLA SEGÚN PORTER}

Una definición bastante aceptada de competitividad: "una industria (un sector) competitiva es aquella que posee la capacidad sostenible de ganar y mantener participación de mercado en forma rentable, tanto en el ámbito doméstico como internacional" (Agriculture Canada) La competitividad es un concepto "relativo". Se es más o menos competitivo que otra firma, otro sector u otro país. Al mismo tiempo, también es un concepto "dinámico", en el sentido de ganar o mantener participación de mercado en el futuro.

La explicación más antigua y difundida del éxito de algunos sectores (de algunos países) en el comercio internacional se basa en la teoría de las ventajas comparativas que suponen que las naciones tienen una tecnología equivalente pero que difieren en sus dotaciones de factores (tierra, trabajo y capital), que son fijas.

Aunque los costos de los factores de la producción siguen siendo un determinante importante de la competitividad de aquellos sectores vinculados a los recursos naturales, o en los que el costo de la mano de obra es una proporción muy elevada del costo total, existen -según Porter- numerosas evidencias que indican que la teoría de las ventajas comparativas no es adecuada para explicar el patrón de comercio internacional entre los países avanzados, caracterizados entre otras cosas, por una dotación similar de factores productivos, que evolucionan y se sustituyen mediante el cambio tecnológico, por un comercio de productos altamente diferenciados, y en el que juegan un papel muy importante las compañías multinacionales.

Por otro lado son las empresas las que compiten en los mercados nacionales e internacionales. Para comprender la naturaleza de esta competencia, la unidad básica de 
análisis es el sector. Dentro del mismo, las empresas tratan de seleccionar una estrategia competitiva en función de dos aspectos esenciales: la estructura del sector y la dinámica estructural del mismo.

Para caracterizar la estructura de un sector Porter utiliza su modelo de " 5 fuerzas”, que determinan la intensidad de la competencia, y son las siguientes: el poder de negociación de los proveedores, el poder de negociación de los clientes, la amenaza de entrada de nuevos competidores, la amenaza de productos sustitutos y la rivalidad entre las empresas existentes.

La estructura de un sector influye sobre la competencia (y la competitividad) por tres razones: a) diferentes sectores tienen diferentes requisitos para competir, b) los sectores más importantes para un alto nivel de vida suelen ser aquellos estructuralmente atractivos (con barreras a la entrada, productos diferenciados, etc.), y c) el cambio estructural crea oportunidades para que competidores de otras naciones penetren en nuevos sectores.

Por otro lado la ventaja comparativa en la que se basaba tradicionalmente la competitividad ha perdido significación a favor de la mejora continua y la innovación, las economías de escala frente a la capacidad de anticipar las necesidades globales y el reto de la globalización, que obliga a adoptar un enfoque más dinámico, y ayuda a entender las diferencias de competitividad entre sectores ubicados en naciones distintas. En este sentido el modelo del diamante de Porter que se basa en relaciones cualitativas entre el subsector y el entorno, establece seis atributos determinantes de la posición competitiva (condiciones de los factores, condiciones de la demanda, sectores afines y de apoyo y estrategia, estructura y rivalidad de las empresas, la casualidad y el gobierno).

\subsection{Intensidad competitiva según el modelo de las cinco fuerzas de Porter}

El objetivo de este apartado es identificar y valorar aquellos factores más significativos en la determinación del grado de rivalidad competitiva existente dentro del subsector vinícola de la Comunidad Valenciana, y que afecta a las bodegas instaladas en su territorio.

Con esta finalidad se ha utilizado el planteamiento conceptual y metodológico propuesto por Porter (1982) con su modelo de las cinco fuerzas, que viene a considerar el nivel de competencia de los sectores como referencia fundamental para poder estimar la rentabilidad potencial de las empresas en ellos instaladas, de manera que cada empresa pueda definir su proyecto estratégico competitivo con el cual defenderse mejor de la amenaza de las cinco fuerzas y conseguir así una rentabilidad mayor que la de sus competidores directos.

A continuación se han analizado cada una de las fuerzas que intervienen en el modelo: el poder de negociación de los proveedores, el poder de negociación de los clientes, la amenaza de entrada de nuevos competidores, la amenaza de productos sustitutos y la rivalidad entre las empresas existentes. 


\section{Poder de negociación de los proveedores}

En el caso de las bodegas en estudio, la relación de los proveedores es extensa, pudiéndose agrupar en cuatro apartados: los proveedores de uva o vino, proveedores de materias auxiliares, proveedores de recursos financieros y el personal de la empresa.

- Proveedores de la uva o el vino. Constituye el elemento más importante y que a la vez significa una parte relevante en el coste total del producto final, se puede considerar reducido debido a la gran atomización de los agentes participantes en esta etapa productiva y a que se enfrentan a un mayor grado de concentración desde las bodegas compradoras.

A pesar de las dificultades administrativas existentes que impiden la materialización del deseo de las bodegas por avanzar en un mayor grado de integración vertical hacia atrás y de la existencia de un mercado cautivo a favor de estos proveedores dada la necesidad de que los compradores adquieran uva-vino procedente del ámbito geográfico de las DDOO, existen otros factores que inclinan la capacidad de presión del lado de las bodegas clientes como son:

a) La existencia de altos costes para el productor por el mantenimiento de su producción ya cortada, que sólo puede conseguirse a través de su transformación en vino.

b) Los reducidos costes que se producen por cambio de proveedor en general, salvo el grupo minoritario de bodegas que demandan una materia prima muy específica, ya que el requisito fundamental para el proveedor consiste en mantener la certificación de origen de la producción y que las diferencias de calidad se resuelven por un diferencial del precio en función del grado alcohólico del producto.

c) El conocimiento completo de las alternativas de oferta. De hecho son las bodegas compradoras o clientes quienes finalmente fijan en cada cosecha el precio de mercado al que se adhieren los productores. La evolución cíclica de los precios indica que, si bien en momentos de escasez de oferta y ante unas perspectivas empresariales favorables, el precio del mercado en origen sube, cuando los resultados alcanzados por las bodegas empeoran, se demuestra una gran facilidad para repercutir hacia estos proveedores tales resultados, llegando en estas últimas ocasiones, a pagar por su producto un precio igual o incluso menor del coste total de su obtención.

- Proveedores de materiales auxiliares. Los productos enológicos, envases de vidrio, tapones etc. en general puede afirmarse que no poseen un poder negociador significativo.

- El sector bancario. Como proveedor de los recursos financieros, reúne muchas condiciones para manifestarse como un sector con alto poder negociador. 
- Los empleados de las bodegas poseen una escasa capacidad de presión y además, su repercusión sobre la estructura de costes del producto final es poco relevante.

- Sustitutos de la materia prima principal (uva-vino) Aunque no haya sustituto para estas materias primas, la situación excedentaria en el sector del vino conlleva una alta disponibilidad de las mismas, lo que reduce el poder negociador de los proveedores.

- Integración vertical hacia atrás de los proveedores. Si bien existe un alto grado de integración vertical hacia atrás de los proveedores, especialmente en antiguas empresas, entidades asociativas, y medianas y grandes empresas (76 en la escala de 0 a 100) la fragmentación de los mismos les confiere poco poder negociador.

- Integración vertical hacia adelante de los proveedores. Existe un grado muy bajo de integración vertical haca delante de los proveedores (13 en la escala de 0 a 100) lo que disminuye las presiones competitivas dentro del sector.

- Poder de discriminación de precios de los proveedores. La elevada fragmentación de los proveedores no les confiere capacidad para discriminar por parte de los proveedores, lo que alivia las tensiones competitivas dentro del sector.

\section{Poder de negociación de los clientes}

La presión negociadora de los clientes, junto con la de los proveedores, afecta de forma directa a los resultados obtenidos por las empresas del sector pues de ello depende el modo de reparto del margen total generado a lo largo de la cadena de valor en la que participan todos ellos. Cuanto mayor sea el poder de los clientes, mayor será su capacidad de negociación con el proveedor (en esta caso las bodegas comerciales), los precios menores, y se erosionarán los beneficios del sector.

- Grado de concentración de los clientes. Un factor importante en la determinación del poder negociador, es la capacidad de compra de tales clientes, aspecto que guarda relación grado de concentración que manifiesten demanda y oferta. Los clientes de las bodegas pueden ser de tres tipos, dependiendo del grado de integración vertical hacia adelante que hayan adoptado las bodegas: los mayoristas u otros agentes intermediarios en el caso de exportación, los detallistas, y el consumidor final.

En el caso de la distribución en el canal horeca, donde las comerciales al por mayor, con una estructura muy fragmentada de agentes independientes de pequeña dimensión, asumen mayoritariamente el papel de intermediación, no lo es tanto en el caso del canal de alimentación donde, además de la presencia de establecimientos de gran dimensión y de la clara tendencia a la concentración en la venta minorista de bienes de gran consumo, es relevante 
la creciente potenciación de los acuerdos de cooperación entre establecimientos independientes para la realización conjunta de la función de compras. Como resultado de estas tendencias, las cuatro mayores empresas de comercio minorista y las dos centrales de compra, que no integran a las anteriores, en la actualidad concentran más de dos tercios del total del mercado de productos de gran consumo en España. Este mayor nivel de concentración, que sin duda seguirá manifestándose en el futuro tanto en el ámbito nacional como en el internacional, acrecienta notablemente el poder de negociación de la distribución, pudiéndose a llegar a la realización de prácticas que modifican las condiciones de eficiencia de las empresas debido a posiciones de dominio (Rebollo, 1999).

Esta amenaza no causa el mismo efecto en todas las bodegas en estudio puesto que aquellas que por su menor dimensión tienen la posibilidad de colocar su producción a través del canal de la hostelería y entre una relación diversificada de distribuidores seleccionados, pueden defenderse mejor que aquellas otras bodegas que por su gran volumen de ventas precisan de la gran distribución.

En cualquier caso, si bien es cierto la inexistencia de una real amenaza de integración hacia atrás por parte de la distribución, las ya referidas limitaciones a la capacidad de diferenciación de la oferta de cada bodega, los bajos costes por cambio de proveedor que suponen al intermediario o consumidor final la sustitución de una marca concreta dentro y entre distintas DDOO, y la dificultad de que disponen los clientes para adquirir información completa de la oferta disponible por parte del conjunto de bodegas en estudio, tiende a aumentar la presión competitiva y permiten transferir a las bodegas la presión de los clientes cuando éstos padecen un deterioro de sus resultados.

Por otra parte, el poder negociador de los clientes no es especialmente grave para las empresas del sector, ya que éstas pueden a su vez repercutir hacia atrás la presión ejercida sobre ellas, debido a la reducida capacidad de negociación de sus proveedores, lo que en definitiva conlleva a una importante presión (reducción) sobre los precios pagados a los proveedores, que en definitiva son los viticultores libres o asociados en cualesquiera de las fórmulas asociativas agrarias.

En cuanto a la venta directa, el volumen medio comercializado por este canal supera muy escasamente el $1 \%$ de la producción comercializada total, distribuido casi a partes iguales entre venta a granel al detall y vino embotellado. Los mayores porcentajes de este tipo de venta respecto al total se han observado en las muy pequeñas, pequeñas y jóvenes empresas.

- Concentración de las ventas de las bodegas en un solo cliente. En el caso de las bodegas antiguas, las muy grandes, y las pertenecientes a la DO Utiel Requena destinan una proporción importante de sus ventas a la gran distribución (cadenas de hiper/supermercados). 
- Disponibilidad de productos substitutivos por los clientes. Si bien el mercado de vino en la Unión Europea se encuentra protegido con aranceles a la importación, las rondas en el seno de la OMC y los acuerdos bilaterales con terceros países entran propiciando la entrada de vinos internacionales a bajos precios, lo que aumenta la presión competitiva y erosiona los beneficios del sector.

- Integración vertical hacia atrás de los clientes. En la actualidad no constituye una amenaza, si se tiene en cuenta la elevada disponibilidad tanto de materia prima principal como de producto elaborado y embotellado a precios bajos.

- Participación del vino en la cesta de la compra. El vino representa solamente un 1,5\% del valor total de los alimentos comprados en los hogares (Mapa, 2003), de lo cual se desprende que el vino no es una de las principales partidas de compra y los clientes serán muy sensibles a un aumento de precios e intentarán presionar para obtener descuentos favorables. Todo ello confirma el reducido poder de negociación de las bodegas que comercializan frente a los clientes, lo que viene a agravar la competencia dentro del sector.

Diferenciación del producto. Dado que cerca del 80 \% de la producción se comercializa a granel, ésta escasa diferenciación entre estos productos por los clientes fomenta una mayor rivalidad.

- Negociación de precios. Lo más generalizado es que los precios se negocien en cada transacción. Las bodegas comercializadoras de vino no están en condiciones favorables de negociar precios, de un lado por la excesiva fragmentación de las mismas, de otro por tratarse de un producto perecedero (caso de los vinos blancos, rosados y vinos jóvenes).

- Coste de cambio para el cliente. Exceptuando un reducido número de empresas, en la mayoría de las bodegas que comercializan vino embotellado el coste de cambio para el cliente es reducido, debido a que la gran mayoría de las empresas ofrecen productos similares a precios semejantes. En el caso del vino a granel este coste es aún más reducido debido a la menor diferenciación del producto y al la existencia de excedentes casi estructurales.

\section{Barreras de ingreso de nuevos competidores.}

La posibilidad de incremento de la oferta proveniente de nuevos competidores que accedan al sector constituye otra fuente de presión competitiva, lo que depende básicamente del grado de existencia de barreras de ingreso y de las medidas que pudieran emprender los actuales competidores para impedir o penalizar esta decisión. La entrada de nuevas empresas erosiona los beneficios por desplazamientos del mercado de las ya existentes y por efecto de la disminución de los márgenes por aumento de la rivalidad y de la oferta. Las barreras de ingreso pueden estar relacionadas con los siguientes aspectos: 
- Economías de escala. La dispersión de la dimensión de las bodegas viene a mostrar que el efecto de economías de escala no es lo suficientemente relevante como para exigir la adopción de un tamaño mínimo importante necesario para posibilitar la viabilidad del proyecto. La posibilidad de implantación de bodegas de pequeños tamaños reduce también la necesidad de disponer de importantes recursos financieros para el inicio de esta actividad, recursos que por otra parte están disponibles por las empresas a costes muy competitivos y capaces de ser utilizados.

Se ha constatado que más del $72 \%$ de las empresas jóvenes que se han instalado en los últimos 15 años pertenecen a la categoría de muy pequeñas empresas. No obstante el posicionamiento como gran empresas en el sector se enfrenta a fuertes barreras de entrada, ya que requiere grandes inversiones en instalaciones y equipamientos, lograr una cuota de mercado a través de una marca conocida, buscar economías de escala para ahorro del costos y una buena gestión en un mercado cada vez más competitivo.

- Economías de alcance. El reducido número de empresas participadas por empresas nacionales, extranjeras o multinacionales, manifiestan en términos generales que no existen beneficios en el sector que se deriven de la reducción de costes por compartir operaciones o etapas comunes, por lo que es perfectamente viable la implantación de empresas que no puedan acceder a este tipo de economías.

- Economías de experiencia. Lógicamente existen ventajas basadas en la experiencia, profesionales o relacionadas con el conocimiento de los aspectos básicos del "know how"pero que de ninguna manera son infranqueables, dado que se trata de un sector maduro con unos procesos de producción, elaboración y envejecimiento muy estandarizados en los propios reglamentos de las DDOO. Las barreras tecnológicas, en la medida en que el sector no predominan los productos patentados de acceso restringido al mercado, ni de utilización de tecnología punta, pueden superarse adquiriendo dicha tecnología y contratando a las personas capaces de poder utilizarla con eficacia.

- La dificultad de acceso a los canales de distribución. Puede constituir una importante barrera de entrada, dado que se trata de un negocio maduro que utiliza canales de distribución de productos de alimentación cuyos puntos de venta tradicionales disponen de una superficie de exposición limitada que dificulta la entrada de una nueva referencia, puesto que ello exigiría la sustitución de otra ya existente que ya posee un determinado reconocimiento de la distribución y del mercado final. En la búsqueda de distribuidores mayoristas como intermediarios entre las bodegas y los puntos de venta en el caso de la hostelería, la posición de haber entrado antes facilita el establecimiento unas relaciones consolidadas en el tiempo, aunque solo sea por no incurrir en los costos de cambio que suponen para el canal cambiar de un proveedor a otro. Todo ello dificulta la entrada de nuevos competidores. 
Por otro lado, la movilidad actual de las estructuras comerciales y la aparición de nuevos establecimientos y formas de venta, contribuyen a disminuir el efecto de barrera de ingreso. En cualquier caso, esta barrera no actúa del mismo modo sobre todas las empresas que pretendan introducirse, ya que cuando la empresa entrante es otra compañía que proviene de un sector relacionado con la alimentación, su contacto previo con esta distribución no sólo le permite diluir la presión de este factor, sino que puede proporcionarle importantes economías de alcance que faciliten su decisión de acceder a esta nueva actividad.

El aumento de la cuota de mercado de la gran distribución y su creciente tendencia a aumentar la utilización de marcas propias genera espacios para las nuevas empresas que pueden acceder al mercado sin marca y sin distribución propia, lo que acrecienta el grado de rivalidad entre las empresas.

- Barreras gubernamentales. El deseo de entrar con un alto grado de integración vertical hacia atrás, puede constituir una barrera dado que no existe libertad de plantación de nuevo viñedo exigiéndose para ello los correspondientes derechos de plantación.. La posibilidad de abastecimiento a través de uvas para su transformación o de vino ya elaborado, no plantea problemas en los momentos actuales de excedentes de producción, como lo demuestra la continua creación de empresas dedicadas al envejecimiento y embotellado del vino adquirido a otras bodegas. En este sentido la reducida difusión de los contratos de suministro a corto y medio plazo con los compradores puede significar una apreciable ventaja a favor de las nuevas bodegas que pretenden instalarse.

- Prestigio de las marcas establecidas en el mercado. En general y salvo un reducido número de empresas con marcas fuertes introducidas en el mercado, no existen diferencias importantes de precios entres las marcas para un mismo tipo o categoría de vino, incluso entre distintas DDOO, lo que propicia que las nuevas empresas puedan competir en estas categorías de precios sin mayores inconvenientes, lo cual propiciará el incremento el número de marcas de empresas, el incremento de la confusión al consumidor y en definitiva el fortalecimiento de la rivalidad entre las bodegas.

Por otro lado el prestigio de la marca, la credibilidad, seriedad, fiabilidad que las empresas tiene en el mercado como consecuencia de actuar en el pasado inmediato, se traduce en una relación de fiabilidad, lealtad por parte de los clientes hacia la empresa, incitándole a adquirir sus productos. Dado que el conocimiento de las marcas colectivas en estudio por los consumidores del mercado nacional es de un $7 \%$ de media de las personas encuestadas, y en el mercado regional no sobrepasa el 28 \% (Ikerfel, 2000) puede inferirse respecto de las marcas privadas acogidas a estas marcas genéricas el reducido conocimiento por parte el consumidor y como consecuencia el bajo prestigio en general de las marcas asociadas a las empresas en estudio, lo que posibilita que una DO fuerte como la de Rioja se instaure y tenga un mayor grado de conocimiento y reconocimiento incluso dentro de la misma región, como lo 
demuestra el estudio de Ikerfel, en el cual ésta DO foránea era conocida por el $53 \%$ de los encuestados dentro de la Comunidad Valenciana. estos hechos demuestran las débiles barreras de entrada que suponen las propias marcas en el ámbito del mercado regional.

- Acciones defensivas de las empresas establecidas. Estas empresas en general no realizan estrategias defensivas, ya que le mercado se halla muy fragmentado y ninguna de ellas ostenta un verdadero poder punitivo.

\section{Amenaza de productos substitutivos.}

La posibilidad de encontrar productos o servicios substitutivos viene de la mano de la aplicación de nuevas tecnologías y en el lanzamiento de nuevos productos y servicios por los departamentos de marketing y de $\mathrm{I}+\mathrm{D}+\mathrm{i}$, bien de las empresas del propio sector o de otro distinto.

Los cambios en los hábitos de consumo y estilo de vida, tales como la preferencia de las bebidas sin alcohol y bajas en calorías y las campañas de concienciación antialcohólica por perjuicios para la salud, el tráfico y la vida laboral, están propiciando la introducción de productos directamente substitutivos del vino.

El peligro derivado de la competencia de otros productos de diferente configuración y que de forma alternativa pueden satisfacer el mismo tipo de necesidades que el producto ofrecido por el sector, constituye igualmente una fuente de competencia que amenaza a los resultados de las empresas. La mejor forma de valorar esta fuerza competitiva es a través de la tasa de crecimiento de ventas de los productos de bienes substitutivos en detrimento de los productos del sector vinícola.

- Disponibilidad de sustitutos cercanos. En general, los productos son sustitutos cercanos cuando se dan las siguientes tres condiciones: a) tienen las mismas o similares características y desempeño, b) se utilizan en las mismas ocasiones, y c) se venden en el mismo mercado geográfico.

En base a estas tres condiciones es fácil deducir que los vinos tienen muchos productos sustitutivos, lo que viene a incrementar el grado de competencia dentro del sector.

- Grado de sustituibilidad de los productos. Por otra parte, el carácter de sustituibilidad de los productos es una cuestión de grado. Así se puede hacer referencia a cuatro grandes tipos de productos sustitutivos en este caso: los vinos vinculados a otras DO españolas, los vinos procedentes de otros países vitivinícolas, los vinos comunes sin DO, y otros tipos de bebidas diferentes del vino.

Las restantes DDOO españolas se constituyen como los competidores directos, en especial en el mercado nacional, de las bodegas en estudio. En este ámbito se asiste a una cierta redistribución en las cuotas de mercado entre las distintas DDOO, poniéndose de manifiesto que, cuando una 
Denominación pierde presencia en el mercado, aumenta en mayor o menor medida la participación las restantes DDOO nacionales.

Los vinos de mesa suponen una opción alternativa más alejada, dada su condición de vinos inicialmente asociados a una menor calidad. No obstante, dentro de esta línea de productos se observan importantes diferencias en función de los distintos formatos de presentación utilizados, el precio y también su calidad, aspecto que en este tipo de productos muestra una mayor heterogeneidad. El vino de mesa envasado del mismo modo que los vinos con DO, esto es en botella de vidrio de tres cuartos de litro, constituye la alternativa de vinos comunes más cercana a los vinos de otras Denominaciones. Cuando los precios de estas DDOO aumentan, se dificulta el mantenimiento de su participación en los segmentos de vinos más populares, provocando su sustitución que se produce de manera más directa en el sector de la alimentación donde existe una mayor sensibilidad de la demanda con respecto al precio.

En cuanto a los vinos de importación, también se pueden considerar una alternativa a los vinos de las DDOO en estudio, como al resto de vinos con $\mathrm{DO}$, con los que guardan una mayor equiparación de precio. Sin embargo, en los mercados internacionales los vinos de otros países constituyen un freno directo a la entrada y crecimiento de los vinos regionales, tanto en aquellos países productores, dada la reconocida fidelidad que demuestran los consumidores a los productos de sus respectivas regiones o países, como en los que no lo son, donde es preciso hacer frente, además de a los exportadores tradicionales, a los vinos procedentes de los países emergentes con una demostrada competitividad.

Otras bebidas no vínicas son los productos alternativos más indirectos, pero no por eso de efecto irrelevante, teniendo en cuenta la potencia económica, financiera, tecnológica, productiva, logística y comercial de que disponen las empresas productoras vinculadas a los diferentes grupos empresariales mundiales del sector agroalimentario La relación de sustituibilidad de cada una de ellas con respecto al vino es importante porque pone de manifiesto las grandes tendencias en los comportamientos de los nuevos consumidores con respecto a este producto. La cerveza, considerada el gran enemigo sustitutivo del vino en los primeros años noventa, también manifiesta una apreciable disminución a partir de 1992, año que también constituye el momento de máximo consumo per cápita de otras bebidas alcohólicas y a partir del cual parece apreciarse una reorientación del consumidor hacia bebidas sin alcohol, como lo demuestra el aumento del consumo de agua mineral envasada, zumos de frutas y gaseosas y refrescos.

Los productos que más han consumido los españoles per cápita en el año 2003 han sido por orden de importancia: gaseosas y refrescos, agua y zumos de frutas, a pesar de que la tasa de crecimiento en el periodo 1987/2003, igualmente por orden de importancia han sido: gaseosas y refrescos, agua mineral y cerveza. 
- Elasticidad precio de la demanda de la demanda de mercado. Se utiliza como indicador indirecto de la presencia de sustitutos. En el caso de los vinos de calidad procedentes de las empresas del estudio, encuadrados por término medio en la categoría de "Popular premim" la elasticidad es alta, ello significa que ante aumentos de precios los consumidores optarán por otros productos. En el caso de los vinos de mesa la elasticidad es más baja (más inelástica) y por consiguiente los aumentos de precios en estos vinos, probablemente no se traducirán en significativas reducciones de la demanda vía entrada de productos sustitutivos.

- Disponibilidad de productos complementarios. En el caso de los vinos de calidad en particular, y en todos los tipos de vino en general, el aumento del consumo está relacionado con las comidas fuera del hogar (negocios, ocio, etc.) y también dentro del mismo (celebraciones, fines de semana, etc.), por lo que cualquier ocasión de comida, aperitivo o degustación gastronómica se traducirá en un aumento del consumo de vino.

- Relación calidad/precio de los productos substitutivos. Representan una amenaza para el sector, ya que cubren las mismas necesidades a un precio menor.

- Costes de cambio para el cliente. En este sector son reducidos, por lo que los compradores no tendrán problemas en utilizar los productos substitutivos.

\section{$\underline{\text { Rivalidad entre los competidores existentes. }}$}

El grado de rivalidad competitiva entre los competidores integrantes de cualquier sector transciende a su propio comportamiento estratégico y se deriva de la configuración de distintos factores estructurales que, en el caso del sector vinícola regional se ponen de manifiesto en las siguientes valoraciones.

- Tamaño y número de competidores. Se ha puesto de manifiesto la alta diversidad de tamaños existente en el sector, lo cual origina una alta propensión a competir dada la inexistencia de una empresa que actúe como líder condicionando el comportamiento de las demás y las dificultades que se evidencian en la realidad para la adopción y mantenimiento de acuerdos colusorios entre las bodegas. Esta alta dispersión de tamaños unido a sus diferentes características en términos de antigüedad, forma jurídica, composición accionarial, vinculación a grupos empresariales, conduce a una importante heterogeneidad de los competidores que tiende a realimentar la tensión competitiva.

- Demanda de vino. En el contexto de los mercados nacional e internacional la demanda global de vino se encuentra en una situación de declive en la cual las empresas recurren a estrategias duras para aumentar sus ventas (promociones, reducciones de precio etc.) que tenderán a vigorizar la rivalidad entra ellas Sin embargo también se puede observar un incremento 
en el consumo de vinos de calidad que ofrece expectativas de cierto crecimiento a las bodegas vinculadas a cualquiera de las tres DDOO existentes en la región. El crecimiento manifestado en el vino comercializado con DO principalmente embotellado, en el mercado internacional, en la última década avala esta posibilidad y la consiguiente menor presión que ello supone para el mantenimiento de los resultados empresariales.

- Heterogeneidad de los productos. Es otra variable que afecta a la capacidad de sustitución entre los productos ofrecidos por las empresas del sector y, en consecuencia, también a su rivalidad competitiva. Las posibilidades de diferenciación técnica de los productos vitivinícolas es alta en base a las distintas alternativas de color, variedad de uva empleada, envejecimiento, zona de origen, etc. Ahora bien, en la práctica la normativa de estas DDOO, al estandarizar las distintas categorías de productos, limita de forma importante las posibilidades de diferenciación de los atributos del producto y por consiguiente sólo cabe pensar en la diferenciación que pueda generarse en términos de información, imagen, etc.

Si el grado de conocimiento de la marca genérica o DO es muy bajo, entorno al $7 \%$ de los consumidores en el mercado nacional (Ikerfel, 2000) y aún menor en el internacional, el nivel de conocimiento de las marcas de los vinos de calidad por los consumidores es aún menor si cabe, lo cual significa considerar directamente sustituibles a productos de distintas bodegas con una misma categoría y acreditación genérica en cuanto a la pertenencia a una misma DO. Este aspecto posibilita una mayor competencia entre las bodegas pertenecientes a la misma DO.

En el caso del vino comercializado a granel (79 \% de la producción total) y a pesar de la cualificación del mercado de graneles consecuencia del aceptable nivel tecnológico de las instalaciones de elaboración, la escasa diferenciación entre estos productos por los clientes fomenta una mayor rivalidad.

- Diferencias de costos entre empresas. Se dan estructuras de costos diferenciadas debido a la heterogeneidad entre las empresas, que obedecen a diferentes razones (escala, alcance, calidad, diferenciación, sobredimensión, etc.) Estas diferencias de costos intensifican la competencia de precios.

- Capacidad instalada sin utilizar. La sobredimensión de la capacidad instalada es posible que conduzca a agudizar la presión competitiva, de un lado en la medida en la que las expectativas de crecimiento de las ventas no se cumplan en la realidad, de otro porque las empresas muy sobredimensionadas tendrán una proporción de costos fijos mayores que las de dimensiones más ajustadas.

- Concentración de las bodegas. El índice de concentración de las bodegas(CR4 menor del $30 \%$ ) denota que se trata de un mercado muy fragmentado, por lo que los precios se fijan en condiciones muy competitivas. 
- Crecimiento sectorial. En un sector maduro como el vino donde no se observa crecimiento, la única forma de aumentar las ventas es quitando mercado a otras empresas, por lo que este hecho agudiza la competencia entre las empresas que conforman el sector.

- Comparabilidad de precios. En general para el mismo tipo, categoría y DO e incluso entre DDOO distintas, los precios son fáciles de comparar en la medida en que se comparen productos similares, lo que favorece la elevada competencia en precios. Sin embargo si las calidades difieren sustancialmente y existe una imagen de marca prestigiosa, la comparación de precios es más difícil, si bien estos supuestos se presentan en un reducido número de bodegas.

- Regularidad en las ventas a lo largo del año. Normalmente los distribuidores y la gran distribución programan sus compras a lo largo del año, lo cual tiende a aliviar la competencia. Pero también se observan las ofertas puntuales de las bodegas, motivadas por excesos de stocks, que tienden a elevar la competencia entre las empresas.

- Liderazgo de precios. Debido a la gran fragmentación empresarial no existen empresas que lideren los precios, lo que intensifica la competencia entre ellas.

- Cooperación en fijación de precios. La escasa vertebración del sector, tanto vertical como horizontalmente indica, que probablemente es bastante difícil lograr algún tipo de acuerdo entre empresas para una política de precios común en el mercado del vino de calidad.

- Barreras de salida. Las empresas de economía social (que suponen el 53 \% de las empresas y el $68 \%$ de la producción total) presentan barreras muy grandes, ya que existe la necesidad de seguir procesando la uva de los socios. Estas altas barreras de salida pueden provocar una guerra de precios y por tanto incrementan la competencia. Las restantes formas jurídicas muestran barreras de salida menores, por los menores costos fijos, y en muchos casos por no procesar uva propia.

A modo de resumen de este apartado, se sintetizan las 5 fuerzas que afectan al sector de vinos en la Comunidad Valenciana:

El poder de negociación de los proveedores. Bajo

El poder de negociación de los clientes. Alto

La amenaza de entrada de nuevos competidores. Media-Alta

La amenaza de productos sustitutos. Media-Alta

La rivalidad entre las empresas existentes. Alta 
Por lo que el sector puede caracterizarse como altamente competitivo, en el sentido de que la competencia por precios es intensa, y erosiona rápidamente cualquier beneficio que pudiera aparecer, lo que no debe de sorprender, ya que se trata de un sector fragmentado y maduro.

\subsection{Determinantes de la situación competitiva según el modelo del diamante de Porter.}

La búsqueda de las causas que explican la ventaja competitiva nacional parte de una serie de "premisas" (Porter, 1991):

- La naturaleza de la competencia y las fuentes de ventajas competitivas difieren mucho de un sector a otro e incluso entre segmentos de un mismo sector.

- Los competidores mundiales frecuentemente llevan a cabo algunas actividades de la cadena de valor fuera de su país de origen (importancia del concepto de "base central” respecto a la mera localización geográfica).

- Las empresas consiguen y mantienen ventaja competitiva en la competencia internacional mediante la mejora, la innovación y el perfeccionamiento.

- Las empresas que consiguen ventaja competitiva en un sector suelen ser con mucha frecuencia aquellas que no sólo detectan una nueva necesidad de mercado o el potencial de una nueva tecnología, sino que son además las primeras y las más agresivas en explotarlo.

Los determinantes de la ventaja competitiva nacional son cuatro atributos genéricos (condiciones de los factores, condiciones de la demanda, sectores afines y de apoyo y estrategia, estructura y rivalidad de las empresas). Estos atributos influyen individualmente o agrupados en un sistema, pero las ventajas competitivas más sostenibles y difíciles de igualar se dan cuando los cuatro atributos están presentes, y especialmente cuando son ventajas creadas de orden superior. Los atributos conforman un sistema mutuamente autoreforzante (la presencia de uno es beneficiosa para el otro). Los otros dos elementos que completan el diamante son el gobierno y la casualidad.

La unidad básica de estudio para comprender la ventaja nacional es el sector, aunque las naciones no alcanzan el éxito en sectores aislados, sino en agrupamientos de sectores conectados por medio de relaciones horizontales y verticales.

A continuación se han analizado cada una de los determinantes del "modelo del diamante de Porter": condiciones de los factores, condiciones de la demanda, sectores afines y de apoyo y estrategia, estructura y rivalidad de las empresas, la casualidad y el gobierno.

\section{Condiciones de los factores}

Porter parte del reconocimiento de que la dotación de factores productivos conforma la base de la teoría (de las ventajas comparativas) del comercio internacional. 
Pero avanza y plantea que el concepto de dotación de factores debe ser "redefinido" y ampliado, prestando más atención a los factores creados, al ritmo de creación, y a ciertas desventajas de factores que a veces contribuyen a hacer más competitiva a una nación. Los "factores" se agrupan en una serie de categorías genéricas: recursos humanos, recursos físicos, recursos de conocimiento, recursos de capital, e infraestructura, siendo que ventaja competitiva que de ellos se derive depende de la eficiencia con que se desplieguen. Es decir, no es una cuestión de mera disponibilidad, sino que influyen otros determinantes del "diamante".

Los factores se clasifican según dos dimensiones. La primera es entre factores básicos y avanzados, y la segunda entre factores generalizados y especializados. La ventaja competitiva nacional depende de la presencia y continua actualización de factores avanzados (básicamente aquellos vinculados con la innovación) y especializados. La competitividad basada exclusivamente en factores básicos baratos suele ser efímera.

Otra distinción adicional es si los factores han sido heredados (como los recursos naturales) o creados (generalmente los avanzados-especializados), por un proceso de inversión social o privada. Estos últimos son los determinantes de la ventaja competitiva sostenible, e incluso, menos que su dotación en un momento determinado, lo que importa es el proceso de creación y de perfeccionamiento permanente.

Los mecanismos institucionales para la creación de factores son diferentes en cada país, y a veces ello determina qué factores se crean y en última instancia, qué sectores se desarrollan competitivamente. Sin embargo, hay una condición importante que plantea Porter para el desarrollo competitivo de los sectores, y es la participación del sector privado en el proceso de creación de factores, especialmente en aquellos avanzados y especializados.

Una diferencia importante entre el enfoque de Porter y la teoría clásica del comercio internacional, es que la ventaja competitiva puede derivar de la desventaja en algunos factores, especialmente en factores básicos, que entonces, debido a la naturaleza dinámica de la competencia y la innovación, se reemplazan por factores avanzados creados, y la ventaja es más sostenible. La desventaja en factores básicos es una de las razones por las cuáles las empresas no se apoyan en estrategias de bajo costo y plantean estrategias de diferenciación, basadas en ventajas de orden superior. Este es un aspecto central de la teoría de Porter, que plantea que la tasa y la orientación de la mejora es función de la atención y del esfuerzo, y que es más probable la innovación para superar puntos débiles que para explotar puntos fuertes.

En cuanto a los recursos físicos agroclimáticos, la insolación y elevadas temperaturas permiten obtener la materia prima principal de una de calidad y grado alcohólico suficientes, sin necesidad de la chaptalización. Sin embargo la escasa superficie de regadío y las condiciones climáticas extremas (sequía, heladas) impiden unos rendimientos regulares y elevados, en relación con los competidores europeos.

Los recursos varietales en su mayoría están conformados por una suficiente diversificación de variedades autóctonas y recomendadas, si bien, existe una elevada 
concentración de la producción en cuatro variedades predominantes. El coste de la uva o materia prima principal es elevado, debido por un lado al fenómeno del minifundismo, de otro a los bajos rendimientos por unidad de superficie.

En cuanto a los recursos humanos, a pesar que la capacitación y estabilidad del empleo sean satisfactorias, las producciones mayoritariamente granelistas propician una baja productividad media por empleado.

Con respecto a los factores relacionados con la tecnología de elaboración, el sobredimensionamiento medio de la capacidad instalada conlleva un mayor tiempo de permanencia de los mostos en autovaciantes y depósitos de fermentación controlada, lo que a su vez propicia una aceptable calidad organoléptica de los vinos elaborados.

Además de los factores de orden inferior tratados con anterioridad (recursos naturales, mano de obra), el subsector vinícola debe tratar de alcanzar ventajas de orden superior ya sea en los factores o en otros componentes del diamante para ser verdaderamente competitivo. En este sentido indicadores seleccionados en el presente estudio, tales como el esfuerzo comercial, el esfuerzo por información al consumidor y el esfuerzo en investigación, desarrollo e innovación se encuentran en umbrales mínimos.

Teniendo en cuenta las consideraciones anteriores, el grado de desarrollo o aportación de esta arista del diamante a la competitividad del subsector es medio-bajo.

\section{Estructura, estrategia y rivalidad entre las empresas.}

Porter identifica varias dimensiones de este componente del diamante: a) la estrategia y estructura de las empresas domésticas, b) las metas (de la nación, de las empresas y de los empresarios), y c) la rivalidad doméstica, y a pesar que abunda en definiciones y comentarios, no es fácil cuantificar este componente del diamante.

Respecto de la estrategia y estructura de las empresas domésticas, Porter menciona, entre otras cosas, aspectos tales como los estilos de conducción, las relaciones intra-empresa, las formas de organización social, las actitudes culturales hacia los viajes y la internacionalización, y las aptitudes linguísticas. No es fácil extraer conclusiones generalizables de estos factores, tan diversos y difíciles de formalizar. Algo similar ocurre con otro de los atributos, las metas, tanto de la compañía como de los empleados.

En cuanto a la dimensión empresarial, el minifundismo empresarial en el caso de las sociedades mercantiles dificulta el acceso a la financiación, el establecimiento de marcas comerciales y la apertura hacia los mercados exteriores, con elevada especialización en el mercado local. El movimiento cooperativista de $1^{\circ}$ grado ha sido esencial para elevar la dimensión empresarial, aunque el deficiente cooperativismo de $2^{\circ}$ grado impide trascender la inadecuada orientación exclusivamente productivista sin la dimensión comercial adecuada. 
La escasa implantación de un modo de control societario, en cuanto a la tipología de los accionistas o grupos de poder, ha imposibilitado que las empresas adscritas a un grupo de poder más amplio se beneficien de las economías de escala y alcance superiores a las que les correspondería por su propia dimensión. El grado de control difuso sobre el capital social dificulta o retrasa la implementación de decisiones estratégicas vitales para el buen funcionamiento de las empresas.

Referente a las variables de comportamiento estratégico, debido a que la mayor parte de la producción es comercializada a granel, en la gran mayoría de las bodegas no existen políticas de productos (marcas, presentaciones, etc), ni de precios (y que este viene fijado por las condiciones de la demanda, en base a las que las empresas tienen pocas posibilidades de negociar), ni distribución, y tampoco de promoción, análisis del consumidor y seguimiento del mercado de la demanda, por lo que en definitiva no puede hablarse de una estrategia de marketing.

La rivalidad competitiva entre las empresas del subsector ha sido calificada como muy alta, sobre la base del modelo de las cinco fuerzas de Porter expuesto en el apartado anterior.

Por lo que la aportación de esta arista del diamante en sus conjunto a la competitividad del subsector es media-baja.

\section{$\underline{\text { Sectores conexos y auxiliares }}$}

Aún considerando la existencia de empresas que realizan todas las etapas intervinientes en la cadena de valor del sector vinícola (producción, elaboración y comercialización), se han distinguido los siguientes tipos de sectores vinculados al subsector elaborador de vinos:

- Los proveedores, que están ubicados más atrás en la cadena de valor. La relación con este subsector se ha cuantificado a partir de la integración vertical hacia atrás, que ha sido calificada de muy alta, lo que conlleva para las empresas un mayor grado de control sobre la materia prima principal y la seguridad del abastecimiento.

- Las empresas conexas que vinculadas horizontalmente con otras empresas pertenecientes a la misma etapa del proceso productivo permiten coordinar o compartir actividades de la cadena de valor, o que comprenden productos que son complementarios. Además de ventajas de economías de escala y de alcance, en sentido amplio, la presencia de un sector conexo internacionalmente competitivo brinda muchas oportunidades para el intercambio técnico y el flujo de información. Se ha detectado una muy baja vertebración horizontal entre las empresas, tanto en las pertenecientes al mismo subsector, como entre las bodegas de subsectores diferentes.

- Los clientes, que están ubicados en la parte final de la cadena de valor La relación con este subsector se ha cuantificado a partir de la integración vertical hacia delante atrás, que ha sido calificada de muy baja, lo que impide ganar 
agilidad a las empresas del subsector elaborador en la adaptación de la oferta a la demanda. Las etapas de envejecimiento, conservación, envasado y etiquetado, en general sólo existen aproximadamente en la mitad de las empresas, lo que supone la cuarta parte de la producción comercializada total.

En definitiva la aportación de esta arista del diamante en su conjunto a la competitividad del subsector es baja.

\section{Condiciones de la demanda}

La demanda interior influye sobre las ventajas competitivas de manera estática (básicamente cuestiones de escala) y dinámica (esta última más importante, pues se trata del ritmo y carácter de la innovación). Hay tres atributos de la demanda doméstica que son significativos para la ventaja nacional: la composición de la demanda en lo que se refiere a la naturaleza de las necesidades del consumidor; la magnitud y pautas de crecimiento, y los mecanismos mediante los cuáles se transmiten a los mercados extranjeros las preferencias de una nación.

La composición de la demanda doméstica interacciona con el modo en que las empresas dan respuesta a esa demanda. Los sectores obtienen ventajas y se tornan más competitivos si los compradores locales presionan a las empresas para mejorar la calidad de los productos, para innovar. El hecho de que exista un segmento doméstico significativo es importante porque influye sobre las economías de escala y de aprendizaje que puede obtener una empresa y contribuyen a definir las prioridades de las empresas de una nación. Por otra parte, la existencia de compradores entendidos y exigentes en calidad y con necesidades precursoras permite la diferenciación de los productos y el desarrollo de innovaciones por parte de las empresas, que finalmente se materialicen en el mercado. En este sentido existen dos grupos diferentes de consumidores de vino: la elite o prescriptores constituida por una minoría de personas expertas e informadas del vino y su entorno, capaces de detectar sutiles diferencias organolépticas, que realmente reclaman innovaciones y diferenciación del producto; por otro lado se encuentran la gran mayoría de la demanda, el consumidor medio, que sólo conoce el vino de una manera muy limitada.

El tamaño y pautas de crecimiento de la demanda, que puede constituir una ventaja competitiva en aquellos sectores que tengan grandes necesidades de $I+D$, economías de escala o de aprendizaje o altos niveles de incertidumbre. Algo similar ocurre con la tasa de crecimiento, ya que estimula un ambiente de innovación y mejora continua de procesos y productos. Desde este punto de vista, la evolución del consumo per cápita de vino viene experimentando una caída progresiva en los últimos años, liderada por la pérdida acelerada del consumo de vino de mesa en el canal de alimentación, lejos de ser compensada por el aumento del consumo de vinos de calidad en horeca y en los propios hogares.

El tercer atributo de interés de la demanda doméstica es su capacidad para proyectarse internacionalmente, contribuyendo de ese modo a la ventaja competitiva de las firmas nacionales. Esa capacidad de proyección puede resultar de la existencia de compradores móviles, que requieren de los mismos productos/servicios en el extranjero, 
o porque la demanda se proyecta con el apoyo de corrientes culturales y/o científicas. En este sentido la propia saturación de los mercados locales y regionales ha obligado a las empresas a posicionarse en los mercados exteriores, como lo demuestra la evolución muy positiva del vino comercializado con DO exportado en el último decenio; las causas de esta evolución habría que buscarlas en la buena relación precio calidad de los vinos regionales que se sitúan en segmentos de precios más reducidos, lo que constituye una ventaja competitiva frente a los principales competidores en mercados exteriores (Francia e Italia).

Considerando todos los aspectos mencionados, la aportación de esta arista a la competitividad del subsector puede calificarse como muy baja.

\section{$\underline{\text { El Gobierno }}$}

Los gobiernos, mediante las políticas vitivinícolas pueden influir positiva o negativamente sobre los determinantes de la ventaja competitiva. Sin embargo, Porter plantea que dicha ventaja será efímera si sólo está basada en el esfuerzo gubernamental.

Las actuales políticas en relación con el sector vitivinícola, recogen entre otros: los acuerdos de la OMC, las relaciones bilaterales, la OCM vitivinícola y las respectivas leyes del vino estatal y regional, si bien la que más relevancia pueda tener es la OCM vitivinícola, la cual ha evolucionado desde el control cuantitativo de la oferta (arranque, destilación, entrega obligatoria, etc), hasta un enfoque esencialmente cualitativo de la oferta (reestructuración varietal, mejora de los equipos de elaboración, etc). En la actualidad se detecta dos graves deficiencias en la OCM: la inexistencia de una política de demanda que oriente las ayudas públicas hacia la comercialización, diferenciación del producto e identificación de los gustos del consumidor, y el desarrollo de las Agrupaciones de Productores y Organizaciones Sectoriales, que vertebren los diferentes subsectores relacionados con el vino.

Considerando todos los aspectos mencionados, la aportación de esta arista a la competitividad del subsector puede calificarse como baja.

\section{La casualidad}

La casualidad crea discontinuidades que alteran las condiciones del diamante, modificando la importancia relativa de estos factores como determinantes de la competitividad. Con relación al componente de azar, el sector vitivinícola se ve afectado por las condiciones agroclimáticos en cuanto a la calidad y cantidad de la uva y del vino elaborado, tratándose de un producto en el que el año de cosecha tiene una gran importancia comercial. También pueden influir alteraciones económicas, políticas, conflictividad laboral y otros, por lo que la aportación de esta arista a la competitividad del subsector puede calificarse como media.

A modo de resumen de este apartado, se sintetiza la aportación de los 6 determinantes a la competitividad del subsector vinícola en la Comunidad Valenciana:

Las condiciones de la factores.

Baja 
La estructura, estrategia y rivalidad de las empresas.

Las condiciones de la demanda.

Los sectores conexos y auxiliares.

El Gobierno.

La casualidad.
Media-baja

Muy baja

Baja

Baja

Media

La aportación conjunta de los seis determinantes del diamante al logro de la competitividad del subsector es baja.

\section{INTEGRACIÓN DEL MODELO DAFO Y MODELOS DE PORTER}

Del modelo DAFO, que considera los factores internos y externos clave de la competitividad, se ha desprendido que la situación competitiva del subsector vinícola merece la calificación de baja.

Del modelo de las 5 fuerzas de Porter se desprende que la rivalidad competitiva entre las empresas del subsector vinícola es alta, lo que debería haber propiciado, según el mismo autor, una elevada competitividad dentro del mismo, pero no ha ocurrido así en el caso de las bodegas granelistas.

Una posible explicación de este comportamiento la ha aportado el modelo del diamante de Porter a través del cual puede afirmarse que la aportación conjunta de las seis aristas del diamante al logro de la competitividad es baja (coincidente con los resultados del modelo DAFO) y no se encuentra ninguna arista bien desarrollada, lo que equivale a afirmar que no existe un verdadero diamante que contribuya significativamente según Porter, al logro de una situación competitiva favorable en el sector.

Por otro lado diversos autores (Lagnevik and Kola, 1998; Yetton y otros, 1992; Neven and Dröge, 2001) han demostrado la importancia de la cooperación y coordinación entre las diferentes etapas de la cadena de valor, como condición necesaria para crear valor agregado o ganar competitividad en un entorno altamente competitivo, como el del presente estudio. También han demostrado, que la falta de cooperación entre actores de la cadena puede ser un determinante de la falta de competitividad. Alternativamente, los autores resaltan la importancia de la cooperación, aunque en el contexto de un ambiente cada vez más competitivo, por lo que el factor clave o de éxito más importante se encuentra en la cohesión intersubsectorial.

Normalmente los sectores más competitivos (de mayor productividad o mayor éxito) suelen estar vinculados por relaciones verticales (entre distintas etapas de la cadena de producción) y horizontales (dentro de la misma etapa de la cadena). 
La alta competencia existente entre las empresas dentro del subsector elaborador y el bajo grado de competitividad que presenta la mayoría de la producción vinícola, debería ser un acicate para unir voluntades en los próximos años y aprovechar las sinergias conjuntas que surjan de la cooperación entre todos los subsectores (productor, elaborador y comercializador). 


\section{CAPITULO VII}

FACTORES EXPLICATIVOS DE LA COMPETITIVIDAD POR DIFERENCIACIÓN DE PRECIOS 



\section{INTRODUCIÓN}

Uno de los principales aspectos relacionados con la diferenciación es la calidad, atributo difícil de definir y mucho más de medir. Con la finalidad de superar esta dificultad se ha arbitrado un indicador objetivo y medible, el precio del vino (precio medio del vino a la salida de la bodega), en su evidente relación con la calidad del mismo.

Conscientes de los múltiples factores que pueden afectar al valor comercial del vino en el mercado, y con la finalidad de cuantificar esta relación, la investigación empírica propia del presente estudio ha sido abordada por etapas:

- En primer lugar se ha tratado de aislar el efecto de la DO y envasado en el precio del mismo.

- En segundo lugar cuantificar la aportación de los factores empresariales (la variedad, la tecnología de vinificación, etc), expuestos en el Capítulo III en los siguientes casos:

a) en los vinos comercializados envasados y con DO, considerando separadamente los vinos blancos, rosados y tintos jóvenes, los crianza y los reserva, por su representatividad en la muestra, y por ser los que más factores pueden recoger en la formulación de sus respectivos precios.

b) en el vino comercializado a granel medio (considerando conjuntamente los de mesa, los de DO, blancos, tintos y rosados), por su importancia en volumen comercializado.

Previamente al desarrollo de la investigación empírica objeto de la actual tesis, se ha efectuado una aproximación teórica y se reflejan los resultados de otras investigaciones relacionadas con los conceptos de valor comercial para los consumidores, precio, calidad intrínseca y calidad percibida.

\section{APROXIMACIÓN TEÓRICA Y ESTUDIOS EMPÍRICOS RELACIONADOS}

El objetivo de este apartado es tratar de hacer una aproximación teórica a los aspectos que contribuyen al logro por parte de las empresas de ventajas competitivas, ligadas a la diferenciación del producto, la calidad, el valor comercial y el precio de los vinos que comercializan.

Fregoni, 1985, establece el orden de importancia de los factores implicados en la de calidad del vino (Cuadro 7.1). En la viticultura tradicional europea, lógicamente los componentes ligados al origen son los primeros (terreno o "terroir", el clima y la variedad), apareciendo en el último lugar los gustos del consumidor. En la viticultura moderna de los países anglosajones o emergentes, sin embargo la variedad es el primer factor, seguida del método de vinificación y los gustos del consumidor, apareciendo en los últimos puestos el clima y el terreno, lo que está afectando mucho (debido a la 
globalización) a la viticultura europea, en la cual se está apostando por la variedad, con la inversión del orden de jerarquía clásico.

\section{CUADRO 7.1}

ORDEN DE IMPORTANCIA DE LOS FACTORES DE CALIDAD

\begin{tabular}{|l|l|l|l|}
\hline $\begin{array}{l}\text { Orden de } \\
\text { importancia }\end{array}$ & $\begin{array}{l}\text { Viticultura tradicional } \\
\text { europea }\end{array}$ & Viticultura moderna & $\begin{array}{l}\text { Consumidor } \\
\text { español }\end{array}$ \\
\hline 1 & Terreno & Variedad & DO \\
\hline 2 & Clima & Vinificación & Añada \\
\hline 3 & Variedad & Gusto del consumidor & Zona de Origen \\
\hline 4 & Vinificación & Clima & Marca \\
\hline 5 & Embalaje & Terreno & Precio \\
\hline 6 & Gusto del consumidor & Embalaje & Variedad \\
\hline
\end{tabular}

Fuente:Adaptado de Fregoni e Ikerfel

Por otro lado sorprende que la viticultura europea relegue al último puesto una variable tan importante relacionada con los intangibles, el gusto del consumidor. En este sentido el Instituto de investigaciones de Mercado y Marketing estratégico (Ikerfel) en el año 2000, ha llevado a cabo un estudio que consistía entre otras cosas, en recoger los criterios que externamente (antes de probarlo) definen un vino de calidad, lo que suponía partir de la percepción del conocimiento (realidad percibida) del consumidor español. Se puede observar que al tratarse de un consumidor europeo los primeros puestos de la clasificación están relacionados con la zona de origen y el último con la variedad.

En el Modelo anglosajón o de los Nuevos Países Productores, relación que se establece entre la calidad y el precio viene dada a través de la formula del profesor australiano Peter Godden: el valor de un producto es igual a su calidad intrínseca multiplicada por su calidad percibida por el consumidor o imagen y dividida por su precio.

$$
\begin{aligned}
& \text { Valor comercial = (Calidad intrínseca * Calidad percibida } / \text { Precio } \\
& \text { Calidad = Calidad intrínseca * Calidad percibida. }
\end{aligned}
$$

Si aumenta el precio, paralelamente debe hacerlo la calidad intrínseca, la calidad percibida o ambas cosas a la vez, si no se quiere perder valor comercial para el consumidor". Puede observarse que de manera indirecta a través del precio, se está midiendo, en términos relativos, el valor comercial que tiene el producto de la empresa para sus clientes (Rivera, 2002).

El precio lo fija el mercado en función de su percepción de la calidad en su conjunto (intrínseca e imagen del producto) dando lugar a una relaciones calidad/precio determinadas. Ello conduce a plantearse la calidad no solo como un conjunto de características del producto, si no que tiene otra dimensión más importante que radica en el consumidor, en el grado de beneficio o satisfacción que este considera que va a encontrar en el producto y que se encuentra ligado también al precio que ha pagado. Se 
trata de un concepto más subjetivo que objetivo que dependerá del cliente y de sus distintas características, resultando pues un concepto bastante relativo.

Ahora bien en un mercado con muchas variantes de productos y de clientes se debería hablar más que de mercado de segmentos distintos. En el mercado del vino existen una serie de variables que repercuten en el precio, porque influyen en la percepción del cliente, $\mathrm{y}$ que se encuentran ligadas a percepciones tanto físicas del producto como psicológicas del consumidor.

En cuanto a las percepciones físicas, la presentación, el envase y la etiqueta afectan al proceso de compra, tanto por la atracción que generan en el punto de venta como por el hecho de relacionar una buena presentación con un vino de calidad. Algunos aspectos propios del producto físico, como el color, aroma, sabor, etc, tienen lugar durante el propio acto del consumo, que en caso de ser favorables tienen el efecto de reafirmar la confianza en la elección hecha admitiendo como válido el precio pagado.

En lo que respecta a las percepciones psicológicas, más asociadas a los intangibles, destacar la marca colectiva o DO, asociada al significado que para el consumidor tenga la imagen lograda en el proceso de comunicación. La marca de empresa o específica del producto en su caso con los significados que concite, de tal modo que una DO prestigiosa permite unos precios de venta más altos, pues el comprador está dispuesto a pagar por esas imagen favorables creada y por la garantía de calidad asociada a ella.

Existe una relación bidireccional entre precio e imagen, ya que aunque toda imagen determina un precio, la dimensión psicológica de éste puede afectar a la imagen del producto en el sentido de que una bajada de precios en una DO prestigiosa puede desprestigiar la imagen percibida de esa DO.

En la mayoría de los mercados de consumo de vino el precio del producto influye de forma tal que a menos precio más demanda. En otro segmento de mercado mucho más reducido y representado por los elitistas y prescriptores, el precio es un elemento estratégico de manera que un precio por encima de un determinado umbral se asocia a una mayor calidad.

El precio es un elemento básico en la comercialización de cualquier producto que tiene connotaciones simbólicas y efectos económicos. Una de las formas tradicionales de medir el valor de marca es el método de los precios primados. Si existe un valor diferencial en el mercado atribuible al valor de la marca DO, éste debe ser reconocido por los agentes implicados de forma explícita o implícita. En este sentido cabe observar importantes diferencias que existen en los precios de venta medios de la botella de vino en función de su procedencia o DO respectiva. Según Nielsen, 2001, mientras que el precio medio por botella de vino español de DO (considerando todo tipo de vinos: del año, crianzas, reservas y grandes reservas) para el consumidor final fue de 2,84 euros, las diferencias son notables entre las distintas DO. La existencia de diferentes valores de marca asociados a las diversas DO, es coherente con la importancia del efecto procedencia en la formación de precios de los vinos (Alden y Hoyer, 1993; Angulo et al., 2000). 
Ruiz y al., 2004, de la Universidad de la Rioja han identificado aquellos factores que según los oferentes influyen en la determinación de los precios de los vinos. Algunos factores señalados por los agentes económicos hacen referencia a cuatro dimensiones:

Calidad del producto. La diferencia de precios se debe a diferencias de calidad. Para los propios agentes económicos la explicación principal se debe más a los atributos de naturaleza simbólica que a los rasgos de tipo técnico o analítico del vino. Entre los argumentos técnicos que explican, según la opinión de los entrevistados, las diferencias en precios de los vinos se citan: el tiempo y el coste de envejecimiento, el coste de la uva, la distribución, el tamaño de la bodega y, finalmente, la inversión en investigación. No obstante, los análisis de costes en el sector difieren respecto a los factores señalados por los agentes económicos (Albisu, 2003).

Política de producto-mercado. La marca de la bodega y la marca de la DO contribuyen a explicar las diferencias en precios. Las diferencias de precios en el vino se deben también a que el precio recoge factores sociales (exclusividad, producto lujo, producto regalo), y la situación de uso o consumo del vino influye en el precio dispuesto a pagar por el consumidor. Para determinados agentes económicos, el precio viene determinado por el mercado debido a los atributos que el productor quiera transferir a su producto.

Aspectos vinculados al precio. Los consumidores valoran los precios altos como un indicador de calidad, como un indicador de prestigio. No obstante, la falta de coherencia en la política de precios dentro de una misma DO puede confundir al consumidor. La ley de la oferta y la demanda en muchas situaciones justifica las diferencias en precios, existiendo DO muy conocidas y con un alta demanda y otras con exceso de producción y escasa demanda, lo cual provoca una reducción del precio.

Dimensiones relacionadas con la comunicación comercial. Las diferencias en precios están relacionadas con la imagen. El precio debe recoger los valores añadidos del producto y la imagen se puede generar en el mercado creando expectativas sobre el producto. Las deficiencias en la comunicación de las DO traen consigo diferencias de notoriedad que son interpretadas por el mercado como diferentes señales de calidad y, por tanto, diferentes precios. Por otro lado, las DO no garantizan un precio, pero influyen en el valor en el que se pueden mover sus bodegas en el mercado por sus políticas de comunicación, habiéndose comprobado que las DO líderes marcan el nivel de precios en el mercado.

A modo de conclusión de la investigación, se puede decir que tanto distribuidores, consejos reguladores como prescriptores argumentan como factor determinante del precio del vino los costes de producción y elaboración del mismo. Para las bodegas y consejos reguladores, la calidad es el principal factor, sin conocer muy bien cómo se mide la calidad. Mientras que para los distribuidores la ley de la oferta y la demanda es el principal factor determinante del precio del vino, para las bodegas lo es la calidad. 


\section{APORTACIÓN DE LA DO Y EMBOTELLADO AL PRECIO DEL VINO}

En el cuadro 7.2 se reflejan los precios medios de los vinos blancos rosados y tintos jóvenes, según la forma de comercialización, granel o embotellado y la pertenencia o no a la figura de calidad media, considerando conjuntamente las Denominaciones de Origen (DDOO) de Alicante, Utiel-Requena y Valencia.

\section{CUADRO 7.2}

PRECIOS MEDIOS DE LOS VINOS (€/l), SEGÚN LA FORMA DE COMERCIALIZACIÓN Y PERTENENCIA A LA FIGURA DE CALIDAD.

\begin{tabular}{|l|l|l|}
\hline & Mesa & DO \\
\hline Granel & $0,34 € / \mathrm{l}$ & $0,37 € / \mathrm{l}$ \\
\hline Embotellado & $0,96 € / \mathrm{l}$ & $1,24 € / \mathrm{l}$ \\
\hline
\end{tabular}

Fuente: Elaboración propia

De la lectura del citado cuadro pueden extraerse las siguientes afirmaciones:

- El efecto DO en vinos a granel se cuantifica en el $9 \%$ respecto del precio del vino de mesa a granel, encontrándose que las diferencias no son significativas $(0,37 € / l$ y $0,34 € / l$,) por lo que el valor añadido que supone la DO se incorpora débilmente al precio del vino cuando éste es comercializado a granel. Este aspecto es el que explica que un gran número de bodegas inscritas en la DO, descalifiquen campaña tras campaña sus vinos calificados con DO, como vía de comercializar sus graneles a embotelladores y granelistas que en muchas ocasiones pertenecen a otras regiones.

- El efecto DO en vinos embotellados es del $29 \%$, respecto del precio del vino de mesa embotellado, con diferencias significativas (1,34 €/l y $0,96 € / \mathrm{l})$. La DO Alicante aparece como la más valorizada con el $85 \%$, seguida de la DO Valencia con el 52 \% y la de Utiel-Requena con el $3 \%$, respecto del precio del vino de mesa embotellado, en los tres casos.

- El efecto botella en vinos de mesa se cuantifica en el $282 \%$ respecto del precio de vino de mesa a granel, con diferencias estadísticamente significativas $(0,96 € / /$ y $0,34 € / l)$.

- El efecto botella en vinos con DO se cuantifica en el $335 \%$ respecto del precio de vino de con DO a granel, con diferencias estadísticamente significativas $(0,96 € / /$ y $0,34 € / l)$.

En conclusión puede observarse la sinergia entre el efecto botella y DO cuando estos aparecen juntos en la comercialización de los vinos. En cuanto al efecto DO en vinos embotellados, podría calificarse como bajo en el conjunto de las tres DDOO, 
siendo muy aceptable en el caso de la DO Alicante y muy bajo en el caso de la DO Utiel-Requena y medio en el de la DO Valencia.

\section{APORTACIÓN DE LOS FACTORES EMPRESARIALES AL PRECIO DEL VINO CON DO Y EMBOTELLADO}

Una vez obtenida la información y después de haber depurado los datos contenidos en ella, se ha procedido a su estudio y análisis orientados a la consecución de uno de los objetivos parciales, centrado en la determinación de los factores explicativos de la diferenciación de precios en las bodegas.

Con objeto de valorar la bondad de los factores propuestos se ha procedido al análisis de la fiabilidad de la escala, con la finalidad de poder evaluar en qué medida estos factores aportan una medición consistente y correcta de las variables que se han resumido. La calidad de la medición de una determinada realidad depende de que el valor obtenido coincida con el valor de esa realidad. Una escala es fiable si cada vez que se mide a los sujetos se obtiene el mismo resultado. Las medidas de fiabilidad intentan cuantificar qué cantidad de la variabilidad de las mediciones obtenidas en una escala ( 0 puntuaciones observadas), se deben a la variabilidad de las puntuaciones verdaderas y qué cantidad se debe a la variabilidad de los errores de medida.

El modelo utilizado en este caso es el de consistencia interna alpha de Cronbach, y asume que la escala (conjunto de indicadores que miden de manera individual la característica que se intenta medir) se encuentra compuesta por elementos o indicadores homogéneos que miden la misma característica y que la consistencia interna de la escala puede evaluarse mediante la correlación existente entre todos sus elementos. El coeficiente $\alpha$ asume que una escala es fiable cuando la variabilidad de las puntuaciones observadas es atribuible a las diferencias existentes entre los sujetos.

El valor del coeficiente $\alpha$ estandarizado oscila entre cero y uno, considerándose que su límite inferior es 0,70 , no considerándose la existencia de valores negativos, ya que supondría que algunas de las variables contempladas miden en un sentido opuesto a las demás. Asimismo un valor elevado indica gran consistencia interna (homogeneidad) entre los elementos de la escala y que la variabilidad observada entre ellos es pequeña en comparación con la variabilidad observada entre los casos o sujetos.

El coeficiente $\alpha$ estandarizado para todos los tipos de vinos que se han analizado supera el valor de 0,70 , lo cual indica una adecuada consistencia interna (homogeneidad) entre los elementos de la escala y que la variabilidad observada entre ellos es pequeña en comparación con la variabilidad observada entre los casos o sujetos.

Por otro lado y dado el amplio número de variables inicialmente consideradas y, a la vista de la existencia de relevantes asociaciones entre ellas, se ha procedido a realizar, antes de realizar nuevos análisis a otro nivel, a su simplificación en un nuevo y más reducido conjunto de factores que resuman la información contenida en las variables originales, sin que ello suponga una pérdida relevante de la información existente. 
El análisis factorial es una técnica de interdependencia con la que se pretende mejorar el modelo propuesto, reduciendo el número de variables contempladas sin disminuir sensiblemente su nivel de significación, renunciando a parte de la información y resumiéndola en un nuevo y menor conjunto de variables denominadas factores, que han sido obtenidos como función lineal de un conjunto de variables originales muy relacionadas entre sí, y a su vez poco relacionadas con las variables vinculadas a otros grupos. Estos factores permiten identificar estructuras subyacentes en la información disponible, que no son observables de forma directa sino que se infieren de esas variables originales (Ferran, 1997). De entre los distintos métodos se ha utilizado el método de Análisis de Componentes Principales, aplicable a variables cuantitativas, como lo son las variables consideradas en este caso.

Los supuestos básicos subyacentes son más de tipo conceptual que estadístico. Desde el punto de vista estadístico se pueden obviar los supuestos de normalidad, homocedasticidad y linealidad, si bien su incumplimiento se traduce en una disminución de la s correlaciones observadas. En realidad sólo es necesaria la normalidad cuando se aplica una prueba estadística a la significación de los factores; sin embargo raramente se utilizan estas pruebas (Hair, 1999).

El primer paso del proceso consiste en calcular una matriz de correlaciones entre todas las variables originales para comprobar la adecuación del método de Análisis Factorial, que exige que las variables estén altamente correlacionadas puesto que, en otro caso, la simplificación buscada puede conducir a una pérdida importante de información. Los indicadores normalmente utilizados son el test de esfericidad de Barlett y el test de medida de adecuación muestral de Kaiser-Meyr-Olkin (KMO), que permiten rechazar la hipótesis nula de no correlación entre las variables originales.

El test de esfericidad de Barlett comprueba la hipótesis de que las intecorrelaciones entre las variables son ceros en cuyo caso no existirían correlaciones significativas entre las variables Cuando este indicador toma valores altos, la hipótesis nula es rechazada con un determinado nivel de significación y se acepta la aplicación del análisis factorial. Si el nivel de significación es menor de 0,05 puede rechazarse la hipótesis nula de esfericidad y consecuentemente se podrá asegurar que el modelo factorial es adecuado para explicar los datos.

El test KMO mide la idoneidad de proceder al análisis factorial en mayor medida cuanto más se aproxime a 1, no siendo aconsejable para valores próximos a cero, pues significaría que las correlaciones entre pares de variables no pueden ser explicadas por otras variables. Según (Hair, 1999), valores por encima de 0,5 de la medida son aceptables.

El siguiente paso consiste en obtener los factores representativos de los datos, tratando de conseguir, por un lado, que cada variable original no tenga una importante presencia llamada carga factorial, en la explicación de más de un factor y que dos factores diferentes tengan distribuciones distintas de cargas factoriales de las variables originales (Bello, Vázquez y Traspalacios, 1996). 
Un avance más en el nivel de la información, es la adopción de un enfoque explicativo, desde el que tratar de identificar las relaciones causa-efecto que puedan manifestarse entre el conjunto de variables dependientes y el precio. De este modo se pretende determinar, entre los diversos factores empresariales contemplados, cuales influyen de forma más relevante en las diferencias de precios alcanzadas por las bodegas, y en qué medida ejercen esa influencia, identificando de este modo la estructura de dependencia que mejor explique su comportamiento. La técnica utilizada ha sido la Regresión Lineal Múltiple que permite, dada una variable dependiente a explicar y un conjunto de variables independientes cuantitativas, obtener una función lineal de tales variables con la cual explicar o predecir el valor de la variable dependiente. Para la aplicación correcta de la técnica deben cumplirse diversos supuestos: linealidad, independencia, homocedasticidad, normalidad y nomulticolinealidad.

La condición de linealidad, se refiere a la existencia de una relación lineal significativa entre la variable dependiente y cada una de las variables independientes por separado, tras eliminar de ellas el efecto del resto de las variables independientes. El estadístico $F$ (ANOVA) permite decidir si se cumple tal condición en el supuesto de que el valor del nivel crítico o de significación sea menor que 0,05.

La condición de independencia, entre los residuos se refiere a que el valor de la variable dependiente o predicción no está relacionada con cualquier otra predicción, esto es, no está ordenada por otra variable predictora o independiente. Si el indicador Durbin-Watson está comprendido entre 1,5-2,5 puede asumirse que los residuos son independientes y es correcta la aplicación del modelo.

La homocedasticidad o igualdad de las varianzas implica que el tamaño de los residuos es independiente del tamaño de los pronósticos. El estadístico de Levene, siempre que el nivel de significación sea mayor de 0,05 permite verificar este supuesto.

La condición de normalidad., referida a que los residuos se distribuyen según el modelo de probabilidad normal, puede ser comprobada mediante el gráfico de probabilidad normal, cuando la nube de puntos se encuentra alineada sobre la diagonal del gráfico.

La condición de no-multicolinealidad entre las variables independientes queda garantizada por la aplicación precedente del modelo de análisis de componentes principales a todo el conjunto de variables independientes propuestas, que transforma estas en un conjunto de factores independientes o no correlacionados entre sí. Suplementariamente cuando el índice de condición toma un valor menor de 15 no existe problema de colinealidad.

El procedimiento aplicado a la técnica de regresión múltiple ha sido el de pasos sucesivos, que consiste en la determinación de las variables explicativas que forman parte la ecuación de regresión a partir de su sucesiva selección, introduciendo o suprimiendo una variable en cada paso en función del grado de correlación parcial de la variable independiente con la variable dependiente, siempre que cumpla la condición de entrada establecida. La salida del programa informático proporciona los coeficientes de 
la recta de regresión de las variables incluidas, y la bondad del ajuste obtenido, mediante el coeficiente de determinación $\left(R^{2}\right)$ que se interpreta con la parte de la variabilidad de la variable dependiente que viene explicada por las variables independientes incluidas en el modelo, y se utiliza como una medida global del ajuste del modelo, pudiendo tomar valores entre 0 y 1 .

Finalmente interesa identificar las características que diferencian o discriminan a dos o más grupos de empresas (las que obtienen los mayores y menores precios) y crear una función estadística capaz de informar sobre las variables independientes que mejor permiten diferenciar entre ambos grupos de empresas mediante la técnica de análisis discriminante. Dada una variable dependiente cualitativa y un conjunto de variables independientes cuantitativas, el análisis discriminante es un método de carácter causal, consistente en obtener unas funciones lineales de las variables independientes (funciones discriminantes), que permitan clasificar los individuos de una población en los distintos grupos establecidos por los valores de la variable dependiente (Ferran, 1997). Se trata de reducir las variables originales que mejor discriminan, en unas pocas nuevas variables, denominadas canónicas.

En el presente estudio se ha optado por aplicar el análisis discriminante, en un enfoque de los extremos polares (Hair, 1999), comparando solamente los dos grupos extremos, resultado de categorizar la variable dependiente precio en terciles y seleccionando el tercil 1 y el tercil 3, constituidos por las terceras partes de las empresas que más bajos y altos precios respectivamente obtienen en la comercialización de sus vinos, excluyendo el grupo medio (tercil 2) del análisis. El objetivo es revelar las variables independientes que resulten claras y determinantes en la diferenciación de las bodegas que obtienen altos precios de las que consiguen bajos precios.

Las condiciones clave para la obtención de la función discriminante son, la de normalidad y homocedasticidad, aunque existe una evidencia contradictoria sobre la sensibilidad de este análisis al incumplimiento de estos supuestos. Otras condiciones que deberían cumplirse son la no-multicolinealidad y la linealidad entre las variables independientes y la dependiente.

La prueba $M$ de Box, y su transformación en el estadístico F, permite aceptar la hipótesis de igualdad de las matrices de varianzas-covarianzas (homocedasticidad), en el supuesto de que el nivel de significación supere el valor de 0,05 y, por tanto, concluir que los grupos considerados poseen la misma variabilidad.

El nivel de tolerancia cercano al valor 1, viene a significar la no existencia de colinealidad existente entre las variables independientes.

El estadístico Lambda de Wilks permite valorar el grado de diferenciación existente entre los grupos tomando como referencia las variables independientes incluidos en cada paso en el modelo. El nivel de significación menor del valor 0,05 permite concluir que las empresas del tercil 1 (bajos precios) y 3 (altos precios) tienen promedios distintos en las variables discriminantes incluidas en el modelo. 


\subsection{Factores explicativos del precio del vino blanco joven}

La aplicación de la técnica de Análisis de Componentes Principales ha permitido una reducción sustancial de los indicadores de variables explicativas originales La imposibilidad de realizar en este caso un único proceso para todo el conjunto de variables explicativas que cumpliese los requisitos exigidos en una aplicación correcta de este método, ha obligado a realizar una aplicación independiente para las distintas variables explicativas vinculadas a un mismo grupo de recursos o factores empresariales, tratando de conseguir en todos los casos una asociación lógica entre las variables originales y los factores obtenidos.

Los resultados se sintetizan en los cuadros 7.3 a 7.7, en los que para cada uno de los análisis realizados se presentan las variables originales, los factores en los que se han agrupado dichas variables, la carga factorial, siempre que ésta sea superiora 0,30, la varianza explicada y los valores de los estadísticos comentados anteriormente. El significado de los factores obtenidos se resume a continuación:

Las cuatro variables relacionadas con la identidad corporativa se han agrupado en dos factores (cuadro 7.3). El factor naturju ha sido el más relevante (capacidad explicativa del $42 \%$ de la varianza) y se define por las variables que indican si la empresas utiliza o no una fórmula jurídica cooperativa, por la antigüedad de la empresa y por el grado de control, en relación con el control mayoritario en la gestión de la bodega por el accionista principal. El segundo factor mcontrol, que satura con la misma variable, indica si el accionista principal es una persona o grupo familiar o se encuentra vinculado a un grupo empresarial.

\section{CUADRO 7.3}

ANÁLISIS FACTORIAL SOBRE VARIABLES DE IDENTIDAD CORPORATIVA EN EL VINO BLANCO JOVEN

\begin{tabular}{|c|c|c|}
\hline & \multicolumn{2}{|c|}{ Factores obtenidos } \\
\hline & \multicolumn{2}{|c|}{ Cargas factoriales } \\
\hline Variables & 0,88 & mcontrol \\
\hline fjurid & 0,72 & \\
\hline gcontrol & $-0,71$ & 0,98 \\
\hline antig & & $25,8 \%$ \\
\hline mcontrol & $41,7 \%$ & \\
\hline Varianza explicada & \multicolumn{2}{|c|}{ KMO: 0,646 Signific:0,050 } \\
\hline Estadísticos & Bartlett: 11,67 . \\
\hline
\end{tabular}

Fuente: Elaboración propia

El tratamiento de los recursos tangibles (cuadro 7.4) han aparecido resumidas claramente en dos factores: el factor dimens, que agrupa las variables: valor del activo fijo, valor de la producción, valor añadido de la empresa, empleados totales, capacidad instalada de, , el y la sobredimensión de la capacidad instalada; el factor tecnoela1, que agrupa a las variables relacionadas con el tiempo de permanencia en los depósitos de fermentación controlada y la incorporación de frío; el factor autovac, que coincide con 
la misma variable relacionada con el tiempo de permanencia en los depósitos autovaciantes.

\section{CUADRO 7.4}

ANÁLISIS FACTORIAL SOBRE VARIABLES DE RECURSOS TANGIBLES EN EL VINO BLANCO JOVEN

\begin{tabular}{|c|c|c|c|}
\hline & \multicolumn{3}{|c|}{ Factores obtenidos } \\
\hline & dimens & tecnoela1 & autovac \\
\hline Variables & \multicolumn{3}{|c|}{ Cargas factoriales } \\
\hline afijo€ & 0,98 & & \\
\hline vp€ & 0,97 & & \\
\hline vae€ & 0,97 & & \\
\hline etc & 0,96 & & \\
\hline capinst & 0,73 & 0,96 & \\
\hline sdimens & $-0,51$ & 0,95 & 0,93 \\
\hline fermcon & & & $12,0 \%$ \\
\hline frío & \multicolumn{3}{|l}{} \\
\hline autovac & $51,2 \%$ & $22,7 \%$ & \\
\hline Varianza explicada. & KMO: 0,75 & & \\
\hline Estadísticos & Bartlett: 262,50 Signific: 0,000 & \\
\hline
\end{tabular}

Fuente: Elaboración propia

Del análisis de los recursos intangibles se han obtenido dos factores (cuadro 7.5): el factor empleo, que agrupa las variables de información al consumidor, calidad y cualificación del empleo, esfuerzo comercial, y productividad del empleo; el factor esftecnol, que agrupa las variables esfuerzo tecnológico y esfuerzo innovador o en $\mathrm{I}+\mathrm{D}+\mathrm{i}$.

\section{CUADRO 7.5}

ANÁLISIS FACTORIAL SOBRE VARIABLES DE RECURSOS INTANGIBLES EN EL VINO BLANCO JOVEN

\begin{tabular}{|c|c|c|}
\hline & \multicolumn{2}{|c|}{ Factores obtenidos } \\
\hline & empleo & esftecnol \\
\hline Variables & \multicolumn{2}{|c|}{ Cargas factoriales } \\
\hline infcon & 0,77 & \\
\hline calemp & 0,74 & \\
\hline cualemp & 0,62 & \\
\hline esfcom & 0,59 & \\
\hline prodemp & $-0,55$ & \\
\hline esftec & & 0,92 \\
\hline esfidi & & 0,88 \\
\hline Varianza explicada. & $31,96 \%$ & $29,96 \%$ \\
\hline Estadísticos & $\begin{array}{l}\text { KMO: } 0,51 \\
\text { Bartlett: } 99,43 \quad \text { Signific:0,000 }\end{array}$ & \\
\hline
\end{tabular}

Fuente: Elaboración propia 
En cuanto a las variables de comportamiento estratégico, (cuadro 7.6) se han obtenido 4 factores: el primer factor mercado, que agrupa las variables cuota de exportación, porcentaje comercializado en la U. Europea, concentración de los mercados y, porcentaje comercializado en la C. Valenciana; el segundo factor referen, está integrado por el número (marcas propias de presentaciones, países, y vinos varietales); el tercer factor marpro, que concentra la variables en porcentaje (marcas propias y vinos varietales, así como el número de marcas blancas); el último factor invert, que agrupa el grado de integración vertical hacia atrás y hacia adelante.

Las restantes variables originales no han podido ser factorizadas, al no cumplir el test de esfericidad de Barlett y el test de medida de adecuación muestral de KaiserMeyr-Olkin (KMO).

\section{CUADRO 7.6}

ANÁLISIS FACTORIAL SOBRE VARIABLES DE COMPORTAMIENTO ESTRATÉGICO EN EL VINO BLANCO JOVEN

\begin{tabular}{|c|c|c|c|c|}
\hline & \multicolumn{4}{|c|}{ Factores obtenidos } \\
\hline & mercado & referen & marpro & invert \\
\hline Variables & \multicolumn{4}{|c|}{ Cargas factoriales } \\
\hline cuotaexp & 0,92 & & & \\
\hline ueuropea & 0,90 & & & \\
\hline dismerc & 0,69 & & & \\
\hline cvalencia & $-0,65$ & & & \\
\hline nmarpro & & 0,85 & & \\
\hline npresen & & 0,80 & & \\
\hline npaís & & 0,76 & & \\
\hline nvivar & & 0,62 & & \\
\hline \%marpro & & & 0,78 & \\
\hline nmarbla & & & $-0,77$ & \\
\hline \%vivar & & & 0,70 & \\
\hline ivadel & & & & 0,82 \\
\hline ivatrás & & & & 0,70 \\
\hline Varianza explicada. & $24,06 \%$ & $20,42 \%$ & $17,73 \%$ & $14,29 \%$ \\
\hline Estadísticos & $\begin{array}{l}\text { KMO: 0,68 } \\
\text { Bartlett: 296, }\end{array}$ & Signific:0,( & & \\
\hline
\end{tabular}

Fuente: Elaboración propia

A continuación se ha aplicado el Análisis de Regresión Múltiple, seleccionando como variables explicativas, tanto las variables factorizadas resultantes del análisis anterior, como las variables originales que no han podido ser factorizadas, habiéndose observado el cumplimiento de las cinco condiciones descritas en el apartado anterior (linealidad, independencia, homocedasticidad, normalidad y nomulticolinealidad). 
CUADRO 7.7

RESUMEN DEL MODELO DE REGRESIÓN MÚLTIPLE EN VINO BLANCO JOVEN

\begin{tabular}{|l|l|l|l|l|l|}
\hline Factores explicativos & \multicolumn{1}{|c|}{$\begin{array}{c}\text { Coeficiente de regresión } \\
\text { estandarizado }\end{array}$} & T & Sig. & Tolerancia & FIV \\
\hline constante & \multicolumn{3}{|l|}{} & & \\
\hline chardonay & 0,732 & 7,573 & 0,000 & & \\
\hline antig & $-0,342$ & 7,365 & 0,000 & 0,984 & 1,016 \\
\hline ho & 0,254 & $-3,429$ & 0,002 & 0,976 & 1,024 \\
\hline $\mathbf{R}^{2}$ corregido & 77,7 & 2,566 & 0,017 & 0,988 & 1,012 \\
\hline Durbin-Watson & 2,037 & & \\
\hline
\end{tabular}

Fuente: Elaboración propia.

Los resultados del modelo de regresión aparecen en el cuadro 7.7, que junto con el cuadro 7.8, permiten comprobar los siguientes aspectos:

- La variable que más contribuye a explicar la variabilidad observada en los precios es la variedad chardonay medida en \% sobre la materia prima total, que aporta un $42,8 \%$ de poder explicativo.

- El variable antigüedad (antig), tiene un poder explicativo del 20,0 \%, en el sentido de que las jóvenes empresas, tienden a situarse en el grupo de altos precios, tal y como puede observarse.

- Por último la variable (horeca) contribuye con el 14,9 \% a la varianza explicada del precio. En el grupo de altos precios este canal supone casi el 10 $\%$ del volumen comercializado, mientras en el grupo de bajos precios no alcanza el $1 \%$.

La caracterización de los grupos de bodegas (cuadro 7.8), procede de categorizar la variable dependiente precio en terciles. El tercil 1 corresponde a las bodegas que han situado sus vinos en el segmento más bajo de precio, con una media de $0,72 €$ / botella de 3/4 (basic), y el tercil 3 se corresponde con aquellas situadas en el segmento más alto de precio con una media de 1,98 €/ botella de 3/4 (premium).

En cuanto a las variables de identidad corporativa, resaltar la elevada presencia relativa en las bodegas premium, de las empresas jóvenes, no cooperativas, y con un control efectivo sobre el capital social.

En relación con los recursos tangibles se han observado diferencias estadísticamente significativas en la capacidad instalada media, que en el caso del grupo premium, se corresponde con las pequeñas empresas; en este grupo la presencia en número, de pequeñas y muy pequeñas empresas es del $83 \%$, frente al $45 \%$ en el caso de las empresas basic. 


\section{CUADRO 7.8}

CARACTERIZACIÓN DE LOS GRUPOS DE BODEGAS QUE COMERCIALIZAN VINO BLANCO JOVEN

\begin{tabular}{|c|c|c|c|}
\hline Concepto & \begin{tabular}{|c|} 
Tercil 3.Grupo \\
alto precio \\
"premium" \\
\end{tabular} & \begin{tabular}{|c|} 
Tercil 1.Grupo \\
bajo precio \\
"basic"
\end{tabular} & $\begin{array}{c}\text { Muestra } \\
\text { "basic" }\end{array}$ \\
\hline \multicolumn{4}{|l|}{ Identidad corporativa } \\
\hline Jóvenes (\%) & 41,67 & 9,08 & 25,71 \\
\hline No cooperativas (\%) & 83,34 & 45,45 & 57,14 \\
\hline Control efectivo (\%) & 33,34 & 9,09 & 17,14 \\
\hline Accionistas societarios (\%) & 16,67 & 9,09 & 17,14 \\
\hline \multicolumn{4}{|l|}{ Recursos tangibles } \\
\hline Valor de la producción medio (€) & 2.008 .584 & 4.357 .741 & 4.751 .732 \\
\hline Valor añadido de la empresa medio (€) & 464.790 & 839.527 & 983.173 \\
\hline Activo fijo medio(€) & 1.592 .167 & 2.547 .979 & 2.590 .335 \\
\hline Empleados a tiempo completo medio & 8,83 & 16,56 & 16,74 \\
\hline Capacidad instalada media (hl) $\left(^{*}\right)$ & 22.071 & 75.278 & 56.546 \\
\hline Pequeñas y muy pequeñas empresas (\%) & 83,33 & 45,45 & 57,14 \\
\hline Sobredimensión de la capacidad instalada (\%) & 20,40 & 31,29 & 20,37 \\
\hline Permanencia en fermentación controlada & 0,88 & 1,00 & 0,95 \\
\hline Incorporación de frío $(\mathrm{Fg} / \mathrm{h} / \mathrm{hl})$ & 25,87 & 22,37 & 22,03 \\
\hline Macabeo (\%) & 35,59 & 32,09 & 30,25 \\
\hline Moscatel (\%) & 37,37 & 11,04 & 16,34 \\
\hline Merseguera (\%)(*) & 0,79 & 37,25 & 27,08 \\
\hline Malvasia (\%) & 3,49 & 0,48 & 12,26 \\
\hline Verdil (\%) & 0,18 & 0,00 & 0,05 \\
\hline Airen (\%) & 20,39 & 18,34 & 9,65 \\
\hline Planta nova (\%) & 0,46 & 0,21 & 3,73 \\
\hline Pedro Ximenez (\%) & 0,13 & 0,44 & 0,35 \\
\hline Chardonay (\%)(*) & 1,61 & 0,00 & 0,15 \\
\hline Forcayat (\%) & 0,00 & 0,15 & 0,06 \\
\hline Parellada (\%) & 0,00 & 0,00 & 0,09 \\
\hline \multicolumn{4}{|l|}{ Recursos intangibles } \\
\hline Calidad del empleo (\%) & 94,38 & 86,20 & 93,72 \\
\hline Cualificación del empleo (\%) & 28,54 & 20,33 & 22,99 \\
\hline Productividad del empleo (€) & 4.825 .110 & 4.148318 & 5.203 .215 \\
\hline Esfuerzo comercial (\%) & 5,00 & 3,59 & 4,62 \\
\hline Información comercial (\%) & 3,21 & 2,39 & 2,97 \\
\hline Esfuerzo tecnológico (\%) & 21,83 & 10,51 & 10,84 \\
\hline Esfuerzo I+D+i (\%) & 0,59 & 0,10 & 0,13 \\
\hline
\end{tabular}

(*) Con diferencias substanciales al nivel de significación del 0,05. 
CUADRO 7.8 (Cont.)

CARACTERIZACIÓN DE LOS GRUPOS DE BODEGAS QUE COMERCIALIZAN VINO BLANCO JOVEN

\begin{tabular}{|c|c|c|c|}
\hline Concepto & $\begin{array}{c}\text { Tercil 3.Grupo } \\
\text { alto precio } \\
\text { "premium" }\end{array}$ & $\begin{array}{l}\text { Tercil 1. Grupo } \\
\text { bajo precio } \\
\text { "basic" }\end{array}$ & $\begin{array}{c}\text { Muestra } \\
\text { "basic" }\end{array}$ \\
\hline \multicolumn{4}{|l|}{ Comportamiento estratégico } \\
\hline Número de presentaciones & 2,00 & 4,00 & 3,17 \\
\hline Número de marcas propias & 1,83 & 4,00 & 3,89 \\
\hline Número de marcas blancas & 0,17 & 2,18 & 3,06 \\
\hline Número de vinos varietales & 1,42 & 0,91 & 1,31 \\
\hline Marcas propias $(\%)(*)$ & 99,44 & 31,03 & 65,79 \\
\hline Marcas blancas (\%) & 0,56 & 68,97 & 34,21 \\
\hline Vinos varietales $(\%)(*)$ & 95,71 & 14,72 & 36,54 \\
\hline Precio medio de venta $(€ / 3 / 4 \mathrm{l})(*)$ & 1,98 & 0,72 & 0,91 \\
\hline O. beneficio & 13,07 & 0,02 & 17,05 \\
\hline C. margen & 21,01 & 11,37 & 9,42 \\
\hline I. competencia & 12,19 & 1,02 & 6,14 \\
\hline C. demanda & 16,05 & 80,20 & 58,77 \\
\hline P. bajo & 0,77 & 7,38 & 5,19 \\
\hline P. alto & 36,92 & 0,02 & 3,43 \\
\hline Integración vertical hacia atrás (\%) & 54,46 & 77,94 & 59,28 \\
\hline Integración vertical hacia adelante (\%) & 51,30 & 51,08 & 51,14 \\
\hline D. mayorista & 64,40 & 85,18 & 52,75 \\
\hline H y supermercado & 20,36 & 11,06 & 38,74 \\
\hline Tienda & 2,89 & 0,91 & 2,84 \\
\hline Club & 0,00 & 0,00 & 0,00 \\
\hline Horeca & 9,75 & 0,69 & 2,83 \\
\hline Bodega & 1,99 & 2,16 & 2,34 \\
\hline Internet & 0,61 & 0,00 & 0,07 \\
\hline Amplitud geográfica de los mercados & 9,33 & 5,45 & 8,97 \\
\hline Dispersión de los mercados (\%) & 0,38 & 0,47 & 0,64 \\
\hline Cuota de exportación (\%) & 3,86 & 71,93 & 58,52 \\
\hline C.Valencia & 75,83 & 20,49 & 27,53 \\
\hline España & 20,31 & 7,58 & 13,95 \\
\hline U.Europea & 3,18 & 69,61 & 50,39 \\
\hline T. Países & 0,68 & 2,32 & 8,13 \\
\hline \multicolumn{4}{|l|}{ Resultados } \\
\hline Valor añadido de la empresa (\%) & 23,14 & 19,27 & 20,69 \\
\hline Resultado Actividades Ordinarias (\%) & 2,39 & 2,56 & 5,82 \\
\hline
\end{tabular}

(*) Con diferencias substanciales al nivel de significación del 0,05.

En las variables relacionadas con la tecnología de elaboración apenas existen diferencias entre ambos grupos de bodegas, lo que conduce a pensar que es probable que se haya alcanzado un cierto techo tecnológico en la elaboración de estos vinos, principalmente en las variables relacionadas con permanencia en los autovaciantes y depósitos de fermentación controlada y menos en cuanto a la incorporación de frío, último aspecto que se supera sensiblemente en las bodegas de altos precios. 
Referente a las variedades de uva han sido detectadas diferencias significativas estadísticamente en los casos de la chardonay y la merseguera, asociadas respectivamente a las bodegas premium y basic. También se han observado diferencias apreciables en el caso de la variedad moscatel, con una presencia del $37 \%$ en las bodegas premium, frente al $11 \%$ en las bodegas basic.

En cuanto a los recursos intangibles se han observado diferencias apreciables, aunque no significativas estadísticamente en todas las variables, esgrimiendo los valores más altos las bodegas premium.

En cuanto a los recursos estratégicos se han observado diferencias significativas estadísticamente en el número de marcas propias y en el porcentaje de vinos varietales, y diferencias apreciables en cuanto el número de presentaciones, número de marcas blancas, en el sentido de que las bodegas premium presentan un menor número de referencias (presentaciones, marcas).

No existen diferencias apreciables en la integración vertical hacia adelante, aunque sí en la integración hacia atrás, que es menor en las bodegas premium.

También existen diferencias apreciables en la cuota de exportación, (menos del $4 \%$ en las premium, frente a más del $70 \%$ en las basic) y en la dispersión de los mercados (el $76 \%$ de la comercialización premium se efectúa en la Comunidad Valenciana, frente al 70 \% de la Unión Europea en el caso del basic).

En lo referente a los canales de distribución, en las bodegas premium, la presencia de los canales alternativos (tienda, club, horeca, bodega e Internet) se cuadruplica respecto de las bodegas basic.

En cuanto a la política de precios, se ha visto que es congruente con los precios a la salida de la bodega, en el sentido de que en las bodegas premium, las estrategias de precios altos y coste más margen comercial son las predominantes, en contrate con las empresas basic, en las que domina aproximadamente en el $80 \%$ de la producción comercializada, las condiciones de la demanda.

En cuanto al grupo de variables relacionadas con los resultados, las bodegas que tienen una alta diferenciación de precios (premium), centran su actividad productiva en mayor medida en las fases posteriores del proceso productivo, que son las actividades susceptibles de generar un mayor valor añadido.

En la variable resultado de las actividades ordinarias no se han observado diferencias apreciables entre grupos de bodegas. 


\subsection{Factores explicativos del precio del vino rosado joven}

En primer lugar se ha aplicado la técnica de Análisis de Componentes Principales, que ha permitido una reducción sustancial de los indicadores de variables explicativas originales.

\section{CUADRO 7.9}

ANÁLISIS FACTORIAL SOBRE VARIABLES DE RECURSOS TANGIBLES EN EL VINO ROSADO JOVEN

\begin{tabular}{|c|c|c|}
\hline & \multicolumn{2}{|c|}{ Factores obtenidos } \\
\hline & \multicolumn{2}{|c|}{ dimens Cargas factoriales } \\
\hline Variables & 0,98 & \\
\hline vp€ & 0,96 & \\
\hline vae€ & 0,96 & \\
\hline etc & 0,96 & \\
\hline afijo€ & 0,87 & $-0,85$ \\
\hline capinst & $-0,57$ & 0,67 \\
\hline sdimens & \multicolumn{2}{|c|}{0,62} \\
\hline autovac & 54,55 & 18,04 \\
\hline fcontrol & \multicolumn{1}{|c|}{} \\
\hline frío & KMO: 0,73 Signific: 0,000 \\
\hline Varianza explicada. & Bartlett: 190,10 S \\
\hline Estadísticos & \multicolumn{2}{|c|}{} \\
\hline
\end{tabular}

Fuente: Elaboración propia

Los recursos tangibles (cuadro 7.9) han aparecido resumidos claramente en dos factores: el factor dimens, que agrupa las variables valor de la producción, valor añadido de la empresa, valor de la producción, empleados totales, el valor del activo fijo, la capacidad instalada, y la sobredimensión de ésta; el factor (tecnoela) agrupa a las variables relacionadas con la permanencia tanto en autovaciantes, como en depósitos de fermentación controlada, e incorporación de frío.

Del análisis de los recursos intangibles se han obtenido cuatro factores (cuadro 7.10): el factor imagen, que agrupa las variables de información al consumidor y esfuerzo comercial; el factor esftecno), que agrupa las variables esfuerzo tecnológico y esfuerzo innovador o en $\mathrm{I}+\mathrm{D}+\mathrm{i}$; el empleo, que concentra la cualificación y calidad del empleo; y por último el factor prodemp, que coincide con esta misma variable. 
CUADRO 7.10

ANÁLISIS FACTORIAL SOBRE VARIABLES DE RECURSOS INTANGIBLES EN EL VINO ROSADO JOVEN

\begin{tabular}{|l|c|c|c|c|}
\hline & \multicolumn{4}{|c|}{ Factores obtenidos } \\
\hline & \multicolumn{3}{|c|}{ imagen } & \multicolumn{2}{|c|}{ esftecno } & empleo & prodemp \\
\hline Variables & \multicolumn{4}{|c|}{ Cargas factoriales } \\
\hline infcon & 0,96 & & & \\
\hline esfcom & 0,89 & & & \\
\hline esftec & & 0,96 & & \\
\hline esfidi & & 0,86 & & \\
\hline cualemp & & & 0,85 & \\
\hline calemp & & & & 0,95 \\
\hline prodemp & & & 20,29 & 17,70 \\
\hline Varianza explicada. & 26,12 & 25,56 & \\
\hline Estadísticos & $\begin{array}{l}\text { KMO: } 0,500 \\
\text { Bartlett: } 72,603\end{array}$ & Signific:0,000 \\
\hline
\end{tabular}

Fuente: Elaboración propia

En cuanto a las variables de comportamiento estratégico, (cuadro 7.11) se han obtenido cuatro factores: el primer factor mercado que agrupa las variables: porcentaje exportado a la Unión Europea, cuota de exportación, porcentaje comercializado en la Comunidad Valenciana, y concentración de los mercados; el factor referen, que está integrado por las siguientes variables en número: presentaciones, marcas propias, países y vinos varietales; el factor invert que agrupa los dos tipos la integración vertical (hacia atrás y hacia delante); por último el factor variet que agrupa en \% las siguientes variables: vinos varietales y marcas propias.

Las restantes variables originales no han podido ser factorizadas, al no cumplir el test de esfericidad de Barlett y el test de medida de adecuación muestral de KaiserMeyr-Olkin (KMO).

En este caso y, debido a que los resultados del análisis de regresión han resultado pobres, se ha optado por el análisis discriminante. En los cuadros 7.12 a 7.16 aparecen los resultados del análisis discriminante, que se han obtenido utilizando el método de inclusión por pasos (Lambda de Wilks), en el que las variables se van incorporando a la función discriminante una a una según unos criterios de entrada y salida, siendo posible, por un lado, construir una función utilizando únicamente aquellas variables que realmente son útiles para la clasificación $\mathrm{y}$, por otro, evaluar la importancia individual de cada variable dentro del modelo discriminante. 
CUADRO 7.11

ANÁLISIS FACTORIAL SOBRE VARIABLES DE COMPORTAMIENTO ESTRATÉGICO EN EL VINO ROSADO JOVEN

\begin{tabular}{|c|c|c|c|c|}
\hline & \multicolumn{4}{|c|}{ Factores obtenidos } \\
\hline & mercado & referen & invert & variet \\
\hline Variables & \multicolumn{4}{|c|}{ Cargas factoriales } \\
\hline ueuropea & 0,88 & & & \\
\hline cuotaexp & 0,86 & & & \\
\hline cvalencia & $-0,86$ & & & \\
\hline conmerc & 0,83 & & & \\
\hline npresen & & 0,88 & & \\
\hline nmarpro & & 0,84 & & \\
\hline npaís & & 0,81 & & \\
\hline nvivar & & 0,79 & & \\
\hline ivatrás & & & 0,80 & \\
\hline ivadel & & & 0,78 & \\
\hline \%vivar & & & & 0,75 \\
\hline \%marpro & & & & 0,73 \\
\hline Varianza explicada. & $26,16 \%$ & 24,77 & 15,09 & 10,32 \\
\hline Estadísticos & $\begin{array}{l}\text { KMO: } 0,57 \\
\text { Bartlett: } 192,038 \\
\end{array}$ & Signific: 0,00 & & \\
\hline
\end{tabular}

Fuente: Elaboración propia

La prueba M de Box, (cuadro 7.12) y su transformación en el estadístico F, permite aceptar la hipótesis de igualdad de las matrices de varianzas-covarianzas (Sig $=0,177>0,05) \mathrm{y}$, por tanto, concluir que los grupos considerados poseen la misma variabilidad.

CUADRO 7.12

RESULTADOS DEL ANÁLISIS DISCRIMINANTE ( Prueba M de Box) EN EL VINO ROSADO JOVEN

\begin{tabular}{|c|r|r|}
\hline \multicolumn{2}{|c|}{ M de Box } & 1,962 \\
\hline \multirow{3}{*}{$F$} & Aprox. & 1,825 \\
\cline { 2 - 3 } & gl1 & 3 \\
\cline { 2 - 3 } & gl2 & 4919,047 \\
\cline { 2 - 3 } & Sig. & 0,177 \\
\hline Contrasta la hipótesis nula de que las matrices de covarianza poblacionales son iguales. \\
\hline
\end{tabular}

Fuente: Elaboración propia

El nivel de tolerancia (cuadro 7.13) está cercano a 1, lo que significa un bajo grado de colinealidad existente entre la variables independientes, lo cual es lógico ya que las variables con las que se trabaja coinciden con los factores independientes entre sí y obtenidos en el anterior análisis factorial de componentes principales. 
CUADRO 7.13

RESULTADOS DEL ANÁLISIS DISCRIMINANTE (Variables incluidas en cada paso) EN EL VINO ROSADO JOVEN

\begin{tabular}{|c|c|c|c|c|}
\hline Paso & & Tolerancia & F para eliminar & Lambda de Wilks \\
\hline 1 & gcontrol & 1,00 & 5,200 & \\
\hline \multirow{2}{*}{2} & gcontrol & 0,839 & 7,976 & 0,777 \\
\hline & variet & $\overline{0,839}$ & 6,357 & 0,714 \\
\hline \multirow{3}{*}{3} & gcontrol & $\overline{0,814}$ & 6,799 & 0,538 \\
\hline & variet & $\overline{0,621}$ & 10,616 & $\overline{0,653}$ \\
\hline & referen & 0,737 & 4,446 & 0,467 \\
\hline
\end{tabular}

Fuente: Elaboración propia

El estadístico Lambda de Wilks (Cuadro 7.14), que toma un valor de 0,333, permite valorar el grado de diferenciación existente entre los grupos tomando como referencia las variables independientes incluidos en cada paso en el modelo. El nivel de significación del 0,005 permite concluir que los grupos tercil 1 (grupo de bajo precio) y tercil 3 (grupo de alto precio) tienen promedios distintos en las variables (factores) discriminantes incluidas en el modelo (gcontrol, variet y referen).

CUADRO 7.14

RESULTADOS DEL ANÁLISIS DISCRIMINANTE (Lambda de Wilks global) EN EL VINO ROSADO JOVEN

\begin{tabular}{|c|r|r|r|r|}
\hline Contraste de las funciones & Lambda de Wilks & Chi-cuadrado & gl & Sig. \\
\hline $\mathbf{1}$ & 0,333 & 12,662 & 3 &, 005 \\
\hline
\end{tabular}

Fuente: Elaboración propia

Los coeficientes estandarizados o tipificados (cuadro 7.15) permiten valorar la contribución neta de cada variable a la función discriminante, y son independientes de la métrica original de las variables discriminantes y, por tanto son preferibles a los coeficientes brutos cuando las variables poseen una métrica distinta, como es el presente caso. Así pues las variables que más contribuyen a diferenciar los grupos de bajos y altos precios son por orden de importancia:

- El factor varietal (variet), que incluye las variables, vinos varietales y marcas propias en porcentaje.

- El grado de control (gcontrol), en el sentido de que un control mayoritario sobre el capital social ejerce una influencia positiva sobre el grado de diferenciación de precios.

- El factor referencias (referen), que incluye las variables de presentaciones, marcas propias, países, y vinos varietales en número, contribuye negativamente a la diferenciación de los grupos, lo que significa que las empresas con mayor número de referencias tendrán una puntuación menor en 
la función discriminante, y consecuentemente es más fácil que sean clasificados en el grupo basic o de bajo precio.

CUADRO 7.15

RESULTADOS DEL ANÁLISIS DISCRIMINANTE (Coeficientes tipificados de las funciones discriminantes canónicas) EN EL VINO ROSADO JOVEN

\begin{tabular}{|c|rr|}
\hline & \multicolumn{2}{|c|}{ Función 1 } \\
\cline { 2 - 3 } & \multicolumn{2}{|c|}{ Coeficientes estandarizados de las funciones discriminantes canónicas } \\
\hline variet & 1,089 \\
\hline gcontrol & 0,838 \\
\hline referen & $-0,765$ \\
\hline
\end{tabular}

Fuente: Elaboración propia

Una vez obtenida la función discriminante puede utilizarse para efectuar una clasificación de los mismos casos utilizados para obtener la función, lo que permite comprobar el grado de eficacia de la función desde el punto de vista de la clasificación. En el cuadro 7.16 se refleja la matriz de confusión, que constituye un procedimiento de validación de la función, ya que resume la capacidad predictiva de ésta. Las empresas asociadas al grupo 1 de bajos precios son clasificadas correctamente en el $89 \%$ de los casos, y las ligadas al grupo (altos precios) en el $100 \%$ de los casos. En total la función consigue clasificar correctamente el 94,4 \% de los casos.

\section{CUADRO 7.16}

RESULTADOS DE LA CLASIFICACIÓN (matriz de confusión) EN EL VINO ROSADO JOVEN

\begin{tabular}{|c|c|c|r|r|r|}
\hline \multirow{4}{*}{} & \multirow{2}{*}{ Precio13 } & \multicolumn{2}{|c|}{$\begin{array}{c}\text { Grupo de pertenencia } \\
\text { pronosticado }\end{array}$} & \multirow{2}{*}{ Total } \\
\cline { 3 - 6 } & & & Tercil 1 & \multicolumn{1}{c|}{ Tercil 3 } & \\
\hline \multirow{3}{*}{ Original } & \multirow{3}{*}{ Recuento } & $\mathbf{1}$ & 8 & 1 & 9 \\
\cline { 3 - 6 } & & $\mathbf{3}$ & 0 & 9 & 100,0 \\
\cline { 2 - 6 } & \multirow{2}{*}{$\%$} & $\mathbf{1}$ & 88,9 & 11,1 & 100,0 \\
\cline { 2 - 6 } & & $\mathbf{3}$ &, 0 & 100,0 & \\
\hline
\end{tabular}

Fuente: Elaboración propia

Referente a la caracterización de los grupos de bodegas (cuadro 7.17), el grupo que ha situado sus vinos en el segmento más bajo de precio, presenta una media de 0,68 $€ /$ botella de $3 / 4$ (basic), y las bodegas situadas en el segmento de más alto precio exhiben una media de 1,61 €/ botella de 3/4 (premium).

En cuanto a las variables de identidad corporativa, resaltar la mayor presencia en las bodegas premium respecto de las basic, de las empresas jóvenes, no cooperativas, las que sus accionistas principales son societarios y ejercen un control efectivo sobre el capital social. Han sido detectadas diferencias significativas estadísticamente en la variable edad y forma jurídica. 
CUADRO 7.17

CARACTERIZACIÓN DE LOS GRUPOS DE BODEGAS QUE COMERCIALIZAN VINO ROSADO JOVEN

\begin{tabular}{|l|c|c|c|}
\hline \multicolumn{1}{|c|}{ Concepto } & $\begin{array}{c}\text { Tercil 3. } \\
\text { Grupo Alto } \\
\text { precio } \\
\text { premium" }\end{array}$ & $\begin{array}{c}\text { Tercil 1 } \\
\text { Grupo bajo } \\
\text { precio } \\
\text { "basic" }\end{array}$ & $\begin{array}{c}\text { Muestra } \\
\text { "popular } \\
\text { premium" }\end{array}$ \\
\hline Identidad corporativa & \multicolumn{3}{|l|}{} \\
\hline Jóvenes (\%)(*) & 44,44 & 11,11 & 32,14 \\
\hline No cooperativas (\%)(*) & 88,89 & 44,44 & 67,86 \\
\hline Control efectivo (\%) & 33,33 & 00,00 & 17,86 \\
\hline Accionistas societarios (\%) & 22,22 & 11,11 & 25,00 \\
\hline Recursos tangibles & \multicolumn{3}{|l}{} \\
\hline Valor de la producción medio (€) & 1.709 .919 & 8.134 .437 & 5.082 .214 \\
\hline Valor añadido de la empresa medio (€) & 461.870 & 1.744 .463 & 1.060 .921 \\
\hline Activo fijo medio (€) & 1.588 .485 & 3.677 .931 & 2.643 .893 \\
\hline Empleados a tiempo completo medio & 8,07 & 25,61 & 17,87 \\
\hline Capacidad instalada media (hl) (*) & 24.292 & 93.392 & 51.059 \\
\hline Pequeñas y muy pequeñas empresas (\%) & 77,78 & 33,34 & 57,14 \\
\hline Sobredimensión de la capacidad instalada (\%) & 25,36 & 14,66 & 12,99 \\
\hline Permanencia en fermentación controlada & 0,51 & 1,49 & 0,93 \\
\hline Incorporación de frío (Fg/h/hl) & 23,78 & 23,91 & 23,97 \\
\hline Garnacha (\%) & 3,41 & 34,03 & 18,21 \\
\hline Tintorera (\%) & 0,00 & 51,05 & 27,10 \\
\hline Bobal (\%) & 28,30 & 6,29 & 43,85 \\
\hline Monastrell (\%) & 62,55 & 2,71 & 6,05 \\
\hline Royal (\%) & 0,00 & 1,93 & 1,02 \\
\hline Tempranillo (\%) & 3,88 & 3,99 & 3,67 \\
\hline Merlot (\%) & 1,86 & 0,00 & 0,08 \\
\hline Recursos intangibles & \multicolumn{3}{|l}{} \\
\hline Calidad del empleo (\%) & 96,37 & 90,24 & 93,15 \\
\hline Cualificación del empleo (\%) & 29,24 & 22,78 & 22,88 \\
\hline Productividad del empleo (€) & 5.086 .671 & 6.054 .535 & 5.301 .531 \\
\hline Esfuerzo comercial (\%) & 2,06 & 4,03 & 5,29 \\
\hline Información comercial (\%) & 0,83 & 2,93 & 3,38 \\
\hline Esfuerzo tecnológico (\%) & 31,47 & 7,98 & 10,45 \\
\hline Esfuerzo I+D+i (\%) & 0,86 & 0,03 & 0,14 \\
\hline & \multicolumn{3}{|l}{} \\
\hline
\end{tabular}

Fuente: Elaboración propia

(*) Con diferencias substanciales al nivel de significación del 0,05. 


\section{CUADRO 7.17 (Cont.)}

\section{CARACTERIZACIÓN DE LOS GRUPOS DE BODEGAS QUE COMERCIALIZAN VINO ROSADO JOVEN}

\begin{tabular}{|c|c|c|c|}
\hline Concepto & $\begin{array}{l}\text { Tercil 3. Grupo } \\
\text { Alto precio } \\
\text { "premium" }\end{array}$ & $\begin{array}{c}\text { Tercil 1.Grupo } \\
\text { bajo precio } \\
\text { "basic" }\end{array}$ & $\begin{array}{c}\text { Muestra } \\
\text { "popular } \\
\text { premium" }\end{array}$ \\
\hline \multicolumn{4}{|l|}{ Comportamiento estratégico } \\
\hline Número de presentaciones & 1,22 & 3,89 & 2,43 \\
\hline Número de marcas propias & 1,44 & 6,89 & 3,57 \\
\hline Número de marcas blancas & 0,11 & 5,11 & 1,75 \\
\hline Número de vinos varietales & 0,67 & 1,22 & 1,18 \\
\hline Marcas propias (\%) (*) & 97,84 & 98,30 & 94,51 \\
\hline Marcas blancas (\%) & 2,16 & 1,70 & 5,49 \\
\hline Vinos varietales $(\%)(*)$ & 92,42 & 27,40 & 52,28 \\
\hline Precio medio de venta $(€ / l)(*)$ & 2,14 & 0,91 & 1.51 \\
\hline O. beneficio (\%) & 7,58 & 34,02 & 32,36 \\
\hline C. y margen (\%) & $66,2$. & 10,82 & 11,46 \\
\hline I. competencia (\%) & 0,00 & 9,29 & 5,40 \\
\hline C. demanda (\%) & 0,00 & 45,81 & 35,61 \\
\hline P. bajo (\%) & 1,86 & 0,00 & 13,59 \\
\hline P. alto (\%) & 24,36 & 0,05 & 1,58 \\
\hline Integración vertical hacia atrás (\%) & 55,42 & 45,23 & 50,09 \\
\hline Integración vertical hacia adelante (\%) & 53,51 & 51,29 & 51,12 \\
\hline D. mayorista (\%) & 66,05 & 13,54 & 31,21 \\
\hline H y supermercado (\%) & 5,26 & 79,15 & 44,33 \\
\hline Tienda (\%) & 3,28 & 2,04 & 10,45 \\
\hline Club (\%) & 0,00 & 0,68 & 0,00 \\
\hline Horeca (\%) & 18,37 & 1,32 & 11,03 \\
\hline Bodega (\%) & 7,04 & 2,93 & 2,38 \\
\hline Internet (\%) & 0,00 & 0,00 & 0,04 \\
\hline Amplitud geográfica de los mercados & 8,00 & 8,78 & 9,97 \\
\hline Dispersión de los mercados (\%) & 0,28 & 0,70 & 0,72 \\
\hline Cuota de exportación (\%) & 4,92 & 58,68 & 52,88 \\
\hline C. Valenciana (\%) & 83,66 & 26,05 & 23,50 \\
\hline España (\%) & 11,42 & 15,27 & 23,63 \\
\hline U.Europea (\%) & 4,92 & 43,04 & 39,25 \\
\hline T. Países (\%) & 0,00 & 15,64 & 13,62 \\
\hline \multicolumn{4}{|l|}{ Resultados } \\
\hline Valor añadido de la empresa (\%) & 27,01 & 21,45 & 20,88 \\
\hline Resultado Actividades Ordinarias (\%) & 0,88 & 6,47 & 6,24 \\
\hline
\end{tabular}

Fuente: Elaboración propia

(*) Con diferencias substanciales al nivel de significación del 0,05. 
En relación con los recursos tangibles se han observado diferencias estadísticamente significativas en la capacidad instalada media, que en el caso del grupo premium, se corresponde con las pequeñas empresas, y en el grupo basic con las grandes empresas. Asimismo en el premium la presencia en número, de pequeñas y muy pequeñas empresas es del 78 \%, frente al $33 \%$ en el caso de las empresas basic.

En las variables relacionadas con la tecnología de elaboración, al igual que en el caso del vino blanco, apenas existen diferencias entre ambos grupos de bodegas, lo que conduce a pensar que es probable que se haya alcanzado un cierto techo tecnológico en la elaboración de estos vinos, principalmente en las variables relacionadas con permanencia en los autovaciantes y depósitos de fermentación controlada.

Referente a las variedades de uva, existen diferencias apreciables aunque no significativas estadísticamente en todas las variedades excepto en el caso del tempranillo, que no llega a alcanzar en ambos grupos una participación del 4\%. La tintorera y garnacha, representan en las bodegas basic el $85 \%$ de la producción comercializada. La monastrell y bobal agrupan el $90 \%$ de los vinos comercializados en las bodegas premium.

En cuanto a los recursos intangibles se han observado diferencias apreciables, aunque no significativas estadísticamente en las variables siguientes: esfuerzo tecnológico e innovador, cualificación y calidad del empleo, con la presencia de los mayores valores en el grupo premium.

En relación con el esfuerzo comercial y por información al consumidor sorprende que las diferencias observadas se decanten a favor de las empresas basic, lo que significa que el esfuerzo comunicativo de estas bodegas no se está recogiendo en la dirección de la diferenciación de precios al alza de los vinos rosados, sino probablemente en el aumento de la cuota de mercado, aspecto último que no ha sido comprobado, ya que se apartaba del objetivo de la investigación.

En cuanto a los recursos estratégicos se han observado diferencias significativas estadísticamente: en el número de presentaciones, en el sentido de que las bodegas premium presentan un menor número de referencias (presentaciones, marcas); $\mathrm{y}$ en la variable vinos varietales en porcentaje.

No existen diferencias apreciables en la integración vertical hacia adelante, aunque sí en la integración hacia atrás, que es mayor en las bodegas premium, al contrario de lo que ocurre en el caso del vino blanco.

De manera similar a lo observado para el vino blanco, también existen diferencias apreciables en la cuota de exportación, (menos del $5 \%$ en las premium, frente al $59 \%$ en las basic) y en la dispersión de los mercados (el $84 \%$ de la comercialización premium se efectúa en la Comunidad Valenciana, frente al $43 \%$ en la Unión Europea en el caso del basic).

En lo referente a los canales de distribución, en las bodegas premium, la presencia de los canales alternativos (tienda, club, horeca, bodega e Internet) se 
cuadruplica respecto de las bodegas basic, de igual manera que se ha detectado para el vino blanco, si bien en el vino rosado la cuota de estos canales minoritarios se ha duplicado respecto a la observada en el vino blanco.

En cuanto a la política de precios, se ha visto que es congruente con los precios a la salida de la bodega, en el sentido de que en las bodegas premium, las estrategias de coste más margen comercial y de precios altos son las predominantes (90\% de la producción comercializada), en contrate con las empresas basic, en las que domina aproximadamente en el $80 \%$ de la producción comercializada, las condiciones de la demanda.

En relación con las variables de resultados, la mayor diferenciación de las bodegas premium se ha traducido en mayor valor añadido para estas bodegas en relación con las basic (27 \% frente al $21 \%$ ). Sorprendentemente esta estrategia de diferenciación por precios no se ha reflejado en la variable resultado de las actividades ordinarias en \% (menos del 1 \% para las premium y más del $6 \%$ para las basic).

\subsection{Factores explicativos del precio del vino tinto joven}

Los resultados del Análisis de Componentes Principales se sintetizan en los cuadros 7.19 a 7.23. El significado de los factores obtenidos se resume a continuación:

Las cuatro variables relacionadas con la identidad corporativa se han agrupado en dos factores (cuadro 7.18). El primer factor control ha sido el más relevante (capacidad explicativa del $36 \%$ de la varianza) indica si el accionista principal es una persona o grupo familiar y ejerce un control mayoritario sobre el capital social. El segundo factor naturju se define por las variables que indican si las empresas utilizan o no una fórmula jurídica cooperativa, y por la antigüedad de las empresas.

\section{CUADRO 7.18}

ANÁLISIS FACTORIAL SOBRE VARIABLES DE IDENTIDAD CORPORATIVA EN EL VINO TINTO JOVEN

\begin{tabular}{|c|c|c|}
\hline & \multicolumn{2}{|c|}{ Factores obtenidos } \\
\hline & \multicolumn{2}{|c|}{ control } \\
\hline Variables & 0,89 & Cargas factoriales \\
\hline mcontrol & 0,75 & $-0,87$ \\
\hline gcontrol & & 0,73 \\
\hline antig & $35,7 \%$ & $34,8 \%$ \\
\hline fjurid & \multicolumn{2}{|c|}{} \\
\hline Varianza explicada & KMO: 0,651 Signific:0,009 \\
\hline Estadísticos & Bartlett: 17,162 . \\
\hline
\end{tabular}

Fuente: Elaboración propia. 
El tratamiento de los recursos tangibles (cuadro 7.19) han aparecido resumidos claramente en tres factores: el factor dimens, que concentra más del $50 \%$ de la varianza, y agrupa las variables: valor del activo fijo, valor de la producción, valor añadido de la empresa, empleados totales y capacidad instalada; el factor tecnoela1, que agrupa a las variables relacionadas con la incorporación de frío y tiempo de permanencia en los depósitos de fermentación controlada y la sobredimensión de la capacidad instalada; por último el factor calor, que coincide con la misma variable relacionada con la incorporación de calor.

CUADRO 7.19

ANÁLISIS FACTORIAL SOBRE VARIABLES DE RECURSOS TANGIBLES EN EL VINO TINTO JOVEN

\begin{tabular}{|c|c|c|c|}
\hline & \multicolumn{3}{|c|}{ Factores obtenidos } \\
\hline & dimens & tecnoela1 & calor \\
\hline Variables & \multicolumn{3}{|c|}{ Cargas factoriales } \\
\hline afijo€ & 0,97 & & \\
\hline $\mathrm{vp} €$ & 0,95 & & \\
\hline vae€ & 0,95 & & \\
\hline etc & 0,94 & & \\
\hline capinst & 0,82 & & \\
\hline frío & & 0,87 & \\
\hline autovac & & 0,78 & \\
\hline sdimens & & 0,60 & \\
\hline calor & & & 0,89 \\
\hline Varianza explicada. & $50,5 \%$ & $19,73 \%$ & $12,69 \%$ \\
\hline Estadísticos & $\begin{array}{l}\text { KMO: } 0,758 \\
\text { Bartlett: } 270,650\end{array}$ & 0,000 & \\
\hline
\end{tabular}

Fuente: Elaboración propia.

Del análisis de los recursos intangibles se han obtenido tres factores (cuadro 7.20): el factor imagen, que concentra agrupa las variables de información al consumidor, esfuerzo comercial y productividad del empleo; factor esftecno, que agrupa las variables esfuerzo tecnológico o inversor y esfuerzo innovador o en $\mathrm{I}+\mathrm{D}+\mathrm{i}$; por último el factor empleo, que agrupa las variables calidad y cualificación del empleo. 
CUADRO 7.20

ANÁLISIS FACTORIAL SOBRE VARIABLES DE RECURSOS INTANGIBLES EN EL VINO TINTO JOVEN

\begin{tabular}{|c|c|c|c|}
\hline & \multicolumn{3}{|c|}{ Factores obtenidos } \\
\hline & imagen & esftecno & empleo \\
\hline Variables & \multicolumn{3}{|c|}{ Cargas factoriales } \\
\hline infcon & 0,91 & & \\
\hline esfcom & 0,86 & & \\
\hline prodemp & $-0,44$ & 0,92 & \\
\hline esftec & & 0,84 & 0,89 \\
\hline esfidi & & & 0,53 \\
\hline calemp & \multicolumn{3}{|c|}{24,45} \\
\hline cualemp & 27,56 & 16,47 \\
\hline Varianza explicada. & KMO: 0,604 & & \\
\hline Estadísticos & Bartlett: $59,408 \quad$ Signific:0,000 \\
\hline
\end{tabular}

Fuente: Elaboración propia.

En cuanto a las variables de comportamiento estratégico, (cuadro 7.21) se han obtenido 4 factores: el factor referen, que resume el número de marcas blancas porcentaje en volumen de marcas propias, y el número de presentaciones; el factor mercado, que agrupa las variables cuota de exportación, y porcentajes en volumen comercializados en el Unión Europea y Comunidad Valenciana (con signo negativo); el factor variet, que agrupa el número de vinos varietales y porcentaje de estos, el número de marcas propias y el número de países; por último el factor invert, que agrupa los dos tipos de integración vertical y la concentración de los mercados (con signo negativo).

Las restantes variables originales no han podido ser factorizadas, al no cumplir el test de esfericidad de Barlett y el test de medida de adecuación muestral de KaiserMeyr-Olkin (KMO). 
CUADRO 7.21

ANÁLISIS FACTORIAL SOBRE VARIABLES DE COMPORTAMIENTO ESTRATÉGICO EN EL VINO TINTO JOVEN

\begin{tabular}{|c|c|c|c|c|}
\hline & \multicolumn{4}{|c|}{ Factores obtenidos } \\
\hline & referen & mercad & variet & invert \\
\hline Variables & \multicolumn{4}{|c|}{ Cargas factoriales } \\
\hline nmarbla & 0,91 & & & \\
\hline \%marpro & $-0,76$ & & & \\
\hline npresen & 0,75 & & & \\
\hline cuotaexp & & 0,93 & & \\
\hline ueuropea & & 0,92 & & \\
\hline cvalencia & & $-0,80$ & & \\
\hline nvivar & & & 0,79 & \\
\hline \%vivar & & & 0,66 & \\
\hline nmarpro & & & 0,66 & \\
\hline npaís & & & 0,64 & \\
\hline ivadel & & & & 0,73 \\
\hline conmerc & & & & $-0,69$ \\
\hline ivatrás & & & & 0,69 \\
\hline Varianza explicada. & 24,88 & 19,98 & 16,58 & 14,83 \\
\hline Estadísticos & $\begin{array}{l}\text { KMO: 0,613 } \\
\text { Bartlett: } 274,593\end{array}$ & Signific:0 & & \\
\hline
\end{tabular}

Fuente: Elaboración propia

A continuación se ha aplicado el Análisis de Regresión Múltiple, seleccionando como variables explicativas, tanto las variables factorizadas resultantes del análisis anterior, como las variables originales que no han podido ser factorizadas, habiéndose observado el cumplimiento de las cinco condiciones descritas en el apartado anterior (linealidad, independencia, homocedasticidad, normalidad y nomulticolinealidad).

\section{CUADRO 7.22}

\section{RESUMEN DEL MODELO DE REGRESIÓN LINEAL MÚLTIPLE EN VINO TINTO JOVEN}

\begin{tabular}{|l|l|l|l|l|l|}
\hline Factores explicativos & \multicolumn{1}{|c|}{$\begin{array}{c}\text { Coeficiente de regresión } \\
\text { estandarizado }\end{array}$} & \multicolumn{1}{|c|}{ t } & Sig. & Tolerancia & FIV \\
\hline Constante & \multicolumn{1}{|c|}{} & 13,700 & 0,000 & & \\
\hline tecnoela 2 & 0,539 & 4,160 & 0,000 & 0,976 & 1,024 \\
\hline merlot & 0,425 & 3,277 & 0,003 & 0,974 & 1,026 \\
\hline tecnoela 1 & 0,398 & 3,103 & 0,005 & 0,998 & 1,002 \\
\hline $\mathbf{R}^{2}$ corregido & 61,3 & & & & \\
\hline Durbin-Watson & 2,328 &
\end{tabular}

Fuente: Elaboración propia 
Los resultados del modelo de regresión aparecen en el cuadro 7.22, que junto con el cuadro 7.23, permiten comprobar los siguientes aspectos:

- El factor que más contribuye a explicar la variabilidad observada en los precios es el calor, que aporta un $24,1 \%$ de poder explicativo.

- $\quad$ La variedad merlot, que aporta el 19,1 de la varianza.

- El factor tecnoela 1 (incorporación de frío, tiempo de permanencia en autovaciantes y sobredimensión de la capacidad instalada, aportan conjuntamente cerca del $17,9 \%$ de la varianza.

La caracterización de los grupos de bodegas (cuadro 7.23), procede de categorizar la variable dependiente precio en terciles. El tercil 1 corresponde a las bodegas que han situado sus vinos en el segmento más bajo de precio, con una media de $0,74 €$ / botella de $3 / 4$ (basic), y el tercil 3 se corresponde con aquellas situadas en el segmento más alto de precio con una media de 1,59 €/ botella de 3/4 (popular premium).

En cuanto a las variables de identidad corporativa, resaltar la elevada presencia relativa en las bodegas popular premium, de las empresas jóvenes, no cooperativas, con accionistas principales societarios, los cuales ejercen un control efectivo sobre el capital social. Han sido detectadas diferencias estadísticamente significativas en la variable edad y forma jurídica.

En relación con los recursos tangibles se han observado diferencias estadísticamente significativas en la capacidad instalada media, que en el caso del grupo popular premium, se corresponde con las muy pequeñas empresas; en este grupo la presencia en número de pequeñas y muy pequeñas empresas asciende al $100 \%$, frente al $34 \%$ en el caso de las empresas basic.

En las variables relacionadas con la tecnología de elaboración existen diferencias apreciables en la incorporación de frío, calor y tiempo de permanencia en los depósitos autovaciantes.

Referente a las variedades de uva han sido detectadas diferencias significativas estadísticamente en el caso de variedad cabernet sauvignon, y diferencias apreciables en el caso de las variedades merlot, shirac y monastrell, asociadas todas ellas a las bodegas popular premium. Por el contrario, las variedades bobal, tintorera y garnacha aparecen ligadas a las bodegas basic.

En cuanto a los recursos intangibles se han observado diferencias significativas estadísticamente en el esfuerzo tecnológico, comercial y por información al consumidor, esgrimiendo los valores más altos las bodegas popular premium. También se han observado diferencias apreciables en el esfuerzo innovador y la cualificación del empleo a favor de las bodegas popular premium. 
CUADRO 7.23

CARACTERIZACIÓN DE LOS GRUPOS DE BODEGAS QUE COMERCIALIZAN VINO TINTO JOVEN

\begin{tabular}{|c|c|c|c|}
\hline Concepto & $\begin{array}{l}\text { Tercil 3.Grupo } \\
\text { alto precio } \\
\text { "popular } \\
\text { premium" }\end{array}$ & $\begin{array}{c}\text { Tercil 1.Grupo } \\
\text { de bajo precio } \\
\text { "basic" }\end{array}$ & $\begin{array}{l}\text { Muestra } \\
\text { "popular } \\
\text { premium" }\end{array}$ \\
\hline \multicolumn{4}{|l|}{ Identidad corporativa } \\
\hline Jóvenes (\%) (*) & 69,23 & 0,00 & 34,21 \\
\hline No cooperativas $(\%)(*)$ & 84,62 & 41,67 & 65,79 \\
\hline Control efectivo (\%) & 30,77 & 0,00 & 18,42 \\
\hline Accionistas societarios (\%) & 23,08 & 8,34 & 21,05 \\
\hline \multicolumn{4}{|l|}{ Recursos tangibles } \\
\hline Valor de la producción medio (€) & 1.262 .110 & 7.717 .047 & 4.122 .927 \\
\hline Valor añadido de la empresa medio $(€)$ & 280.685 & 1.658 .638 & 868.980 \\
\hline Activo fijo medio(€) & 1.078 .401 & 3.643 .686 & 2.273 .625 \\
\hline Empleados a tiempo completo medio & 5,19 & 23,06 & 15,53 \\
\hline Capacidad instalada media (hl) $(*)$ & 7.694 & 102.100 & 50.079 \\
\hline Pequeñas y muy pequeñas empresas (\%) & 100 & 0,34 & 63,15 \\
\hline Sobredimensión de la capacidad instalada (\%) & 21,79 & 22,58 & 19,92 \\
\hline Permanencia en autovaciantes & 0,45 & 0,32 & 0,33 \\
\hline Incorporación de calor (Kcal/h/hl) & 11,58 & 8,08 & 8,85 \\
\hline Incorporación de frío (Fg/h/hl) & 16,78 & 6,31 & 7,40 \\
\hline Bobal (\%) & 11,35 & 36,77 & 40,76 \\
\hline Tempranillo (\%) & 35,46 & 31,23 & 24,76 \\
\hline Tintorera (\%) & 0,25 & 17,01 & 7,84 \\
\hline Garnacha (\%) & 0,47 & 7,22 & 3,36 \\
\hline Cabernet sauvignon(\%) (*) & 5,70 & 0,09 & 1,04 \\
\hline Merlot (\%) & 4,10 & 0,36 & 0,51 \\
\hline Shirac (\%) & 1,26 & 0,00 & 0,06 \\
\hline Pinor (\%) & 2,93 & 0,00 & 0,00 \\
\hline Monastrell (\%) & 41,48 & 6,48 & 19,56 \\
\hline Forcayat (\%) & 0,00 & 0,83 & 2,10 \\
\hline \multicolumn{4}{|l|}{ Recursos intangibles } \\
\hline Calidad del empleo (\%) & 90,36 & 91,42 & 92,16 \\
\hline Cualificación del empleo (\%) & 33,09 & 20,42 & 22,95 \\
\hline Productividad del empleo (€) & 4.989 .215 & 5.993 .270 & 5.152 .344 \\
\hline Esfuerzo comercial $(\%)(*)$ & 6,49 & 3,54 & 4,72 \\
\hline Información comercial $(\%)(*)$ & 4,41 & 2,55 & 3,03 \\
\hline Esfuerzo tecnológico (\%)(*) & 30,30 & 8,40 & 11,36 \\
\hline Esfuerzo I+D+i (\%) & 0,86 & 0,06 & 0,12 \\
\hline
\end{tabular}

Fuente: Elaboración propia.

(*) Con diferencias substanciales al nivel de significación del 0,05. 


\section{CUADRO 7.23 (Cont.)}

\section{CARACTERIZACIÓN DE LOS GRUPOS DE BODEGAS QUE COMERCIALIZAN VINO TINTO JOVEN}

\begin{tabular}{|c|c|c|c|}
\hline Concepto & $\begin{array}{c}\text { Tercil 3.Grupo } \\
\text { alto precio } \\
\text { "popular } \\
\text { premium" } \\
\end{array}$ & $\begin{array}{l}\text { Tercil 1.Grupo } \\
\text { de bajo precio } \\
\text { "basic" }\end{array}$ & $\begin{array}{c}\text { Muestra } \\
\text { "popular } \\
\text { premium" }\end{array}$ \\
\hline \multicolumn{4}{|l|}{ Comportamiento estratégico } \\
\hline Número de presentaciones $(*)$ & 1,85 & 4,83 & 3,11 \\
\hline Número de marcas propias & 2,85 & 7,25 & 4,55 \\
\hline Número de marcas blancas & 1,31 & 4,08 & 3,27 \\
\hline Número de vinos varietales(*) & 2,00 & 1,17 & 1,40 \\
\hline Marcas propias (\%) & 89,54 & 95,92 & 70,63 \\
\hline Marcas blancas (\%) & 10,46 & 4,08 & 29,37 \\
\hline Vinos varietales (\%) & 57,71 & 51,66 & 44,38 \\
\hline Precio medio de venta $(€ / 3 / 41)(*)$ & 1,59 & 0,74 & 0,94 \\
\hline O. beneficio (\%) & 12,62 & 18,80 & 12,51 \\
\hline C. y margen (\%) & 39,04 & 19,67 & 12,46 \\
\hline I. competencia (\%) & 12,48 & 10,28 & 4,13 \\
\hline C. demanda (\%) & 20,11 & 47,14 & 61,75 \\
\hline P. bajo (\%) & 2,91 & 4,11 & 6,98 \\
\hline P. alto (\%) & 12,85 & 0,00 & 2,18 \\
\hline Integración vertical hacia atrás (\%) & 46,60 & 56,79 & 57,91 \\
\hline Integración vertical hacia adelante (\%) & 55,13 & 52,41 & 51,40 \\
\hline D. mayorista (\%) & 64,27 & 28,95 & 61,88 \\
\hline H y supermercado (\%) & 8,98 & 60,69 & 23,70 \\
\hline Tienda (\%) & 2,74 & 1,15 & 4,44 \\
\hline Club (\%) & 0,00 & 0,38 & 0,28 \\
\hline Horeca (\%) & 13,75 & 3,64 & 6,78 \\
\hline Bodega (\%) & 9,02 & 5,00 & 2,72 \\
\hline Internet (\%) & 1,24 & 0,00 & 0,14 \\
\hline Amplitud geográfica de los mercados & 8,62 & 8,34 & 8,71 \\
\hline Dispersión de los mercados (\%) & 0,67 & 0,65 & 0,69 \\
\hline Cuota de exportación (\%) & 44,97 & 42,44 & 49,83 \\
\hline C. Valenciana (\%) & 36,96 & 47,79 & 24,55 \\
\hline España (\%) & 18,07 & 9,77 & 25,61 \\
\hline U.Europea (\%) & 39,41 & 32,38 & 42,31 \\
\hline T. Países (\%) & 5,56 & 10,06 & 7,53 \\
\hline \multicolumn{4}{|l|}{ Resultados } \\
\hline Valor añadido de la empresa (\%) & 22,24 & 21,49 & 21,08 \\
\hline Resultado Actividades Ordinarias (\%) & 1,39 & 5,55 & 5,80 \\
\hline
\end{tabular}

Fuente: Elaboración propia.

(*) Con diferencias substanciales al nivel de significación del 0,05. 
Destacar diferencias apreciables en la productividad del empleo, que es menor en el caso de las bodegas popular premium, lo que puede explicarse por la elaboración más artesanal y cuidada que requiere un tipo de vino de categoría superior.

En cuanto a los recursos estratégicos se han observado diferencias significativas estadísticamente en el número, tanto de presentaciones como de vinos varietales, en el sentido de que las bodegas popular premium presentan un menor número de referencias (presentaciones, marcas propias y blancas) que las bodegas basic, en concordancia con lo observado con los otros tipos de vinos.

No existen diferencias apreciables en la integración vertical hacia adelante, aunque sí en la integración hacia atrás, que es menor en las bodegas popular premium.

Tampoco existen diferencias apreciables en la cuota de exportación, ni en la dispersión de los mercados ni la amplitud geográfica de los mismos, si bien los destinos geográficos preponderantes en el caso de las bodegas popular premium son la Unión Europea y la Comunidad Valenciana, contrariamente a lo observados en los restantes tipos de vinos.

En lo referente a los canales de distribución, en las bodegas popular premium, la presencia de los canales alternativos (tienda, club, horeca, bodega e Internet) casi se triplica respecto de las bodegas basic, de manera similar a lo observado en el resto de tipos de vinos considerados en el estudio.

En cuanto a la política de precios, se ha visto que es congruente con los precios a la salida de la bodega, en el sentido de que en las bodegas popular premium, las estrategias de coste más margen comercial son las predominantes, en contrate con las empresas basic, en las que domina aproximadamente en el $47 \%$ de la producción comercializada, las condiciones de la demanda.

En relación con las variables de resultados, la diferenciación de las bodegas popular premium, no se ha traducido en una diferencia apreciable de mayor valor añadido para estas bodegas en relación con las basic (22 \% frente al $21 \%$, respectivamente).

Al igual que para el caso del vino rosado, esta estrategia de diferenciación por precios de manera sorprendente, no se ha reflejado en la variable resultados de las actividades ordinarias en \% (menos del $2 \%$ para las popular premium y más del $5 \%$ para las basic). 


\subsection{Factores explicativos del precio del vino crianza}

Los resultados del Análisis de Componentes Principales, se sintetizan en los cuadros 7.24 a 7.25. El significado de los factores obtenidos se resume a continuación:

El tratamiento de los recursos tangibles (cuadro 7.24) han aparecido resumidas claramente en tres factores: el factor dimens, que concentra más del 50 \% de la varianza, y agrupa las variables: valor añadido de la empresa, valor de la producción, valor del activo fijo, empleados totales, capacidad instalada y la sobredimensión de ésta; el factor tecnoela1, que agrupa a las variables relacionadas con tiempo de permanencia en los depósitos autovaciantes, y la incorporación de frío; por último el factor calor, que coincide con la misma variable relacionada la incorporación de calor.

\section{CUADRO 7.24}

ANÁLISIS FACTORIAL SOBRE VARIABLES DE RECURSOS TANGIBLES EN EL VINO CRIANZA

\begin{tabular}{|c|c|c|c|}
\hline & \multicolumn{3}{|c|}{ Factores obtenidos } \\
\hline & dimens & tecnoela1 & calor \\
\hline Variables & \multicolumn{3}{|c|}{ Cargas factoriales } \\
\hline vae€ & 0,97 & & \\
\hline vp€ & 0,94 & & \\
\hline afijo€ & 0,93 & & \\
\hline etc & 0,93 & & \\
\hline capinst & 0,79 & & \\
\hline sdimens & $-0,594$ & 0,74 & 0,95 \\
\hline autovac & & 0,70 & $11,83 \%$ \\
\hline frío & & & \\
\hline calor & $52,17 \%$ & $14,32 \%$ & \\
\hline Varianza explicada. & KMO: 0,780 & & \\
\hline Estadísticos & Bartlett: $182,699 \quad$ Signific: 0,000 & \\
\hline
\end{tabular}

Fuente: Elaboración propia.

En cuanto a las variables de comportamiento estratégico, (cuadro 7.25) se han obtenido 4 factores: el factor mercado, que agrupa las variables, concentración de los mercados, cuota de exportación porcentajes en volumen comercializados en el Unión Europea y Comunidad Valenciana (con signo negativo) y la integración vertical hacia delante (signo negativo); factor referen, que resume el número de marcas blancas porcentaje en volumen de marcas propias (signo negativo), y el número de presentaciones; el factor país, que agrupa el número de marcas propias y el número de países; el factor variet, que agrupa el porcentaje de vinos varietales y en número de éstos; por último el factor ivatrás, que solo satura a la misma variable integración vertical hacia atrás. 
CUADRO 7.25

ANÁLISIS FACTORIAL SOBRE VARIABLES DE COMPORTAMIENTO ESTRATÉGICO EN EL VINO CRIANZA

\begin{tabular}{|c|c|c|c|c|c|}
\hline & \multicolumn{5}{|c|}{ Factores obtenidos } \\
\hline & mercado & referen & país & variet & ivatrás \\
\hline Variables & \multicolumn{5}{|c|}{ Cargas factoriales } \\
\hline conmerc & 0,91 & & & & \\
\hline cvalencia & $-0,87$ & & & & \\
\hline cuotaexp & 0,85 & & & & \\
\hline ueuropea & 0,83 & & & & \\
\hline ivadel & $-0,59$ & & & & \\
\hline nmarbla & & 0,95 & & & \\
\hline \%marpro & & $-0,94$ & & & \\
\hline npresen & & 0,80 & & & \\
\hline nmarpro & & & 0,90 & & \\
\hline npaís & & & 0,63 & & \\
\hline \%vivar & & & & 0,81 & \\
\hline nvivar & & & & 0,80 & \\
\hline ivatrás & & & & & 0,97 \\
\hline Varianza explicada. & 28,62 & 21,85 & 13,05 & 12,91 & 8,44 \\
\hline Estadísticos & $\begin{array}{l}\text { KMO: } 0,706 \\
\text { Bartlett: } 398 \\
\end{array}$ & & & & \\
\hline
\end{tabular}

Fuente: Elaboración propia

Las restantes variables originales no han podido ser factorizadas, al no cumplir el test de esfericidad de Barlett y el test de medida de adecuación muestral de KaiserMeyr-Olkin (KMO).

A continuación se ha aplicado el Análisis de Regresión Múltiple, seleccionando como variables explicativas, tanto las variables factorizadas resultantes del análisis anterior, como las variables originales que no han podido ser factorizadas, habiéndose observado el cumplimiento de las cinco condiciones descritas en el apartado anterior (linealidad, independencia, homocedasticidad, normalidad y nomulticolinealidad).

Los resultados del modelo de regresión aparecen en el cuadro 7.26, que junto con el cuadro 7.27, permiten comprobar los siguientes aspectos:

- El factor que más contribuye a explicar la variabilidad observada en los precios es calor (incorporación de calor), con el 24,6 \% de la varianza observada.

- La variable esftecno (esfuerzo tecnológico) que aporta casi un 20,4 \% de poder explicativo.

- $\quad$ La variedad cabernet sauvignon que aporta cerca del 16,0 \% de la varianza. 
CUADRO 7.26

RESUMEN DEL MODELO DE REGRESIÓN LINEAL MÚLTIPLE EN VINOS DE CRIANZA

\begin{tabular}{|c|c|c|c|c|c|}
\hline Factores explicativos & $\begin{array}{c}\text { Coeficiente de regresión } \\
\text { estandarizado }\end{array}$ & $\mathbf{T}$ & Sig. & Tolerancia & FIV \\
\hline constante & & 10,306 & 0,000 & & \\
\hline calor & 0,528 & 4,316 & 0,000 & 0,985 & 1,015 \\
\hline esftec & 0,436 & 3,326 & 0,003 & 0,860 & 1,163 \\
\hline cabernet sauvignon & 0,343 & 2,701 & 0,013 & 0,916 & 1,091 \\
\hline $\mathbf{R}^{2}$ corregido & 61,0 & & & & \\
\hline Durbin-Watson & 2,487 & & & & \\
\hline
\end{tabular}

Fuente: Elaboración propia.

La caracterización de los grupos de bodegas (cuadro 7.27), procede de categorizar la variable dependiente precio en terciles. El tercil 1 corresponde a las bodegas que han situado sus vinos en el segmento más bajo de precio, con una media de $1,43 € /$ botella de $3 / 4$ (popular premium), y el tercil 3 se corresponde con aquellas situadas en el segmento más alto de precio con una media de 3,51 €/ botella de 3/4 (ultra premium).

En cuanto a las variables de identidad corporativa, resaltar la elevada presencia relativa en las bodegas ultra premium, de las empresas jóvenes, no cooperativas y las que sus accionistas principales cuales ejercen un control efectivo sobre el capital social. Han sido detectadas diferencias estadísticamente significativas en todas estas variables.

En relación con los recursos tangibles se han observado diferencias estadísticamente significativas en la capacidad instalada media, que en el caso del grupo popular premium, se corresponde con las muy pequeñas empresas; en este grupo la presencia en número, de pequeñas y muy pequeñas empresas es del $100 \%$, frente al 46 $\%$ en el caso de las empresas popular premium.

En las variables relacionadas con la tecnología de elaboración existen diferencias apreciables en la incorporación de frío, calor y tiempo de permanencia en los depósitos autovaciantes.

Referente a las variedades de uva han sido detectadas diferencias apreciables aunque no significativas estadísticamente en las variedades tempranillo, cabernet sauvignon ,merlot, shirac y pinor, merlot y shirac asociadas todas ellas a las bodegas ultra premium. Por el contrario, las variedades bobal, tintorera, garnacha y monastrell aparecen ligadas a las bodegas popular premium.

En cuanto a los recursos intangibles se han observado diferencias significativas estadísticamente en el esfuerzo comercial, esgrimiendo los valores más altos las bodegas ultra premium. También se han observado diferencias apreciables en el esfuerzo innovador, tecnológico, por información al consumidor a favor de las bodegas ultra premium. 
CUADRO 7.27

CARACTERIZACIÓN DE LOS GRUPOS DE BODEGAS QUE COMERCIALIZAN VINO CRIANZA

\begin{tabular}{|c|c|c|c|}
\hline Concepto & $\begin{array}{l}\text { Tercil 3.Grupo } \\
\text { alto precio } \\
\text { "ultra } \\
\text { premium" }\end{array}$ & $\begin{array}{c}\text { Tercil 1.Grupo } \\
\text { bajo precio } \\
\text { "popular } \\
\text { premium" }\end{array}$ & $\begin{array}{l}\text { Muestra } \\
\text { "popular } \\
\text { premium" }\end{array}$ \\
\hline \multicolumn{4}{|l|}{ Identidad corporativa } \\
\hline Jóvenes (\%) (*) & 69,23 & 23,08 & 45,00 \\
\hline No cooperativas $(\%)(*)$ & 100,00 & 61,54 & 30,00 \\
\hline Control efectivo (\%) & 38,46 & 15,38 & 22,50 \\
\hline Accionistas societarios (\%) & 7,70 & 15,38 & 20,00 \\
\hline \multicolumn{4}{|l|}{ Recursos tangibles } \\
\hline Valor de la producción medio (€) & 967.822 & 6.961 .699 & 3.759 .042 \\
\hline Valor añadido de la empresa medio (€) & 307.129 & 1.468 .798 & 795.211 \\
\hline Activo fijo medio(€) & 997.171 & 2.953 .771 & 2.190 .114 \\
\hline Empleados a tiempo completo medio & 5,86 & 21,45 & 14,06 \\
\hline Capacidad instalada media (hl) (*) & 5.682 & 78.986 & 44.639 \\
\hline Pequeñas y muy pequeñas empresas (\%) & 100,00 & 46,15 & 65,00 \\
\hline Sobredimensión de la capacidad instalada (\%) & 23,53 & 100,00 & 17,00 \\
\hline Permanencia en autovaciantes & 0,86 & 0,60 & 0,68 \\
\hline Incorporación de calor (Kcal/h/hl) & 17,42 & 8,47 & 9,07 \\
\hline Incorporación de frío (Fg/h/hl) & 16,65 & 6,04 & 6,99 \\
\hline Bobal (\%) & 4,06 & 67,57 & 59,45 \\
\hline Tempranillo (\%) & 38,12 & 20,66 & 23,12 \\
\hline Tintorera (\%) & 0,00 & 1,61 & 1,53 \\
\hline Garnacha (\%) & 0,37 & 5,30 & 4,66 \\
\hline Cabernet sauvignon (\%) (*) & 32,26 & 0,38 & 2,67 \\
\hline Merlot (\%) & 16,30 & 0,06 & 1,24 \\
\hline Shirac (\%) & 5,50 & 0,00 & 0,37 \\
\hline Pinor (\%) & 2,93 & 0,00 & 0,18 \\
\hline Monastrell (\%) & 0,46 & 4,42 & 6,67 \\
\hline Forcallat (\%) & 0,00 & 0,00 & 0,13 \\
\hline \multicolumn{4}{|l|}{ Recursos intangibles } \\
\hline Calidad del empleo (\%) & 93,26 & 97,91 & 91,58 \\
\hline Cualificación del empleo (\%) & 24,64 & 21,37 & 24,34 \\
\hline Productividad del empleo (€) & 4.841 .128 & 6.321 .488 & 5.373 .595 \\
\hline Esfuerzo comercial (\%)(*) & 11,43 & 3,80 & 4,75 \\
\hline Información comercial $(\%)(*)$ & 4,31 & 2,79 & 3,06 \\
\hline Esfuerzo tecnológico (\%)(*) & 11,47 & 7,31 & 10,55 \\
\hline Esfuerzo I+D+i (\%) & 0,33 & 0,05 & 0,07 \\
\hline
\end{tabular}

Fuente: Elaboración propia

(*) Con diferencias substanciales al nivel de significación del 0,05. 
CUADRO 7.27 (Cont.)

CARACTERIZACIÓN DE LOS GRUPOS DE BODEGAS QUE COMERCIALIZAN VINO CRIANZA

\begin{tabular}{|c|c|c|c|}
\hline Concepto & $\begin{array}{l}\text { Tercil 3.Grupo } \\
\text { alto precio } \\
\text { "ultra premium" }\end{array}$ & $\begin{array}{c}\text { Tercil 1.Grupo } \\
\text { bajo precio } \\
\text { "popular } \\
\text { premium" } \\
\end{array}$ & $\begin{array}{c}\text { Muestra } \\
\text { "popular } \\
\text { premium" }\end{array}$ \\
\hline \multicolumn{4}{|l|}{ Comportamiento estratégico } \\
\hline Número de presentaciones $(*)$ & 1,46 & 2,31 & 2,05 \\
\hline Número de marcas propias & 1,46 & 5,77 & 3,08 \\
\hline Número de marcas blancas & 0,00 & 3,23 & 2,05 \\
\hline Número de vinos varietales(*) & 1,08 & 0,92 & 0,85 \\
\hline Marcas propias (\%) & 100,00 & 79,45 & 81,26 \\
\hline Marcas blancas (\%) & 0,00 & 20,55 & 18,74 \\
\hline Vinos varietales (\%) & 92,59 & 18,41 & 25,23 \\
\hline Precio medio de venta $(€ / 3 / 41)(*)$ & 3,51 & 1,43 & 1,62 \\
\hline O. beneficio (\%) & 9,21 & 41,22 & 36,71 \\
\hline C. y margen (\%) & 20,61 & 1,42 & 3,86 \\
\hline I. competencia (\%) & 0,31 & 1,00 & 1,29 \\
\hline C. demanda (\%) & 5,52 & 51,48 & 48,42 \\
\hline P. bajo (\%) & 12,52 & 0,74 & 1,40 \\
\hline P. alto (\%) & 51,83 & 4,13 & 8,32 \\
\hline Integración vertical hacia atrás (\%) & 34,94 & 51,99 & 56,72 \\
\hline Integración vertical hacia adelante (\%) & 54,87 & 50,41 & 50,79 \\
\hline D. mayorista (\%) & 62,28 & 11,78 & 20,08 \\
\hline H y supermercado (\%) & 10,15 & 79,97 & 70,29 \\
\hline Tienda (\%) & 7,22 & 3,06 & 3,12 \\
\hline Club (\%) & 2,20 & 0,81 & 0,83 \\
\hline Horeca (\%) & 8,40 & 2,76 & 3,40 \\
\hline Bodega (\%) & 9,25 & 1,23 & 1,89 \\
\hline Internet (\%) & 0,49 & 0,00 & 0,04 \\
\hline Amplitud geográfica de los mercados & 6,23 & 9,85 & 8,08 \\
\hline Dispersión de los mercados (\%) & 0,67 & 0,65 & 0,68 \\
\hline Cuota de exportación (\%) & 39,09 & 69,66 & 65,07 \\
\hline C. Valenciana (\%) & 48,41 & 17,49 & 21,53 \\
\hline España (\%) & 12,50 & 12,85 & 13,39 \\
\hline U.Europea (\%) & 20,36 & 51,81 & 47,59 \\
\hline T. Países (\%) & 18,73 & 17,85 & 17,48 \\
\hline \multicolumn{4}{|l|}{ Resultados } \\
\hline Valor añadido de la empresa (\%) & 31,73 & 21,10 & 21,15 \\
\hline Resultado actividades ordinarias (\%) & 0,99 & 8,55 & 6,12 \\
\hline
\end{tabular}

Fuente: Elaboración propia

(*) Con diferencias substanciales al nivel de significación del 0,05. 
Destacar diferencias apreciables en la productividad del empleo, que es menor en el caso de las bodegas ultra premium.

En cuanto a los recursos estratégicos se han observado diferencias apreciables, aunque no significativas estadísticamente, en el número, tanto de presentaciones como marcas propias y blancas, en el sentido de que las bodegas ultra premium presentan los valores menores. En cuanto a las marcas propias y vinos varietales en porcentaje también se han observado diferencias apreciables a favor de las bodegas ultra premium.

No existen diferencias apreciables en la integración vertical hacia atrás, aunque sí en la integración hacia adelante, que es mayor en las bodegas ultra premium.

Asimismo se han detectado diferencias apreciables en la cuota de exportación, y en el número de países destino de la producción comercializada, presentando los valores menores las bodegas ultra premium, que concentran casi la mitad de su producción comercializada en los mercados regionales, en contraste con el destino preponderante de las bodegas de baja diferenciación en precios (popular premium), en las cuales más del 50 \% de su producción se dirige hacia la Unión Europea.

En lo referente a los canales de distribución, en las bodegas ultra premium, la presencia de los canales alternativos (tienda, club, horeca, bodega e Internet) casi se triplica respecto de las bodegas popular premium, de manera similar a lo observado en el resto de tipos de vinos considerados en el estudio.

En cuanto a la política de precios, se ha visto que es congruente con los precios a la salida de la bodega, en el sentido de que en las bodegas ultra premium, las estrategias de precios altos son las predominantes (más del $50 \%$ ), en contrate con las empresas popular premium, en las que domina (igualmente en más del 50 \%) de la producción comercializada, las condiciones de la demanda.

En relación con las variables de resultados, la diferenciación de las bodegas ultra premium, se ha traducido en una diferencia apreciable de mayor valor añadido para estas bodegas en relación con las popular premium (32 \% frente al $21 \%$, respectivamente).

Al igual que para el caso de los vinos rosado y tinto, esta estrategia de diferenciación por precios no ha reflejado en la variable resultados de las actividades ordinarias en \% (menos del $1 \%$ para las ultra premium y más del $8 \%$ para las popular premium). 


\subsection{Factores explicativos del precio del vino reserva}

Los resultados del Análisis de Componentes Principales, se sintetizan en los cuadros 7.27 a 7.29. El significado de los factores obtenidos se resume a continuación:

El tratamiento de los recursos tangibles (cuadro 7.28) han aparecido resumidos claramente en tres factores: el factor dimens, que concentra más del 50 \% de la varianza, y agrupa las variables: valor añadido de la empresa, valor de la producción, empleados totales, valor del activo fijo, la sobredimensión de la capacidad instalada (signo negativo) y capacidad instalada; el factor tecnoela1, que agrupa las variables relacionadas con la incorporación de frío y tiempo de permanencia en los depósitos autovaciantes; el factor calor, que coincide con la misma variable relacionada la incorporación de calor.

\section{CUADRO 7.28}

ANÁLISIS FACTORIAL SOBRE VARIABLES DE RECURSOS TANGIBLES EN EL VINO RESERVA

\begin{tabular}{|c|c|c|c|}
\hline & \multicolumn{3}{|c|}{ Factores obtenidos } \\
\hline & dimens & tecnoela1 & calor \\
\hline Variables & 0,98 & & \\
\hline vae€ & 0,96 & & \\
\hline vp€ & 0,93 & & \\
\hline etc & 0,91 & & \\
\hline afijo€ & 0,80 & & \\
\hline sdimens & 0,73 & 0,91 & 0,94 \\
\hline capinst & \multicolumn{3}{|c|}{} \\
\hline frío & $52,48 \%$ & 0,77 & $14,92 \%$ \\
\hline autovac & & $17,52 \%$ & \\
\hline calor & KMO: 0,545 & & \\
\hline Varianza explicada. & Bartlett: $131,6760 \quad$ Signific: 0,000 & \\
\hline Estadísticos & \multicolumn{3}{|c|}{} \\
\hline
\end{tabular}

Fuente: Elaboración propia

Del análisis de los recursos intangibles se han obtenido tres factores (cuadro 7.29): el factor imagen, que concentra agrupa las variables de información al consumidor, esfuerzo comercial y calidad del empleo; el factor esftecno, que agrupa las variables de productividad del empleo y esfuerzo tecnológico o inversor (signo negativo); por último el factor empleo, que concentra las variables de cualificación del empleo y esfuerzo innovador o en $\mathrm{I}+\mathrm{D}+\mathrm{i}$. 
CUADRO 7.29

ANÁLISIS FACTORIAL SOBRE VARIABLES DE RECURSOS INTANGIBLES EN EL VINO RESERVA

\begin{tabular}{|c|c|c|c|}
\hline & \multicolumn{3}{|c|}{ Factores obtenidos } \\
\hline & imagen & esftecno & empleo \\
\hline Variables & \multicolumn{3}{|c|}{ Cargas factoriales } \\
\hline infcons & 0,89 & & \\
\hline esfcom & 0,87 & & \\
\hline calempl & $-0,66$ & 0,80 & \\
\hline prodemp & & $-0,75$ & 0,81 \\
\hline esftec & & & 0,74 \\
\hline cualemp & \multicolumn{3}{|l}{21,53} \\
\hline esfidi & 29,47 & 18,36 \\
\hline Varianza explicada. & $\begin{array}{l}\mid l \\
\text { EMtadísticos }\end{array}$ & Bartlett: $32,268 \quad$ Signific:0,026 \\
\hline
\end{tabular}

Fuente: Elaboración propia

En cuanto a las variables de comportamiento estratégico, (cuadro 7.30) se han obtenido 4 factores: el factor referen, que resume el número de presentaciones, número de marcas blancas, número de países, número de marcas propias y porcentaje en volumen de marcas propias (signo negativo); el factor mercado, que agrupa las variables cuota de exportación, porcentajes en volumen comercializados en el Unión Europea y Comunidad Valenciana (signo negativo); el facto variet, que agrupa el número de vinos varietales y porcentaje de estos; por último el factor invert, que agrupa los dos tipos de integración vertical hacia atrás (signo negativo) y hacia adelante.

Las restantes variables originales no han podido ser factorizadas, al no cumplir el test de esfericidad de Barlett y el test de medida de adecuación muestral de KaiserMeyr-Olkin (KMO). 
CUADRO 7.30

ANÁLISIS FACTORIAL SOBRE VARIABLES DE COMPORTAMIENTO ESTRATÉGICO EN EL VINO RESERVA

\begin{tabular}{|c|c|c|c|c|}
\hline & & Factores & & \\
\hline & referen & mercado & variet & invert \\
\hline Variables & & Cargas & & \\
\hline npresen & 0,94 & & & \\
\hline nmarbla & 0,91 & & & \\
\hline npaís & 0,78 & & & \\
\hline nmarpro & 0,65 & & & \\
\hline \%marpro & $-0,59$ & & & \\
\hline cuotaexp & & 0,96 & & \\
\hline ueuropea & & 0,94 & & \\
\hline cvalencia & & $-0,79$ & & \\
\hline conmerc & & 0,54 & & \\
\hline nvivar & & & 0,79 & \\
\hline \%vivar & & & 0,73 & \\
\hline ivatrás & & & & $-0,78$ \\
\hline ivadel & & & & 0,57 \\
\hline Varianza explicada. & 27,35 & 24,22 & 14,99 & 9,92 \\
\hline Estadísticos & $\begin{array}{l}\text { KMO: 0,569 } \\
\text { Bartlett: 232,916 }\end{array}$ & Signific: & & \\
\hline
\end{tabular}

Fuente: Elaboración propia

A continuación se ha aplicado el Análisis de Regresión Múltiple, seleccionando como variables explicativas, tanto las variables factorizadas resultantes del análisis anterior, como las variables originales que no han podido ser factorizadas, habiéndose observado el cumplimiento de las cinco condiciones descritas en el apartado anterior (linealidad, independencia, homocedasticidad, normalidad y nomulticolinealidad).

\section{CUADRO 7.31}

RESUMEN DEL MODELO DE REGRESIÓN LINEAL MÚLTIPLE EN EL VINO RESERVA

\begin{tabular}{|l|l|l|l|l|l|}
\hline Factores explicativos & \multicolumn{1}{|c|}{$\begin{array}{c}\text { Coeficiente de regresión } \\
\text { estandarizado }\end{array}$} & T & Sig. & Tolerancia & FIV \\
\hline Constante & \multicolumn{1}{|c|}{} & 10,890 & 0,000 & & \\
\hline cabernet sauvignon & 0,500 & 4,387 & 0,000 & 0,785 & 1,047 \\
\hline tecnoela 1 & 0,410 & 3,368 & 0,002 & 0,865 & 1,453 \\
\hline esftecno & 0,380 & 2,548 & 0,010 & 0,958 & 1,032 \\
\hline $\mathbf{R}^{2}$ corregido & 63,4 & \multicolumn{5}{|l|}{} \\
\hline Durbin-Watson & 2,435 &
\end{tabular}

Fuente: Elaboración propia. 
Los resultados del modelo de regresión aparecen en el cuadro 7.31, que junto con el cuadro 7.32, permiten comprobar los siguientes aspectos:

- El factor que más contribuye a explicar la variabilidad observada en los precios es la variedad cabernet sauvignon, que contribuye aproximadamente con el 31,7 \% de la varianza observada.

- La variable tecnoela 1(permanencia en autovaciantes, incorporación de frío), con el 20,3\% de la varianza observada.

- El factor esftecno que se compone de las variables esfuerzo tecnológico y la productividad del empleo (influencia negativa) que aporta más del $11 \%$ de poder explicativo.

La caracterización de los grupos de bodegas (cuadro 7.32), procede de categorizar la variable dependiente precio en terciles. El tercil 1 corresponde a las bodegas que han situado sus vinos en el segmento más bajo de precio, con una media de $1,74 € /$ botella de $3 / 4$ (premium), y el tercil 3 se corresponde con aquellas situadas en el segmento más alto de precio con una media de 4,94 €/ botella de 3/4 (ultra premium).

En cuanto a las variables de identidad corporativa, resaltar la elevada presencia relativa en las bodegas ultra premium, de las empresas jóvenes, y las no cooperativas.

En relación con los recursos tangibles se han observado diferencias estadísticamente significativas en la capacidad instalada media, que en el caso del grupo ultra premium, se corresponde con las pequeñas empresas; en este grupo la presencia en número, de pequeñas y muy pequeñas empresas es del 87,50 \%, frente al 25,00 \% en el caso de las bodegas premium.

En las variables relacionadas con la tecnología de elaboración existen diferencias apreciables, aunque no significativas estadísticamente en la sobredimensión de la capacidad instalada y tiempo de permanencia en los depósitos autovaciantes.

Referente a las variedades de uva han sido detectadas diferencias significativas estadísticamente en las variedades bobal y cabernet-sauvignon, $y$ diferencias apreciables en las variedades tempranillo, garnacha, merlot, shirac y pinor, monastrell. Estas últimas cuatro variedades, junto con la cabernet-sauvignon tienen un mayor peso en las en las bodegas ultra premium.

En cuanto a los recursos intangibles, se han observado diferencias apreciables en el esfuerzo comercial, innovador, tecnológico, por información al consumidor, a favor de las bodegas ultra premium.

Destacar diferencias apreciables en la productividad del empleo, que es menor en el caso de las bodegas ultra premium. 
CUADRO 7.32

\section{CARACTERIZACIÓN DE LOS GRUPOS DE BODEGAS QUE COMERCIALIZAN VINO RESERVA}

\begin{tabular}{|c|c|c|c|}
\hline Concepto & $\begin{array}{l}\text { Tercil 3.Grupo } \\
\text { alto precio } \\
\text { "ultra } \\
\text { premium" }\end{array}$ & $\begin{array}{c}\text { Tercil 1.Grupo } \\
\text { bajo precio } \\
\text { "premium" }\end{array}$ & $\begin{array}{l}\text { Muestra } \\
\text { "ultra } \\
\text { premium" }\end{array}$ \\
\hline \multicolumn{4}{|l|}{ Identidad corporativa } \\
\hline Jóvenes (\%) & 62,50 & 25,00 & 36,00 \\
\hline No cooperativas (\%) & 87,50 & 50,00 & 64,00 \\
\hline Control efectivo (\%) & 25,00 & 25,00 & 20,00 \\
\hline Accionistas societarios (\%) & 25,00 & 25,00 & 20,00 \\
\hline \multicolumn{4}{|l|}{ Recursos tangibles } \\
\hline Valor de la producción medio $(€)$ & $1,830.448$ & 9.590 .279 & 5.091 .108 \\
\hline Valor añadido de la empresa medio (€) & 513.714 & 2.043 .125 & 1.089 .852 \\
\hline Activo fijo medio(€) & 1.729 .140 & 4.228 .508 & 2.902 .603 \\
\hline Empleados a tiempo completo medio & 11,04 & 31,01 & 19,43 \\
\hline Capacidad instalada media (hl) (*) & 18.196 & 90.986 & 64.137 \\
\hline Pequeñas y muy pequeñas empresas (\%) & 87,50 & 25,00 & 52,00 \\
\hline Sobredimensión de la capacidad instalada (\%) & 16,62 & 4,23 & 16,68 \\
\hline Permanencia en autovaciantes & 1,77 & 0,86 & 1,29 \\
\hline Incorporación de calor (Kcal/h/hl) & 11,35 & 11,20 & 9,04 \\
\hline Incorporación de frío (Fg/h/hl) & 10,30 & 8,11 & 7,52 \\
\hline Bobal (\%) (*) & 0,72 & 23,61 & 19,80 \\
\hline Tempranillo (\%) & 18,92 & 60,37 & 54,36 \\
\hline Tintorera(\%) & 0,00 & 0,10 & 0,42 \\
\hline Garnacha (\%) & 0,13 & 12,70 & 10,38 \\
\hline Cabernet sauvignon (\%) (*) & 20,44 & 0,59 & 3,20 \\
\hline Merlot (\%) & 6,61 & 0,29 & 1,08 \\
\hline Shirac (\%) & 3,28 & 0,43 & 0,76 \\
\hline Pinor (\%) & 2,09 & 0,00 & 0,26 \\
\hline Monastrell (\%) & 47,81 & 1,91 & 9,44 \\
\hline Forcallat (\%) & 0,00 & 0,00 & 0,31 \\
\hline \multicolumn{4}{|l|}{ Recursos intangibles } \\
\hline Calidad del empleo (\%) & 96,27 & 91,10 & 93,44 \\
\hline Cualificación del empleo (\%) & 23,61 & 19,82 & 23,52 \\
\hline Productividad del empleo (€) & 4.654 .788 & $6,588.866$ & 5.607 .734 \\
\hline Esfuerzo comercial (\%) & 8,91 & 3,99 & 4,57 \\
\hline Información comercial (\%) & 3,31 & 2,97 & 2,91 \\
\hline Esfuerzo tecnológico (\%) & 13,70 & 7,98 & 9,53 \\
\hline Esfuerzo I+D+i (\%) & 0,09 & 0,03 & 0,03 \\
\hline
\end{tabular}

Fuente: Elaboración propia

(*) Con diferencias substanciales al nivel de significación del 0,05. 


\section{CUADRO 7.32 (Cont.)}

\section{CARACTERIZACIÓN DE LOS GRUPOS DE BODEGAS QUE COMERCIALIZAN VINO RESERVA}

\begin{tabular}{|c|c|c|c|}
\hline Concepto & $\begin{array}{l}\text { Tercil 3.Grupo } \\
\text { alto precio } \\
\text { "ultra premium" }\end{array}$ & $\begin{array}{l}\text { Tercil 1.Grupo } \\
\text { bajo precio } \\
\text { "premium" }\end{array}$ & $\begin{array}{c}\text { Muestra } \\
\text { "ultra } \\
\text { premium" }\end{array}$ \\
\hline \multicolumn{4}{|l|}{ Comportamiento estratégico } \\
\hline Número de presentaciones & 1,88 & 3,13 & 2,40 \\
\hline Número de marcas propias & 1,88 & 7,88 & 3,84 \\
\hline Número de marcas blancas & 0,00 & 6,25 & 3,60 \\
\hline Número de vinos varietales) & 1,25 & 1,25 & 1,08 \\
\hline Marcas propias (\%) & 100,00 & 89,55 & 88,92 \\
\hline Marcas blancas (\%) & 0,00 & 10,45 & 11,08 \\
\hline Vinos varietales (\%) & 92,90 & 27,75 & 36,60 \\
\hline Precio medio de venta $(€ / 3 / 41)(*)$ & 4,94 & 1,74 & 3,44 \\
\hline O. beneficio (\%) & 6,52 & 12,71 & 11,18 \\
\hline C. y margen (\%) & 11,98 & 14,48 & 14,21 \\
\hline I. competencia (\%) & 0,00 & 9,05 & 7,39 \\
\hline C. demanda (\%) & 2,35 & 12,66 & 13,97 \\
\hline P. bajo (\%) & 6,46 & 1,93 & 2,37 \\
\hline P. alto (\%) & 72,69 & 49,16 & 50,87 \\
\hline Integración vertical hacia atrás (\%) & 47,00 & 48,76 & 55,29 \\
\hline Integración vertical hacia adelante (\%) & 53,64 & 51,48 & 53,53 \\
\hline D. mayorista (\%) $\left(^{*}\right)$ & 74,33 & 39,84 & 46,36 \\
\hline H y supermercado (\%) & 7,31 & 40,91 & 34,50 \\
\hline Tienda (\%) & 5,04 & 1,45 & 1,81 \\
\hline Club (\%) & 0,65 & 0,05 & 0,12 \\
\hline Horeca (\%) & 9,71 & 2,42 & 10,11 \\
\hline Bodega (\%) & 11,22 & 7,30 & 7,07 \\
\hline Internet (\%) & 0,13 & 0,00 & 0,02 \\
\hline Amplitud geográfica de los mercados & 7,13 & 16,25 & 9,72 \\
\hline Dispersión de los mercados (\%) & 0,49 & 0,53 & 0,59 \\
\hline Cuota de exportación (\%)(*) & 12,69 & 65,28 & 55,36 \\
\hline C. Valenciana (\%) & 67,73 & 30,90 & 36,51 \\
\hline España (\%) & 19,57 & 3,83 & 8,13 \\
\hline U.Europea (\%) (*) & 11,85 & 61,19 & 51,50 \\
\hline T. Países (\%) & 0,84 & 4,09 & 3,86 \\
\hline \multicolumn{4}{|l|}{ Resultados } \\
\hline Valor añadido de la empresa (\%) & 28,06 & 21,30 & 21,41 \\
\hline Resultado actividades ordinarias (\%) & $-0,52$ & 9,23 & 6,58 \\
\hline
\end{tabular}

Fuente: Elaboración propia

(*) Con diferencias substanciales al nivel de significación del 0,05.

Asimismo se han detectado diferencias apreciables en la cuota de exportación, y en el número de países destino de la producción comercializada, presentando los valores menores las bodegas ultra premium, que concentran más de las dos terceras partes de su producción comercializada en los mercados regionales, en contraste con el destino 
preponderante de las bodegas de baja diferenciación en precios (premium), en las que más del 61 \% de su producción se dirige hacia la Unión Europea.

En cuanto a los recursos estratégicos se han observado diferencias apreciables, aunque no significativas estadísticamente, en el número, tanto de presentaciones como marcas propias y blancas, en el sentido de que las bodegas ultra premium presentan los valores menores. En cuanto a las marcas propias y vinos varietales en porcentaje también se han observado diferencias apreciables a favor de las bodegas ultra premium.

En lo referente a los canales de distribución, sólo han sido observadas diferencias estadísticamente significativas en el caso del distribuidor mayorista, que aparece asociada a las bodegas ultra premium. En los canales alternativos (tienda, club, horeca, bodega e Internet) prácticamente no se han observados diferencias, lo que contrasta con el resto de los tipos de vinos analizados.

En cuanto a la política de precios, las estrategias de precios altos son las predominantes, en ambos grupos de bodegas, con más del $70 \%$ en bodegas ultra premium, y cerca del $50 \%$ en las premium.

En relación con las variables de resultados, la diferenciación de las bodegas ultra premium, se ha traducido en una diferencia apreciable, de mayor valor añadido para estas bodegas en relación con las premium (28 \% frente al $21 \%$, respectivamente).

En cuanto a la variable resultados de las actividades ordinarias en \%, las bodegas ultra premium presentan valores por debajo de cero, en contraste con la cifra superior al $9 \%$ observada en las premium).

\subsection{Factores explicativos del precio del vino con DO y embotellado}

Este apartado se configura como una síntesis y recapitulación de los cinco apartados precedentes, en relación con los factores empresariales explicativos de los diferentes tipos de vinos tratados en la investigación.

Por otra parte se ha tratado de dar una explicación a los resultados obtenidos en los diferentes análisis o apartados para las distintas variables agrupadas, según los grupos de recursos que a continuación se detallan:

\section{a) Recursos relacionados con la identidad corporativa.}

En cuanto a las variables de identidad corporativa, resaltar la elevada presencia en las bodegas de altos precios respecto a las de bajos precios, de las empresas jóvenes, no cooperativas, y con un control efectivo sobre el capital social, en todos los tipos de vinos excepto en el reserva. En cuanto a la naturaleza jurídica de los accionistas principales, y en lo que respecta a los vinos blancos, rosados y tintos, en el grupo de bodegas de elevada diferenciación por precios, la presencia de los accionistas societarios es más elevada respecto a las de baja diferenciación por precios. 
La evidencia empírica vuelve a apoyar la teoría "evolucionista lamarkista", sobre la cual las bodegas jóvenes que se configuran sobre la base de nuevos recursos productivos y capacidades que les permitan explotar los segmentos de mercado demandantes de vinos de mayor valor comercial. Destacar que en el vino blanco, la antigüedad ha resultado ser la segunda variable con mayor poder explicativo de la diferenciación de precios.

La naturaleza del accionista principal y el grado de control de éste sobre el capital social también refuerzan otras evidencias empíricas puestas de manifiesto por otros autores (Galve y Salas, 1993), en el sentido de que un control mayoritario en el grupo familiar o un control difuso con bajo número de accionistas favorece la agilidad en la toma de decisiones estratégicas, como lo es la de posicionarse sin dilación en los segmentos de mercados que generan un mayor valor añadido. Posicionarse los primeros en el tiempo, y en primer lugar, en este segmento de precios es importante, ya que es difícil dar saltos posteriores de precios cuando se tienen los vinos posicionados en segmentos de precios más bajos (Albisu, 2003).

\section{b) Recursos tangibles}

En relación con los recursos tangibles se han observado diferencias estadísticamente significativas en la capacidad instalada media, en ambos grupos de empresas y para todos los tipos de vinos estudiados, en el sentido de que la presencia en número, de pequeñas y muy pequeñas empresas es mayor en el grupo de alta diferenciación de precios.

La comercialización de los vinos exige una gran agilidad, ya que los mercados cambian con rapidez, lo que implica una gran versatilidad de las estructuras de elaboración, conservación, envejecimiento y comercialización. Las empresas de pequeña dimensión poseen una mayor versatilidad y capacidad de adaptación a las nuevas exigencias de los mercados, en relación con las de mayor dimensión, lo cual podría explicar su capacidad para satisfacer a esos segmentos de mercado que va asociado a las producciones de alto valor comercial.

Referente a las variedades de uva en el caso del vino blanco han sido detectadas diferencias significativas estadísticamente en las variedades chardonay (responsable del 42,8 \% de la variabilidad de los precios) y merseguera, asociadas ambas respectivamente a las bodegas de alta y baja diferenciación de precios. También se han observado diferencias apreciables en el caso de la variedad moscatel asociada con las bodegas de altos precios.

Asimismo han sido observadas diferencias significativas estadísticamente en el caso de la variedad cabernet-sauvignon (responsable del $16 \%$ de la varianza en los crianzas y del $31,7 \%$ en los reservas), asociada a los bodegas del segmento alto de precios.

En el vinos tintos, la variedad merlot ejerce un poder explicativo próximo al 19,1 \% de la variabilidad de los precios, asociada a las bodegas de alta diferenciación de precios. 
Otras variedades tintas que aparecen ligadas a los precios altos son la monastrell, tempranillo, shirac y pinor, a pesar de que no hayan sido incluidas en los modelos de regresión. Por el contrario las variedades tintas relacionadas con el segmento de precios bajos son la bobal, tintorera y garnacha.

El aumento valor comercial de un vino, la calidad del mismo o una diferenciación al alza del precio, no es posible conseguirla si no se parte de una buena materia prima o variedad de uva. En este sentido, destacar la influencia relevante en la diferenciación al alza de precios, por un lado, de muchas de las variedades autóctonas recomendadas (macabeo, tempranillo, monastrell); por otro lado, de las variedades mejorantes foráneas, que han sido adaptadas y cultivadas en la región, tanto en los vinos blancos (chardonay) como en los tintos (merlot, shirac, cabernet sauvignon).

En cuanto a las variables relacionadas con la tecnología de elaboración, en el ámbito de los vinos blancos y rosados, apenas existen diferencias entre ambos grupos de bodegas, lo que conduce a pensar que es probable que se haya alcanzado un cierto techo tecnológico en la elaboración de estos vinos, principalmente en las variables relacionadas con permanencia en los depósitos de fermentación controlada (ya que es mayor en el grupo de baja diferenciación de precios), y menos en cuanto a la incorporación de frío, último aspecto que se supera sensiblemente en las bodegas de altos precios.

En los vinos tintos, crianzas y reservas, y en lo que respecta a las variables incorporación de frío, calor, permanencia en autovaciantes, y consecuentemente sobredimensión de la capacidad instalada, se han observado diferencias apreciables entre ambos grupos de bodegas, presentando los mayores valores las bodegas de alta diferenciación de precios. Estas variables tienen un poder explicativo medio de los precios de los vinos: del 17,9 \% en tintos, del 24,6 \% en crianza y, del 20,3 \% en reserva.

\section{c) Recursos intangibles}

En cuanto a las variables de esfuerzo comercial y de información al consumidor han aparecido diferencias estadísticamente significativas en los vinos tintos y de crianza, y apreciables en los vinos blancos y reservas, de manera que el esfuerzo comunicativo ha contribuido a una percepción por el consumidor y en consecuencia a una diferenciación al alza del precio del producto. Únicamente en el caso del vino rosado este esfuerzo comunicativo no se ha traducido en una mayor diferenciación de precios.

En el esfuerzo tecnológico o inversor se han detectado diferencias estadísticamente significativas entre ambos grupos de bodegas en el vino tinto, en que esta variable junto con el esfuerzo innovador contribuye a explicar en un 25,6 \% la varianza en los precios. En los vinos crianza y reserva también se han detectado diferencias apreciables en estas variables, en los dos grupos de bodegas y ejercen un poder explicativo de los precios del 20,4\% y 11,4\% respectivamente. 
En el esfuerzo innovador, se han detectado diferencias apreciables aunque no estadísticamente significativas entre ambos grupos de bodegas en todos los tipos de vinos.

En cuanto a la cualificación y calidad del empleo no se observan diferencias apreciables entre ambos grupos de bodegas en todos los tipos de vinos, ni tampoco han presentado ningún poder explicativo sobre la diferenciación de precios en los modelos de regresión múltiple aplicados, por lo que es posible que estas variables ejerzan una influencia muy indirecta y limitada en la diferenciación de precios.

En cuanto a la productividad del empleo se observan diferencias apreciables, aunque no significativas estadísticamente entre ambos grupos de bodegas en todos los tipos de vinos, apareciendo las menores productividades asociadas con el grupo de elevada diferenciación de precios, excepto en el vino blanco. Esta pauta podría estar relacionada con los procesos de elaboración, conservación y envejecimiento más artesanales en el caso de las bodegas de alta diferenciación de precios.

\section{d) Comportamiento estratégico}

En el número de presentaciones se han observado diferencias significativas estadísticamente en los vinos rosados y tinto, y diferencias apreciables en el resto, en la dirección de un menor números de éstas en los vinos de alta diferenciación de precios. Destacar que en el vino rosado esta variable ha resultado ser la cuarta variable en capacidad discriminante sobre la base de la diferenciación de precios.

En el número de marcas propias y marcas blancas, se han observado diferencias significativas estadísticamente en los vinos blancos (en relación con las propias), y diferencias apreciables en el resto, en la dirección de un menor número de ambas marcas en los vinos de alta diferenciación de precios.

Las bodegas de alta diferenciación de precios concurren en el mercado con un menor número de marcas y de presentaciones, lo cual contribuye a fijar más la atención y el recuerdo del consumidor sobre estas pocas marcas determinadas.

En el porcentaje de marcas propias, y marcas blancas se han observado diferencias apreciables en la mayoría de los vinos, en la dirección de un valor más alto y más bajo respectivamente en las bodegas de alta diferenciación de precios. Destacar que en el vino rosado el porcentaje de marcas propias ha resultado ser la tercera variable en capacidad discriminante sobre la base de la diferenciación de precios.

De este comportamiento se desprende la importancia del intangible imagen de la marca propia en la calidad percibida por el consumidor y en definitiva en el segmento de precios en que pueden posicionarse los vinos.

En el número de vinos varietales, se han observado diferencias apreciables en la mayoría de los vinos, en la dirección de un mayor número de éstos en las bodegas de alta diferenciación de precios. 
En relación con el porcentaje de vinos varietales se han detectado diferencias estadísticamente significativas en los vinos blancos y rosados y apreciables en el resto, en el sentido de un valor más alto en las bodegas de alta diferenciación de precios. Destacar que en el vino rosado esta variable ha resultado ser la segunda en capacidad discriminante sobre la base de la diferenciación de precios.

Parece ser que existe un segmento de mercado integrado por gente conocedora de la cultura del vino y prescriptores, capaces de crear opinión positiva en cuanto a los vinos varietales que aumentan la demanda en el segmento alto de precios.

En la integración vertical hacia atrás, existen diferencias apreciables, en el sentido que es menor en las bodegas de altos precios en todos los tipos de vinos, (excepto en la rosado), por lo que las bodegas que tienen una baja diferenciación de precios centran su actividad productiva en mayor medida en las fases iniciales del proceso productivo, que son las actividades de menor valor añadido.

En la integración vertical hacia adelante, no existen diferencias apreciables, a pesar de que se hayan detectado mayores valores en las bodegas de altos precios (para todos los tipos de vinos), por lo que las bodegas que tienen una alta diferenciación de precios centran su actividad productiva en mayor medida en las fases finales del proceso productivo, que son las actividades capaces de generar mayor valor añadido.

En lo referente a los canales de distribución, en las bodegas posicionadas en el segmento de altos precios, en la mayoría de los tipos de vinos la presencia de los canales alternativos (tienda, club, horeca, bodega e Internet) se cuadruplica respecto de las bodegas de bajos precios, por lo que se confirma la potencialidad de estos canales minoritarios y alternativos de incorporar un mayor valor añadido a los productos que se comercializan a través de ellos. Añadir, que en el caso del vino blanco la variable horeca (hostelería, restauración y catering), ejerce un poder explicativo de cerca del $14,9 \%$ de la variabilidad de precios.

En la cuota de exportación, han sido detectadas diferencias estadísticamente significativas en el caso del vino reserva, y diferencias apreciables en el resto de los vinos, excepto en el vino tinto, en el sentido de que las bodegas de altos precios exhiben los menores valores. Paralelamente en lo que respecta a la dispersión de los mercados, han sido detectadas diferencias apreciables en todos los vinos (excepto en el vino tinto), en la dirección de que las bodegas de altos precios exhiben los menores valores.

Las bodegas de altos precios se encuentran concentradas mayoritariamente en el mercado regional, en contraste con las de bajos precios que se han posicionado en el europeo. Parece existir una cierta memoria gustativa (Albisu, 2003) entre los consumidores de vino regionales que están dispuestos a pagar por el vino regional un mayor precio, que por ejemplo los consumidores de otros países.

En cuanto a la estrategia de fijación de precios, se ha visto que es congruente con los precios a la salida de la bodega, en el sentido de que para las bodegas posicionadas en el segmento alto de precios, las estrategias de precios altos y coste más margen comercial son las predominantes, en contraste empresas situadas en el segmento 
bajo de precio, en las que domina, las condiciones de la demanda. Las bodegas posicionadas en la gama alta de precios intentan conseguir una imagen de marca o de prestigio para el producto elevando su precio, si bien dicha elevación ha de acompañarse de un aumento más que proporcional de la calidad, si se pretende crear un aumento de valor sostenido del vino para el consumidor.

\section{e) Resultados}

Las bodegas ubicadas en el segmento de precio alto, la mayor diferenciación de precios se ha traducido lógicamente, en mayor valor añadido para estas bodegas, en contraste con las bodegas de precio bajo, habiéndose detectado diferencias apreciables en todos los tipos de vinos (excepto en el tinto).

En el resultado de las actividades ordinarias, en porcentaje sobre el valor de la producción comercializada, han sido observadas diferencias apreciables en todos los tipos de vinos (excepto en el blanco), en la dirección de que las bodegas que presentan los valores más bajos son las de elevada diferenciación por precios. La explicación a esta pauta, aparentemente contradictoria, podría estar relacionada con alguno de los siguientes razonamientos:

- Las economías de escala que se dan en las grandes y muy grandes empresas, las cuales participan en más de las dos terceras partes de las bodegas de bajos precios, es posible que tengan una mayor repercusión (vía menores costes) en los resultados de las actividades ordinarias.

- El mayor esfuerzo inversor o tecnológico e innovador de las bodegas del segmento de alto precio, (que precisa en muchos casos recursos ajenos), está lastrando los resultados de este grupo de bodegas a través de los intereses que han de pagar por la financiación ajena. Por otro lado, ese impulso inversor es probable que exija una elevadas dotaciones para amortizaciones de inmovilizado material, que reducen los resultados de estas bodegas.

- Por ultimo, incidir en que más del 45 \% de las bodegas del grupo de alto precio, son jóvenes, muchas de las cuales no han tenido tiempo material de completar todo un ciclo de negocio, con la inclusión del proceso completo de transformación de los productos con mayor periodo de maduración (varios años en el caso de los vinos crianzas, reservas y grandes reservas) y, por tanto no han podido consolidar su cuenta de resultados.

Como síntesis de este apartado, para el conjunto de los cinco tipos de vinos con DO embotellados (a excepción del vino rosado) y, fundamentalmente a través de los modelos de regresión lineal múltiple, se ha puesto de manifiesto una relación causal significativa entre las siguientes variables y el valor comercial de los vinos:

- $\quad$ La variedad, con una aportación estimada del 27,4% del precio del vino. 
- La tecnología de vinificación, fundamentalmente en lo que respecta a la incorporación de calor, frío y permanencia en los autovaciantes, que contribuye con un 21,8 \% al valor comercial del mismo.

- El esfuerzo tecnológico o inversor contribuye con el 7,9 \% a la variabilidad de los precios. Esta variable recoge mayoritariamente inversiones en bienes, equipos, instalaciones y tecnología de vinificación que ha sido implantadas en las instalaciones de las bodegas en los últimos tres años.

\section{APORTACIÓN DE LOS FACTORES EMPRESARIALES AL PRECIO DEL VINO A GRANEL}

De acuerdo con la importancia en volumen comercializado del vino a granel, se ha considerado de interés realizar el mismo tipo de análisis que los efectuados en los vinos con DO embotellados.

La caracterización de los grupos de bodegas (cuadro 7.33), al igual que se ha procedido en los análisis anteriores, procede de categorizar la variable dependiente precio en terciles. El tercil 1 corresponde a las bodegas que han situado sus vinos en el segmento más bajo de precio, con una media de 0,25 €/l (bajos precios), y el tercil 3 se corresponde con aquellas situadas en el segmento más alto de precio con una media de $0,36 € / l$ (altos precios).

Tanto el análisis de regresión lineal múltiple como el discriminante no han incluido ninguna variable que permita o bien establecer una relación causal entre las variables independientes y el precio del vino, o seleccionar variables que permitan discriminar entre las bodegas de altos y bajos precios. Es posible que la razón por la cual los análisis multivariantes no hayan proporcionado ninguna variable explicativa, radique en la insuficiente diferencia de precios entre ambos grupos de bodegas, a pesar de que el análisis de la varianza, haya establecido la existencia de diferencias significativas estadísticamente, en cuanto a la variables precio en ambos grupos de bodegas. En este sentido en ninguno de dichos grupos de empresas, el precio a la salida de la bodega supera la gama "basic".

No obstante, de la lectura del cuadro 7.33 pueden destacarse los siguientes aspectos:

a) Mayor presencia de las cooperativas y mayor dimensión de la capacidad instalada media (correspondiente a la mediana empresa) en las bodegas de altos precios, en contraste con el mayor porcentaje de mercantiles y una menor dimensión media (coincidente con la pequeña empresa), que se ha observado en las bodegas de bajo precio. Este comportamiento viene a explicar que las bodegas cooperativas granelistas consigan mejores precios en los graneles que las mercantiles, ya que las formas asociativas debido a su dimensión consiguen, por una parte una mayor homogeinización de los vinos, de otra aumentar la capacidad para negociar el precio del vino dentro de un pequeño margen. Estos aspectos podrían ser algunos de los principales motivos impulsores del cooperativismo de $1^{\circ}$ grado en el sector. 
CUADRO 7.33

CARACTERIZACIÓN DE LOS GRUPOS DE BODEGAS QUE COMERCIALIZAN VINO A GRANEL

\begin{tabular}{|c|c|c|c|}
\hline Concepto & $\begin{array}{l}\text { Tercil 3.Grupo } \\
\text { alto precio } \\
\text { "basic" }\end{array}$ & $\begin{array}{l}\text { Tercil 1.Grupo } \\
\text { bajo precio } \\
\text { "basic" }\end{array}$ & $\begin{array}{c}\text { Muestra } \\
\text { "basic" }\end{array}$ \\
\hline \multicolumn{4}{|l|}{ Identidad corporativa } \\
\hline Jóvenes (\%) & 11,76 & 11,76 & 21,05 \\
\hline No cooperativas (\%) & 29,41 & 41,18 & 31,58 \\
\hline Control efectivo (\%) & 23,53 & 17,65 & 15,79 \\
\hline Accionistas societarios (\%) & 0,00 & 5,90 & 3,51 \\
\hline \multicolumn{4}{|l|}{ Recursos tangibles } \\
\hline Valor de la producción medio $(€)$ & 1.469 .157 & 781.628 & 1.133 .628 \\
\hline Valor añadido de la empresa medio $(€)(*)$ & 123.101 & 49.880 & 90.573 \\
\hline Activo fijo medio(€)(*) & 672.429 & 495.689 & 598.640 \\
\hline Empleados a tiempo completo medio & 3,18 & 2,94 & 2,91 \\
\hline Capacidad instalada media (hl) $\left(^{*}\right)$ & 33.040 & 26.764 & 37.291 \\
\hline Pequeñas y muy pequeñas empresas (\%) & 47,06 & 64,71 & 56,14 \\
\hline Sobredimensión de la capacidad instalada (\%) & 39,76 & 48,24 & 40,42 \\
\hline Permanencia en autovaciantes & 0,21 & 0,28 & 0,25 \\
\hline Permanencia en fermentación controlada & 0,44 & 1,34 & 0,66 \\
\hline Incorporación de calor $(\mathrm{Kcal} / \mathrm{h} / \mathrm{hl})$ & 10,70 & 2,98 & 5,22 \\
\hline Incorporación de frío (Fg/h/hl) & 8,94 & 10,24 & 7,00 \\
\hline Macabeo (\%) & 4,40 & 0,00 & 2,69 \\
\hline Moscatel (\%) & 8,60 & 0,68 & 3,02 \\
\hline Merseguera (\%) & 0,04 & 1,12 & 0,35 \\
\hline Malvasia (\%) & 0,24 & 3,27 & 0,90 \\
\hline Airen (\%) & 0,84 & 0,00 & 0,27 \\
\hline Planta Nova (\%) & 4,43 & 4,65 & 2,94 \\
\hline Tortosí (\%) & 0,48 & 2,32 & 0,72 \\
\hline Bobal (\%) & 37,05 & 48,89 & 56,79 \\
\hline Tempranillo (\%) & 11,79 & 6,09 & 8,80 \\
\hline Tintorera (\%) & 9,18 & 13,31 & 10,40 \\
\hline Garnacha (\%) & 1,48 & 5,60 & 2,13 \\
\hline Cabernet sauvignon (\%) & 0,00 & 0,12 & 0,13 \\
\hline Merlot (\%) & 0,86 & 2,30 & 0,97 \\
\hline Shirac(\%) & 0,00 & 0,00 & 0,02 \\
\hline Monastrell (\%) & 19,39 & 11,33 & 9,32 \\
\hline Forcallat (\%) & 0,00 & 0,27 & 0,06 \\
\hline Bonicaire (\%) & 0,00 & 0,05 & 0,01 \\
\hline Royal( \%) & 1,20 & 0,00 & 0,48 \\
\hline
\end{tabular}

Fuente: Elaboración propia

(*) Con diferencias substanciales al nivel de significación del 0,05. 


\section{CUADRO 7.33 (Cont.)}

CARACTERIZACIÓN DE LOS GRUPOS DE BODEGAS QUE COMERCIALIZAN VINO A GRANEL

\begin{tabular}{|l|c|c|c|}
\hline \multicolumn{1}{|c|}{ Concepto } & $\begin{array}{c}\text { Tercil 3.Grupo } \\
\text { alto precio } \\
\text { "basic" }\end{array}$ & $\begin{array}{c}\text { Tercil 1.Grupo } \\
\text { bajo precio } \\
\text { "basic" }\end{array}$ & $\begin{array}{c}\text { Muestra } \\
\text { "basic" }\end{array}$ \\
\hline Recursos intangibles & & & \\
\hline Calidad del empleo (\%) & 71,00 & 72,37 & 64,45 \\
\hline Cualificación del empleo (\%) & 34,13 & 27,80 & 25,42 \\
\hline Productividad del empleo (€)(*) & 21.849 & 12.523 & 25.097 \\
\hline Esfuerzo comercial (\%) & 0,01 & 0,39 & 0,00 \\
\hline Información comercial (\%) & 0,00 & 0,00 & 0,00 \\
\hline Esfuerzo tecnológico (\%) & 30,72 & 33,12 & 16,48 \\
\hline Esfuerzo I+D+i (\%) & 1,44 & 0,00 & 0,53 \\
\hline Comportamiento estratégico & & & \\
\hline Precio medio de venta (€/l) (*) & $\mathbf{0 , 3 6}$ & $\mathbf{0 , 2 5}$ & $\mathbf{0 , 3 1}$ \\
\hline O. beneficio (\%) & 3,61 & 2,98 & 1,89 \\
\hline C. y margen (\%) & 0,00 & 8,52 & 2,53 \\
\hline I. competencia (\%) & 2,54 & 2,98 & 1,54 \\
\hline C. demanda (*) & 93,85 & 84,65 & 93,83 \\
\hline P. bajo (\%) & 0,00 & 0,46 & 0,11 \\
\hline P. alto (\%) & 0,00 & 0,42 & 0,10 \\
\hline Integración vertical hacia atrás (\%) & 97,61 & 96,40 & 97,76 \\
\hline Integración vertical hacia adelante (\%) & 0,00 & 0,00 & 0,00 \\
\hline Amplitud geográfica de los mercados & 0,00 & 0,09 & 0,11 \\
\hline Dispersión de los mercados (\%) & 0,49 & 0,58 & 0,54 \\
\hline Cuota de exportación (\%) & 7,57 & 8,97 & 6,79 \\
\hline C. Valenciana (\%) & 65,69 & 47,63 & 56,37 \\
\hline España (\%) & 26,74 & 43,40 & 36,84 \\
\hline U.Europea (\%) & 7,57 & 8,97 & 6,79 \\
\hline T. Países (\%) & 0,00 & 0,00 & 0,00 \\
\hline Resultados & & & \\
\hline Valor añadido de la empresa (\%) & 8,38 & 6,38 & 7,99 \\
\hline Resultado actividades ordinarias (\%) & 0,07 & $-1,61$ & $-0,40$ \\
\hline Fuent E (\%boraton propia & & \\
\hline
\end{tabular}

Fuente: Elaboración propia

(*) Con diferencias significativas al nivel de significación del 0,05.

b) En las bodegas de alto precio aparece un mayor porcentaje de las variedades autóctonas recomendadas (macabeo, moscatel, tempranillo y monastrell) y un menor porcentaje de las variedades alóctonas recomendadas (cabernet sauvignon, merlot y Shirac), por lo que la introducción de estas últimas variedades mejorantes no se traduce en una diferenciación positiva de precios cuando el vino se comercializa a granel. Esta razón constituye el principal argumento de la reticencia observada en los viticultores socios de cooperativas granelistas, a la introducción de éstas variedades foráneas, generalmente de menor rendimiento que las autóctonas.

c) Sorprende la existencia de una relación negativa entre la mayor parte de las variables relacionadas con la tecnología de elaboración (excepto la incorporación de 
calor) y los recursos intangibles (a excepción de la productividad del empleo) y las precios alcanzados en los graneles. En este sentido el valor añadido que supone una adecuada tecnología de elaboración del vino no se incorpora al vino cuando éste es comercializado a granel; ello explicaría la paradoja consistente en que algunas bodegas adecuadamente equipadas con instalaciones de elaboración, no las utilicen, ya que su uso implica costes variables que no son recuperados vía mayores precios de los vinos elaborados. En este tipo de comercialización la variable que más influencia positiva ejerce sobre el precio del vino, es su grado alcohólico.

d) En las bodegas de alto precio, la mayor dimensión se traduce vía ecomomías de escala, en una productividad del empleo que casi duplica la que presentan las bodegas de bajo precio.

\section{APRECIACIÓN POR LOS DIRECTIVOS DE LAS EMPRESAS DE LA CONTRIBUCIÓN DE LOS FACTORES EMPRESARIALES AL PRECIO DEL VINO}

Este apartado se han analizado las valoraciones de los directivos de las bodegas regionales, a los distintos factores que determinan el valor comercial de los vinos, con la finalidad de contrastar los resultados objetivos de la investigación empírica, con las apreciaciones subjetivas del personal directivo de las bodegas, que responden siempre a una realidad percibida del sector elaborador de vinos.

Estas comparaciones permitirán reflexionar a los responsables de las bodegas, con el objetivo de acercar esos puntos de vista subjetivos a la realidad objetiva y, fundamentada en los factores empresariales como factores determinantes de la diferenciación de precios.

En el cuadro 7.34, aparecen tanto las frecuencias absolutas, el valor medio y la desviación típica de las valoraciones efectuadas por las empresas para cada uno de los 10 factores propuestos. La escala de valoración utilizada tiene 5 categorías distribuidas de la siguiente manera:

1: Muy baja importancia.

2: Baja importancia.

3: Media importancia.

4: Alta importancia.

5: Muy alta importancia.

En el mismo cuadro se reflejan las valoraciones jerarquizadas para los distintos factores analizados, en función del porcentaje agregado de respuestas que respondieron al mismo como "muy alta importancia” y "alta importancia”, es decir que contestaron con las puntuaciones 5 ó 4 respectivamente de la escala utilizada. 
CUADRO 7.34

FRECUENCIAS DE LAS VALORACIONE CONCEDIDAS POR LOS DIRECTIVOS DE LAS BODEGAS

\begin{tabular}{|c|c|c|c|c|c|c|c|c|c|c|}
\hline & \multicolumn{8}{|c|}{ VALORACIÓN } & \multirow[b]{2}{*}{ Media } & \multirow[b]{2}{*}{$\begin{array}{c}\text { Desviación } \\
\text { Típica }\end{array}$} \\
\hline & 1 & 2 & 3 & 4 & 5 & $4+5$ & Total & $\begin{array}{c}\% \\
(4+5) / \text { Total }\end{array}$ & & \\
\hline FACTORES & \multicolumn{8}{|c|}{ NUMERO DE RESPUESTAS } & & \\
\hline Marca de empresa & 8 & 6 & 15 & 43 & 34 & 77 & 106 & 72,6 & 3,84 & 1,164 \\
\hline Canal comercial & 6 & 5 & 18 & 50 & 27 & 77 & 106 & 72,6 & 3,82 & 1,049 \\
\hline Método vinificación & 6 & 5 & 19 & 40 & 36 & 76 & 106 & 71,7 & 3,90 & 1,103 \\
\hline Variedad & 5 & 10 & 31 & 37 & 23 & 60 & 106 & 56,6 & 3,59 & 1,076 \\
\hline Vinos varietales & 7 & 16 & 28 & 44 & 11 & 55 & 106 & 51,9 & 3,34 & 1,068 \\
\hline Gasto comercial & 9 & 12 & 40 & 31 & 14 & 45 & 106 & 42,4 & 3,27 & 1,100 \\
\hline Mercados meta & 7 & 22 & 41 & 26 & 10 & 36 & 106 & 34,0 & 3,09 & 1,047 \\
\hline Marca colectiva & 17 & 26 & 27 & 22 & 14 & 36 & 106 & 34,0 & 2,91 & 1,276 \\
\hline Fijación precios & 16 & 16 & 40 & 20 & 14 & 34 & 106 & 32,1 & 3,00 & 1,219 \\
\hline Presentaciones & 23 & 19 & 36 & 19 & 9 & 28 & 106 & 26,4 & 2,74 & 1,229 \\
\hline TOTAL & 104 & 137 & 295 & 332 & 192 & 524 & 1060 & & & \\
\hline
\end{tabular}

Fuente: Elaboración propia

De la inspección de la ordenación de la citada tabla, se desprende que los cuatro factores más valorados por los directivos de las bodegas de toda la muestra, por orden de importancia son los siguientes:

- La marca de empresa.

- El canal de comercialización.

- El método de vinificación.

- La variedad de la uva.

Las puntuaciones agregadas de 4 y 5 , dadas a los cuatro factores citados anteriormente, suponen respectivamente el 72,6 \%, el 72,6 \%, el 71,7 \%, y el 56,6 \% del conjunto total de las puntuaciones. Estos factores por lo general presentan las menores dispersiones, por lo que existe un grado de acuerdo aceptable en la respuesta de los directivos.

Sorprende que los factores más valorados por los directivos de las bodegas posicionadas, tanto en el segmento alto de precios como en el bajo sean coincidentes, tanto en los factores en sí, como en el orden de prelación entre los mismos, y que por orden de importancia son:

- $\quad$ El método de vinificación.

- El canal de comercialización.

- La marca de empresa.

- La variedad de la uva. 
Por el contrario los tres factores menos valorados, tanto en las bodegas de altos precios, bajos precios y la muestra total son:

- El número de presentaciones.

- El criterio de fijación de precios.

- La marca colectiva.

- Los mercados meta.

Las puntuaciones en dichos factores no alcanzan el umbral del aprobado (50 \% de las puntuaciones agregadas de 4 y 5 . Referente a la dispersión de los valores, estos factores en general aparecen con las mayores desviaciones, por lo que los resultados deben ser tomados con cautela, debido a la gran dispersión o grado de desacuerdo obtenido en las respuestas.

Efectuando una comparativa entre los resultados obtenidos mediante el estudio empírico y la apreciación de los gerentes de las bodegas de toda la muestra, en cuanto a los factores determinantes de la diferenciación por precios, puede hablarse de concordancia entre la opinión de dichos los gerentes y la realidad analizada, si bien con las siguientes matizaciones:

- La variedad y el método de vinificación han sido infravalorados por los directivos, ya que aparecen en el cuarto y tercer puesto respectivamente, mientras la evidencia empírica los sitúa en el primero y segundo lugar respectivamente.

- La buena valoración que establecen a la marca de empresa no puede rebatirse desde la evidencia empírica presente, ya que los únicos indicadores con los que se ha trabajado en relación con este concepto son: el número y porcentaje de marcas propias, insuficientes para recoger el concepto de imagen de marca. Existe una señal ineludible de que la imagen de marca es muy importante en cuanto a la diferenciación de precios y, radica en que la diferencia de precios puede llegar a triplicarse dentro de un mismo grupo de empresas, circunstancia que ha sido constatada, tanto en las bodegas situadas en el segmento de precios alto como en el bajo.

- Es posible que el canal comercial se encuentre sobrevalorado por los responsables de las bodegas, ya que la evidencia empírica, sólo ha encontrado una relación causal en el caso del vino blanco, y para el canal horeca, pero con una capacidad explicativa baja (menos del $15 \%$ de la varianza total explicada). No obstante existe una constatación empírica de su importancia, que radica en que, en la mayor parte de los vinos analizados, la presencia de los canales alternativos o minoritarios en las bodegas del segmento alto de precios, puede triplicar los valores observados en las del segmento bajo.

- Se ha constatado una infravaloración del número de presentaciones, ya que la apreciación de los responsables la sitúan en el último puesto, cuando la evidencia empírica ha demostrado en el caso del vino rosado, que las 
variables que hacen referencia en número a las presentaciones, marcas propias y vinos varietales, han resultado (aunque en último lugar) tener una capacidad discriminante negativa, en cuanto a la diferenciación por precios. Por otro lado, en todos los tipos de vinos analizados, el menor número de presentaciones se encuentra asociado a las empresas pertenecientes al segmento alto de precios.

- La estrategia de fijación de precios al alza también aparece infravalorada, en el sentido de que mediante esta estrategia las bodegas pueden conseguir una imagen de marca o de prestigio, siempre y cuando la elevación del precio vaya acompañada de una elevación más que proporcional de la calidad.

- El antepenúltimo lugar adjudicado por los gerentes de las bodegas a la marca colectiva en su conjunto, pone de manifiesto, la percepción actual del subsector elaborador de vinos respecto de éstas figuras de calidad en su conjunto, en el sentido de su escasa contribución al valor añadido del producto. Esta valoración parece justa, si se tiene en cuenta que la DO en vinos a granel aporta solo un $9 \%$ respecto del precio del vino de mesa a granel y un $29 \%$ respecto del precio del vino de mesa embotellado, con diferencia apreciables en este último caso, que van desde el $85 \%$ en la DO Alicante al $3 \%$ en el caso de la DO Utiel-Requena, para los vinos blancos, rosados y tintos jóvenes. En realidad se tratan de DDOO poco valorizadas en su conjunto.

La valorización de las DDOO regionales implica, que la calidad intrínseca del producto (sensorial más organoléptica), que es responsabilidad de las bodegas, sea controlada y garantizada por los correspondientes Consejos Reguladores, los cuales han de aportar la información necesaria sobre el origen, lo que facilita la apreciación e identificación de la calidad percibida por parte de los consumidores. La evidencia empírica ha constatado que alguno de los dos aspectos arriba indicados esta fallando, en la consecución de DDOO consolidadas y eficaces.

- Por último destacar una cierta infravaloración por los gerentes de los mercados meta, si se tiene en cuenta que los vinos de gama alta se distribuyen mayoritariamente en los mercados regionales. Esta señal es la que está enviando el mercado a las bodegas y, que se ha puesto de manifiesto a través de la investigación. En consecuencia las bodegas deberían cuidar estos mercados de radio corto con el fin de hacerlos sostenibles en el tiempo. 

CAPÍTULO VIII

CONCLUSIONES Y VALORACIÓN FINAL 



\section{CONCLUSIONES}

Las conclusiones más relevantes que pueden deducirse del trabajo de investigación en su planteamiento conceptual y a la vista de los resultados derivados de su aplicación empírica, se resumen en las siguientes consideraciones:

1. El análisis descriptivo realizado sobre las diversas variables y dimensiones que caracterizan a un subsector vitivinícola en la Comunidad Valenciana, permiten afirmar que se trata de un sector con las siguientes características:

a) Las características estructurales de este sector, deducidas del modelo de las cinco fuerzas de Porter, sitúan a las bodegas en un ambiente de alta rivalidad competitiva entre éstas mismas, potenciada por un importante y creciente poder de negociación de los clientes, por una notable posibilidad real de incorporación de oferta o nuevos competidores, y asimismo por una significativa presión de los presión de los productos sustitutivos, en contraposición con un reducido poder de negociación de los viticultores o proveedores.

b) La situación competitiva derivada del modelo dafo, permiten calificar al subsector como de baja competitividad.

b) Los determinantes de la dinámica estructural, resultantes del modelo del diamante de Porter, han venido a explicar la razón por la cual una alta rivalidad competitiva no ha propiciado dentro subsector a una competitividad alta, ya que la aportación de las seis aristas a la buena configuración del diamante de la competitividad es reducida, principalmente en los aspectos relacionados con las condiciones de los factores, de la demanda, sectores conexos y auxiliares y políticas vitivinícolas.

2. El estudio de los precios alcanzados por las bodegas que han constituido la muestra representativa utilizada, permite justificar la realización de esta investigación fundamentada en la hipótesis de que las condiciones del entorno genérico y específico no expliquen completamente la estrategia de diferenciación de precios llevadas a cabo por las empresas. El hecho de que los precios manifiestan una alta variabilidad indica la necesidad de contemplar otro tipo de factores diferentes de los contextuales, y por lo tanto con un carácter intraempresarial, como posibles factores explicativos de las diferencias existentes.

Los factores empresariales que han sido considerados como potenciales variables explicativas de la diferenciación de precios, manifiestan también una alta variabilidad entre las bodegas incluidas en la muestra, lo que viene a mostrar la diversidad de las unidades empresariales que conforman el subsector analizado, a pesar de tratarse de una actividad productiva fuertemente regulada, tanto en lo que respecta a la producción de uva, como a la elaboración del vino. Las diferencias observadas avalan la hipótesis de heterogeneidad en la dotación de recursos entre las empresas, condición necesaria desde la lógica de la Teoría de Recursos y Capacidades, para pensar en los factores empresariales como razón justificativa de la diversidad de estrategias de diferenciación de precios. 
3. El efecto Denominación de Origen (DO) en vinos a granel se ha cuantificado en el $9 \%$ respecto del precio del vino de mesa a granel. El efecto DO en vinos embotellados ha sido cuantificado en un $29 \%$, respecto del precio del vino de mesa embotellado. La DO Alicante aparece como la más valorizada con el $85 \%$, seguida de la DO Valencia con el 52 \% y la de Utiel-Requena con el 3 \%, respecto del precio del vino de mesa embotellado, en los tres casos.

4. La técnica de análisis de regresión lineal múltiple ha permitido identificar relaciones causales existentes entre el conjunto de factores empresariales y los precios alcanzados por las bodegas se han llevado a cabo. La técnica análisis discriminante ha posibilitado identificar las características que diferencian o discriminan a los dos grupos de empresas, (las que obtienen los mayores y menores precios respectivamente) y crear una función estadística capaz de informar sobre las variables independientes que mejor permiten diferenciar entre ambos grupos. El análisis de la varianza, aplicado a los valores medios de las variables que no han sido recogidas en las dos técnicas analíticas anteriores, ha hecho posible establecer diferencias significativas estadísticamente entre las variables empresariales en los dos grupos de bodegas definidos anteriormente. Los valores medios de las variables que no han sido recogidas en las tres técnicas analíticas anteriores ha posibilitado establecer diferencias apreciables o no apreciables (aunque no estadísticamente significativas) en los dos grupos de bodegas, para las citadas variables o factores empresariales.

5. En el conjunto de los vinos comercializados con DO embotellados, de los resultados de los análisis mencionados, se puede concluir que los factores implicados en el valor comercial, calidad o precios de los vinos regionales se hayan más cercanos al modelo de viticultura moderna de los países anglosajones o emergentes (Fregoni, 1985), el cual preconiza los siguientes factores por orden de importancia: la variedad, método de vinificación y gustos del consumidor. La evidencia empírica presente establece que la estrategia de diferenciación de precios al alza se encuentra asociada con los siguientes factores empresariales:

- El mayor porcentaje de variedades alóctonas mejorantes (chardonay, cabernetsauvignon y merlot) y autóctonas recomendadas (moscatel, tempranillo, monastrell, shirac y pinor). Las primeras aportan un poder explicativo medio del 27,4 \% de los precios de los vinos blancos, tintos, crianzas y reservas. En el caso de las segundas, han sido detectadas diferencias apreciables en ambos grupos de bodegas.

- Las modernas tecnologías de vinificación (incorporación de frío, calor, permanencia en autovaciantes), ejercen un poder explicativo medio del 21,8 \% de los precios de los vinos tintos, crianza y reserva. En el caso de los vinos blancos y rosados, la incorporación de frío y permanencia del mosto en los depósitos de fermentación controlada no se han traducido en una diferenciación de precios al alza.

- El mayor esfuerzo tecnológico o inversor, que ejerce un poder explicativo medio entorno al 7,9\% de los precios de los vinos crianza y reserva. También han sido detectadas diferencias estadísticamente significativas en el caso del vino tinto. 
- El mayor porcentaje de empresas jóvenes, no cooperativas, las que sus accionistas son societarios, y en las que aquellos ejercen un control efectivo sobre el capital social se encuentran asociadas a las bodegas de altos precios. De hecho en el vino blanco la juventud de las empresas aporta un poder explicativo sobre los precios del 20,0 \% y, en el vino rosado el control efectivo sobre el capital social aparece como la primera variable discriminante de ambos grupos de bodegas.

- El mayor esfuerzo comercial y por información al consumidor han aparecido diferencias estadísticamente significativas en los vinos tintos y de crianza y, apreciables en los blancos y reservas.

- El menor número de presentaciones y de marcas propias y blancas junto con el mayor porcentaje de marcas propias, blancas y vinos varietales En el vino rosado estas variables han resultado ser variables con capacidad discriminante entre ambos grupos de bodegas.

- El menor grado de integración vertical hacia atrás de las empresas ancladas en las fases iniciales del proceso productivo (acopio y elaboración de vino) y, el mayor grado de integración vertical hacia delante, que presentan las empresas que han abordado las fases finales del proceso de comercialización (envejecimiento, embotellado y comercialización).

- La mayor participación de los canales de distribución minoritarios (tienda, club, horeca, bodega e internet). En el vino blanco el canal horeca contribuye con el $14,9 \%$ a la variabilidad de los precios.

- La mayor participación en la estrategia de fijación de precios al alza que están practicando las bodegas en aquellos segmentos de mercado que identifican los precios altos con la imagen de calidad y prestigio del vino.

- La menor actividad exportadora o cuota de exportación que se traduce en un ámbito de sus mercados más reducido (menor grado de dispersión de los mercados.

- El mayor porcentaje en valor añadido que presentan las bodegas que se han situado en las fases finales de la cadena de valor.

6. En el conjunto de los vinos comercializados a granel, se puede concluir que el valor añadido que suponen las variedades mejorantes, las modernas tecnologías de vinificación y las marcas colectivas o figuras de calidad reconocidas (DDOO), no se incorporan al precio del vino. En este sentido las bodegas que presentan los mayores precios se encuentran asociadas con los siguientes factores empresariales:

- Mayor presencia de las cooperativas y mayor dimensión de la capacidad instalada media (correspondiente a la mediana empresa).

- Mayor porcentaje de las variedades autóctonas recomendadas (macabeo, moscatel, tempranillo y monastrell) y un menor porcentaje tanto de las variedades 
alóctonas recomendadas (cabernet sauvignon, merlot y Shirac) como de otras variedades autóctonas (bobal, tintorera, garnacha).

7. En cuanto a las valoraciones de los directivos de las bodegas regionales, a los distintos factores que determinan el valor comercial de los vinos destacar:

- Los factores más valorados por los directivos de las bodegas de toda la muestra, por orden de importancia son los siguientes: La marca de empresa, el canal de comercialización, el método de vinificación y la variedad de la uva; los menos valorados por orden de importancia: el número de presentaciones, el criterio de fijación de precios, la marca colectiva, y los mercados meta.

- Comparando la evidencia empírica resultado de la investigación, con la realidad percibida o valoración concedida por los gerentes de las bodegas, destacar: la infravaloración de la variedad, el método de vinificación, el número de presentaciones y los mercados meta o destino; la sobrevaloración que conceden al canal comercial y, la justa valoración de la marca comercial y la marca colectiva o DO.

\section{IMPLICACIONES PARA LA DIRECCIÓN DE LAS EMPRESAS}

Las conclusiones que se acaban de referir y el conocimiento general del subsector vinícola regional, permiten establecer distintas proposiciones dirigidas a la consideración de los diversos agentes participantes en la elaboración y comercialización de los vinos regionales.

En primer lugar para las bodegas que comercializan vino con DO embotellado, dirigir una serie de reflexiones:

La necesidad de que valoren en su justa medida la variedad del vino y el método de vinificación, el número de presentaciones y los mercados meta.

En cuanto a la variedad de uva y tecnología de vinificación, se estima que estos dos factores, por orden de importancia ejercen un poder explicativo conjunto sobre los precios que supera el $50 \%$. Estas dos variables son las principales determinantes de la calidad intrínseca de los vinos, lo cual viene a significar que en un vino con una baja calidad intrínseca, el precio ha de bajar más que proporcionalmente para que no se pierda valor comercial del mismo. En definitiva una baja calidad intrínseca no puede dar lugar a una alta calidad percibida, y por tanto no puede conducir a un elevado precio del vino.

Del análisis del subsector vinícola regional se desprende que la tecnología de vinificación presenta un aceptable nivel medio en general. En cuanto al mapa varietal regional se ha evidenciado que la participación en volumen de vino de las variedades asociadas a los precios altos apenas superan el $25 \%$ del volumen de vino total comercializado; valor que debería ir en aumento apoyado por los programas de reconversión varietal, si el subsector pretende explotar la ventaja competitiva sobre la base de la diferenciación de precios. 
En relación con el número de presentaciones, teniendo en cuenta que el subsector elaborador regional está muy atomizado, con la presencia de un número elevado de tanto bodegas como de número de marcas por bodega, conduce a una situación con una abrumadora presencia de marcas, en la cual el conocimiento de las mismas es mínimo, debido a la elevada desinformación y confusión del consumidor medio. Con este escenario una estrategia de marcas tendente a su disminución en número y reestructuración de sus nombres y presentaciones del etiquetado (en algunos casos desafortunados) pueden conducir a una diferenciación de precios al alza.

En cuanto mercados meta, las empresas deberían cuidar más los mercados regionales, ya que la diferenciación de precios al alza se encuentra asociada a estos. La posible saturación de estos mercados en cuanto al segmento de vinos de precios alto, debería constituir un estímulo para comercializar progresivamente en el exterior esta gama de vinos.

Con relación a la marca comercial de empresa, la valoración efectuada por la gerencia del subsector vinícola regional la ha situado en primer lugar, hecho que se distancia de la tendencia general del sector productor y elaborador, que no le concede la importancia que en realidad tiene. La evidencia empírica apoya la valoración efectuada, desde la constatación, de la gran diferencia de precios existentes dentro de un mismo grupo de bodegas (tanto del segmento alto como del bajo), que no ha podido atribuirse a otros factores empresariales. Teniendo en cuenta que la imagen de marca de un vino cobra paulatinamente más importancia relativa a medida que la demanda se va situando en segmentos de precios más altos, la marca como intangible capta la mayor parte del valor total del vino.

Respecto a los canales comerciales, las empresas son conscientes de las posibilidades de valorización de sus vinos a través de los canales alternativos (tienda, club, horeca, bodega e internet), ya que esta variable la segunda mejor valorada. Incidir en que la presentación, los formatos, las denominaciones de las marcas, entre otros, son aspectos importantes a la hora de aprovechar las posibilidades de comercialización de estos canales, ya que a través de ellos se venden los vinos de gamas más altas, generalmente por consumidores informados y habituados a recoger información de productos antes de comprarlo. Por otra parte estos canales posiblemente sean los que de manera más eficientes trasladen al precio del vino el esfuerzo innovador, el comercial y por información al consumidor.

En cuanto al esfuerzo comercial y por información al consumidor, a pesar de que otras evidencias empíricas cuestionen su efectividad, desde el presente trabajo se ha puesto de manifiesto su efectividad, en el sentido de elevar la calidad percibida de los vinos por el consumidor. De hecho, aunque se parta de un vino con una calidad intrínseca alta, si ésta no es percibida por el consumidor, aquella no podrá transmitirse al valor comercial del vino vía precios. El mensaje es claro: la calidad intrínseca y la percibida han de ir indisolublemente unidas, si se pretende que el valor añadido que suponen estas dos componentes se traslade al valor comercial del mismo para el consumidor, vía diferenciación de precios al alza. 
La estrategia de fijación de precios a alza, ha resultado asociada a la gama alta de precios, en su objetivo de presentar una imagen de calidad, marca o prestigio del producto, que cobra interés cuando los segmentos de mercados meta no son sensibles al precio, como de hecho ocurre en muchos mercados regionales. Incidir en que esta estrategia de elevación de precios ha de ir acompañada de una elevación más que proporcional de la calidad, si no se quiere perder valor comercial del producto, en cuyo caso el mercado lo detectaría y castigaría esta iniciativa. Otras evidencias empíricas han verificado que una marca con precio alto se asocia a una percepción positiva sobre la calidad del producto.

También ha sido puesto de manifiesto que el esfuerzo innovador se haya vinculado positivamente a la diferenciación de precios al alza, si bien por la pequeña dimensión de la gran mayoría de las bodegas y, los reducidos porcentajes de inversión, posiblemente se trate de pequeñas innovaciones mayormente relacionadas con la presentación e imagen de los productos.

En segundo lugar, para las bodegas que comercializan vino a granel, lo más significativo es trasladar al subsector la evidencia empírica constatada, en la dirección de que el valor añadido potencial que llevan aparejados las variedades mejorantes, las modernas tecnologías de vinificación y las distintas figuras de calidad (DDOO) asociadas a los vinos regionales, no llega a trasladarse, o lo hace de manera poco notoria, al precio del vino, cuando este es comercializado a granel. Estas bodegas están desaprovechando recursos muy valiosos al no abordar etapas trascendentales en la cadena de valor, como el envejecimiento y el embotellado en la comercialización de sus producciones.

\section{LIMITACIONES DEL ESTUDIO}

Para efectuar una valoración final del trabajo, en este apartado se intentará identificar aquellas restricciones que afectan a su planteamiento y desarrollo, limitando por tanto la bondad de sus conclusiones y resultados.

Según Porter (1991), las principales cuestiones que surgen cuando se plantea una investigación sobre el problema estratégico son: en primer lugar construir una teoría de la estrategia, estableciendo modelos o marcos en los que se recojan aquellas variables relevantes y las interrelaciones que de mayor o menor modo nos acerquen a la realidad; en segundo lugar, determinar el alcance de la cadena de causalidad; en tercer lugar fijar el horizonte temporal en que debe medirse la variables dependiente; y por último cómo contrastar la teoría estratégica formulada teóricamente.

La empresa no puede considerarse como un ente aislado, sino inmerso en un entorno concreto, y la evaluación de sus recursos debe realizarse desde un determinado contexto espacial y temporal (Fernández y Suarez, 1996). Las relaciones entre condiciones estructurales del medio externo de la empresa (el sector industrial), el comportamiento empresarial (conjunto de recursos y capacidades de la empresa) y la diferenciación de precios, es difícil analizar, no sólo por el elevado número de variables relevantes a considerar y por la complejidad de sus vinculaciones, sino porque tales 
interdependencias son consecuencia de u proceso dinámico y acumulativo en el tiempo y en el espacio.

Una primera limitación se deriva del planteamiento adoptado, a través del cual no se puede averiguar la dimensión longitudinal del problema estratégico en el tiempo, sino que se relaciona con la dimensión transversal de mismo, que trata de identificar las causas que explican un posicionamiento en la gama superior de precios de las bodegas en un momento dado en el tiempo, lo cual implica una aproximación incompleta a un problema estratégico que precisa de una perspectiva dinámica con el objeto de juzgar satisfactoriamente el grado de eficacia de los recursos, de las decisiones adoptadas, y del modo en que son ejecutadas. Esta limitación resulta especialmente relevante en ese trabajo, puesto que el comportamiento cíclico del subsector analizado dificulta la generalización de los resultados obtenidos a partir de la observación de una parte concreta del mismo.

Una segunda limitación que amenaza la calidad de los resultados, se deriva de la selección de los factores empresariales introducidos en el modelo y su medición: La relación de posibles factores a considerar es evidentemente más amplia, habiéndose contemplado solo aquellos considerados con mayor interés en este caso y que a la vez pueden resultar más fácilmente observables o cuantificables. En cuanto a la medición de los recursos, puesto que no existe una única medida plenamente satisfactoria, la solución adoptada ha sido utilizar en cada supuesto distintos criterios, que por otro lado siempre pueden ser objeto de discusión.

Así por ejemplo, el esfuerzo por información al consumidor no es función únicamente del input capital (inversión publicitaria) sino también del input trabajo (creatividad), de forma que la inversión publicitaria debe ser entendida en términos cualitativos más que cuantitativos.

Otro ejemplo lo podría constituir la tecnología de elaboración, proceso muy complejo, que comprende como operaciones más comunes de las diferentes vinificaciones: toma de muestras, análisis de las muestras, recepción de la uva, la separación del raspón, el estrujado, el prensado, el desfangado, sistemas de control de la fermentación, la adición de levaduras, la clarificación, la filtración, la estabilización, el envejecimiento, y el embotellado. Sin embargo debido a la dificultad de encontrar para cada operación una variable explicativa cuantitativa con su indicador de medición correspondiente, en el modelo propuesto se ha simplificado el proceso de vinificación mediante la adopción de variables relacionadas con la incorporación de calor, frío y permanencia del mosto en los depósitos autovaciantes y de fermentación controlada. Esta limitación podría haber infravalorado la aportación del proceso de vinificación al precio del vino en general.

Por otra parte las competencias profesionales y tecnológicas esenciales se crean a través de un proceso de mejora continua, que se puede dilatar en el tiempo, consideración que supone una limitación a la utilización del criterio de gasto económico medio anual del trienio, como estimador del esfuerzo acumulado en la generación o adquisición de recurso y capacidades. Crear recursos y capacidades es algo más complejo que hacer inversiones, pues está relacionado con las capacidades de los 
directivos de las bodegas, la integración del personal y la creación de una determinada cultura dentro de la empresa (Cuervo, 1993). La capacidad distintiva de las empresas consiste no sólo en tener mejores recursos, sino en hacer un mejor uso de ellos.

Una tercera limitación es la relacionada con la metodología analítica utilizada, en el sentido de que se han encontrado correlaciones y vinculaciones entre diversos tipos de variables explicativas utilizadas, en base a las cuales estas variables pueden verse afectados entre sí de forma directa o indirecta, propiciando que cada una de ellas, contemplada aisladamente, aporte un poder explicativo menor del que le correspondería en el supuesto de considerarlas dentro de una combinación de factores independientes. Los métodos de ecuaciones estructurales permiten analizar esta red de relaciones y proporcionar mejores resultados analíticos cuando se cumplen estos supuestos. El elevado número de variables y relaciones a considerar, junto con el reducido tamaño de la muestra disponible en este estudio, ha impedido la aplicación de estas metodologías.

Añadir por último que existe una dimensión muy importante, que escapa al ámbito de la Teoría de Recursos y Capacidades empresariales, en concreto las preferencias y gustos del consumidor; éstos pueden verse modificados positivamente por la política de comunicación de la empresa (publicidad de la marca, de las características de un vino determinado, promociones, ofertas, participación en ferias, exposiciones, etc.). Determinadas dimensiones simbólicas y afectivas influyen en la decisión final de que un consumidor se decante hacia un determinado vino, a pesar de que sea a mayor precio, dentro de un rango de vinos supuestamente pertenecientes a la misma categoría. Contemplar este factor, de importancia decisiva en cuanto a su contribución a la valorización comercial de los vinos, hubiera desembocado en el planteamiento de una encuesta de satisfacción de los clientes, referente a las cuales existen numerosos y actuales estudios realizados por las distintas administraciones con competencias en materia alimentaria.

\section{FUTURAS LÍNEAS DE INVESTIGACIÓN}

Las limitaciones apuntadas abren distintas líneas de trabajo que pueden permitir progresar en el propósito de la investigación planteada más allá de los resultados obtenidos con la labor desarrollada hasta estos momentos. Se proponen las siguientes líneas de avance:

1. En relación con la selección y medición de los factores o variables empresariales, estaría relacionada:

a) Ampliación de los factores que modelizan la compleja tecnología de vinificación, con el fin de hacerla más próxima a la realidad.

b) Determinar las variables y sus correspondientes indicadores en relación con el intangible imagen de marca, que no esté relacionado con los siguientes aspectos: el sobreprecio de marcas de vinos comparables de otras empresas; el valor suplementario que alcanza la empresa por encima de sus activos materiales, ni con el activo inmaterial propiedad intelectual, ya que estos 
elementos raramente figuran en la contabilidad de las pequeñas y medianas empresas.

2. Ampliar el periodo de observación de la actuación empresarial del presente trabajo (desde un año hasta un trienio), aumentando la perspectiva temporal del análisis realizado hasta contemplar todo un ciclo de negocio con la inclusión del proceso completo de transformación de los productos con mayor periodo de maduración, así como de la evolución cíclica del conjunto del sector derivada del comportamiento de los precios. Este aspecto contribuiría a mejorar el rendimiento de la investigación en varios aspectos: a) incorporaría una nueva referencia para valorar la diferenciación de precios existente entre las bodegas, como es el grado de variabilidad de los mismos obtenidos a lo largo del tiempo; b) permitiría añadir una orientación más dinámica a la investigación y acometer objetivos relacionados con una aportación sustancial de la Teoría de Recursos y Capacidades empresariales.

La cuestión a clarificar no termina con la identificación y cuantificación de los factores determinantes de la diferenciación de precios observada entre las empresas, sino que es preciso comprender el mecanismo por el que la organización aprende, cambia y se adapta. Es decir como y porqué las empresas alcanzan una ventaja competitiva y son capaces de mantenerla en el tiempo, a pesar de los cambios producidos en el sector, que pueden modificar la relevancia de esta ventaja competitiva.

3. Contrastar la utilidad de metodologías alternativas, entre las que cabe destacar: el método del caso y los modelos de ecuaciones estructurales.

a) El método del caso está indicado para un horizonte temporal más extenso y permite incorporar otros aspectos empresariales con un carácter más cualitativo y no por ello con menor potencial explicativo.

b) En cuanto a los modelos de ecuaciones estructurales, su aportación principal reside en la posibilidad de contemplar no sólo los efectos directos que las variables independientes pueden ejercer sobre la diferenciación de precios, sino también añadir los efectos indirectos derivados de las interrelaciones entre dichas variables, que no son considerados por las técnicas de regresión lineal y análisis discriminante, y que permiten reproducir de una manera más próxima a la realidad la complejidad de las relaciones de dependencia existentes. Dado el limitado tamaño de la muestra disponible, la utilización correcta de ésta técnica exigiría considerar un menor número de variables, pudiéndose utilizar inicialmente aquellas que han demostrado una mayor capacidad explicativa según los análisis efectuados.

4. Señalar la posibilidad de replicar el planteamiento seguido en este trabajo en ámbitos territoriales diferentes, como pueden ser otras denominaciones de origen u otras figuras de calidad asociadas a los vinos. 

BIBLIOGRAFÍA 



\section{BIBLIOGRAFÍA CITADA Y CONSULTADA}

ALBISU, L.M. 2003. "El mercado nacional del vino". Colección ciencia y técnica $n^{\circ}$ 43. Ed. Universidad de Castilla- La Mancha.

ALBISU, L.M. 2004. "Estrategias empresariales y mercado internacional del vino". Cuadernos agroambientales $n^{\circ} 5$ Ed. IVIFA.

ALCHIAN, A . A.;DEMSETZ, H. 1972. "Production, Information Costs, and Economic Organization". The American Economic Review, vol 62 ,pp. 777-795.

ALIMARKET. Varios años. http://alimarket.es (consulta 15 Diciembre 2005).

AMIT, R; SCHOEMAKER, P.J.H. 1993. "Strategic Assets and Organizational Rent". Strategic Management Journal, vol 14, pp. 33-46.

ARRUÑADA, B. 1990. "Economía de la empresa: Un enfoque contractual". Ed. Ariel, Barcelona.

BARCO, E. 2002. "El sector vitivinícola en el siglo XXI." Distribución y Consumo, septiembre-octubre 2002. http://mercasa.es (consulta 23 Octubre de 2005).

BARCO, E et al. 2005. "Cambios en el mercado internacional del vino". Distribución y Consumo, marzo-abril 2005. http://mercasa.es (consulta 23 Octubre de 2005).

BARDAJí, I. 2004. "Tendencias en el mercado español del vino". Distribución y Consumo, noviembre-diciembre 2004. http://mercasa.es (consulta 2 Octubre de 2005).

BARNEY, J. 1991. "Firm Resources and Sustained Competitive Advantage". Journal of Management, vol 17,pp. 99-120.

BELLO, L.;GÓMEZ. J.T. 1996."Las Denominaciones de Origen y otras señales de calidad en las estrategias de diferenciación de los productos agroalimentarios. Una propuesta metodológica. Cuadernos Aragoneses de Economía, vol 6, pp.365-387.

BERNABEU, R, et al. 2001. Comunicación del IV Coloquio Hispano-Portugués de Estudios Rurales. "La producción de vinos de calidad en las bodegas de Castilla La Mancha".

BERNABEU, R. 2002. "Factores que condicionan la frecuencia de consumo de vino". Distribución y Consumo, septiembre-octubre 2002. http://mercasa.es (consulta 3 Octubre de 2005).

BONACHE, J. 1996. "El papel de las políticas de recursos humanos en la internacionalización de la empresa. Una aplicación al caso español". Economía Industrial, $\mathrm{n}^{\circ}$ 307, pp. 37-48.

BRIZ, J; DE FELIPE, I. 1999." Competitividad y estrategias comerciales en el sector vínico español". Cuadernos de Agricultura, Pesca y Alimentación, n 10, pp. 23-32. Ed. MAPA.

CAMISÓN,C. 1999. "La medición de los resultados empresariales desde una óptica estratégica: construcción de un instrumento a partir de un estudio Delphi y aplicación a la empresa industrial española en el periodo 1983-1996". Estudios financieros $\mathrm{n}^{\circ}$ 199, pp. 205-264.

CASTILLO, J.S. et al. 2003. "El mercado del vino. Reflexiones y propuestas de futuro". Colección ciencia y técnica n ${ }^{\circ} 43$. Ed. Universidad de Castilla-La Mancha.

CCAE. 2004. "Estudio sobre la comercialización agroalimentaria en el sector cooperativo español”. http://www.mapa.es (consulta 28 Octubre 2005).

CLARKE, R. 1993. "Economía industrial". Colegio de economistas de Madrid.

COASE, R. 1937. "The natura of de firm. Economica, vol 4, $\mathrm{n}^{\circ} 16$, utilizada la traducción en R.H. Coase. "La empresa, el mercado y la ley". Ed. Alianza, 1994. 
COMISIÓN EUROPEA. Varios años. "La situación de la agricultura en la Unión Europea. Informes”. http://ec.europa.eu/agricultura (consulta 20 Septiembre 2005).

COMISIÓN EUROPEA. 2002.”Evaluación ex-post de la organización común de mercado del vino”. http://ec.europa.eu/agricultura (consulta 10 Septiembre 2005).

COMISIÓN EUROPEA. 2006. "Hacia un sector vitivinícola europeo sostenible. Comunicación de la Comisión Europea al Consejo y al Parlamento Europeo del 22-062006". http://ec.europa.eu/agricultura (consulta 5 Julio 2006).

CONSEJO REGULADOR DE DENOMINACIÓN DE ORIGEN ALICANTE. Varios años. "Memorias". http://www.crdo-alicante.org (consulta 12 agosto 2005).

CONSEJO REGULADOR DE DENOMINACIÓN DE ORIGEN UTIELREQUENA. "VI Jornadas Vitivinícolas de la Denominación de Origen Utiel-Requena". Ed. Consejo Regulador de Denominación de Origen Utiel-Requena. http://www.utielrequena.org (consulta 12 agosto 2005).

CONSEJO REGULADOR DE DENOMINACIÓN DE ORIGEN UTIELREQUENA. Varios años. "Memorias". Ed. Consejo Regulador de Denominación de Origen. Utiel-Requena. http://www.utielrequena.org (consulta 12 agosto 2005).

CONSEJO REGULADOR DE DENOMINACIÓN DE ORIGEN VALENCIA. Varios años. Memorias. Ed. Consejo Regulador de Denominación de Origen. Valencia. http://www.verema.com (consulta 10 Junio 2005).

COOL, K.O.;SCHENDEL, D. 1987."Estrategic group formation and performance: the case of the U.S. pharmaceutical industry, 1963-1982". Management science, vol 33, $\mathrm{n}^{\circ}$ 9, pp. 1102-1124.

CUBBIN, J.;GEROSKI, P. 1987. "The convergence of profits in the long run: interfirm and inter-industry comparasions". The journal of industrial economics, vol XXXV, n 4 , pp. 427-442.

CUERVO, A. 1993. "El papel de la empresa en la competitividad". Papeles de economía española, $\mathrm{n}^{\circ}$ 56, pp. 363-378.

CUERVO, A. 1999. "La dirección estratégica de la empresa. Reflexiones desde la economía de la empresa". Papeles de economía española, nº 78-79, p. 34-55.

DE LA FUENTE, J.M. et al. 1997. "Diseño organizativo de la empresa" Ed. Civitas.

DELACROIX, J.;SWAMINATHAN,A. 1991. "Cosmetic speculative, and adaptive organizational change in the wine industy: a longitudinal study". Administrative science quarterly, $\mathrm{n}^{\circ}$ 36, pp. 631-661.

DEL REY, R. 2002. "Un futuro posible para el vino español". Distribución y Consumo, septiembre-octubre 2002. http://mercasa.es (consulta 6 noviembre 2005).

FEDERACIÓN ESPAÑOLA DEL VINO. 2004. “El mundo del vino en cifras, 2003”. http://fev.es (consulta 16 diciembre 2005).

FERNÁNDEZ, A.; MARTINEZ, E. 2004. "Las marcas de distribuidor y el consumidor español: un estudio empírico". Distribución y Consumo septiembre-octubre 2004. http://mercasa.es (consulta 3 noviembre 2005).

FERNÁNDEZ, E.; FERNÁNDEZ, Z. 1988. "Manual de dirección estratégica de la tecnología". Ed. Ariel economía.

FERNÁNDEZ, E.; MONTES, J.M.: VÁZQUEZ, C.J. 1996a. "Factores explicativos de la rentabilidad empresarial". Revista de economía aplicada, vol IV n ${ }^{\circ} 12$, pp.

FERNÁNDEZ, E.; MONTES, J.M.: VÁZQUEZ, C.J. 1996b. "Efecto industria y conducta empresarial". Revista europea de dirección y economía de la empresa, vol. 5 $\mathrm{n}^{\mathrm{o}} 2$, pp. $145-158$. 
FERNÁNDEZ, E.; MONTES, J.M.: VÁZQUEZ, C.J. 1997. "La teoría de la ventaja competitiva basada en los recursos: síntesis y estructura conceptual". Revista europea de dirección y economía de la empresa, vol. 6 nº 3, pp. 11-32.

FERNÁNDEZ RODRÍGUEZ, Z. 1992. "Algunas reflexiones sobre la competitividad empresarial y sus causas". Información comercial española, ${ }^{\circ}$ 705, mayo, pp. 139-152.

FERNÁNDEZ RODRÍGUEZ, Z. 1993. "La organización interna como ventaja competitiva para la empresa". Papeles de economía española nº 56, pp. 178-193.

FERNÁNDEZ RODRÍGUEZ, Z. 1993. "El estudio de las organizaciones (la jungla dominada)". Papeles de economía española, nº 78-79, pp. 56-76.

FERRÁN, M. 1997 "SPSS para Windows. "Programación y análisis estadístico". Ed. McGrauw Hill .

FLANCY, C. 2000. “Enología, fundamentos científicos y tecnológicos”. Ed. MundiPrensa.

FLAVIÁN, C; GURREA, R. 2003."El empleo de Internet como nuevo canal de distribución. Un análisis de sus principales ventajas e inconvenientes. Distribución y Consumo, noviembre-diciembre 2003. http://mercasa.es (consulta 16 noviembre 2005).

FORO MUNDIAL DE VINO DE LA RIOJA III MILENIO. Años 2000, 2002 y 2004. http://www.forovino.com (consulta10 Enero 2006)

GALÁN, J.L.; VECINO, J. 1997. "Las fuentes de rentabilidad de la empresa". Revista europea de dirección y economía de la empresa, vol. 6 nº 1, pp. 21-36.

GALVE, C. 1992. "Propiedad, control y resultados de la empresa española". Tesis doctoral, Universidad de Zaragoza.

GARCÍA, J.I.et al. 2002. “Comercialización y marketing del vino”. Ed. INEA.

GRANDE, I et al. 2001. "Fundamentos y técnicas de investigación comercial". Ed. ESIC.

GRANT, R.M. 1991. "The Resource-based theory of competitive adventage:implications for strategy formulation". California managemente review, vol 33, no 3, pp. 114-135.

GRANT, R.M. 1996. "Dirección estratégica. Conceptos, técnicas y aplicaciones". Ed. Civitas.

GUILLEM, J.V. 2000. "Condiciones que determinan la calidad de los vinos de la Comunidad Valenciana". Ed. Universidad Politécnica de Valencia.

GUILLEM, J.V. 1997. "Uvas, vinos y espirituosos en la Comunidad Valenciana. Ed. Consellería de Agricultura, Pesca y Alimentación.

HAIR, J.F. et al. 1999. "Análisis multivariante". Ed. Prentice Hall Ibria.

HALL, R. 1992. "The strategy analysis of intangible resources." Strategic management journal vol 13, pp. 135-144.

HANSEN, G.S.; WERNERFELT, B. 1989. "Determinants of firm performance: the relative importance of economic and organizational factors". Strategic management journal, vol 10, pp.399-441.

HARRIGAN, K. R. 1986. "Matching vertical integration strategies to competitive conditions". Strategic management journal, vol 7, pp. 535-555.

HENDERSON, R.; MITCHELL, W. 1997. "The interations of organizational and comptetitive influences of strategy and performance". Strategic management journal, vol 18, pp. 5-14.

HUERTA, E. 1989. "Análisis de la integración vertical de empresas en España". Papeles de economía española, $\mathrm{n}^{\circ}$ 39. pp 149-163. 
HUNT, S.D. 1997. "Resource-adventage theory: An evolutionary theory of competitive firm behavior", Journal of economic issues, vol. 31, pp. 59-77.

IKERFEL. 2000. "El consumidor español de los vinos de calidad". Ed. MAPA.

INFORME DEL SECTOR AGRARIO VALENCIANO. Varios años. Ed. Consellería de Agricultura, Pesca y Alimentación. http://agricultura.gva.es (consulta 12 Diciembre 2005)

ITAMI, H; ROEHL, T.W. 1991. "Mibilizing invisible assete". Harvard University Press, Cambridge.

JACOBSEN, R. 1988. "The persistence of abnormal returns". Strategic management journal, vol 9, pp. 415-430.

JACQUEMIN, A. 1982. "Economía industrial. Estructuras de mercado y estrategias europeas de empresa. Ed. Hispano Europea .

JAUMANDREU, J.; MATO, G. 1990. "Concentración y beneficios en la industria española, en X. Vives y J. Gual (eds): Concentración empresarial y competitividad: España en la CEE. Ed. Ariel economía.

JENSEN, M.C.; MECKLING,W. 1976. "Theory of the firm: managerial behavior, Agency Costs and Ownership Structure". Journal of financial economics, 3, pp. 305360.

KALIKA, M. 1985. "L'efficacyté des interprises est-elle liée à leur structure?". Revue française de gestión, enero-febrero, pp. 93-104.

LANGREO, A. 2003. "Los mercados de vinos y las estrategias de las bodegas españolas”. Distribución y Consumo, septiembre-octubre 2002. http://mercasa.es (consulta 20 Enero 2006).

LA SEMANA VITIVINÍCOLA. Varios años. http://sevi.net (consulta 30 Marzo 2005).

LÓPEZ SINTAS, J. 1996. "Los recursos intangibles en la competitividad de las empresas. Un análisis desde la Teoría de los Recursos. Economía industrial, nº 307, pp. 25-35.

MAPA. 1993. "Estudios sobre la posición competitiva del sector de alimentación y bebidas en España”. http://www.mapa.es (consulta 30 Abril 2005).

MAPA. 2000. "Las denominaciones de origen de vinos en el mercado nacional". Ed. MAPA.

MAPA. 2003. "Identificación de las necesidades de servicios orientados a aumentar la competitividad. http://www.mapa.es (consulta 22 Marzo 2005).

MAPA. 2003. “Análisis de la innovación”. http://www.mapa.es (consulta 23 Marzo 2005).

MAPA. Varios años. Cuadernos de información económica sobre la industria agroalimentaria”. http://www.mapa.es(consulta 30 Marzo 2005).

MAPA. 2003. ”Diagnóstico y análisis estratégico del sector agroalimentario español”. http://www.mapa.es (consulta 13 Mayo 2005).

MAPA. 2003. "Libro Blanco de la Agricultura y el Desarrollo Rural". Ed. MAPA. http://www.mapa.es (consulta 23 Marzo 2005).

MAPA. Varios años. “La Alimentación en España”. http://www.mapa.es (consulta 30 Marzo 2005).

MAPA. 2003. “Análisis de las relaciones de las Pymes agroalimentarias con la distribución comercial. http://www.mapa.es (consulta 5 Marzo 2005).

MAPA. 2004. "Borrador del Plan Estratégico del Sector vitivinícola español".http://www.mapa.es (consulta 5 Junio 2005). 
MILLER, D. 1986. "Configurations of strategy and structure:towards a synthesis". Strategic managemente journal, vol 7. pp. 233-249.

MINTZBERG, H. 1993. "La estructuración de las organizaciones", Ed. Ariel.

MOLLÁ, A; SÁNCHEZ, A. 2000."Análisis de los cambios en los canales de comercialización de productos agroalimentarios". Estudios agrarios y pesqueros, $\mathrm{n}^{\circ}$ 186, pp. 39-73.

MÚGICA, J.M.;YAGÜE, M.J. 1993. "Impacto del capital comercial en la competitividad empresarial". Papeles de economía española, n ${ }^{\circ}$ 56, pp. 242-256.

NELSON, R.R.; WINTER, S.G.1982. "An evolutionary theory of economic change". The Belknap Press of Harvard University Press.

OLMEDA, M.et al. 2002. "Estrategias del sector vinícola en Castilla-La Mancha". Colección ciencia y técnica, ${ }^{\circ}$ 39. Ed. Universidad de Castilla-La Mancha.

OLMEDA, M. et al. 2003. "El viñedo y el vino en Castilla-La Mancha.” Colección ciencia y técnica, $\mathrm{n}^{\circ} 44$. Ed. Universidad de Castilla-La Mancha.

ORGANIZACIÓN INTERNACIONAL DEL VINO. Varios años. "Nota de coyuntura mundial”. http://oiv.org (consulta 8 Noviembre 2005)

PENROSE, E.T. 1962. "Teoría del crecimiento de la empresa. Ed. Aguilar.

PETERAF, M.A. 1993. "The cornestones of competitive advantage: A resource-based view. Strategic managemente journal, vol 14, pp. 179-191.

PLANELLS, J.M; MIR, J. 2000. "La distribución del próximo siglo". Cuadernos de Agricultura, Pesca y Alimentación, $\mathrm{n}^{0}$ 12, pp. 45-52.

PORTER, M.E. 1976. "Interbrand choice, strategy, and bilateral market power". Harvard University Press.

PORTER, M.E. 1979. "The structure within industries and companies performance. CECSA.

PORTER, M.E. 1982. Estrategia competitiva. Técnicas para el análisis de los sectores industriales y de la competencia. CECSA.

PORTER. 1991a "La ventaja competitiva de las naciones". Ed. Plaza y Janés.

PORTER. 1991b. " Towards a Dynamic Theory of strategy. Strategic management journal, vol 12, pp. 95-117.

POWELL, T.C. 1996 "How much does industry matter?. An alternative empirical test. Strategic managemene journal, vol 17, pp. 323-334.

PUELLES, J.A; PUELLES, M. 2003. "Marcas de distribuidor". Distribución y Consumo, mayo-junio 2003. http://mercasa.es (consulta 25 Junio 2005

RABOBANK INTERNATIONAL. 2003. "El vino ¿es negocio?". Ponencias y presentaciones.

RECOLETOS. 2004. " III encuentro especializado del sector vitivinícola". Recoletos Conferencias y Formación.

RODRIGUEZ et al. 1990. "Gestión comercial de la empresa agroalimentaria". Ed. Mundi-Prensa.

RUIZ, A, et al. 2004. "Las Denominaciones de Origen vitivinícolas españolas. Percepciones de bodegas, distribuidores y líderes de opinión". Distribución y Consumo, julio-agosto 2004. http://mercasa.es (consulta 15 Junio 2005).

RUMELT, R.P.; SCHENDEL, D; TEECE, D.J. 1991. "Strategy management and economics". Strategic managemene journal, vol 12, pp. 5-29.

SÁINZ, A. 2002. "Análisis de los factores explicativos del éxito empresarial: una aplicación al sector de Denominación de Origen Calificada Rioja". 
SALAS, V. 1993. "Factores de competitividad empresarial. Consideraciones generales". Papeles de economía española, ${ }^{\circ}$ 56, pp. 379-396.

SALAS, V. 1996a "Economía de la empresa. Decisiones y organización". Ed. Ariel.

SALAS, V. 1996b "Economía y gestión de los intangibles". Economía industrial, no 307, pp. 17-24.

SANTOS, $\mathbf{M}^{\mathbf{a}}$ V. 1997. "Los procesos de evolución empresarial: cambio organizativo y desaparición. Una aplicación a las Cajas de Ahorro españolas (1986-1995)". Tesis Doctoral. Universidad de Valladolid.

SEBASTIÁN, J. 2003. "El sector vitivinícola". Comunicación .Libro Blanco de la Agricultura y el Desarrollo Rural". http://www.mapa.es (consulta 14 Diciembre 2005).

SERRA, A. 1993. "La empresa. Análisis económico". Ed.Labor,

STRATEGOR. 1995. "Estrategia, estructura, decisión, identidad. Política general de la empresa. Ed. Biblio empresa.

TEECE, D. J.; PISANO, G; SHUEN, A. 1990. "Firm capabilities, resources and concept of strategy". Working papaer EAP-38. Universidad de California, pp. 28.

UNIVERSIDAD DEL CEMA. 2005. “Competitividad en los agronegocios”. http://cema.es (consulta 26 Enero 2006

UNIVERSIDAD POLITÉCNICA CDE VALENCIA. 1990. "Lecturas de análisis sectorial". Ed. Universidad Politécnica de Valencia.

UNIVERSIDAD POLITÉCNICA CDE VALENCIA. 1995. "Análisis estratégico de sectores industriales". Ed. Universidad Politécnica de Valencia.

VIÑALS, J. 1993. "La competitividad, sus determinantes y el papel de la política macroeconómica. Papeles de economía española, nº 56, pp. 278-294.

VISAUTA, B. 2002. "Análisis estadístico con SPSS para Windows".

WILLIAMSON, O. E. 1989. "Las instituciones económicas del capitalismo. Fondo cultura económica. México D.F. 
ANEXOS 

ANEXO I

CUESTIONARIO BODEGAS 



\section{CUESTIONARIO BODEGAS(*)}

\section{IDENTIFICACIÓN DE LA EMPRESA}

1.1 Nombre o razón social

1.2 Año de fundación

1.3 Número de establecimientos

\section{IDENTIFICACIÓN DEL ESTABLECIMIENTO (1)}

2.1 Localización geográfica

2.2 Año de puesta en marcha del establecimiento

2.3 Teléfono

2.4 E-mail

2.5 Posee página de internet

SI Dirección

NO

(1) En las empresas con varios establecimientos, para cada uno de éstos se rellenarán los apartados 2, 3 y 4 , debiendo realizar las fotocopias necesarias de dichos apartados.

\section{CAPACIDAD DE LAS INSTALACIONES}

3.1 Indicar para la campaña 2002/03, la capacidad total de los depósitos e instalaciones existentes, en su caso, en el establecimiento.

\begin{tabular}{|c|c|c|}
\hline Tipo de depósitos & Depósito/Instalación & Capacidad total \\
\hline \multirow{8}{*}{$\begin{array}{l}\text { Fermentación, } \\
\text { estabilización } \\
\text { almacenamiento y } \\
\text { envejecimiento }\end{array}$} & Fermentación controlada & $\mathrm{Hl}$ \\
\hline & Autovaciantes & $\mathrm{Hl}$ \\
\hline & Acero negro & $\mathrm{Hl}$ \\
\hline & Acero inoxidable (1) & $\mathrm{Hl}$ \\
\hline & Hormigón armado & $\mathrm{Hl}$ \\
\hline & Poliéster-fibra de vidrio & $\mathrm{Hl}$ \\
\hline & Barricas y conos $(<5 \mathrm{Hl})$ & $\mathrm{Hl}$ \\
\hline & Conos y depósitos de roble (> $5 \mathrm{Hl}$ ) & $\mathrm{Hl}$ \\
\hline & Embotelladora & litros/h \\
\hline & Equipo de frío & Frigorías/h \\
\hline & Caldera & Kcalorías/h \\
\hline
\end{tabular}

(1) Sin incluir depósitos de fermentación controlada ni autovaciantes.

(*) Las instrucciones se presentan al final del cuestionario. 
4. ASPECTOS TECNOLÓGICOS RELACIONADOS CON LA CALIDAD Y LA SEGURIDAD ALIMENTARIAS

4.1 Señalar las normas o sistemas que ha implantado o en las cuales se encuentra inscrito el establecimiento.

Normas ISO 9001(2000)

Normas ISO 9002

Normas ISO 9003

$\square$ Normas ISO 14001

$\square$ Sistemas de trazabilidad

$\square$ Análisis de peligros y puntos de control críticos (APPCC)

$\square$ Inscrito como elaborador en Producción Integrada

$\square$ Inscrito como elaborador en Agricultura Ecológica

4.2 Señalar el área de la empresa que dispone de software de gestión.

Campos y producción

Elaboración

Contable y financiera

Comercial

4.3 Señalar si dispone de sistemas u otras herramientas que permitan capturar la información de sensores, autómatas u otros elementos de control, incorporados a las maquinarias y equipos (que se describen a continuación), para su posterior informatización y regulación automática de todo el proceso de elaboración y envasado.

Recepción y caracterización de la uva

Despalilladora-estrujadora

Prensadora

Fermentadores

Estabilización

Envejecimiento

Embotellado 


\section{PERSONAL}

5.1 Indicar el número medio de empleados y el periodo de ocupación, teniendo en cuenta el nivel de cualificación, en las tres últimas campañas (2000/01-2002/03).

\begin{tabular}{|l|l|l|}
\hline \multicolumn{1}{|c|}{ Nivel de cualificación } & $\begin{array}{c}\text { Número de empleados desagregados } \\
\text { por periodo de ocupación (1) }\end{array}$ & $\begin{array}{c}\text { Periodo de ocupación } \\
\text { en días al año (2) }\end{array}$ \\
\hline \multirow{3}{*}{ Titulación superior } & & \\
\cline { 2 - 3 } & & \\
\cline { 2 - 3 } Titulación media & & \\
\cline { 2 - 3 } & & \\
\cline { 2 - 3 } Formación profesional & & \\
\cline { 2 - 3 } & & \\
\cline { 2 - 3 } & & \\
\hline \multirow{2}{*}{ Sin titulación } & & \\
\cline { 2 - 3 } & & \\
\cline { 2 - 3 } & & \\
\hline
\end{tabular}

(1) En caso necesario se añadirán tantas casillas como periodos de ocupación distintos, tenga cada nivel de cualificación

(2) Considerando un máximo de 240 días/año y jornadas de 8 horas/día.

\section{APROVISIONAMIENTO}

6.1 Indicar en su caso, el porcentaje anual medio, sobre el total de la producción comercializada en hl por la empresa, en las tres últimas campañas (2000/01-2002/03).

\begin{tabular}{|l|r|}
\hline Uva propia & $\%$ \\
\hline Uva adquirida por acuerdos o contratos previos, anuales o plurianuales & $\%$ \\
\hline Uva adquirida según necesidades, sin acuerdos o contratos. & $\%$ \\
\hline Vino adquirido por acuerdos o contratos previos, anuales o plurianuales & $\%$ \\
\hline Vino adquirido según necesidades, sin acuerdos o contratos. & $100 \%$ \\
\hline Total & $\%$ \\
\hline
\end{tabular}

6.2 Señalar la forma de fijación del precio para las uvas, en la campaña (2002/03).

Control de azúcar y acidez

Control varietal

Control sanitario

Control de polifenoles.

Otros controles (especificar) 


\section{PRODUCCIÓN}

7.1 Indicar la producción comercializada en $\mathrm{Hl}$ y los ingresos por ventas de vino en euros, de los diferentes tipos de vinos, según corresponda, para la campaña 2002/03, o el ejercicio económico mayoritariamente coincidente con esta campaña.

\begin{tabular}{|c|c|c|c|c|}
\hline Tipo de vino & $\begin{array}{c}\text { Nivel de } \\
\text { protección } \\
(1) \\
\end{array}$ & Presentación & $\begin{array}{c}\text { Producción } \\
\text { comercializada en hl } \\
\text { (2) }\end{array}$ & $\begin{array}{l}\text { Ingresos por ventas de } \\
\text { vino (euros) }\end{array}$ \\
\hline \multirow{4}{*}{ Blanco } & \multirow{2}{*}{ v.c.p.r.d. } & Embotellado & & \\
\hline & & Granel & & \\
\hline & \multirow{2}{*}{ Vinos de mesa } & Embotellado & & \\
\hline & & Granel & & \\
\hline \multirow{4}{*}{ Rosado } & \multirow{2}{*}{ v.c.p.r.d. } & Embotellado & & \\
\hline & & Granel & & \\
\hline & \multirow{2}{*}{ Vinos de mesa } & Embotellado & & \\
\hline & & Granel & & \\
\hline \multirow{4}{*}{ Tinto } & \multirow{2}{*}{ v.c.p.r.d. } & Embotellado & & \\
\hline & & Granel & & \\
\hline & \multirow{2}{*}{ Vinos de mesa } & Embotellado & & \\
\hline & & Granel & & \\
\hline \multirow{2}{*}{ Crianza } & \multirow{2}{*}{ v.c.p.r.d. } & Embotellado & & \\
\hline & & Granel & & \\
\hline \multirow{2}{*}{ Reserva } & \multirow{2}{*}{ v.c.p.r.d. } & Embotellado & & \\
\hline & & Granel & & \\
\hline
\end{tabular}

(1) A efectos de la encuesta, en vinos de calidad producidos en una región determinada, como marca colectiva, se incluyen los vinos de la tierra, los vinos con denominación de origen y los vinos de pagos.

(2) Tener en cuenta que la producción comercializada no siempre coincide con la producción amparada o calificada.

7.2 Indicar el volumen real en $\mathrm{Hl}$ de vino de mesa, de productos entregados a la intervención en las tres últimas campañas (2000/01-2002/03).

\begin{tabular}{|l|l|l|l|}
\hline & Campaña 2000/01 & Campaña 2001/02 & Campaña 2002/03 \\
\hline Destilación para uso de boca & & & \\
\hline Destilación de crisis & & & \\
\hline
\end{tabular}

\section{VARIEDAD}

8.1 Indicar el nombre de las cinco primeras variedades, ordenadas por orden decreciente de importancia, en Tm (1.000 kg.) sobre el total en cada tipo de vino, para la campaña 2002/03.

\begin{tabular}{|l|l|l|l|l|l|l|l|}
\hline \multicolumn{2}{|c|}{ Blanco } & \multicolumn{2}{c|}{ Rosado } & \multicolumn{2}{c|}{ Tinto } & \multicolumn{2}{c|}{ Reserva y crianza } \\
\hline Variedad & Tm & Variedad & Tm & Variedad & Tm & Variedad & Tm \\
\hline & & & & & & & \\
\hline & & & & & & & \\
\hline & & & & & & & \\
\hline & & & & & & & \\
\hline & & & & & & & \\
\hline Otras (1) & & Otras (1) & & Otras (1) & & Otras (1) & \\
\hline
\end{tabular}

(1) Por diferencia con el total, para cada tipo de vino. 


\section{TECNOLOGÍA DE VINIFICACIÓN}

9.1 Señalar, en su caso, las operaciones de producción, así como los sistemas/opciones utilizados en la campaña 2002/03

\begin{tabular}{|c|c|}
\hline Operaciones & Sistemas/opciones \\
\hline$\square$ Toma de muestras & $\square$ Brazo articulado $\quad \square$ Pincho manual \\
\hline$\square$ Análisis de muestras & 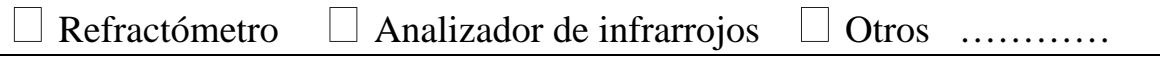 \\
\hline$\square$ Despalillado-estrujado & $\square$ Eje horizontal y rejilla rotativa $\quad \square$ Rodillos $\square$ Otros \\
\hline$\square$ Prensado & $\square$ Tornillo sinfín $\quad \square$ Neumático $\square$ Bandas $\square$ Otros ........ \\
\hline$\square$ Desfangado o decube & $\begin{array}{l}\square \text { Sedimentación } \square \text { Filtro rotativo a vacío } \square \text { Filtro prensa } \\
\square \text { Decantador centrífugo } \square \text { Químicos } \square \text { Otros ........... }\end{array}$ \\
\hline$\square$ Maceración & $\square$ En caliente $\square$ En frío $\square$ Otros $\ldots \ldots \ldots \ldots$ \\
\hline$\square$ Fermentación & $\square$ Levaduras seleccionadas $\quad \square$ Pie de cuba $\quad \square$ Otros ............. \\
\hline$\square$ Fermentación en frío & $\begin{array}{l}\square \text { Ducha agua } \square \text { Placas inmersas } \square \text { Camisas perimetrales } \\
\square \text { Tubos intercambiadores } \square \text { Otros ........... }\end{array}$ \\
\hline$\square$ Trasiego & $\begin{array}{l}\square \text { Sedimentación } \quad \square \text { Decanter centrífugo } \quad \square \text { Filtración } \\
\square \text { Microfiltración tangencial } \quad \square \text { Otros............ }\end{array}$ \\
\hline$\square$ Filtración & $\square$ Aluvionado $\square$ Placas y cartuchos $\square$ Membranas $\square$ Otros ...... \\
\hline$\square$ Estabilización & $\begin{array}{l}\square \text { Frío } \square \text { Encolado } \square \text { Filtración } \square \text { Intercambiador iónico } \\
\square \text { Electrodiálisis } \quad \square \text { Otros.............. }\end{array}$ \\
\hline$\square$ Envejecimiento & $\square$ Climatizado $\square$ Cavas $\square$ Otros ............. \\
\hline$\square$ Embotellado & $\square$ Pasteurización $\quad \square$ Filtro estéril $\quad \square$ En caliente $\quad \square$ Otros ........... \\
\hline$\square$ Control de calidad & 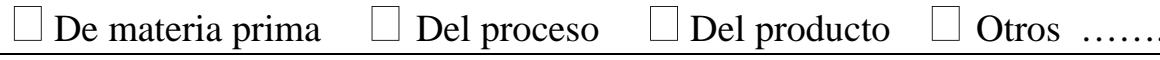 \\
\hline
\end{tabular}

9.2 Cumplimentar el cuadro siguiente, según el método de fermentación concreto, para cada tipo de vino elaborado por la empresa, en la campaña 2002/03.

\begin{tabular}{|l|c|c|c|c|}
\hline & $\begin{array}{c}\text { Fermentación } \\
\text { tradicional }\end{array}$ & \multicolumn{2}{|c|}{ Fermentación con nuevas tecnologías } \\
\hline $\begin{array}{c}\text { Tipo de } \\
\text { vino }\end{array}$ & $\begin{array}{c}\text { Producción } \\
\text { elaborada (HI) }\end{array}$ & $\begin{array}{c}\text { Producción } \\
\text { elaborada (H) }\end{array}$ & $\begin{array}{c}\text { Capacidad de los depósitos utilizados en } \\
\text { Hl (1) }\end{array}$ \\
\cline { 4 - 5 } & & & $\begin{array}{c}\text { Fermentación } \\
\text { controlada }\end{array}$ & Autovaciantes \\
\hline Blanco & & & & \\
\hline Rosado & & & & \\
\hline Tinto & & & & \\
\hline Crianza & & & & \\
\hline Reserva & & & & \\
\hline
\end{tabular}

(1) La capacidad total debe ser inferior o coincidir con la reflejada en el apartado 3, y su distribución por tipos de vinos es función del periodo de permanencia del mosto en los fermentadores. 


\section{OTRAS VARIABLES DE PRODUCTO}

10.1 Indicar en su caso, el número y el porcentaje aproximado sobre la producción comercializada embotellada en Hl para cada tipo de vino, en la campaña 2002/03.

\begin{tabular}{|l|c|c|r|r|r|r|}
\hline \multicolumn{2}{|c|}{ Variables } & \multicolumn{5}{c|}{ Tipo de vino } \\
\cline { 3 - 7 } & Blanco & Rosado & Tinto & Crianza & Reserva \\
\hline \multirow{2}{*}{ Marcas propias } & Número & & & & & \\
\cline { 2 - 7 } & $\%$ & & & & & \\
\hline Marcas blancas (1) & Número & & & & & \\
\cline { 2 - 7 } & $\%$ & & & & & \\
\hline Total & $\%$ & $100 \%$ & $100 \%$ & $100 \%$ & $100 \%$ & $100 \%$ \\
\hline
\end{tabular}

(1) Incluye marcas de la distribución y de clientes.

10.2 Indicar en su caso, el número aproximado de tamaños y forma de envases distintos para cada tipo de vino, en la campaña 2002/03.

\begin{tabular}{|l|c|c|c|c|c|}
\hline \multirow{2}{*}{\multicolumn{1}{|c|}{ Envases de vidrio }} & \multicolumn{5}{c|}{ Tipo de vino } \\
\cline { 2 - 6 } & Blanco & Rosado & Tinto & Crianza & Reserva \\
\hline Número de tamaños & & & & & \\
\hline Número de formas de envases & & & & & \\
\hline
\end{tabular}

10.3 Indicar en su caso, el número y el porcentaje aproximado sobre la producción comercializada en Hl para cada tipo de vino, en la campaña 2002/03.

\begin{tabular}{|l|c|c|r|r|r|r|}
\hline \multicolumn{2}{|c|}{ Variables } & \multicolumn{5}{c|}{ Tipo de vino } \\
\cline { 5 - 7 } & Blanco & Rosado & Tinto & Crianza & Reserva \\
\hline \multirow{2}{*}{ Vinos varietales (1) } & Número & & & & & \\
\cline { 2 - 7 } & $\%$ & & & & & \\
\hline Vinos de pagos & $\%$ & & & & & \\
\hline Vinos ecológicos & $\%$ & & & & & \\
\hline Otros & $\%$ & & & & & \\
\hline Total & $\%$ & $100 \%$ & $100 \%$ & $100 \%$ & $100 \%$ & $100 \%$ \\
\hline
\end{tabular}

(1) La variedad que da origen a la denominación del vino, ha de representar como mínimo el $85 \%$.

\section{COMERCIALIZACIÓN}

11.1 Expresar en un porcentaje aproximado sobre la producción comercializada en $\mathrm{Hl}$, el destino de las ventas, en los distintos tipos de vinos, para la campaña 2002/03.

\begin{tabular}{|l|r|r|r|r|r|}
\hline \multirow{2}{*}{\begin{tabular}{c}
\multirow{2}{*}{$\begin{array}{c}\text { Destino de la } \\
\text { comercialización }\end{array}$} \\
\cline { 3 - 6 }
\end{tabular}} & Blanco & Rosado & Tinto & Crianza & Reserva \\
\hline Comunidad Valenciana & & & & & \\
\hline Nacional & & & & & \\
\hline Unión Europea & & & & & \\
\hline Países Terceros & & & & & \\
\hline Total & $100 \%$ & $100 \%$ & $100 \%$ & $100 \%$ & $100 \%$ \\
\hline
\end{tabular}


11.2 Indicar el número total de países en los que están presentes los productos de la empresa .........

11.3 Expresar en un porcentaje aproximado sobre la producción comercializada en $\mathrm{Hl}$, los canales de comercialización utilizados por la empresa, en los distintos tipos de vinos, para la campaña 2002/03.

\begin{tabular}{|l|l|l|l|l|l|}
\hline \multirow{2}{*}{ Canal de comercialización } & \multicolumn{5}{|c|}{ Tipo de vino (\% Hl) } \\
\cline { 2 - 6 } & Blanco & Rosado & Tinto & Crianza & Reserva \\
\hline Mayorista (1) & & & & & \\
\hline Mayorista distribuidor (2) & & & & & \\
\hline $\begin{array}{l}\text { Hipermercados y } \\
\text { supermercados }\end{array}$ & & & & & \\
\hline $\begin{array}{l}\text { Tiendas tradicionales y } \\
\text { especializadas }\end{array}$ & & & & & \\
\hline $\begin{array}{l}\text { Club de vino y venta por } \\
\text { catálogo }\end{array}$ & & & & & \\
\hline Hostelería (3) & & & & & \\
\hline En bodega & & & & & \\
\hline Internet & & & & & \\
\hline Otros (especificar) & & & & & \\
\hline Total & $100 \%$ & & & & \\
\hline
\end{tabular}

(1) Incluye granelistas, embotelladores (previo tratamiento, mezcla y tipificación)

(2) Venden a su vez, fundamentalmente a hostelería y tiendas.

(3) Incluye hoteles, restaurantes, bares, etc.

\section{COMUNICACIÓN}

12.1 Desglosar en su caso, el gasto comercial anual medio en euros, por conceptos y tipos de vinos en las tres últimas campañas (2000/01-2002/03).

\begin{tabular}{|l|l|l|l|l|l|l|}
\hline \multirow{2}{*}{ Conceptos } & \multicolumn{5}{|c|}{ Tipos de vino (euros) } \\
\cline { 2 - 7 } & Blanco & Rosado & Tinto & Crianza & Reserva & Total (3) \\
\hline $\begin{array}{l}\text { Publicidad, y promociones } \\
\text { y relaciones públicas }\end{array}$ & & & & & & \\
\hline Información comercial (2) & & & & & & \\
\hline Gastos de personal comercial & & & & & & \\
\hline Otros (especificar) & & & & & & \\
\hline Total gasto comercial & & & & & & \\
\hline
\end{tabular}

(1) Publicidad. Televisión, radio, teléfono, fax, mailing, internet, ferias exposiciones, folletos etc.

Promociones, ofertas de precio o de artículos, regalos, premios, etc.

(2) Se refiere a investigación de mercados, estudios (de consumo, competencia, posicionamiento de productos, segmentación etc.)

(3) Indicar el total, solamente en caso de que no sea posible desglosar por tipos de vinos. 


\section{PRECIOS}

13.1 Señalar con una cruz en su caso, el criterio de fijación de precios utilizado por la empresa para cada tipo de vino, en la campaña 2002/03.

\begin{tabular}{|l|l|l|l|l|l|l|}
\hline \multirow{2}{*}{ Fijación del precio por/al } & \multicolumn{5}{|c|}{ Tipo de vino } \\
\cline { 2 - 7 } & Blanco & Rosado & Tinto & Crianza & Reserva & En general (3) \\
\hline Optimización de beneficios & & & & & & \\
\hline Coste + margen comercial & & & & & & \\
\hline Imitación a la competencia & & & & & & \\
\hline Condiciones de la demanda & & & & & & \\
\hline Estrategia de precios bajos (1) & & & & & & \\
\hline Estrategia de precios altos (2) & & & & & & \\
\hline Otros (especificar) & & & & & & \\
& & & & & & \\
\hline Total & & & & & & \\
\hline
\end{tabular}

(1) Con el objetivo de aumentar la cuota de mercado e introducirse en el mismo.

(2) Con referencia a los productos de alta calidad, para tratar de lograr una imagen de calidad y prestigio.

(3) Indicar en general, en caso de que no sea posible desglosar por tipos de vinos.

\section{INVERSIONES}

14.1 Indicar la inversión anual media en euros, así como el destino de las mismas en porcentaje sobre aquella en las tres últimas campañas (2000/01-2002/03).

\begin{tabular}{|l|r|}
\hline Terrenos y construcciones & $\%$ \\
\hline $\begin{array}{l}\text { Depósitos de fermentación controlada, autovaciantes y } \\
\text { similares }\end{array}$ & $\%$ \\
\hline Depósitos de almacenamiento (1) & $\%$ \\
\hline Depósitos de envejecimiento & $\%$ \\
\hline Instalaciones, maquinaria y mobiliario & $\%$ \\
\hline Embotellado & $\%$ \\
\hline Control de calidad & $\%$ \\
\hline Informática & $\%$ \\
\hline Medio ambiente & $\%$ \\
\hline Investigación y Desarrollo & $\%$ \\
\hline Otros (especificar) & $100 \%$ \\
\hline Total & euros \\
\hline
\end{tabular}

(1) Excluidos los depósitos de fermentación controlada, autovaciantes y similares. 
14.2 Indicar el porcentaje medio aproximado de las siguientes formas de financiación de las inversiones, en las tres últimas campañas (2000/01-2002/03)

\begin{tabular}{|l|r|}
\hline Fondos propios & $\%$ \\
\hline Préstamos & $\%$ \\
\hline Subvenciones & $\%$ \\
\hline Otros (especificar) & $\%$ \\
\hline Total & $100 \%$ \\
\hline
\end{tabular}

15. DATOS ECONÓMICOS (referidos, en su caso, a la sección bodega)

15.1 Indicar en euros las cantidades correspondientes a los siguientes conceptos, en la campaña 2002/03, o del ejercicio 2003.

\begin{tabular}{|l|l|}
\hline \multicolumn{1}{|c|}{ Datos económicos de la Cuenta de Pérdidas y Ganancias Analítica } & Euros \\
\hline Valor de la Producción & \\
\hline Valor Añadido de la Empresa & \\
\hline Resultado de las Actividades Ordinarias & \\
\hline
\end{tabular}

\section{VALORIZACIÓN COMERCIAL}

16.1 Puntuar de 1 a 5 por orden de importancia (5 el más importante), y a su juicio, la contribución de cada uno de los siguientes factores (tratados en los apartados anteriores), sobre los precios a la salida de bodega, para cada uno de los tipos de vino comercializados embotellados.

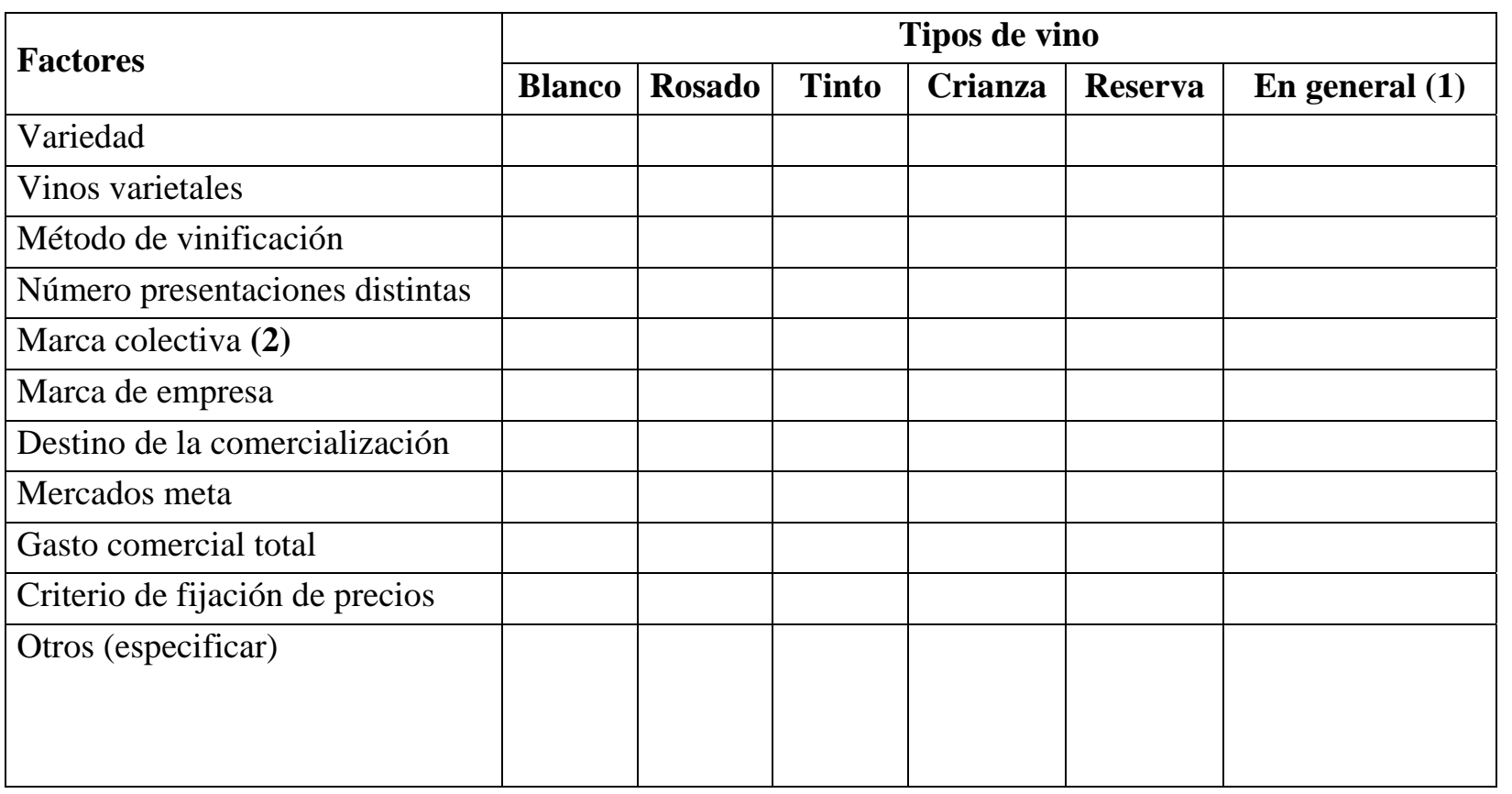

(1) Indicar en general, solamente en el caso que no sea posible puntuar por tipos de vinos.

(2) Incluye vinos con DO, vinos de la Tierra, y vinos de Pagos. 


\section{INSTRUCCIONES PARA LA CUMPLIMENTACIÓN DEL CUESTIONARIO}

A efectos de la presente encuesta, se tendrán en cuenta las siguientes definiciones y consideraciones:

- Tipos de productos. Solo se tendrán en cuenta los vinos tranquilos (sin gas), quedando excluidos otros vinos (licor, espumosos, de aguja, aromatizados, alcoholizados, para vinagre, etc) y productos (zumos, mostos, etc).

- Fermentación con nuevas tecnologías. Emplea fundamentalmente, y en mayor o menor medida, depósitos de fermentación controlada y autovaciantes o similares. Las elaboraciones por maceración carbónica y criomaceración también se incluyen.

- Depósito de fermentación controlada. Depósitos cilíndricos de base plana, con sistemas de refrigeración y calentamiento (ducha de agua, placas o tubos intercambiadores de calor)

- Autovaciente. Depósitos cilíndricos de base cónica o plana, con camisas de refrigeración y calentamiento y sistemas de vaciado automáticos, utilizados para macerar ( en caliente o no) y fermentar.

- Vinos blancos y vinos rosados. Vinos jóvenes, elaborados en mayor o menor medida a baja temperatura en depósitos de fermentación controlada, pudiendo haber sufrido o no, una maceración previa en autovaciantes.

- Vinos tintos. Vinos jóvenes, macerados en autovaciantes y fermentados o no en depósitos de fermentación controlada o en autovaciantes. Evolucionan a crianzas o reservas en función de los periodos de permanencia en botella o barrica, que regulan los distintos Consejos Reguladores.

- La denominación joven, incluye, según los distintos sistemas de protección del origen y la calidad de los vinos, las siguientes indicaciones: joven o nuevo, cosecha o vendimia, primero de cosecha o del año, superior, vendimia inicial, etc., y excluye las indicaciones: rancio, roble, añejo, fondillón, misa, etc.

- Fermentación tradicional. No emplea depósitos de fermentación controlada ni autovaciantes en el proceso de elaboración de los vinos definidos anteriormente. 
ANEXO II

LISTADO BODEGAS ENCUESTADAS 



\section{RELACIÓN DE EMPRESAS ENCUESTADAS}

- ENGUERA VITIVINÍCOLA, S.A.

- COOPERATIVA VINÍCOLA LA VIÑA, COOP.V.

- LA BARONIA DE TURÍS, COOP.V.

- BODEGAS MURVIEDRO, S.A.

- Ma VICTORIA ESCANDELL PEREZ.

- BODEGAS BATALLER, S.A.

- CRIANZO, S.L.

- VICENTE GANDIA PLA, S.A.

- COBIVEX, COOP. V.

- ROMERAL VINÍCOLA, S.L.

- CRIADORES ARTESANOS, S.L.

- COOPERATIVA VINÍCOLA ONTENIENSE, COOP.V.

- COOPERATIVA VINÍCOLA SAN ANTONIO ABAD, COOP. V.

- COOPERATIVA AGRÍCOLA LA PURÍSIMA CONCEPCIÓN, COOP.V.

- COOPERATIVAVINÍCOLA REQUENENSE, COOP.V.

- VINS DEL COMTAT, S.L.

- RESERVAS Y CRIANZAS REQUENENSES, S.L.

- BODEGAS Y DESTILERÍAS VIDAL, S.L.

- BODEGAS COOPERATIVAS DE ALICANTE, COOP.V.

- BODEGA NUESTRA SEÑORA DE LAS VIRTUDES, COOP.V.

- COOPERATIVA AGRÍCOLA SAN VICENTE FERRER, COOP.V.

- AGRO DE BAZAN, S.A.

- FINCA SAN BLAS, S.L.

- TORRE ORIA, S.L. UNIPERSONAL.

- COOPERATIVA AGRÍCOLA VALENCIANA VIRGEN DE LORETO, COOP.V.

- LATORRE AGROVINÍCOLA, S.A.

- ANTONIO ARRAEZ, S.L.

- SEBIRAN, S.L.

- BODEGAS BERNABÉ NAVARRO, S.L.

- PORTILLO SL

- COOPERATIVA AGRÍCOLA SANTA BARBARA DE TITAGUAS, COOP.V.

- BODEGAS COMECHE, S.C.T.A.

- BODEGAS PALMERA, S.L.

- HIJOS DE ERNESTO CÁRCEL, S.L.

- BODEGAS E. MENDOZA, S.L.

- DOMINIO DE LA VEGA, S.L.

- SALVADOR POVEDA, S.A.

- BODEGAS FERNANDO FRANCÉS, S.L.

- SAT N 7683 BODEGAS Y VIÑEDOS DE UTIEL.

- BODEGAS MANUEL POLO MONLEÓN

- CHESTE AGRARIA, COOP.V.

- BODEGAS VEREDA REAL, S.L.

- SAT CV 267 ECOVITIS.

- VIRASA VINÍCOLA, S.L.

- COOPERATIVA AGRÍCOLA UTIEL, COOP.V.

- BODEGAS TORROJA, S.L. 


\section{RELACIÓN DE EMPRESAS ENCUESTADAS (cont.)}

- BODEGAS VICENTE RIBERA E HIJOS, S.L.

- COOPERATIVA VALENCIANA VITIVINÍCOLA LA PROTECTORA, COOP.V.

- VIFRUT MONTROY, COOP.V.

- COVIÑAS, COOP.V.

- DOMINIO DE ARANLEÓN, S.L.

- BODEGAS FUSO, S.L.

- ANDRÉS VALIENTE E HIJOS, S.L.

- COOPERTATIVA DE VILLAR DEL ARZOBISPO, COOP.V.

- BODEGAS IRANZO,S.L.

- COOPERATIVA AGRÍCOLA VALECIANA SAN PEDRO APOSTOL, COOP.V.

- COOPERATIVA AGRÍCOLA JARAGÜENSE, COOP.V.

- BODEGAS SANBERT, S.L.

- BODEGAS LOS FRAILES, S.L.

- BODEGAS GIMENEZ, S.L.

- COOPERATIVA AGRÍCOLA SAN JUAN BAUTISTA, COOP.V.

- COOPERATIVA VALENCIANA AGRÍCOLA VIRGEN DEL REMEDIO, COOP.V.

- ERNESTO DEBON VIADEL.

- BODEGA COOPERATIVA AGRÍCOLA DE PETRER, COOP.V.

- MARTIN BELDA JUAN.

- COOPERATIVA VALENCIANA DEL CAMPO SAN ISIDRO LABRADOR, COOP.V.

- COOPERATIVA VALENCIANA SAN ROQUE, COOP.V.

- COOPERATIVA VALENCIANA AGRÍCOLA LA UNIÓN, COOP.V.

- SAT N 266 CV LA CUBERA.

- BODEGA COOPERATIVA DE MONOVAR, COOP.V.

- BODEGA COOPERATIVA PINOSO R.L., COOP. V.

- COPERATIVA VALENCIANA AGRÍCOLA APOSTOL SANTIAGO, COOP.V.

- MOSTOS Y VINOS BENIGANIM, S.L.

- FACUNDO CHAFER MARTÍ.

- BODEGA COOPERATIVA DE LA ALGEÑA, COOP.V.

- SOCIEDAD COOPERATIVA AGROVINÍCOLA DE MONSERRRAT, COOP.V.

- COOPERATIVA VINÍCOLA SAN PEDRO APOSTOL, COOP.V.

- VICENTE GANDÍA GANDÍA.

- PEDRO HERNANDEZ CLEMENTE.

- COOPERATIVA VALENCIANA AGRÍCOLA VIRGEN DEL CARMEN, COOP.V

- COOPERATIVA SAT N 1143 SOLIDARIDAD.

- DEL CAMPO SAN ISIDRO LABRADOR, COOP V.

- COOPERATIVA AGRÍCOLA ALBOSA, COOP.V.

- COOPERATIVA DE VITICULTORES Y SECCIÓN DE CRÉDITO DEL PROGRESO, COOP.V

- COOPERATIVA AGRÍCOLA SAN MIGUEL, COOP.V.

- COOPERATIVA DEL CAMPO LA UNION, COOP.V.

- VIÑAS DEL PORTILLO, S.L.

- COOPERATIVA AGRÍCOLA LA INMACULADA, COOP.V.

- COOPERATIVA DEL CAMPO DE CAMPORROBLES, COOP.V. 


\section{RELACIÓN DE EMPRESAS ENCUESTADAS (cont.)}

- JOSE M ${ }^{\mathrm{a}}$ SANCHIS CAÑAMARES.

- BODEGA COOPERATIVA DE CASTALLA, COOP.V.

- COOPERATIVA VALENCIANA DEL CAMPO NTRA. SRA. DE LAS VIÑAS, COOP.V

- BODEGAS ORTIZ LATORRE, SDAD.COOP.V.

- COOPERATIVA VALENCIANA DE VITICULTORES LTDA., COOP.V.

- VINÍCOLA DEL VALLE DE ALBAIDA, S.L.

- BODEGA NTRA. SRA. DEL MILAGRO, COOP.V

- COOPERATIVA VALENCIANA DE VITIVULTORES SANTA RITA, COOP.V.

- SOCIEDAD COOPERATIVA AGRÍCOLA NIÑO JESUS, COOP.V.

- VINÍCOLA DELS ALFORINS, S.L.

- COOPERATIVA VINÍCOLA DE QUATRETONDA, COOP.V.

- COOPERATIVA VALENCIANA DEL CAMPO SAN JOSE OBRERO, COOP.V.

- BODEGA COOPERATIVA AGRÍCOLA DIVINA AURORA, COOP.V.

- COOPERATIVA AGRÍCOLA VALENCIANA LA ENCARNACIÓN DE NTRA. SRA., COOP.V.

- ALEJANDO PEREZ MARTÍNEZ.

- SAT N 7237 FINCA CABALLERO.

- CHOZAS CARRASCAL, S.L.

- VITICULTORES DE LOS RUICES, COOP.V.

- BODEGAS SIERRA SALINAS, S.L.

- PAGO DE THARSYS, S.L.

- FOMENTO AGROINDUSTRIAL, S.L. 